UNIVERSIDADE DE BRASÍLIA

FACULDADE DE TECNOLOGIA

DEPARTAMENTO DE ENGENHARIA MECÂNICA

\title{
MODELAGEM E SIMULAÇÃO DO IMPACTO DA VAZÃO DE AR EXTERIOR VARIÁVEL E RECUPERAÇÃO DE ENERGIA SOBRE O DESEMPENHO DE SISTEMAS DE AR CONDICIONADO
}

\section{MATHEUS SODRÉ VALVERDE}

ORIENTADOR: MÁRIO BENJAMIM B. DE SIQUEIRA

DISSERTAÇÃO DE MESTRADO EM CIÊNCIAS MECÂNICAS

$$
\text { BRASÍLIA/DF -ABRIL/2016 }
$$


UNIVERSIDADE DE BRASÍLIA

FACULDADE DE TECNOLOGIA DEPARTAMENTO DE ENGENHARIA MECÂNICA

MODELAGEM E SIMULAÇÃO DO IMPACTO DA VAZÃO DE AR EXTERIOR VARIÁVEL E RECUPERAÇÃO DE ENERGIA SOBRE O DESEMPENHO DE SISTEMAS DE AR CONDICIONADO

MATHEUS SODRÉ VALVERDE

DISSERTAÇÃO SUBMETIDA AO DEPARTAMENTO DE ENGENHARIA MECÂNICA DA FACULDADE DE TECNOLOGIA DA UNIVERSIDADE DE BRASÍLIA COMO PARTE DOS REQUISITOS NECESSÁRIOS PARA A OBTENÇÃO DO GRAU DE MESTRE EM CIÊNCIAS MECÂNICAS

APROVADA POR:

Prof. Mário Benjamim B. de Siqueira, Dr. ～(ENM-UnB) (Orientador)

Prof. Armando de A. Caldeira Pires, Dr.

(Examinador Interno)

(ENM-UnB)

Prof. João Manoel Dias Pimenta, Dr. (Examinador Externo) 


\section{FICHA CATALOGRÁFICA}

\section{SODRE VALVERDE, MATHEUS}

Modelagem e simulação do impacto da vazão de ar exterior variável e recuperação de energia sobre o desempenho de sistemas de ar condicionado.

xvii, 258p, 210 x 297 mm (ENM/FT/UnB, Mestre, Engenharia Mecânica, 2013).

Dissertação de Mestrado - Universidade de Brasília. Faculdade de Tecnologia.

Departamento de Engenharia Mecânica.

1.ERV

3. Recuperador de energia

5. DCV

I. ENM/FT/UnB
2.Vazão de ar externo variável

4.Ar condicionado

6.Eficiência Energética

\section{REFERÊNCIA BIBLIOGRÁFICA}

VALVERDE, M.S. (2016). Modelagem e simulação do impacto da vazão de ar exterior variável e recuperação de energia sobre o desempenho de sistemas de ar condicionado.

Dissertação de Mestrado em Ciências Mecânicas, Publicação ENM 239/2016, Departamento de Engenharia Mecânica, Universidade de Brasília, Brasília, DF, 267p.

\section{CESSÃO DE DIREITOS}

AUTOR: Matheus Sodré Valverde.

TÍTULO: Modelagem e simulação do impacto da vazão de ar exterior variável e recuperação de energia sobre o desempenho de sistemas de ar condicionado.

GRAU: Mestre

ANO: 2016

É concedida à Universidade de Brasília permissão para reproduzir cópias desta dissertação de mestrado e para emprestar ou vender tais cópias somente para propósitos acadêmicos e científicos. O autor reserva outros direitos de publicação e nenhuma parte dessa dissertação de mestrado pode ser reproduzida sem autorização por escrito do autor.

Matheus Sodré Valverde

SQN 215 BLOCO A PTO 507

BRASÍLIA/DF - CEP 70874-010

e-mail: theuvalverde@gmail.com 


\section{Dedicatória}

Dedico este trabalho aos meus pais, Carlos e Marguita, que sempre estiveram ao meu lado e nunca pouparam esforços para educar seus filhos, permitindo-me chegar até aqui.

Matheus Sodré Valverde 


\section{AGRADECIMENTOS}

Agradeço primeiramente a Deus, por ter me dado o dom da vida, por ter colocado pessoas maravilhosas ao meu redor e também por ter me colocado em lugares que jamais sonhei estar, mesmo não sendo merecedor.

Ao professor Pimenta, por nunca ter desistido de mim e por ter me incentivado a realizar este trabalho. Também agradeço pela sua dedicação como profissional e como professor. Ao professor Mario, por toda a colaboração e atenção despendida para este trabalho.

Aos meus pais e minha irmã por tudo que são e representam na minha vida.

Aos amigos Gabriel Galvão, Rodrigo Neiva, Elson Cumaru, Tiago Tolentino, Vander Ribeiro, Rafael Gontijo e Renato Muniz por terem colaborado de alguma forma para este trabalho.

Aos demais amigos por fazerem a vida ser mais alegre, amigos da UnB (Inmensos), os Brothers, amigos da banda (Outono09), amigos do trabalho e todos os outros.

Em especial, a minha namorada Mariana, que sempre me apoiou nesta e em outras empreitadas. Ela foi a única que acompanhou passo a passo os dilemas vividos e o progresso dessa jornada, e tenho certeza que até aprendeu um pouco de engenharia depois disso, hahaha.

Matheus Sodré Valverde 
"Vamos viver nossos sonhos, temos tão pouco tempo..."

Chorão, CBJr. 


\section{RESUMO}

\section{MODELAGEM E SIMULAÇÃO DO IMPACTO DA VAZÃO DE AR EXTERIOR VARIÁVEL E RECUPERAÇÃO DE ENERGIA SOBRE O DESEMPENHO DE SISTEMAS DE AR CONDICIONADO}

Este trabalho tem por finalidade apresentar uma metodologia que possibilite analisar os efeitos anuais das técnicas da recuperação de energia e da vazão de ar exterior variável em um sistema de ar condicionado operando em cidades do Brasil. Essa análise busca mensurar os efeitos de eficiência energética e financeiros em edifícios comerciais, com o intuito de fornecer dados que viabilizem essas aplicações em sistemas de AVAC e que subsidiem decisões técnicas de projeto a partir de análises de retorno de investimento, evitando o superdimensionamento dos sistemas de ar condicionado, conferindo redução de custos de aquisição, instalação, manutenção e operação.

O modelo proposto foi aplicado em um ambiente definido, com perfil de carga, parâmetros de conforto de ar interno e sistema de condicionamento de ar definidos. Esse ambiente foi avaliado por meio de análise econômica em quatro cenários diferentes: i) o primeiro cenário constitui um sistema sem nenhum cuidado com variação de vazões e recuperação de energia; ii) o segundo utiliza o recurso da vazão de ar exterior variável, sem utilizar a recuperação de energia; iii) o terceiro utiliza apenas o recurso da recuperação de energia com vazão fixa de ar exterior; iv) por último, um caso utilizando vazão de ar exterior variável e recuperação de energia.

Os resultados mostraram que a utilização das tecnologias avaliadas geram grandes economias no custo operacional de sistemas de ar condicionado que atendem ambientes com perfil de ocupação bastante variável. Os valores encontrados variam de $12 \%$ a $30 \%$ de economia de energia anual para a cidade de Brasília e de $18 \%$ a 37\% de economia para a cidade de Manaus, de acordo com o cenário utilizado. Especificamente em relação ao equipamento de ERV, como seus efeitos são principalmente influenciados pelo clima da cidade de projeto e pelas vazões de ar, a sua utilização tem grande potencial para ser aplicada em diversos tipos de ambientes e em diversas cidades do Brasil. 


\section{ABSTRACT \\ MODELING AND SIMULATION OF DEMAND CONTROLLED VENTILATION (DCV) AND ENERGY RECOVERY (ERV) IMPACT ON AIR CONDITIONING SYSTEMS PERFORMANCE}

This work aims to present a methodology that allows to analyze the effects of annual energy recovery techniques (ERV) and the variable flow of outside air (DCV) in an air conditioning system operating in Brazilian cities. This analysis seeks to measure the effects of financial and energy efficiency in commercial buildings, in order to provide data that enable these applications in HVAC systems and support technical design decisions based on analysis of return on investment, avoiding oversizing air conditioning systems, providing reduced costs of purchase, installation, maintenance and operation .

The model was implemented in a defined environment with thermal load profile, parameters of internal air comfort and air-conditioning system defined. This environment was assessed by means of economic analysis under four different scenarios: i) the first scenario is a system without any care with varying air flow rates and energy recovery; ii) the second uses the feature of variable flow of outside air, without using energy recovery; iii) the third feature only uses energy recovery with fixed flow of outside air; iv ) Finally, a case using variable flow of outside air and energy recovery.

The results showed that the use of the technologies evaluated generate large savings in operating cost of air conditioning systems serving environments with highly variable occupancy profile. The values obtained range from $12 \%$ to $30 \%$ annual energy savings for the city of Brasilia and from $18 \%$ to $37 \%$ savings to the city of Manaus, according to the scenario used. Specifically in relation to the ERV equipment, as its effects are mainly influenced by the climate of the city and the design air flow, its use has great potential to be applied in various types of environments and in different cities of Brazil. 


\section{SUMÁRIO}

1 - INTRODUÇÃO ..............................................................................................................1

1.1 - O PROBLEMA EM ESTUDO E SUA IMPORTÂNCIA …........................................ 1

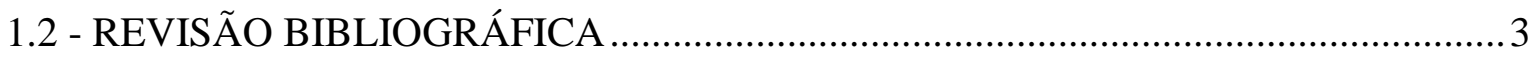

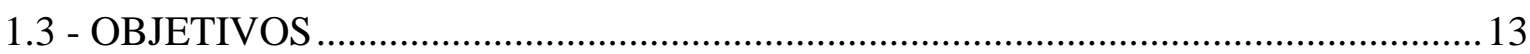

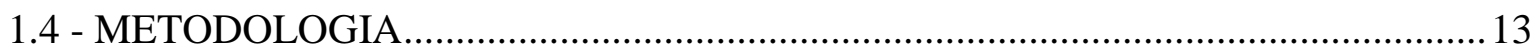

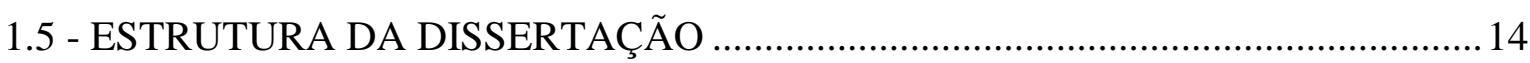

2 - REVISÃO DE CONCEITOS FUNDAMENTAIS ..........................................................16

2.1 - REGULAMENTOS DE EFICIÊNCIA ENERGÉTICA EM EDIFÍCIOS .................. 16

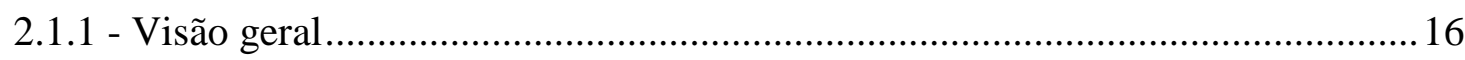

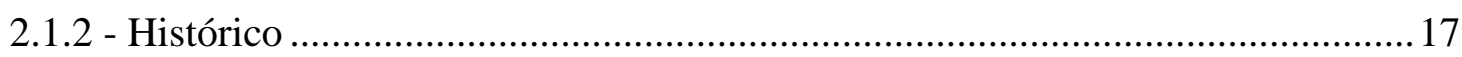

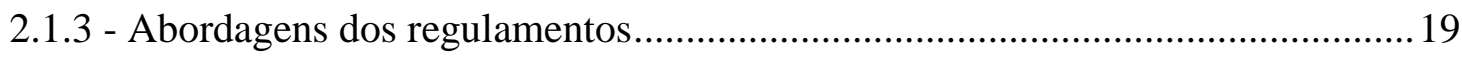

2.2 - PROGRAMAS DE CERTIFICAÇÕES DE EDIFICAÇÕES ...................................21

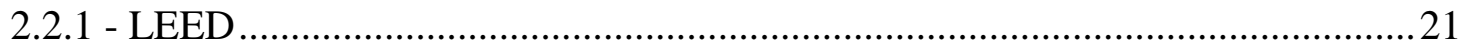

2.2.1.1 - Visão geral e histórico .................................................................... 21

2.2.1.2 - Pontuação LEED para sistemas ............................................................2 23

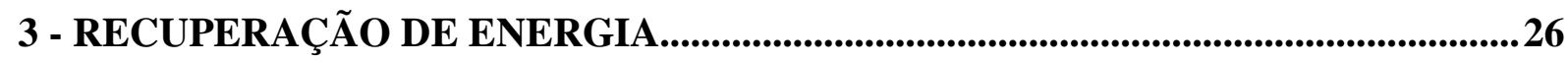

3.1 - SISTEMAS E EQUIPAMENTOS DE RECUPERAÇÃO DE ENERGIA ..................26

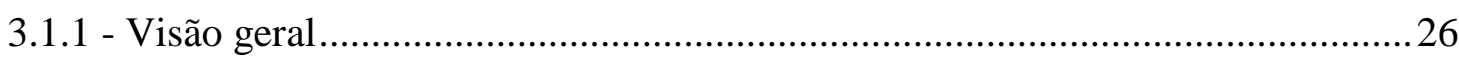

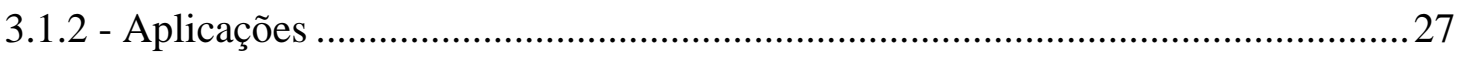

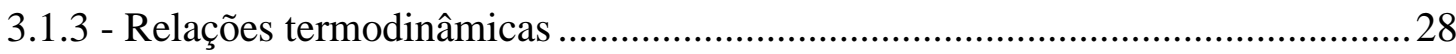

3.1.3.1 - Relações termodinâmicas para o ventilador de recuperação de calor .....29

3.1.3.2 - Relações termodinâmicas para o ventilador de recuperação de energia .31

4 - VENTILAÇÃO DE AR EXTERIOR ...........................................................................36

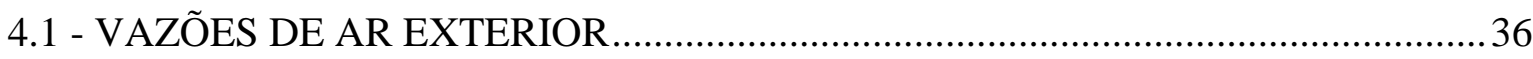

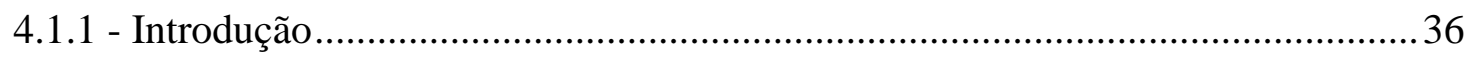

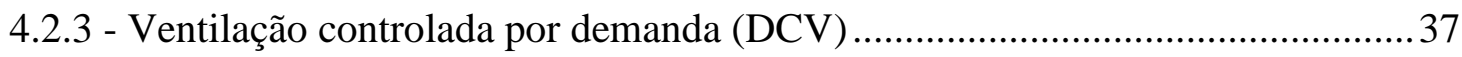

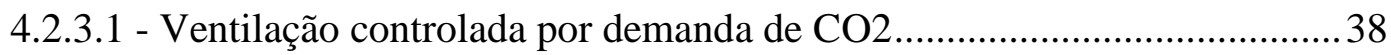

4.2.3.2 - DCV baseado em CO2 para sistemas de zona única................................39

4.2.3.3 - Estratégida de controle proporcional de $\mathrm{CO} 2$.......................................4 40

4.2.3.4 - Estratégida de controle por set point de $\mathrm{CO} 2$...................................... 42

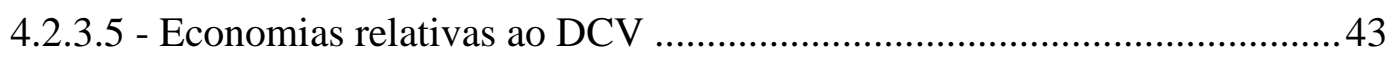


5 - DESENVOLVIMENTO DO MODELO MATEMÁTICO ...........................................45

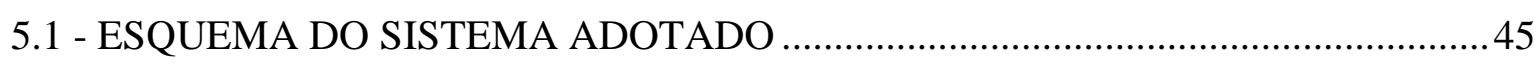

5.2 - FORMULAÇÃO MATEMÁTICA DO SUBSISTEMA DO AMBIENTE CONDICIONADO 46

5.3 - FORMULAÇÃO MATEMÁTICA DO SUBSISTEMA DO EQUIPAMENTO DE

AR CONDICIONADO

5.4 - FORMULAÇÃO MATEMÁTICA DO SUBSISTEMA DE CONTROLE DE

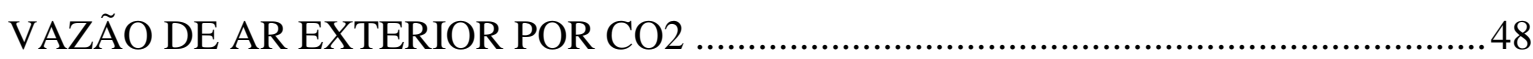

5.5 - FORMULAÇÃO MATEMÁTICA DO SUBSISTEMA DO RECUPERADOR DE

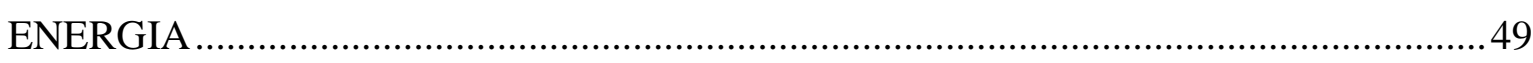

5.5.1 - Eficiências do ERV - Influência das vazões de ar..............................................50

5.5.2 - Eficiências do ERV - Influência das condições de ar externo.............................50

5.5.3 - Potência elétrica consumida pelo ERV ...........................................................54

5.6 - FLUXOGRAMA DE FUNCIONAMENTO DA FORMULAÇÃO

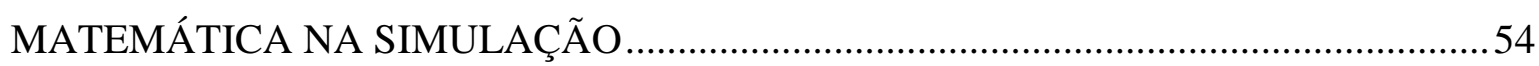

5.7 - METODOLOGIA DE CONTROLE ADOTADA PARA O SISTEMA .....................57

6 - ESTUDO DE CASO E APRESENTAÇÃO DE CENÁRIOS ......................................58

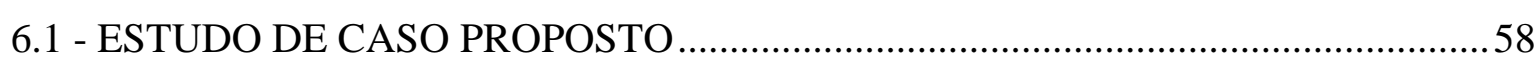

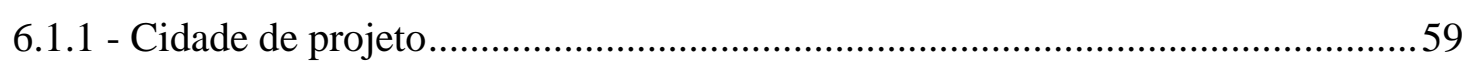

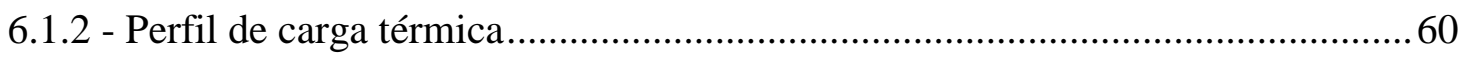

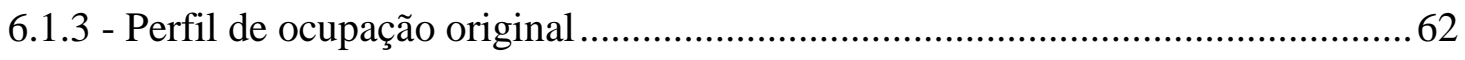

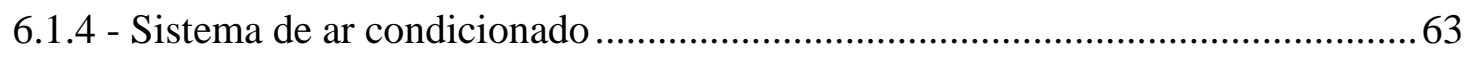

6.1.4.1 - Sistema de ar condicionado padrão - 43 kW (12 TR) .............................64

6.1.4.2 - Sistema de ar condicionado para uso com ERV - $35 \mathrm{~kW}(10 \mathrm{TR})$..........67

6.1.5 - Sistema do recuperador de energia e controle de vazão por $\mathrm{CO} 2$.................... 71

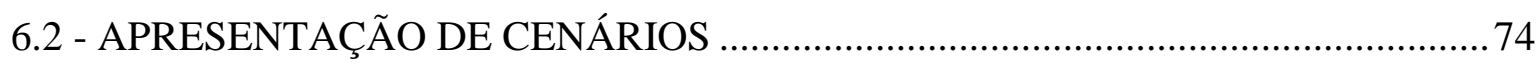

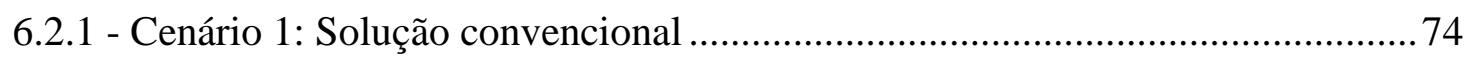

6.2.2 - Cenário 2: Solução com vazão de ar exterior variável ...................................... 75

6.2.3 - Cenário 3: Solução com recuperação de energia............................................. 76

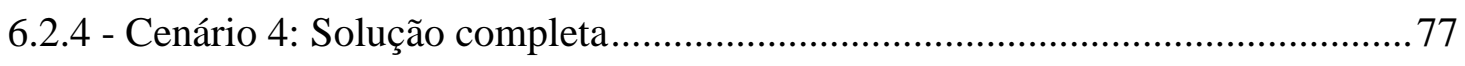

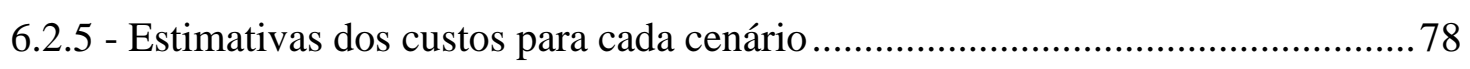

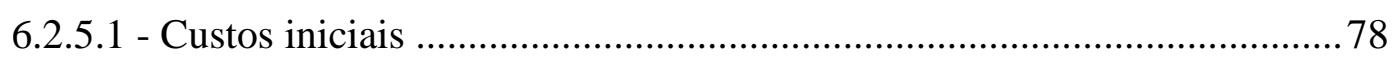

6.2.5.2 - Custos operacionais - operação e manutenção ...................................... 81 
6.2.5.3 - Custos operacionais - custos dos insumos energéticos 82

6.2.5.4 - Custos totais dos cenários e retorno do investimento .82

7 - RESULTADOS E DISCUSSÃO 84

7.1 - INTRODUÇÃO .84

7.2 - RESULTADOS DOS CENÁRIOS COM OCUPAÇÃO ORIGINAL.......................... 84

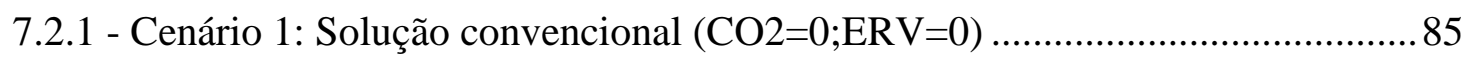

7.2.2 - Cenário 2: Solução com vazão de ar exterior variável $(\mathrm{CO} 2=1 ; \mathrm{ERV}=0) \ldots \ldots . . . .88$

7.2.3 - Cenário 3: Solução com recuperação de energia $(\mathrm{CO} 2=0 ; \mathrm{ERV}=1)$................... 91

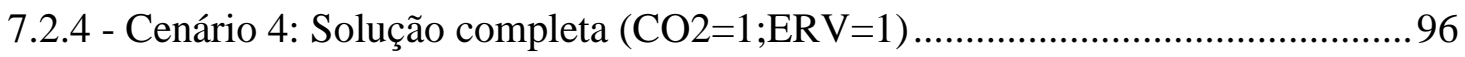

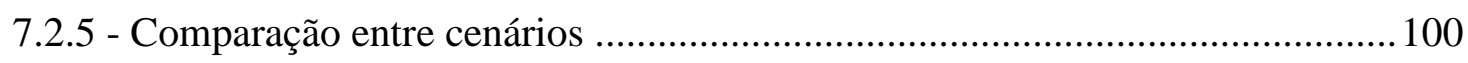

7.3 - RESULTADOS DOS CENÁRIOS COM DIVERSAS OCUPAÇÕES E HORAS

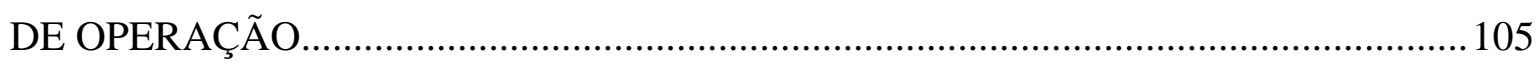

7.3.1 - Análise comparativa dos cenários e influência da variação da ocupação ........ 106

7.4 - RESULTADOS DOS CENÁRIOS COM OCUPAÇÃO ORIGINAL EM OUTRA

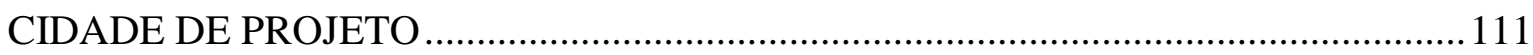

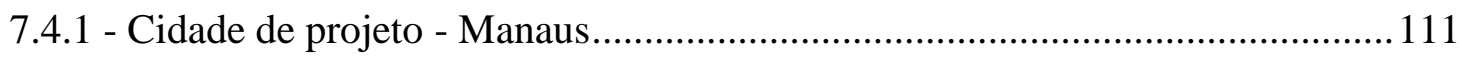

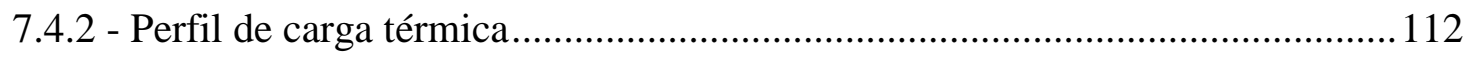

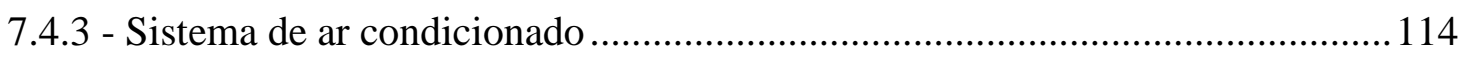

7.4.3.1 - Sistema de ar condicionado padrão - $55 \mathrm{~kW}(15 \mathrm{TR})$............................. 114

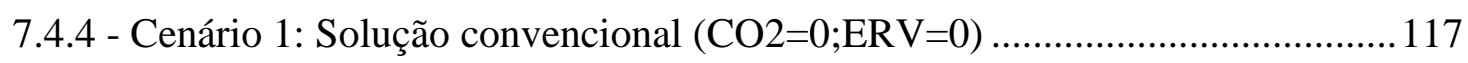

7.4.5 - Cenário 2: Solução com vazão de ar exterior variável $(\mathrm{CO} 2=1 ; \mathrm{ERV}=0)$........ 121

7.4.6 - Cenário 3: Solução com recuperação de energia $(\mathrm{CO} 2=0 ; \mathrm{ERV}=1) \ldots \ldots \ldots \ldots \ldots . . . . .124$

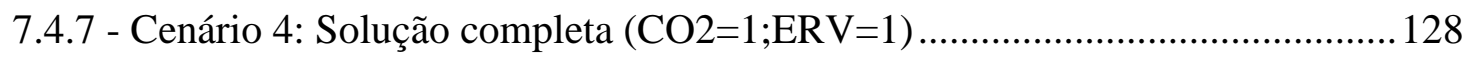

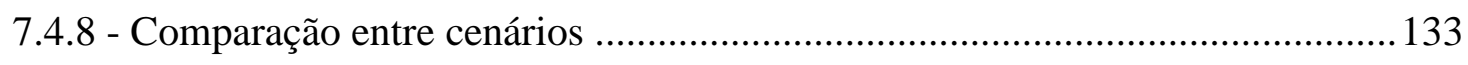

7.5 - ANÁLISE DA INFLUÊNCIA DO CLIMA DA CIDADE DE PROJETO ...............137

7.5.1 - Análise dos coeficientes de calor sensível e latente ....................................... 139

7.5.2 - Análise das quantidades de calor sensível e latente recuperadas ..................... 142

7.6 - AVALIAÇÃO DA METODOLOGIA PROPOSTA................................................. 144

8 - CONCLUSÕES E PROPOSTAS DE TRABALHOS FUTUROS............................147

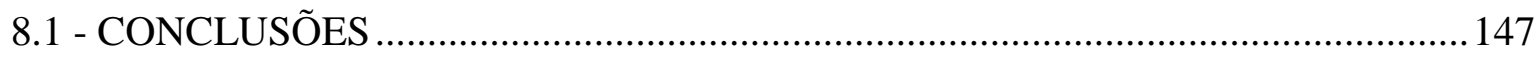

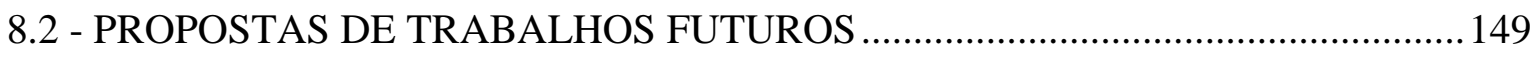

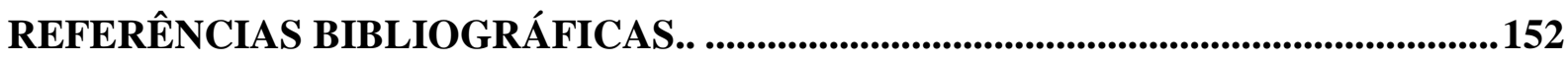

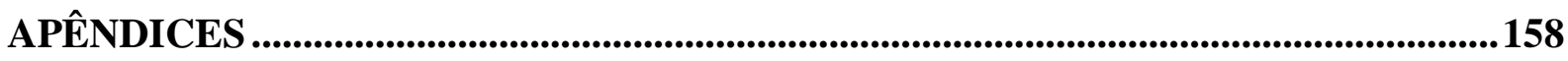

A - SISTEMAS E EQUIPAMENTOS DE RECUPERAÇÃO DE ENERGIA ..................... 159 
A.1 - Idealizações para os Recuperadores de Energia Ar-Ar

A.2 - Arranjos de fluxo de ar.....

A.2.1 - Eficiência

A.2.2 - Taxa de transferência de energia (NTU) ....................................................... 161

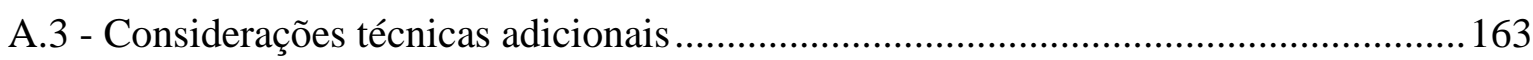

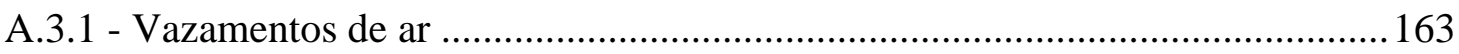

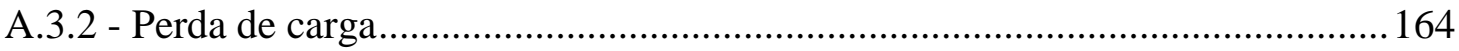

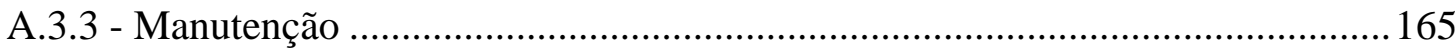

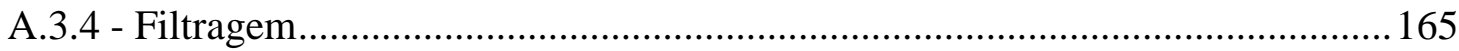

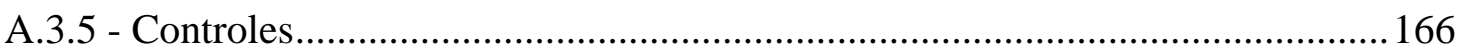

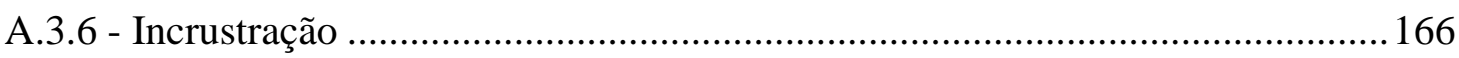

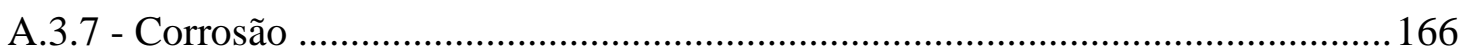

A.3.8 - Condensação e congelamento...................................................................... 167

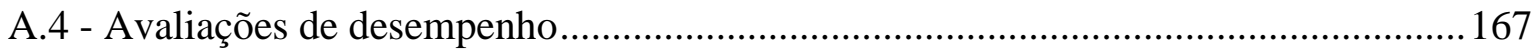

A.5 - Tipos e aplicações de recuperadores de energia ar-ar .............................................. 168

A.5.1 - Recuperadores de energia de placas fixas .................................................... 168

A.5.2 - Recuperadores rotativos - rodas giratórias entálpicas .................................. 172

A.5.3 - Recuperadores de calor por meio de bombeamento de fluido em serpentinas

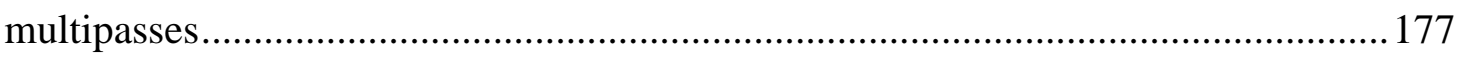

A.5.4 - Recuperadores de calor de tubos quentes .................................................... 179

A.5.5 - Recuperadores de calor do tipo termossifão ….............................................. 182

A.5.6 - Recuperadores de calor tipo torres gêmeas ................................................. 184

A.6 - Comparação entre os sistemas de recuperação de energia ar-ar................................ 186

A.6.1 - Caracterização da eficiência do sistema de HRV ou ERV ............................ 189

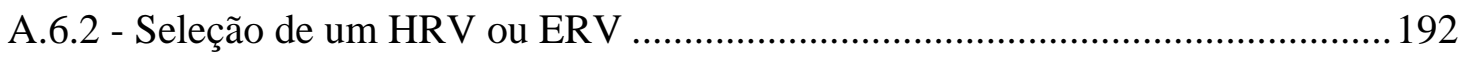

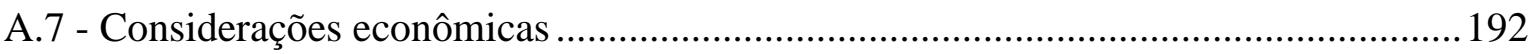

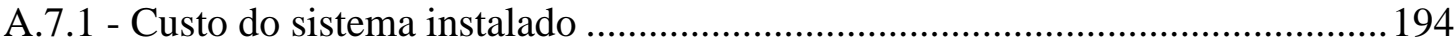

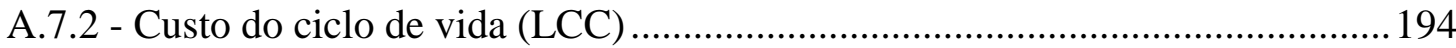

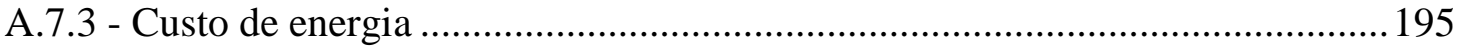

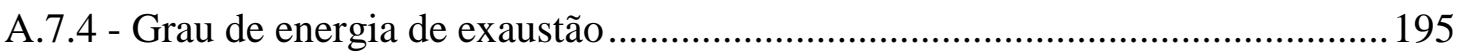

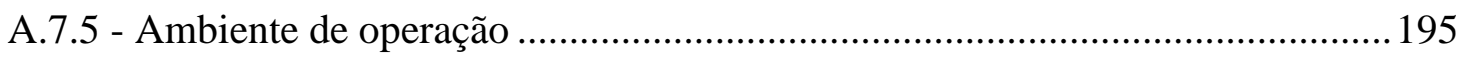

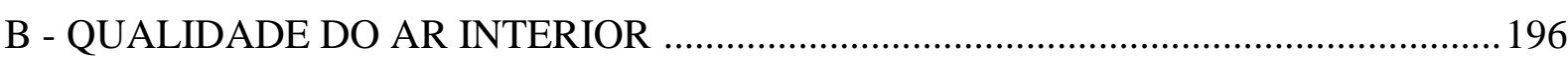

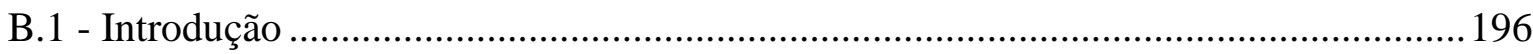

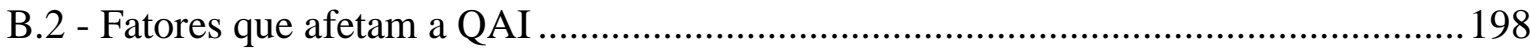




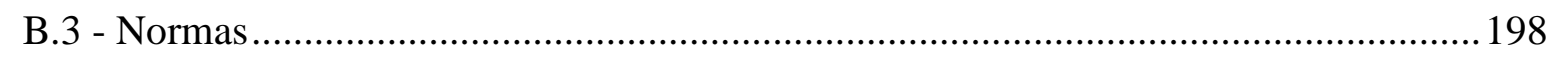

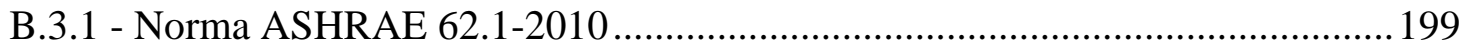

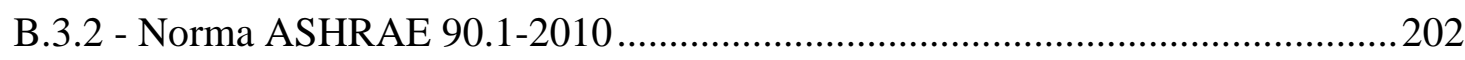

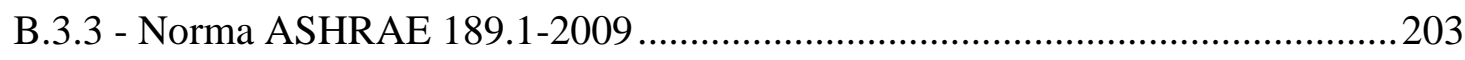

B.3.4 - Norma ABNT NBR 16401-3/2008 _.............................................................. 203

B.3.5 - Portaria 3.523/1998 do Ministério da Saúde .................................................205

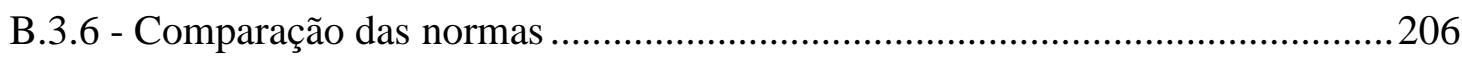

C - FORMULAÇÃO MATEMÁTICA INSERIDA NO EES................................................208

D - RELATÓRIO DE CÁlCULO DE CARGA TÉRMICA DO ESTUDO DE CASO .......222

E - RELATÓRIO DE SELEÇÃO DO CHILLER DE 12 TR E DEMAIS DADOS..............242

F - RELATÓRIO DE SELEÇÃO DO FAN COIL DE 12 TR E DEMAIS DADOS.. ..........244

G - RELATÓRIO DE SELEÇÃO DO CHILLER DE 10 TR E DEMAIS DADOS .............246

H - RELATÓRIO DE SELEÇÃO DO FAN COIL DE 10 TR E DEMAIS DADOS ............249

I - DADOS DO RECUPERADOR DE ENERGIA DO CATÁLOGO DA LG ......................251

J - PLANILHAS E CATÁLOGOS PARA LEVANTAMENTO DE CUSTOS ....................253

L - TABELAS COM DIVERSOS PERFIS DE OCUPAÇÃO (CAP. 7) ..............................259 


\section{LISTA DE TABELAS}

Tabela 2.1 - Pontuação LEED para sistemas com recuperação de calor e vazão de ar exterior variável).

Tabela 3.1 - Aplicações típicas para recuperadores de energia ar-ar - modificada (ASHRAE,2012)

Tabela 6.1 - Principais características do ambiente escolhido 59

Tabela 6.2 - Perfil de ocupação original (\%) semanal do auditório em estudo.

Tabela 6.3 - Principais características do Chiller de 12 TR (CARRIER 2013, modificado)....

Tabela 6.4 - Tabela de potência consumida para diversas cargas de operação e temperaturas do ar externo do Chiller 12 TR (CARRIER 2013, modificado).

Tabela 6.5 - Principais características do fan coil 12 TR (CARRIER 2013, modificado).

Tabela 6.6 - Principais características do Chiller de 10 TR (CARRIER 2013, modificado) .68

Tabela 6.7 - Tabela de potência consumida para diversas cargas de operação e temperaturas do ar externo do Chiller 10 TR (CARRIER 2013, modificado)

Tabela 6.8 - Principais características do fan coil de 10 TR (CARRIER 2013, modificado) .70

Tabela 6.9 - Principais características do ERV (LG 2011, modificado) .71

Tabela 6.10 - Taxas de renovação de ar para o nível 1 de um edifício de escritórios (ABNT NBR 16401-3, 2008)

Tabela 6.11 - Taxa de renovação de ar externo requerida pela norma de acordo com a ocupação proposta (valores em $\mathrm{m}^{3} / \mathrm{h}$ )

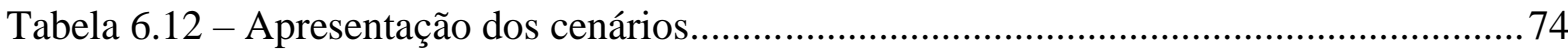

Tabela 6.13 - Custos iniciais dos cenários (aquisição, transporte e instalação)....................78

Tabela 6.14 - Referências para estimativa dos custos iniciais............................................ 79

Tabela 6.15 - Custos operacionais de alguns contratos de manutenção e operação

(Pesquisa realizada em abril/2012)

Tabela 6.16 - Custos iniciais dos cenários. .82

Tabela 6.17 - Custos operacionais dos cenários. 83

Tabela 6.18 - Retorno do investimento de cada cenário 83 
Tabela 7.1 - Valores absolutos e relativos do perfil de ocupação do ambiente condicionado 84

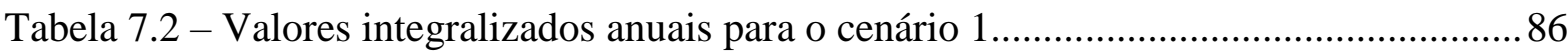

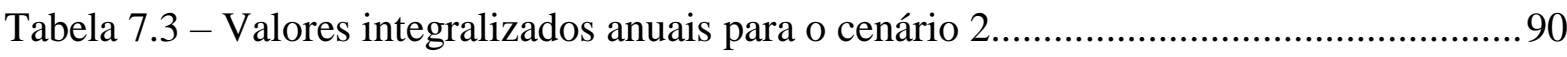

Tabela 7.4 - Valores integralizados anuais para o cenário 3.............................................94

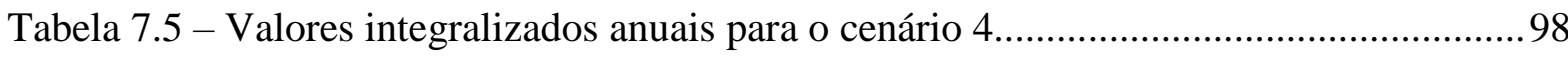

Tabela 7.6 - Comparação dos custos energéticos para os quatro cenários........................... 102

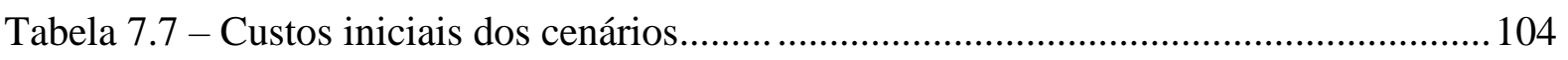

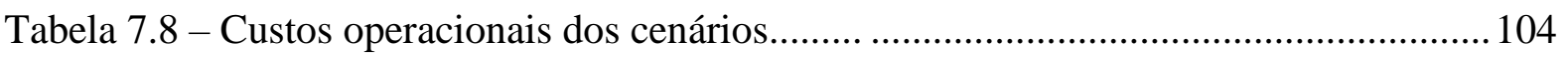

Tabela 7.9 - Retorno do investimento de cada cenário......................................................... 104

Tabela 7.10 - Perfis de ocupação e horas de operação dos sistemas.................................... 106

Tabela 7.11 - Retorno do investimento para os diversos perfis de ocupação no cenário 2 .. 107

Tabela 7.12 - Retorno do investimento para os diversos perfis de ocupação no cenário 2 .. 107

Tabela 7.13 - Retorno do investimento para os diversos perfis de ocupação no cenário 3 .. 108

Tabela 7.14 - Retorno do investimento para os diversos perfis de ocupação no cenário 3 .. 109

Tabela 7.15 - Retorno do investimento para os diversos perfis de ocupação no cenário 4 .. 110

Tabela 7.16 - Retorno do investimento para os diversos perfis de ocupação no cenário 4 .. 110

Tabela 7.17 - Principais características do Chiller de 15 TR (CARRIER 2013, modificado)

Tabela 7.18 - Tabela de potência consumida para diversas cargas de operação e temperaturas do ar externo do Chiller 15 TR (CARRIER 2013, modificado).

Tabela 7.19 - Principais características do fan coil de 15 TR (CARRIER 2013, modificado)

Tabela 7.20 - Valores integralizados anuais para o cenário 1 ............................................119

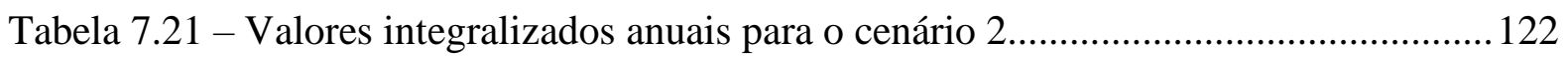

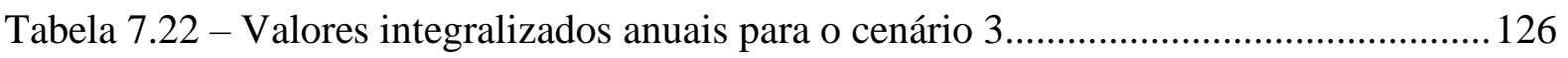

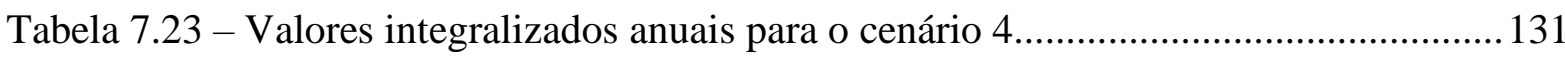

Tabela 7.24 - Comparação dos custos energéticos para os quatro cenários......................... 135 
Tabela 7.25 - Custos iniciais dos cenários. 136

Tabela 7.26 - Custos operacionais dos cenários. 136

Tabela 7.27 - Retorno do investimento de cada cenário 137

Tabela A.1 - Comparação entre os dispositivos de recuperação de energia ar-ar (ASHRAE 2012, modificado).

Tabela B.1 - Vazões mínimas de ar externo para edifício de escritórios com ocupação de $10 \mathrm{~m}^{2} /$ pessoa (Perez-Lombard et al 2011, modificado). 206

Tabela L.1 - Perfil de ocupação (\%) semanal do auditório para 33 horas de operação........259

Tabela L.2 - Perfil de ocupação (\%) semanal do auditório para 43 horas de operação........259

Tabela L.3 - Perfil de ocupação (\%) semanal do auditório para 57 horas de operação........260

Tabela L.4 - Perfil de ocupação (\%) semanal do auditório para 65 horas de operação........260

Tabela L.5 - Perfil de ocupação (\%) semanal do auditório para 80 horas de operação........261

Tabela L.6 - Perfil de ocupação (\%) semanal do auditório para 18 horas de operação........261

Tabela L.7 - Perfil de ocupação (\%) semanal do auditório para 36 horas de operação........262

Tabela L.8 - Perfil de ocupação (\%) semanal do auditório para 72 horas de operação........262

Tabela L.9 - Perfil de ocupação (\%) semanal do auditório para 42 horas de operação........263

Tabela L.10 - Perfil de ocupação (\%) semanal do auditório para 56 horas de operação.......264

Tabela L.11 - Perfil de ocupação (\%) semanal do auditório para 73 horas de operação.......264

Tabela L.12 - Perfil de ocupação (\%) semanal do auditório para 84 horas de operação.......265

Tabela L.13 - Perfil de ocupação (\%) semanal do auditório para 68 horas de operação.......265

Tabela L.14 - Perfil de ocupação (\%) semanal do auditório para 80 horas de operação.......266

Tabela L.15 - Perfil de ocupação (\%) semanal do auditório para 90 horas de operação.......266

Tabela L.16 - Perfil de ocupação (\%) semanal do auditório para 90 horas de operação.......267 


\section{LISTA DE FIGURAS}

Figura 2.1 - Elementos básicos em regulamentos de energia de edificações...... .20

Figura 3.1 - Convenção numérica para os estágios das correntes de ar de alimentação e exaustão (ASHRAE 2012, modificado).

Figura 4.1 - Esquema de controle do sistema de DCV baseado em sensores de CO2 para zonas únicas (Zhang 2012, modificado)....

Figura 4.2 - Estratégia de controle proporcional para DCV baseado em $\mathrm{CO} 2$ pela

ASHRAE 62.1 (Murphy 2008, modificada).....

Figura 4.3 - Estratégia de controle por simples set point para DCV baseado em $\mathrm{CO} 2$ pela

ASHRAE 62.1 (Murphy 2008, modificado).

Figura 5.1 - Esquema do sistema adotado para desenvolvimento do modelo. 45

Figura 5.2 - Esquema detalhado do sistema adotado (detalhamento da Figura 5.1)..... 48

Figura 5.3 - Gráfico de Eficiência x Vazão de ar para o equipamento ERV modelo ECO-V

LZ-H150GBA2 (LG, 2012)

Figura 5.4 - Esquema das correntes de ar de alimentação e exaustão no ERV (LIU et al 2010, modificado).

Figura 5.5 - Fluxograma de funcionamento da simulação.

Figura 5.6 - Fluxograma da metodologia de controle adotada.

Figura 6.1 - Objeto do estudo de caso: Auditório de um edifício de escritórios. .58

Figura 6.2 - Temperatura de bulbo seco e umidade relativa para a cidade de Brasília/DF no ano de 2012 (INMET, 2012)

Figura 6.3 - Perfil de carga térmica anual......

Figura 6.4 - Perfil de carga térmica para o dia de projeto.

Figura 6.5 - Perfil de carga térmica para o dia de projeto com o uso do recurso de ERV......62

Figura 6.6 - Perfil de ocupação original (\%) semanal do auditório em estudo.....

Figura 6.7 - Gráfico de "Potência consumida x Carga de operação" para diversas temperaturas do ar externo - Chiller 12 TR (CARRIER 2013, modificado).

Figura 6.8 - Gráfico de "COP x Carga de operação" para diversas temperaturas do ar externo - Chiller 12 TR (CARRIER 2013, modificado)

Figura 6.9 - Gráfico de "Potência elétrica consumida x Vazão de ar" para o equipamento fan coil VORTEX 12 TR (CARRIER 2013, modificado) 
Figura 6.10 - Gráfico de "Potência consumida x Carga de operação" para diversas temperaturas do ar externo - Chiller 10 TR (CARRIER 2013, modificado).

Figura 6.11 - Gráfico de "COP x Carga de operação" para diversas temperaturas do ar externo - Chiller 10 TR (CARRIER 2013, modificado).

Figura 6.12 - Gráfico de "Potência elétrica consumida x Vazão de ar" para o equipamento fan coil VORTEX 10 TR (CARRIER 2013, modificado).

Figura 6.13 - Gráfico de "Eficiência x Vazão de ar" para o equipamento ERV modelo ECO-V LZ-H150GBA2 (LG 2011, modificado)

Figura 6.14 - Especificações técnicas do ERV (LG, 2011). .71

Figura 6.15 - Perfil Gráfico de "Potência elétrica consumida x Vazão de ar" para o equipamento ERV modelo ECO-V LZ-H150GBA2 (LG 2011, modificado) 71

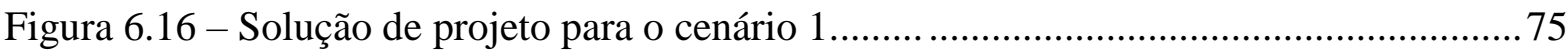

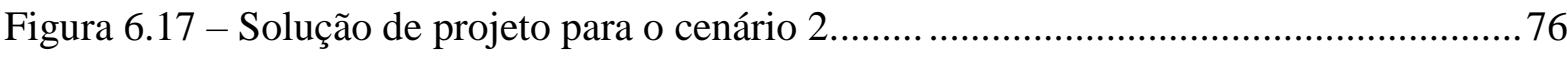

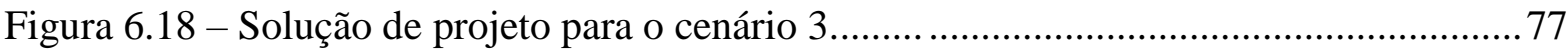

Figura 6.19 - Solução de projeto para o cenário 4 …............................................................... 78

Figura 7.1 - Carga térmica do ar de renovação para o cenário 1 ao longo do ano..................85

Figura 7.2 - Entalpia do ar externo e interno para o cenário 1 ao longo do ano ......................86

Figura 7.3 - Consumo elétrico mensal dos ventiladores de renovação para o cenário 1 ........87

Figura 7.4 - Consumo elétrico mensal do fan coil para o cenário 1 ....................................... 87

Figura 7.5 - Consumo elétrico mensal chiller para o cenário 1 .........................................8 88

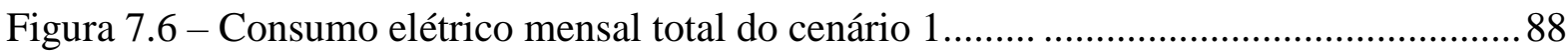

Figura 7.7 - Carga térmica do ar de renovação para o cenário 2 ao longo do ano..................89

Figura 7.8 - Consumo elétrico mensal dos ventiladores de renovação para o cenário 2 ........90

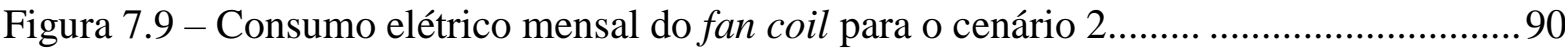

Figura 7.10 - Consumo elétrico mensal do chiller para o cenário 2..................................91

Figura 7.11 - Consumo elétrico mensal total do cenário 2 2..............................................91

Figura 7.12 - Consumo elétrico mensal dos ventiladores de renovação para o cenário 3......92

Figura 7.13 - Entalpia do ar externo e interno para o cenário 3 ao longo do ano...................92 
Figura 7.14 - Energia recuperada no ERV ao longo do ano no cenário 3 93

Figura 7.15 - Consumo elétrico mensal dos ventiladores de renovação para o cenário 3.....94

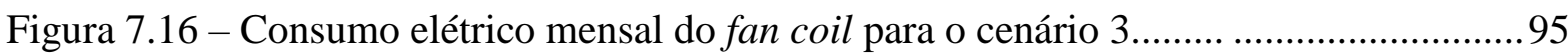

Figura 7.17 - Consumo elétrico mensal chiller para o cenário 3......................................95

Figura 7.18 - Consumo elétrico mensal total do cenário 3 ..............................................96

Figura 7.19 - Carga térmica do ar de renovação para o cenário 4 ao longo do ano.................96

Figura 7.20 - Entalpia do ar externo e interno para o cenário 4 ao longo do ano...................97

Figura 7.21 - Energia recuperada no ERV ao longo do ano no cenário 4............................97

Figura 7.22 - Consumo elétrico mensal dos ventiladores de renovação para o cenário 4 ......99

Figura 7.23 - Consumo elétrico mensal do fan coil para o cenário 4...................................99

Figura 7.24 - Consumo elétrico mensal chiller para o cenário 4...................................... 100

Figura 7.25 - Consumo elétrico mensal total do cenário 4 .................................................... 100

Figura 7.26 - Comparação entre as cargas térmicas do ar de renovação para os quatro cenários ao longo do ano

Figura 7.27 - Comparação entre as cargas térmicas do ar de renovação para os quatro cenários integralizadas ao longo do ano

Figura 7.28 - Comparação dos custos energéticos para os quatro cenários

Figura 7.29 - Retorno do investimento para diversos perfis de ocupação no cenário 2........108

Figura 7.30 - Retorno do investimento para diversos perfis de ocupação no cenário 3 ....... 109

Figura 7.31 - Retorno do investimento para diversos perfis de ocupação no cenário 4 ....... 110

Figura 7.32 - Temperatura de bulbo seco e umidade relativa para a cidade de Manaus/AM no ano de 2012 (INMET, 2012)

Figura 7.33 - Perfil de carga térmica anual

Figura 7.34 - Perfil de carga térmica anual com o uso do recurso de ERV

Figura 7.35 - Gráfico de "Potência consumida x Carga de operação" para diversas temperaturas do ar externo - Chiller 15 TR (CARRIER 2013, modificado) 
Figura 7.36 - Gráfico de "COP x Carga de operação" para diversas temperaturas do ar externo - Chiller 15 TR (CARRIER 2013, modificado).

Figura 7.37 - Gráfico de "Potência elétrica consumida x Vazão de ar" para o equipamento fan coil VORTEX 15 TR (CARRIER 2013, modificado).................................................... 117

Figura 7.38 - Carga térmica do ar de renovação para o cenário 1 ao longo do ano............... 118

Figura 7.39 - Entalpia do ar externo e interno para o cenário 1 ao longo do ano.................118

Figura 7.40 - Consumo elétrico mensal dos ventiladores de renovação para o cenário 1 ....119

Figura 7.41 - Consumo elétrico mensal do fan coil para o cenário 1 ..................................120

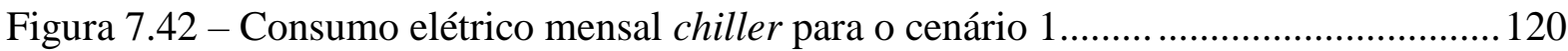

Figura 7.43 - Consumo elétrico mensal total do cenário 1 ................................................. 121

Figura 7.44 - Carga térmica do ar de renovação para o cenário 2 ao longo do ano.............. 122

Figura 7.45 - Consumo elétrico mensal dos ventiladores de renovação para o cenário 2 .....123

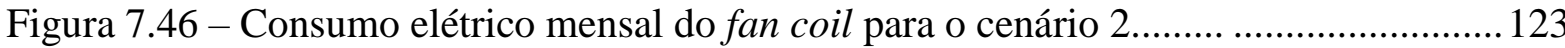

Figura 7.47 - Consumo elétrico mensal chiller para o cenário 2 ....................................... 124

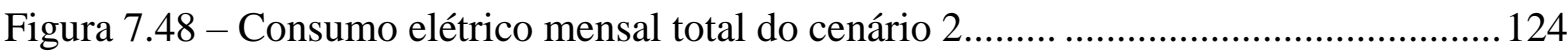

Figura 7.49 - Carga térmica do ar de renovação para o cenário 3 ao longo do ano.............. 125

Figura 7.50 - Entalpia do ar externo e interno para o cenário 3 ao longo do ano.................125

Figura 7.51 - Energia recuperada no ERV ao longo do ano no cenário 3......................... 126

Figura 7.52 - Consumo elétrico mensal dos ventiladores de renovação para o cenário $3 \ldots . . .127$

Figura 7.53 - Consumo elétrico mensal do fan coil para o cenário 3.................................. 127

Figura 7.54 - Consumo elétrico mensal chiller para o cenário 3....................................... 128

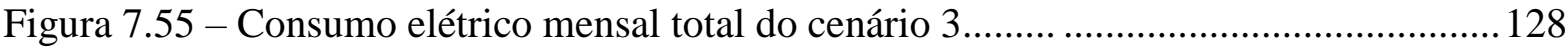

Figura 7.56 - Carga térmica do ar de renovação para o cenário 4 ao longo do ano............... 129

Figura 7.57 - Entalpia do ar externo e interno para o cenário 4 ao longo do ano................. 129

Figura 7.58 - Energia recuperada no ERV ao longo do ano no cenário 4......................... 130

Figura 7.59 - Consumo elétrico mensal dos ventiladores de renovação para o cenário 4.....131 
Figura 7.60 - Consumo elétrico mensal do fan coil para o cenário 4

Figura 7.61 - Consumo elétrico mensal chiller para o cenário 4

Figura 7.62 - Consumo elétrico mensal total do cenário 4.

Figura 7.63 - Comparação entre as cargas térmicas do ar de renovação para os quatro cenários ao longo do ano

Figura 7.64 - Comparação entre as cargas térmicas do ar de renovação integralizadas ao longo do ano para os quatro cenários

Figura 7.65 - Comparação dos custos energéticos para os quatro cenários. 135

Figura 7.66 - Energia total recuperada pelo ERV na cidade de Brasília/DF, no cenário 4 .. 138

Figura 7.67 - Energia total recuperada pelo ERV na cidade de Manaus/AM, no cenário 4.139

Figura 7.68 - Coeficientes de ponderação de calor sensível e latente para Brasília 140

Figura 7.69 - Coeficientes de ponderação de calor sensível e latente para Manaus.....

Figura 7.70 - Eficiência total do ERV para a cidade de Brasília/DF 141

Figura 7.71 - Eficiência total do ERV para a cidade de Manaus/AM 142

Figura 7.72 - Energia sensível recuperada no ERV para a cidade de Brasília/DF 143

Figura 7.73 - Energia latente recuperada no ERV para a cidade de Brasília/DF...... 143

Figura 7.74 - Energia sensível recuperada no ERV para a cidade de Manaus/AM 144

Figura 7.75 - Energia latente recuperada no ERV para a cidade de Manaus/AM 144

Figura A.1 - Tipos de arranjos de fluxo de ar para recuperadores de energia (ASHRAE 2012, modificado).

Figura A.2 - Vazamento de ar de fluxo cruzado em ERVs (ASHRAE 2012, modificado).. 164 Figura A.3 - Recuperador de energia de placas fixas e fluxo (ASHRAE 2012, modificado) 170 Figura A.4 - Recuperador de energia de placas fixas e fluxo cruzado (Green Angel Energy 2013, modificado).

Figura A.5 - Variação na perda de carga e na eficiência com a vazão para recuperadores de placas (ASHRAE 2012, modificado)

Figura A.6 - Típica estratificação de temperatura nas saídas de um ERV de fluxo cruzado (ASHRAE 2012, modificado)

Figura A.7 - Recuperador de energia rotativo (ASHRAE 2012, modificado). 173 
Figura A.8 - Eficiências latente e sensível x Rotação da roda (ASHRAE 2012, modificado)

Figura A.9 - Eficiências latente e sensível x by-pass de ar (ASHRAE 2012, modificado).. 176

Figura A.10 - Eficiência de um recuperador de calor contracorrente (ASHRAE 2012, modificado).

Figura A.11 - Recuperador de energia por meio de serpentina (ASHRAE 2012, modificado)

Figura A.12 - Capacidade de recuperação de energia x Temperatura do ar externo para um recuperador de serpentina (ASHRAE 2012, modificado)

Figura A.13 - Arranjo de tubos quentes (ASHRAE 2012, modificado) 180

Figura A.14 - Operação de tubos quentes (ASHRAE 2012, modificado) 180

Figura A.15 - Processos de transferência de calor sensível no verão e inverno (MUNTERS 2012, modificado)

Figura A.16 - Termossifão tipo tubo selado (ASHRAE 2012, modificado) 182

Figura A.17 - Termossifão tipo serpentina (ASHRAE 2012, modificado)

Figura A.18 - Termossifão tipo serpentina com 8 passes, $2 \mathrm{~mm}$ de espaço entre aletas, carga estática de $80 \%$ (ASHRAE 2012, modificado)....

Figura A.19 - Sistema de torres gêmeas realizando um resfriamento evaporativo indireto do ar: (a) Esquema e (b) Instalação em um edifício (ASHRAE 2012, modificado) 


\section{LISTA DE SÍMBOLOS, NOMENCLATURAS E ABREVIAÇÕES}

\section{Símbolos Latinos}

A

$\mathrm{A}_{\mathrm{Z}}$

$\mathrm{C}_{\mathrm{e}}$

$\mathrm{C}_{\max }$

$\mathrm{C}_{\min }$

$\mathrm{c}_{\mathrm{p} . \mathrm{d}}$

$\mathrm{c}_{\text {pe }}$

$\mathrm{c}_{\mathrm{p} . \mathrm{m}}$

$\mathrm{c}_{\mathrm{ps}}$

CRF

$\mathrm{C}_{\mathrm{S}}$

$\mathrm{C}_{\mathrm{s} \text {,init }}$

$\mathrm{C}_{0}$

d

$\mathrm{E}_{\mathrm{Z}}$

$\mathrm{F}_{\mathrm{p}}$

h

$\mathrm{h}_{\mathrm{fg}}$

$\mathrm{h}_{1}$

ITC

i"
Área de troca de calor

$\left[m^{2}\right]$

Área útil ocupada pelas pessoas do ambiente

Custo da energia para operar o sistema por um período de um ano

Maior valor entre $c_{p s} \cdot \dot{m}_{\mathrm{s}}$ e $c_{p e} \cdot \dot{m}_{\mathrm{e}}$

Menor valor entre $\mathrm{c}_{\mathrm{ps}} \cdot \dot{\mathrm{m}}_{\mathrm{s}} \mathrm{e} \mathrm{c}_{\mathrm{pe}} \cdot \dot{\mathrm{m}}_{\mathrm{e}}$

Calor específico à pressão constante do ar seco

$[\mathrm{kJ} / \mathrm{kg} . \mathrm{K}]$

Calor específico à pressão constante do ar de exaustão úmido

$[\mathrm{kJ} / \mathrm{kg} . \mathrm{K}]$

Calor específico à pressão constante do vapor de água

$[\mathrm{kJ} / \mathrm{kg} . \mathrm{K}]$

Calor específico à pressão constante do ar de alimentação úmido

$[\mathrm{kJ} / \mathrm{kg} . \mathrm{K}]$

Fator de recuperação de capital

Concentração de $\mathrm{CO} 2$ no recinto

$[\mathrm{ppm}]$

Custo inicial do sistema

Concentração de $\mathrm{CO} 2$ no ar exterior

[ppm]

Umidade absoluta

$[\mathrm{kg} / \mathrm{kg}$ de ar seco]

Eficiência de distribuição de ar na zona

Vazão volumétrica de ar externo por ocupante

$\left[\mathrm{m}^{3} / \mathrm{h} /\right.$ pessoa $]$

Entalpia dos pontos das correntes de ar

$[k J / k g]$

Entalpia de vaporização

$[\mathrm{kJ} / \mathrm{kg}]$

Entalpia no estado 1 (entrada do ar de alimentação)

$[k J / k g]$

Taxa de investimento para melhorias em eficiência energética

Taxa de desconto efetivo ajustado pela inflação da energia 
$\dot{\mathrm{m}}_{\mathrm{e}} \quad$ Vazão mássica do ar seco de exaustão

$\dot{\mathrm{m}}_{\min } \quad$ Menor valor entre $\dot{m}_{s}$ e $\dot{m}_{e}$

$\dot{\mathrm{m}}_{\mathrm{s}} \quad$ Vazão mássica do ar seco de alimentação

Número total de períodos avaliados

$\mathrm{N}$

Taxa de geração de $\mathrm{CO} 2$ por pessoa

[ppm/hora/pessoa]

$\mathrm{P}_{\text {blower }}$

Potência de ventilação para o recuperador

$\mathrm{P}_{\text {comp }} \quad$ Potência de entrada direta para o recuperador

$\dot{\mathrm{P}}_{\mathrm{e}}$

Potência de ventilação para o ar de exaustão

$\dot{\mathrm{P}}_{\mathrm{S}} \quad$ Potência de ventilação para o ar de alimentação

$\mathrm{P}_{\mathrm{Z}} \quad$ Número de ocupantes do ambiente

$\mathrm{Q}_{\text {blower }} \quad$ Perda de carga da corrente de ar de alimentação ou exaustão

Q $\quad$ Vazão volumétrica de ar de exaustão

$\dot{\mathrm{q}}_{\mathrm{L}}$

Taxa de transferência de calor latente

Máxima taxa de transferência de calor latente

$\mathrm{Q}_{\mathrm{S}} \quad$ Vazão volumétrica de ar de alimentação

$\dot{\mathrm{q}}_{\mathrm{s}, \max } \quad$ Máxima taxa de transferência de calor sensível

$\mathrm{R}_{\mathrm{a}} \quad$ Vazão volumétrica de ar externo por unidade de área

$\mathrm{R}_{\mathrm{p}} \quad$ Vazão volumétrica de ar externo por ocupante

$\mathrm{T}_{\mathrm{inc}}=\quad$ Taxa de imposto de renda líquida aonde as taxas são baseadas no último dólar ganho (taxa marginal) 


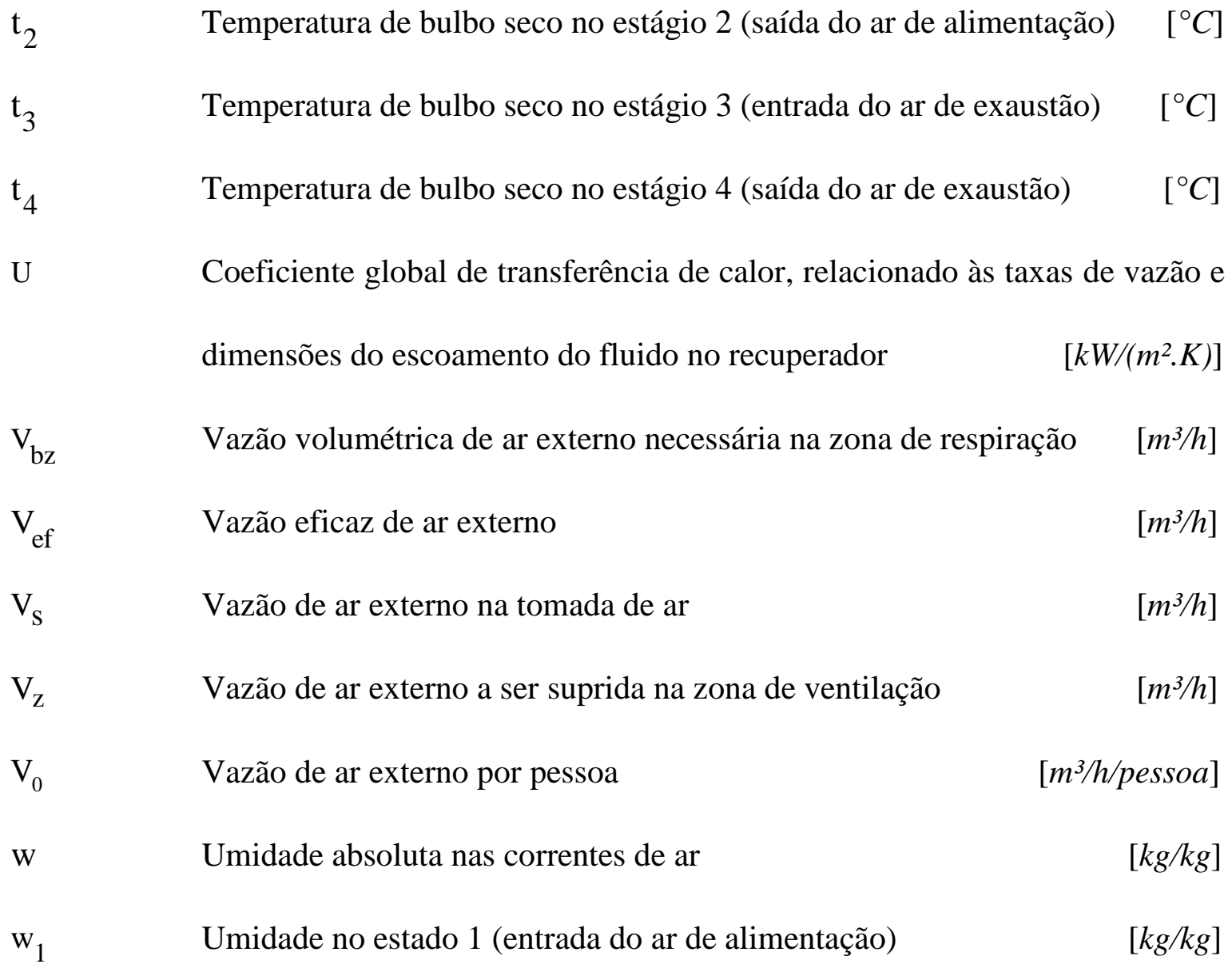

\section{Símbolos Gregos}

$\Delta \mathrm{p} \quad$ Perda de carga da corrente de ar de alimentação ou exaustão $\quad[k P a]$

$\Delta \mathrm{p}_{\mathrm{e}} \quad$ Perda de carga da corrente de ar de exaustão causada pela fricção do

fluido $\quad[\mathrm{Pa}]$

$\Delta \mathrm{p}_{\mathrm{s}} \quad$ Perda de carga da corrente de ar de alimentação causada pela fricção do

fluido

$\varepsilon_{\mathrm{L}} \quad$ Eficiência latente

$\varepsilon_{\mathrm{S}} \quad$ Eficiência sensível

$\varepsilon_{\mathrm{t}} \quad$ Eficiência total 
$\eta_{\mathrm{f}} \quad$ Eficiência global do ventilador e do motor ou o produto dessas duas

eficiências

$\rho_{\mathrm{s}} \quad$ Massa específica do ar seco de alimentação

$\left[\mathrm{kg} / \mathrm{m}^{3}\right]$

$\rho_{\mathrm{e}}$

Massa específica do ar seco de alimentação

$\left[\mathrm{kg} / \mathrm{m}^{3}\right]$

\section{Grupos Adimensionais}

Biot Número de Biot

\section{Subscritos}

Entrada do ar externo de alimentação

2

Saída do ar externo de alimentação

3

Entrada do ar de exaustão

4

Saída do ar de exaustão

blow ventilador

max máximo

min mínimo

\section{Sobrescritos}

Variação temporal

Valor médio 


\section{Siglas}

ABNT Associação Brasileira de Normas Técnicas

AC Alternating Current (Corrente Alternada)

AIV Air Handler Vortex

ANEEL Agência Nacional de Energia Elétrica

ANVISA Agência Nacional de Vigilância Sanitária

ASHRAE American Society of Heating and Air-Conditioning Engineers (Sociedade

Americana dos Engenheiros de Refrigeração e Ar Condicionado)

ASTM American Society for Testing and Materials

AVAC Aquecimento, Ventilação e Ar Condicionado

CABO Council of America Building Officials

CEF Combined Efficiency (Eficiência Combinada)

CFD Computational Fluid Dynamics

CGIEE Comitê Gestor de Indicadores e Níveis de Eficiência Energética

CO2 Dióxido de Carbono

COP Coeficiente de Performance

DC Direct Current (Corrente Contínua)

DCV Demand-Controlled Ventilation (Ventilação por Controle de Demanda)

DOE Department of Energy (Departamento de Energia)

EER Energy Efficiency Ratio (Taxa de Eficiência Energética)

EES Engineering Equation Solver

EPA Environmental Protection Agency

ERV Energy Recovery Ventilator (Ventilador de recuperação de energia) 
EUA Estados Unidos da América

GT MME Grupo Técnico para Eficientização de Energia nas Edificações

HAP Hourly Analysis Program

HRV Heat Recovery Ventilator (Ventilador de recuperação de calor)

IAQ Interior Air Quality (Qualidade do Ar Interior)

ICC Internation Code Council

IECC International Energy Conservation Code

INMET Instituto Nacional de Meteorologia

LCCA Life Cycle Cost Analysis (Análise do custo do ciclo de vida)

LEED Leadership in Energy and Environmental Desing

MEC Model Energy Code (Código de Modelo de Energia)

NBR Norma Brasileira

NTU Number of Transfer Unit (Número de unidades de transferência)

PID Proportional-Integral-Derivative

PMOC Plano de Manutenção, Operação e Controle

PP Payback Period (Período de Retorno)

PPM Partes por Milhão

PROCEL Programa Nacional de Conservação de Energia Elétrica

QAI Qualidade do Ar Interior

RER Recovery Efficiency Ratio (Taxa de Eficiência de Recuperação)

ROI Return of Investment (Retorno do Investimento)

SBS Sick Building Syndrome (Síndrome do Edifício Doente)

USGBC United States Green Building Council 
VAV Variable Air Volume (Volume de Ar Variável)

VFD Variable-Frequency Drive (Inversor de Frequência)

VRP Ventilation Rate Procedure (Procedimento de Taxa de Ventilação) 


\section{1 - INTRODUÇÃO}

\section{1 - O PROBLEMA EM ESTUDO E SUA IMPORTÂNCIA}

No cenário atual, a necessidade de conservação de energia tem recebido maior atenção no campo das pesquisas científicas e tecnológicas. Soma-se a esse fato o aumento das discussões acerca dos impactos ambientais causados pelo crescimento desenfreado das populações. Assim, diversas pesquisas, nas mais variadas áreas das ciências, têm sido desenvolvidas com o intuito de buscar tecnologias que aumentem a eficiência dos sistemas atuais e diminuam os impactos ambientais causados.

Uma das principais preocupações do país é a questão energética, pois o crescimento industrial e demográfico tem exigido cada vez mais dos recursos de energia. Nesse sentido, o Brasil vem fazendo constantemente programas de racionalização para diminuir a demanda. De acordo com dados da Agência Nacional de Energia Elétrica (ANEEL, 2012), a potência demandada por instalações de ar condicionado e refrigeração é da ordem de 14.000 MW, representando 11,8\% da capacidade instalada no país. Dessa forma, soluções mais eficientes também são necessárias nos diversos sistemas de engenharia, de maneira a manter as mesmas funções exigidas com a utilização de menos recursos que os sistemas tradicionais.

Esse é caso em sistemas de Aquecimento, Ventilação, Ar Condicionado (AVAC), que são sistemas requeridos para prover conforto térmico e qualidade do ar interno em edifícios ou escritórios, com razoáveis custos de instalação, manutenção e operação.

É notório o desenvolvimento de equipamentos e meios para diminuir e evitar maiores danos ao ambiente em sistemas AVAC. Exemplos disso são as substituições de fluidos refrigerantes por outros mais ecológicos, como os hidrocarbonetos, soluções alternativas para a climatização, como o resfriamento evaporativo, o aumento da eficiência de trocadores de calor, bombas e compressores, demandando, assim, uma menor quantidade de energia. No entanto, tais equipamentos devem ser alocados em uma concepção de projeto que também prime por requisitos de eficiência.

Assim, os projetos de climatização atuais devem levar em conta diversos critérios que visam à eficiência e redução do impacto ambiental. Dentre eles, podem ser citados os critérios de operação do sistema em cargas térmicas parciais, o que requer sistemas capazes de modular seu funcionamento de maneira eficiente. Sistemas que não operam em cargas 
parciais geram um alto consumo energético, já que estará sempre atuando em carga máxima, mesmo que o ambiente não demande tal carga térmica.

Além da preocupação com a operação em cargas parciais, outro requisito importante é a utilização de meios que garantam a regeneração do calor que, inicialmente, seria rejeitado para o meio. Nesse quesito, aparecem, nos sistemas atuais, os recuperadores de energia alocados entre o ar de exaustão e a tomada de ar externo. Esses equipamentos têm por objetivo realizar uma troca de calor, por meio de condução indireta, do ar frio que é retirado da sala com o ar quente obtido do ambiente externo. Dessa forma, o equipamento de climatização precisaria retirar uma menor quantidade de calor do ar da mistura, reduzindo o consumo de energia.

Outra característica importante de sistemas AVAC é a qualidade do ar interno. Apesar de não ser recente, com a normatização de parâmetros de conforto e qualidade do ar por órgãos brasileiros e internacionais, o assunto tem entrado cada vez mais em pauta, estando presente em praticamente todos os projetos que visem conforto térmico. Além disso, análises da qualidade do ar têm sido realizadas em edifícios, de forma a verificar se os parâmetros estão de acordo com as normas, além de ser uma espécie de auditoria da manutenção e operação do sistema de AVAC local.

Nesse sentido, tendo em vista que a introdução de ar externo no sistema acarreta um aumento de carga térmica devido aos parâmetros de temperatura de bulbo seco e umidade absoluta, estudos em relação às vazões necessárias de ar de renovação também são de fundamental importância quando se trata aspectos de eficiência energética. Tal situação privilegia a utilização de sistemas com renovação de ar variável.

Assim, o uso de sistemas tradicionais de AVAC que requerem altas taxas de renovação de ar irá demandar também uma maior potência de ventilação para atender às demandas do edifício. Nesse sentido, serão necessários maiores climatizadores de ar, com maiores serpentinas e ventiladores. Esse conjunto de fatores acarreta um sistema superdimensionado e que não prima pelos requisitos de conservação de energia. Portanto, estudos direcionados para as análises das vazões ideais de renovação de ar, associadas ainda com recuperação de energia, têm grande potencial para a economia de custos significativos nas fases de concepção, dimensionamento do sistema, operação e manutenção. 


\section{2 - REVISÃO BIBLIOGRÁFICA}

O setor da construção civil no Brasil consome, ainda hoje, aproximadamente um terço da energia primária utilizada na maioria dos países em desenvolvimento, envolvendo, além da emissão de toneladas de dióxido de carbono e esgotamento das fontes de energia, um custo da ordem de milhões (Colmenar-Santos et al., 2013).

Esse fato tem tornado prioritárias estratégias de eficiência e economia energética nas políticas do setor na maioria dos países (Perez-Lombard et al., 2008). Além disso, esse esforço oferece grande potencial de redução do consumo de energia primária e da emissão de dióxido de carbono a partir da redução de demandas de aquecimento, do aumento da eficiência nas cadeias de abastecimento energético e do aumento do uso de recursos renováveis para materiais e combustíveis.

Diversas estratégias podem ser utilizadas para a consumação desse potencial incluindo requisitos de eficiência energética em normas aplicadas à construção civil, como a especificação, por exemplo, de exigências mínimas de eficiência energética para os edifícios (European Commission, Action Plan for Energy Efficiency, 2006).

O consumo de energia de um escritório ou edifício comercial durante o seu tempo de vida operacional é significativamente maior que a energia incorporada nos materiais e na construção (Claridge et al., 1994). Dessa forma, cada vez mais esforços têm sido empregados no sentido de conferir ao edifício e às suas instalações um nível maior de eficiência, atendendo aos requisitos e padrões de normas nacionais e internacionais definidos por leis, normas, códigos, estratégias, políticas ou sistemas de certificação.

Dentre as diversas instalações existentes, os sistemas de AVAC são os maiores consumidores de energia das edificações não residenciais, respondendo por cerca de 10$20 \%$ do consumo final de energia em países desenvolvidos (Perez-Lombard et al., 2008).

Perez-Lombard et al (2011) analisaram o desenvolvimento dos códigos de eficiência energética de sistemas de AVAC para edificações em relação ao seu escopo e conformidade. Foram analisados doze dos principais códigos de eficiência energética de edifícios espalhados pelo mundo, cobrindo mais de trinta nações em quatro continentes distintos. Também foram classificadas seis categorias de prescrições normativas que serviriam como base para uma seleção eficiente dos diversos componentes de sistemas de AVAC: a) eficiência mínima de equipamentos; b) sistemas de distribuição de fluidos; c) sistemas de controle; d) ventilação de ar externo; e) recuperação de energia e f) ciclo economizador. 
A ventilação de ar externo é um requisito obrigatório para a obtenção de uma aceitável Qualidade do Ar Interior (QAI). As normas geralmente definem um valor mínimo de vazão de ar exterior e de nível de filtragem com vistas à redução da concentração dos contaminantes do ar a níveis aceitáveis. Os sistemas de ventilação geralmente usam energia térmica para tratamento do ar exterior e energia elétrica para filtragem e distribuição do ar nos espaços condicionados, consequentemente, os requisitos de QAI estão diretamente associados à eficiência energética em sistemas de AVAC (PerezLombard et al., 2011).

Dessa forma, quanto maior a taxa de renovação de ar, maior o consumo de energia e os custos de operação dos sistemas de climatização. Assim, tendo em vista que as vazões de ar externo são dimensionadas geralmente com base na área do espaço condicionado e no número de ocupantes, as taxas mínimas são estimadas considerando-se o número máximo de ocupantes. Por esse motivo, é recomendável que os sistemas de AVAC sejam ajustáveis de modo que as taxas de ventilação possam ser reduzidas de acordo com a demanda, evitando uma ventilação em excesso (PEREZ-LOMBARD et a.l, 2011).

Em termos gerais, as cargas térmicas de resfriamento ou aquecimento da ventilação de ar externo constituem de $20 \%$ a $40 \%$ da carga térmica total para edifícios comerciais (ASHRAE, 1997). Felizmente, uma grande fração dessa energia requerida para condicionar o ar externo pode ser recuperada se os ventiladores de recuperação de energia são utilizados (energy recovery ventilators - ERV) (Dorer and Breer, 1998).

As tecnologias de recuperação de energia, outra categoria de prescrição normativa abordada, são bem conhecidas e amplamente utilizadas como medida de eficiência energética, tanto na construção civil como na indústria. Dentre os principais processos de recuperação de energia em instalações de AVAC, pode-se destacar a recuperação térmica a partir do ar de exaustão.

Nela, o ar externo adentra o edifício nas condições climáticas externas e é exaurido aproximadamente nas condições internas. Consequentemente, esse processo requer a adição ou extração de carga térmica de ventilação. A energia térmica do ar exaurido pode ser recuperada para pré-aquecer ou resfriar o ar externo de renovação, gerando uma redução na carga térmica devido à ventilação (Perez-Lombard et al., 2011).

Os equipamentos que realizam esse processo são chamados de recuperadores de energia ar-ar (air-to-air energy recovery equipment). Esses recuperadores de energia entre fluxos de ar podem ser divididos em dois grupos: i) sistemas de recuperação que transferem apenas calor sensível (heat recovery ventilator $-H R V$ ) e ii) sistemas de 
recuperação de calor e umidade que transferem tanto calor sensível quanto calor latente (energy recovery ventilator $-E R V)$.

No passado, as pesquisas tiveram como foco apenas a recuperação de calor sensível, sendo desprezado o tratamento da umidade do ar da ventilação externa. Esses sistemas utilizam normalmente trocadores de calor tradicionais, como os trocadores de placas fixas (fixed plates), rodas trocadoras de calor sensível (sensible heat exchange wheels), tubos de calor (heat pipes) e trocadores de calor por meio de bombeamento de fluido em serpentina (run-around loop heat exchangers), os quais possuem fácil implementação.

Dhital et al (1995) investigaram os efeitos dos sistemas de trocadores de calor por meio de bombeamento de fluido em serpentina (run-around heat exchangers) no consumo de energia e na análise de custo do ciclo de vida energético (life cycle cost analysis LCCA) de um edifício de escritórios típico. As simulações foram feitas em quatro cidades americanas e os resultados apresentaram economias anuais de energia de até 4,8\%, associados à redução de até $8 \%$ na capacidade dos chillers.

Johnson et al (1995) dimensionaram e simularam um sistema de bombeamento de fluido em serpentina (multiple-coil run-around system) em um amplo conjunto (range) de condições de operação, desde climas frios até climas quentes com altas cargas térmicas de resfriamento. Foi realizada uma simulação anual com base em informações horárias de temperatura e umidade, em que foi possível determinar os custos operacionais anuais e as economias devidas ao uso do sistema. Para o edifício típico analisado, o período de retorno do investimento dos sistemas de recuperação de energia aplicados foi menor que 3,4 anos.

Manz et al (2000) investigaram uma unidade de ventilação com recuperação de calor em uma sala única, a partir de análises numéricas e experimentais, em relação aos requisitos de eficiência na ventilação, conforto térmico, recuperação de calor, consumo de energia elétrica e parâmetros acústicos. Usando essas unidades de ventilação, ficou demonstrado que a sala foi ventilada com eficiência (eficiência de troca de ar igual a 0,6) em um ótimo nível de conforto térmico, apresentando ainda razoável economia de energia devido à recuperação de calor utilizada.

Nos últimos anos, tem crescido a atenção dispensada à recuperação de energia, também chamada de recuperação entálpica, na qual tanto o calor sensível quanto o calor latente são recuperados. A técnica de recuperação de entalpia se baseia principalmente nos processos de sorção alternada (absorção e adsorção) e regeneração, a partir da utilização de materiais dessecantes, quer sob a forma de leitos cíclicos fechados (cycling packed beds) 
(San, 1993) ou rodas giratórias (rodas entálpicas) (rotary wheels or rotary enthalpy wheels).

Klein et al (1990) desenvolveram um modelo computacional de um trocador ar-ar entálpico com um dessecante sólido. Foram estabelecidas correlações para as quais a eficiência entálpica do trocador seria máxima e definida como função apenas do número unitário de trocas (number of transfer unit - NTU). As correlações apresentadas se mostraram eficazes para determinadas condições de operação em que existe troca entálpica.

Stiesch et al (1995) estudaram recuperadores de energia do tipo rodas entálpicas giratórias aplicadas em edifícios, com o objetivo de analisar sua eficiência anual. Foram analisados edifícios de escritórios em três cidades americanas, com taxa de ventilação de acordo com a norma da ASHRAE à época (20 cfm/pessoa). Foram medidas as economias no consumo de energia, tanto para aquecimento quanto para resfriamento, durante 15 anos para trocadores de entalpia e trocadores de calor sensível apenas. As economias acumuladas foram da ordem de $\$ 28.000$ a $\$ 38.000$ para o trocador entálpico e de $\$ 7.000$ a $\$ 24.000$ para o trocador de calor sensível.

Simonson e Besant (1998) apresentaram e validaram experimentalmente um modelo numérico para a análise de rodas entálpicas com transferência de calor, umidade, condensação e congelamento. A presença de condensado e gelo aumenta com a umidade em certos níveis de umidade relativa do ar, se acumulando permanentemente na roda entálpica. Foram estudadas as sensibilidades aos processos de condensação e congelamento em rodas entálpicas com dois tipos de materiais dessecantes: i) dessecante com um tipo de sorção isotérmica (ex: peneira molecular) e ii) dessecante com sorção isotérmica linear (ex: sílica gel). Os resultados da simulação mostraram que o dessecante com curva de sorção linear é mais favorável para a recuperação de energia, pois tem melhores características de eficiência e menores quantidades de condensação/congelamento em condições de operação extremas.

Simonson e Besant (1999a) apresentaram os grupos adimensionais fundamentais para os trocadores ar-ar tipo rodas entálpicas (rotary wheels) que transferem calor sensível e vapor de água. Esses grupos são derivados das equações governantes de transferência de calor e massa acopladas. Ao contrário das rodas de energia, que trocam apenas calor sensível, a eficiência das rodas entálpicas se dá em função das condições operacionais de temperatura e umidade, conforme verificado por diversos fabricantes e pesquisadores. Simonson e Besant (1999b) conferiram o significado físico para esses grupos 
adimensionais e os utilizaram para desenvolver correlações de eficiência para as rodas de energia. As correlações de eficiência apresentadas permitem ao projetista prever as eficiências de calor sensível, latente e total das rodas de energia quando as condições de operação são conhecidas. Os resultados mostraram que a sua eficiência total pode ser maior que $70 \%$.

Além das rodas entálpicas, existe outro tipo de tecnologia de recuperação entálpica baseada em placas de membrana (membrane plates), que são uma variação da tecnologia de recuperação de calor sensível do tipo placas fixas (fixed plates). Membranas têm sido bastante utilizadas nos processos de separação umidade/ar em processos industriais ao longo dos anos (Pan et al., 1978; Asaeda e Du, 1986; Wang et al., 1992; Cha et al., 1996).

Entretanto, embora os produtos que utilizam membranas hidrofílicas para recuperação de entalpia estejam disponíveis no mercado, sua eficiência na recuperação de energia de ventilação não foi amplamente documentada até o início do século XXI como foram os produtos do tipo roda entálpica. $\mathrm{O}$ sistema de membrana se baseia na utilização de novas membranas hidrofílicas, permitindo que o calor e umidade sejam transferidos simultaneamente, ao contrário do trocador tradicional de placas fixas, que troca apenas calor sensível. Ele é fácil de construir e instalar e requer pouca manutenção.

Zhang e Jiang (1999) analisaram numericamente os processos simultâneos de transferência de calor e massa por meio de uma membrana hidrofílica como uma descoberta fortuita por meio do desenvolvimento de uma bomba de umidade. Posteriormente, Zhang e Niu (2002) analisaram os mecanismos de transferência de calor e massa que ocorrem em rodas dessecantes baseadas em um modelo bidimensional, em que foram discutidos os efeitos da espessura da parede sobre as velocidades de rotação ideais para aplicações de desumidificação e recuperação entálpica. A partir de simulações numéricas, foram calculadas as velocidades ideais com vistas à recuperação de calor sensível, de calor latente e de desumidificação do ar.

Zhang et al (2000) investigaram as características das transferências de calor e massa de uma membrana permeável à água, com o intuito de criar uma referência visando a seleção de uma membrana apropriada para ventiladores de recuperação de energia (ERV). Os cálculos resultantes desse trabalho foram validados experimentalmente. Zhang e Niu (2001) compararam a economia de energia entre um ventilador de recuperação de energia (ERV) e um ventilador de recuperação de energia sensível apenas (HRV) no clima quente e úmido da cidade de Hong Kong. Os resultados da simulação sugeriram que quanto mais úmido o clima, melhores são os resultados do ERV em relação ao HRV. 
Abe et al (2006) apresentaram um modelo analítico para prever a eficiência de rodas de energia usando apenas as características medidas na mesma roda em condições estacionárias expostas a mudanças de temperatura e umidade. A comparação entre as eficiências latente e sensível previstas em relação aos testes experimentais se apresentaram dentro de certos limites de incerteza. As simulações numéricas também apresentaram resultados coerentes dentro de certos limites.

Nasif et al (2005) avaliaram experimentalmente o desempenho, em termos de eficiência sensível e latente, de um recuperador de energia ar-ar tipo Z que utiliza papel como superfície de transferência. Um modelo no software CFD (computational fluid dynamics) foi desenvolvido nesse estudo a fim de analisar a distribuição de calor e umidade, e os resultados foram validados experimentalmente a partir de medições em uma plataforma experimental.

Sphaier e Worek (2006) fizeram uma comparação entre as formulações matemáticas que descrevem o fenômeno de transporte que ocorre dentro das rodas entálpicas, incluindo efeitos da transferência de calor axial, da difusão de massa, e, ainda, uma versão simplificada, sem considerar esses efeitos. Os resultados mostraram que a razão de aspecto do substrato dessecante juntamente com o número de Biot são parâmetros relevantes para determinar se a difusão axial deve ser incluída na análise.

Li et al (2005) propuseram um novo tipo de unidade de ar externo, composto basicamente por um líquido dessecante recuperador de entalpia e de um ciclo de refrigeração de pequena capacidade. Testes experimentais dessa unidade instalada em um hospital apresentaram uma taxa de eficiência energética (energy efficiency ratio - EER) variando entre 6.3-7.3 no verão e entre 4.7-5.0 no inverno. O equipamento se mostrou confiável na eliminação de superfícies molhadas em sistemas de ar condicionado, proporcionando melhores qualidades no ar interior.

Yin (2006) propôs um novo tipo de recuperador de energia de placas fixas, utilizando membranas separadas de gás de nanocompósitos, cujos valores de eficiência entálpica alcançaram $75 \%$, além de uma drástica redução na resistência do ar devido ao cancelamento da estrutura de papel corrugado.

Zhou et al (2007) simularam um sistema de ERV em dois locais da China com diferentes condições climáticas utilizando o software EnergyPlus, a partir um modelo de simulação dinâmica das condições operacionais. Foi determinada uma nova variável, definida como a razão entre a recuperação de energia e a entrada total de energia no sistema de ar condicionado. Os resultados das simulações mostraram que a média sazonal 
dessa variável possui uma relação linear com os valores de temperatura interna do ambiente condicionado. Ainda, eles reportaram que a aplicação do ERV reduziu mais o consumo de energia durante o inverno em Shangai do que em Pequim, e, durante o verão, a utilização do ERV em Pequim não era econômica quando a temperatura interna do ambiente fosse maior que $24^{\circ} \mathrm{C}$.

Fauchoux et al (2007) apresentaram os impactos indesejáveis de um ERV (roda entálpica) funcionando sem controle de operação em cargas de resfriamento em climas frios e amenos (Vancouver e Saskatoon, no Canadá). Os resultados apontaram que a energia para resfriamento poderia ser reduzida utilizando-se uma estratégia de controle baseada na temperatura interna do ambiente. Ainda, verificaram que a utilização do ERV nessas cidades conferiu melhorias na qualidade do ar interior e na redução da umidade relativa.

Mumma (2001) utilizou uma estratégia de controle para rodas entálpicas empregadas em sistemas dedicados de ar externo. A estratégia implementada não permitiu que o ERV operasse quando a entalpia do ar externo fosse menor que a entalpia do ar interno enquanto a umidade do ar externo fosse maior que a umidade necessária para o suprimento de ar no ambiente condicionado.

Os estudos mais recentes têm mostrado influência das condições de temperatura e umidade do ar externo no desempenho dos ERV. Esse fato gera a necessidade da avaliação do desempenho desses equipamentos em diversos locais, com condições climáticas distintas, e em diferentes estações do ano, para que sejam disponibilizados dados técnicos suficientes que embasem decisões de projetos que utilizem esses equipamentos. Com essas análises aplicadas para cada local e estação do ano, é possível, ainda, definir uma melhor estratégia de operação para cada equipamento, no sentido de maximizar seu desempenho ao longo do ano.

Yanming et al (2009) estudaram a aplicabilidade de sistemas ERV na China. Por causa das diferenças dos climas locais entre as regiões sul e norte do país, as frações de calor sensível e latente por unidade de vazão de ar externo são diferentes entre as regiões, assim como a eficiência global dos recuperadores de energia. Foi avaliada a composição anual do consumo de ar externo por unidade de vazão a partir dos dados climáticos de oito cidades analisadas. A análise verificou a aplicabilidade dos sistemas de ERV na China em diferentes condições de operação, de forma a atender às prescrições normativas de eficiência energética em edifícios comerciais chineses. 
Os resultados mostraram que a eficiência do recuperador de energia é significantemente maior que a eficiência do recuperador de calor sensível apenas, nas aplicações em sistemas de ventilação controlada em edifícios com pequena emissão de umidade ao longo do ano. Por esse fator, os preços dos ERV são maiores que dos HRV. Ainda, a relação entre os consumos de energia sensível e latente são o fator chave para a utilização de um ERV ou de um HRV, uma vez que esses consumos dependem do clima, das condições de projeto do ar interno e das aproximações utilizadas para caracterização do ar externo. Dessa forma, foi mostrado que, para climas quentes e úmidos, a utilização do ERV é melhor que a do HRV. As análises apresentadas consideraram valores fixos para as eficiências globais dos recuperadores de energia e não foram abordadas questões relativas à vazão de ar variável e nem às perdas de carga inerentes aos equipamentos.

Rasouli et al (2010) estudaram a aplicabilidade e a definição de uma estratégia de controle ideal para recuperadores de energia em diferentes condições climáticas. Os impactos da utilização do ERV no consumo anual de energia para resfriamento e aquecimento foram investigados por meio de um modelo de um edifício comercial de dez pavimentos em quatro cidades americanas. Os resultados mostraram que a recuperação de calor e umidade pode levar a significativas reduções anuais no consumo de energia para aquecimento, registrando acima de $40 \%$ de economia.

Além disso, um ERV operando sob uma estratégia ótima de controle foi capaz de economizar acima de $20 \%$ no consumo anual de energia para cargas de resfriamento, dependendo da localização e da eficiência do recuperador. Foi mostrado também que um ERV sem controle de operação pode aumentar o consumo de energia para cargas de resfriamento durante o verão. Nesse sentido, uma estratégia de controle ótimo foi proposta, sendo comparada com o controle baseado na temperatura apenas. Esse controle depende do fator $\mathrm{H}$, que relaciona as eficiências de calor sensível e latente do equipamento. Assim, dependendo da taxa de eficiência latente, a operação do ERV em estações com cargas de resfriamento estaria limitada a condições específicas do ar exterior, dentro de certos limites apresentados.

Por exemplo, o controle ótimo de um ERV que possui valores iguais para as eficiências sensível e latente ocorre quando o ar exterior possui maior entalpia ou maior temperatura que o ar interior. Os resultados da simulação, de acordo com as formulações teóricas, indicaram que um ERV pode operar em uma gama mais ampla para condições externas frias e úmidas quando o equipamento possui uma eficiência latente maior que a sensível. As análises apresentadas consideraram valores fixos (padrões da norma) para as 
eficiências globais dos recuperadores de energia e, em relação à vazão de ar exterior variável, foram levantados três níveis de variação de vazão apenas. Não foram abordadas questões relativas à perda de carga nos equipamentos.

Liu et al (2010) analisaram a eficiência de ERVs em diversas condições climáticas e seu desempenho na economia de energia em apartamentos residenciais. Atualmente, ERVs têm sido usados frequentemente em edifícios comerciais, industriais e residenciais na China. Baseando-se nas relações entre as eficiências de calor sensível, latente, e eficiência total, foram analisadas as equações com coeficientes ponderados que descrevem o desempenho do ERV em diferentes zonas climáticas no país. De acordo com as informações climáticas, a eficiência total do recuperador depende principalmente da eficiência de calor sensível no inverno e da eficiência de calor latente no verão.

Assim, os desempenhos na economia de energia foram estudados em cinco condições climáticas distintas, também em função da eficiência total ou entálpica, da potência de ventilação consumida e de certas variações na vazão de ar exterior. Os resultados mostraram que, em condições de inverno e verão, o coeficiente ponderado de eficiência de calor sensível diminui com a diminuição da temperatura externa, enquanto o coeficiente de eficiência de calor latente aumenta, porém, essa tendência é mais suave no inverno. As potências de ventilação e também os percentuais de energia economizada aumentam com o aumento das taxas de ventilação de ar externo também.

Kim et al (2012) determinaram programações de operação de um HRV visando a maximização da economia de energia em grandes edifícios residenciais. Os resultados medidos mostraram que o consumo de energia de cada edifício foi reduzido quando o HRV foi operado de acordo com as taxas de ventilação recomendas e em certas faixas de temperatura de conforto. As simulações apresentaram uma contribuição anual na economia de energia de 9,45\% para cargas de aquecimento e 8,8\% para cargas de resfriamento, quando o HRV operou de forma intermitente. Uma verificação importante foi a de que o HRV é mais significativo para recuperação de energia quando são grandes as diferenças de temperatura entre o ar de exaustão do ambiente interno e o ar exterior.

Por fim, o estudo sugeriu que a influência do HRV na melhoria da qualidade do ar interior (QAI) deve ser examinada em conjunto com a economia de energia provida pelo equipamento, uma vez que a aplicação dele no estudo em questão melhorou as condições do ar interno, já que as taxas de ventilação recomendadas foram mantidas em todo o período de análise. 
Yaici et al (2013) analisaram numericamente a recuperação de energia em ERVs e HRVs de membranas utilizando o software CFD. O modelo proposto incluiu os mecanismos de transferência de calor e massa para escoamentos laminares a fim de investigar o desempenho térmico desses sistemas. Foram analisados equipamentos com fluxos paralelos em mesmo sentido e em contra corrente nas estações de verão e inverno no Canadá. Os resultados numéricos confirmaram a superioridade na eficiência do recuperador de fluxo em contra corrente.

Foi apresentada, ainda, uma redução na eficiência dos recuperadores com o aumento na velocidade do ar externo de suprimento ou no ar interior de exaustão. A eficiência do ERV no verão foi maior em comparação com o inverno, sob as condições climáticas do Canadá. A estação do ano também mostrou efeito significativo no desempenho do HRV e na potência de ventilação consumida, cujo valor foi aproximadamente $18 \%$ maior no verão em relação ao inverno. Os resultados da análise do ERV mostraram que a temperatura e a umidade relativa do ar exterior não tem efeito significativo na eficiência de calor sensível do recuperador, ao contrário da eficiência de calor latente, que aumenta com o aumento da umidade relativa tanto no verão quanto no inverno.

Existem diversos outros trabalhos que abordam a utilização de sistemas de ERV em aplicações de AVAC, porém, eles não se diferem muito do que foi aqui apresentado. Em conclusão, o atual estágio do conhecimento de aplicações de recuperadores de energia, juntamente com vazões variáveis de ar externo, suscita a possibilidade de se analisar os efeitos de economia de energia e de recursos financeiros do uso dessas técnicas em sistemas de AVAC operando em condições climáticas do Brasil, uma vez que não existem dados disponíveis na literatura nesse sentido, levando-se em conta ainda os efeitos dessas técnicas na qualidade do ar interior dos ambientes, em confronto com as exigências das normas brasileiras.

Além disso, percebe-se na literatura uma lacuna em relação a abordagens mais apropriadas para as estimativas das eficiências de calor sensível, latente e total dos recuperadores. A maioria dos estudos utilizam valores de eficiências de normas, ou valores fixos que não consideram sua variação com outros parâmetros, ou ainda consideram sua variação apenas com a vazão ou com os efeitos de temperatura e umidade do ar externo de forma separada. Nesse sentido, a proposição de um modelo que inclua os diversos efeitos agindo de forma conjunta traria melhorias significativas nas estimativas de economia de energia e de retorno de investimento. 


\section{3 - OBJETIVOS}

O presente trabalho objetiva elaborar uma metodologia para análise dos efeitos anuais das técnicas de recuperação de energia e de vazão de ar exterior variável em um sistema de ar condicionado. Essa análise busca mensurar os efeitos de eficiência energética, financeiros e de qualidade de ar interior em edifícios comerciais, com o intuito de fornecer dados que viabilizem essas aplicações em sistemas de AVAC e que subsidiem decisões técnicas de projetos, a partir de análises de retorno de investimento, evitando o superdimensionamento dos sistemas de ar condicionado e conferindo redução de custos de aquisição, instalação, manutenção e operação.

Também, será proposta uma formulação para a simulação do desempenho de um recuperador de energia que será aplicado em um sistema de AVAC, operando com vazão de ar variável, a partir do qual será possível verificar a influência de parâmetros climáticos, eficiências dos equipamentos, vazões de ar externo necessárias, perfis de ocupação dos ambientes condicionados e parâmetros de conforto interno.

Por fim, será proposto um estudo de caso para que o modelo seja aplicado, com o intuito de se realizar a análise para um auditório de um edifício de escritórios nas cidades de Brasília/DF e Manaus/AM, avaliando o retorno do investimento dessas tecnologias e como as condições climáticas e os perfis de ocupação influenciam nas análises.

\section{4 - METODOLOGIA}

A metodologia utilizada será baseada, primeiramente, na elaboração de um modelo matemático que será implementado no software EES (Engineering Equation Solver). Esse modelo deverá permitir a inserção de dados de certos parâmetros de entrada que permitam a análise de recuperadores de energia disponíveis no mercado. O modelo também deverá levar em consideração os efeitos climáticos do ar exterior na eficiência dos equipamentos, em conjunto com os efeitos devidos às variações de vazão de ar externo. Essas vazões de ar externo serão determinadas de acordo com as normas técnicas brasileiras, com base nos perfis de ocupação dos ambientes condicionados.

O modelo proposto será aplicado em um ambiente pré-estabelecido, com perfil de carga, parâmetros de conforto de ar interno e sistema de condicionamento de ar definidos. Esse ambiente será avaliado por meio de análise econômica em quatro cenários diferentes: i) o primeiro cenário constitui um sistema sem nenhum cuidado com variação de vazões e 
recuperação de energia; ii) o segundo, utiliza o recurso da vazão de ar exterior variável, sem utilizar a recuperação de energia; iii) o terceiro, utiliza apenas o recurso da recuperação de energia com vazão fixa de ar exterior e, por último, o iv), um caso utilizando vazão de ar exterior variável e recuperação de energia.

As análises realizadas abordarão os efeitos anuais de economia de energia para os quatros cenários. A partir desses dados, será possível calcular o retorno de investimento em cada um deles, levando em consideração os custos de aquisição, manutenção, instalação e operação dos sistemas.

Por fim, serão realizadas análises críticas quanto à variação dos parâmetros que possam influenciar nos resultados encontrados, como a taxa de ocupação do ambiente, a partir da simulação de vários perfis de ocupação, e as variações nas condições do ar externo, a partir da utilização de duas cidades de projeto com climas diferentes (Brasília e Manaus).

\section{5 - ESTRUTURA DA DISSERTAÇÃO}

O capítulo 1 traz uma visão geral sobre o problema proposto e sua importância, apresentando uma revisão bibliográfica sobre eficiência energética, sistemas de recuperação de energia e sua utilização em sistemas AVAC, bem como os objetivos e metodologia utilizados.

O capítulo 2 contém uma revisão de conceitos teóricos referentes aos requisitos de eficiência energética dispostos em normas internacionais e às certificações e programas de etiquetagem existentes.

O capítulo 3 apresenta uma revisão de conceitos teóricos referentes às tecnologias de recuperação de energia.

O capítulo 4 faz uma revisão de conceitos teóricos relativos à Qualidade do $\mathrm{Ar}$ Interior, dispondo sobre a evolução do tema ao longo dos anos e apresentando uma análise das normais atuais vigentes na legislação brasileira.

A modelagem matemática é detalhada no capítulo 5, que também traz a metodologia de controle utilizada com todos os parâmetros de entrada do modelo simulado.

A partir dessa modelagem matemática pertinente, define-se um estudo de caso e passa-se á aplicação do modelo para simular o desempenho do sistema de ar condicionado nos quatro cenários propostos. Trata-se do capítulo 6. 
No capítulo 7, são apresentados os resultados das simulações e as análises econômicas e energéticas propostas, bem como uma análise dos parâmetros de operação que influenciam os resultados das simulações.

As conclusões finais e propostas para trabalhos futuros estão dispostas no último capítulo. 


\section{2 - REVISÃO DE CONCEITOS FUNDAMENTAIS}

Este capítulo faz uma breve revisão de conceitos fundamentais sobre os regulamentos de eficiência energética e programas de certificações em edificações. Os conceitos fundamentais relativos à recuperação de energia e vazão de ar exterior variável serão apresentados nos Capítulos 3 e 4, respectivamente, devido à especificidade de cada tema.

\section{1 - REGULAMENTOS DE EFICIÊNCIA ENERGÉTICA EM EDIFÍCIOS}

\subsection{1 - Visão geral}

Os regulamentos de eficiência energética em edifícios, também chamados de códigos de eficiência energética, emergiram nos anos 1970 como uma ferramenta essencial para melhorar a eficiência no uso da energia, reduzindo desperdícios nas edificações. Basicamente, eles visam definir requisitos mínimos para que os projetos de edificações novas, as construções e as modernizações de edifícios sejam eficientes na utilização da energia (Pérez-Lombard, 2011).

A promoção da eficiência energética é um dos principais objetivos das políticas de energia, uma vez que contribui para a melhoria na gestão dos recursos, reduzindo o consumo de energia e o impacto ambiental do projeto.

Atualmente, a maioria das nações desenvolvidas incluem uma seção de eficiência energética em suas políticas de planejamento energético, normalmente implementadas por meio de uma variedade de leis, códigos, estratégias, regulamentos e processos de certificação. Esses processos abrangem qualquer procedimento, permitindo uma determinação de qualidade comparativa em termos de consumo de energia em edifícios novos ou existentes. Portanto, a certificação energética de edifícios está diretamente ligada aos sistemas de tarifas de energia, programas de aferição e rotulagem energética de edificações.

De acordo com os dados levantados anteriormente, referentes ao consumo de energia de sistemas de AVAC, a definição de requisitos mínimos de eficiência energética é fator chave para o sucesso dos códigos de energia na promoção da eficiência energética. Entretanto, uma análise crítica nos requisitos em sistemas de AVAC em diversos regulamentos de energia evidenciam marcantes diferenças, qualitativas e quantitativas 
(Pérez-Lombard, 2011). Isso pode ser consequência da falta de homogeneidade nas terminologias, da complexidade técnica inerente aos múltiplos sistemas de AVAC e do grande impacto do clima e das técnicas construtivas nas tecnologias de AVAC.

\subsection{2 - Histórico}

Depois de algumas tentativas anteriores isoladas, os códigos de eficiência energética em edificações se constituíram nos anos 1970, após a crise do petróleo. A ameaça de esgotamento das fontes convencionais de energia e o aumento nos preços fizeram os governos se conscientizarem da necessidade de se economizar energia, estabelecendo, como consequência, organizações públicas (agências de energia) para abordar especificamente as questões energéticas.

Assim, os regulamentos de energia começaram a se desenvolver no setor da construção. $\mathrm{Na}$ Europa, os primeiros regulamentos que abordavam princípios de transferência de calor na construção civil foram publicados no fim dos anos 1970. A partir daí, foram criados regulamentos para instalações térmicas em edificações, para projeto, instalação e manutenção de sistemas AVAC, sistemas hidrossanitários e de água quente.

Os primeiros regulamentos consideraram de forma separada a envoltória do edifício e a envoltória das instalações de serviço. Nos anos 1980, mudanças foram introduzidas em alguns regulamentos com o intuito de abordar o efeito da radiação solar. No início dos anos 1990, novas propostas de integração mostraram novas abordagens para o edifício como um todo, transferindo, portanto, o conceito de eficiência energética para o setor da construção civil.

A fim de reduzir a emissão de dióxido de carbono a partir da implementação dos requisitos de eficiência energética, os primeiros métodos para cálculo do consumo de energia e para os programas de certificação de energia foram desenvolvidos em conformidade com norma 93/76 do Conselho Diretor Europeu (Council Directive 93/76, 1993). Desde então, o quadro técnico e legal da energia em edificações tem passado por uma transformação completa para incorporar os novos requisitos estabelecidos na norma 2002/91 (Directive 2002/91, 2002) sobre desempenho energético, certificação energética e inspeções em sistemas de AVAC.

O quadro regulatório é notavelmente diferente nos Estados Unidos. A American Society of Heating, Refrigerating and Air-Conditioning Engineers (ASHRAE), fundada em 1894, é uma associação internacional que em 1975 implantou a sua primeira norma de 
eficiência energética para projetos e construções de novas edificações, a ASHRAE Standard 90.

Em 1989, a ASHRAE implantou a Standard 90.1, considerando a envoltória da edificação, sistemas de condicionamento de ar, iluminação artificial e aquecimento de água, e incluindo, ainda, motores e equipamentos (Knijnik, 2011). O escopo da primeira regulamentação sobre eficiência energética em edificações (ASHRAE 90, 1975) demonstra claramente que o foco inicial estava principalmente em assuntos de conservação de energia.

Nos anos 1980, duas significantes mudanças tomaram lugar: a separação entre edificações residenciais e comerciais (CABO, 1993) e o duplo caminho de desempenhos prescritivos para o cumprimento das regulamentações (California Code of Regulations, 1978). Em 1992, a partir da aprovação do Ato de Política Energética (Energy Policy Act, 1992), o governo federal exigiu a intervenção ativa do Departamento de Energia (Department of Energy - DOE) no desenvolvimento dos códigos de energia para as edificações.

A norma 90.1-1989 da ASHRAE para edifícios comerciais e o Código de Modelo energético (MEC 1992) do Conselho Oficial de Edifícios da América (Council of America Building Officials - CABO) para edifícios residenciais foram propostos como base para as determinações de economia de energia estabelecidas pelo DOE. Na última década, o Código Internacional de Conservação de Energia (International Energy Conservation Code - IECC) desenvolvido pelo Conselho Internacional de Códigos (Internation Code Council - ICC) se tornou o código modelo para aplicação pela comunidade, para edifícios comerciais e residenciais.

Os últimos passos para o desenvolvimento de padrões de eficiência energética nos Estados Unidos para edifícios comerciais se basearam nos programas de certificações, também referenciados como programas de edifícios verdes (green building programmes). Nessa linha, a ASHRAE desenvolveu a norma 189.1-2009, uma norma de alto desempenho para edifícios verdes com o objetivo de fornecer requisitos mínimos para reduzir os impactos globais das edificações na saúde humana e no meio ambiente por meio do uso eficiente da energia, água e outros recursos naturais. Vale ressaltar que a cooperação efetiva entre as entidades profissionais, agências de energia, organizações normativas e associações de fabricantes tem contribuído significativamente para a adoção, implementação e aplicação dos regulamentos de energia naquele país. 
Já no Brasil, antes da década de 80, havia pouco interesse e incentivo à adoção de medidas para reduzir o consumo de energia elétrica ou aumentar a eficiência de sua utilização, pois a estrutura do segmento elétrico brasileiro apresentava forte participação governamental e tarifas reduzidas em relação ao mercado internacional. Porém, com o crescimento do tema pelo mundo, principalmente nos países desenvolvidos, seria inevitável a construção de políticas públicas visando à racionalização do uso da energia e dos recursos naturais também no Brasil.

Em 1985 foi criado o PROCEL - Programa Nacional de Conservação de Energia Elétrica, pelos Ministérios de Minas e Energia e de Indústria e Comércio. O objetivo do programa era promover a racionalização da produção e do consumo de energia elétrica, a fim de eliminar os desperdícios e reduzir os custos e os investimentos setoriais (Knijnik, 2011). Em 1993, o PROCEL elaborou o Selo Procel de Economia de Energia, que é concedido anualmente aos equipamentos elétricos que apresentam os melhores índices de eficiência energética dentro de suas categorias (PROCEL, 2009).

Depois da crise do setor elétrico, em 2001, o Brasil começou a estabelecer ações para estimular o uso eficiente da energia elétrica. O primeiro passo foi a elaboração da Lei $\mathrm{N}^{\circ} 10.295 / 2001$, que estabeleceu a criação de mecanismos que resultassem em edificações mais energeticamente eficientes. Essa lei foi regulamentada pelo Decreto $N^{\circ} 4.049$, que obrigava os fabricantes e importadores de máquinas e aparelhos elétricos a adotar níveis máximos de consumo de energia e níveis mínimos de eficiência energética. $\mathrm{O}$ decreto também instituiu competências ao Comitê Gestor de Indicadores e Níveis de Eficiência Energética - CGIEE e determinou a constituição do Grupo Técnico para a Eficientização de Energia nas Edificações - GT MME (Knijnik, 2011).

\subsection{3 - Abordagem dos regulamentos}

O desempenho energético de um edifício depende de vários fatores que se interrelacionam, os quais variam desde as estratégias de manutenção adotadas pela administração, as condições locais do clima, as características arquitetônicas da edificação, os sistemas de instalações e equipamentos utilizados, até os fatores humanos e culturais que interferem nas condições de seu uso. Nesses termos, a tomada de decisão no momento do projeto do edifício é crucial, exigindo que o arquiteto e os outros profissionais envolvidos na concepção e execução da obra trabalhem em sincronia. Tais medidas são 
consideradas estruturais, tendo em vista sua influência no produto final e seu poder de permanência no tempo, haja vista o alto custo de reformas posteriores (Veloso, 2004).

Esses estudos preliminares e anteprojetos podem ser responsáveis por $50 \%$ do potencial de economia de energia. Um dos estágios mais importantes da elaboração de uma edificação é a escolha dos materiais que irão compor sua envoltória, pois caracteriza as necessidades energéticas necessárias para proporcionar o mínimo de conforto nos ambientes internos. Caso as características da envoltória da edificação não sejam pensadas de forma adequada, serão realizadas trocas térmicas significativas com o exterior, fazendo com que seja necessário o uso de mais energia para equilibrar a temperatura interior (Knijnik, 2011). A busca pelo equilíbrio térmico, assim como por corretos níveis de iluminação, é de fundamental importância para o bem-estar dos usuários das edificações (Fernandes, 2001).

O escopo de aplicação dos regulamentos de eficiência energética pode ser analisado em termos do tipo, do tamanho e das instalações das edificações. Em relação ao tipo, existem regulamentos que separam as edificações em residenciais e comerciais. Grandes edifícios residenciais algumas vezes podem ser cobertos pelos regulamentos para edifícios comerciais, caso o regulamento residencial seja restrito a edifícios pequenos. Além disso, alguns países impõem requerimentos específicos para alguns tipos de edificações comerciais, como hospitais, laboratórios, etc. $\mathrm{O}$ tamanho das edificações pode ser definido por número de pavimentos, área condicionada, por contrato de demanda elétrica ou por capacidade térmica instalada.

Em relação às instalações, os regulamentos de energia geralmente abordam os principais serviços consumidores de energia em edificações: sistemas de AVAC, iluminação, sistemas de aquecimento em geral e equipamentos. Ainda, esses regulamentos devem considerar a qualidade da envoltória, uma vez que essa tem grande impacto nos sistemas de AVAC e na energia utilizada para iluminação. Como resultado, os regulamentos de energia se organizam em cinco sessões (Figura 2.1):

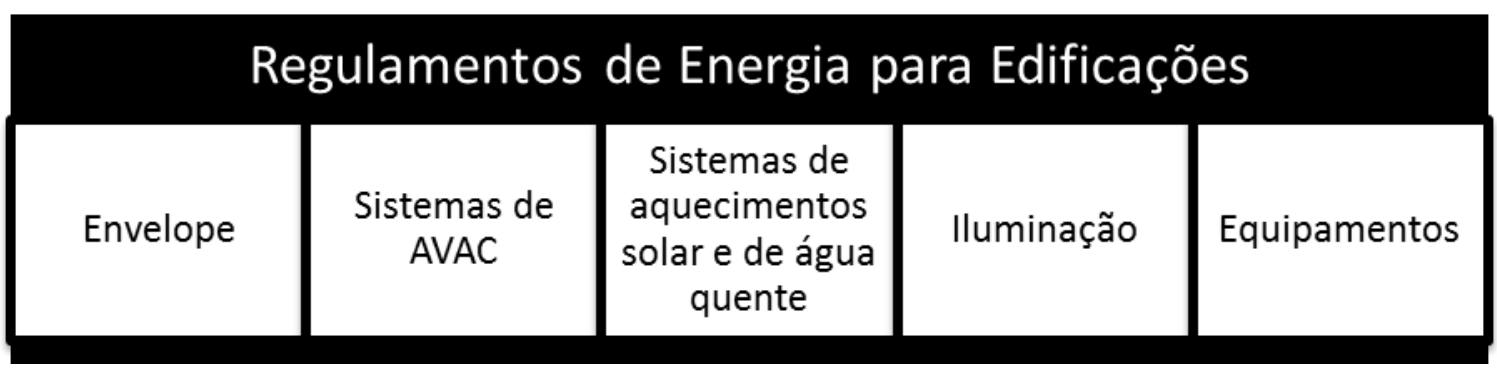

Figura 2.1 - Elementos básicos em regulamentos de energia de edificações 
Mais especificamente, os requisitos para sistemas de AVAC são classificados em seis categorias de prescrições normativas: i) eficiência mínima de equipamentos; ii) sistemas de distribuição de fluidos; iii) sistemas de controle; iv) ventilação de ar externo; v) recuperação de energia e vi) ciclo economizador. Assim, verifica-se a preocupação dos regulamentos de energia em tratar de requisitos que envolvam o estudo de sistemas com ventilação de ar externo variável e recuperação de energia, itens importantes que conferem mais eficiência energética aos sistemas.

\section{2 - PROGRAMAS DE CERTIFICAÇÃO DE EDIFICAÇÕES}

\subsection{1 - LEED}

\subsubsection{1 - Visão geral e histórico}

Em 1996 foram iniciados nos Estados Unidos os trabalhos para a criação do Leadership in Energy and Environmental Desing - LEED ${ }^{\mathrm{TM}}$, com o objetivo de facilitar a transferência de conceitos de construção ambientalmente responsáveis para os profissionais da indústria de construção americana, proporcionando reconhecimento junto ao mercado pelos esforços despendidos para essa finalidade. O protocolo LEED ${ }^{\mathrm{TM}}$ avalia de forma multidisciplinar o desempenho ambiental do edifício ao longo de todo o seu ciclo de vida.

O critério mínimo de nivelamento exigido para a avaliação de uma edificação pelo LEED é o cumprimento de uma série de pré-requisitos. Uma vez satisfeitos esses prérequisitos, passa-se à etapa de classificação de desempenho, em que a atribuição de créditos indica o grau de conformidade do atendimento aos itens avaliados (Knijnik, 2011).

Com uma estrutura simples, o LEED constitui um meio termo entre critérios puramente prescritivos e especificações de desempenho e toma por referência princípios ambientais e de uso de energia consolidados em normas e recomendações de organismos com credibilidade reconhecida, como é o caso da ASHRAE, da American Society for Testing and Materials - ASTM, da U.S. Environmental Protection Agency - EPA e do U.S. Department of Energy - DOE. Essas práticas conhecidas e sedimentadas são então balanceadas com princípios emergentes, de forma a estimular a adoção de tecnologias e conceitos inovadores (Silva et al, 2003). A certificação LEED atualmente é utilizada em 143 países, incluindo o Brasil. 
A certificação de Edifícios Verdes é realizada por entidades não governamentais como a USGBC (United States Green Building Council). No Brasil, recentemente, foi criado o "Green Building Council Brasil" (www.gbcbrasil.org.br), entidade que será responsável pela adaptação dos critérios do LEED para as condições e realidades brasileiras.

Para obter a certificação LEED de uma edificação, primeiramente, o projeto deve ser registrado junto ao USGBC para indicar se atenderá a todos os pré-requisitos exigidos para atingir uma determinada pontuação. A certificação só será efetivada após a construção do prédio e a confirmação de que os pré-requisitos foram atendidos. Essa certificação possui sete dimensões a serem avaliadas nas edificações, todas possuindo pré-requisitos (práticas obrigatórias) e créditos, recomendações que quando atendidas garantem pontos à edificação. De acordo com o número de pontos obtidos por uma determinada edificação (de 40 a 110 pontos), ela poderá ser certificada em uma das seguintes classificações: Platinum (platina), Gold (ouro) ou Silver (prata).

Atualmente, existem no Brasil mais de 700 empreendimentos registrados para a obtenção da certificação LEED, deixando o país em $4^{\circ}$ lugar no ranking mundial dos países mais sustentáveis. As pontuações do LEED são divididas nas seguintes dimensões avaliadas:

1) Sustainable Sites - Espaço sustentável;

2) Water Efficiency - Eficiência do uso da água;

3) Energy \& Atmosphere - Eficiência energética e os cuidados com as emissões para a atmosfera;

4) Materials \& Resources - Otimização dos materiais e recursos naturais a serem utilizados na construção e operação da edificação;

5) Indoor Environmental Quality - Qualidade dos ambientes internos da edificação;

6) Innovation \& Design Process - Inovações empregadas no projeto da edificação;

7) Regional Priority Credits - Créditos de prioridade regional, que levam em consideração as diferenças sociais, ambientais e culturais existentes em cada local.

As pontuações e pré-requisitos de uma certificação LEED dependem, ainda, do tipo de empreendimento, conforme lista a seguir: 
1) New Construction \& Major Renovation (Novas construções e Grandes reformas) - A certificação é realizada considerando o terreno e a edificação como um todo, destinado a edificações que serão construídas ou passarão por grandes reformas. Geralmente são prédios de utilização de uma única empresa ou entidade, tais como corporações, universidades, escolas, hospitais, etc;

2) Existing Buildings - Operation and Maintance (Edifícios existentes - Operação e Manutenção) - A certificação é realizada com base no desempenho de operação e manutenção, visando aumentar sua eficiência em edificações existentes;

3) Commercial Interiors (Interiores de edificações comerciais) - É a certificação que reconhece escritórios de alto desempenho, que, por possuírem ambientes internos mais saudáveis, auxiliam na produtividade de seus ocupantes;

4) Core and Shell (Envoltória e Estrutura Principal) - A certificação é realizada para o terreno e para as áreas comuns da edificação, onde o empreendedor não tem responsabilidade sobre o projeto das áreas internas de cada unidade. Geralmente são prédios de uso coletivo para venda ou locação posterior das áreas internas;

5) Retail (Lojas de Varejo) - Reconhece as diferentes características de uma loja de varejo. Tem duas modalidades: i) para novas construções ou grandes reformas; ii) para interiores comerciais (loja dentro de um edifício);

6) Neighborhood Development (Desenvolvimento de Bairros) - A certificação é realizada para a parte urbanística de um condomínio, de um bairro ou de uma quadra residencial ou comercial, integrando princípios de crescimento planejado e inteligente;

7) Schools (Escolas) - Cria ambientes escolares mais saudáveis e confortáveis e possibilita a criação de práticas de educação ambiental dentro do ambiente escolar;

8) Healthcare (Hospitais) - É a certificação que engloba todas as necessidades de um hospital.

2.2.1.2 - Pontuação LEED para sistemas com vazão de ar externo variável e recuperação de energia.

A especificação e utilização de sistemas recuperadores de energia e com vazão de ar exterior variável podem contribuir de forma significativa para a obtenção de créditos LEED em projetos de Novas Construções, Edifícios Existentes, Interiores de Edificações Comerciais e outros. Esses sistemas podem contribuir em até três categorias: i) Qualidade dos ambientes internos da edificação (Indoor Environmental Quality); ii) Energia e 
Atmosfera (Energy \& Atmosphere) e iii) Inovações empregadas em projeto (Innovation Priority Credits). Essas categorias e seus requisitos estão mais bem detalhados na Tabela 2.1:

Tabela 2.1 - Pontuação LEED para sistemas com recuperação de calor e vazão de ar exterior variável

\begin{tabular}{|c|c|c|c|}
\hline $\begin{array}{l}\text { Categoria } \\
\text { LEED }\end{array}$ & Descrição & Requisito & Créditos possíveis \\
\hline $\begin{array}{c}\text { Energia \& } \\
\text { Atmosfera } \\
\text { EA Crédito } 1\end{array}$ & $\begin{array}{l}\text { Otimização do } \\
\text { desempenho } \\
\text { energético }\end{array}$ & $\begin{array}{l}\text { A ventilação de edifícios } \\
\text { energeticamente eficientes } \\
\text { pode ser responsável por } \\
50 \% \text { ou mais dos custos } \\
\text { totais estimados de } \\
\text { energia. ERV e vazão de ar } \\
\text { variável podem } \\
\text { economizar de 50\% a 70\% } \\
\text { da carga total de } \\
\text { ventilação. }\end{array}$ & $\begin{array}{c}7-12 \text { pontos } \\
\text { (Novas } \\
\text { Construções) } \\
\\
10-14 \text { (Edifícios } \\
\text { Existentes) }\end{array}$ \\
\hline $\begin{array}{c}\text { Qualidade do } \\
\text { Ambiente } \\
\text { Interno } \\
\text { EQ Crédito 1 }\end{array}$ & $\begin{array}{l}\text { Monitoramento } \\
\text { da ventilação de } \\
\text { ar externo }\end{array}$ & $\begin{array}{c}\text { O uso de } \\
\text { controle/monitoramento } \\
\text { por concentração de CO2 } \\
\text { permite uma taxa de } \\
\text { ventilação de ar externo } \\
\text { que cumpra os requisitos } \\
\text { de Qualidade do Ar } \\
\text { Interior. }\end{array}$ & 1 ponto \\
\hline $\begin{array}{c}\text { Qualidade do } \\
\text { Ambiente } \\
\text { Interno } \\
\text { EQ Crédito 2 }\end{array}$ & $\begin{array}{l}\text { Aumento da } \\
\text { ventilação de ar } \\
\text { externo }\end{array}$ & $\begin{array}{c}\text { Métodos que fornecem, } \\
\text { com fácil aplicação e } \\
\text { eficiência, uma taxa de } \\
\text { ventilação superior a } 30 \% \\
\text { das prescrições da norma } \\
\text { ASHRAE } 62.1\end{array}$ & 1 ponto \\
\hline $\begin{array}{c}\text { Qualidade do } \\
\text { Ambiente } \\
\text { Interno } \\
\text { EQ Crédito } \\
\mathbf{3 . 1 , 5}\end{array}$ & $\begin{array}{c}\text { Construção de um } \\
\text { plano de } \\
\text { gerenciamento da } \\
\text { Qualidade do ar } \\
\text { Interior; Controle } \\
\text { químico de fontes } \\
\text { poluentes }\end{array}$ & $\begin{array}{l}\text { Utilização de filtros de ar } \\
\text { com alto desempenho } \\
\text { (MERV } 8 \text { a 13) para } \\
\text { manutenção de um } \\
\text { ambiente interno limpo } \\
\text { com a utilização de } \\
\text { ventilação mecânica. }\end{array}$ & $\begin{array}{l}1 \text { ponto (IEQ 3.1) } \\
1 \text { ponto (IEQ 5) }\end{array}$ \\
\hline $\begin{array}{l}\text { Qualidade do } \\
\text { Ambiente } \\
\text { Interno } \\
\text { EQ Crédito 7.1 }\end{array}$ & $\begin{array}{c}\text { Projeto de } \\
\text { conforto térmico }\end{array}$ & $\begin{array}{c}\text { A utilização de } \\
\text { equipamentos de ERV } \\
\text { mantém os requisitos de } \\
\text { conforto térmico na } \\
\text { maioria das condições } \\
\text { climáticas, sem a } \\
\text { utilização adicional de } \\
\text { serpentinas de }\end{array}$ & 1 ponto \\
\hline
\end{tabular}




\begin{tabular}{cccc}
\hline Inovações e \\
$\begin{array}{c}\text { Processos } \\
\text { ID Crédito 1 }\end{array}$ & $\begin{array}{c}\text { Inovação em } \\
\text { projeto }\end{array}$ & $\begin{array}{c}\text { umidificação ou } \\
\text { desumidificação. }\end{array}$ & $\begin{array}{c}\text { Projetos criativos de } \\
\text { instalações }\end{array}$ \\
\hline $\begin{array}{c}\text { Inovações e } \\
\text { Processos } \\
\text { ID Crédito 2.1 }\end{array}$ & $\begin{array}{c}\text { Profissional com } \\
\text { acreditação LEED }\end{array}$ & $\begin{array}{c}\text { Suporte de profissional } \\
\text { com acreditação LEED nas } \\
\text { fases de projeto dos } \\
\text { sistemas de ventilação. }\end{array}$ & $1-5$ pontos \\
\hline
\end{tabular}




\section{3 - RECUPERAÇÃO DE ENERGIA}

\section{1 - SISTEMAS E EQUIPAMENTOS DE RECUPERAÇÃO DE ENERGIA}

(ASHRAE, 2012)

\subsection{1 - Visão geral}

Recuperação de energia ar-ar é o processo de recuperação de calor e/ou umidade entre duas correntes de ar a diferentes temperaturas e umidades. Esse processo é importante na manutenção da Qualidade do Ar Interior (QAI) e, ao mesmo tempo, reduz os custos de operação e o consumo global de energia.

Energia pode ser recuperada tanto na sua forma sensível (temperatura apenas) quanto na forma latente (umidade) ou, ainda, em uma combinação de ambas a partir de fontes múltiplas. Energia sensível pode ser extraída, por exemplo, de correntes de ar de saída em secadores, fogões, fornos, câmaras de combustão, e dos gases de exaustão de turbinas a gás para pré-aquecer o ar de entrada. As unidades utilizadas para esse propósito são chamadas de equipamentos trocadores de calor sensível ou ventiladores recuperadores de calor (Heat Recovery Ventilators - HRVs).

Dispositivos que transferem tanto calor quanto umidade são conhecidos como dispositivos de energia ou entálpicos ou ventiladores recuperadores de energia (Energy Recovery Ventilators - ERVs). HRVs e ERVs estão disponíveis para aplicações comerciais ou industriais, assim como para aplicações residenciais e comerciais de pequena escala.

$\mathrm{O}$ ar condicionado utiliza muita energia para desumidificar correntes de ar úmidas. A umidade excessiva no ar de uma edificação pode resultar em mofo, alergias e crescimento de bactérias, entretanto, os equipamentos ERVs podem aumentar a desumidificação em sistemas unitários de ar condicionado. Introduzir ar externo é o primeiro meio de diluir os contaminantes do ar interior a fim de atingir uma QAI aceitável, dessa forma, ERVs podem prover grandes quantidades de ar exterior com uma ótima relação custo-benefício para atingir os requisitos mínimos de ventilação estabelecidos em normas (Nos EUA, as normas ASHRAE Standards 62.1 e 62.2 de 2010; no Brasil a norma ABNT NBR 16401-3 de 2008).

Os tipos de ERVs incluem os trocadores de calor de placas (fixed plates), rodas giratórias (rotary wheels), tubos de calor (heat pipes), trocadores de calor por meio de bombeamento de fluido em serpentina (runaround loops), termossifões (thermosiphons), e 
recuperadores de entalpia tipo torres gêmeas (twin-tower enthalpy recovery loops). $\mathrm{O}$ desempenho desses equipamentos é geralmente caracterizado pela eficiência, pela perda de carga, pelo bombeamento ou potência de ventilação, pelo fluxo cruzado (vazamento de ar de uma corrente para outra) e pelo controle de congelamento, usado para prevenir o congelamento do trocador de calor. A eficiência de recuperação, razão entre a saída do equipamento e a sua entrada, também é frequentemente considerada. Em ERVs, o termo "eficiência" se refere à razão entre a atual recuperação de energia e o máximo possível de energia que poderia ser recuperado teoricamente no dispositivo.

A perda de carga na corrente de ar ocorre devido à fricção entre o fluido e a superfície sólida e também pela complexidade geométrica das passagens do escoamento. A potência de bombeamento ou ventilação é o produto da taxa de fluxo de volume de líquido e a perda de carga. Fatores econômicos tais como custo da energia recuperada e os custos de capital e manutenção,incluindo o custo de potência de bombeamento,desempenham papel fundamental na determinação da viabilidade econômica para utilização de ERVs em uma dada aplicação.

\subsection{2 - Aplicações}

Sistemas de recuperação de energia ar-ar podem ser categorizados de acordo com suas aplicações em: (1) processo para processo, (2) processo para conforto e (3) conforto para conforto. Nas aplicações processo para processo, o calor é capturado da corrente de exaustão do processo e transferido para a corrente de entrada. Os dispositivos que realizam essa recuperação transferem apenas calor sensível, uma vez que a transferência de umidade é normalmente prejudicial ao processo.

Nas aplicações processo para conforto, o calor desperdiçado é recuperado dos processos de exaustão para aquecer as edificações durante o inverno. Nesses casos, uma vez que o calor é recuperado apenas no inverno e a recuperação é modulada durante condições climáticas moderadas, as aplicações de processo para conforto economizam menos energia anualmente do que as aplicações processo para processo. Os equipamentos dessas aplicações geralmente recuperam apenas calor sensível e não transferem umidade entre as correntes de ar.

Em aplicações conforto para conforto, o equipamento recuperador de energia diminui a entalpia do ar de entrada no edifício durante o verão e aumenta a entalpia durante o inverno, a partir da transferência de energia entre a corrente de ventilação de ar externo e 
a corrente do ar de exaustão do ambiente interno. Esses dispositivos podem ser recuperadores de calor sensível apenas ou de calor sensível e umidade. A Tabela 3.1 apresenta as aplicações típicas para cada tipo de categoria.

Quando a umidade do ar externo é baixa e o espaço condicionado tem uma apreciável carga latente, um dispositivo de ERV pode recuperar calor sensível enquanto aumenta suavemente a carga latente do espaço condicionado, uma vez que o vapor de água é transferido dentro do ERV para o ar externo que entra na edificação. Assim, é importante determinar quando a dada aplicação requer um dispositivo de HRV ou um de ERV.

HRVs são desejáveis quando a umidade do ar externo é baixa e a carga latente do edifício é alta durante a maior parte do ano, e, ainda em aplicações em piscinas, exaustões químicas, cabines de pinturas e resfriadores evaporativos indiretos. ERVs são desejáveis para aplicações em escolas, escritórios, residências e outras aplicações que requeiram um pré-aquecimento ou um pré-resfriamento econômico da ventilação de ar externo.

Tabela 3.1 - Aplicações típicas para recuperadores de energia ar-ar (ASHRAE, 2012, modificado)

\begin{tabular}{cc}
\hline Método & Aplicação \\
\hline Processo para & Secadores \\
Processo e & Fornos \\
Processo para & Queimadores \\
Conforto & Incineradores \\
& Exaustão de câmaras de pintura \\
Exaustão de câmaras de soldagem
\end{tabular}

\subsection{3 - Relações termodinâmicas}

A segunda lei da termodinâmica preceitua que a direção da transferência de calor sempre se dá da região de maior temperatura para a de menor temperatura. Essa lei pode ser estendida para dizer que a transferência de massa sempre ocorre da região de maior pressão de vapor para a região de menor pressão de vapor. O ERV facilita essa transferência através de uma parede de separação (mostrada por uma fina linha horizontal 
na Figura 3.1) feita de um material que conduz calor e é permeável ao vapor de água. A umidade é transferida quando existe uma diferença na pressão de vapor entre as duas correntes de ar.

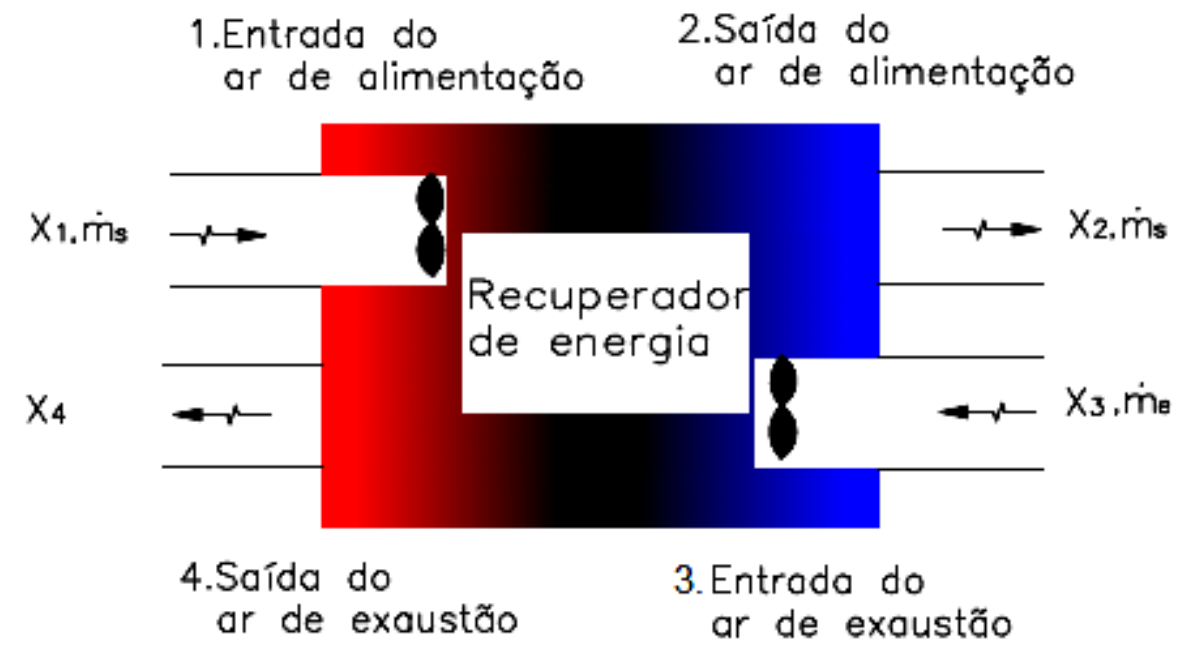

Figura 3.1 - Convenção numérica para os estágios das correntes de ar de alimentação e exaustão (ASHRAE, 2012, modificado)

Em um dia típico de verão, o ar externo de alimentação a uma dada temperatura, umidade ou entalpia $x_{1}$ e vazão mássica $m_{s}$ entra no ERV, enquanto o ar de exaustão do espaço condicionado entra no equipamento nas condições $x_{3}$ e $m_{E}$. Uma vez que as condições em $x_{3}$ são mais baixas que as condições em $x_{1}$, a transferência de calor e massa da corrente de alimentação para a de exaustão acontece devido à diferença de temperatura e pressão de vapor de água por meio da parede separadora. Consequentemente, as propriedades na saída do ar de alimentação diminuem, enquanto aquelas do ar de exaustão aumentam. As propriedades na saída das duas correntes de ar podem ser estimadas, conhecendo-se as taxas de vazão e a eficiência do recuperador de energia.

A norma ASHRAE Standard 84 define eficiência como:

$$
\varepsilon=\frac{\text { Transferência atual de umidade ou energia }}{\text { Transferência máxima possível entre as correntes de ar }}
$$

\subsubsection{1 - Relações termodinâmicas para o Ventilador de Recuperação de Calor (HRV)}

Na Figura 3.1, a eficiência sensível $\varepsilon_{\mathrm{s}}$ de um HRV é dada pela equação: 


$$
\varepsilon_{\mathrm{s}}=\frac{\dot{\mathrm{q}}_{\mathrm{s}}}{\dot{\mathrm{q}}_{\mathrm{s}, \max }}=\frac{\dot{\mathrm{m}}_{\mathrm{s}} \cdot \mathrm{c}_{\mathrm{ps}} \cdot\left(\mathrm{t}_{2}-\mathrm{t}_{1}\right)}{\mathrm{C}_{\min } \cdot\left(\mathrm{t}_{3}-\mathrm{t}_{1}\right)}=\frac{\dot{\mathrm{m}}_{\mathrm{s}} \cdot \mathrm{c}_{\mathrm{pe}} \cdot\left(\mathrm{t}_{2}-\mathrm{t}_{1}\right)}{\mathrm{C}_{\min } \cdot\left(\mathrm{t}_{3}-\mathrm{t}_{1}\right)}
$$

Onde $\dot{\mathrm{q}}_{\mathrm{s}}$ é a atual taxa de transferência de calor sensível, dada por:

$$
\dot{\mathrm{q}}_{\mathrm{s}}=\varepsilon_{\mathrm{s}} \cdot \dot{\mathrm{q}}_{\mathrm{s}, \text { max }}
$$

Onde $\dot{\mathrm{q}}_{\mathrm{s}, \max }$ é máxima taxa de transferência de calor sensível, dada por:

$$
\dot{\mathrm{q}}_{\mathrm{s}, \max }=\mathrm{C}_{\min } \cdot\left(\mathrm{t}_{3}-\mathrm{t}_{1}\right)
$$

$\dot{\mathrm{q}}_{\mathrm{s}}=\quad$ Taxa de transferência de calor sensível $[k W]$;

$\dot{\mathrm{q}}_{\mathrm{s}, \max }=\quad$ Máxima taxa de transferência de calor sensível $[k W]$;

$\varepsilon_{\mathrm{S}}=\quad$ Eficiência sensível [-];

$\mathrm{t}_{1}=\quad$ Temperatura de bulbo seco no estágio $1\left[{ }^{\circ} \mathrm{C}\right]$;

$\dot{\mathrm{m}}_{\mathrm{S}}=\quad$ Vazão mássica do ar seco de alimentação $[\mathrm{kg} / \mathrm{s}]$;

$\dot{\mathrm{m}}_{\mathrm{e}}=\quad$ Vazão mássica do ar seco de exaustão $[\mathrm{kg} / \mathrm{s}]$;

$\mathrm{C}_{\min }=\quad$ Menor valor entre $\mathrm{c}_{\mathrm{ps}} \cdot \dot{\mathrm{m}}_{\mathrm{s}} \mathrm{e} \mathrm{c}_{\mathrm{pe}} \cdot \dot{\mathrm{m}}_{\mathrm{e}}$

$\mathrm{c}_{\mathrm{ps}}=\quad$ Calor específico à pressão constante do ar de alimentação úmido $[\mathrm{kJ} / \mathrm{kg} . \mathrm{K}]$;

$\mathrm{c}_{\mathrm{pe}}=\quad$ Calor específico à pressão constante do ar de exaustão úmido $[\mathrm{kJ} / \mathrm{kg} \cdot \mathrm{K}]$.

Assumindo que não há condensação de vapor de água no HRV, a condição de saída do ar de alimentação é:

$$
\mathrm{t}_{2}=\mathrm{t}_{1}-\varepsilon_{\mathrm{s}} \cdot \frac{\mathrm{C}_{\min }}{\dot{\mathrm{m}}_{\mathrm{s}} \cdot \mathrm{c}_{\mathrm{ps}}} \cdot\left(\mathrm{t}_{1}-\mathrm{t}_{3}\right)
$$

A condição do ar de saída de exaustão é:

$$
\mathrm{t}_{4}=\mathrm{t}_{3}-\varepsilon_{\mathrm{s}} \cdot \frac{\mathrm{C}_{\min }}{\dot{\mathrm{m}}_{\mathrm{e}} \cdot \mathrm{c}_{\mathrm{pe}}} \cdot\left(\mathrm{t}_{1}-\mathrm{t}_{3}\right)
$$

As Equações (3.2), (3.3), (3.4), (3.5) e (3.6) assumem condições de operação em regime permanente: inexiste transferência de calor ou umidade entre o recuperador e a 
vizinhança; inexistem vazamentos cruzados e inexistem ganhos ou perdas de energia dos motores, ventiladores ou dispositivos anticongelamento. Além disso, condensação ou congelamento não ocorre ou é desprezível. Essas suposições são geralmente próximas da verdade para a grande maioria das aplicações comerciais de HRV. O dispositivo de HRV somente permite a transferência de energia em forma de calor sensível, associada a uma diferença de temperatura entre as correntes de ar ou entre uma corrente de ar e uma superfície sólida. Essas equações também são aplicadas no inverno, caso não exista condensação no HRV. O calor sensível $\dot{\mathrm{q}}_{\mathrm{s}}$ transferido do HRV pode ser estimado:

$$
\begin{gathered}
\dot{\mathrm{q}}_{\mathrm{s}}=\dot{\mathrm{m}}_{\mathrm{s}} \cdot \mathrm{c}_{\mathrm{ps}} \cdot\left(\mathrm{t}_{2}-\mathrm{t}_{1}\right)=\mathrm{Q}_{\mathrm{s}} \cdot \rho_{\mathrm{s}} \cdot \mathrm{c}_{\mathrm{ps}} \cdot\left(\mathrm{t}_{2}-\mathrm{t}_{1}\right) \\
\dot{\mathrm{q}}_{\mathrm{s}}=\dot{\mathrm{m}}_{\mathrm{e}} \cdot \mathrm{c}_{\mathrm{pe}}\left(\mathrm{t}_{4}-\mathrm{t}_{3}\right)=\mathrm{Q}_{\mathrm{e}} \cdot \rho_{\mathrm{e}} \cdot \mathrm{c}_{\mathrm{pe}} \cdot\left(\mathrm{t}_{4}-\mathrm{t}_{3}\right) \\
\dot{\mathrm{q}}_{\mathrm{s}}=\varepsilon_{\mathrm{s}} \cdot \mathrm{m}_{\min } \cdot \mathrm{c}_{\mathrm{p}} \cdot\left(\mathrm{t}_{1}-\mathrm{t}_{3}\right)
\end{gathered}
$$

$\mathrm{Q}_{\mathrm{S}}=\quad$ Vazão volumétrica de ar de alimentação $\left[\mathrm{m}^{3} / \mathrm{s}\right]$;

$\mathrm{Q}_{\mathrm{e}}=\quad$ Vazão volumétrica de ar de exaustão $\left[\mathrm{m}^{3} / \mathrm{s}\right]$;

$\rho_{\mathrm{S}}=\quad$ Massa específica do ar seco de alimentação $\left[\mathrm{kg} / \mathrm{m}^{3}\right]$;

$\rho_{\mathrm{e}}=\quad$ Massa específica do ar seco de alimentação $\left[\mathrm{kg} / \mathrm{m}^{3}\right]$;

$\mathrm{t}_{1} \mathrm{t}_{2,} \mathrm{t}_{3,} \mathrm{t}_{4}=$ Temperaturas de entrada e saída das correntes $\left[{ }^{\circ} \mathrm{C}\right]$;

$\dot{\mathrm{m}}_{\min }=\quad$ Menor valor entre $\dot{\mathrm{m}}_{\mathrm{s}} \mathrm{e} \dot{\mathrm{m}}_{\mathrm{e}}$;

Uma vez que $c_{p s}$ e $c_{p e}$ são aproximadamente iguais, eles podem ser omitidos das equações apresentadas.

HRVs podem ser utilizados praticamente em qualquer situação, especialmente para aplicações em piscinas e câmaras de pintura. As Equações (3.1) a (3.9) se aplicam tanto a HRVs quanto a ERVs.

\subsubsection{2 - Relações termodinâmicas para o Ventilador de Recuperação de Energia (ERV)}

Os equipamentos ERV permitem tanto a transferência de calor sensível quanto de calor latente, ocorrendo essa última devido a uma diferença na pressão de vapor entre as 
correntes de ar ou entre a corrente de ar e a superfície sólida. ERVs estão disponíveis nos tipos de rodas giratórias dessecantes (rodas entálpicas) e também como no formato de placas (membranas) fixas. Uma vez que outros gases também podem passar por meio da membrana no recuperador tipo placas fixas, é assumido nas equações seguintes que apenas o vapor de água é transportado através da membrana.

A partir da Figura 3.1, assumindo que não há condensação no ERV, a eficiência latente $\varepsilon_{\mathrm{L}}$ é dada por:

$$
\varepsilon_{\mathrm{L}}=\frac{\dot{\mathrm{q}}_{\mathrm{L}}}{\dot{\mathrm{q}}_{\mathrm{L}, \max }}=\frac{\dot{\mathrm{m}}_{\mathrm{s}} \cdot \mathrm{h}_{\mathrm{fg}} \cdot\left(\mathrm{w}_{1}-\mathrm{w}_{2}\right)}{\dot{\mathrm{m}}_{\min } \cdot \mathrm{h}_{\mathrm{fg}} \cdot\left(\mathrm{w}_{1}-\mathrm{w}_{3}\right)}=\frac{\dot{\mathrm{m}}_{\mathrm{e}} \cdot \mathrm{h}_{\mathrm{fg}} \cdot\left(\mathrm{w}_{4}-\mathrm{w}_{3}\right)}{\dot{\mathrm{m}}_{\min } \cdot \mathrm{h}_{\mathrm{fg}} \cdot\left(\mathrm{w}_{1}-\mathrm{w}_{3}\right)}
$$

Onde $\dot{\mathrm{q}}_{\mathrm{L}}$ é a atual taxa de transferência de calor latente dada por:

$$
\dot{\mathrm{q}}_{\mathrm{L}}=\varepsilon_{\mathrm{L}} \cdot \dot{\mathrm{q}}_{\mathrm{L}, \max }
$$

Onde $\dot{\mathrm{q}}_{\mathrm{L}, \max }$ é máxima taxa de transferência de calor latente dada por:

$$
\dot{\mathrm{q}}_{\mathrm{L}, \max }=\dot{\mathrm{m}}_{\min } \cdot \mathrm{h}_{\mathrm{fg}} \cdot\left(\mathrm{w}_{1}-\mathrm{w}_{3}\right)
$$

$\dot{\mathrm{q}}_{\mathrm{L}}=\quad$ Taxa de transferência de calor latente $[k W]$

$\dot{\mathrm{q}}_{\mathrm{L}, \max }=\quad$ Máxima taxa de transferência de calor latente $[k W]$;

$\varepsilon_{\mathrm{L}}=\quad$ Eficiência latente $[-]$;

$\dot{\mathrm{m}}_{\mathrm{S}}=\quad$ Vazão mássica do ar seco de alimentação $[\mathrm{kg} / \mathrm{s}]$;

$\dot{\mathrm{m}}_{\mathrm{e}}=\quad$ Vazão mássica do ar seco de exaustão $[\mathrm{kg} / \mathrm{s}]$;

$\dot{\mathrm{m}}_{\min }=\quad$ Menor valor entre $\dot{\mathrm{m}}_{\mathrm{s}}$ e $\dot{\mathrm{m}}_{\mathrm{e}}$;

$\mathrm{h}_{\mathrm{fg}}=\quad$ Entalpia de vaporização $[\mathrm{kJ} / \mathrm{kg}]$;

$\mathrm{W}=\quad$ Umidade absoluta nas correntes de ar $[\mathrm{kg} / \mathrm{kg}] ;$

Uma vez que a entalpia de vaporização da Equação (3.10) pode ser removida do numerador e denominador, essa equação pode ser reescrita como: 


$$
\varepsilon_{\mathrm{m}}=\frac{\dot{\mathrm{m}}_{\mathrm{w}}}{\dot{\mathrm{m}}_{\mathrm{w}, \max }}=\frac{\dot{\mathrm{m}}_{\mathrm{s}} \cdot\left(\mathrm{w}_{1}-\mathrm{w}_{2}\right)}{\dot{\mathrm{m}}_{\min } \cdot\left(\mathrm{w}_{1}-\mathrm{w}_{3}\right)}=\frac{\dot{\mathrm{m}}_{\mathrm{e}} \cdot\left(\mathrm{w}_{4}-\mathrm{w}_{3}\right)}{\dot{\mathrm{m}}_{\min } \cdot\left(\mathrm{w}_{1}-\mathrm{w}_{3}\right)}
$$

Onde $\varepsilon_{\mathrm{m}}$ é eficiência de umidade, numericamente igual à eficiência de calor latente $\varepsilon_{\mathrm{L}}$, e $\dot{\mathrm{m}}_{\mathrm{w}}$ é a taxa atual de transferência de umidade, dada por:

$$
\dot{\mathrm{m}}_{\mathrm{w}}=\varepsilon_{\mathrm{m}} \cdot \dot{\mathrm{m}}_{\mathrm{w}, \max }
$$

Onde $\dot{\mathrm{m}}_{\mathrm{w}, \text { max }}$ é máxima taxa de transferência de umidade, dada por:

$$
\dot{\mathrm{m}}_{\mathrm{w}, \max }=\dot{\mathrm{m}}_{\min } \cdot\left(\mathrm{w}_{1}-\mathrm{w}_{3}\right)
$$

Assumindo que não há condensação de água no ERV, a umidade na saída da corrente de alimentação é:

$$
\mathrm{w}_{2}=\mathrm{w}_{1}-\varepsilon_{\mathrm{L}} \cdot \frac{\dot{\mathrm{m}}_{\min }}{\dot{\mathrm{m}}_{\mathrm{s}}} \cdot\left(\mathrm{w}_{1}-\mathrm{w}_{3}\right)
$$

A umidade do ar de saída na exaustão é:

$$
\mathrm{w}_{4}=\mathrm{w}_{3}-\varepsilon_{\mathrm{L}} \cdot \frac{\dot{\mathrm{m}}_{\min }}{\dot{\mathrm{m}}_{\mathrm{s}}} \cdot\left(\mathrm{w}_{1}-\mathrm{w}_{3}\right)
$$

A eficiência total $\varepsilon_{\mathrm{t}}$ de energia recuperada de um ERV é dada por:

$$
\varepsilon_{\mathrm{t}}=\frac{\dot{\mathrm{q}}_{\mathrm{t}}}{\dot{\mathrm{q}}_{\mathrm{t}, \max }}=\frac{\dot{\mathrm{m}}_{\mathrm{s}} \cdot\left(\mathrm{h}_{2}-\mathrm{h}_{1}\right)}{\dot{\mathrm{m}}_{\min } \cdot\left(\mathrm{h}_{3}-\mathrm{h}_{1}\right)}=\frac{\dot{\mathrm{m}}_{\mathrm{e}} \cdot\left(\mathrm{h}_{3}-\mathrm{h}_{4}\right)}{\dot{\mathrm{m}}_{\min } \cdot\left(\mathrm{h}_{3}-\mathrm{h}_{1}\right)}
$$

Onde $\dot{\mathrm{q}}_{\mathrm{t}}$ é a taxa atual de transferência de energia, dada por:

$$
\dot{\mathrm{q}}_{\mathrm{t}}=\varepsilon_{\mathrm{t}} \cdot \dot{\mathrm{q}}_{\mathrm{t}, \max }
$$


Onde $\dot{\mathrm{q}}_{\mathrm{t}, \mathrm{max}}$ é máxima taxa de transferência de energia, dada por:

$$
\dot{\mathrm{q}}_{\mathrm{t}, \max }=\dot{\mathrm{m}}_{\min } \cdot\left(\mathrm{h}_{1}-\mathrm{h}_{3}\right)
$$

$\varepsilon_{\mathrm{t}}=\quad$ Eficiência total $[-]$;

$\dot{\mathrm{m}}_{\mathrm{S}}=\quad$ Vazão mássica do ar seco de alimentação $[\mathrm{kg} / \mathrm{s}]$;

$\dot{\mathrm{m}}_{\mathrm{e}}=\quad$ Vazão mássica do ar seco de exaustão $[\mathrm{kg} / \mathrm{s}]$;

$\dot{\mathrm{m}}_{\text {min }}=\quad$ Menor valor entre $\dot{\mathrm{m}}_{\mathrm{s}} \mathrm{e} \dot{\mathrm{m}}_{\mathrm{e}}$;

$\mathrm{h}=\quad$ Entalpia dos pontos das correntes de ar $[\mathrm{kJ} / \mathrm{kg}]$;

A condição do ar de saída da corrente de alimentação é:

$$
\mathrm{h}_{2}=\mathrm{h}_{1}-\varepsilon_{\mathrm{t}} \frac{\dot{\mathrm{m}}_{\min }}{\dot{\mathrm{m}}_{\mathrm{s}}} \cdot\left(\mathrm{h}_{1}-\mathrm{h}_{3}\right)
$$

A condição do ar de saída na exaustão é:

$$
\mathrm{h}_{4}=\mathrm{h}_{3}-\varepsilon_{\mathrm{t}} \cdot \frac{\dot{\mathrm{m}}_{\min }}{\dot{\mathrm{m}}_{\mathrm{s}}} \cdot\left(\mathrm{h}_{1}-\mathrm{h}_{3}\right)
$$

Assumindo que o estado 1 da corrente é o de maior umidade, o calor latente recuperado $\dot{\mathrm{q}}_{\mathrm{L}}$ pelo ERV pode ser estimado por:

$$
\begin{gathered}
\dot{\mathrm{q}}_{\mathrm{L}}=\dot{\mathrm{m}}_{\mathrm{s}} \cdot \mathrm{h}_{\mathrm{fg}} \cdot\left(\mathrm{w}_{1}-\mathrm{w}_{2}\right)=\mathrm{Q}_{\mathrm{s}} \cdot \rho_{\mathrm{s}} \cdot \mathrm{h}_{\mathrm{fg}} \cdot\left(\mathrm{w}_{1}-\mathrm{w}_{2}\right) \\
\dot{\mathrm{q}}_{\mathrm{L}}=\dot{\mathrm{m}}_{\mathrm{e}} \cdot \mathrm{h}_{\mathrm{fg}} \cdot\left(\mathrm{w}_{4}-\mathrm{w}_{3}\right)=\mathrm{Q}_{\mathrm{e}} \cdot \rho_{\mathrm{e}} \cdot \mathrm{h}_{\mathrm{fg}} \cdot\left(\mathrm{w}_{4}-\mathrm{w}_{3}\right) \\
\dot{\mathrm{q}}_{\mathrm{L}}=\varepsilon_{\mathrm{L}} \cdot \dot{\mathrm{m}}_{\min } \cdot \mathrm{h}_{\mathrm{fg}} \cdot\left(\mathrm{w}_{1}-\mathrm{w}_{3}\right)
\end{gathered}
$$

A energia total transferida entre as correntes é dada por: 


$$
\dot{\mathrm{q}}_{\mathrm{t}}=60 \cdot \varepsilon_{\mathrm{t}} \cdot \dot{\mathrm{m}}_{\min } \cdot\left(\mathrm{h}_{1 \mathrm{~s}}-\mathrm{h}_{3 \mathrm{e}}\right)
$$

ERVs podem ser usados onde existe a oportunidade para transferir calor e massa (vapor de água), em áreas úmidas, escolas, escritórios com grande ocupação, etc. A transferência de calor latente pode ser positiva ou negativa dependendo da direção de decrescimento do vapor de água. Dependendo das condições, a corrente de alimentação escoando pelo ERV pode ganhar energia em forma de calor $\left(+\dot{\mathrm{q}}_{\mathrm{s}}\right)$ da corrente adjacente, mas perder energia latente $\left(-\dot{\mathrm{q}}_{\mathrm{L}}\right)$ se ela transferir vapor de água para a corrente adjacente. Os ganhos de calor e energia latente podem estar na mesma direção ou em direções opostas. O ganho total de energia é a soma algébrica entre $\dot{\mathrm{q}}_{\mathrm{s}} \mathrm{e} \dot{\mathrm{q}}_{\mathrm{L}}$.

A potência de ventilação $\dot{\mathrm{P}}_{\mathrm{S}}$ requerida para a corrente de alimentação pode ser estimada por:

$$
\begin{aligned}
& \dot{\mathrm{P}}_{\mathrm{S}}=\mathrm{Q}_{\mathrm{s}} \cdot \Delta \mathrm{p}_{\mathrm{s}} / \eta_{\mathrm{f}} \\
& \dot{\mathrm{P}}_{\mathrm{e}}=\mathrm{Q}_{\mathrm{e}} \cdot \Delta \mathrm{p}_{\mathrm{e}} / \eta_{\mathrm{f}}
\end{aligned}
$$

$\dot{\mathrm{P}}_{\mathrm{S}}=\quad$ Potência de ventilação para o ar de alimentação $[W]$;

$\dot{\mathrm{P}}_{\mathrm{e}}=\quad$ Potência de ventilação para o ar de exaustão $[W]$;

$\Delta \mathrm{p}_{\mathrm{s}}=\quad$ Perda de carga da corrente de ar de alimentação causada pela fricção do fluido $[\mathrm{Pa}]$

$\Delta \mathrm{p}_{\mathrm{e}}=\quad$ Perda de carga da corrente de ar de exaustão causada pela fricção do fluido $[\mathrm{Pa}]$;

$\eta_{\mathrm{f}}=\quad$ Eficiência global do ventilador e do motor ou o produto dessas duas eficiências [-];

Demais informações relativas aos equipamentos de recuperação de energia encontram-se no Apêndice A. 


\section{4 - VENTILAÇÃO DE AR EXTERIOR}

\section{1 - VAZÕES DE AR EXTERIOR}

\subsection{1 - Introdução}

Milhões de pessoas trabalham em edifícios com sistemas mecânicos de aquecimento, ventilação e ar condicionado (AVAC). Esses sistemas são projetados para fornecer ar com temperatura e umidade adequadas, livre de concentrações perigosas de poluentes do ar, sendo que o processo mais complexo envolvido na ventilação é o mais importante na determinação de uma boa qualidade do ar interno. A ventilação é uma combinação de processos que resultam não só no fornecimento de ar externo, mas também na retirada do ar de circulação de dentro de um edifício. Esses processos envolvem normalmente a entrada de ar externo, condicionamento e mistura do ar por todas as partes do edifício e a exaustão de alguma parcela do ar interno (Prado et al., 1999).

A qualidade do ar interno pode ficar prejudicada quando uma ou mais partes desse processo forem inadequadas. Por exemplo, o dióxido de carbono pode se acumular em algumas partes do edifício, caso quantidades insuficientes de ar forem introduzidas e misturadas dentro do mesmo. O $\mathrm{CO} 2$ é apenas um de muitos poluentes gasosos que, isoladamente ou em combinação entre si, podem provocar efeitos adversos à saúde, como dor de cabeça, mal estar, tontura e até problemas de pele, conforme EPA (1991).

O controle dos poluentes é a maneira mais efetiva de manter o ar interno limpo. Entretanto, o controle de todas as fontes, ou pelo menos a mitigação de suas emissões, nem sempre é possível ou praticável. A ventilação, natural ou mecânica, é a segunda maneira mais efetiva de proporcionar condições aceitáveis de ar interno. O Instituto Nacional de Segurança Ocupacional e Saúde relata que uma ventilação pobre e inadequada é um fator que contribui de maneira importante em muitos casos de edifícios doentes (Prado et al., 1999).

As taxas nas quais o ar externo é introduzido no ambiente interno são especificadas por algumas normas, nacionais e internacionais. Essas taxas são baseadas na necessidade de controle dos odores e dos níveis de $\mathrm{CO} 2$. O dióxido de carbono é um componente do ar externo, mas ele pode ser produzido internamente e seu excesso, sua acumulação interna, pode indicar uma ventilação inadequada. No começo do século, as normas de ventilação 
para edificações, conforme descreve EPA, requeriam aproximadamente $25 \mathrm{~m}^{3} / \mathrm{h}$ de ar externo por ocupante (Prado et al., 1999). Essa taxa era usada basicamente para diluir os poluentes e remover odores originários do metabolismo humano. Como resultado da crise do petróleo na década de 70, medidas nacionais de economia de energia impuseram uma redução nessas taxas para aproximadamente $8 \mathrm{~m} / \mathrm{h}$ para cada um dos usuários do edifício, segundo a ASHRAE (1989).

Em muitos casos, essas taxas reduzidas de fornecimento de ar foram inadequadas para manter a saúde e o conforto dos ocupantes. Como já colocado acima, uma ventilação inadequada é uma das causas da síndrome dos edifícios doentes. Assim, em uma tentativa de providenciar taxas de troca de ar mais adequadas e em concordância com a necessidade de economia de energia, a ASHRAE revisou os padrões de ventilação e concluiu que era possível, com a tecnologia da época, fornecer uma taxa de $25 \mathrm{~m} 3 / \mathrm{h}$ por usuário, sem gastos adicionais de energia. Dependendo das atividades desenvolvidas no local, uma taxa de 100 $\mathrm{m}^{3} / \mathrm{h}$ pode ser necessária (Prado et al., 1999).

Ao longo dos anos essas normas foram sendo atualizadas, e as tendências atuais levam para uma relação da qualidade do ar interior com a economia de energia, prevendo a utilização de sistemas que controlem as vazões necessárias de acordo com a demanda, chamados de sistemas DCV (demand controlled ventilation) (ASHRAE 62.1-2010 e 189.12009). No Brasil, a Portaria 3.523 do Ministério da Saúde publicada em 1998 regula sobre a qualidade do ar interior, definindo rotinas de manutenção necessárias, vazões de ar externo, e etc. Após ela, a norma ABNT NBR 16401-3 de 2008 é a mais recente sobre o tema, e traz inovações baseadas na norma americana mais atual que versa sobre os requisitos de ventilação para manutenção da qualidade do ar interior (ASHRAE 62.12010).

Um breve histórico relativo à qualidade do ar interior e às normas pertinentes é apresentado no Apêndice B.

\subsection{2 - Ventilação controlada por demanda (Demand-controlled ventilation - DCV)}

Sistemas de ventilação são projetados para prover um nível mínimo de ar externo baseado na ocupação de projeto dos espaços atendidos. O sistema DCV pode ser definido como a ventilação que automaticamente é ajustada com base na ocupação do ambiente. Ainda, o DCV reduz a vazão de entrada de ar externo abaixo dos valores de projeto quando a ocupação atual do ambiente está abaixo da ocupação de projeto. O sistema inclui 
hardware, software, e uma estratégia de controle, e é parte integrante do projeto de ventilação do edifício. O conceito da ventilação automática baseada na ocupação tem sido reconhecido como uma medida de eficiência energética por quase 30 anos. Os métodos mais comuns utilizados para estimar a população da zona incluem programações horárias de utilização, sensores de ocupação, e sensores de CO2 (Zhang, 2012).

\subsubsection{1 - Ventilação controlada por demanda CO2}

Além da contagem populacional, sensores de $\mathrm{CO} 2$, cronômetros, programas de ocupação horária e sensores de ocupação também são listados como meios aceitáveis para definir a ocupação instantânea de acordo com as normas da ASHRAE. Desses meios listados, o sistema de DCV baseado em sensores de $\mathrm{CO} 2$ são os mais comumente utilizados em projetos (Zhang, 2012). Won e Yang (2005) analisaram diversos sensores em sistemas de DCV e recomendaram os sensores de $\mathrm{CO} 2$ com base em três critérios: desempenho, custo e qualidade do ar interior. As pessoas consomem oxigênio e geram $\mathrm{CO} 2$ e outros gases odoríferos. As taxas de geração de $\mathrm{CO} 2$ e outros gases por um indivíduo dependem primeiramente de sua massa corporal e do nível de atividade física realizada. Estudos experimentais mostraram que as duas taxas de emissão são proporcionais, assim, a concentração de CO2 tem sido considerada um indicador confiável de concentração de gases oriundos da respiração humana. Emmerich e Persily (2001) concluíram que o sistema de DCV baseado em sensores de $\mathrm{CO} 2$ tem maior probabilidade de ser eficaz para edifícios com as seguintes características: i) variações imprevisíveis de ocupação; ii) edificação aonde o resfriamento ou aquecimento é requerido praticamente durante todo o ano; iii) pouca emissão de poluente por fontes não humanas.

A partir da Equação (B.7), a implementação do DCV com base em sensores de $\mathrm{CO} 2$ depende da estimativa da taxa de geração de $\mathrm{CO} 2$ dos ocupantes, da medição da diferença de concentração de $\mathrm{CO} 2$ entre o ar interno e o ar externo, e, a partir desses dados, determinar a taxa no qual a ventilação de ar é entregue ao espaço condicionado por pessoa. $\mathrm{Na}$ maioria dos locais, a concentração externa do CO2 pode variar em mais de 100 ppm do valor nominal. Por conta disso e ao invés de se instalar um sensor externo de $\mathrm{CO} 2$, a maioria dos projetistas usam ou uma leitura da medida de concentração de CO2 no ar externo ou um valor conservador de um histórico de medidas. Isso simplifica o controle, diminui o custo de instalação, e geralmente aumenta a precisão, pois evita as imprecisões devidas às medições do sensor externo (Zhang, 2012). 
Também, geralmente utiliza-se um valor constante para a taxa de geração de CO2 por pessoa, a fim de simplificar o dimensionamento do sistema de DCV. Cabe ressaltar que essa simplificação introduz imprecisões, uma vez que essa taxa de geração varia com o nível da atividade do ocupante, dieta, saúde, etc (Zhang, 2012).

\subsubsection{2 - DCV baseado em CO2 para sistemas de zona única}

Sistemas de DCV têm sido utilizados em zonas únicas por diversos anos. O primeiro método utilizado usa a concentração de $\mathrm{CO} 2$ medida na zona para controlar a vazão do ar externo de entrada. As estratégias de controle são desenvolvidas para usos práticos, e elas podem atender ou não às normas de ventilação de maneira contínua (Zhang, 2012). A Fig. 4.1 ilustra o esquema de controle do sistema de DCV baseado em sensores de $\mathrm{CO} 2$ para zonas únicas.

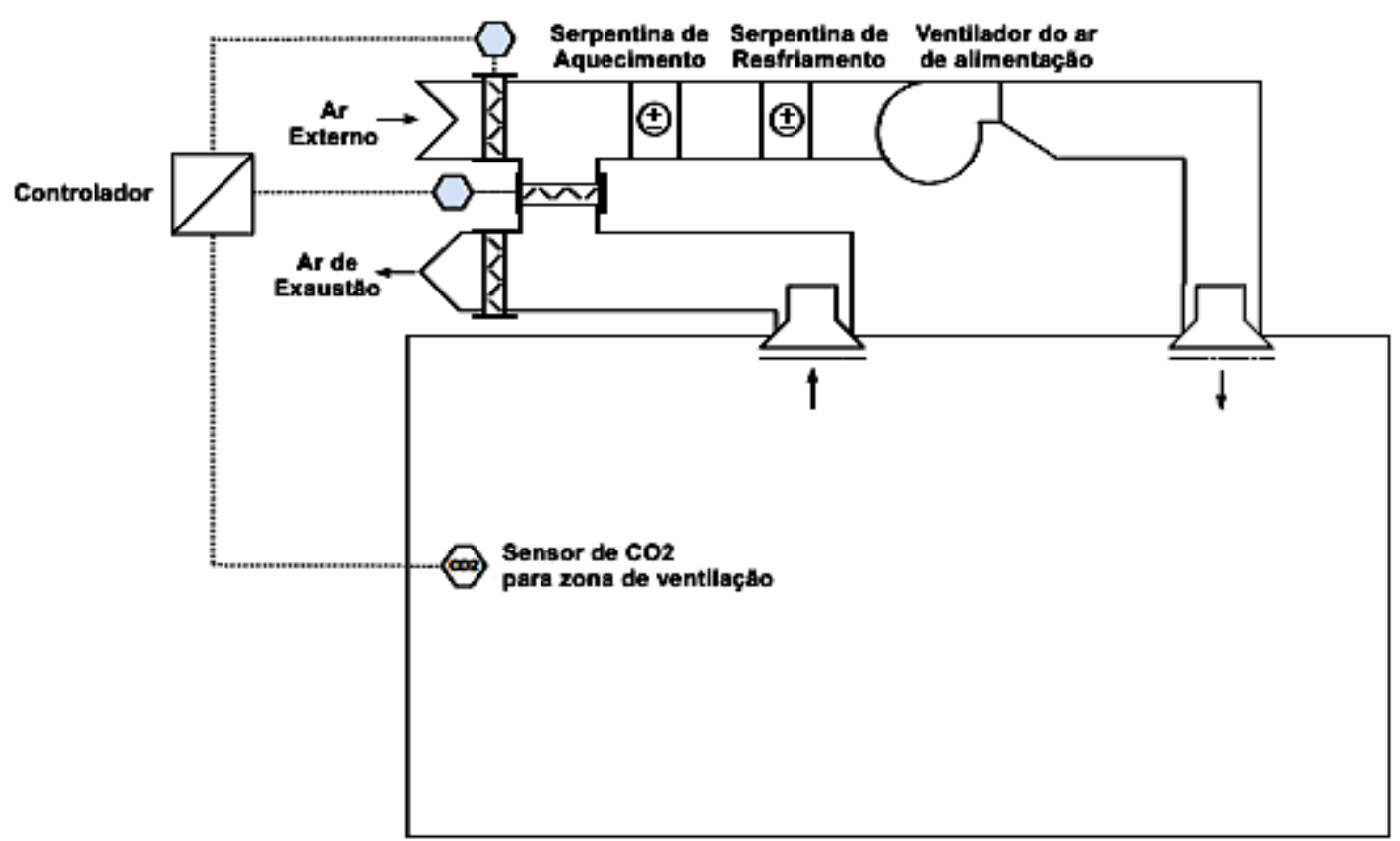

Figura 4.1 - Esquema de controle do sistema de DCV baseado em sensores de CO2 para zonas únicas (Zhang 2012, modificado)

O sistema funciona basicamente por meio da medição da concentração de $\mathrm{CO} 2$ no ambiente interno. O controlador faz a comparação do nível medido no ambiente interno e compara com o nível de concentração do ambiente externo, atuando assim no damper de ar externo. As estratégias de controle incluem o simples controle de set point de $\mathrm{CO} 2$ para atuação do damper de ar externo entre as posições totalmente aberto e totalmente fechado, o controle proporcional no qual o damper é aberto proporcionalmente à concentração de 
$\mathrm{CO} 2$ medida, e o controle proporcional, integral e derivativo (PID), que considera a taxa de variação na concentração de CO2 (Zhang, 2012).

\subsubsection{3 - Estratégia de controle proporcional de CO2}

Murphy (2008) propõe uma situação detalhada para exemplificar melhor essa forma de controle. Consideremos uma sala de leitura com ocupação máxima de projeto de 65 pessoas e área de 1.000 pés quadrados. A norma ASHRAE 62.1 requer 7,5 cfm de ar externo por pessoa mais 0,06 cfm de ar externo para cada pé quadrado de área. Assim, para uma ocupação de 65 pessoas, o valor total de ar externo requerido é de $550 \mathrm{cfm}$ e para o ambiente desocupado é de $60 \mathrm{cfm}$. O apêndice A da norma menciona os seguintes passos:

Passo 1: Calcular a vazão de ar externo para a população de projeto da zona pelas Equações (B.4) e (B.5).

$$
\mathrm{V}_{\mathrm{z}}=\left(\mathrm{F}_{\mathrm{p}} \cdot \mathrm{P}_{\mathrm{z}}+\mathrm{F}_{\mathrm{a}} \cdot \mathrm{A}_{\mathrm{z}}\right) / \mathrm{E}_{\mathrm{z}}=[(7,5 \cdot 65)+(0,06 \cdot 1000)] \div 1=550 \mathrm{cfm}
$$

Passo 2: Calcular a vazão de ar externo quando a zona está desocupada pelas Equações (B.4) e (B.5).

$$
\mathrm{V}_{\mathrm{z}, \text { min }}=[(7,5 \cdot 0)+(0,06 \cdot 1000)] \div 1=60 \mathrm{cfm}
$$

Passo 3: Calcular o alvo da concentração de $\mathrm{CO} 2$ para a vazão de projeto de ar externo pela Equação (B.7).

$$
\mathrm{C}_{\mathrm{s}}=\mathrm{C}_{0}+\left[\mathrm{N} /\left(\mathrm{V}_{0}\right)\right]=350 \mathrm{ppm}+[0,0105 \div(550 \mathrm{cfm} \div 65 \text { pessoas })]=1600 \mathrm{ppm}
$$

Passo 4: Definir o alvo de concentração de CO2 para a vazão mínima de ar externo igual à concentração de $\mathrm{CO} 2$ do ar externo.

$$
\mathrm{C}_{\mathrm{s}, \min }=350 \mathrm{ppm}
$$


Quando a concentração atual de CO2 é igual à concentração de projeto (1600ppm no caso em questão), a vazão de ar externo atual deve ser igual à vazão de projeto (550 cfm). Quando a concentração atual de $\mathrm{CO} 2$ do ambiente interno é igual à concentração mínima de CO2 (350 ppm), a vazão atual de ar externo deve ser igual à vazão mínima de ar externo (60 cfm). Quando a concentração atual de CO2 no ambiente interno está entre o mínimo e o valor de projeto, o controlador deve ajustar a vazão de ar externo proporcionalmente entre seus valores mínimos e de projeto:

$$
\mathrm{V}_{\mathrm{z}, \text { atual }}=\left[\left(\mathrm{C}_{\mathrm{s}, \text { atual }}-\mathrm{C}_{\mathrm{s}, \text { min }}\right) \div\left(\mathrm{C}_{\mathrm{s}}-\mathrm{C}_{\mathrm{s}, \min }\right)\right] \cdot\left(\mathrm{V}_{\mathrm{z}}-\mathrm{V}_{\mathrm{z}, \min }\right)+\mathrm{V}_{\mathrm{z}, \min }
$$

Como a Figura 4.2 mostra, a estratégia de controle proporcional produz uma vazão de ar exterior que equivale ou excede os requisitos das normas (ASHRAE 62.1 e ABNT 6401-3). Essa estratégia é fácil de ser implementada, mas permite uma ventilação excessiva para ocupações parciais do ambiente. Um damper modulado de ar externo, bem como um controlador com dois limites de concentração de $\mathrm{CO} 2$ e dois limites para o damper correspondentes às vazões de entrada de ar são requeridos. Também, pode-se notar que a vazão de ar externo e a concentração de CO2 são proporcionais (ou lineares) entre sim, mas nenhum dos dois é proporcional em relação à população que ocupa a zona. $\mathrm{O}$ controlador ajusta os valores da vazão de ar externo proporcionalmente à faixa percentual do sinal de $\mathrm{CO} 2$, mas quando o controlador altera a vazão de ar externo, a concentração interna de $\mathrm{CO} 2$ também varia. O controlador, assim, deve ajustar os valores de vazão em pequenos incrementos até que o nível de CO2 interno alcance um valor estável. Quando plotado em relação à população da zona, os resultados desses controles são curvas tanto para a vazão de ar externo quanto para a concentração interna de $\mathrm{CO} 2$. 


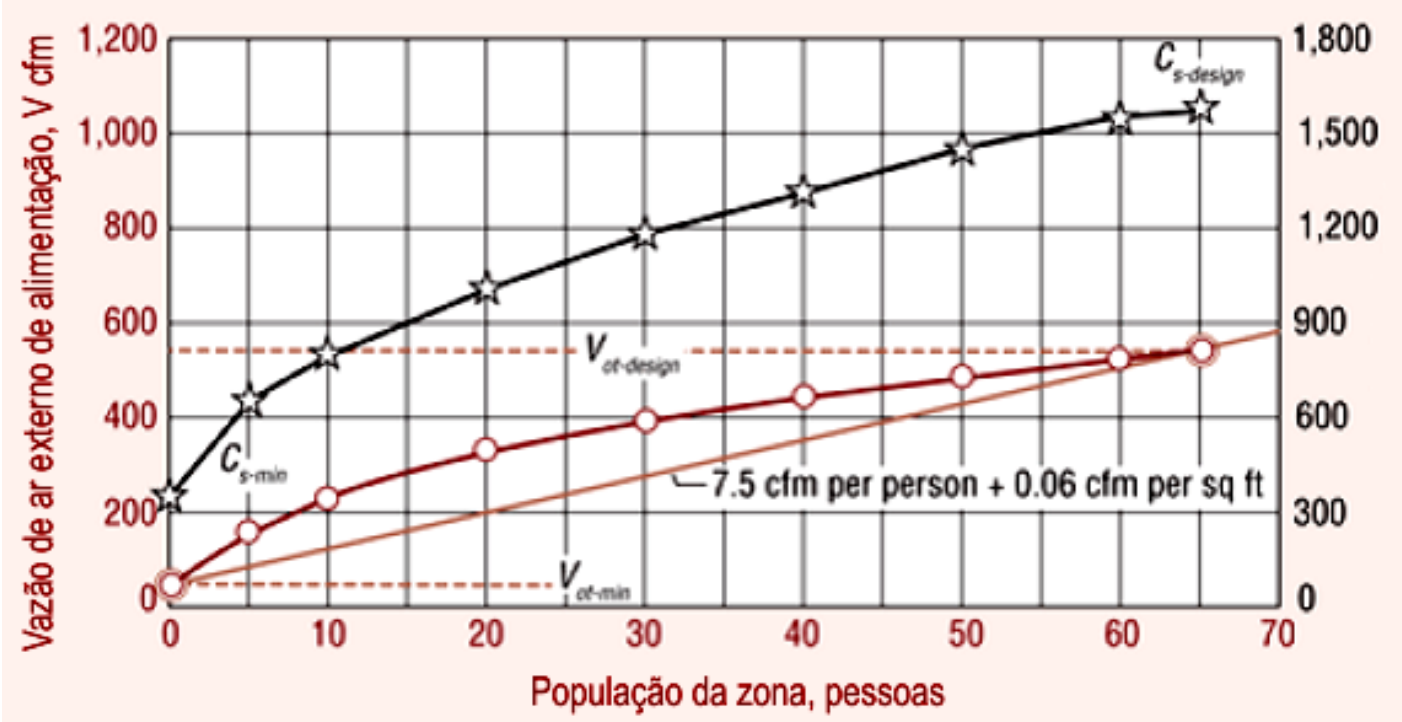

Figura 4.2 - Estratégia de controle proporcional para DCV baseado em CO2 pela ASHRAE 62.1 (Murphy 2008, modificada)

\subsubsection{4 - Estratégia de controle por set point de CO2}

A estratégia de controle por simples set point pode, em alguns casos, evitar a ventilação excessiva para algumas categorias de ocupação (Murphy, 2008):

Passo 1: Selecionar um valor razoável (diferente de zero) para representar a ocupação mínima, e calcular a vazão de ar externo requerida para essa população pelas Equações (B.4) e (B.5).

$$
\begin{gathered}
\mathrm{P}_{\mathrm{z}, \min }=25 \text { pessoas } \\
\mathrm{V}_{\mathrm{z}, \min }=[(7,5 \cdot 25)+(0,06 \cdot 1000)] \div 1=250 \mathrm{cfm}
\end{gathered}
$$

Passo 2: Calcular o alvo de concentração de $\mathrm{CO} 2$ para a vazão mínima de ar externo pela Equação (B.7).

$$
\mathrm{C}_{\mathrm{s}, \min }=\mathrm{C}_{0}+\left[\mathrm{N} /\left(\mathrm{V}_{0}\right)\right]=350 \mathrm{ppm}+[0,0105 \div(250 \mathrm{cfm} \div 25 \text { pessoas })]=1400 \mathrm{ppm}
$$

A vazão de entrada é ajustada de maneira a manter a concentração interna de $\mathrm{CO} 2$ em seu valor mínimo (1400 ppm). Se o damper de ar externo alcança sua vazão mínima (250 cfm), e a população da zona cai, o damper vai manter o valor mínimo de vazão de ar 
externo. Isso vai ventilar a zona em excesso, causando uma redução na concentração de $\mathrm{CO} 2$ do ambiente interno. Reciprocamente, enquanto a população da zona vai chegando ao seu valor de projeto, a zona também receberá ventilação em excesso.

Conforme mostra a Figura 4.3, a abordagem de controle por set point resulta em uma vazão de ar externo que equivale ou excede as vazões requeridas pela norma ASHRAE 62.1. Essa abordagem é fácil de ser implementada e, dependendo das características da zona, pode resultar em excessos menores de vazão em uma ocupação proporcional do que o método de controle proporcional. Assim como no método proporcional, esse método também querer o damper de modulação de ar externo, entretanto, o controlador necessita de apenas um valor de set point para o damper e um valor de set point para a concentração de $\mathrm{CO} 2$.

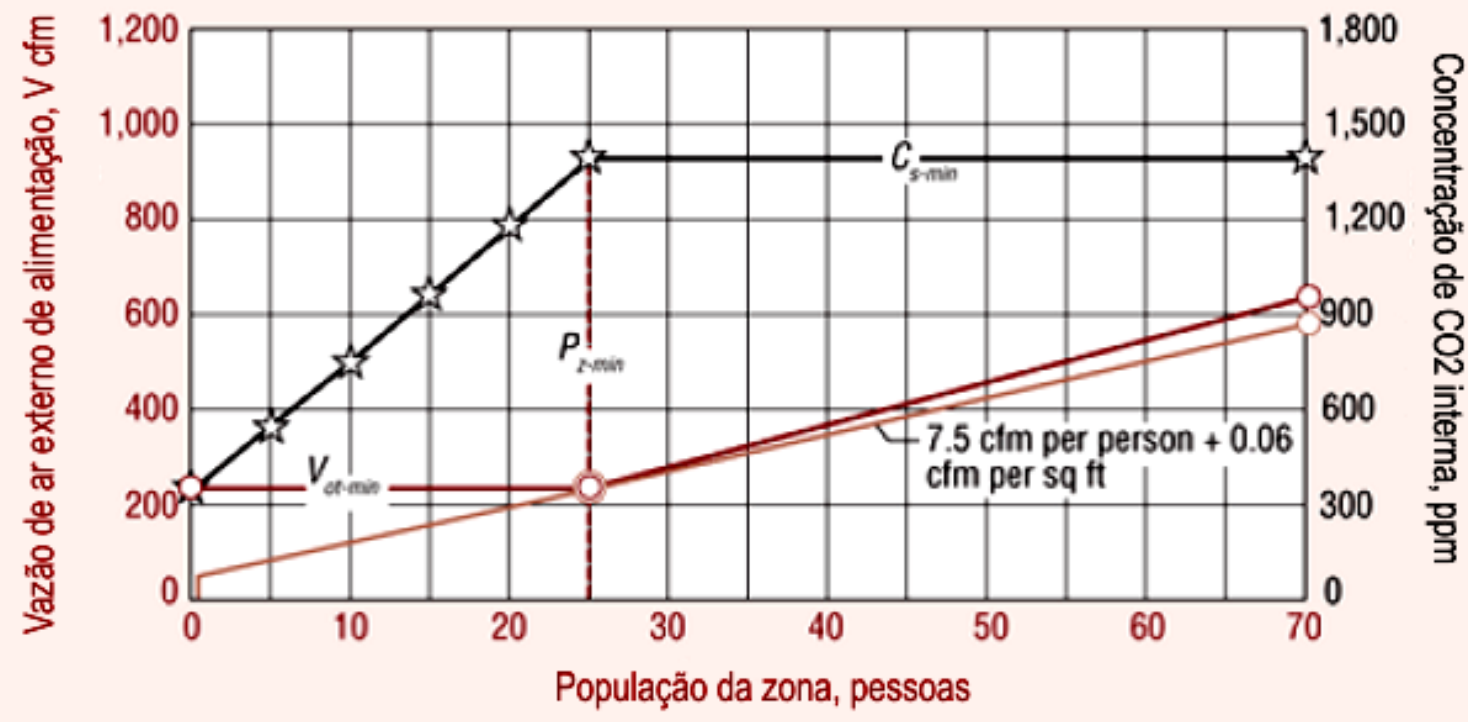

Figura 4.3 - Estratégia de controle por simples set point para DCV baseado em CO2 pela ASHRAE 62.1 (Murphy 2008, modificado)

\subsubsection{5 - Economias relativas ao DCV}

Muitos edifícios atualmente utilizam sistemas de DCV, e uma ampla gama de resultados tem sido relatada. Mansson (1994) e Meier (1998) estimaram as economias no custo de energia pelos sistemas de DCV para vários tipos de edifícios e espaços. Os resultados mostraram economias de $20 \%$ a $30 \%$ para escritórios de espaços abertos com ocupação média de $40 \%, 20 \%$ a 50\% para restaurantes e salas de leitura, e acima de $60 \%$ para salas de montagem, teatros, cinemas, salas de espera, áreas de check-in em aeroportos, 
e halls de entrada. Sand (2004) relatou a partir de uma revisão bibliográfica economias de $\$ 0,05$ por pé quadrado até mais de $\$ 1$ por pé quadrado a partir do uso de sistemas de DCV.

\subsubsection{6 - Limitações relativas ao DCV}

Apesar de sistemas de DCV baseados em CO2 serem aceitos como uma solução energeticamente eficiente de projeto, questionamentos têm sido levantados a respeito da manutenção, frequência de calibração, efeitos da temperatura, e localização apropriada dos sensores. A confiabilidade dos sensores é frequentemente identificada como um potencial problema. Se apenas um dos sensores estiver descalibrado, de forma que a concentração de $\mathrm{CO} 2$ medida seja maior que o valor real, o sistema vai prover uma quantidade excessiva de ar externo para corrigir a medição incorreta da concentração na zona atendida (Zhang, 2012).

Ainda, os sistemas de DCV não controlam os contaminantes provenientes de fontes que não sejam os ocupantes. Também não controlam o excesso de ventilação caso o ambiente atendido possua uma ocupação menor que a ocupação de projeto. Algumas orientações específicas para sistemas de zona única são disponíveis na literatura, porém, um guia de aplicação consistente e confiável para sistemas de DCV em sistemas multizona não se encontra disponível na literatura (Zhang, 2012). 


\section{5 - DESENVOLVIMENTO DO MODELO MATEMÁTICO}

\section{1 - ESQUEMA DO SISTEMA ADOTADO}

Para que seja possível analisar os efeitos anuais das técnicas de recuperação de energia e de vazão de ar exterior variável operando em um sistema de ar condicionado, é necessário definir o sistema que será adotado, a partir do qual será possível levantar a formulação matemática pertinente. O sistema adotado constitui-se basicamente de 04 (quatro) subsistemas, conforme mostra a Figura 5.1: i) subsistema do ambiente condicionado; ii) subsistema do equipamento de ar condicionado; iii) subsistema do controle de vazão de ar exterior por $\mathrm{CO} 2$; iv) subsistema do recuperador de energia $(\mathrm{ERV})$.

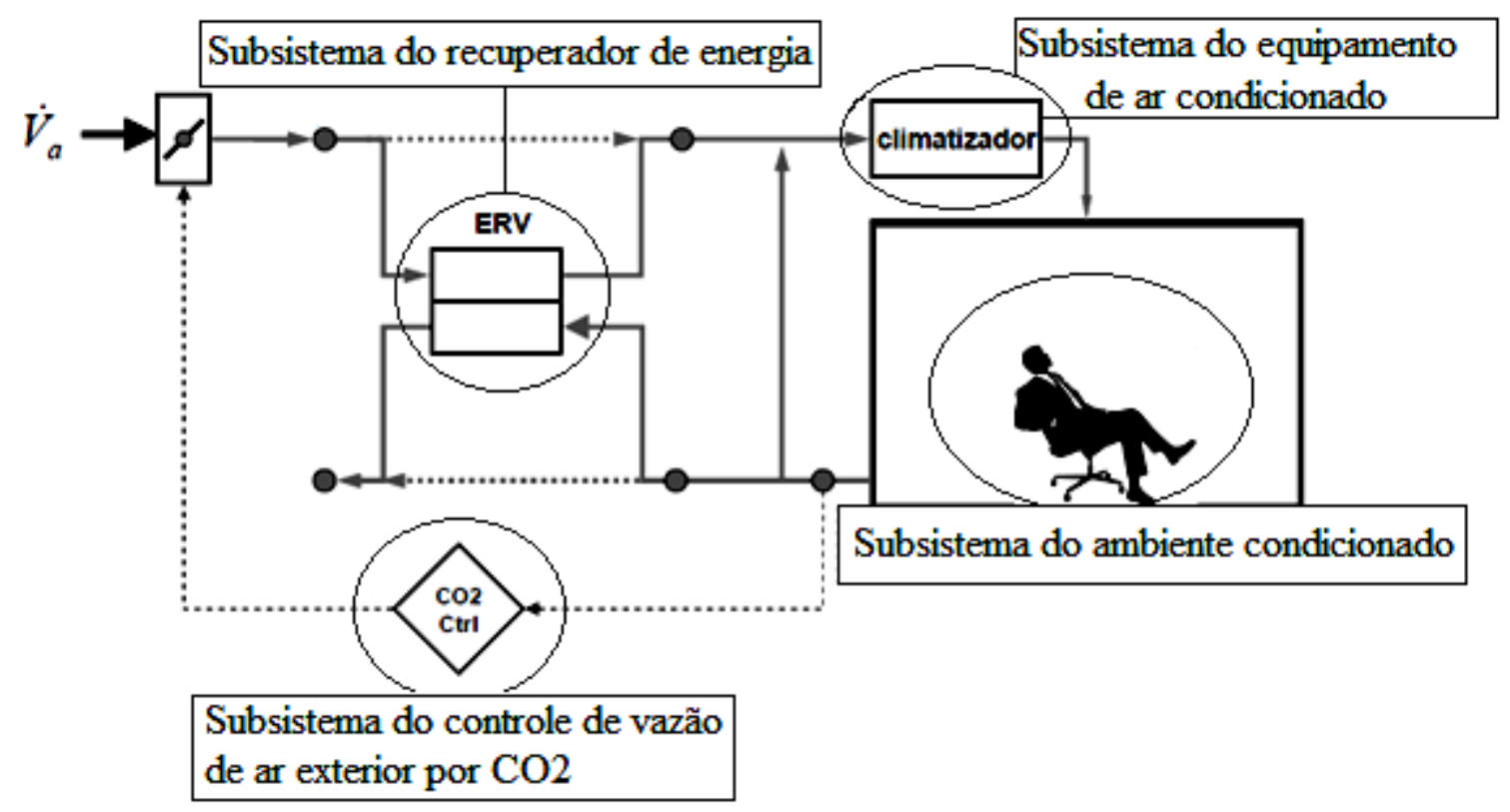

Figura 5.1 - Esquema do sistema adotado para desenvolvimento do modelo

O funcionamento simplificado do esquema pode ser resumido da seguinte forma:

a) o subsistema do ambiente condicionado representa o espaço destinado à ocupação, que receberá o equipamento de ar condicionado. Esse espaço será definido a partir de um perfil de carga térmica, cujas cargas de geração interna foram definidas a partir de um perfil de ocupação populacional.

b) o subsistema do equipamento de ar condicionado será responsável pelo atendimento da carga térmica do ambiente, e será definido a partir das curvas de consumo 
elétrico dos componentes do sistema, com o objetivo de simular o desempenho do sistema em diversas condições de operação.

c) o subsistema do controle de vazão de ar exterior por $\mathrm{CO} 2$ será responsável pelo controle da quantidade de ar externo de renovação que será inserido no ambiente. Esse controle será feito mediante medições reais das taxas de $\mathrm{CO} 2$ geradas no ambiente, com o intuito de estimar a população real presente, a fim de garantir que as vazões de ar externo satisfaçam os valores normativos.

d) o subsistema do recuperador de energia será responsável pela redução da carga térmica do ar externo de renovação, quando possível, de acordo com a análise comparativa entre as cargas térmicas sensível e latente do ar externo e do ar interno. $\mathrm{O}$ funcionamento desse equipamento acontece mediante a transferência de calor entre o ar externo que entra e o ar do ambiente interno que é exaurido.

A operação dos subsistemas apresentados está totalmente interligada, variando com diversos parâmetros, como variações na carga térmica, ocupação, temperatura e umidade do ambiente externo, etc. Dessa forma, para que os resultados das simulações apresentem valores coerentes, é necessário caracterizar cada um desses subsistemas e as influências que esses exercem entre si.

\section{2 - FORMULAÇÃO MATEMÁtiCA DO SUBSISTEMA DO AMBIENTE CONDICIONADO}

O ambiente escolhido representa um ambiente de zona térmica única, com um único regime de utilização e perfil de carga térmica, sendo mantido por um único equipamento condicionador de ar e com controle único para todo o ambiente. Ainda, considerou-se a zona de ventilação equivalente à zona de controle térmico, para efeito do dimensionamento das vazões de ar externo. O tipo de ambiente escolhido também foi delimitado entre auditórios, salas de leitura, salas de convenção, dentro outros, que são ambientes que possuem regimes de ocupação bem variável, com o intuito de dar mais opções para as análises das simulações, e também para atender a norma ASHRAE 90.12010, que exige sistemas de DCV para ambientes com área superior a $46 \mathrm{~m}^{2}$ e com ocupação populacional igual ou superior a 0,43 pessoas/metro quadrado.

Esse espaço será definido a partir de um perfil de carga térmica gerado para todas as horas do ano (8760 horas), que levará em conta a sua carga devida à envoltória, para a cidade definida, a carga devido à geração interna com base na programação de ocupação 
populacional definida, cargas de infiltração e demais também definidas. A carga térmica devido à renovação de ar externo, por sua vez, será calculada pela própria formulação da simulação, uma vez que essa carga varia de acordo com a vazão real de ar externo e com a utilização ou não do equipamento recuperador de energia. Para o levantamento do perfil de carga térmica foi utilizado o software HAP (Hourly Analysis Program) do fabricante CARRIER, que atende as normas da ASHRAE em relação às metodologias de cálculo de carga térmica.

\section{3 - FORMULAÇÃO MATEMÁTICA DO SUBSISTEMA DO EQUIPAMENTO DE AR CONDICIONADO}

O subsistema do equipamento de ar condicionado adotado consiste em um sistema central de expansão indireta, com um equipamento resfriador de líquido (chiller), com condensação à ar, que opera segundo um ciclo de compressão a vapor, e um climatizador do tipo fan coil como unidade terminal. O chiller é responsável por fornecer água gelada, por meio de uma bomba, para o climatizador fan coil, que por sua vez é responsável por manter as condições internas de acordo com os parâmetros de conforto estabelecidos.

Para que o sistema de ar condicionado seja bem caracterizado é necessário definir a curva de potência consumida pelo chiller (compressor e ventilador do sistema de condensação), para dadas temperaturas ambientes, cargas parciais de operação e taxa de vazão de água no evaporador da unidade por capacidade de refrigeração fornecida. Além disso, é necessário levantar a curva de potência do conjunto motor-ventilador do climatizador tipo fan coil em função da vazão, já que o sistema foi dimensionado para operar em cargas parciais (utilização de inversores de frequência para controle do chiller e do fan coil). Esses dados foram levantados a partir dos catálogos dos fabricantes dos equipamentos.

Assim, a partir dos dados de temperatura externa e de carga de operação (razão entre a carga térmica atual e a carga térmica máxima de projeto) e com as curvas de potência do chiller é possível verificar o consumo para cada hora de operação. Já para o climatizador, é necessário determinar os pontos de operação do sistema (encontro da curva da instalação com a curva do ventilador). Com os pontos de operação traçados na curva de vazão do ventilador é possível obter a potência elétrica consumida em cada ponto. 
Ainda, com os dados de consumo elétrico do sistema e da carga térmica instantânea torna-se possível determinar o COP (coeficiente de desempenho) do sistema para cada hora de operação.

\section{4 - FORMULAÇÃO MATEMÁTICA DO SUBSISTEMA DE CONTROLE DE VAZÃO DE AR EXTERIOR POR CO2}

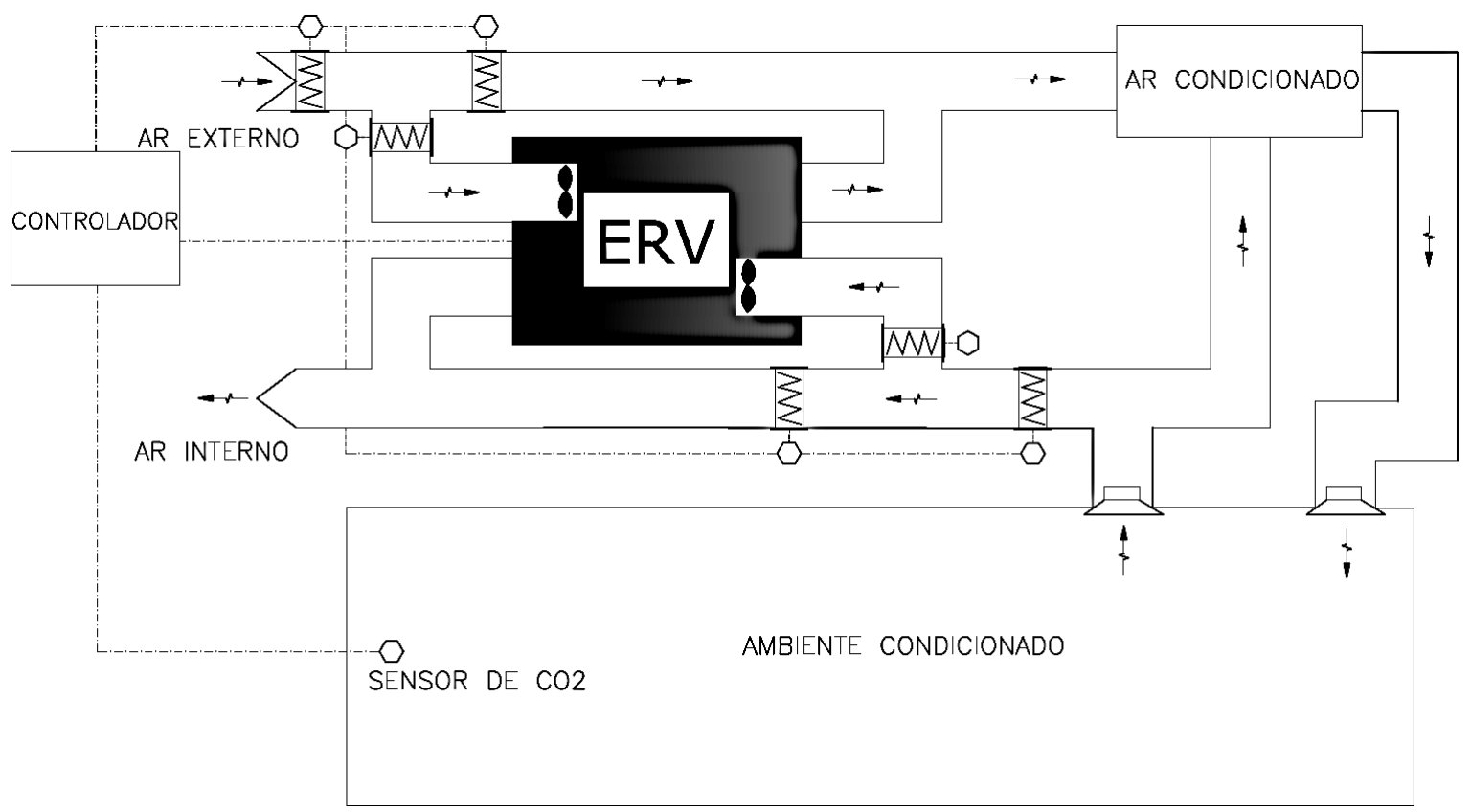

Figura 5.2 - Esquema detalhado do sistema adotado (detalhamento da Figura 5.1)

O subsistema de controle de vazão de ar exterior por CO2 é composto por sensores de $\mathrm{CO} 2$, sensores de pressão, controlador, e dispositivos de regulagem motorizados (dampers), conforme mostra a Figura 5.2. O sistema funciona basicamente por meio da medição da concentração de $\mathrm{CO} 2$ no ambiente interno. O controlador faz a comparação do nível medido no ambiente interno e compara com o nível de concentração do ambiente externo, atuando assim no damper de ar externo.

A estratégia de controle adotada é uma estratégia de controle proporcional, uma vez que ela produz uma vazão de ar exterior que equivale ou excede os requisitos das normas (ASHRAE 62.1 e ABNT 6401-3). Quando a concentração atual de CO2 é igual à concentração máxima de projeto, a vazão de ar externo atual deve ser igual à vazão máxima de projeto. Quando a concentração atual de $\mathrm{CO} 2$ do ambiente interno é igual à concentração mínima de $\mathrm{CO} 2$, a vazão atual de ar externo deve ser igual à vazão mínima de ar externo. Quando a concentração atual de $\mathrm{CO} 2$ no ambiente interno está entre o 
mínimo e o valor de projeto, o controlador deve ajustar a vazão de ar externo proporcionalmente entre seus valores mínimos e máximos de projeto.

Os ventiladores das correntes de ar de ar externo e de exaustão do ar interno podem ficar alocados ou não no próprio equipamento de recuperação de energia. No caso em questão, os ventiladores estão alocados dentro do equipamento. De acordo com a posição do damper e do nível de pressão na rede de dutos, os sensores de pressão enviam o sinal para o controlador regular a rotação dos motores dos ventiladores e consequentemente a vazão de ar das correntes.

A formulação matemática utilizada para prever a vazão de ar externo nas simulações baseia-se nos requisitos das normas técnicas (ABNT 16401-3 e ASHRAE 62.1), especificadas no Capítulo 4. Como a programação de ocupação do ambiente é definida previamente, é possível estabelecer a vazão de ar externo necessária para cada hora de operação, uma vez que a vazão de ar externo requerida pelas normas é composta pela soma de uma parcela proporcional ao número de ocupantes e uma parcela referente a área de ocupação (valor fixo). Ainda, foi definido um parâmetro chamado de "fator de ocupação", que é um valor percentual da taxa de ocupação real em relação à ocupação máxima de projeto.

\section{5 - FORMULAÇÃO MATEMÁTICA DO SUBSISTEMA DO RECUPERADOR DE ENERGIA}

O subsistema do recuperador de energia é composto pelo equipamento ERV (recuperador de energia ar-ar), de um controlador e sensores de temperatura e umidade para as medições das condições do ar externo. O controlador é responsável por regular a operação do equipamento a partir das medições instantâneas das condições de temperatura e umidade do ar externo, permitindo seu funcionamento apenas em situações que haja efetiva redução da carga térmica do ar externo que adentra o ambiente. Também, é responsável por operar o equipamento de acordo com o nível de vazão requerido pelo sistema de controle de $\mathrm{CO} 2$, bem como desligar o equipamento caso o fator de ocupação do ambiente seja zero.

Para que o equipamento ERV seja bem definido é necessário definir as eficiências sensível, latente e total do equipamento, bem como os fenômenos que modificam essas eficiências, como as variações de vazão de ar que atravessam o equipamento e as variações nas temperatura e umidade do ar externo. Além disso, é necessário computar a potência 
elétrica consumida pelo equipamento para operar e movimentar as correntes de ar de alimentação e de exaustão entre o ambiente interno e externo.

\subsection{1 - Eficiências do ERV - Influência das vazões de ar}

Conforme mostrado no Capítulo 3, as eficiências dos equipamentos ERV são fortemente influenciadas pela vazão das correntes de ar pelo equipamento. Esses dados são geralmente disponibilizados pelos fabricantes, de forma a possibilitar o dimensionamento e a análise do equipamento ideal para cada situação. A Figura 5.3 apresenta as relações das eficiências em função da vazão de ar de um dado equipamento.

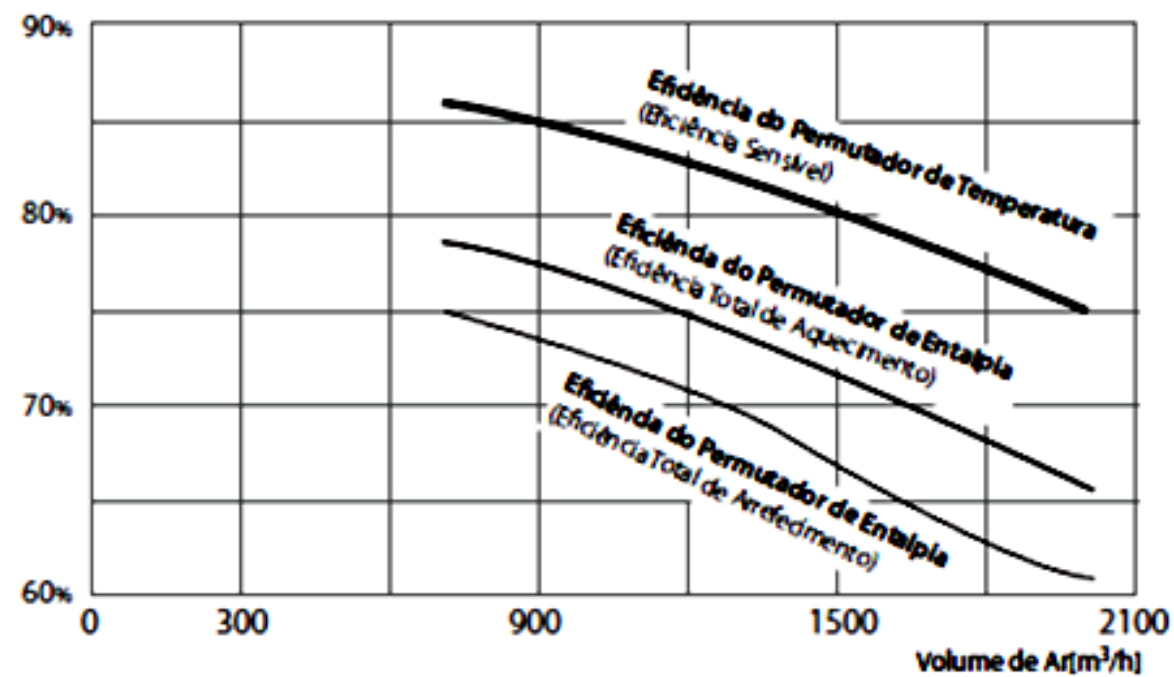

Figura 5.3 - Gráfico de Eficiência x Vazão de ar para o equipamento ERV modelo ECO-V LZ-H150GBA2 (LG, 2012)

Dessa forma, para determinação das eficiências sensível e latente do equipamento ERV, serão inseridas as equações das curvas de "eficiência x vazão". Como a vazão é um parâmetro de entrada, já que é definida em função do número de ocupantes, as eficiências reais podem ser definidas para cada instante.

\subsection{2 - Eficiências do ERV - Influência das condições do ar externo}

A eficiência total (ou entálpica) do equipamento ERV é influenciada tanto pela quantidade de calor sensível trocado como pela quantidade de calor latente. Dessa forma, para uma correta definição da eficiência total de um equipamento, o ideal seria considerar 
um valor de "eficiência total ponderado", que seria uma soma dos valores de eficiência sensível e latente ponderados por coeficientes que exprimam as condições climáticas (temperatura e umidade do ar externo) (LIU et al., 2010).

Dessa forma, com o intuito de levar em consideração as influências do ambiente externo na eficiência total do ERV, foi utilizada a formulação apresentada por LIU et al (2010).

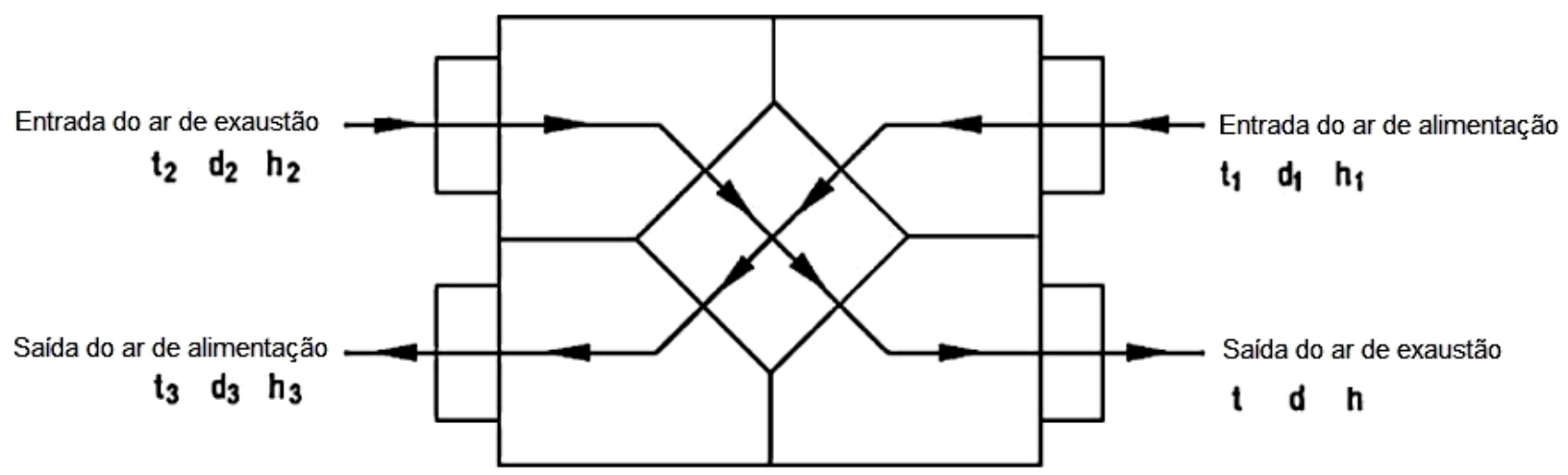

Figura 5.4 - Esquema das correntes de ar de alimentação e exaustão no ERV (LIU et al., 2010, modificado).

As Equações (3.2), (3.10) e (3.18) apresentam as formulações para os três tipos de eficiência (sensível, latente e total), e são todas baseadas na razão entra a taxa de energia recuperada e a diferença de energia entre o ar externo de alimentação e o ar de exaustão, conforme mostrado nas Equações (5.1), (5.2) e (5.3).

$$
\begin{gathered}
\varepsilon_{\mathrm{s}}=\frac{\dot{\mathrm{q}}_{\mathrm{s}}}{\mathrm{C}_{\min } \cdot\left(\mathrm{t}_{1}-\mathrm{t}_{2}\right)} \\
\varepsilon_{\mathrm{L}}=\frac{\dot{\mathrm{q}}_{\mathrm{L}}}{\dot{\mathrm{m}}_{\min } \cdot\left(\mathrm{h}_{\mathrm{fg}}-\mathrm{d}_{2}\right)} \\
\varepsilon_{\mathrm{t}}=\frac{\dot{\mathrm{q}}_{\mathrm{t}}}{\dot{\mathrm{m}}_{\min } \cdot\left(\mathrm{h}_{1}-\mathrm{h}_{2}\right)}
\end{gathered}
$$

$\dot{\mathrm{q}}_{\mathrm{s}}=\quad$ Taxa de transferência de calor sensível $[k W]$

$\varepsilon_{\mathrm{S}}=\quad$ Eficiência sensível [-];

$\mathrm{t}_{1}=\quad$ Temperatura de bulbo seco no estágio 1 , Figura $5.4\left[{ }^{\circ} \mathrm{C}\right]$; 
$\dot{\mathrm{m}}_{\mathrm{s}}=\quad$ Vazão mássica do ar seco de alimentação $[\mathrm{kg} / \mathrm{s}]$;

$\dot{\mathrm{m}}_{\mathrm{e}}=\quad$ Vazão mássica do ar seco de exaustão $[\mathrm{kg} / \mathrm{s}]$;

$\mathrm{C}_{\min }=\quad$ Menor valor entre $\mathrm{c}_{\mathrm{ps}} \cdot \dot{\mathrm{m}}_{\mathrm{s}} \mathrm{e} \mathrm{c}_{\mathrm{pe}} \cdot \dot{\mathrm{m}}_{\mathrm{e}}$;

$\mathrm{c}_{\mathrm{ps}}=\quad$ Calor específico à pressão constante do ar de alimentação úmido $[\mathrm{kJ} / \mathrm{kg} . \mathrm{K}]$;

$\mathrm{c}_{\mathrm{pe}}=\quad$ Calor específico à pressão constante do ar de exaustão úmido $[\mathrm{kJ} / \mathrm{kg} . \mathrm{K}]$.

$\dot{\mathrm{q}}_{\mathrm{L}}=\quad$ Taxa de transferência de calor latente $[k W]$;

$\varepsilon_{\mathrm{L}}=\quad$ Eficiência latente $[-] ;$

$\dot{\mathrm{m}}_{\min }=\quad$ Menor valor entre $\dot{m}_{s}$ e $\dot{m}_{e}$;

$\mathrm{h}_{\mathrm{fg}}=\quad$ Entalpia de vaporização $[\mathrm{kJ} / \mathrm{kg}]$;

$\mathrm{d}=\quad$ Índices de umidade nos locais indicados na Figura $5.4[\mathrm{~kg} / \mathrm{kg}]$;

$\varepsilon_{\mathrm{t}}=\quad$ Eficiência total [-];

$\mathrm{h}=\quad$ Entalpia nos locais indicados na Figura $5.4[\mathrm{~kJ} / \mathrm{kg}]$;

A Equação (5.4) apresenta a formulação para cálculo da entalpia do ar úmido:

$$
\mathrm{h}=\mathrm{c}_{\mathrm{p} . \mathrm{d}}+\left(2500+\mathrm{c}_{\mathrm{p} . \mathrm{m}} \cdot \mathrm{t}\right) \cdot \mathrm{d}
$$

$\mathrm{c}_{\mathrm{p} . \mathrm{d}}=\quad 1,005$ - Calor específico à pressão constante do ar seco $[\mathrm{kJ} / \mathrm{kg} . \mathrm{K}] ;$

$\mathrm{c}_{\mathrm{p} \cdot \mathrm{m}}=\quad 1,84$ - Calor específico à pressão constante do vapor de água $[\mathrm{kJ} / \mathrm{kg} . K]$.

$\mathrm{t}=\quad$ Temperatura do ar úmido $\left[{ }^{\circ} \mathrm{C}\right]$;

$\mathrm{d}=\quad$ Umidade absoluta $[\mathrm{kg} / \mathrm{kg}$ de ar seco $]$;

Conforme as equações mostradas acima, pode-se notar uma certa relação entre os três tipos de eficiência do ERV. Supondo que o ERV seja usado no verão, com os parâmetros definidos conforme a Figura 5.4, e os valores de $\mathrm{C}_{\min }$ e $\dot{\mathrm{m}}_{\min }$ referentes à vazão do ar externo de alimentação, as Equações (5.1), (5.2) e (5.3) podem ser transformadas nas equações a seguir, considerando que as vazões sejam balanceadas, podendo ser retiradas dos numerados e denominadores das relações:

$$
\varepsilon_{\mathrm{s}}=\left(\frac{\mathrm{t}_{1}-\mathrm{t}_{3}}{\mathrm{t}_{1}-\mathrm{t}_{2}}\right)
$$




$$
\begin{aligned}
& \varepsilon_{\mathrm{L}}=\left(\frac{\mathrm{d}_{1}-\mathrm{d}_{3}}{\mathrm{~d}_{1}-\mathrm{d}_{2}}\right) \\
& \varepsilon_{\mathrm{t}}=\left(\frac{\mathrm{h}_{1}-\mathrm{h}_{3}}{\mathrm{~h}_{1}-\mathrm{h}_{2}}\right)
\end{aligned}
$$

Na Equação (5.4), $c_{\text {p.m }}$ é muito menor que 2500, então ele pode ser omitido com um erro inferior a $5 \%$.

$$
\mathrm{h}=\mathrm{c}_{\mathrm{p} . \mathrm{d}} \cdot \mathrm{t}+2500 \cdot \mathrm{d}
$$

Combinando as Equações (5.7) e (5.8):

$$
\varepsilon_{\mathrm{t}}=\left(\frac{1,005 \cdot\left(\mathrm{t}_{1}-\mathrm{t}_{3}\right)+2500 \cdot\left(\mathrm{d}_{1}-\mathrm{d}_{2}\right)}{1,005 \cdot\left(\mathrm{t}_{1}-\mathrm{t}_{2}\right)+2500 \cdot\left(\mathrm{d}_{1}-\mathrm{d}_{2}\right)}\right)
$$

Dividindo por $\left(\mathrm{t}_{1}-\mathrm{t}_{2}\right) \cdot\left(\mathrm{d}_{1}-\mathrm{d}_{2}\right)$ no numerador e no denominador:

$$
\varepsilon_{\mathrm{t}}=\left(\frac{\left(1,005 \div\left(\mathrm{d}_{1}-\mathrm{d}_{2}\right)\right) \cdot \varepsilon_{\mathrm{s}}+\left(2500 \div\left(\mathrm{t}_{1}-\mathrm{t}_{2}\right)\right) \cdot \varepsilon_{\mathrm{L}}}{\left(1,005 \div\left(\mathrm{d}_{1}-\mathrm{d}_{2}\right)\right)+\left(2500 \div\left(\mathrm{t}_{1}-\mathrm{t}_{2}\right)\right)}\right)=\frac{\mathrm{A} \cdot \varepsilon_{\mathrm{S}}+\mathrm{B} \cdot \varepsilon_{\mathrm{L}}}{\mathrm{A}+\mathrm{B}}
$$

Onde:

$$
A=\frac{1,005}{d_{1}-d_{2}} \quad ; \quad B=\frac{2500}{t_{1}-t_{2}}
$$

Assim, é possível definir os coeficientes de ponderação:

$$
\mathrm{C}_{\mathrm{S}}=\frac{\mathrm{A}}{\mathrm{A}+\mathrm{B}} ; \quad \mathrm{C}_{\mathrm{L}}=\frac{\mathrm{B}}{\mathrm{A}+\mathrm{B}}
$$

Após, é possível deduzir a eficiência total ponderada: 


$$
\varepsilon_{\mathrm{t}}=\mathrm{C}_{\mathrm{s}} \cdot \varepsilon_{\mathrm{s}}+\mathrm{C}_{\mathrm{L}} \cdot \varepsilon_{\mathrm{L}}
$$

A equação acima indica claramente a relação entre os três tipos de eficiência, onde a eficiência entálpica é igual à soma ponderada das eficiências sensível e latente. A situação de cálculo acima é para o verão. Para as condições de inverno, as equações de cálculo dos parâmetros A e B devem ser negativas. Dessa forma, para um cálculo anual, as equações devem ser:

$$
A=\frac{1,005}{\max \left(\mathrm{d}_{1}, \mathrm{~d}_{2}\right)-\min \left(\mathrm{d}_{1}, \mathrm{~d}_{2}\right)} \quad ; \quad B=\frac{2500}{\max \left(\mathrm{t}_{1}, \mathrm{t}_{2}\right)-\min \left(\mathrm{t}_{1}, \mathrm{t}_{2}\right)}
$$

A partir das equações acima é possível concluir que os coeficientes A e B são fortemente afetados pelos parâmetros de entrada do ar externo e do ar de exaustão (temperatura e umidade), mas independentes do ERV em termos de suas eficiências de transferência de calor e umidade. Baseado nos valores dos coeficientes A e B pode-se concluir qual tipo de eficiência domina a eficiência entálpica. Por exemplo, em situações com grande diferença de temperatura entre os ambientes interno e externo e pequena diferença nas umidades, a eficiência sensível domina a eficiência total, e a eficiência latente tem pequena influência.

Assim, a partir da aplicação desses coeficientes de ponderação sobre as eficiências sensível e latente apresentadas pelos fabricantes, é possível estimar a quantidade total de calor recuperado no ERV para as dadas condições dos ambientes interno e externo.

\subsection{3 - Potência elétrica consumida pelo ERV}

Para estimativa da potência elétrica consumida pelos ventiladores do equipamento foi utilizado o mesmo procedimento utilizado para determinação do consumo do climatizador tipo fan coil, relatado no item 5.3, a partir das curvas de vazão dos ventiladores apresentadas no catálogo do fabricante.

\section{6 - FLUXOGRAMA DE FUNCIONAMENTO DA FORMULAÇÃO MATEMÁTICA NA SIMULAÇÃO}

A partir da caracterização completa para o sistema adotado, pode-se levantar o fluxograma de funcionamento da simulação, apontando os dados de entrada necessários de 
cada subsistema, as equações, e os dados de saída, que por sua vez permitirão a realização das análises propostas (Figura 5.5). Esse fluxograma será implementado no software EES (Engineering Equation Solver), tendo em vista a necessidade de cálculos a partir das tabelas termodinâmicas contidas no programa. Assim, o programa será responsável por realizar as simulações das formulações matemáticas propostas juntamente com a metodologia de controle adotada, a ser explicada no subitem 5.7 desse capítulo.

Os parâmetros de entrada variáveis (temperatura e umidade do ar externo, fator de ocupação e carga térmica ambiente) serão inseridos para cada hora do ano (8760 horas). Os demais parâmetros de entrada serão fixados. Dessa forma, os resultados das simulações (dados de saídas) apresentarão os valores reais para cada hora do ano, permitindo assim as análises anuais das quantidades de energia recuperadas no ERV, da carga térmica anual devido ao ar de renovação, e de análises de retorno de investimento para cada situação simulada.

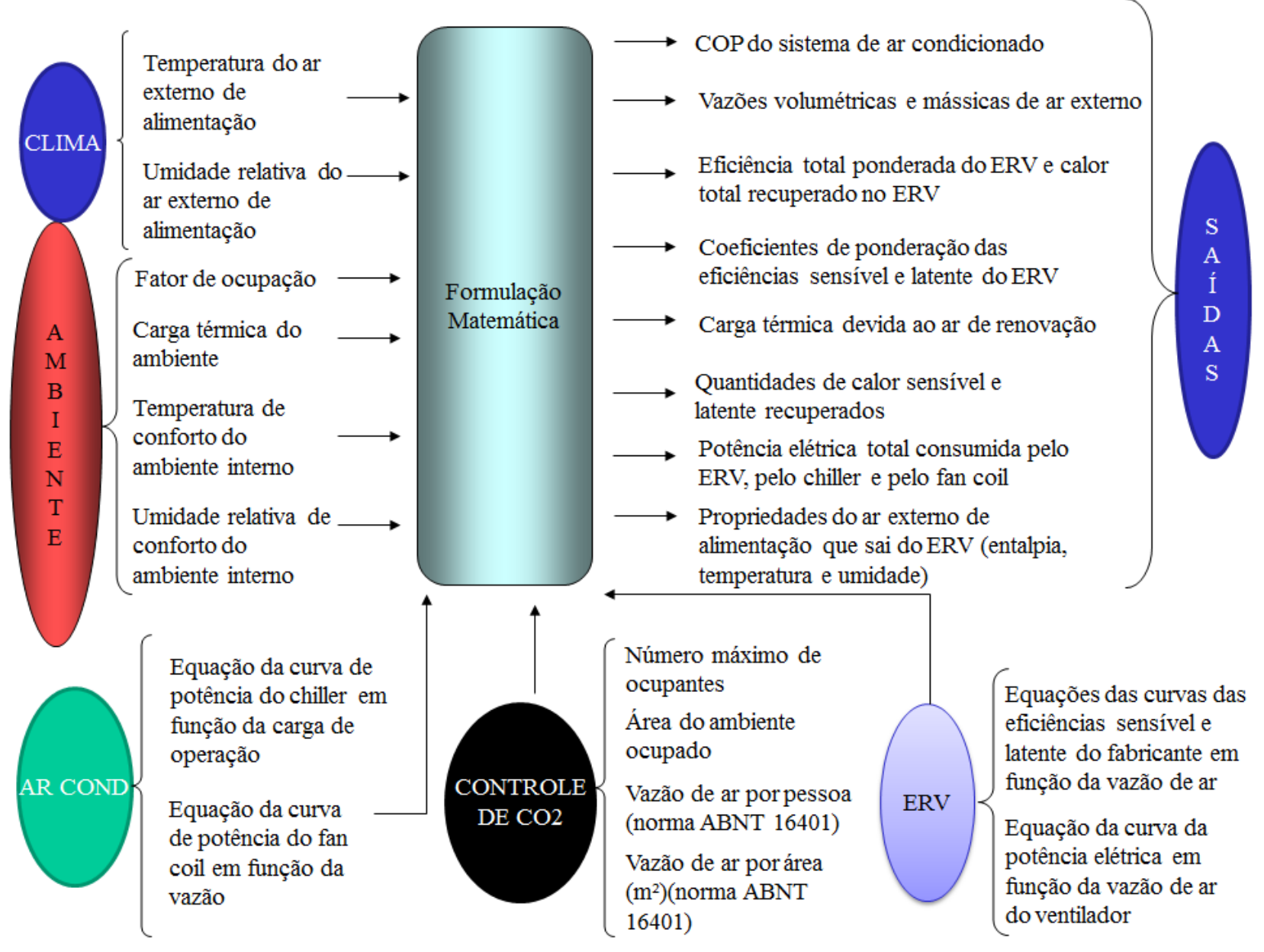

Figura 5.5 - Fluxograma de funcionamento da simulação 


\section{7 - METODOLOGIA DE CONTROLE ADOTADA PARA O SISTEMA}

Conforme apontado na revisão bibliográfica no Capítulo 1, a metodologia de controle é fundamental para uma correta aplicação do ERV, visando potencializar o seus efeitos e evitar o seu funcionamento em situações desnecessárias. Por exemplo, o controle ótimo de um ERV que possui valores iguais para as eficiências sensível e latente é quando o ar exterior possui maior entalpia ou maior temperatura que o ar interior. Entretanto, os valores das eficiências sensível e latente dificilmente são iguais, e ainda, conforme apontado anteriormente, as condições climáticas influenciam nessas eficiências. Ainda, a transferência de calor latente pode ser positiva ou negativa dependendo da direção de decrescimento do vapor de água. Dependendo das condições externas e internas, a corrente de alimentação escoando pelo ERV pode ganhar energia em forma de calor $\left(+\dot{\mathrm{q}}_{\mathrm{s}}\right)$ da corrente adjacente, mas perder energia latente $\left(-\dot{\mathrm{q}}_{\mathrm{L}}\right)$ se ela transferir vapor de água para a corrente adjacente. Os ganhos de calor e energia latente podem estar na mesma direção ou em direções opostas. O ganho total de energia é a soma algébrica entre $\dot{\mathrm{q}}_{\mathrm{S}} \mathrm{e} \dot{\mathrm{q}}_{\mathrm{L}}$.

Nesse sentido, uma estratégia de controle ótimo foi proposta, visando desacoplar as cargas latente e sensível, analisar a magnitude de cada, e permitir o funcionamento do ERV apenas em situações quando o saldo de transferência de calor da corrente de alimentação de ar externo para a corrente de exaustão for positivo, ou seja, sempre quando houver redução da carga térmica do ar externo de renovação. Quando não houver redução na carga térmica do ar de renovação, as correntes de ar circularão pelos dampers de by-pass mostrados na Figura 5.2, impedindo que essas correntes passem pelo equipamento de ERV. Ainda, o controle será capaz de desligar o ERV quando o ambiente estiver desocupado. A Figura 5.6 resume a metodologia de controle utilizada.

Mais detalhes sobre a formulação matemática proposta, as equações utilizadas e a metodologia de controle são apresentados no Apêndice C. Esse apêndice contém toda a formulação matemática inserida no software EES que foi utilizada para as simulações. 


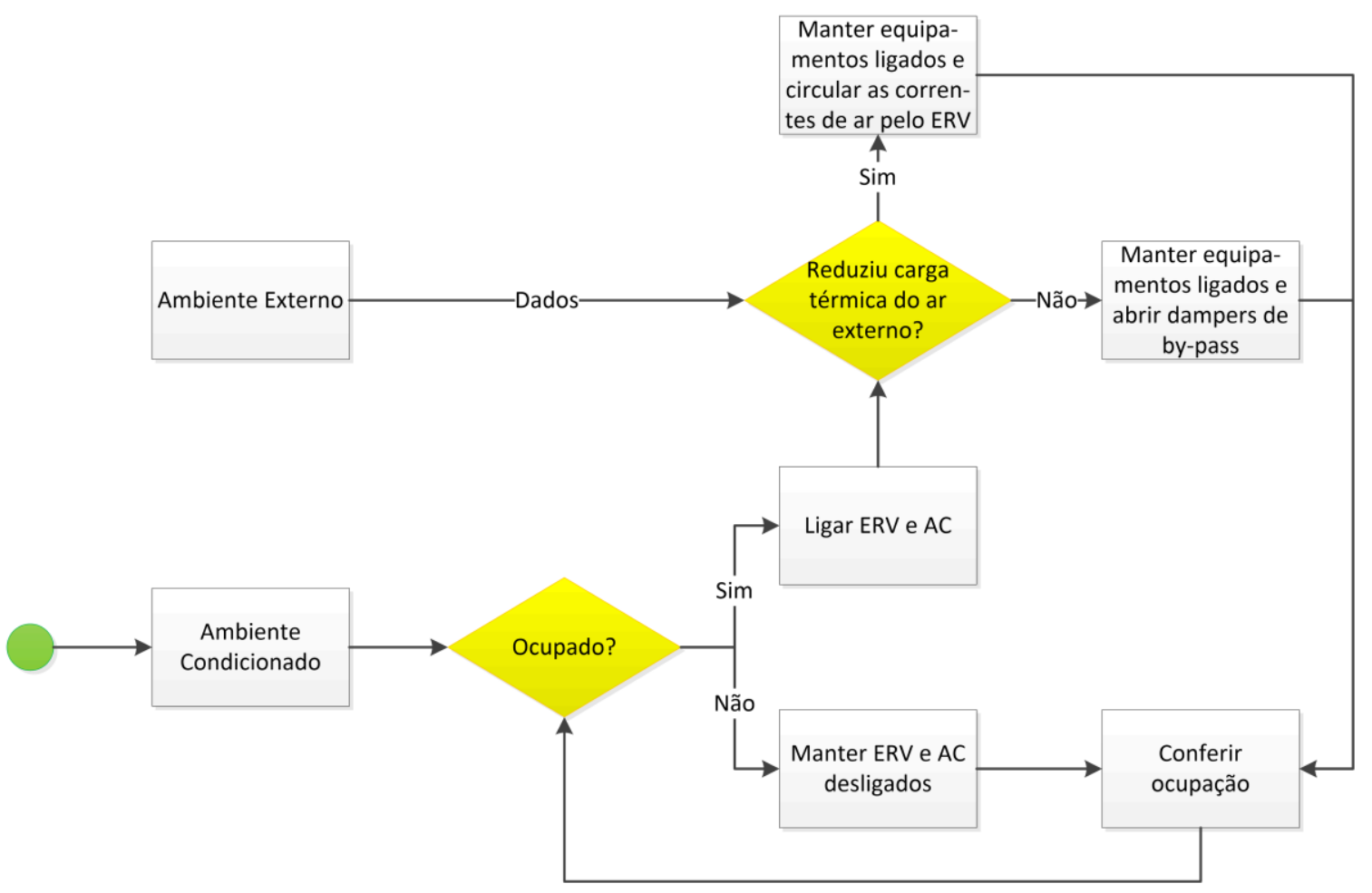

Figura 5.6 - Fluxograma da metodologia de controle adotada 


\section{6 - ESTUDO DE CASO E APRESENTAÇÃO DE CENÁRIOS}

\section{1 - ESTUDO DE CASO PROPOSTO}

Nesta etapa do trabalho objetiva-se aplicar a metodologia proposta para avaliação de um ambiente condicionado, com ocupação variável, operando com recuperação de energia e vazão de ar exterior variável. Para tal, conforme estabelecida na formulação do capítulo anterior, foi escolhido um auditório que faça parte de uma edificação de escritórios. Esse auditório trata-se de um ambiente de zona térmica única, atendido por um sistema individual de ar condicionado e com controle único (Figura 6.1). Esse ambiente foi escolhido principalmente por sua característica de ocupação, que é bem variável durante os dias da semana, podendo variar de zero a 100\% de ocupação em um único dia, de acordo com a programação de atividades estabelecida. Tal característica favorece o estudo de caso, no qual é possível se obter resultados claros para avaliação da metodologia proposta.

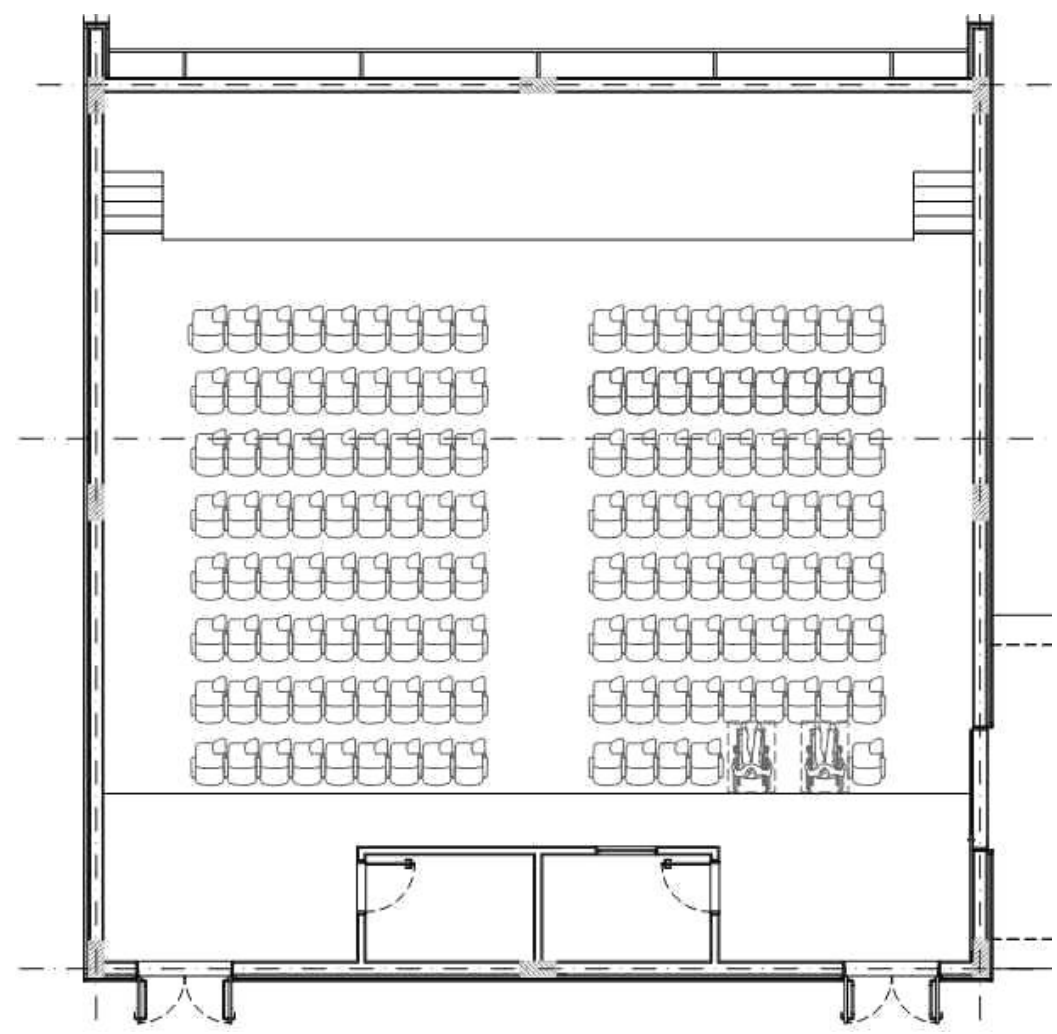

Figura 6.1 - Objeto do estudo de caso: Auditório de um edifício de escritórios

As principais características do ambiente que foram levadas em consideração para sua caracterização bem como para o cálculo de carga térmica são descritas na Tabela 6.1. 
O ambiente foi considerado sem janelas e sem contato com ambientes não climatizados, não gerando assim cargas de transmissão por paredes e carga radiante de janelas.

Tabela 6.1 - Principais características do ambiente escolhido

\begin{tabular}{cc}
\hline Parâmetro & Valor \\
\hline Área & $196 \mathrm{~m}^{2}$ \\
Pé direito & $5 \mathrm{~m}$ \\
Ocupação máxima & 142 pessoas \\
Cidade de projeto & Brasília/DF \\
Temperatura interna de conforto & $23^{\circ} \mathrm{C}$ \\
Umidade relativa interna de projeto & $50 \%$ \\
Carga de iluminação & $32 \mathrm{~W} / \mathrm{m}^{2}$ \\
Carga de equipamentos elétricos & $3000 \mathrm{~W}$ \\
Taxa de infiltração & $10 \mathrm{~L} / \mathrm{s} . \mathrm{m}^{2}$ \\
Carga de ocupação & $130 \mathrm{~W} /$ pessoa \\
Carga de ventilação do ar externo & Conforme perfil de ocupação e tipo de \\
& solução adotada* \\
\hline \hline
\end{tabular}

(*a carga térmica devida ao ar externo varia se a solução adotada utiliza ou não o ERV e utiliza ou não o sistema de vazão de ar externo variável por controle de $\mathrm{CO} 2$ )

\subsection{1 - Cidade de projeto}

Conforme mostrado na formulação apresentada no Capítulo 5, as temperaturas e umidades relativas da cidade de projeto são parâmetros de entrada para o sistema, uma vez que influenciam o funcionamento do ERV, carga térmica do ar externo e o funcionamento do ciclo de compressão a vapor do equipamento de ar condicionado. A Figura 6.2 apresenta o perfil de temperatura de bulbo seco e de umidade relativa para a cidade de Brasília/DF no ano de 2012 (INMET, 2012), os valores dos parâmetros internos de conforto definidos (temperatura e umidade do ambiente condicionado, definidos na Tabela 6.1) e também os valores médios diários da temperatura e umidade do ar ambiente. 

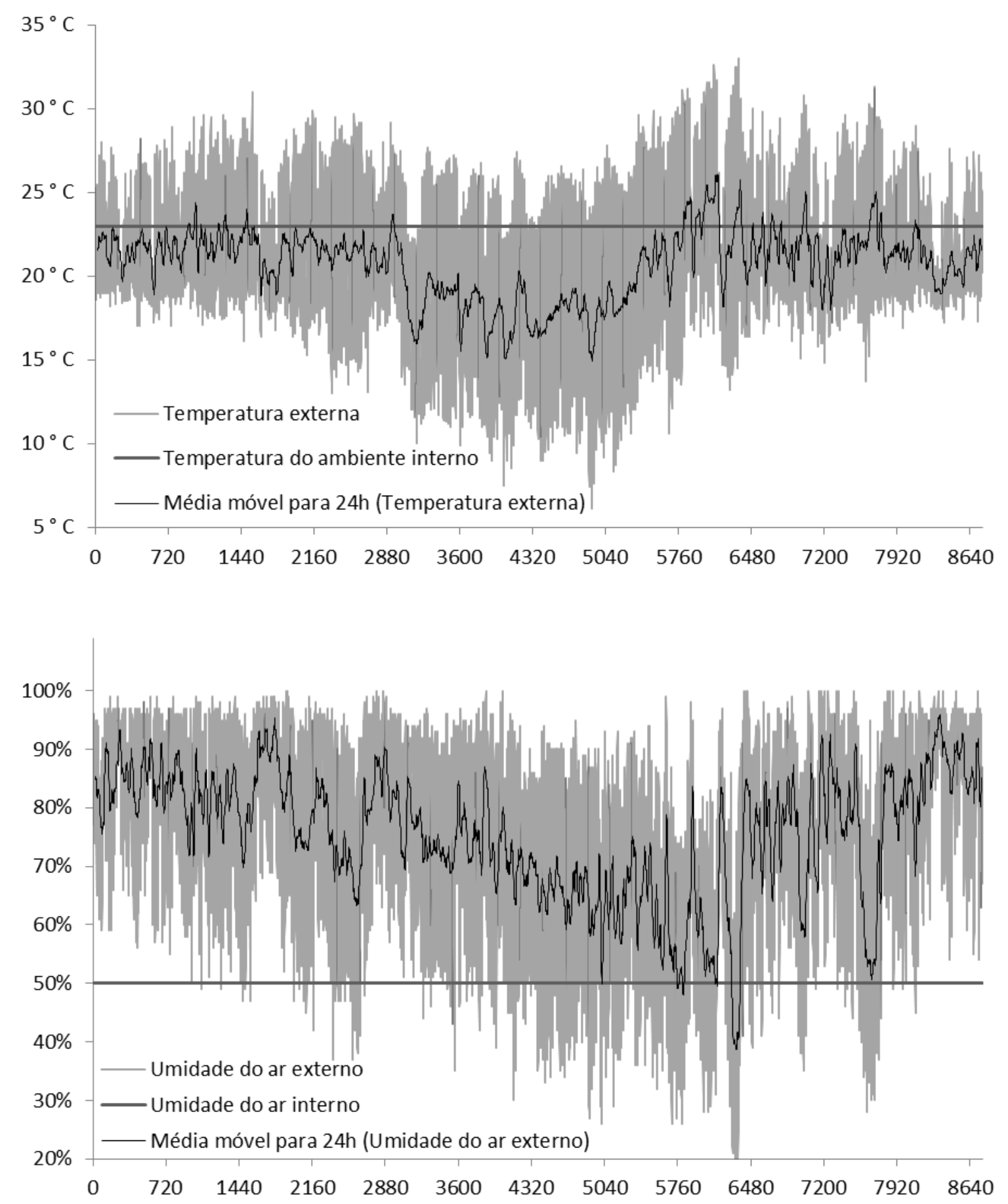

Figura 6.2 - Temperatura de bulbo seco e umidade relativa para a cidade de Brasília/DF x horas do ano (INMET, 2012)

\subsection{2 - Perfil de carga térmica}

O perfil de carga térmica foi levantado de acordo com as informações apresentadas na Tabela 6.1, juntamente com o perfil de ocupação apresentado no item 6.1.3. Para o levantamento do perfil de carga foi utilizado o software HAP do fabricante CARRIER. Os resultados dos cálculos de carga térmica são apresentados no Apêndice D. O componente 
de carga térmica devido ao ar de renovação foi calculado pela própria formulação da metodologia proposta, uma vez que o valor da carga depende do uso ou não dos sistemas de recuperação de energia e de controle de vazão de ar externo por CO2.

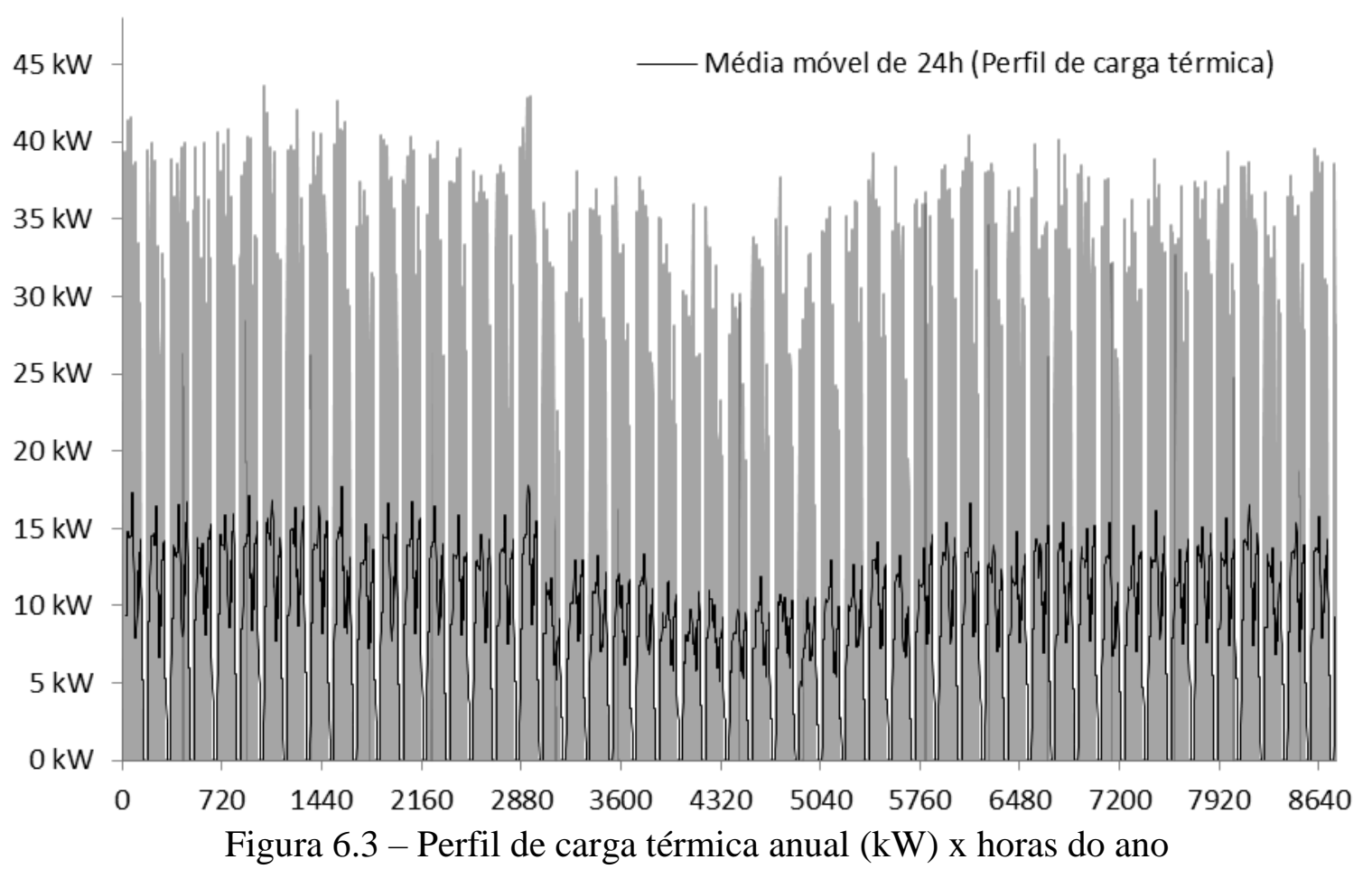

A Figura 6.3 apresenta o perfil de carga anual máximo (sem considerar a utilização do ERV e do controle de vazão de ar externo) para o perfil de ocupação original.

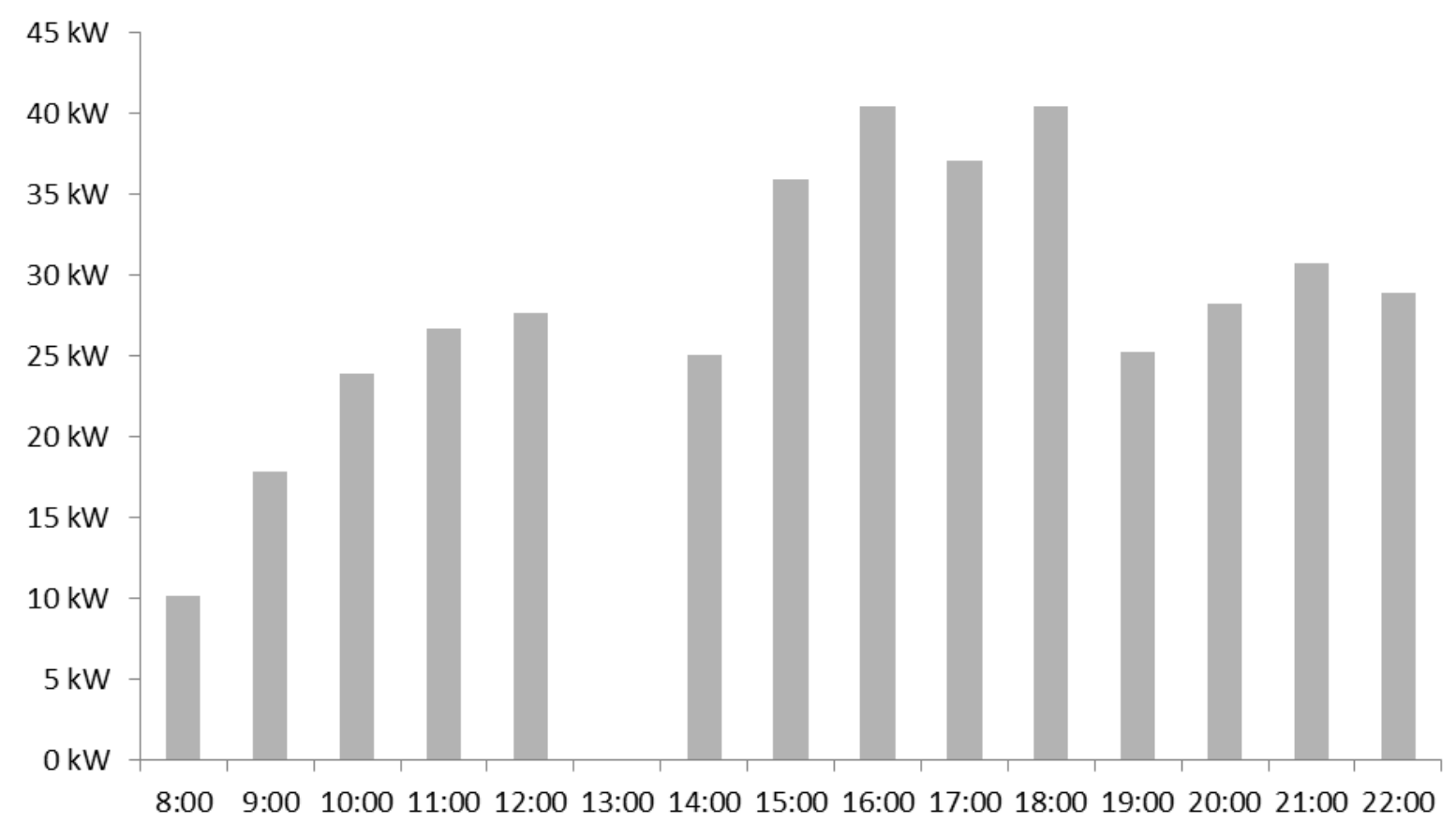

Figura 6.4 - Perfil de carga térmica para o dia de projeto $(\mathrm{kW}) \mathrm{x}$ horas do dia 
A Figura 6.4 apresenta o perfil máximo para o dia de projeto. A Figura 6.5 apresenta o perfil máximo para o dia de projeto calculado com a utilização do ERV, uma vez que a utilização desse recurso diminui a carga térmica de pico.

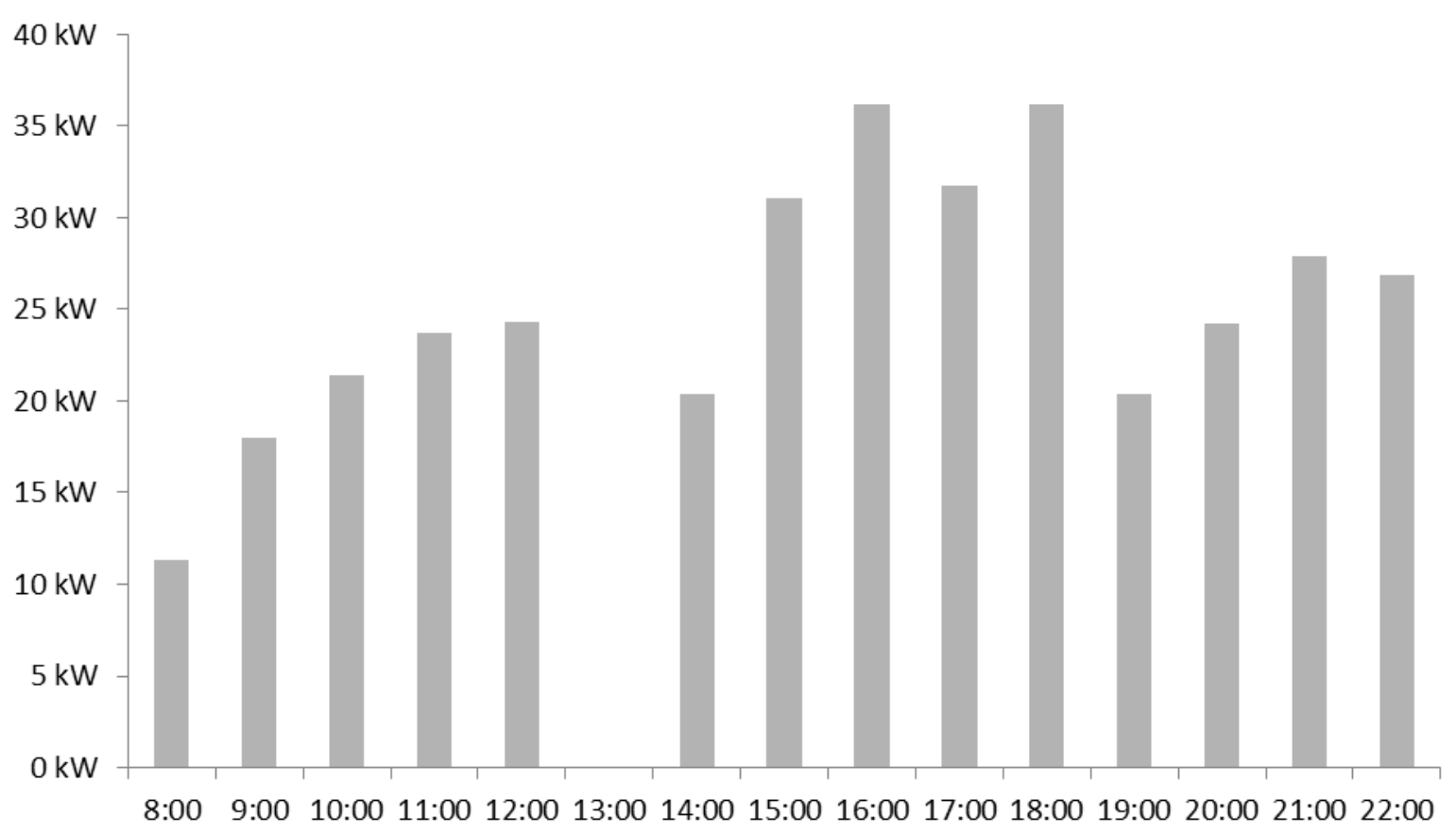

Figura 6.5 - Perfil de carga térmica para o dia de projeto com o uso do recurso de ERV $(\mathrm{kW}) \mathrm{x}$ horas do dia

\subsection{3 - Perfil de ocupação original}

Por se tratar de um tipo de ambiente com ocupação bastante sazonal, foi considerado um regime de operação do auditório condizente com essa realidade. A Tabela 6.2 apresenta um perfil semanal de uso com os horários e os respectivos percentuais relativos à ocupação máxima (142 pessoas). A Figura 6.6 apresenta o perfil em função do número total de horas de uma semana (segunda à domingo, 168 horas).

Tabela 6.2 - Perfil de ocupação original (\%) semanal do auditório em estudo

\begin{tabular}{ccccccc}
\hline Horário & Seg. & Ter. & Qua. & Qui. & Sex. & Sab. \\
\hline $08: 00$ & 0 & 25 & 25 & 0 & 25 & 25 \\
$09: 00$ & 0 & 50 & 50 & 0 & 25 & 50 \\
$10: 00$ & 0 & 50 & 50 & 0 & 25 & 75 \\
$11: 00$ & 0 & 50 & 50 & 0 & 25 & 75 \\
$12: 00$ & 0 & 50 & 50 & 0 & 25 & 50 \\
$13: 00$ & 0 & 0 & 0 & 0 & 0 & 0 \\
\hline
\end{tabular}




\begin{tabular}{ccccccc}
\hline $14: 00$ & 25 & 25 & 25 & 25 & 0 & 0 \\
$15: 00$ & 75 & 75 & 75 & 75 & 25 & 0 \\
$16: 00$ & 100 & 100 & 100 & 100 & 25 & 0 \\
$17: 00$ & 75 & 75 & 75 & 75 & 50 & 0 \\
$18: 00$ & 100 & 100 & 100 & 100 & 50 & 0 \\
$19: 00$ & 25 & 25 & 25 & 25 & 50 & 0 \\
$20: 00$ & 50 & 50 & 50 & 0 & 75 & 0 \\
$21: 00$ & 0 & 0 & 75 & 0 & 100 & 0 \\
$22: 00$ & 0 & 0 & 75 & 0 & 100 & 0 \\
\hline
\end{tabular}

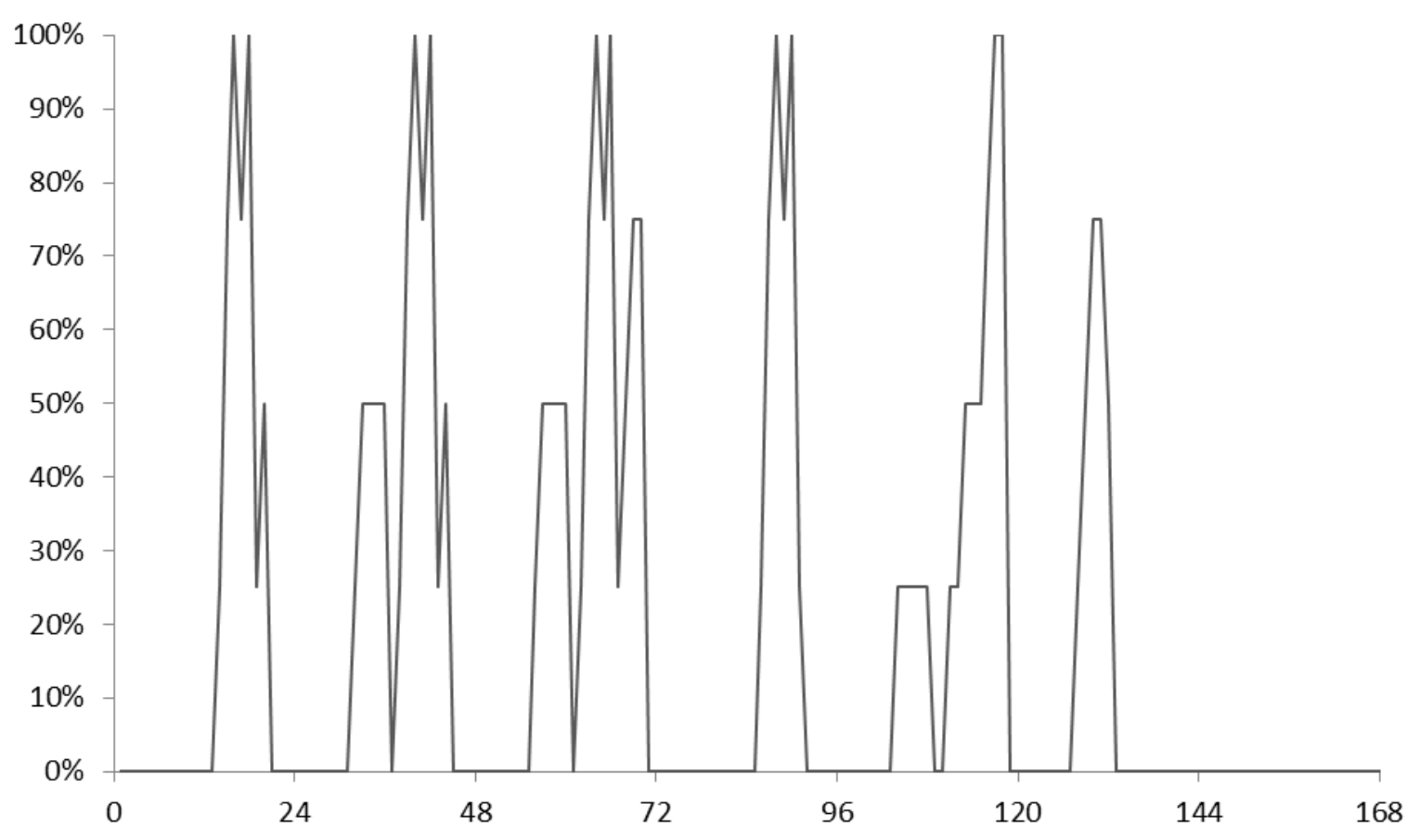

Figura 6.6 - Perfil de ocupação original (\%) semanal do auditório em estudo x horas da semana

\subsection{4 - Sistema de ar condicionado}

O sistema de ar condicionado projetado para atendimento do ambiente em questão é do tipo expansão indireta, com uma unidade resfriadora de líquido com condensação a ar e unidade climatizadora do tipo fan coil. Conforme apresentado no Capítulo 5, a formulação matemática para o sistema de ar condicionado requer a caracterização do sistema que realiza o ciclo de compressão a vapor, para que seja possível o cálculo da energia utilizada 
no sistema, bem como a definição do coeficiente de desempenho (COP) do sistema para cada hora de operação.

Além disso, serão levantados os dados do fan coil, para que seja possível a estimativa do consumo elétrico desses equipamentos. O fan coil operará com inversor de frequência para controle de rotação do motor, fornecendo a vazão de ar necessária para atendimento da carga térmica real. A bomba de água gelada operará com vazão variável, com válvula de 2 vias no condicionador de ar. O próprio fabricante do chiller especificado também disponibiliza o kit hidráulico (bomba de água gelada e válvulas) para esses equipamentos. Assim, as potências consumidas nas operações da bomba e do ventilador do sistema de condensação do chiller já estão computadas nas curvas de potência apresentadas, uma vez que o fabricante disponibiliza esses dados.

Ainda, como o sistema de ar condicionado será dimensionado conforme o perfil de carga térmica levantado, dois tipos de sistemas foram previstos, uma vez que a utilização do equipamento ERV reduz a carga térmica máxima de pico, possibilitando o dimensionamento de sistemas menores.

\subsubsection{1 - Sistema de ar condicionado padrão - 43 kW (12 TR)}

A Tabela 6.3 apresenta os dados de seleção do equipamento resfriador de líquido (chiller) selecionado para atendimento do ambiente em estudo. Demais dados de seleção encontram-se no Apêndice E. A seleção foi feita pelo software HAP do fabricante CARRIER, cujos dados de potência elétrica consumida e de desempenho são apresentados na Tabela 6.4, Figura 6.7 e Figura 6.8.

Tabela 6.3 - Principais características do Chiller de 12 TR (CARRIER 2013, modificado)

Parâmetro Valor

Chiller

Fabricante

Modelo

Capacidade máxima

Potência elétrica máxima consumida

Compressor

Temperatura de saída de água gelada
Resfriador de líquido com condensação a ar

\section{CARRIER}

30RA012

$12 \mathrm{TR}$

$16,4 \mathrm{~kW}$

Scroll

$6,7^{\circ} \mathrm{C}$ 
Temperatura externa do ar

Taxa de vazão no evaporador

Carga mínima $35^{\circ} \mathrm{C}$

$0,043 \mathrm{~L} /(\mathrm{s}-\mathrm{kW})$

$20 \%$

Tabela 6.4 - Tabela de potência consumida para diversas cargas de operação e temperaturas do ar externo do Chiller 12 TR (CARRIER 2013, modificado)

$\begin{array}{lllllllllll}\mathrm{T} & \mathrm{P} & 100 \% & 90 \% & 80 \% & 70 \% & 60 \% & 50 \% & 40 \% & 30 \% & 20 \%\end{array}$

$\left({ }^{\circ} \mathrm{C}\right) \quad(\mathrm{kW})$

\begin{tabular}{ccccccccccc}
\hline 46,1 & 22,2 & 22,2 & 19,5 & 16,7 & 14,1 & 12,1 & 10,1 & 8,0 & 6,0 & 4,2 \\
35,0 & 16,4 & 16,4 & 14,4 & 12,4 & 10,5 & 9,0 & 7,5 & 6,0 & 4,5 & 3,1 \\
29,4 & 13,4 & 13,4 & 11,8 & 10,2 & 8,6 & 7,4 & 6,2 & 4,9 & 3,7 & 2,6 \\
23,9 & 12,3 & 12,3 & 10,8 & 9,4 & 8,0 & 6,8 & 5,7 & 4,6 & 3,4 & 2,4 \\
$-17,8$ & 11,4 & 11,4 & 9,9 & 8,5 & 7,1 & 5,9 & 4,8 & 3,7 & 2,6 & 1,5
\end{tabular}

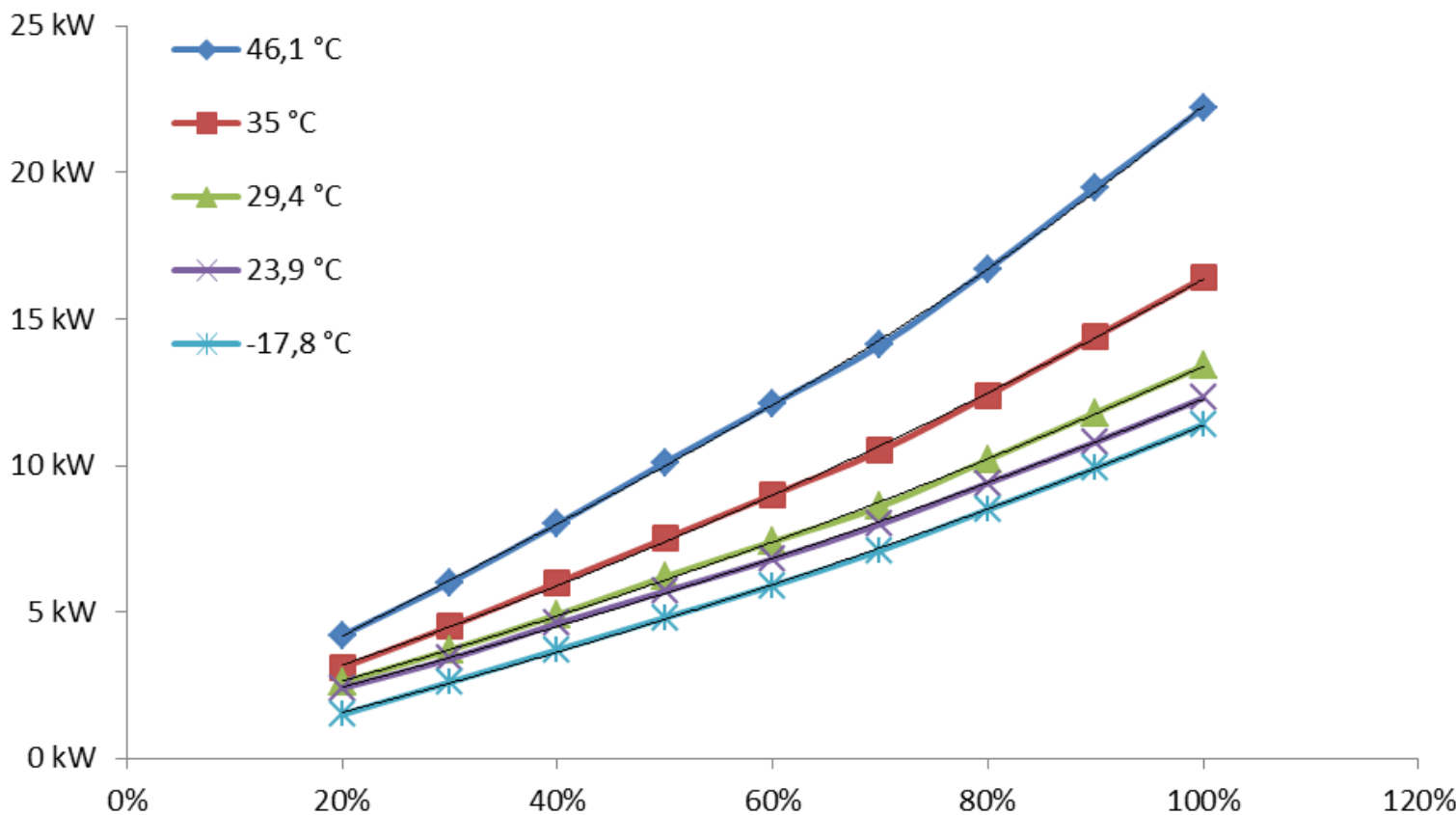

Figura 6.7 - Gráfico de "Potência consumida (kW) x carga de operação" para diversas temperaturas do ar externo - Chiller 12 TR (CARRIER 2013, modificado)

As Equações das curvas da Figura 6.7 são definidas abaixo, e serão utilizadas na simulação para definir o consumo em cada hora de operação do chiller.

$$
y=7,0707 x^{3}-5,5087 x^{2}+20,456 x+0,2452 \text {; para temp. de } 46,1^{\circ} \mathrm{C}
$$




$$
\begin{aligned}
& y=4,88 x^{2}+10,593 x+0,8729 ; \text { para temp. de } 35^{\circ} \mathrm{C} \\
& y=3,9069 x^{2}+8,7284 x+0,7405 ; \text { para temp. de } 29,4^{\circ} \mathrm{C} \\
& y=3,2576 x^{2}+8,3742 x+0,63 ; \text { para temp. de } 23,9^{\circ} \mathrm{C} \\
& y=3,3333 x^{2}+8,2333 x-0,2067 ; \text { para temp. de }-17,8^{\circ} \mathrm{C}
\end{aligned}
$$

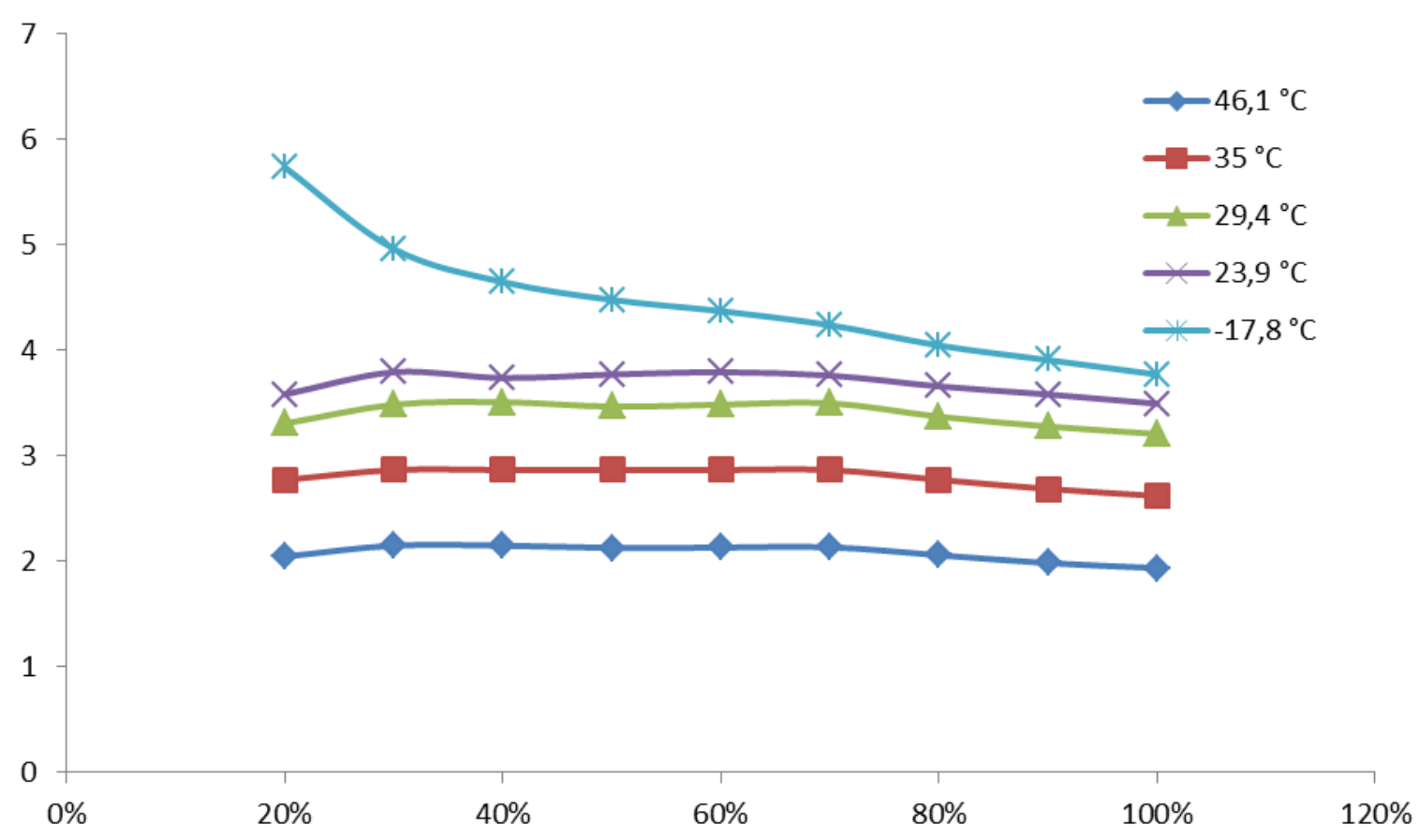

Figura 6.8 - Gráfico de "COP x carga de operação" para diversas temperaturas do ar externo - Chiller 12 TR (CARRIER 2013, modificado)

A Tabela 6.5 apresenta os dados de seleção do equipamento condicionador tipo fan coil selecionado para atendimento do ambiente em estudo. Demais dados de seleção encontram-se no Apêndice F. A seleção foi feita pelo software AIV (Air Handler Vortex) do fabricante CARRIER, cujos dados de potência elétrica consumida são apresentados na Figura 6.9. Os dados de potência elétrica do fan coil foram determinados a partir do encontro da curva de vazão do ventilador com a curva da instalação, apresentada no Apêndice F, a partir da utilização da lei dos ventiladores. Para cada valor horário da carga térmica real, o ventilador do fan coil fornece a vazão necessária, a partir da variação de rotação do ventilador com o uso de um inversor de frequência, variando consequentemente a vazão de ar fornecida pelo equipamento e seu consumo elétrico para cada hora de operação. 
Tabela 6.5 - Principais características do fan coil 12 TR (CARRIER 2013, modificado)

\begin{tabular}{cc} 
Parâmetro & Valor \\
Fabricante & CARRIER \\
Modelo & VORTEX 39V12 \\
Capacidade máxima & $12 \mathrm{TR}$ \\
Potência elétrica consumida (cap. máxima) & $2,17 \mathrm{~kW}$ \\
Ventilador & Sirocco $18 / 18$ \\
Vazão de ar & $10.320 \mathrm{~m}^{3} / \mathrm{h}$ \\
Rotação & $825 \mathrm{RPM}$ \\
Vazão de água & $7,27 \mathrm{~m}^{3} / \mathrm{h}$ \\
Temperatura de entrada de água & $8{ }^{\circ} \mathrm{C}$ \\
\hline
\end{tabular}

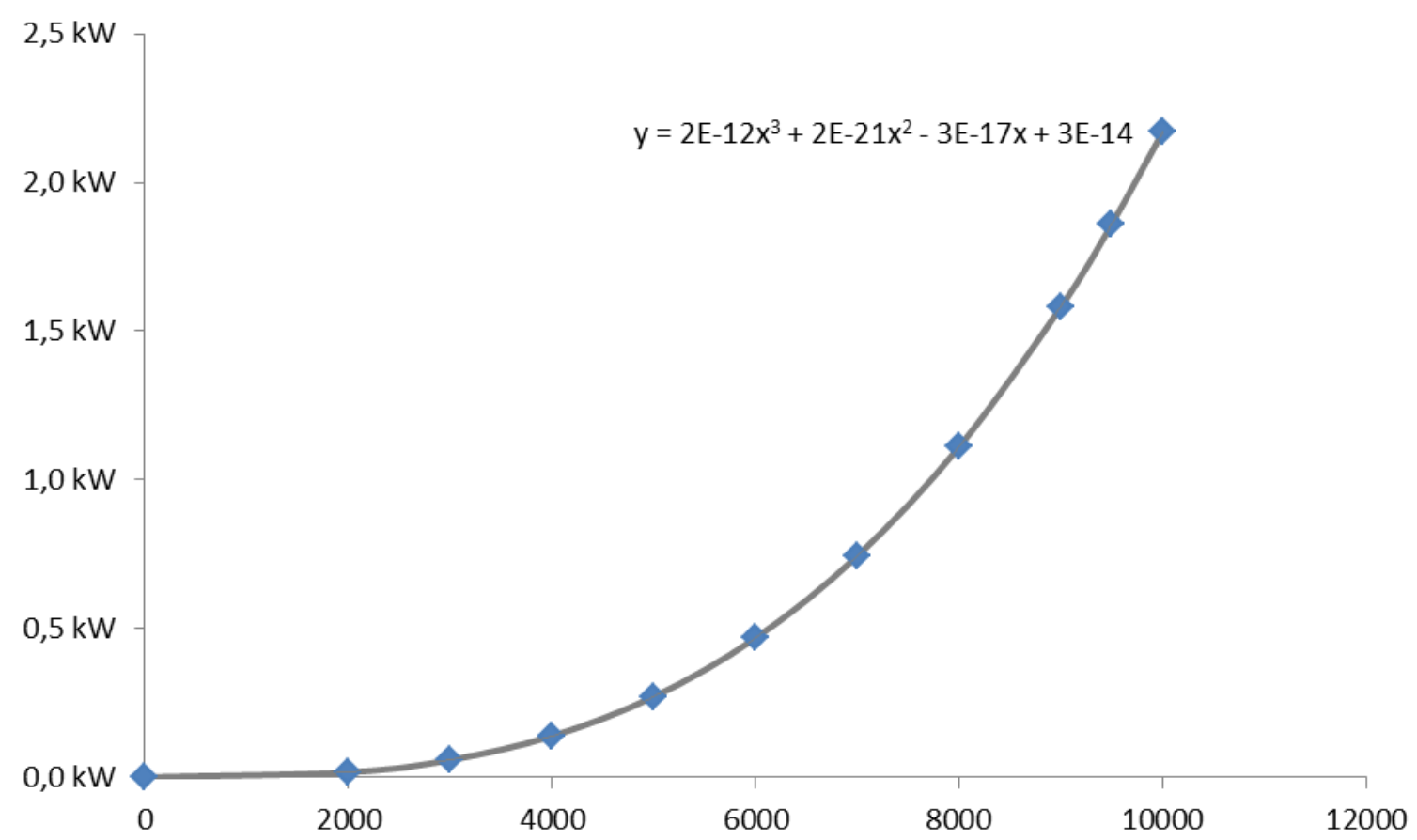

Figura 6.9 - Gráfico de "Potência elétrica consumida $(\mathrm{kW})$ x Vazão de ar $\left(\mathrm{m}^{3} / \mathrm{h}\right)$ " para o equipamento fan coil VORTEX 12 TR (CARRIER 2013, modificado)

6.1.4.2 - Sistema de ar condicionado para uso com o ERV - 35 kW (10 TR)

A Tabela 6.6 apresenta os dados de seleção do equipamento resfriador de líquido (chiller) selecionado para atendimento do ambiente em estudo operando em conjunto com o ERV. Demais dados de seleção encontram-se no Apêndice G. A seleção foi feita pelo 
software HAP do fabricante CARRIER, cujos dados de potência elétrica consumida e de desempenho são apresentados na Tabela 6.7, Figura 6.10 e Figura 6.11.

Tabela 6.6 - Principais características do Chiller de 10 TR (CARRIER 2013, modificado)

Parâmetro

Chiller

Fabricante

Modelo

Capacidade máxima

Potência elétrica máxima consumida

Compressor

Temperatura de saída de água gelada

Temperatura externa do ar

Taxa de vazão no evaporador

Carga mínima
Valor

Resfriador de líquido com condensação a ar

CARRIER

30AJ010

$10 \mathrm{TR}$

$11,5 \mathrm{~kW}$

Scroll

$6,7^{\circ} \mathrm{C}$

$35^{\circ} \mathrm{C}$

$0,043 \mathrm{~L} /(\mathrm{s}-\mathrm{kW})$

$20 \%$

Tabela 6.7 - Tabela de potência consumida para diversas cargas de operação e temperaturas do ar externo do Chiller 10 TR (CARRIER 2013, modificado)

\begin{tabular}{ccccccccccc}
\hline $\mathrm{T}$ & $\mathrm{P}$ & $100 \%$ & $90 \%$ & $80 \%$ & $70 \%$ & $60 \%$ & $50 \%$ & $40 \%$ & $30 \%$ & $20 \%$ \\
$\left({ }^{\circ} \mathrm{C}\right)$ & $(\mathrm{kW})$ & & & & & & & & & \\
\hline 46,1 & 15,6 & 15,6 & 13,7 & 11,7 & 9,9 & 8,5 & 7,0 & 5,6 & 4,2 & 2,9 \\
35,0 & 11,5 & 11,5 & 10,1 & 8,7 & 7,4 & 6,3 & 5,2 & 4,2 & 3,2 & 2,2 \\
29,4 & 9,4 & 9,4 & 8,2 & 7,1 & 6,0 & 5,2 & 4,3 & 3,5 & 2,6 & 1,8 \\
23,9 & 8,6 & 8,6 & 7,6 & 6,6 & 5,6 & 4,8 & 4,0 & 3,2 & 2,4 & 1,7 \\
$-17,8$ & 8,0 & 8,0 & 7,0 & 5,9 & 5,0 & 4,2 & 3,4 & 2,6 & 1,8 & 1,1 \\
\hline
\end{tabular}

As Equações das curvas da Figura 6.10 são definidas abaixo, e serão utilizadas na simulação para definir o consumo em cada hora de operação do chiller.

$$
\begin{gathered}
y=5,1515 x^{2}+9,5515 x+0,86 ; \text { para temp. de } 46,1^{\circ} \mathrm{C} \\
y=3,6039 x^{2}+7,1923 x+0,6805 ; \text { para temp. de } 35^{\circ} \mathrm{C} \\
y=2,7381 x^{2}+6,0643 x+0,5376 ; \text { para temp. de } 29,4^{\circ} \mathrm{C}
\end{gathered}
$$




$$
\begin{aligned}
& y=2,2511 x^{2}+5,8987 x+0,4448 ; \text { para temp. de } 23,9^{\circ} \mathrm{C} \\
& y=2,3377 x^{2}+5,7615 x-0,121 ; \text { para temp. de }-17,8^{\circ} \mathrm{C}
\end{aligned}
$$

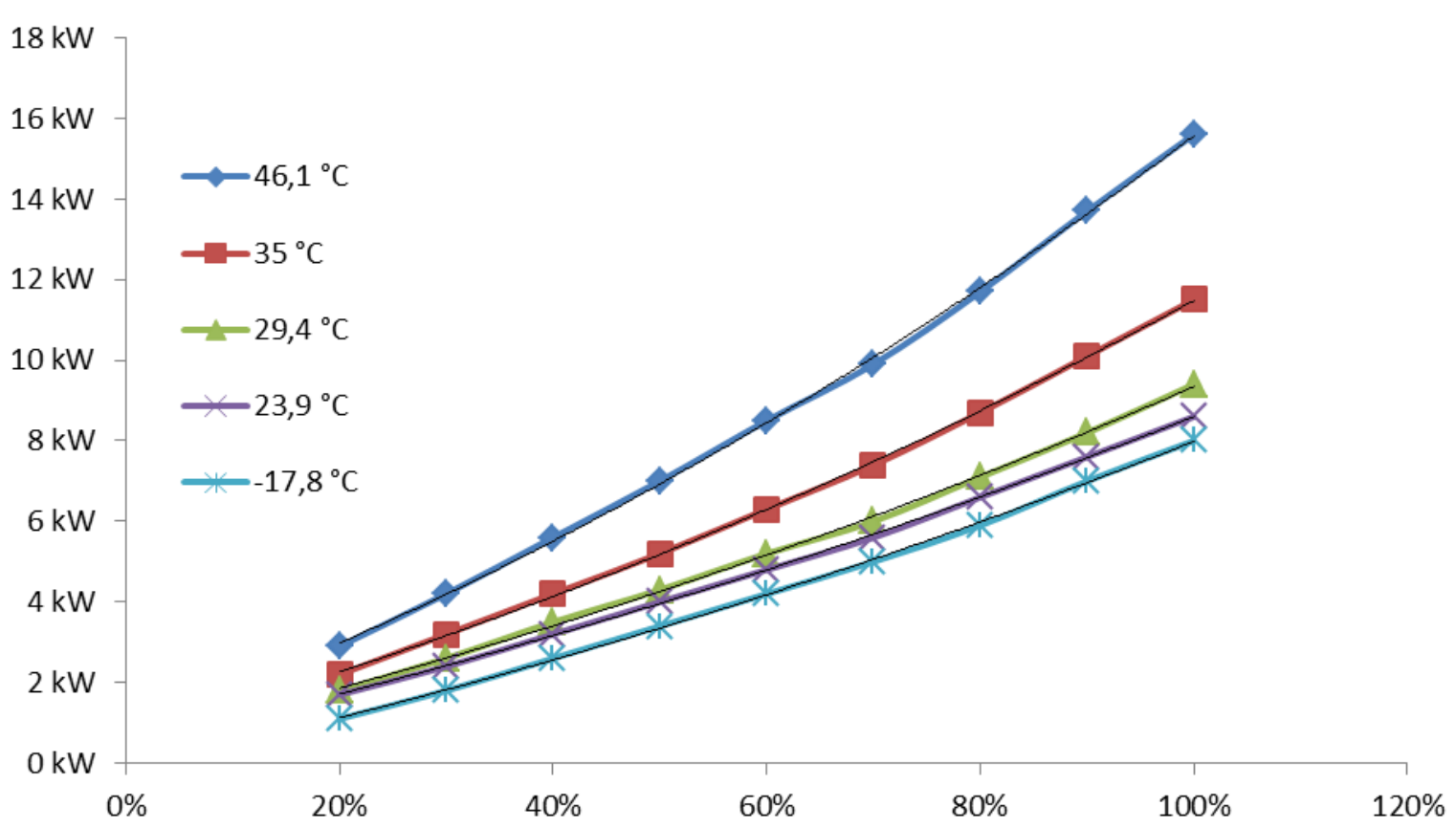

Figura 6.10 - Gráfico de "Potência consumida $(\mathrm{kW})$ x carga de operação" para diversas temperaturas do ar externo - Chiller 10 TR (CARRIER 2013, modificado)

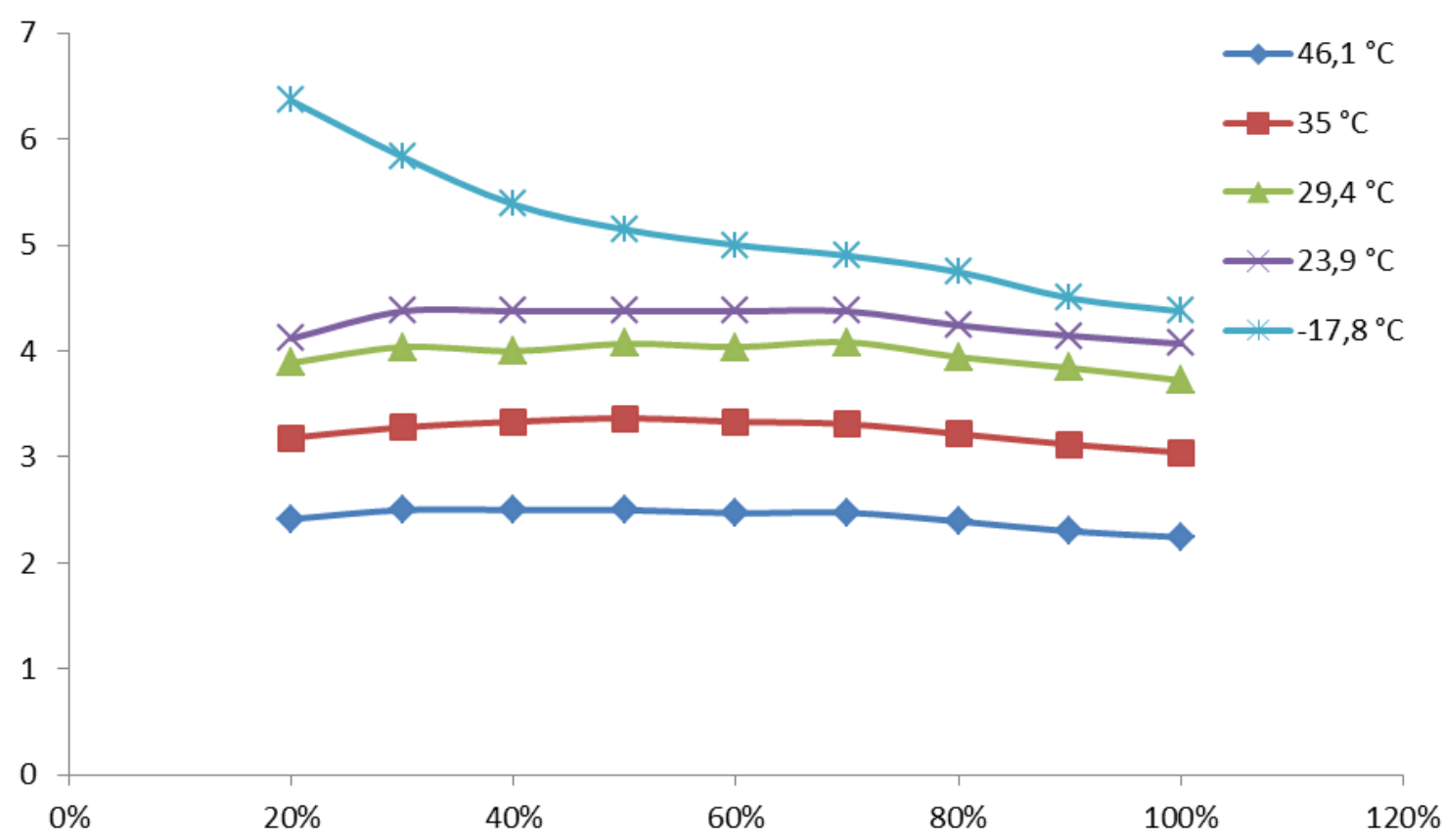

Figura 6.11 - Gráfico de "COP x Carga de operação" para diversas temperaturas do ar externo - Chiller 10 TR (CARRIER 2013, modificado) 
A Tabela 6.8 apresenta os dados de seleção do equipamento condicionador tipo fan coil selecionado para atendimento do ambiente em estudo operando em conjunto com o ERV. Demais dados de seleção encontram-se no Apêndice H. A seleção foi feita pelo software AIV (Air Handler Vortex) do fabricante CARRIER, cujos dados de potência elétrica consumida em função da vazão de ar são apresentados na Figura 6.12.

Tabela 6.8 - Principais características do fan coil de 10 TR (CARRIER 2013, modificado)

\begin{tabular}{cc}
\hline Parâmetro & Valor \\
\hline Fabricante & CARRIER \\
Modelo & VORTEX 39V10 \\
Capacidade máxima & $10 \mathrm{TR}$ \\
Potência elétrica máxima consumida & $2,12 \mathrm{~kW}$ \\
Ventilador & Sirocco $15 / 15$ \\
Vazão de ar & $8150 \mathrm{~m}^{3} / \mathrm{h}$ \\
Rotação & $922 \mathrm{RPM}$ \\
Vazão de água & $7,75 \mathrm{~m}^{3} / \mathrm{h}$ \\
\hline Temperatura de entrada de água & $8 \mathrm{C}$
\end{tabular}

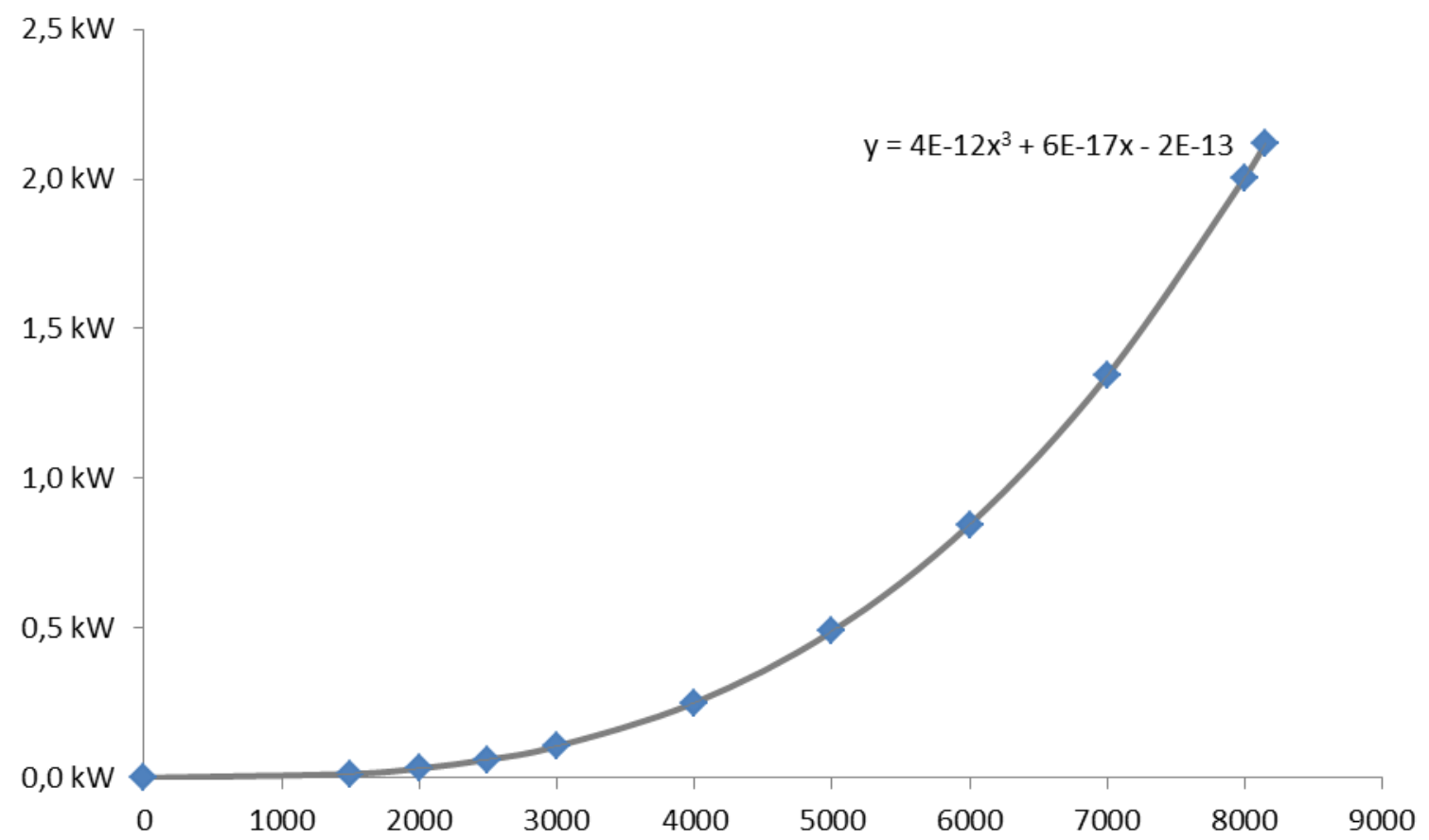

Figura 6.12 - Gráfico de "Potência elétrica consumida $(\mathrm{kW})$ x Vazão de $\operatorname{ar}\left(\mathrm{m}^{3} / \mathrm{h}\right)$ " para o equipamento fan coil VORTEX 10 TR (CARRIER 2013, modificado) 


\subsection{5 - Sistema do recuperador de energia e controle de vazão por CO2}

Para caracterização do sistema de recuperação de energia é necessário definir o equipamento que será utilizado, juntamente com suas curvas de desempenho, e dados de consumo elétrico (Tabela 6.9, Figura 6.13 e Figura 6.14). Demais dados de catálogo do equipamento encontram-se no Apêndice I.

Tabela 6.9 - Principais características do ERV (LG 2011, modificado)

\begin{tabular}{cc}
\hline Parâmetro & Valor \\
\hline Tipo de ERV & $\begin{array}{c}\text { Trocador de placas fixas, configuração } \\
\text { contracorrente, com ventiladores inclusos. } \\
\text { Fabricante } \\
\text { Modelo }\end{array}$ \\
LG \\
Capacidade nominal & ECO - V / LZ-H150GBA2 \\
\end{tabular}

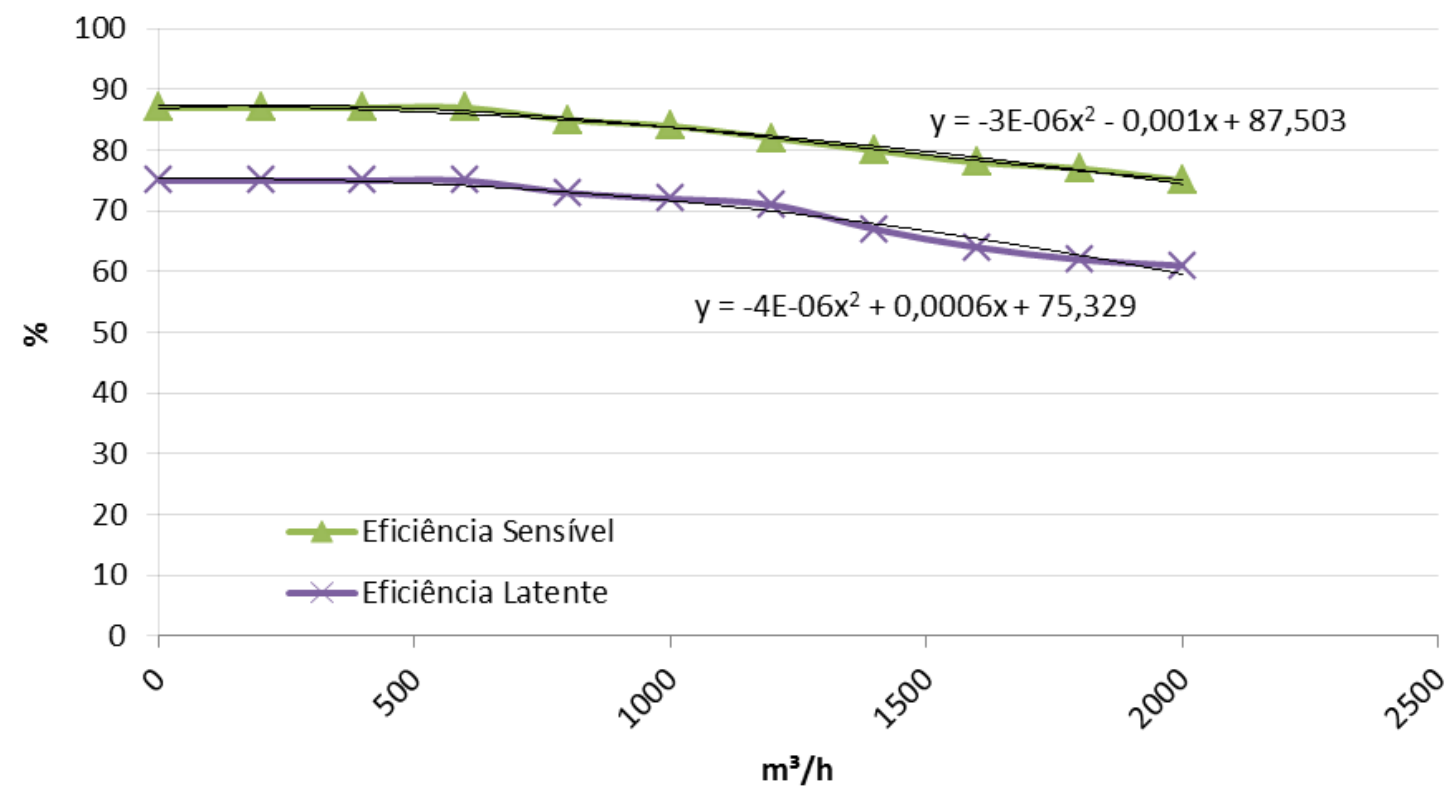

Figura 6.13 - Gráfico de "Eficiência (\%) x Vazão de ar $\left(\mathrm{m}^{3} / \mathrm{h}\right)$ " para o equipamento ERV modelo ECO-V LZ-H150GBA2 (LG 2011, modificado) 


\begin{tabular}{|c|c|c|c|c|}
\hline \multicolumn{3}{|c|}{ Item } & Unit & LZ-H150GBA2 \\
\hline \multicolumn{3}{|c|}{ Capacidade Nominal } & $\mathrm{m}^{3} / \mathrm{h}$ (LIS) & $1500(883)$ \\
\hline \multicolumn{3}{|c|}{ Alimentação Eléctrica } & $ø, \mathrm{~V}, \mathrm{~Hz}$ & $1,220-240,50-60$ \\
\hline \multirow{9}{*}{ 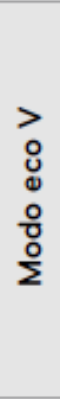 } & Intensidade Corrente & & - & SUPER ALTO / ALTO / BAIXO \\
\hline & Corrente & SA/A/B & A & $5.6 / 5.4 / 2.9$ \\
\hline & Potência de Entrada & SA/A/B & W & $720 / 540 / 340$ \\
\hline & Fluxo de Ar & SA/A/B & $\mathrm{m}^{3} / \mathrm{h}$ & $1500 / 1500 / 1200$ \\
\hline & Pressão Estática Disponível & SA/A/B & $\mathrm{Pa}$ & $200 / 110 / 60$ \\
\hline & Eficiência de Permuta Entálpica & SA/A/B & $\%$ & $79 / 79 / 82$ \\
\hline & Eficiência da Permuta Entálpica & Aquec. (SA/A/B) & $\%$ & $70 / 70 / 75$ \\
\hline & & Arref. (SA/A/B) & $\%$ & $65 / 65 / 70$ \\
\hline & 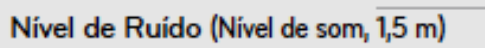 & SA/A/B & dBA & $39 / 37 / 33$ \\
\hline \multirow{8}{*}{ 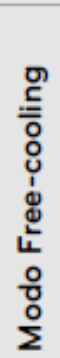 } & Nivel & & - & SUPER ALTO / ALTO / BAIXO \\
\hline & Intensidade Corrente & SA/A/B & A & $5.6 / 5.4 / 2.9$ \\
\hline & Potência Absorvida & SA/A/B & W & $720 / 540 / 340$ \\
\hline & Fluxo de $\mathrm{Ar}$ & SA/A/B & $\mathrm{m}^{3} / \mathrm{h}$ & $1500 / 1500 / 1200$ \\
\hline & Pressão Estática Disponível & SA/A/B & $\mathrm{Pa}$ & $200 / 110 / 60$ \\
\hline & Eficiência de Permuta Térmica & SA/A/B & $\%$ & $-1-1-$ \\
\hline & \multirow[t]{2}{*}{ Eficiência da Permuta de Entálpica } & Aquec. (SA/A/B) & $\%$ & $-/-1-$ \\
\hline & & Arref. (SA/A/B) & $\%$ & $-1-1-$ \\
\hline
\end{tabular}

Figura 6.14 - Especificações técnicas do ERV (LG, 2011)

Pela lei dos ventiladores e de acordo com a curva dos ventiladores do ERV, é possível determinar a curva de potência elétrica consumida em função da vazão, seguindo o mesmo procedimento utilizado para determinação das curvas dos ventiladores dos fan coils (Figura 6.15).

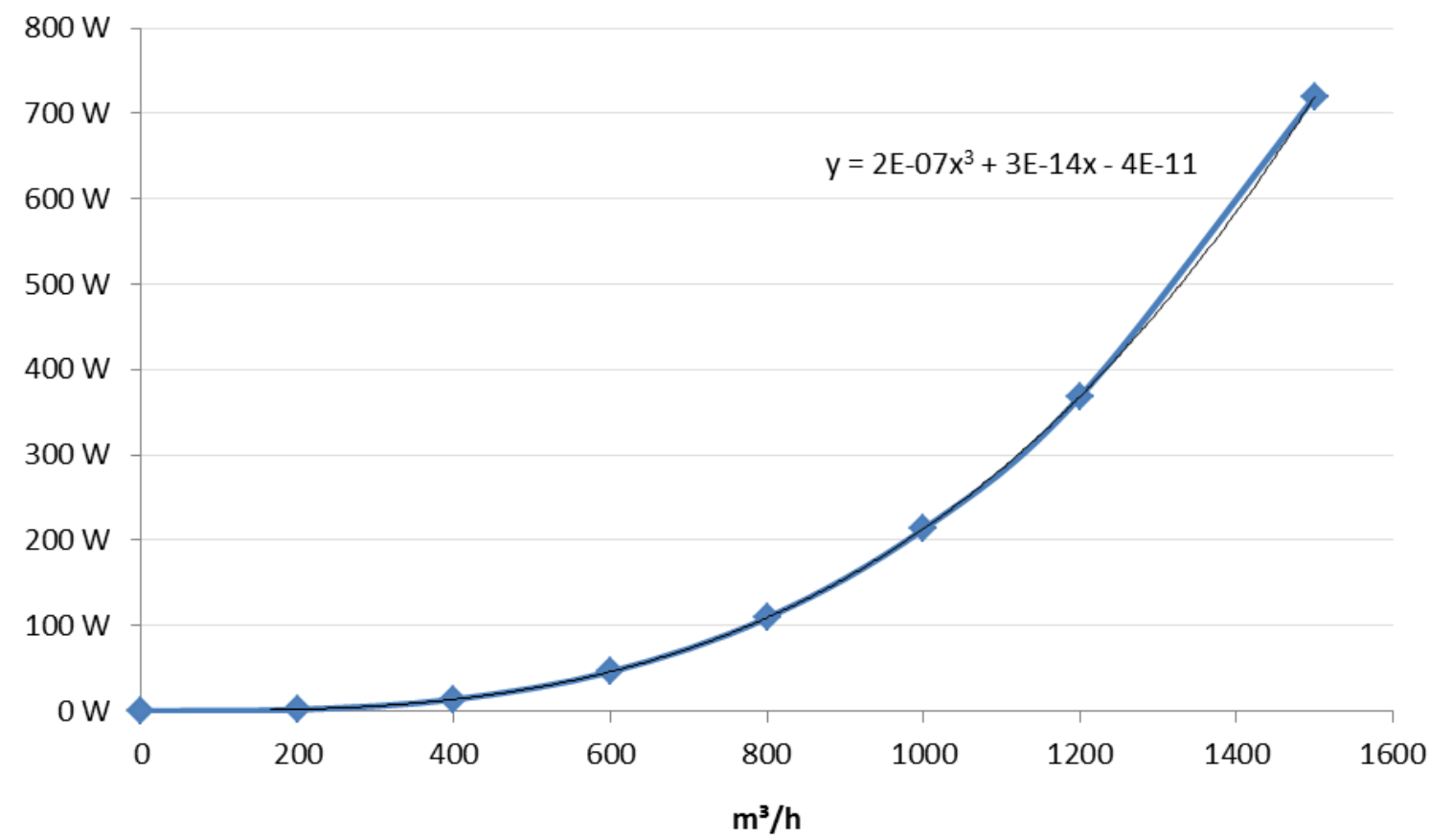

Figura 6.15 - Gráfico de "Potência elétrica consumida (W) x vazão de $\operatorname{ar}\left(\mathrm{m}^{3} / \mathrm{h}\right)$ para o equipamento ERV modelo ECO-V LZ-H150GBA2 (LG 2011, modificado) 
Para caracterização do sistema de controle de vazão de ar exterior por $\mathrm{CO} 2$ é necessário definir as taxas de renovação de ar por pessoa e por área, conforme a norma ABNT NBR 16401-3. A partir dessas taxas é possível calcular o valor exato da vazão requerida de ar externo para cada hora do dia, de acordo com o perfil de ocupação original apresentado anteriormente. A Tabela 6.10 apresenta os valores das taxas de renovação de ar da norma e a Tabela 6.11 apresenta os valores de vazão de ar externo requeridos para cada hora do dia, de acordo com o perfil de ocupação, considerando que a taxa de renovação é zero quando o ambiente está desocupado, conforme a metodologia de controle proposta no Capítulo 5.

Tabela 6.10 - Taxas de renovação de ar para o nível 1 de um edifício de escritórios (ABNT NBR 16401-3, 2008)

\begin{tabular}{cr}
\hline Taxa de ar externo & Vazão \\
\hline Taxa de ar externo por pessoa & $9,0 \mathrm{~m}^{3} / \mathrm{h}$ \\
Taxa de ar externo por área & $1,08 \mathrm{~m}^{3} / \mathrm{h}^{*} \mathrm{~m}^{2}$ \\
\hline
\end{tabular}

Tabela 6.11 - Taxa de renovação de ar externo requerida pela norma de acordo com a ocupação proposta (valores em $\mathrm{m}^{3} / \mathrm{h}$ ).

\begin{tabular}{ccccccc}
\hline Horário & Seg & Ter & Qua & Qui & Sex & Sab \\
\hline 8:00 & 0 & 531 & 531 & 0 & 531 & 531 \\
9:00 & 0 & 851 & 851 & 0 & 531 & 851 \\
10:00 & 0 & 851 & 851 & 0 & 531 & 1170 \\
$11: 00$ & 0 & 851 & 851 & 0 & 531 & 1170 \\
$12: 00$ & 0 & 851 & 851 & 0 & 531 & 851 \\
13:00 & 0 & 0 & 0 & 0 & 0 & 0 \\
$14: 00$ & 531 & 531 & 531 & 531 & 0 & 0 \\
15:00 & 1170 & 1170 & 1170 & 1170 & 531 & 0 \\
16:00 & 1490 & 1490 & 1490 & 1490 & 531 & 0 \\
17:00 & 1170 & 1170 & 1170 & 1170 & 851 & 0 \\
$18: 00$ & 1490 & 1490 & 1490 & 1490 & 851 & 0 \\
19:00 & 531 & 531 & 531 & 531 & 851 & 0 \\
20:00 & 851 & 851 & 851 & 0 & 1170 & 0 \\
$21: 00$ & 0 & 0 & 1170 & 0 & 1490 & 0 \\
$22: 00$ & 0 & 0 & 1170 & 0 & 1490 & 0 \\
\hline
\end{tabular}




\section{2 - APRESENTAÇÃO DE CENÁRIOS}

A partir da definição da formulação matemática, da metodologia de controle e da caracterização de todos os componentes do estudo de caso proposto, torna-se necessário levantar os cenários que serão propostos, de maneira que os cenários sejam avaliados segundo a metodologia desenvolvida, e os resultados sejam analisados comparativamente. A divisão dos cenários foi feita com base na solução de projeto adotada para cada cenário, considerando o mesmo ambiente a ser condicionado com o mesmo perfil de ocupação proposto. Assim, os 4 (quatro) cenários ou configurações de uso são apresentados na Tabela 6.12, onde "ERV" significa o recurso de recuperação de energia e "CO2" significa o recurso de controle de vazão de ar externo. Quando o valor "zero" é atribuído, quer dizer que o cenário não utiliza o recurso, e quando o valor unitário é atribuído, o recurso é empregado.

Tabela 6.12 - Apresentação dos cenários

\begin{tabular}{ccc}
\hline Cenário & ERV & CO2 \\
\hline 1 & 0 & 0 \\
2 & 0 & 1 \\
3 & 1 & 0 \\
4 & 1 & 1 \\
\hline
\end{tabular}

\subsection{1 - Cenário 1: Solução convencional}

O primeiro cenário levantado consiste em uma solução convencional de projeto, sem utilização dos recursos de recuperação de energia e vazão de ar exterior variável. Esse cenário será utilizado como base para comparação com os demais cenários, uma vez que, notadamente, apesar de seu custo inicial de aquisição e instalação ser menor, seu custo operacional é maior, se tornando mais custoso ao longo dos anos.

A solução desse cenário considera a utilização do sistema de ar condicionado padrão de 12 TR e a utilização de dois ventiladores para introdução do ar externo no ambiente e retirada da parte do ar de retorno, conforme mostra a Figura 6.16. Os ventiladores utilizados possuem as mesmas curvas de operação dos ventiladores que serão utilizados nos outros cenários. A vazão de ar externo é constante e igual à máxima vazão calculada de $1490 \mathrm{~m}^{3} / \mathrm{h}$ (considerando ocupação de $100 \%$ de pessoas em todos os momentos de utilização). 


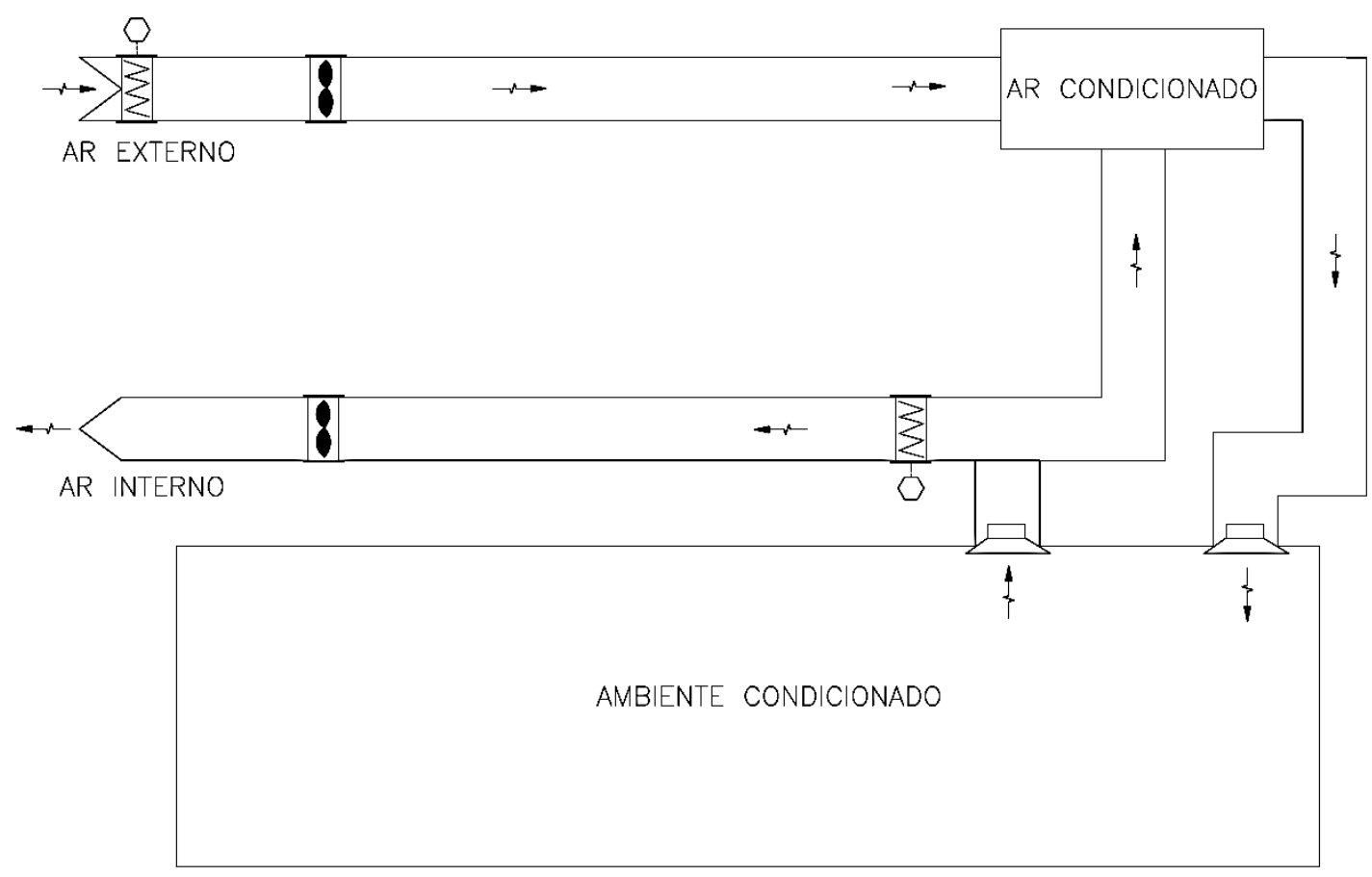

Figura 6.16 - Solução de projeto para o cenário 1

\subsection{2 - Cenário 2: Solução com vazão de ar exterior variável}

O segundo cenário levantado consiste em uma solução de projeto utilizando apenas o recurso da vazão de ar exterior variável.

A solução desse cenário considera a utilização do sistema de ar condicionado padrão de 12 TR e a utilização de dois ventiladores para introdução do ar externo no ambiente e retirada da parte do ar de retorno, conforme mostra a Figura 6.17. Os ventiladores utilizados possuem as mesmas curvas de operação dos ventiladores que serão utilizados nos outros cenários. A vazão de ar externo é variável, de acordo com a ocupação, fornecendo os valores de vazão levantados na Tabela 6.11. Para esse controle de vazão, será utilizado um sensor de $\mathrm{CO} 2$ no ambiente condicionado, um controlador, sensores de pressão, inversor de frequência e dispositivos de regulagem de vazão (dampers). 


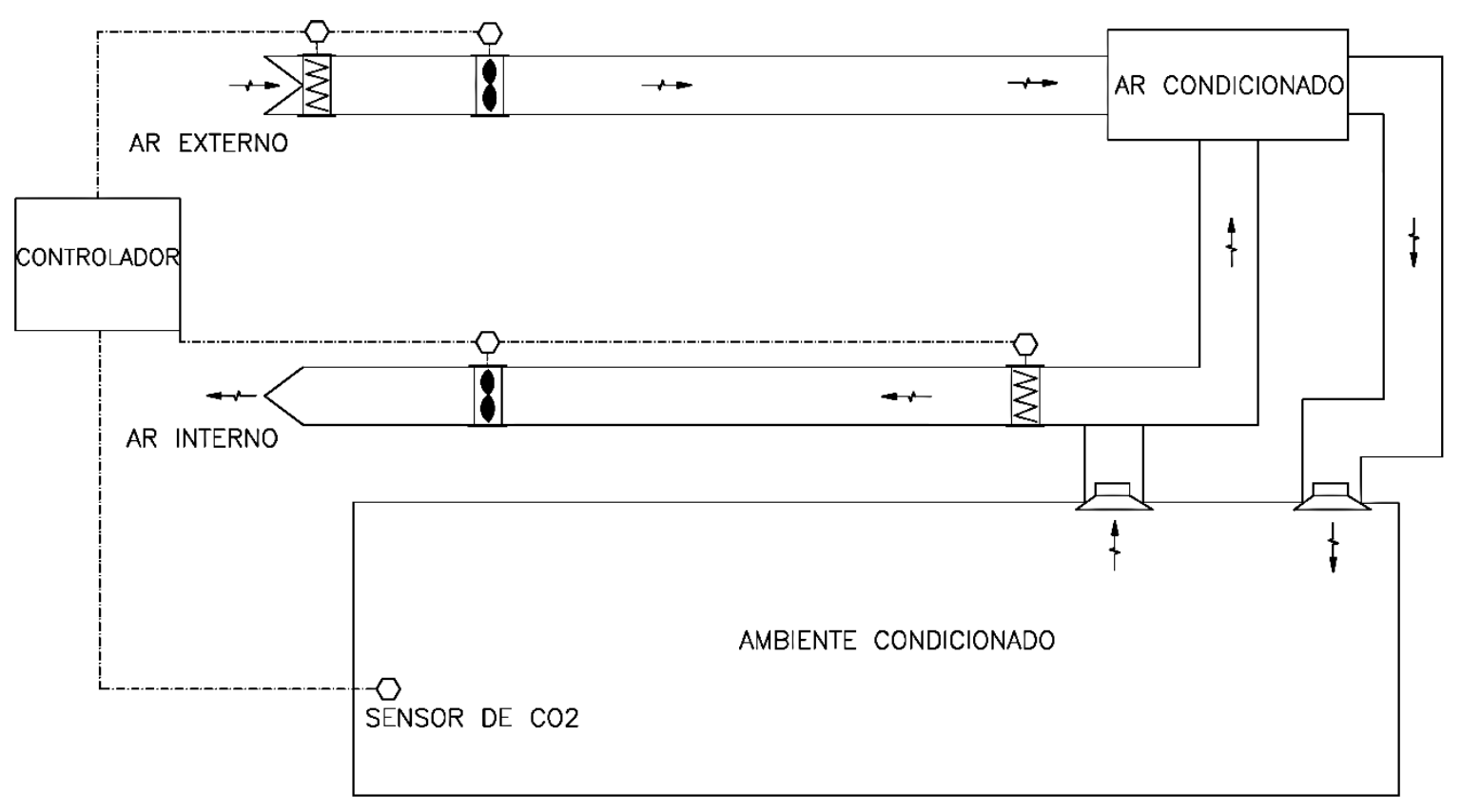

Figura 6.17 - Solução de projeto para o cenário 2

\subsection{3 - Cenário 3: Solução com recuperação de energia}

O terceiro cenário levantado consiste em uma solução de projeto utilizando apenas o recurso da recuperação de energia.

A solução desse cenário considera a utilização do sistema de ar condicionado de 10 TR e a utilização do equipamento ERV que será responsável pela introdução do ar externo no ambiente e retirada da parte do ar de retorno, conforme mostra a Figura 6.18. Os ventiladores do ERV utilizado possuem as mesmas curvas de operação dos ventiladores que serão utilizados nos outros cenários. A vazão de ar externo é constante e igual à máxima vazão calculada de 1490 m³/h (considerando ocupação de $100 \%$ de pessoas em todos os momentos de utilização). Para o controle do funcionamento do ERV será utilizada a metodologia descrita no Capítulo 5, a partir da utilização de sensores de temperatura e umidade e de um controlador. 


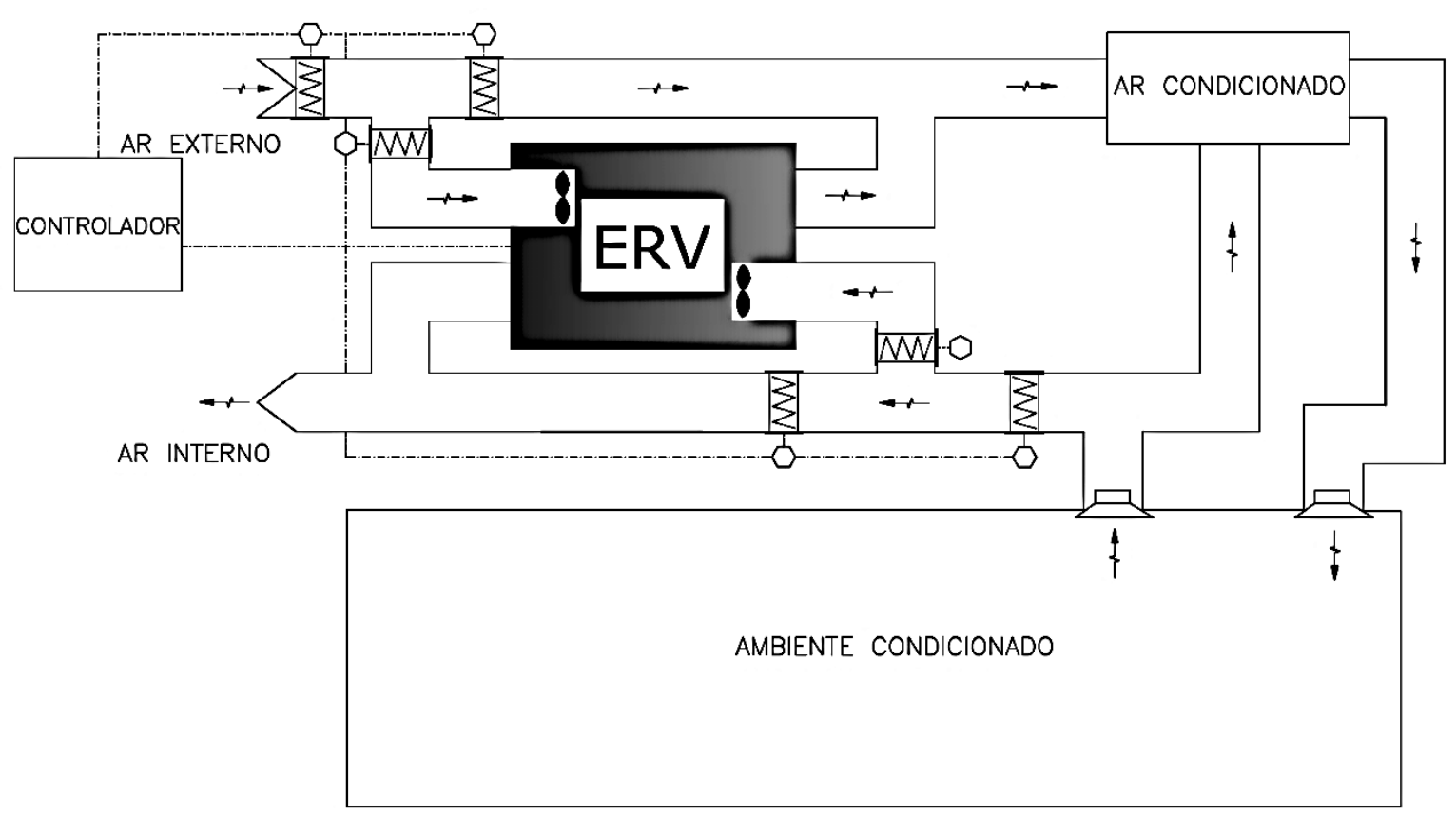

Figura 6.18 - Solução de projeto para o cenário 3

\subsection{4 - Cenário 4: Solução completa}

O quarto cenário levantado consiste em uma solução de projeto utilizando os recursos da recuperação de energia e da vazão variável de ar exterior.

A solução desse cenário considera a utilização do sistema de ar condicionado de 10 TR e a utilização do equipamento ERV que será responsável pela introdução do ar externo no ambiente e retirada da parte do ar de retorno, conforme mostra a Figura 6.19. Os ventiladores do ERV utilizado possuem as mesmas curvas de operação dos ventiladores que serão utilizados nos outros cenários. A vazão de ar externo é variável, de acordo com a ocupação, fornecendo os valores de vazão levantados na Tabela 6.11. Para esse controle de vazão, será utilizado um sensor de $\mathrm{CO} 2$ no ambiente condicionado, um controlador, sensores de pressão, inversor de frequência e dispositivos de regulagem de vazão (dampers). Para o controle do funcionamento do ERV será utilizada a metodologia descrita no Capítulo 5, a partir da utilização de sensores de temperatura e umidade e de um controlador. 


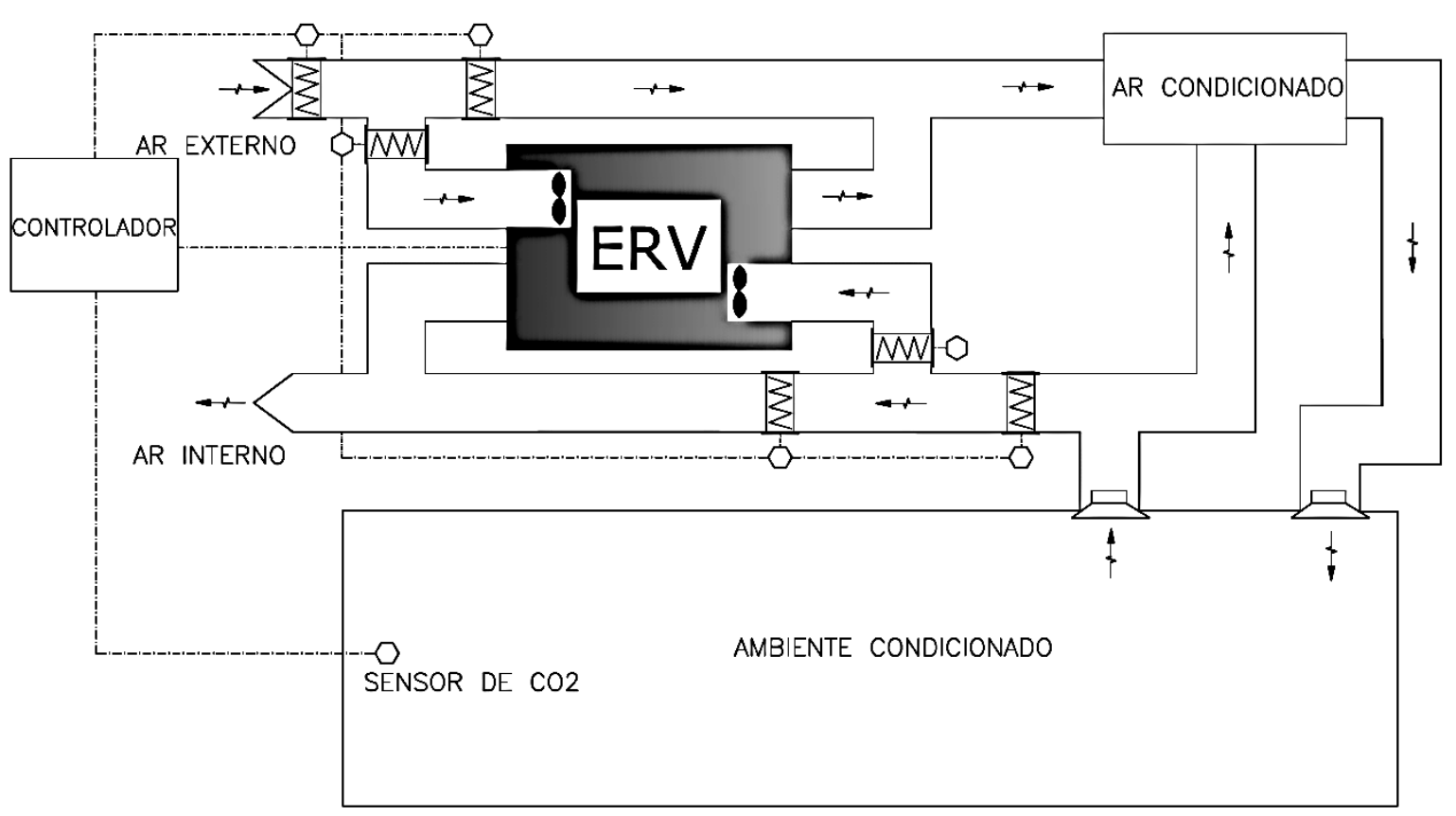

Figura 6.19 - Solução de projeto para o cenário 4

\subsection{5 - Estimativas dos custos para cada cenário}

Para que seja possível a análise de retorno de investimento de cada cenário proposto é necessário estimar os custos totais de cada instalação. Os custos compõem-se basicamente dos custos iniciais (aquisição, transporte e instalação) e custos operacionais (operação, manutenção e custo do insumo energético). Os custos médios foram levantados com base em estimativas de fabricantes, instaladores e pesquisas de mercado.

\subsubsection{1 - Custos iniciais}

Para os custos iniciais foram levantados os custos mais relevantes das instalações de cada cenário, referentes principalmente aos equipamentos, uma vez que os demais custos de materiais de consumo, rede de dutos, registros, difusores, quadro elétrico, e demais infraestruturas necessárias são praticamente os mesmos para todos os cenários.

As Tabelas 6.13 e 6.14 apresentam os custos iniciais dos sistemas dos cenários e as fontes de referência para as estimativas. Mais detalhes da Tabela 6.14 encontram-se no Apêndice $\mathrm{H}$.

Tabela 6.13 - Custos iniciais dos cenários (aquisição, transporte e instalação)

Sistema/Equipamento Detalhamento Custo




\begin{tabular}{|c|c|c|}
\hline $\begin{array}{l}\text { (1) Sistema de ar condicionado } \\
\text { (todos os cenários) }\end{array}$ & $\begin{array}{l}\text { Sistema de expansão indireta, com central } \\
\text { de água gelada, bombas e climatizadores } \\
\text { tipo fan coil. Incluindo a instalação dos } \\
\text { demais equipamentos de controle, } \\
\text { alimentação elétrica e distribuição de ar. }\end{array}$ & $\begin{array}{l}\mathrm{R} \$ 5.000,00 / \mathrm{TR} \\
\quad \text { instalado }\end{array}$ \\
\hline $\begin{array}{l}\text { (2) Equipamento ERV } \\
\text { (cenários } 3 \text { e } 4 \text { ) }\end{array}$ & $\begin{array}{l}\text { Equipamento recuperador de energia de } \\
\text { placas fixas, com ventiladores inclusos - } \\
\text { referência LG ECO - V / LZ-H150GBA2 } \\
-1.500 \mathrm{~m} / \mathrm{h}\end{array}$ & $\mathrm{R} \$ 12.000,00$ \\
\hline $\begin{array}{l}\text { (3) Ventiladores - renovação de } \\
\text { ar (cenários } 1 \text { e 2) }\end{array}$ & $\begin{array}{l}\text { Ventilador centrífugo, tipo sirocco, vazão } \\
1.500 \mathrm{~m} 3 / \mathrm{h} \text {, pressão estática } 45 \mathrm{mmCA}\end{array}$ & $\mathrm{R} \$ 1.800,00 /$ unidade \\
\hline $\begin{array}{c}\text { (4) Sistema de controle de } \\
\text { vazão por CO2 (cenários } 2 \text { e } 4 \text { ) }\end{array}$ & Sensores de $\mathrm{CO} 2$ e infraestrutura & $\mathrm{R} \$ 2.400,00 /$ zona \\
\hline (5) Automação - Cenário 2 & $\begin{array}{l}\text { Controlador, } 02 \text { (dois) inversores de } \\
\text { frequência, } 02 \text { (dois) sensores de pressão, } \\
02 \text { (dois) dispositivos de regulagem de } \\
\text { vazão motorizados. }\end{array}$ & $\mathrm{R} \$ 7.299,88$ \\
\hline (6) Automação - Cenário 3 & $\begin{array}{l}\text { Controlador, } 01 \text { (um) sensor de } \\
\text { temperatura e } 01 \text { (um) de umidade, } 06 \\
\text { (seis) dispositivos de regulagem de vazão } \\
\text { motorizados. }\end{array}$ & $\mathrm{R} \$ 7.138,47$ \\
\hline (7) Automação - Cenário 4 & $\begin{array}{l}\text { Controlador, } 02 \text { (dois) inversores de } \\
\text { frequência, } 02 \text { (dois) sensores de pressão, } \\
01 \text { (um) sensor de temperatura e } 01 \text { (um) } \\
\text { sensor de umidade, } 06 \text { (seis) dispositivos } \\
\text { de regulagem de vazão motorizados. }\end{array}$ & $\mathrm{R} \$ 10.204,07$ \\
\hline
\end{tabular}

Tabela 6.14 - Referências para estimativa dos custos iniciais

\section{Referência Custo}

(1) “http://www.consultoriaeanalise.com/2009/03/sistema-de-ar-condicionadovrv.html"

$\mathrm{R} \$ \quad 5.000,00 / \mathrm{TR}$

"http://www.arcondicionado.refrigeracao.net/ar-condicionado-com-

instalado

sistema-vrf-estao-aumentando-participacao-no-mercado/\#more-122"

(2) (LG, 2013) - Apêndice J

$\mathrm{R} \$ 12.000,00$ 
(3) “http://www.novaexaustores.com.br/ecommerce_site/produto_2104_5763_ Exaustor-Centrifugo-Siroco-Monofasico-Mod-EC1-MN-“

$\mathrm{R} \$ 1.800,00 / \mathrm{un}$.

(4) U.S Department of Energy “http://www1.eere.energy.gov/femp/pdfs/fta_co2.pdf”pág 2.

$\mathrm{R} \$ 2.400,00 /$ zona

(5) 1) Controlador - Ref: Carel PCO-5 - Planilha TCU (Apêndice J)

2) Inversor de frequência $-3 \mathrm{CV}$

"http://loja.tray.com.br/loja/produto-261635-8614-

1) $\mathrm{R} \$ 3.393,00$

inversor_de_frequencia_3cv_220v_cfw100100s2024psz_weg"

2) $\mathrm{R} \$ 1.245,74$

3) Sensor de pressão

3) $\mathrm{R} \$ 287,06$

"http://www.webmercato.com.br/ecommerce_site/produto_3160_6377_Se

4) $\mathrm{R} \$ 420,64$ nsor-de-pressao-diferencial-para-ar-0-3-WC-616K-02"

4) Damper motorizado

"http://www.webmercato.com.br/ecommerce_site/categoria_1782_6377_A

tuadores-para-damper"

(6) 1) Controlador - Ref: Carel PCO-5 - Planilha TCU (Apêndice J)

2) Sensor de temperatura - Planilha TCU (Apêndice J)

1) $R \$ 3.393,00$

3) Sensor de umidade - Planilha TCU (Apêndice J)

2) $\mathrm{R} \$ 441,14$

4) Damper motorizado

3) $\mathrm{R} \$ 780,49$

"http://www.webmercato.com.br/ecommerce_site/categoria_1782_6377_A

4) $R \$ 420,64$ tuadores-para-damper"

(7) 1) Controlador - Ref: Carel PCO-5 - Planilha TCU (Apêndice J)

2) Inversor de frequência $-3 \mathrm{CV}$

"http://loja.tray.com.br/loja/produto-261635-8614-

inversor_de_frequencia_3cv_220v_cfw100100s2024psz_weg”

1) $\mathrm{R} \$ 3.393,00$

3) Sensor de pressão

2) $\mathrm{R} \$ 1.245,74$

“http://www.webmercato.com.br/ecommerce_site/produto_3160_6377_Se

3) $\mathrm{R} \$ 287,06$

nsor-de-pressao-diferencial-para-ar-0-3-WC-616K-02"

4) $\mathrm{R} \$ 441,14$

4) Sensor de temperatura - Planilha TCU (Apêndice J)

5) $\mathrm{R} \$ 780,49$

5) Sensor de umidade - Planilha TCU (Apêndice J)

6) $\mathrm{R} \$ 420,64$

6) Damper motorizado

"http://www.webmercato.com.br/ecommerce_site/categoria_1782_6377_A

tuadores-para-damper" 


\subsubsection{2 - Custos operacionais - operação e manutenção}

Para a estimativa dos custos operacionais (operação e manutenção) dos sistemas, foram levantados os custos médios de operação e manutenção de alguns contratos que prestam esses serviços em sistemas de ar condicionado. A Tabela 6.15 apresenta um resumo da pesquisa realizada. A pesquisa de preços completa se encontra no Apêndice J. Cabe ressaltar que todas as instalações levantadas na pesquisa possuem centrais de água gelada, e equipamentos similares aos projetos para cada cenário. Assim, para a estimativa dos custos de manutenção de cada cenário será utilizado o valor médio do custo mensal por tonelada de refrigeração encontrado na pesquisa.

Ainda, a manutenção do equipamento ERV selecionado é bastante similar à manutenção de ventiladores, já que é composto basicamente por dois ventiladores, filtros e a membrana fixa que permite a troca de calor. Dessa forma, a utilização desse equipamento não acarreta custos muito maiores de manutenção e operação aos sistemas.

Tabela 6.15 - Custos operacionais de alguns contratos de manutenção e operação (Pesquisa realizada em abril/2012)

\begin{tabular}{|c|c|c|c|c|}
\hline Instituição & $\begin{array}{l}\text { Senado } \\
\text { Federal }\end{array}$ & $\begin{array}{l}\text { Câmara dos } \\
\text { Deputados }\end{array}$ & $\begin{array}{c}\text { Procuradoria- } \\
\text { Geral da } \\
\text { República }\end{array}$ & $\begin{array}{c}\text { Supremo } \\
\text { Tribunal } \\
\text { Federal }\end{array}$ \\
\hline Empresa contratada & ENTHERM & TECTENGE & $\begin{array}{l}\text { ALMEIDA } \\
\text { FRANÇA }\end{array}$ & $\begin{array}{c}\text { ALMEIDA } \\
\text { FRANÇA }\end{array}$ \\
\hline Preço mensal (R\$) & $299.166,02$ & $212.073,48$ & $72.890,00$ & $65.800,33$ \\
\hline $\begin{array}{l}\text { Potência instalada } \\
\text { (TR) }\end{array}$ & 5000 & 3180 & 1150 & 1200 \\
\hline $\begin{array}{c}\text { Custo mensal por TR } \\
\qquad(\mathrm{R} \$ / \mathrm{TR})\end{array}$ & 59,83 & 66,69 & 63,38 & 54,83 \\
\hline $\begin{array}{c}\text { Custo médio mensal } \\
\text { por TR (R\$/TR) }\end{array}$ & \multicolumn{4}{|c|}{61,18} \\
\hline $\begin{array}{l}\text { Custo médio anual } \\
\text { por } T R(R \$ / T R)\end{array}$ & \multicolumn{4}{|c|}{734,16} \\
\hline
\end{tabular}


6.2.5.3 - Custos operacionais - custos dos insumos energéticos

Para a estimativa dos custos dos insumos energéticos (no caso em questão, energia elétrica) é necessário estimar o consumo de cada equipamento da instalação em cada hora de operação ao longo do ano. Esses dados de consumo elétrico (kWh) foram levantados a partir da simulação realizada no EES, uma vez que as curvas de potência consumida dos componentes foram inseridas na formulação matemática, fornecendo os valores consumidos para cada hora de operação, de acordo com a demanda térmica nessa dada hora.

Ainda, para que seja possível levantar a economia de energia provida pelo equipamento ERV, é necessário levantar o COP (coeficiente de desempenho) do sistema de ar condicionado para cada hora, e, a partir da redução da carga térmica do ar de renovação, calcular quanto essa redução de carga térmica representa em energia elétrica economizada.

Nesse sentido, a partir dos levantamentos dos consumos dos equipamentos de cada instalação será possível comparar os cenários levantados. Foi definido um valor fixo de R\$ 0,30 por cada $\mathrm{kWh}$ consumido (RESOLUÇÃO ANEEL N 1.606/2013, Classe B3).

\subsubsection{4 - Custos totais dos cenários e retorno do investimento}

As Tabelas 6.16 e 6.17 apresentam os custos totais e parte dos custos operacionais para os cenários apresentados. Conforme mencionado anteriormente, os custos de consumo elétrico serão definidos a partir das simulações realizadas para cada cenário, e, a partir desses dados, poderá ser realizada a análise comparativa entre eles, abordando a diferença dos custos totais entre os cenários, a economia de energia e retorno do investimento de cada cenário, conforme apresentado na Tabela 6.18

Tabela 6.16 - Custos iniciais dos cenários

\begin{tabular}{|c|c|c|c|c|}
\hline Cenário & $\begin{array}{c}\text { Cenário } 1 \\
(\mathrm{ERV}=\mathbf{0} ; \mathrm{CO} 2=0)\end{array}$ & $\begin{array}{c}\text { Cenário 2 } \\
(\mathrm{ERV}=\mathbf{0} ; \mathbf{C O 2}=\mathbf{1})\end{array}$ & $\begin{array}{c}\text { Cenário } 3 \\
(\mathrm{ERV}=\mathbf{1} ; \mathrm{CO} 2=0)\end{array}$ & $\begin{array}{c}\text { Cenário } 4 \\
(\mathrm{ERV}=\mathbf{1} ; \mathrm{CO} 2=1)\end{array}$ \\
\hline \multicolumn{5}{|c|}{ CUSTOS INICIAIS } \\
\hline $\begin{array}{c}\text { Sistema de } \\
\text { de } 10 \text { TR }\end{array}$ & - & - & $\mathrm{R} \$ 50.000,00$ & $\mathrm{R} \$ 50.000,00$ \\
\hline
\end{tabular}




\begin{tabular}{|c|c|c|c|c|}
\hline $\begin{array}{l}\text { Sistema de } \\
\text { de } 12 \text { TR }\end{array}$ & $\mathrm{R} \$ 60.000,00$ & $\mathrm{R} \$ 60.000,00$ & - & - \\
\hline $\begin{array}{c}\text { Equipamento } \\
\text { ERV }\end{array}$ & - & - & $\mathrm{R} \$ 12.000,00$ & $\mathrm{R} \$ 12.000,00$ \\
\hline $\begin{array}{c}\text { Ventiladores } \\
\text { de ar }\end{array}$ & $\mathrm{R} \$ 3.600,00$ & $\mathrm{R} \$ 3.600,00$ & - & - \\
\hline $\begin{array}{l}\text { Controle de } \\
\text { vazão }\end{array}$ & - & $\mathrm{R} \$ 2.400,00$ & - & $\mathrm{R} \$ 2.400,00$ \\
\hline Automação & - & $\mathrm{R} \$ 7.299,88$ & $\mathrm{R} \$ 7.138,47$ & $\mathrm{R} \$ 10.204,07$ \\
\hline TOTAL & $\mathrm{R} \$ 63.600,00$ & $\mathrm{R} \$ 73.299,88$ & $\mathrm{R} \$ 69.138,47$ & $\mathrm{R} \$ 74.604,07$ \\
\hline \multicolumn{5}{|c|}{ Tabela 6.17 - Custos operacionais dos cenários } \\
\hline Cenário & 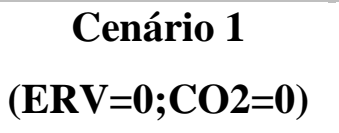 & $\begin{array}{c}\text { Cenário 2 } \\
(\mathrm{ERV}=\mathbf{0} ; \mathrm{CO2}=1)\end{array}$ & $\begin{array}{c}\text { Cenário } 3 \\
(\mathrm{ERV=1;CO2=0)}\end{array}$ & $\begin{array}{c}\text { Cenário } 4 \\
(\mathrm{ERV}=\mathbf{1 ; C O 2 = 1 )}\end{array}$ \\
\hline \multicolumn{5}{|c|}{ CUSTOS OPERACIONAIS } \\
\hline $\begin{array}{l}\text { Operação e } \\
\text { manutenção }\end{array}$ & $\mathrm{R} \$ 8.809,92$ & $\mathrm{R} \$ 8.809,92$ & $\mathrm{R} \$ 7.341,60$ & $\mathrm{R} \$ 7.341,60$ \\
\hline $\begin{array}{l}\text { Energia } \\
\text { consumida }\end{array}$ & - & - & - & - \\
\hline TOTAL & & & & \\
\hline \multicolumn{5}{|c|}{ Tabela 6.18 - Retorno do investimento de cada cenário } \\
\hline Cenário & $\begin{array}{c}\text { Cenário } 1 \\
(\mathrm{ERV}=0 ; \mathrm{CO} 2=0)\end{array}$ & $\begin{array}{c}\text { Cenário } 2 \\
(\mathrm{ERV}=0 ; \mathrm{CO} 2=1)\end{array}$ & $\begin{array}{c}\text { Cenário } 3 \\
(\mathrm{ERV}=1 ; \mathrm{CO2}=\mathbf{0})\end{array}$ & $\begin{array}{c}\text { Cenário } 4 \\
(\mathrm{ERV}=\mathbf{1} ; \mathrm{CO2}=1)\end{array}$ \\
\hline \multicolumn{5}{|c|}{ RETORNO DO INVESTIMENTO } \\
\hline Custos totais & - & - & - & - \\
\hline $\begin{array}{l}\text { Diferença } \\
\text { custos totais }\end{array}$ & - & - & - & - \\
\hline $\begin{array}{l}\text { Economia } \\
\text { de energia }\end{array}$ & - & - & - & - \\
\hline $\begin{array}{l}\text { Retorno do } \\
\text { investimento }\end{array}$ & - & - & - & - \\
\hline
\end{tabular}




\section{7 - RESULTADOS E DISCUSSÃO}

\section{1 - INTRODUÇÃO}

Esse capítulo apresentará os resultados obtidos a partir da metodologia apresentada e do estudo de caso proposto. Os resultados dos cenários propostos serão comparados com o cenário 1 (solução convencional) para que seja avaliado o retorno do investimento de cada cenário. Ainda, serão apresentados os resultados considerando variações de ocupação e horas de operação para cada cenário, com o objetivo de verificar quais condições de projeto (ocupação e horas de operação) permitem a utilização dos cenários apresentados.

Por último, serão apresentados os resultados obtidos dos mesmos cenários com o perfil de ocupação original em outra cidade de projeto, com o objetivo de analisar a influência do clima nos resultados.

\section{2 - RESULTADOS DOS CENÁRIOS COM OCUPAÇÃO ORIGINAL}

O perfil original de ocupação foi apresentado na Tabela 6.2. A partir dele, foi determinado o número de ocupantes em cada dia da semana e o número total de ocupantes ao longo de uma semana. A Tabela 7.1 apresenta os valores absolutos e percentuais do perfil de ocupação original por dia e o valor acumulado em uma semana, além do tempo de operação semanal do sistema de ar condicionado (juntamente com os ventiladores de renovação de ar ou o recuperador de energia, de acordo com o cenário):

Tabela 7.1 - Valores absolutos e relativos do perfil de ocupação do ambiente condicionado

\begin{tabular}{cccc}
\hline Dia da semana & Ocupação máxima & Ocupação absoluta & Ocupação relativa \\
\hline Segunda & 2130 & 639 & $30 \%$ \\
Terça & 2130 & 958,5 & $45 \%$ \\
Quarta & 2130 & 1171,5 & $55 \%$ \\
Quinta & 2130 & 568 & $26,67 \%$ \\
Sexta & 2130 & 852 & $40 \%$ \\
Sábado & 2130 & 390,5 & $18,33 \%$ \\
Domingo & 2130 & 0 & $0 \%$ \\
\hline
\end{tabular}


Ocupação relativa semanal acumulada

Tempo de operação semanal do sistema
$35,83 \%$

57 horas

\subsection{1 - Cenário 1: Solução convencional $(\mathrm{CO2}=0 ; \mathrm{ERV}=0)$}

A Figura 7.1 apresenta o perfil de carga térmica devido ao ar externo de renovação para o cenário em questão ao longo do ano. A Figura 7.2 apresenta os valores de entalpia do ar exterior e do ar interno, mostrando claramente a possibilidade de utilização de um equipamento de recuperação de energia em grande parte do ano. Pela análise dos gráficos, também é possível observar que a carga térmica e a entalpia média do ar externo são maiores nos meses de janeiro a abril (hora zero à hora 2880), correspondendo à estação do verão e parte do outono, e menores no fim do outono (maio), passando pelo inverno (junho a setembro), seguindo até o início da primavera (fim de setembro), a partir da qual a entalpia média volta a subir (hora 2880 à hora 6480):

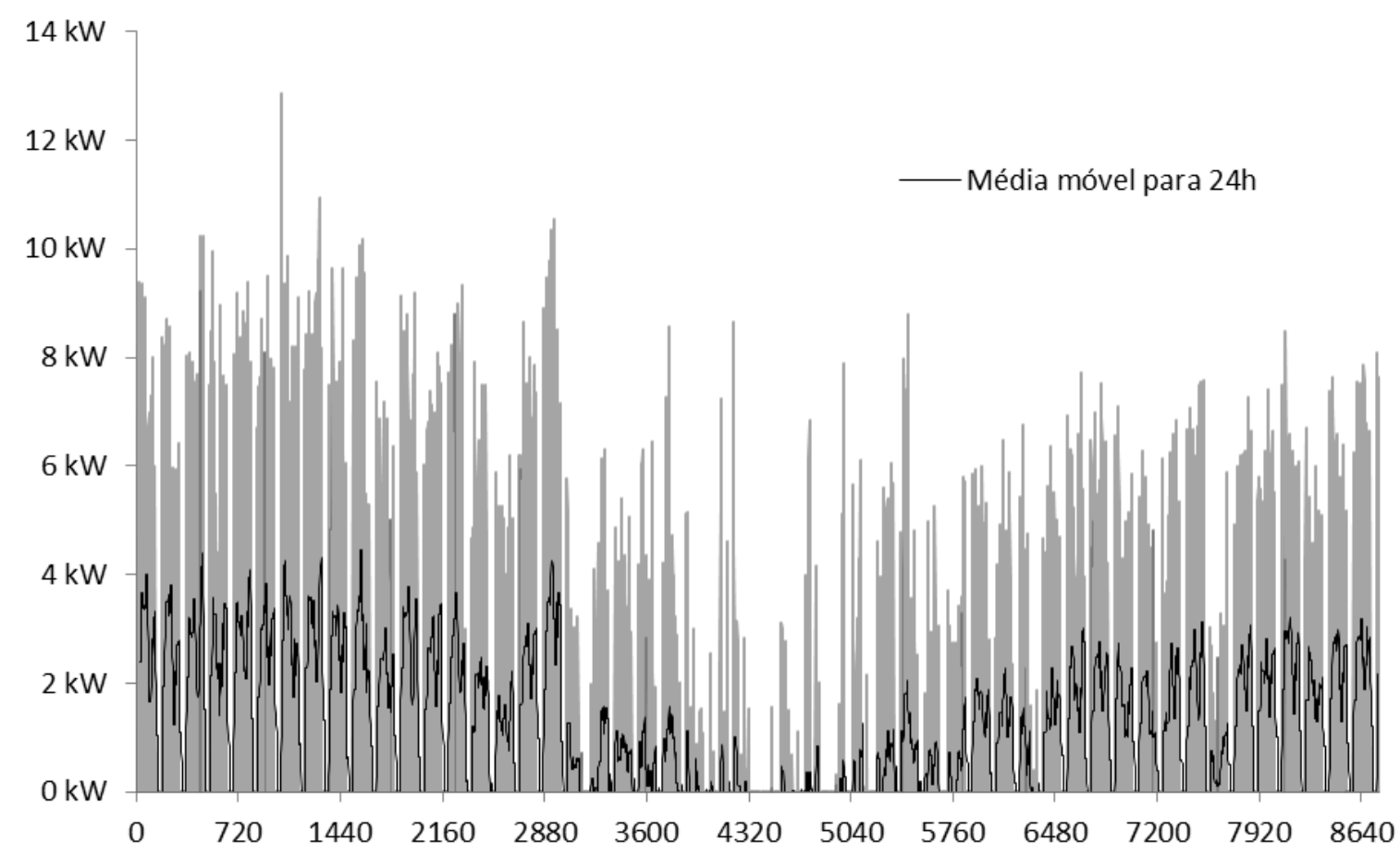

Figura 7.1 - Carga térmica do ar de renovação $(\mathrm{kW})$ x horas do ano (cenário 1) 


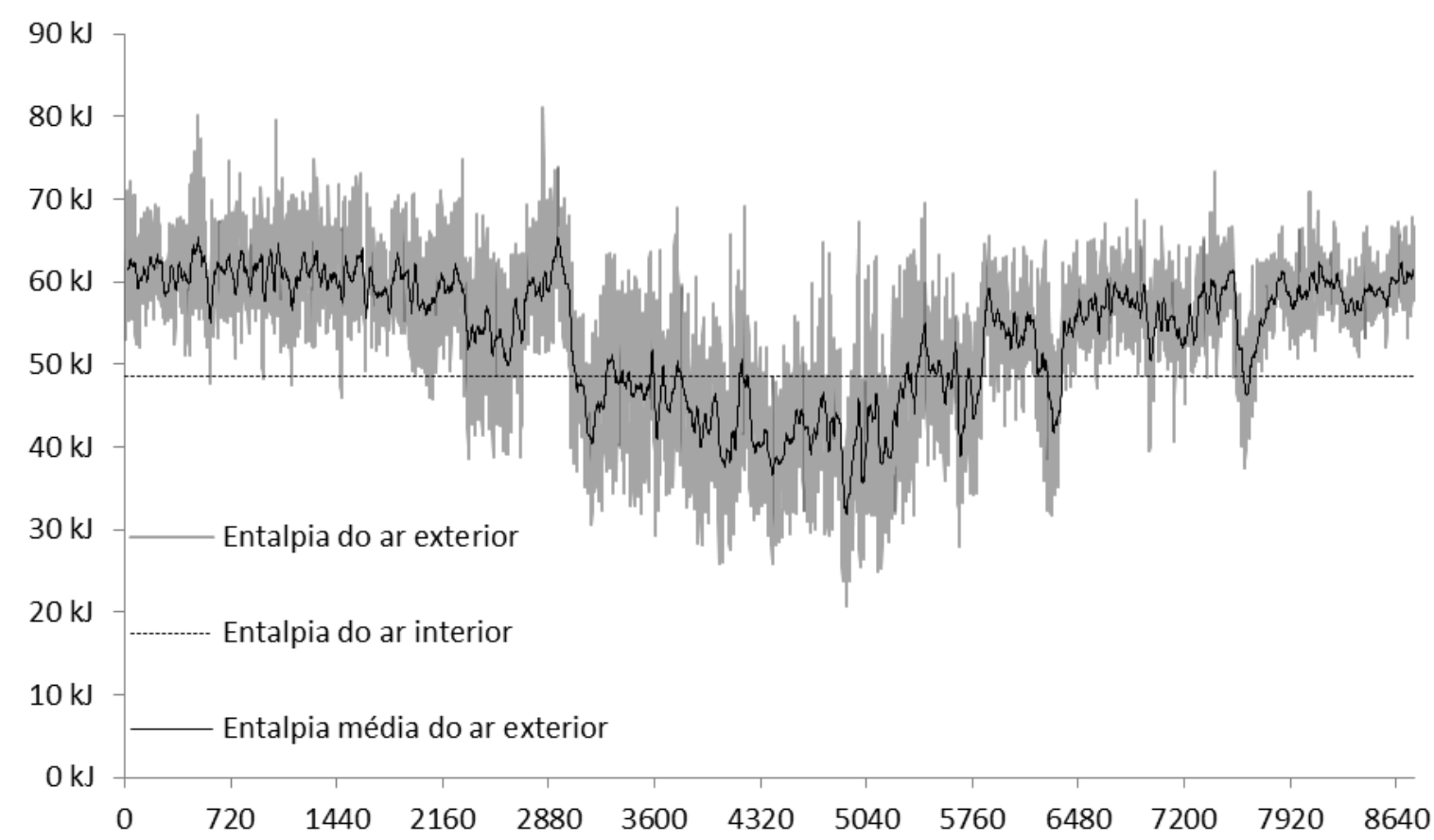

Figura 7.2 - Entalpia do ar externo e interno $(\mathrm{kJ} / \mathrm{kg})$ x horas do ano (cenário 1)

A Tabela 7.2 traz os valores integralizados hora a hora ao longo do ano da carga térmica do ar externo de renovação e do consumo de energia elétrica dos ventiladores de renovação de ar, do fan coil, do chiller e o consumo elétrico total do cenário. As Figuras 7.3, 7.4, 7.5 e 7.6 apresentam esses consumos elétricos em cada mês do ano. O perfil referente ao consumo dos ventiladores (Figura 7.3) é praticamente constante ao longo dos meses, uma vez que o perfil de ocupação é semanal e a vazão de ar externo é sempre constante e igual ao valor máximo. As pequenas diferenças encontradas se devem às diferenças dos dias da semana que compõem cada mês, gerando uma pequena diferença na ocupação acumulada mensal.

Os perfis apresentados pelo consumo elétrico dos equipamentos de ar condicionado e pelo consumo elétrico total acompanham o perfil de carga térmica anual (cf. Figura 6.3):

Tabela 7.2 - Valores integralizados anuais para o cenário 1

\begin{tabular}{cccc}
\hline $\begin{array}{c}\text { Carga térmica do } \\
\text { ar externo }\end{array}$ & $\begin{array}{c}\text { Consumo elétrico } \\
\text { dos ventiladores }\end{array}$ & $\begin{array}{c}\text { Consumo elétrico } \\
\text { do } \text { fan coil }\end{array}$ & $\begin{array}{c}\text { Consumo elétrico } \\
\text { do chiller }\end{array}$ \\
\hline $12.928,00 \mathrm{kWh}$ & $3.624,00 \mathrm{kWh}$ & $2.386,00 \mathrm{kWh}$ & $19.569,00 \mathrm{kWh}$ \\
\hline
\end{tabular}




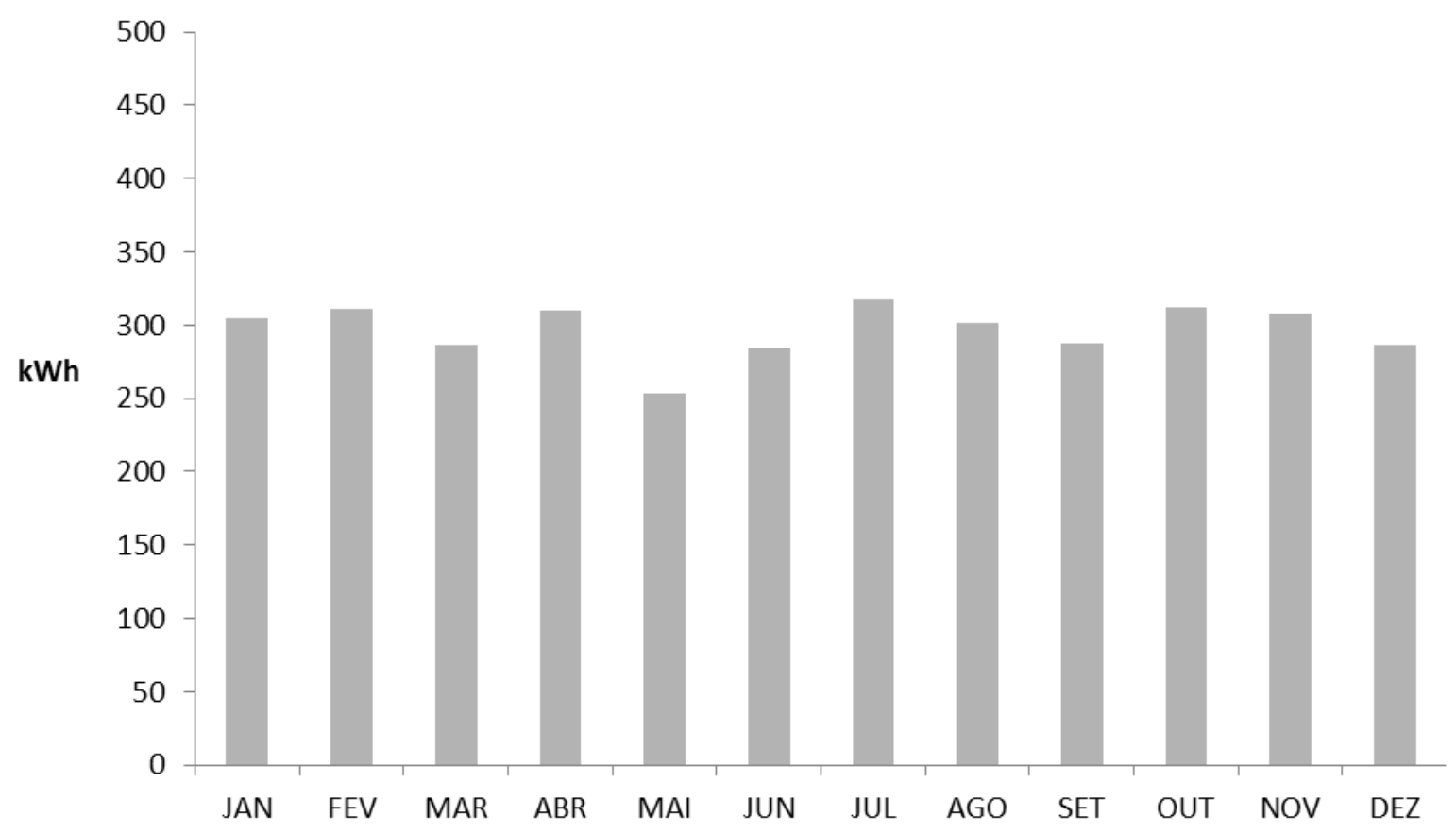

Figura 7.3 - Consumo elétrico mensal dos ventiladores $(\mathrm{kWh}) \times$ meses do ano (cenário 1$)$

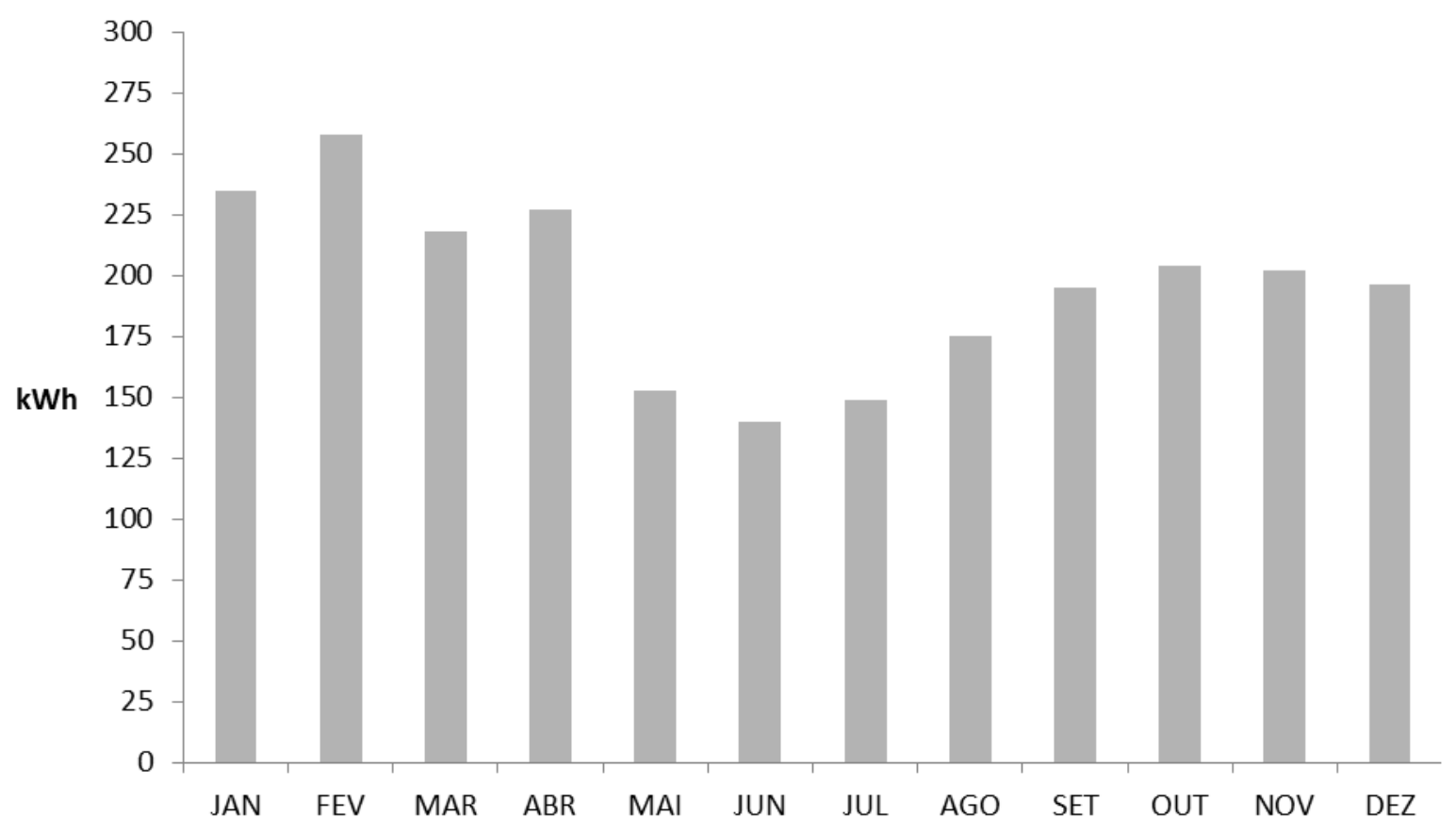

Figura 7.4 - Consumo elétrico mensal do fan coil $(\mathrm{kWh}) \mathrm{x}$ meses do ano (cenário 1) 


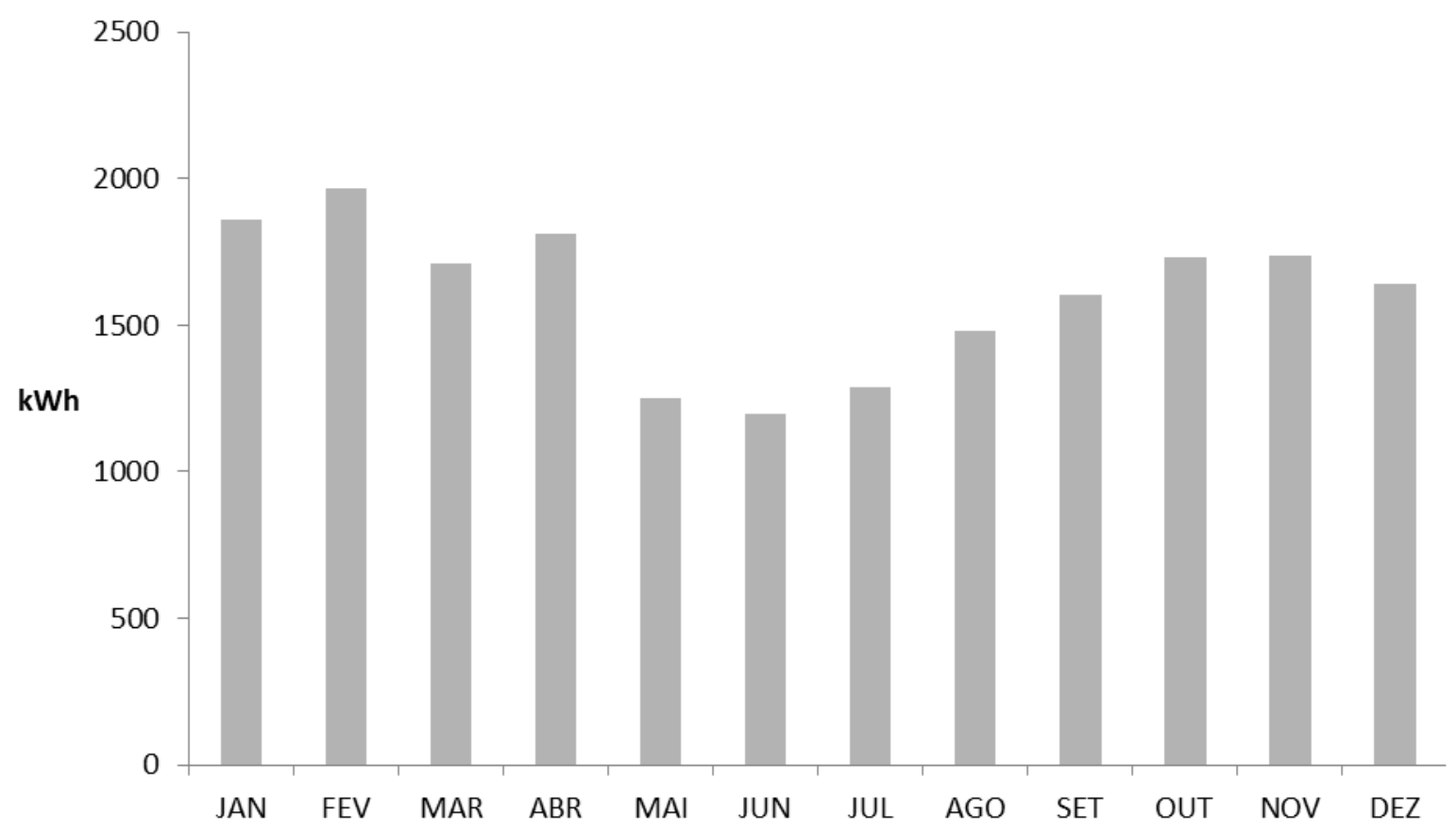

Figura 7.5 - Consumo elétrico mensal do chiller (kWh) x meses do ano (cenário 1)

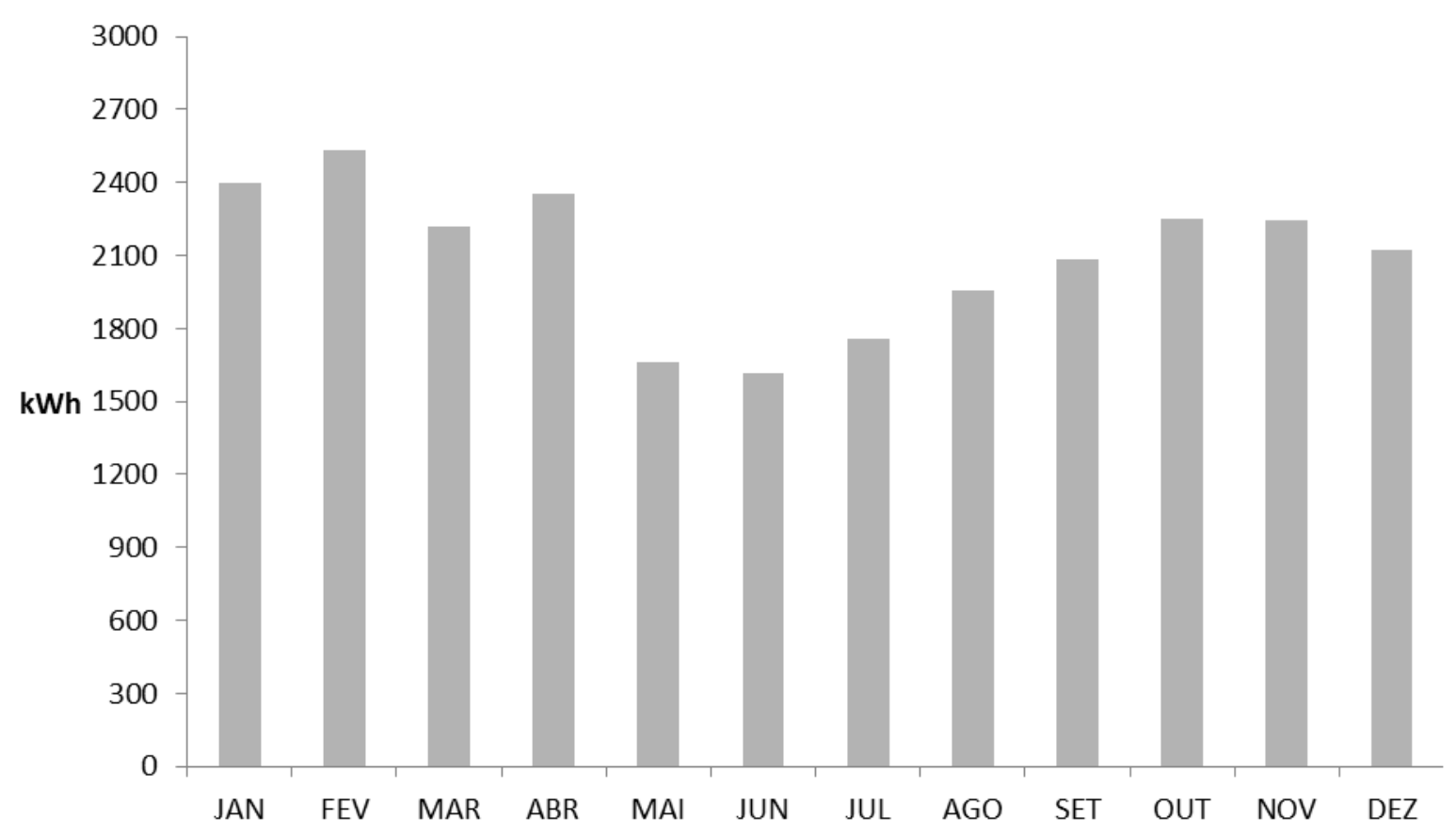

Figura 7.6 - Consumo elétrico mensal total do cenário $1(\mathrm{kWh})$ x meses do ano

\subsection{2 - Cenário 2: Solução com vazão de ar exterior variável $(C O 2=1 ; E R V=0)$}

A Figura 7.7 apresenta o perfil de carga térmica devido ao ar externo de renovação para o cenário em questão ao longo do ano. Claramente é possível observar pelos valores médios diários que a carga térmica de renovação é menor que a carga apresentada no 
cenário 1 (Figura 7.1), devido ao recurso da vazão de ar exterior variável, conforme mostrado na Tabela 7.3:

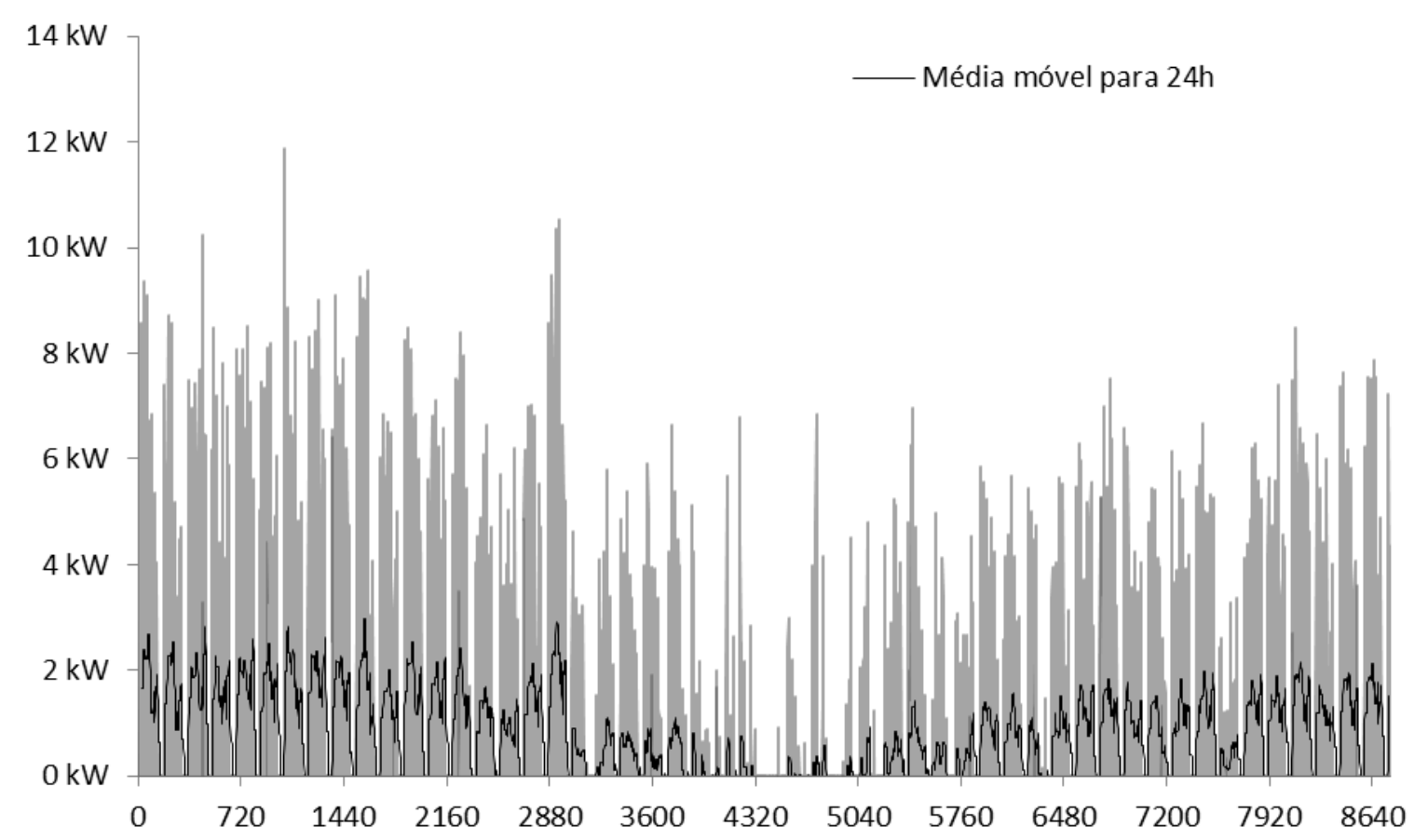

Figura 7.7 - Carga térmica do ar de renovação $(\mathrm{kW}) \mathrm{x}$ horas do ano (cenário 2)

A Tabela 7.3, a seguir, apresenta os valores integralizados ao longo do ano da carga térmica do ar externo de renovação e do consumo de energia elétrica dos ventiladores de renovação de ar, do fan coil, do chiller e o consumo elétrico total do cenário. As Figuras 7.8, 7.9, 7.10 e 7.11 apresentam esses consumos elétricos em cada mês do ano. O perfil referente ao consumo dos ventiladores (Figura 7.8) é praticamente constante ao longo dos meses, uma vez que o perfil de ocupação é semanal, porém, a vazão é variável de acordo com a ocupação, apresentando, assim, valores de consumo elétrico bem abaixo dos apresentados no cenário 1 (Figura 7.3).

Os perfis apresentados pelo consumo dos equipamentos de ar-condicionado e pelo consumo total acompanham o perfil de carga térmica anual (cf. Figura 6.3). O consumo elétrico total desse cenário também é menor que o do cenário 1, conforme mostra a Tabela 7.3: 
Tabela 7.3 - Valores integralizados anuais para o cenário 2

\begin{tabular}{cccc}
\hline $\begin{array}{c}\text { Carga térmica do } \\
\text { ar externo }\end{array}$ & $\begin{array}{c}\text { Consumo elétrico } \\
\text { dos ventiladores }\end{array}$ & $\begin{array}{c}\text { Consumo elétrico } \\
\text { do } \text { fan coil }\end{array}$ & $\begin{array}{c}\text { Consumo elétrico } \\
\text { do } \text { chiller }\end{array}$ \\
\hline $8.213,00 \mathrm{kWh}$ & $1.625,00 \mathrm{kWh}$ & $2.210,00 \mathrm{kWh}$ & $18.598,00 \mathrm{kWh}$ \\
\hline
\end{tabular}

Consumo elétrico total

22.435,00 kWh

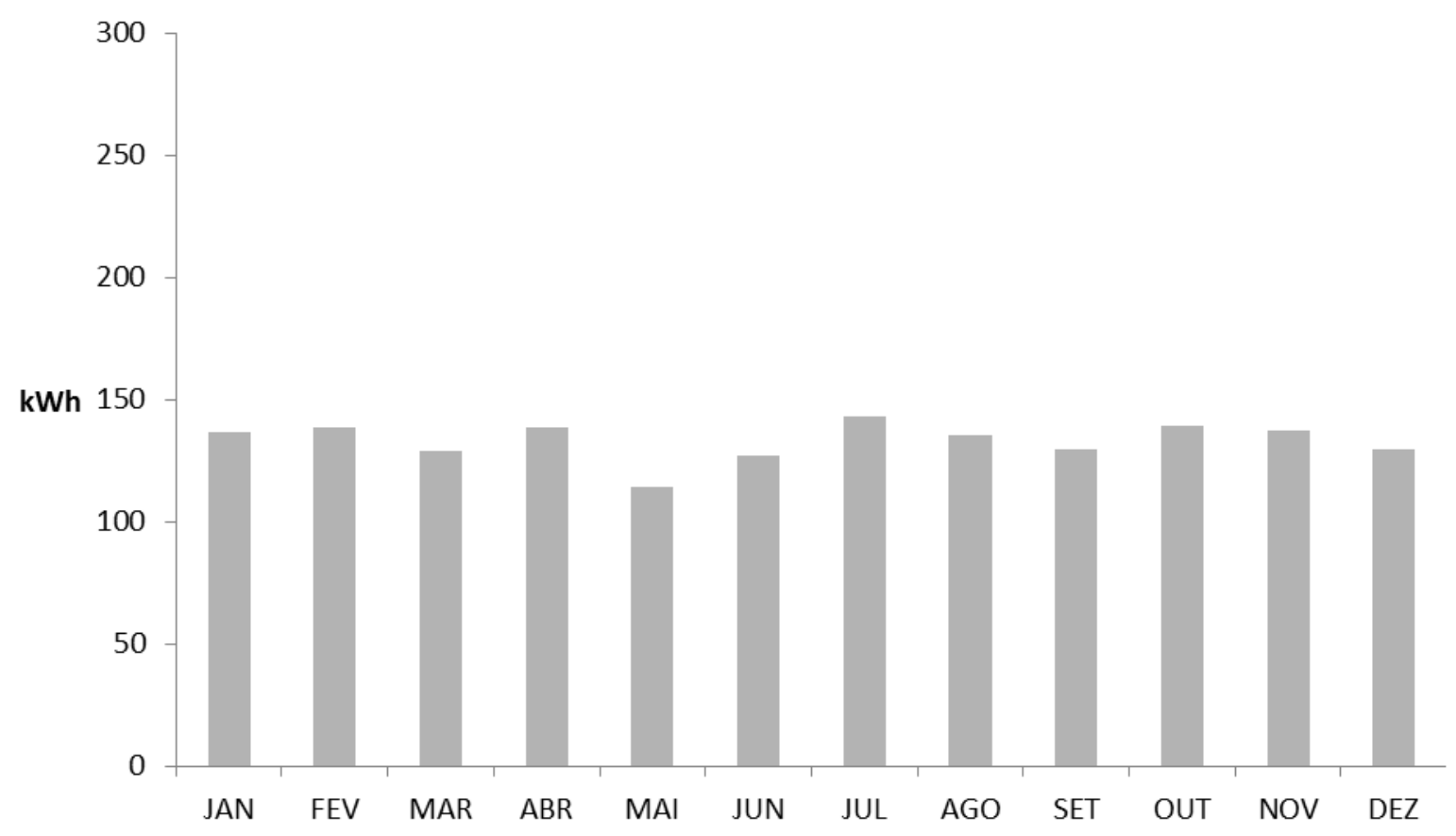

Figura 7.8 - Consumo elétrico mensal dos ventiladores $(\mathrm{kWh})$ x meses do ano (cenário 2)

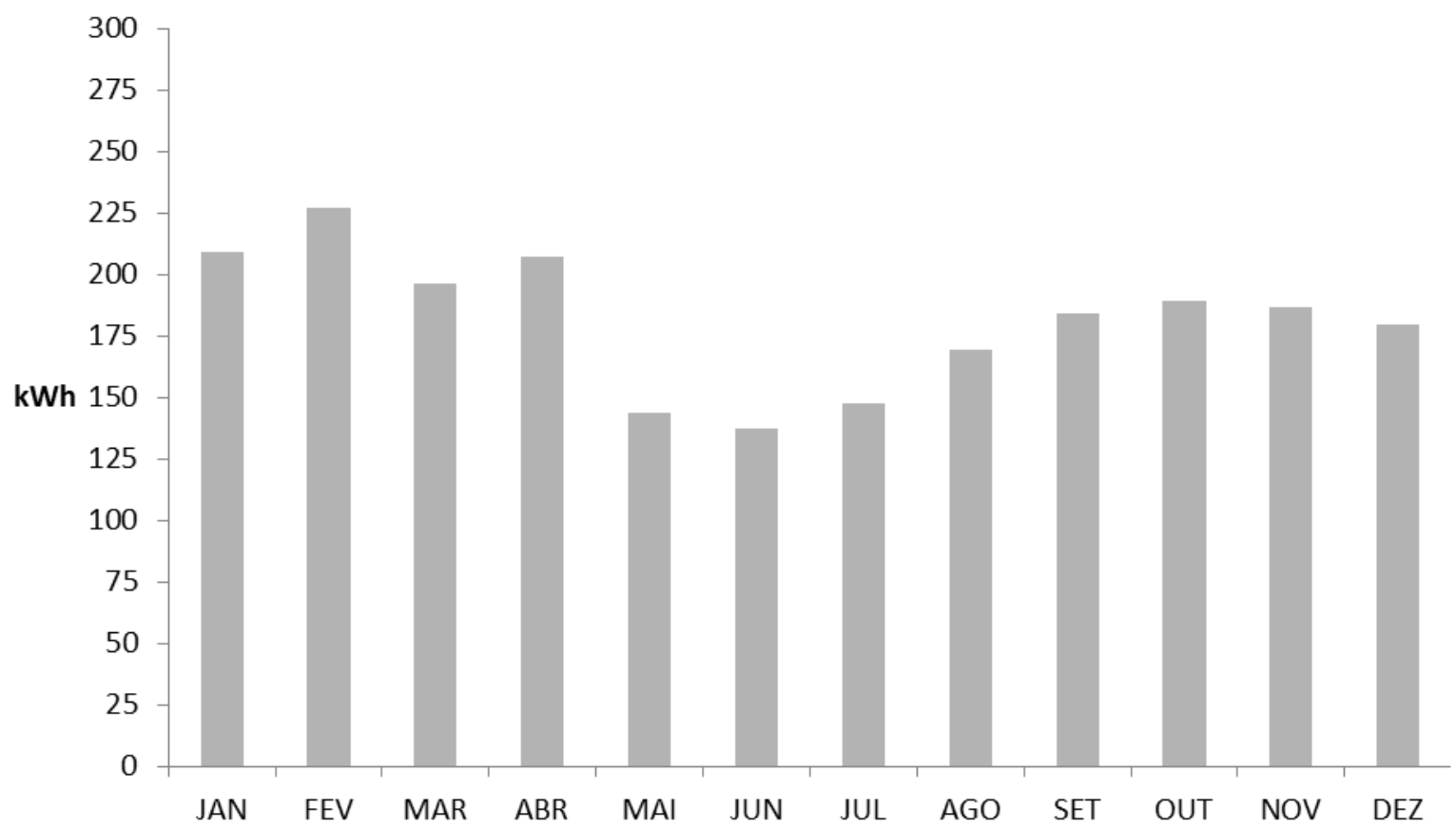

Figura 7.9 - Consumo elétrico mensal do fan coil $(\mathrm{kWh})$ x meses do ano (cenário 2) 


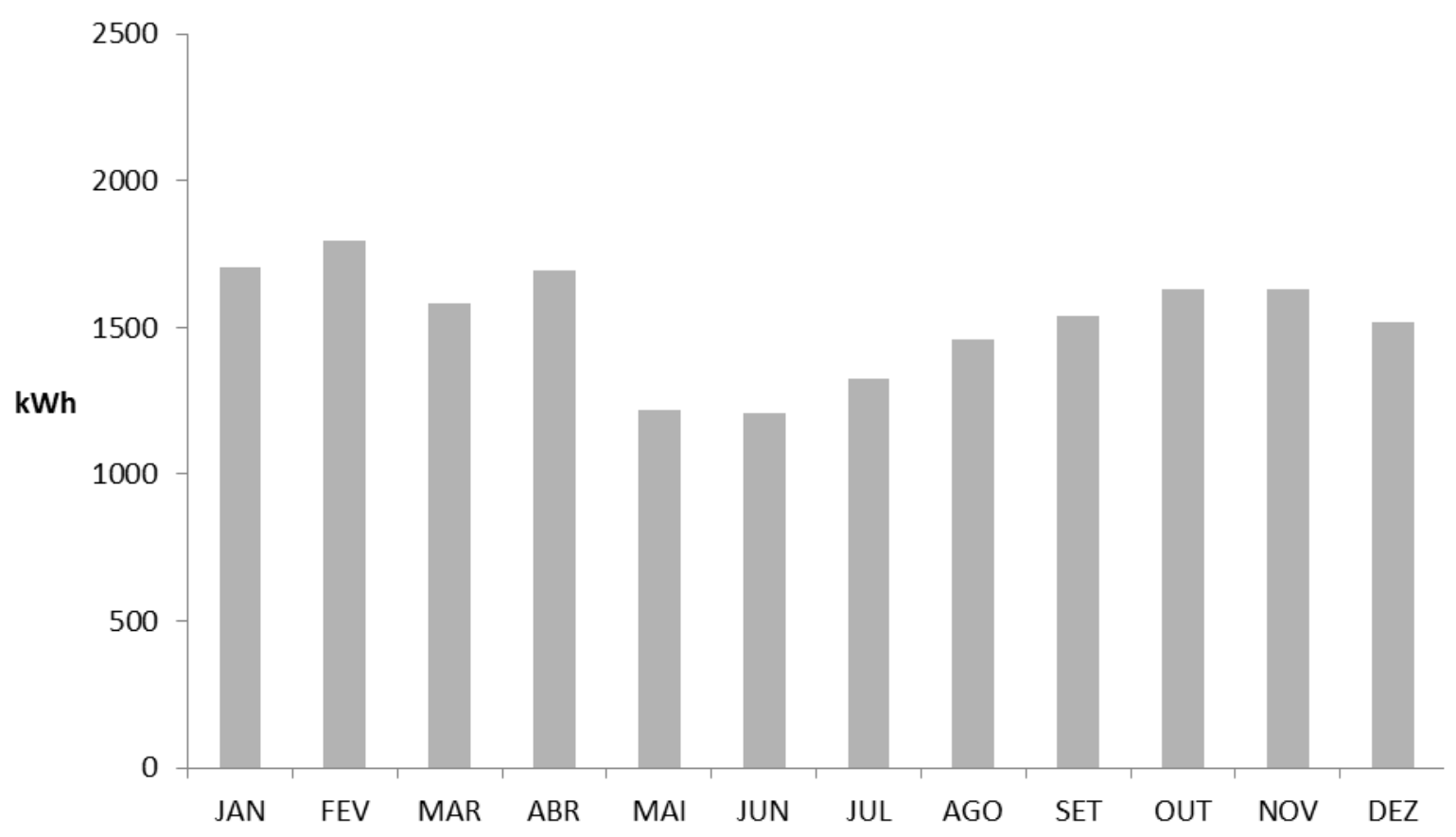

Figura 7.10 - Consumo elétrico mensal do chiller (kWh) x meses do ano (cenário 2)

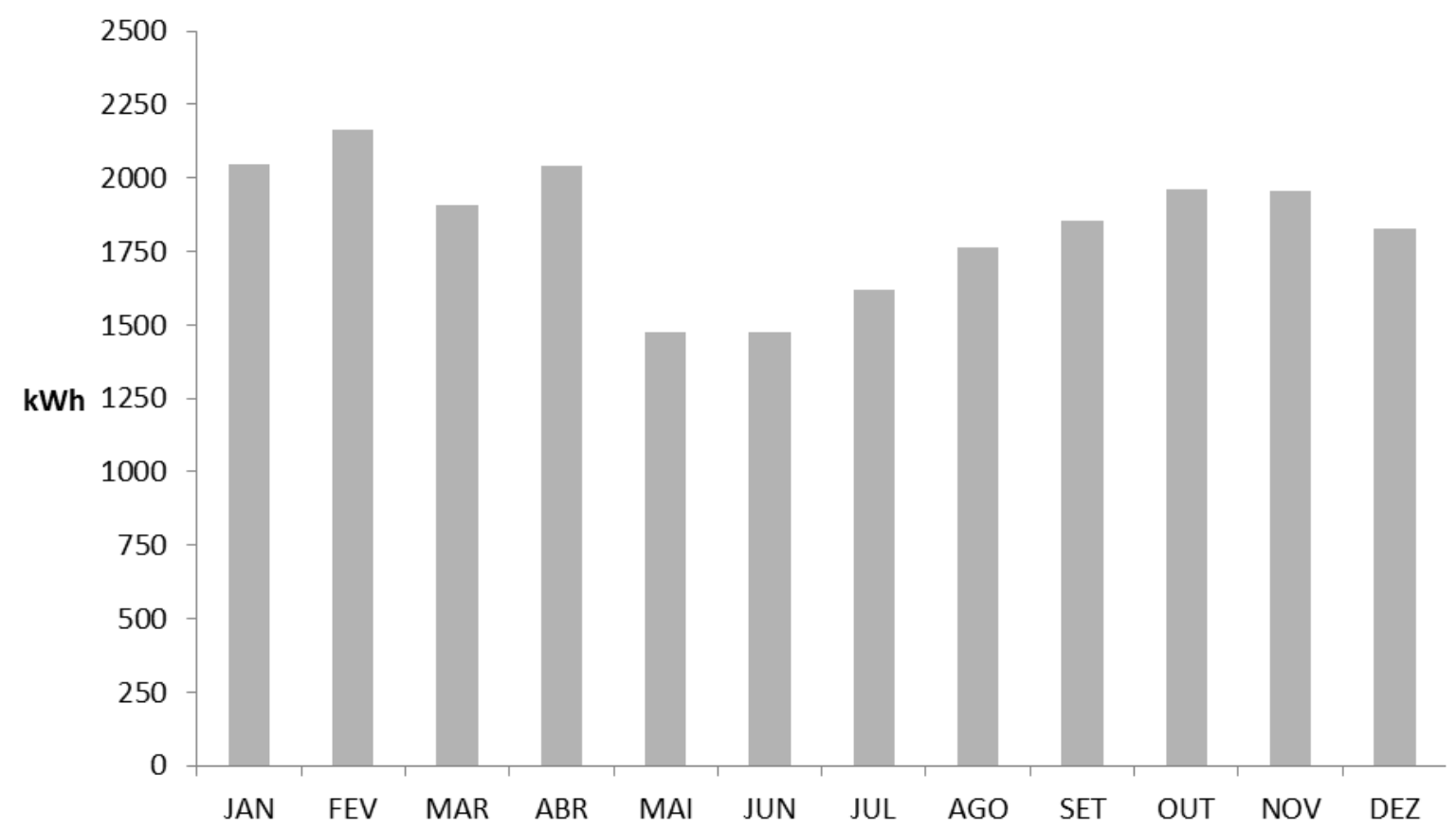

Figura 7.11 - Consumo elétrico mensal total $(\mathrm{kWh})$ x meses do ano (cenário 2)

\subsection{3 - Cenário 3: Solução com recuperação de energia $(\mathrm{CO2}=0 ; \mathrm{ERV}=1)$}

A Figura 7.12 apresenta o perfil de carga térmica devido ao ar externo de renovação para o cenário em questão ao longo do ano, que apresenta valores médios menores que os apresentados nos cenários 1 e 2. A Figura 7.13, por sua vez, apresenta os valores de 
entalpia do ar exterior, do ar interno e do ar na saída do ERV, mostrando claramente a redução da entalpia do ar externo que sai do ERV e adentra o ambiente condicionado, reduzindo a carga térmica do ar de renovação em grande parte do ano:

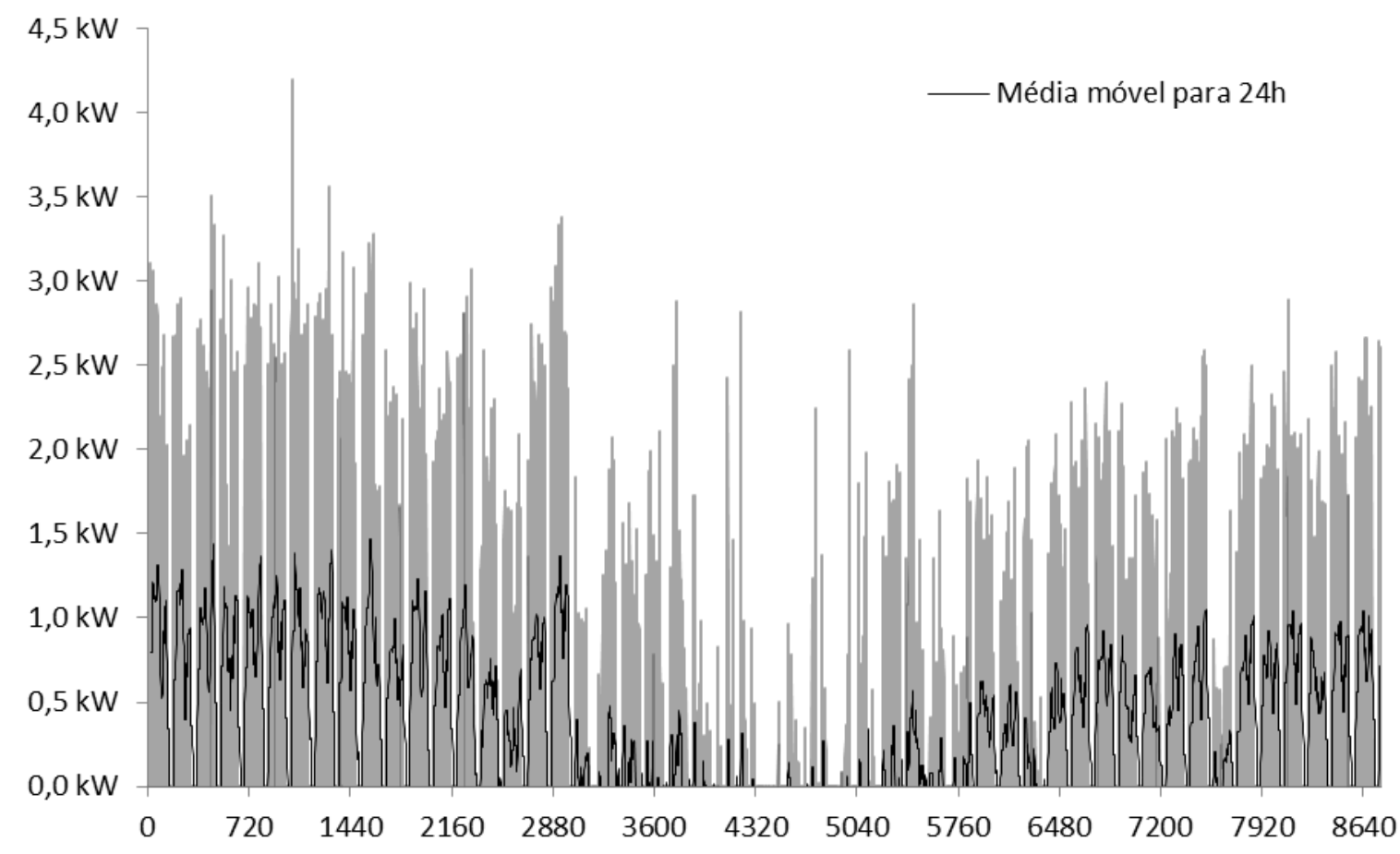

Figura 7.12 - Carga térmica do ar de renovação $(\mathrm{kW})$ x horas do ano (cenário 3)

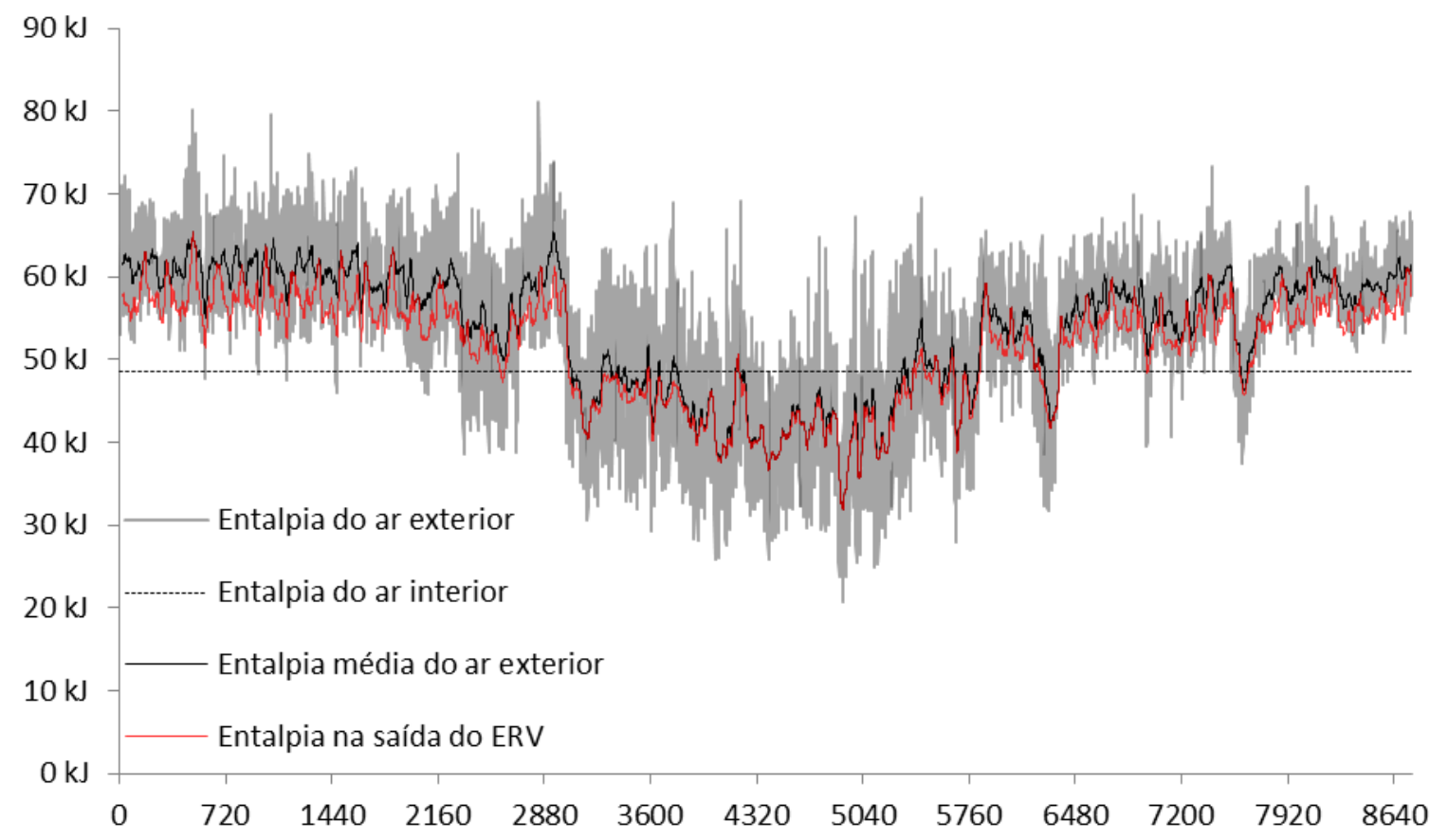

Figura 7.13 - Entalpia do ar externo e interno (kJ/kg) x horas do ano (cenário 3) 
Pela análise dos gráficos também é possível observar que a recuperação de energia se dá apenas nos meses cujos valores da entalpia média do ar externo são maiores que o valor da entalpia do ar interno, ocorrendo nos meses de janeiro a abril e de setembro a dezembro. No período de maio a agosto, que compreende o fim do outono e o inverno, a recuperação de energia apresenta valores bem menores, uma vez que a entalpia média do ar externo é menor que a do ar interno na maior parte do período compreendido, conforme mostra a Figura 7.14:

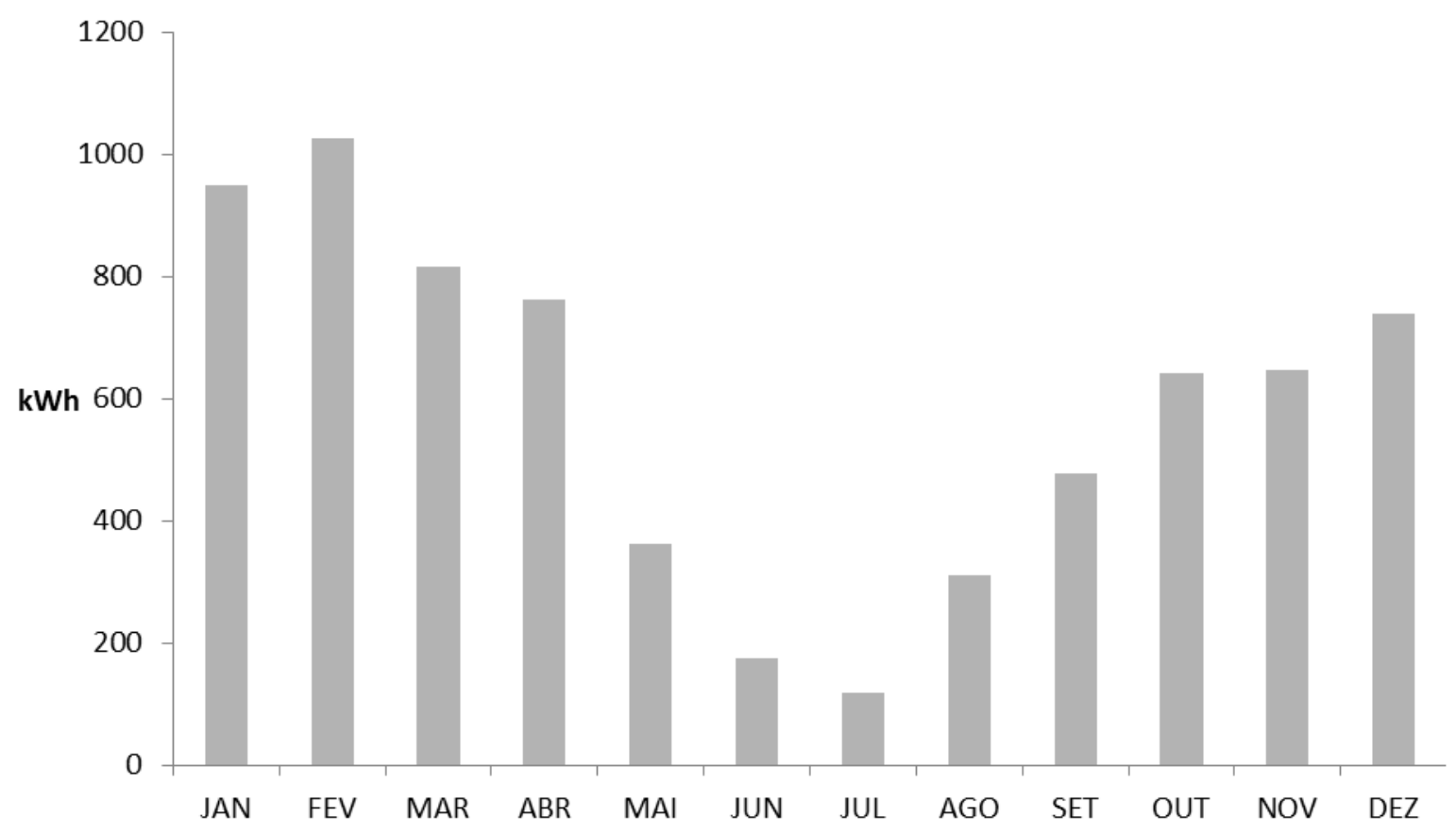

Figura 7.14 - Energia recuperada no VER (kWh) x horas do ano (cenário 3)

A Tabela 7.4, a seguir, apresenta os valores integralizados ao longo do ano da carga térmica do ar externo de renovação e do consumo de energia elétrica dos ventiladores de renovação de ar, do fan coil, do chiller e o consumo elétrico total do cenário. As Figuras 7.15, 7.16, 7.17 e 7.18 apresentam esses consumos elétricos em cada mês do ano. O perfil referente ao consumo dos ventiladores (Figura 7.15) é praticamente constante ao longo dos meses, uma vez que o perfil de ocupação é semanal e a vazão de ar externo é sempre constante e igual ao valor máximo. As pequenas diferenças são devido às diferenças dos dias da semana que compõem cada mês, gerando uma pequena diferença na ocupação acumulada mensal. O valor total do consumo elétrico dos ventiladores é igual ao consumo apresentado no cenário 1, uma vez que ambos os cenários não possuem controle de vazão do ar exterior. 
Os perfis apresentados pelo consumo dos equipamentos de ar-condicionado e pelo consumo total acompanham o perfil de carga térmica anual (cf. Figura 6.3). O consumo elétrico total desse cenário também é menor que os consumos dos cenários $1 \mathrm{e} 2$, conforme mostra a Tabela 7.4. Esse se fato se dá pela maior redução da carga térmica do ar de renovação, o que, consequentemente, reduziu o consumo dos equipamentos do sistema de ar condicionado:

Tabela 7.4 - Valores integralizados anuais para o cenário 3

\begin{tabular}{cccc}
\hline $\begin{array}{c}\text { Carga térmica do } \\
\text { ar externo }\end{array}$ & $\begin{array}{c}\text { Consumo elétrico } \\
\text { dos ventiladores }\end{array}$ & $\begin{array}{c}\text { Consumo elétrico } \\
\text { do fan coil }\end{array}$ & $\begin{array}{c}\text { Consumo elétrico } \\
\text { do chiller }\end{array}$ \\
\hline $5.102,00 \mathrm{kWh}$ & $3.624,00 \mathrm{kWh}$ & $1.773,00 \mathrm{kWh}$ & $15.034,00 \mathrm{kWh}$ \\
\hline
\end{tabular}

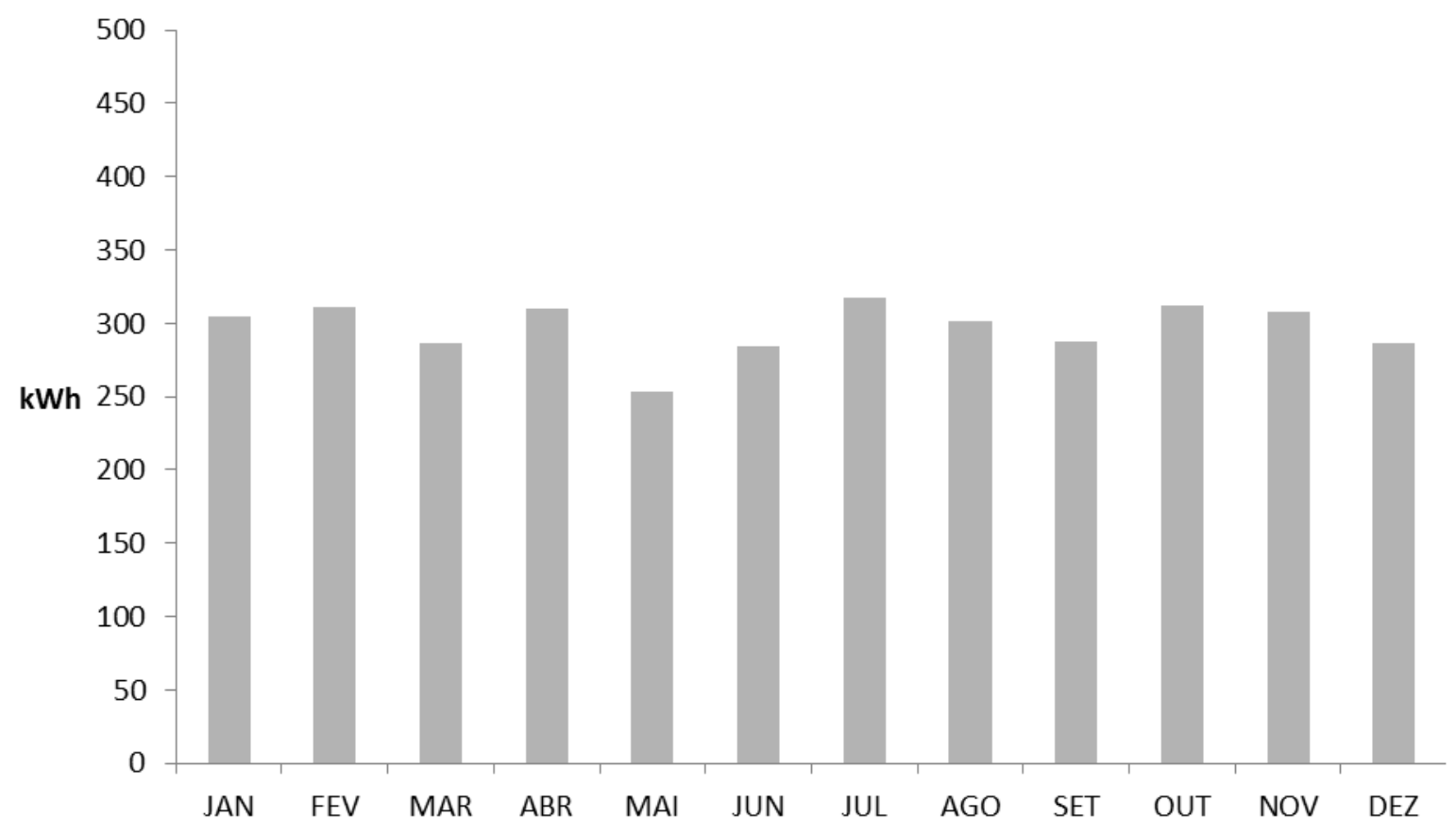

Figura 7.15 - Consumo elétrico mensal dos ventiladores $(\mathrm{kWh}) \mathrm{x}$ horas do ano para o cenário 3 


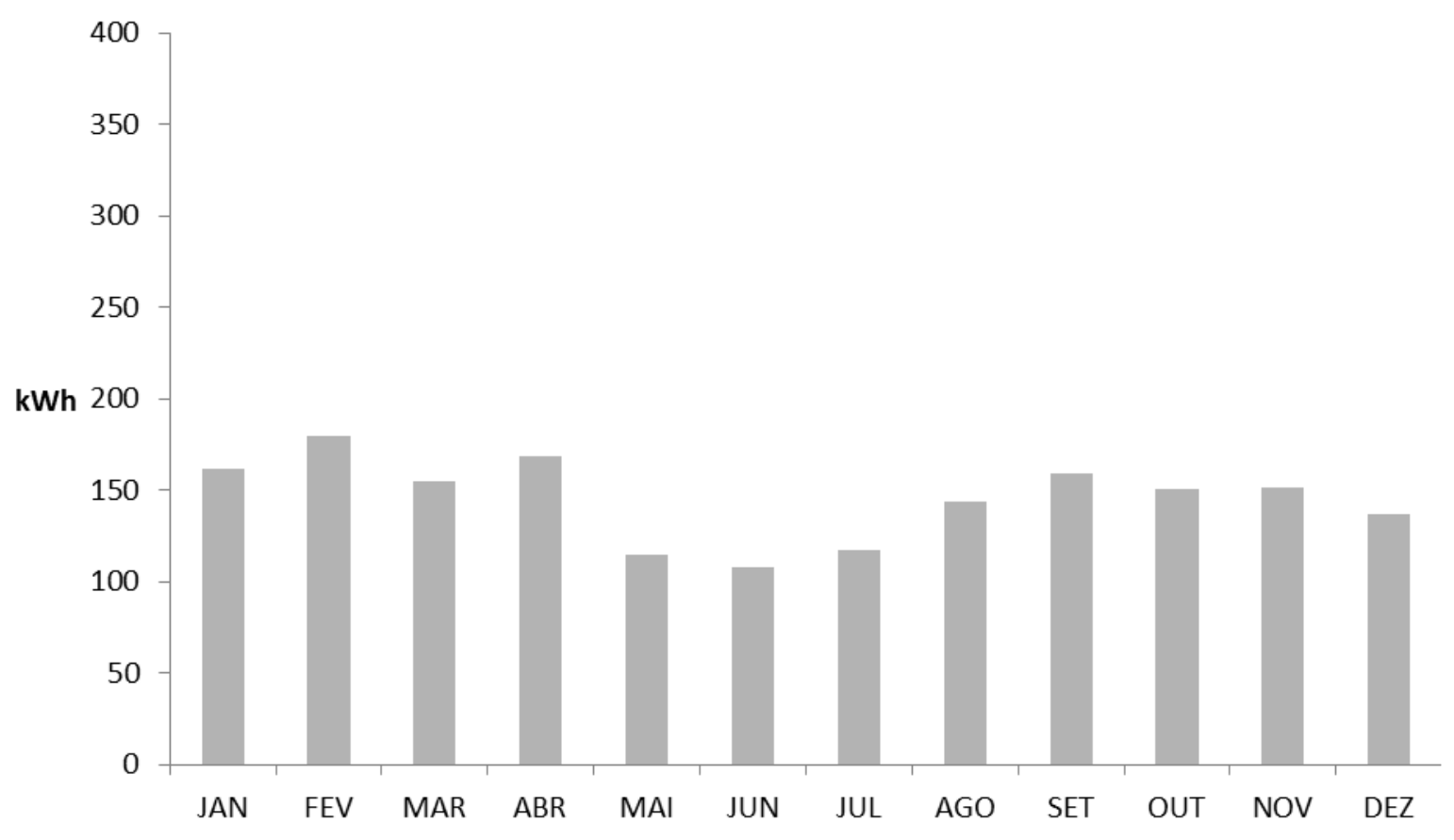

Figura 7.16 - Consumo elétrico mensal do fan coil $(\mathrm{kWh}) \mathrm{x}$ horas do ano (cenário 3)

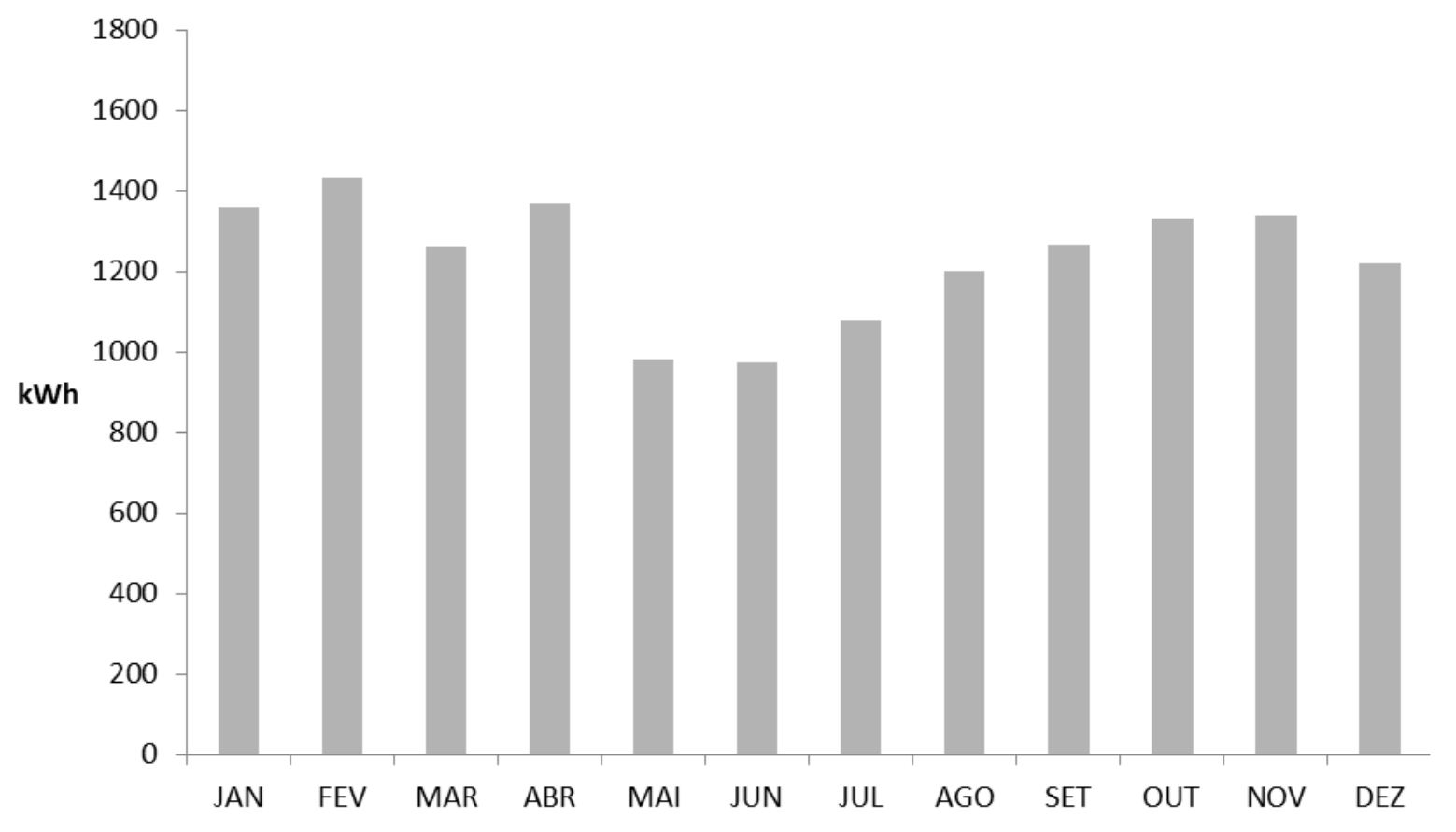

Figura 7.17 - Consumo elétrico mensal do chiller $(\mathrm{kWh})$ x meses do ano (cenário 3) 


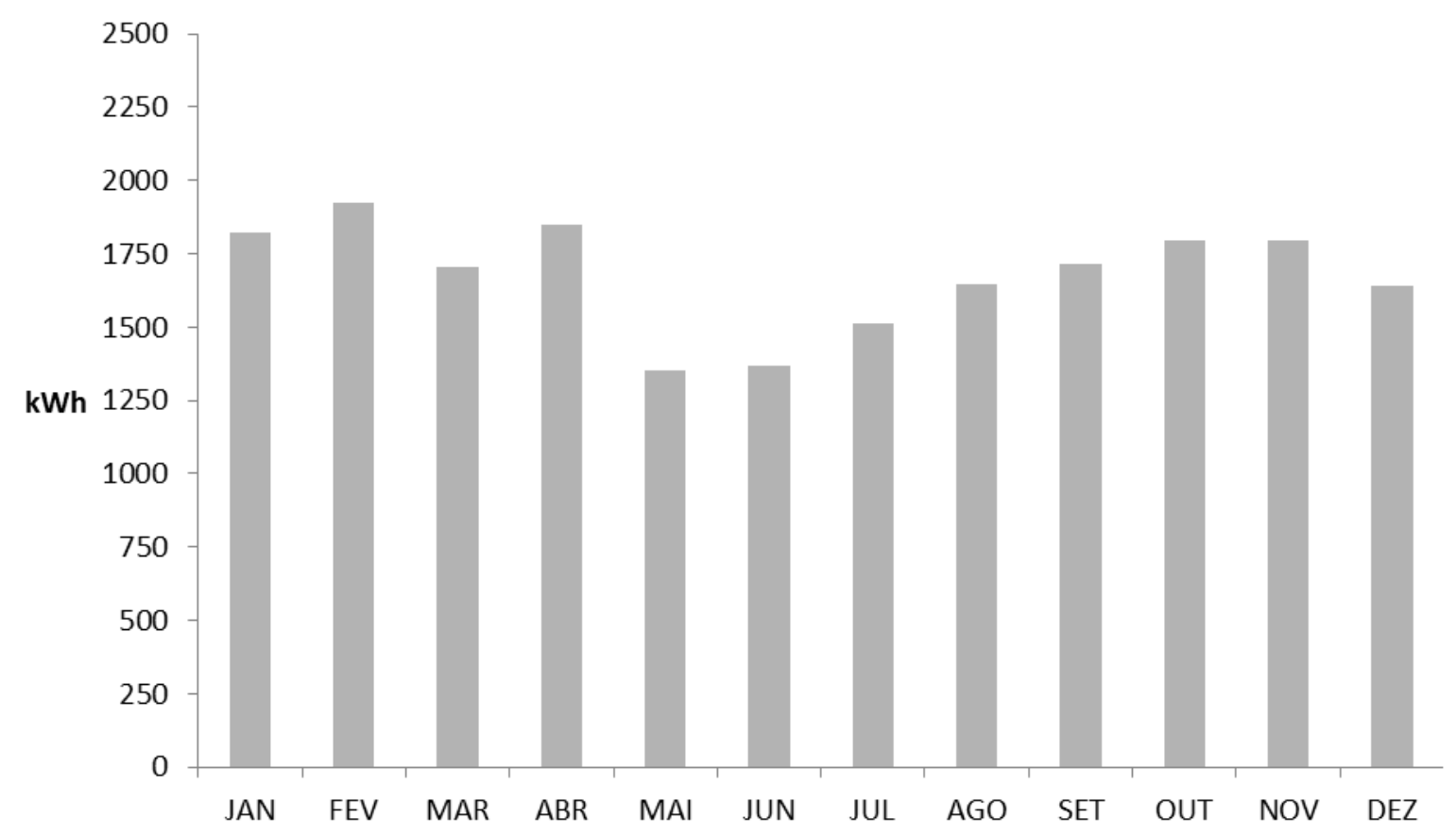

Figura 7.18 - Consumo elétrico mensal total do cenário $3(\mathrm{kWh})$ x meses do ano

\subsection{4 - Cenário 4: Solução completa $(\mathrm{CO2=1;ERV=1)}$}

A Figura 7.19 apresenta o perfil de carga térmica devido ao ar externo de renovação para o cenário em questão ao longo do ano, que apresenta valores médios menores que os apresentados nos cenários 1,2 e 3:

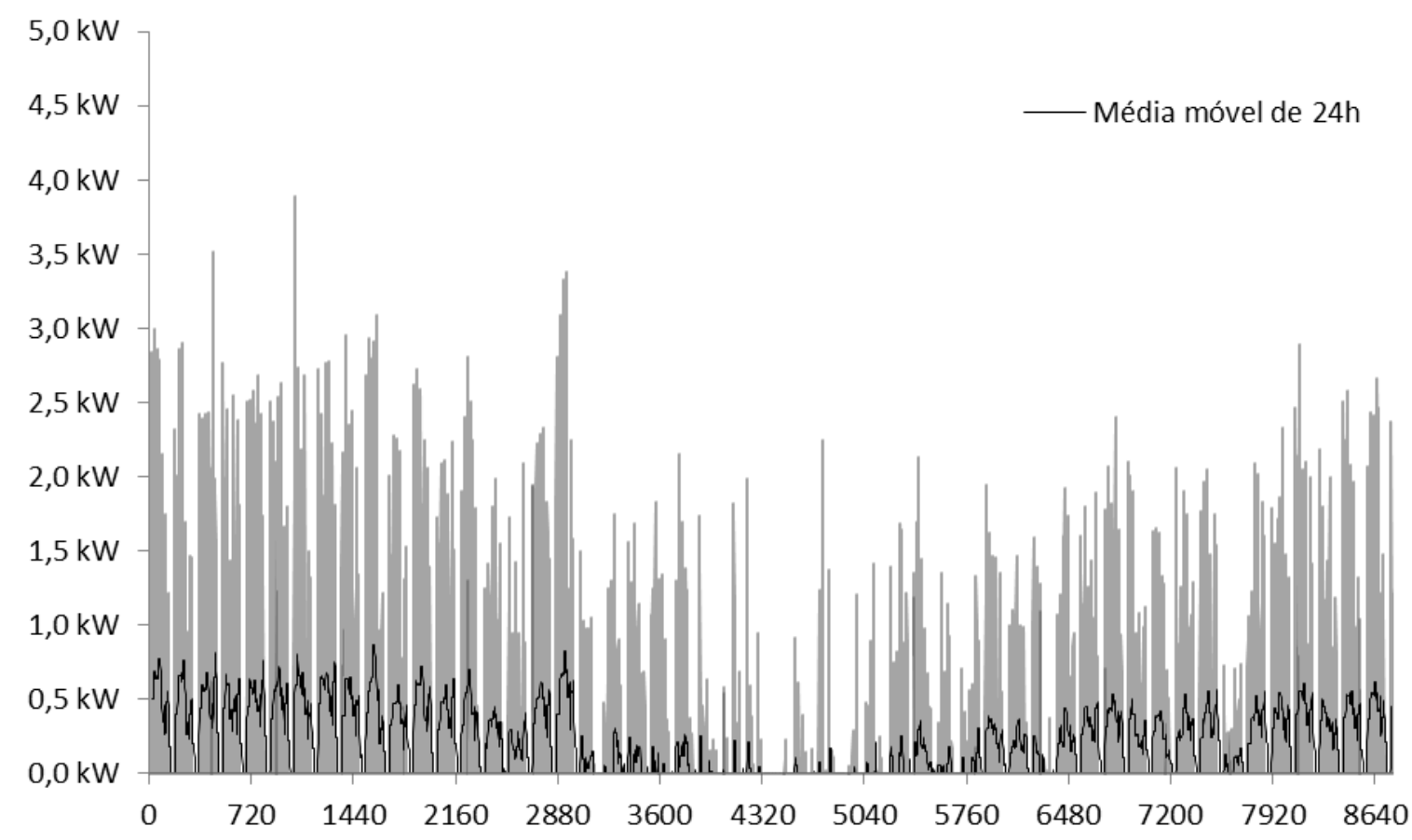

Figura 7.19 - Carga térmica do ar de renovação $(\mathrm{kW})$ x horas do ano (cenário 4) 
A Figura 7.20 apresenta os valores de entalpia do ar exterior, do ar interno e do ar na saída do ERV, mostrando claramente a redução da entalpia do ar externo que adentra o ambiente condicionado, reduzindo a carga térmica do ar de renovação em grande parte do ano:

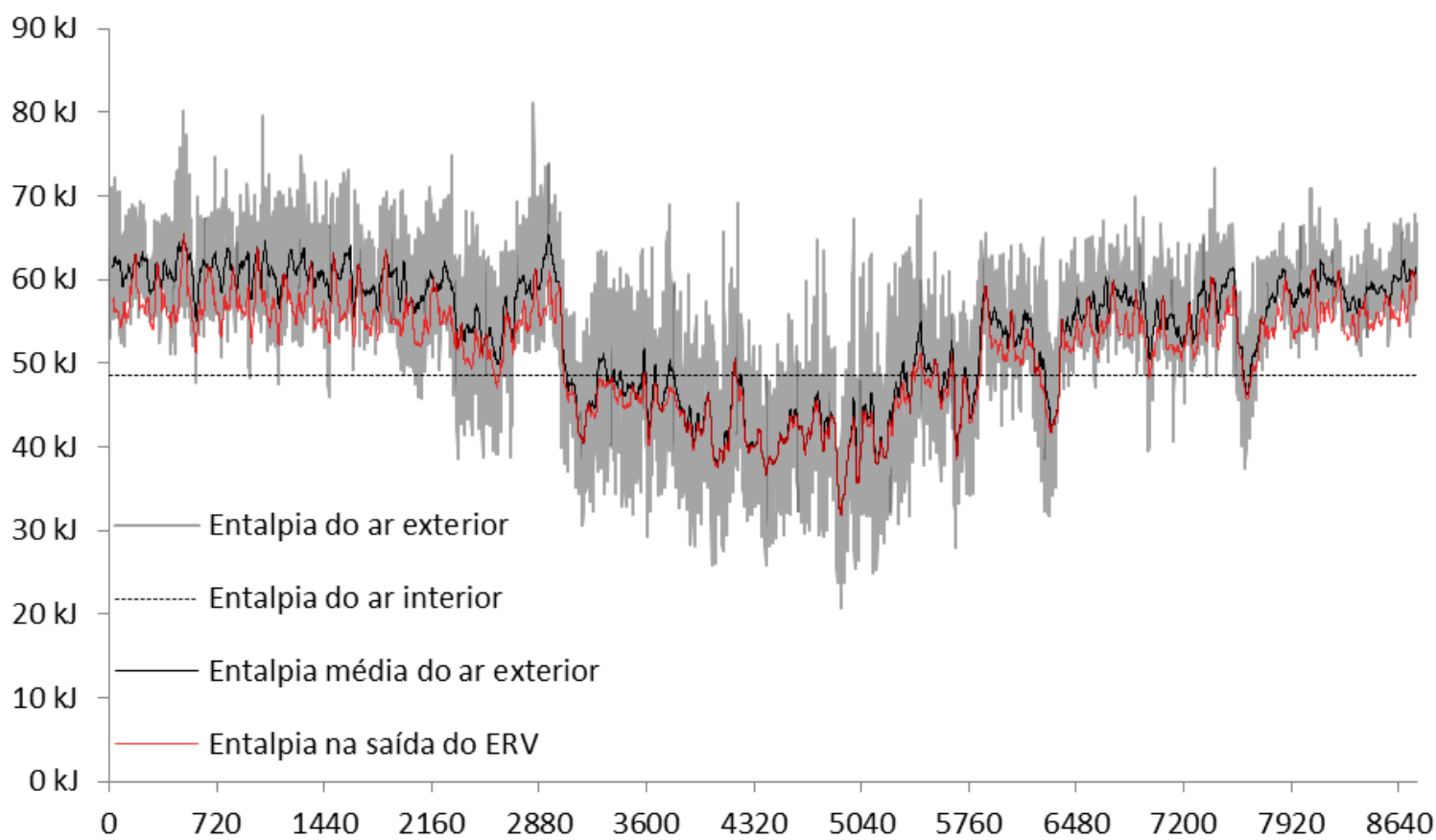

Figura 7.20 - Entalpia do ar externo e interno $(\mathrm{kJ} / \mathrm{kg})$ x horas do ano (cenário 4)

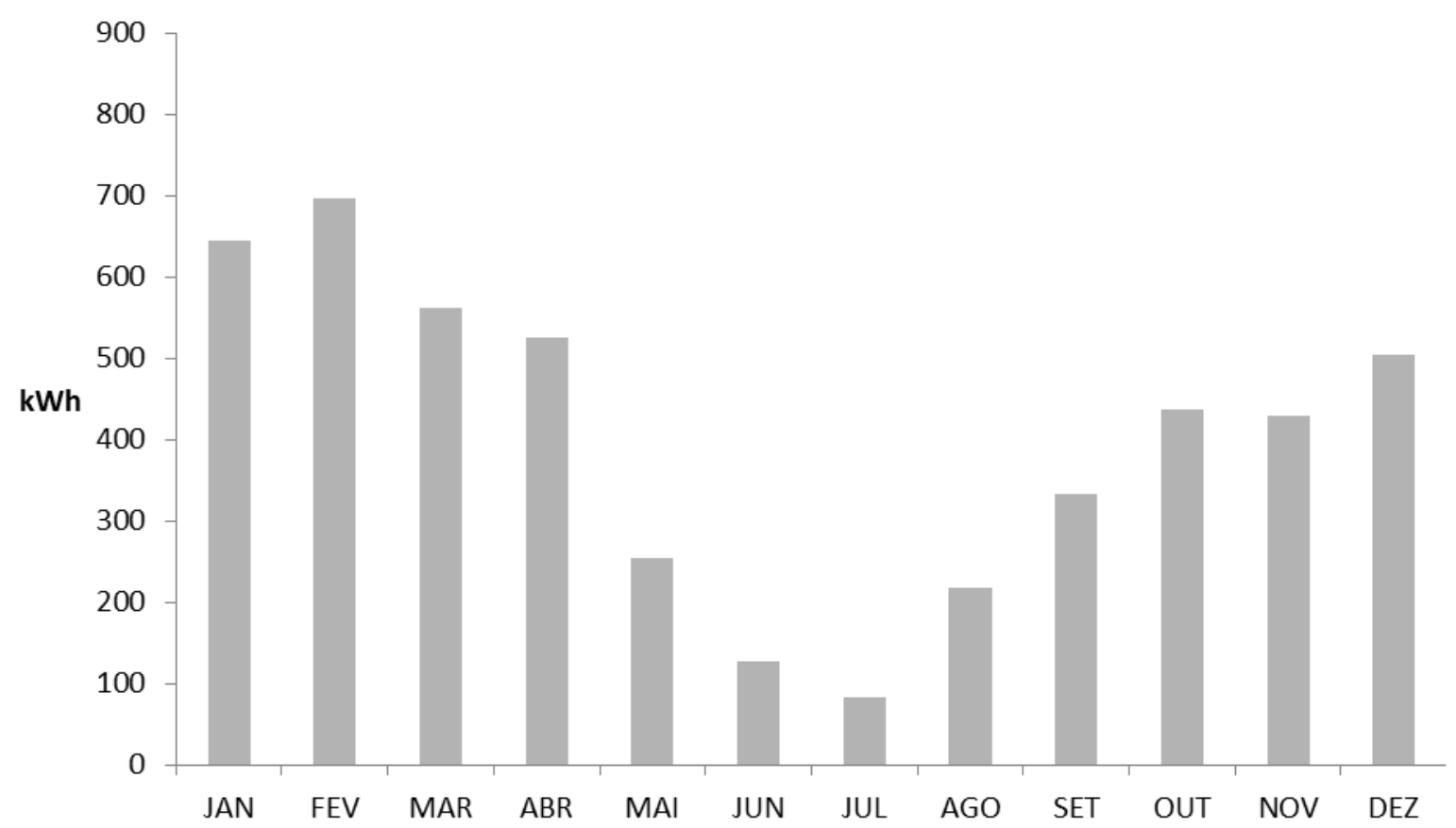

Figura 7.21 - Energia recuperada no ERV $(\mathrm{kWh})$ x meses do ano (cenário 4) 
Pela análise dos gráficos também é possível notar que a recuperação de energia se dá apenas nos meses cujos valores da entalpia média do ar externo são maiores que o valor da entalpia do ar interno, ocorrendo nos meses de janeiro a abril e de setembro a dezembro. No período de maio a agosto, que compreende o fim do outono e o inverno, a recuperação de energia apresenta valores bem menores, uma vez que a entalpia média do ar externo é menor que a do ar interno na maior parte do período compreendido, conforme demonstrado na Figura 7.21. A partir dessa figura também é possível verificar que os valores médios de energia recuperada no ERV são menores nesse cenário que os valores apresentados no cenário 3 (cf. Figura 7.14), uma vez que as vazões médias são menores, já que há controle de vazão de ar exterior.

A Tabela 7.5, abaixo, apresenta os valores integralizados ao longo do ano da carga térmica do ar externo de renovação e do consumo de energia elétrica dos ventiladores de renovação de ar, do fan coil, do chiller e o consumo elétrico total do cenário. As Figuras 7.22, 7.23, 7.24 e 7.25 apresentam esses consumos elétricos em cada mês do ano. O perfil referente ao consumo dos ventiladores (Figura 7.22) é praticamente constante ao longo dos meses, uma vez que o perfil de ocupação é semanal e a vazão de ar externo é sempre constante e igual ao valor máximo. As pequenas diferenças são devido às diferenças dos dias da semana que compõem cada mês, gerando uma pequena diferença na ocupação acumulada mensal. O valor total do consumo elétrico dos ventiladores é igual ao consumo apresentado no cenário 2 , uma vez que ambos os cenários possuem controle de vazão do ar exterior.

Os perfis apresentados pelo consumo dos equipamentos de ar-condicionado e pelo consumo total acompanham o perfil de carga térmica anual (cf. Figura 6.3). O consumo elétrico total desse cenário também é menor que os consumos dos cenários 1,2 e 3 , conforme mostra a Tabela 7.5, abaixo. Esse fato se dá pela maior redução da carga térmica do ar de renovação, devido aos recursos da recuperação de energia e controle de vazão do ar exterior, o que, consequentemente, reduziu o consumo dos equipamentos do sistema de ar condicionado:

Tabela 7.5 - Valores integralizados anuais para o cenário 4

\begin{tabular}{cccc}
\hline $\begin{array}{c}\text { Carga térmica do } \\
\text { ar externo }\end{array}$ & $\begin{array}{c}\text { Consumo elétrico } \\
\text { dos ventiladores }\end{array}$ & $\begin{array}{c}\text { Consumo elétrico } \\
\text { do } \text { fan coil }\end{array}$ & $\begin{array}{c}\text { Consumo elétrico } \\
\text { do } \text { chiller }\end{array}$ \\
\hline $2.852,00 \mathrm{kWh}$ & $1.625,00 \mathrm{kWh}$ & $1.695,00 \mathrm{kWh}$ & $14.778,00 \mathrm{kWh}$ \\
\hline
\end{tabular}




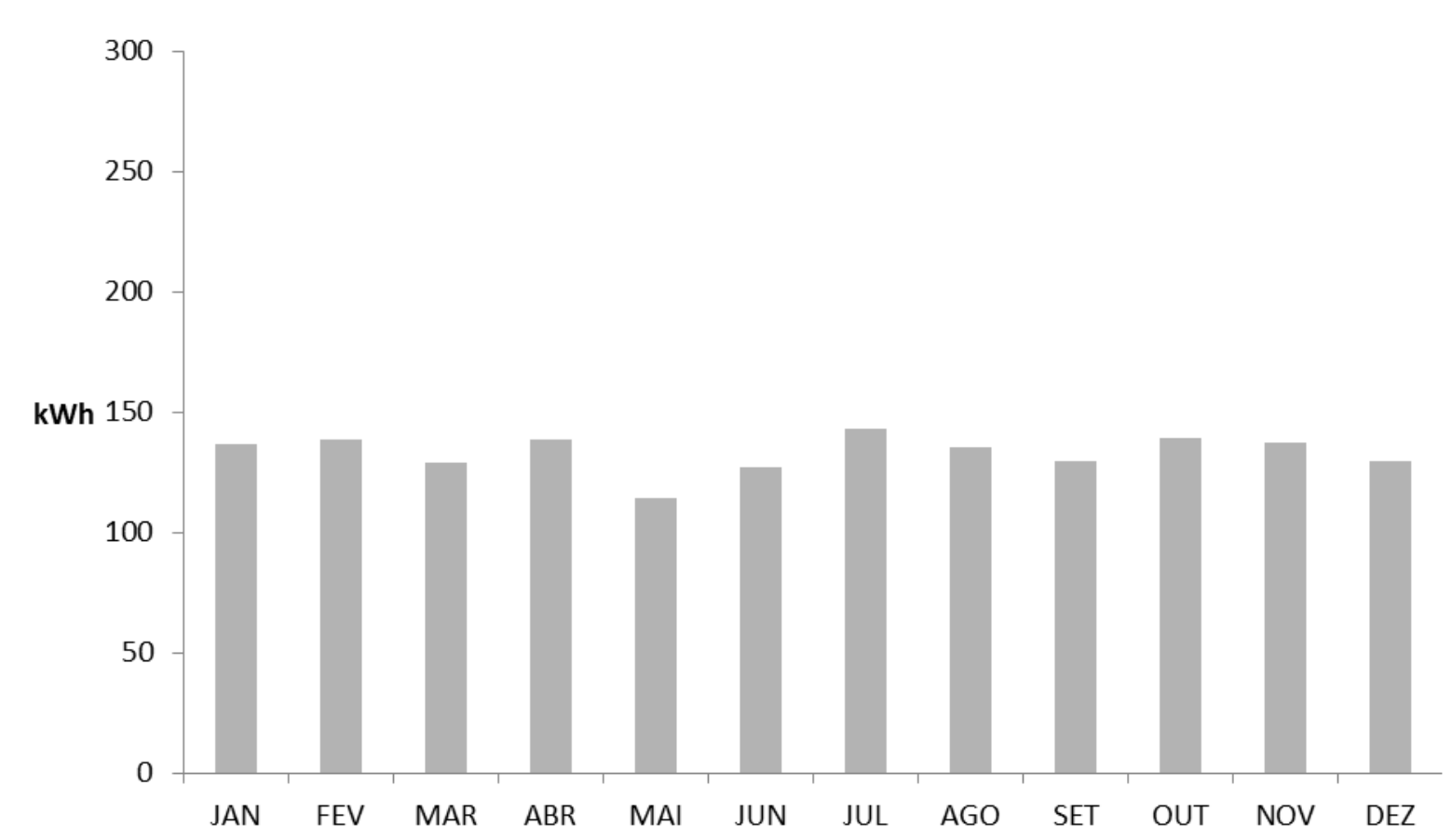

Figura 7.22 - Consumo elétrico mensal dos ventiladores (kWh) x meses do ano (cenário 4)

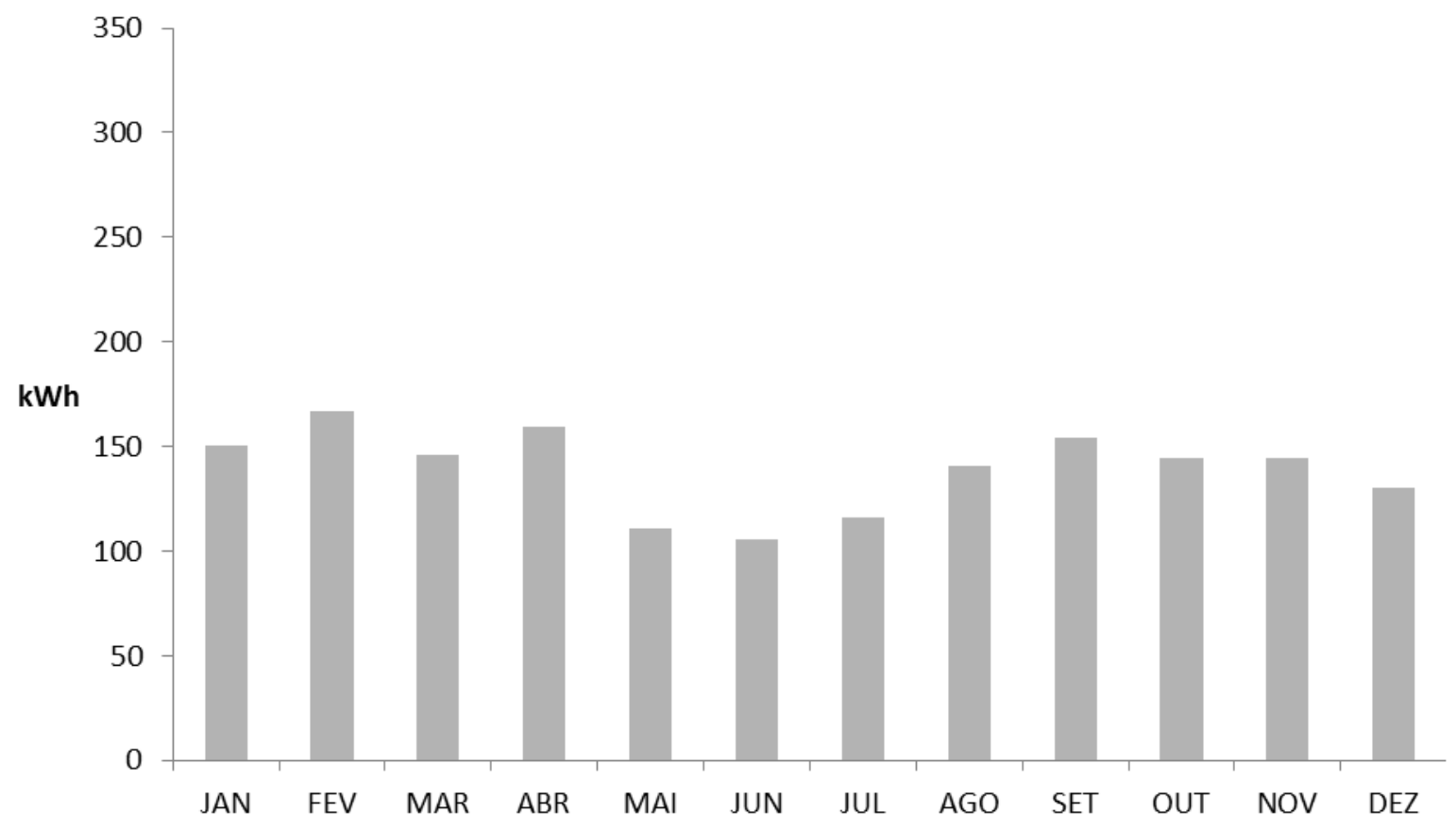

Figura 7.23 - Consumo elétrico mensal do fan coil (kWh) x meses do ano (cenário 4) 


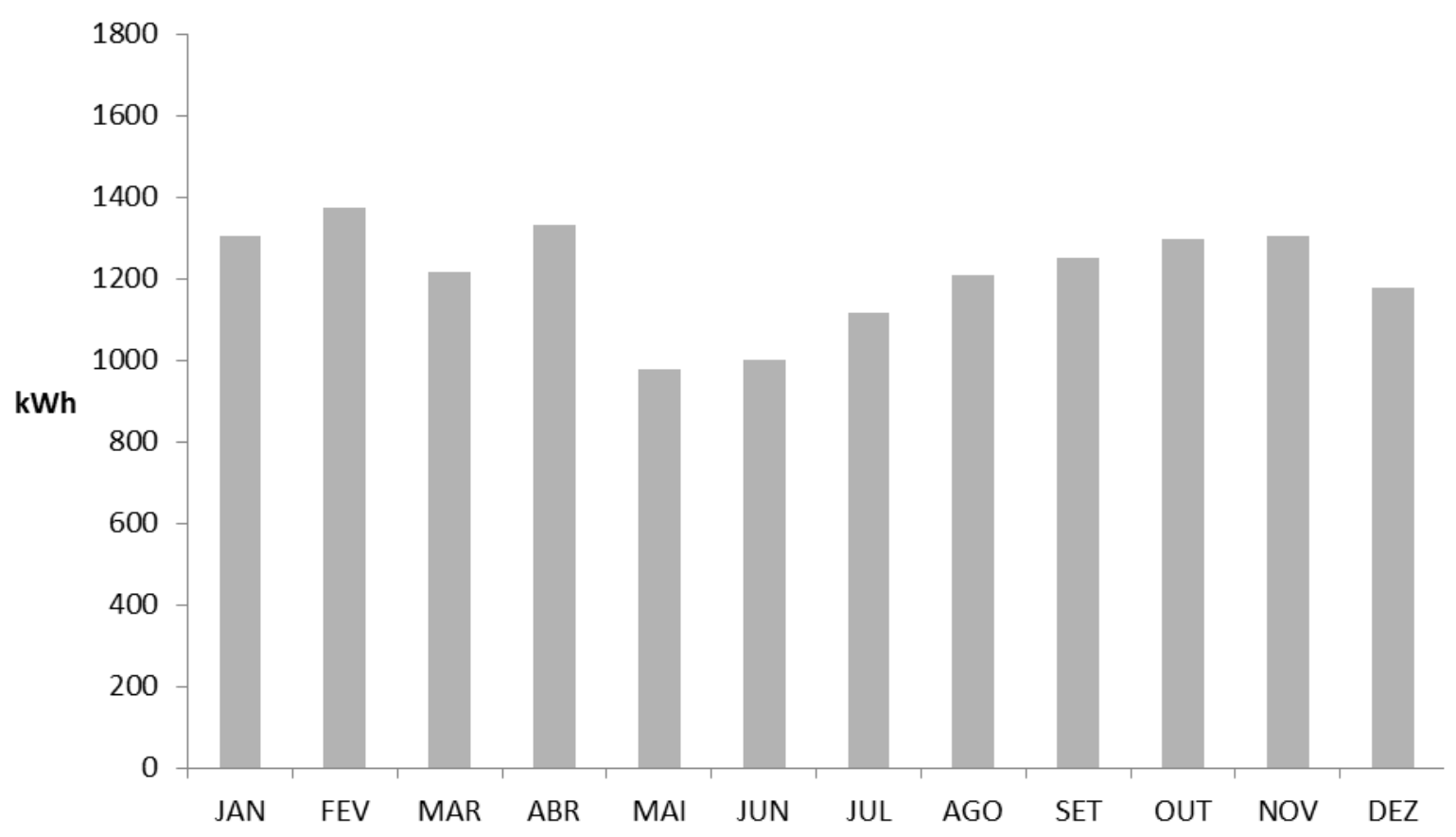

Figura 7.24 - Consumo elétrico mensal do chiller (kWh) x meses do ano (cenário 4)

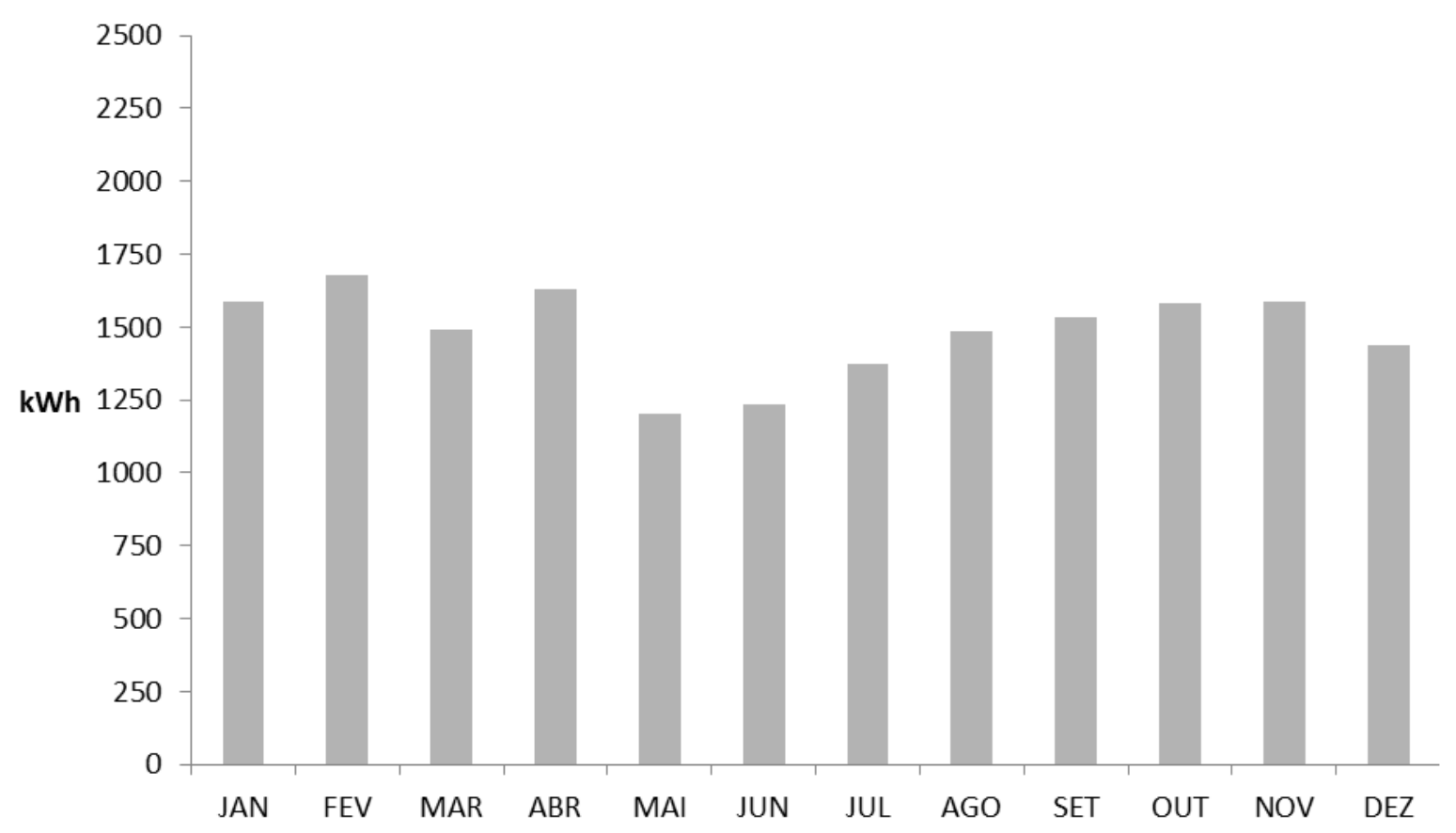

Figura 7.25 - Consumo elétrico mensal total $(\mathrm{kWh})$ x meses do ano (cenário 4)

\subsection{5 - Comparação entre os cenários}

A partir dos resultados apresentados é possível realizar uma análise comparativa com o objetivo de verificar a economia de energia proporcionada pelos recursos 
apresentados em cada cenário, relacionando essa economia aos custos iniciais e operacionais com o intuito de avaliar o retorno do investimento de cada cenário.

A Figura 7.26 apresenta os valores médios da carga térmica do ar de renovação para os quatro cenários apresentados. A Figura 7.27 apresenta os valores da carga térmica do ar de renovação integralizados hora a hora ao longo do ano para cada cenário:

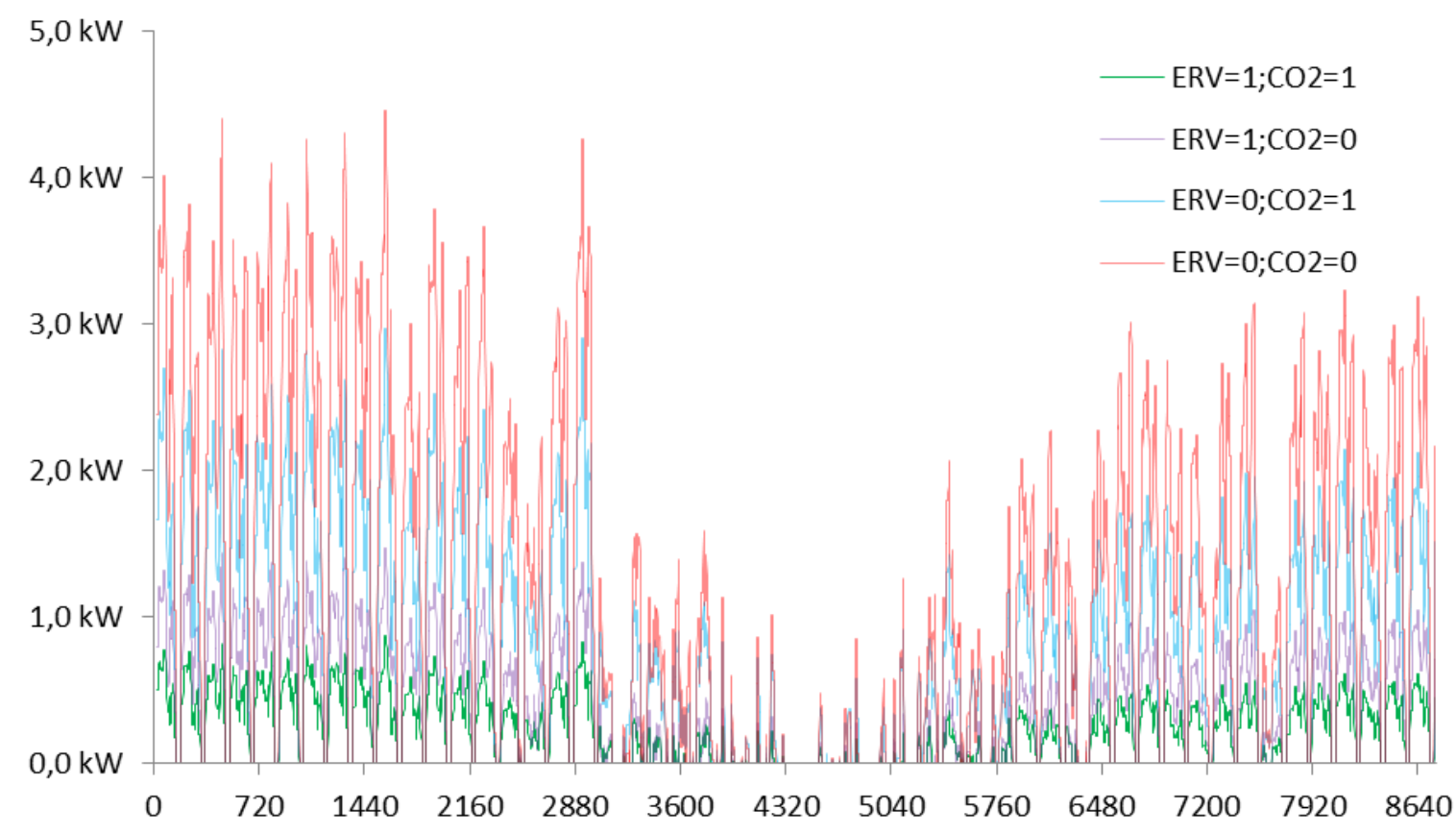

Figura 7.26 - Perfil de carga térmica do ar de renovação $(\mathrm{kWh}) \mathrm{x}$ horas do ano x cenário 14000

12000

10000

8000

kWh

6000

4000

2000

0

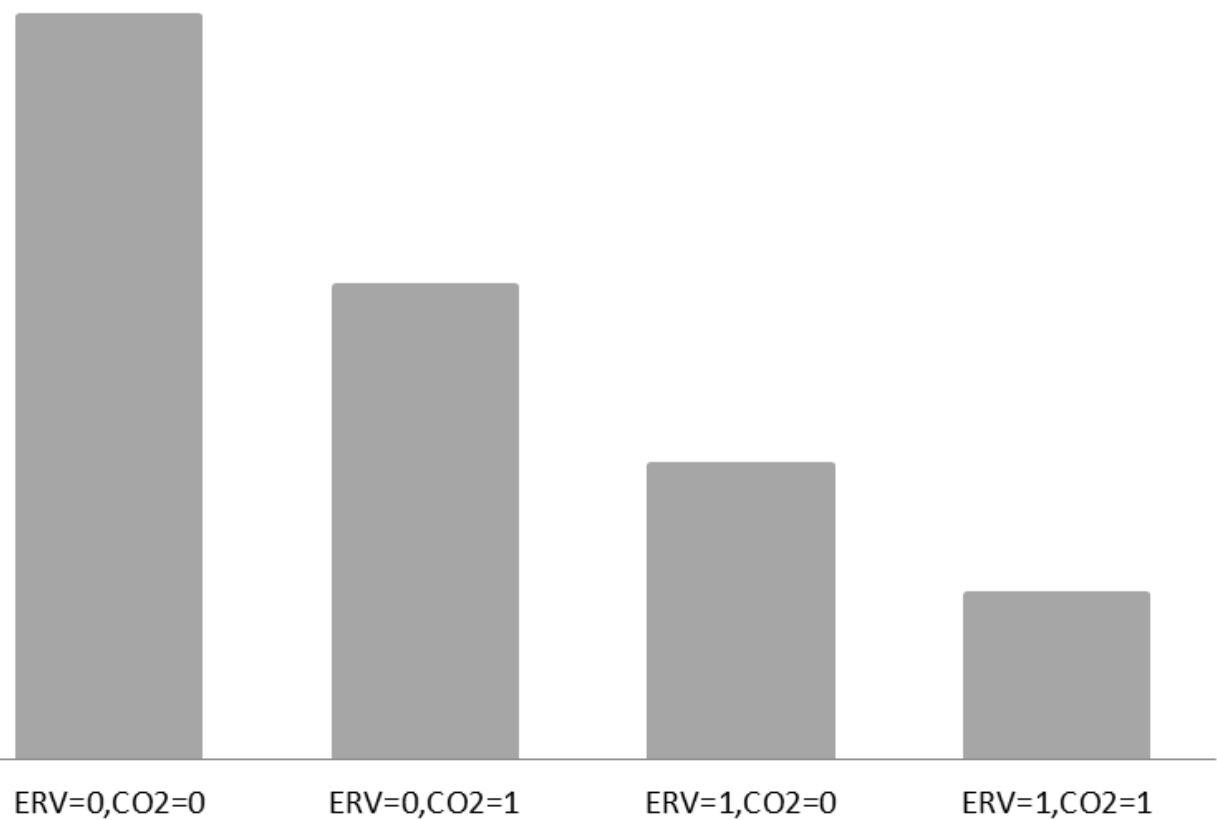

Figura 7.27 - Carga térmica do ar de renovação $(\mathrm{kWh})$ x cenário 
A Tabela 7.6, abaixo, é uma tabela comparativa entre os valores apresentados de consumo de energia para cada cenário que apresenta os valores integralizados hora a hora da energia total consumida em cada caso, a diferença da energia total dos cenários 2,3 e 4 em relação ao cenário 1 , o custo dessa energia total por ano, as economias absoluta e relativa dos cenários 2,3 e 4 em relação ao cenário 1 e o custo total de cada cenário integralizado ao longo de 5 (cinco) anos de operação. É possível verificar que a solução mais econômica é a proposta no cenário 4, que implica em uma economia anual de 29,24\% no consumo de energia elétrica, conforme apresentado também na Figura 7.28:

Tabela 7.6 - Comparação dos custos energéticos para os quatro cenários

Cenário 1 Cenário 2 Cenário $3 \quad$ Cenário 4

\begin{tabular}{ccccc}
\hline $\mathrm{E}(\mathrm{kWh})$ & $25.580,00$ & $22.435,00$ & $20.432,00$ & $18.100,00$ \\
$\mathrm{DE}(\mathrm{kWh})$ & - & $3.145,00$ & $5.148,00$ & $7.479,00$ \\
$\mathrm{R} \$$ /ano & $\mathrm{R} \$ 7.674,00$ & $\mathrm{R} \$ 6.731,00$ & $\mathrm{R} \$ 6.130,00$ & $\mathrm{R} \$ 5.430,00$ \\
Economia $(\mathrm{R} \$)$ & - & $\mathrm{R} \$ 944,00$ & $\mathrm{R} \$ 1.544,00$ & $\mathrm{R} \$ 2.244,00$ \\
Economia $(\%)$ & - & $12,3 \%$ & $20,13 \%$ & $29,24 \%$
\end{tabular}

$\begin{array}{ccccc}\text { Anos } & & & & \\ 1 & \mathrm{R} \$ 7.674,08 & \mathrm{R} \$ 6.730,51 & \mathrm{R} \$ 6.129,65 & \mathrm{R} \$ 5.430,08 \\ 2 & \mathrm{R} \$ 15.348,16 & \mathrm{R} \$ 13.461,02 & \mathrm{R} \$ 12.259,30 & \mathrm{R} \$ 10.860,17 \\ 3 & \mathrm{R} \$ 23.022,23 & \mathrm{R} \$ 20.191,54 & \mathrm{R} \$ 18.388,95 & \mathrm{R} \$ 16.290,25 \\ 4 & \mathrm{R} \$ 30.696,31 & \mathrm{R} \$ 26.922,05 & \mathrm{R} \$ 24.518,60 & \mathrm{R} \$ 21.720,34 \\ 5 & \mathrm{R} \$ 38.370,39 & \mathrm{R} \$ 33.652,56 & \mathrm{R} \$ 30.648,25 & \mathrm{R} \$ 27.150,42\end{array}$




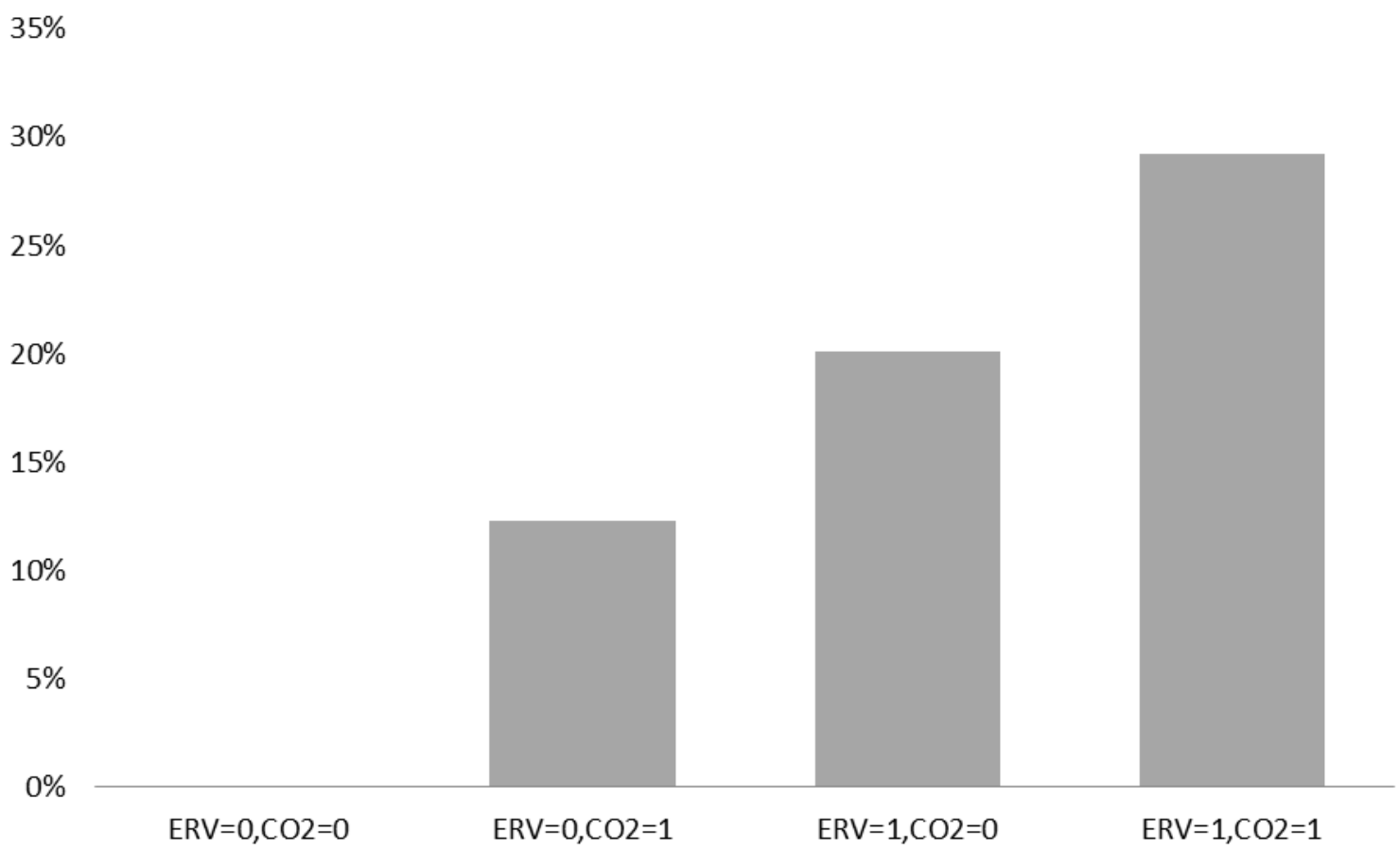

Figura 7.28 - Energia elétrica economizada anualmente $(\%)$ x cenário

Assim, como mostrado na Figura 7.28, é possível verificar que o recurso da recuperação de energia fornece uma economia de energia maior que o recurso do controle de vazão de ar exterior para o perfil de ocupação proposto no estudo de caso. O principal motivo para isso é que o recurso do ERV proporciona uma maior redução da carga térmica do ar de renovação, e, como permite o dimensionamento de sistemas de ar condicionado com menos potência, o consumo também é menor, já que a carga térmica total é menor que em sistemas que operam sem esse recurso.

A partir dos dados dos custos operacionais com energia elétrica, é possível verificar o retorno do investimento de cada solução, conforme apresentado nas Tabelas 7.7, 7.8 e 7.9. Pelos valores encontrados para o retorno do investimento no estudo de caso em questão, verifica-se que o cenário com o menor retorno de investimento é o 3. Esse fato deve-se principalmente ao fato de os custos iniciais desse cenário serem mais próximos dos custos do cenário 1, reduzindo, assim, o tempo de retorno do investimento do cenário 3. Por sua vez, o cenário 4 é o que gera uma maior economia anual na operação, fornecendo uma economia maior que a do cenário 3 quando se leva em conta o valor acumulado ao longo de 10 anos, por exemplo.

Verificou-se também que um aumento de $10 \%$ no custo da energia elétrica (kWh) gera uma redução no período de retorno do investimento de $10 \%$ para o cenário $2,14,6 \%$ para o cenário 3 e $12 \%$ para o cenário 4. 
Tabela 7.7 - Custos iniciais dos cenários

\begin{tabular}{|c|c|c|c|c|}
\hline Cenário & $\begin{array}{c}\text { Cenário } 1 \\
(\mathrm{ERV}=\mathbf{0} ; \mathrm{CO} 2=0)\end{array}$ & $\begin{array}{c}\text { Cenário } 2 \\
(\mathrm{ERV}=\mathbf{0} ; \mathrm{CO} 2=\mathbf{1})\end{array}$ & $\begin{array}{c}\text { Cenário } 3 \\
(\mathrm{ERV}=\mathbf{1} \text {;CO2=0) }\end{array}$ & $\begin{array}{c}\text { Cenário } 4 \\
(\mathrm{ERV}=\mathbf{1} ; \mathrm{CO2}=\mathbf{1})\end{array}$ \\
\hline \multicolumn{5}{|c|}{ CUSTOS INICIAIS } \\
\hline $\begin{array}{l}\text { Sistema de } \\
10 \mathrm{TR}\end{array}$ & - & - & $\mathrm{R} \$ 50.000,00$ & $\mathrm{R} \$ 50.000,00$ \\
\hline $\begin{array}{l}\text { Sistema de } \\
12 \mathrm{TR}\end{array}$ & $\mathrm{R} \$ 60.000,00$ & $\mathrm{R} \$ 60.000,00$ & - & - \\
\hline $\begin{array}{c}\text { Equipamento } \\
\text { ERV }\end{array}$ & - & - & $\mathrm{R} \$ 12.000,00$ & $\mathrm{R} \$ 12.000,00$ \\
\hline $\begin{array}{c}\text { Ventiladores } \\
\text { de ar }\end{array}$ & $\mathrm{R} \$ 3.600,00$ & $\mathrm{R} \$ 3.600,00$ & - & - \\
\hline $\begin{array}{l}\text { Controle de } \\
\text { vazão }\end{array}$ & - & $\mathrm{R} \$ 2.400,00$ & - & $\mathrm{R} \$ 2.400,00$ \\
\hline Automação & - & $\mathrm{R} \$ 7.299,88$ & $\mathrm{R} \$ 7.138,47$ & $\mathrm{R} \$ 10.204,07$ \\
\hline TOTAL & $\mathbf{R} \$ 63.600,00$ & $\mathbf{R} \$ \mathbf{7 3 . 2 9 9 , 8 8}$ & R\$ 69.138,47 & R\$ 74.604,07 \\
\hline \multicolumn{5}{|c|}{ Tabela 7.8 - Custos operacionais dos cenários } \\
\hline Cenário & $\begin{array}{c}\text { Cenário } 1 \\
(\mathrm{ERV}=\mathbf{0} ; \mathrm{CO}=\mathbf{0})\end{array}$ & 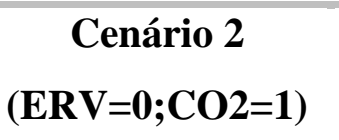 & $\begin{array}{c}\text { Cenário } 3 \\
(\text { ERV=1;CO2=0) }\end{array}$ & $\begin{array}{c}\text { Cenário } 4 \\
(\text { ERV=1;CO2=1) }\end{array}$ \\
\hline \multicolumn{5}{|c|}{ CUSTOS OPERACIONAIS } \\
\hline $\begin{array}{l}\text { Operação e } \\
\text { manutenção }\end{array}$ & $\mathrm{R} \$ 8.809,92$ & $\mathrm{R} \$ 8.809,92$ & $\mathrm{R} \$ 7.341,60$ & $\mathrm{R} \$ 7.341,60$ \\
\hline $\begin{array}{l}\text { Energia } \\
\text { consumida }\end{array}$ & $\mathrm{R} \$ 7.674,08$ & $\mathrm{R} \$ 6.730,51$ & $\mathrm{R} \$ 6.129,65$ & $\mathrm{R} \$ 5.430,08$ \\
\hline TOTAL & $\mathrm{R} \$ \mathbf{1 6 . 4 8 4 , 0 0}$ & R\$ $15.540,43$ & R\$ 13.471,25 & R\$ 12.771,68 \\
\hline
\end{tabular}

Tabela 7.9 - Retorno do investimento de cada cenário

\begin{tabular}{|c|c|c|c|c|}
\hline Cenário & 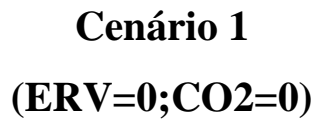 & $\begin{array}{c}\text { Cenário 2 } \\
(\mathrm{ERV}=0 ; \mathrm{CO} 2=1)\end{array}$ & $\begin{array}{c}\text { Cenário 3 } \\
(\mathrm{ERV}=\mathbf{1 ; C O 2 = 0 )}\end{array}$ & $\begin{array}{c}\text { Cenário } 4 \\
(\mathrm{ERV}=1 ; \mathrm{CO} 2=1)\end{array}$ \\
\hline \multicolumn{5}{|c|}{ RETORNO DO INVESTIMENTO } \\
\hline Custos totais & $\mathrm{R} \$ 80.084,00$ & $\mathrm{R} \$ 88.840,31$ & $\mathrm{R} \$ 82.609,72$ & $\mathrm{R} \$ 87.375,75$ \\
\hline Diferença & $\mathrm{R} \$ 0,00$ & $\mathrm{R} \$ 8.756,31$ & $\mathrm{R} \$ 2.525,72$ & $\mathrm{R} \$ 7.291,76$ \\
\hline
\end{tabular}


custos totais

\begin{tabular}{lcccr}
\hline $\begin{array}{l}\text { Economia de } \\
\text { energia }\end{array}$ & $\mathrm{R} \$ 0,00$ & $\mathrm{R} \$ 943,57$ & $\mathrm{R} \$ 1544,43$ & $\mathrm{R} \$ 2.243,99$ \\
\hline $\begin{array}{l}\text { Retorno do } \\
\text { investimento }\end{array}$ & - & $\mathbf{9 , 2 8}$ anos & $\mathbf{1 , 6 4}$ anos & $\mathbf{3 , 2 5}$ anos \\
\hline $\begin{array}{l}\text { Economia } \\
\text { em 10 anos }\end{array}$ & $\mathbf{R} \$ \mathbf{- 2 6 4 , 2 2}$ & $\mathbf{R} \$ \mathbf{1 1 . 3 7 4 , 1 2}$ & $\mathbf{R} \$ \mathbf{1 2 . 9 0 4 , 1 9}$ \\
\hline & & & \\
$\begin{array}{l}\text { 7.3 - RESULTADOS DOS CENÁRIOS COM DIVERSAS OCUPAÇÕES E HORAS } \\
\text { DE OPERAÇÃO }\end{array}$
\end{tabular}

O perfil de ocupação é um parâmetro que influencia os resultados das simulações e, consequentemente, a análise do retorno do investimento dos cenários apresentados. Alterações no fator de ocupação do ambiente modificam o valor da carga térmica, o valor da vazão necessária de ar exterior para atender os valores normativos, bem como o número de horas de operação do sistema, considerando que o sistema não opera quando não há ocupação de pessoas no ambiente.

A princípio, quanto maior a vazão de ar externo e maior o número de horas de operação do sistema, mais energia pode ser recuperada no ERV. Por outro lado, quanto maior a vazão de ar externo, maior também é carga térmica inserida no ambiente condicionado e maior o consumo elétrico dos ventiladores de renovação. Quanto maior as horas de operação do sistema também maior é o consumo elétrico dos equipamentos do sistema de ar condicionado. Os custos de manutenção dos equipamentos foram considerados constantes, independendo da quantidade de horas de operação.

Ainda, considerando um perfil de ocupação que nunca apresente a ocupação máxima do ambiente condicionado, esse fator irá beneficiar o recurso do controle de vazão de ar exterior, uma vez que a carga térmica devido ao ar de renovação será menor do que o sistema que trabalha com vazão constante.

Dessa forma, considerando que essas variáveis se relacionam intimamente com o perfil de ocupação e com as horas de operação do sistema, pela importância da análise também desses efeitos, verifica-se a complexidade requerida em sua avaliação.

Para que toda essa análise seja possível, foram definidas algumas ocupações relativas semanais acumuladas. A Tabela 7.10 apresenta esses perfis de ocupação e as 
horas de operação consideradas para cada perfil. As horas de operação foram estimadas em no máximo 90 horas na semana, considerando o intervalo de funcionamento do ambiente condicionado de 8 h00 da manhã às 23 h00 da noite ( 15 horas por dia, de segunda a sábado).

Necessariamente, com o aumento do percentual de ocupação semanal, as horas mínimas de operação aumentam, já que o ambiente estará ocupado por mais horas durante a semana. O perfil de ocupação relativo semanal acumulado foi definido com base na ocupação máxima absoluta (2130 pessoas por dia, 6 dias por semana, resultando num total máximo semanal de 12780 pessoas). As tabelas com as composições dos perfis de ocupação encontram-se no Apêndice L.

Tabela 7.10 - Perfis de ocupação e horas de operação dos sistemas

\begin{tabular}{ccccc}
\hline $\begin{array}{c}\text { Perfil de } \\
\text { ocupação } \\
\text { original }-\end{array}$ & $\begin{array}{c}\text { Variação de } \\
\text { ocupação 1 } \\
\mathbf{3 5 , 8 3 \%}\end{array}$ & $\begin{array}{c}\text { Variação de } \\
\text { ocupação 2 } \\
\mathbf{4 6 , 6 7 \%}\end{array}$ & $\begin{array}{c}\text { Variação de } \\
\text { ocupação 3 } \\
\mathbf{7 5 , 5 6 \%}\end{array}$ & $\begin{array}{c}\text { Variação de } \\
\text { ocupação 4 - } \\
\mathbf{1 0 0 \%}\end{array}$ \\
\hline 33 horas & 18 horas & 42 horas & 68 horas & 90 horas \\
43 horas & 36 horas & 56 horas & 80 horas & - \\
57 horas & 72 horas & 73 horas & 90 horas & - \\
65 horas & - & 84 horas & - & - \\
80 horas & - & - & - & - \\
\hline
\end{tabular}

\subsection{1 - Análise comparativa dos cenários e influência da variação da ocupação e das horas de operação}

Os perfis de ocupação apresentados nas Tabelas L.1 a L.16 foram inseridos na simulação e os resultados dos cenários 2, 3 e 4 são apresentados a seguir nas Tabelas 7.11 a 7.16, respectivamente.

As Tabelas 7.11 e 7.12 apresentam os resultados do cenário 2. Percebe-se que não há valor para o retorno do investimento para todos os perfis de ocupação operando com seu menor número de horas de operação, uma vez que esses perfis consideram $100 \%$ da ocupação em todas as horas de operação, não permitindo, assim, o uso do recurso do controle de vazão de ar exterior.

A Figura 7.29 mostra que quanto maior o número de horas de operação, menor o retorno do investimento para um mesmo perfil de ocupação. Esse padrão se mantém para 
os outros cenários, já que quanto maior o número de horas de operação, mais os recursos da recuperação de energia e do controle de vazão de ar exterior têm seus efeitos majorados, economizando mais energia em relação ao cenário 1 , o que, por sua vez, reduz mais seus custos operacionais e, consequentemente, reduz o retorno do investimento do cenário.

Tabela 7.11 - Retorno do investimento para os diversos perfis de ocupação no cenário 2

\begin{tabular}{cc|cc|cc}
\hline $\begin{array}{c}\text { Perfil de } \\
\text { ocupação } \\
\text { original } \\
\mathbf{3 5 , 8 3 \%}\end{array}$ & $\begin{array}{c}\text { Retorno do } \\
\text { investimento }\end{array}$ & $\begin{array}{c}\text { Variação } \\
\text { de } \\
\text { ocupação 1 } \\
\mathbf{2 0 \%}\end{array}$ & $\begin{array}{c}\text { Retorno do } \\
\text { investimento }\end{array}$ & $\begin{array}{c}\text { Variação } \\
\text { de } \\
\text { ocupação 2 } \\
\mathbf{4 6 , 6 7 \%}\end{array}$ & $\begin{array}{c}\text { Retorno do } \\
\text { investimento }\end{array}$ \\
\hline 33 horas & - & 18 horas & - & 42 horas & - \\
43 horas & 13,53 anos & 36 horas & 10,04 anos & 56 horas & 10,34 anos \\
57 horas & 9,28 anos & 72 horas & 4,14 anos & 73 horas & 7,35 anos \\
65 horas & 5,58 anos & - & & 84 horas & 4,36 anos \\
80 horas & 4,11 anos & - & - & - & - \\
\hline
\end{tabular}

Entretanto, para esse cenário, verifica-se que quanto maior o percentual de ocupação do perfil avaliado, maiores são os prazos de retorno do investimento, uma vez que o recurso da vazão de ar variável torna-se pouco eficaz. Esse fato ocorre porque os valores de vazão se aproximam mais do valor da vazão para a ocupação máxima, aumentando a carga térmica do ar de renovação e o consumo elétrico dos ventiladores de renovação.

Por esse motivo, para o perfil de ocupação 4 (75,56\%), os prazos de retorno do investimento são bastante elevados, praticamente inviabilizando a utilização dessa solução nessa situação.

Tabela 7.12 - Retorno do investimento para os diversos perfis de ocupação no cenário 2

\begin{tabular}{cc|cc}
\hline $\begin{array}{c}\text { Variação de } \\
\text { ocupação } 3\end{array}$ & $\begin{array}{c}\text { Retorno do } \\
\mathbf{7 5 , 5 6 \%}\end{array}$ & $\begin{array}{c}\text { Variação de } \\
\text { ocupação } 4 \\
\mathbf{1 0 0 \%}\end{array}$ & $\begin{array}{c}\text { Retorno do } \\
\text { investimento }\end{array}$ \\
\hline 68 horas & - & 90 horas & - \\
80 horas & 11,41 anos & - & \\
90 horas & 7,45 anos & - & \\
- & & - \\
\hline
\end{tabular}




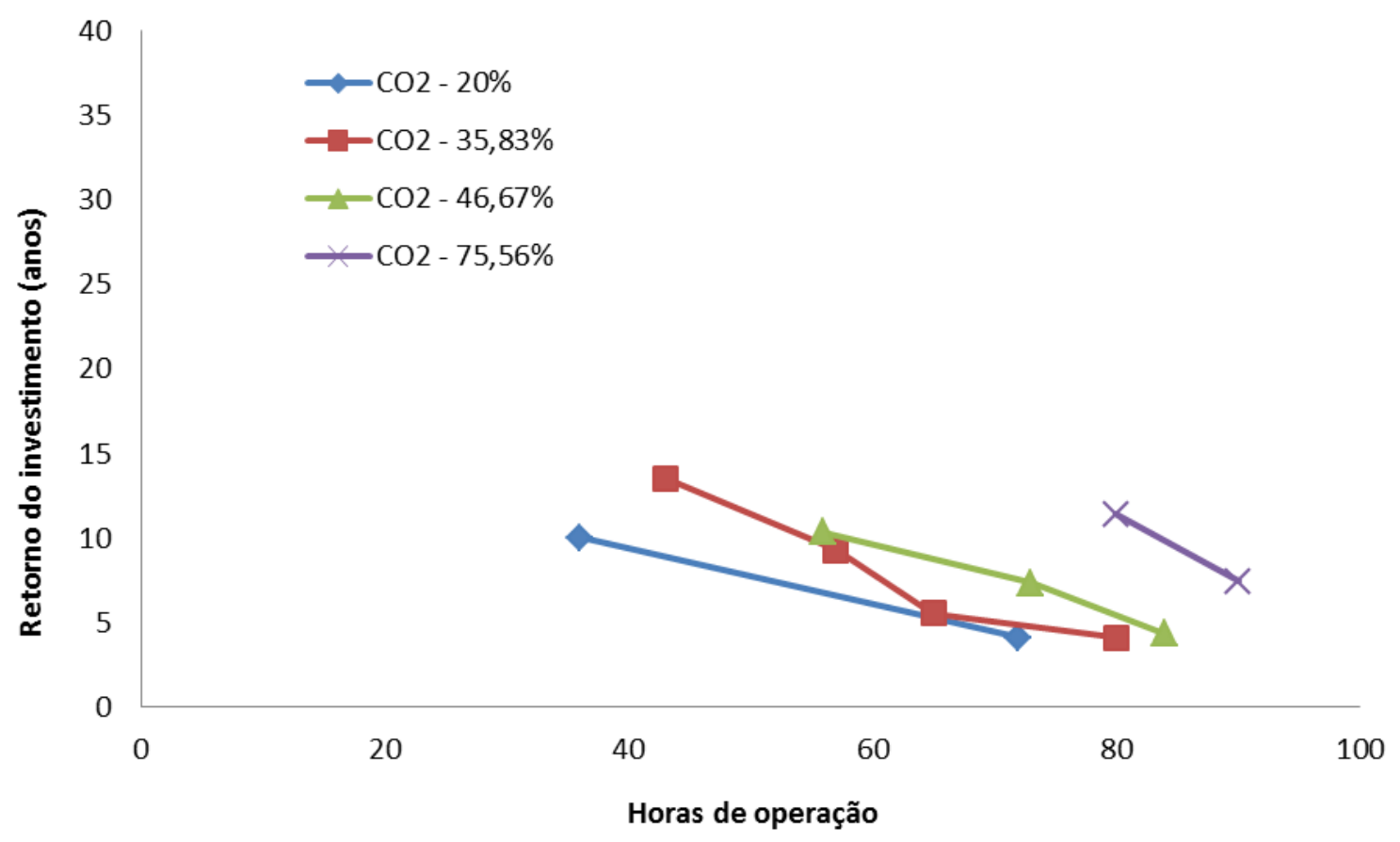

Figura 7.29 - Retorno do investimento (anos) x tempo de operação (horas) no cenário 2

As Tabelas 7.13 e 7.14, abaixo, apresentam os resultados do cenário 3. Para esse cenário, verifica-se que quanto maior o percentual de ocupação do perfil avaliado, menores são os prazos de retorno do investimento, uma vez que, com o aumento da ocupação, os valores necessários de vazão de ar externo são maiores, ocorrendo maior recuperação de energia no ERV. Assim, com maior recuperação de energia, a carga térmica do ar externo de renovação é menor, requisitando menos energia dos equipamentos de ar-condicionado.

A Figura 7.30 mostra a curva de tendência do retorno do investimento em função do número de horas de operação para cada perfil de ocupação proposto:

Tabela 7.13 - Retorno do investimento para os diversos perfis de ocupação no cenário 3

\begin{tabular}{cc|cc|cc}
\hline $\begin{array}{c}\text { Perfil de } \\
\text { ocupação } \\
\text { original } \\
\mathbf{3 5 , 8 3 \%}\end{array}$ & $\begin{array}{c}\text { Retorno do } \\
\text { investimento }\end{array}$ & $\begin{array}{c}\text { Variação } \\
\text { de } \\
\text { ocupação 1 } \\
\mathbf{2 0 \%}\end{array}$ & $\begin{array}{c}\text { Retorno do } \\
\text { investimento }\end{array}$ & $\begin{array}{c}\text { Variação } \\
\text { de } \\
\text { ocupação } \\
\mathbf{2 ~ 4 6 , 6 7 \%}\end{array}$ & $\begin{array}{c}\text { Retorno do } \\
\text { investimento }\end{array}$ \\
\hline 33 horas & 2,98 anos & 18 horas & 6,07 anos & 42 horas & 2,18 anos \\
43 horas & 2,01 anos & 36 horas & 2,64 anos & 56 horas & 1,36 anos \\
57 horas & 1,63 anos & 72 horas & 1,15 anos & 73 horas & 1,11 anos \\
65 horas & 1,17 anos & - & & 84 horas & 0,76 anos \\
80 horas & 0,86 anos & - & - & - & - \\
\hline
\end{tabular}


Tabela 7.14 - Retorno do investimento para os diversos perfis de ocupação no cenário 3

\begin{tabular}{cc|cc}
\hline $\begin{array}{c}\text { Variação de } \\
\text { ocupação } 3\end{array}$ & $\begin{array}{c}\text { Retorno do } \\
\text { investimento }\end{array}$ & $\begin{array}{c}\text { Variação de } \\
\text { ocupação } 4 \\
\mathbf{1 0 0 \%}\end{array}$ & $\begin{array}{c}\text { Retorno do } \\
\text { investimento }\end{array}$ \\
\hline 68 horas & 1,03 anos & 90 horas & 0,52 anos \\
80 horas & 0,74 anos & - & \\
90 horas & 0,6 anos & - & \\
\hline
\end{tabular}

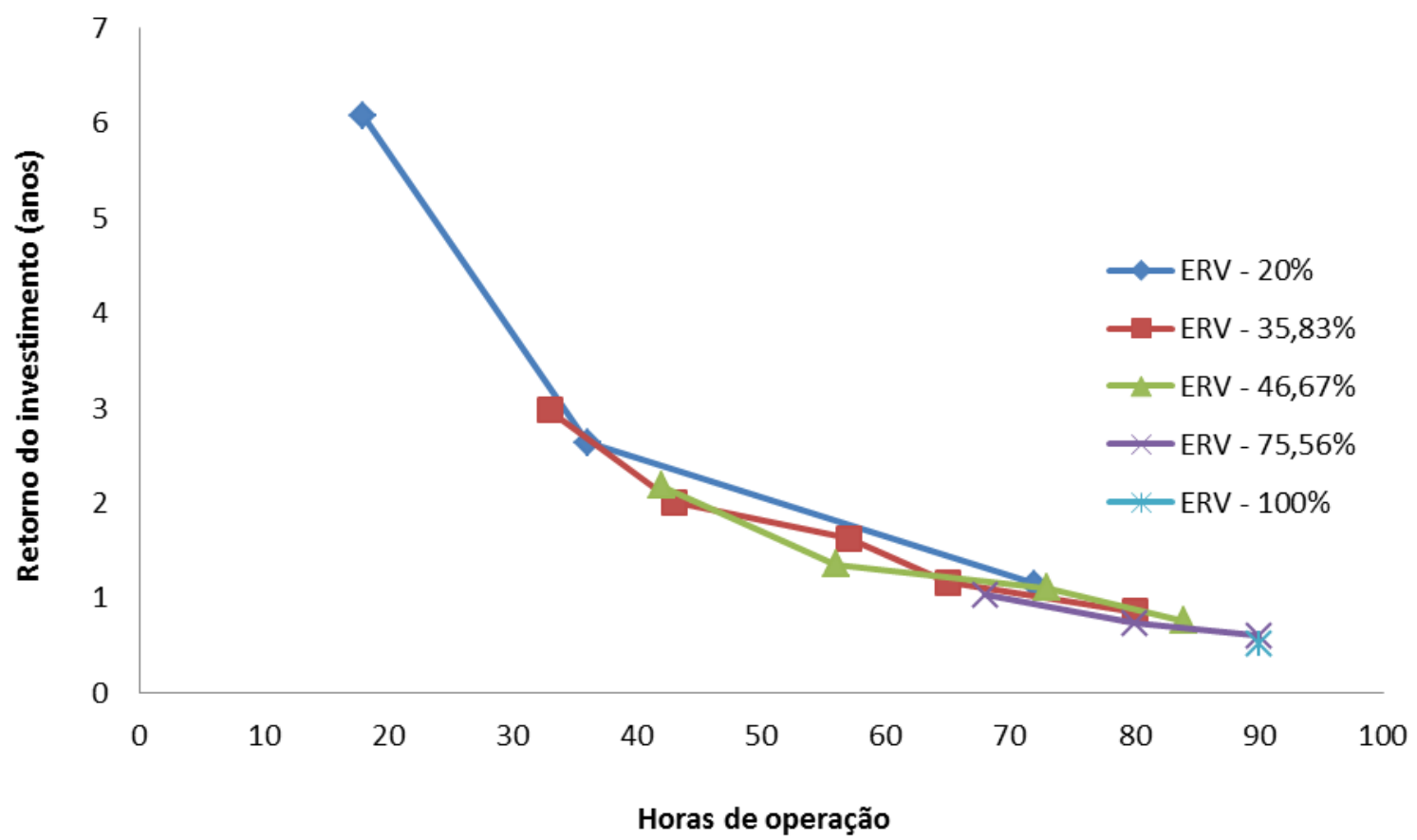

Figura 7.30 - Retorno do investimento (anos) x tempo de operação (horas) no cenário 3

As Tabelas 7.15 e 7.16, a seguir, apresentam os resultados do cenário 4. Como esse cenário leva em conta os recursos de controle de vazão de ar exterior e de recuperação de energia, e como o efeito do aumento do percentual de ocupação tem efeitos contrários nos dois recursos (em um aumenta o prazo de retorno do investimento e no outro, o reduz), os resultados desse cenário apresentam os efeitos ponderados dos dois recursos.

Assim, o perfil de ocupação que apresenta os menores prazos de retorno de investimento para uma maior faixa de horas de ocupação é o perfil de ocupação original $(35,83 \%)$. A Figura 7.31 mostra a curva de tendência do retorno do investimento em função do número de horas de operação para cada perfil de ocupação proposto: 
Tabela 7.15 - Retorno do investimento para os diversos perfis de ocupação no cenário 4

\begin{tabular}{cc|cc|cc}
\hline $\begin{array}{c}\text { Perfil de } \\
\text { ocupação } \\
\text { original } \\
\mathbf{3 5 , 8 3 \%}\end{array}$ & $\begin{array}{c}\text { Retorno do } \\
\text { investimento }\end{array}$ & $\begin{array}{c}\text { Variação } \\
\text { de } \\
\text { ocupação 1 } \\
\mathbf{2 0 \%}\end{array}$ & $\begin{array}{c}\text { Retorno do } \\
\text { investimento }\end{array}$ & $\begin{array}{c}\text { Variação } \\
\text { de } \\
\text { ocupação 2 } \\
\mathbf{4 6 , 6 7 \%}\end{array}$ & $\begin{array}{c}\text { Retorno do } \\
\text { investimento }\end{array}$ \\
\hline 33 horas & 8,33 anos & 18 horas & 15,58 anos & 42 horas & 6,45 anos \\
43 horas & 4,09 anos & 36 horas & 4,46 anos & 56 horas & 2,97 anos \\
57 horas & 3,25 anos & 72 horas & 2,01 anos & 73 horas & 2,39 anos \\
65 horas & 2,22 anos & - & & 84 horas & 1,60 anos \\
80 horas & 1,68 anos & - & - & - & - \\
\hline
\end{tabular}

Tabela 7.16 - Retorno do investimento para os diversos perfis de ocupação no cenário 4

\begin{tabular}{cc|cc}
\hline $\begin{array}{c}\text { Variação de } \\
\text { ocupação } 3 \\
\mathbf{7 5 , 5 6 \%}\end{array}$ & $\begin{array}{c}\text { Retorno do } \\
\text { investimento }\end{array}$ & $\begin{array}{c}\text { Variação de } \\
\text { ocupação } 4 \\
\mathbf{1 0 0 \%}\end{array}$ & $\begin{array}{c}\text { Retorno do } \\
\text { investimento }\end{array}$ \\
\hline 68 horas & 3,75 anos & 90 horas & 2,57 anos \\
80 horas & 2,20 anos & - & \\
90 horas & 1,77 anos & - & \\
\hline
\end{tabular}

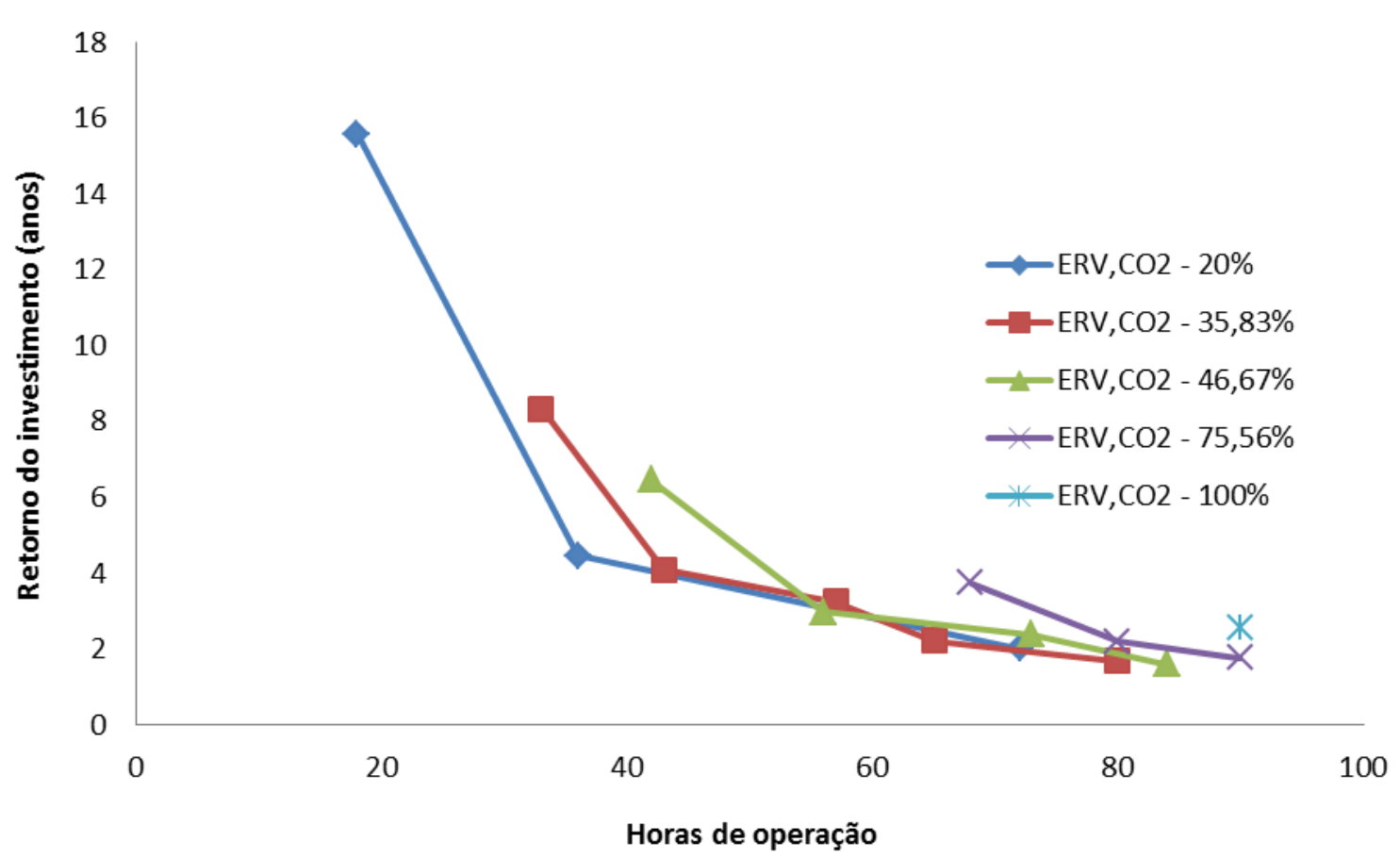

Figura 7.31 - Retorno do investimento (anos) x tempo de operação (horas) no cenário 4 


\section{4 - RESULTADOS DOS CENÁRIOS COM OCUPAÇÃO ORIGINAL EM OUTRA CIDADE DE PROJETO}

As condições climáticas da cidade de projeto também influenciam os resultados das simulações e, consequentemente, a análise do retorno do investimento dos cenários apresentados. As variações climáticas alteram o valor da carga térmica devida ao ar externo, bem como o funcionamento do ERV, que opera a partir da comparação dos dados de temperatura e umidade do ar externo com os dados do ar interno.

Ainda, conforme o modelo proposto para o ERV, os parâmetros de temperatura e umidade impactam nas eficiências sensível e latente, respectivamente, afetando a eficiência total do equipamento e, por conseguinte, a quantidade de energia recuperada. Dessa forma, essas variações também modificam o período de retorno do investimento de cada cenário.

Assim, foi escolhida uma cidade de projeto com clima diferente do clima de Brasília, com o objetivo de se avaliar os efeitos climáticos nos cenários propostos.

\subsection{1 - Cidade de projeto - Manaus}

Conforme mostrado na formulação apresentada no Capítulo 4, as temperaturas e umidades relativas da cidade de projeto são parâmetros de entrada para o sistema, uma vez que influenciam o funcionamento do ERV, carga térmica do ar externo e o funcionamento do ciclo de compressão a vapor do equipamento de ar-condicionado. A Figura 7.32 apresenta o perfil de temperatura de bulbo seco e de umidade relativa para a cidade de Manaus/AM no ano de 2012: 

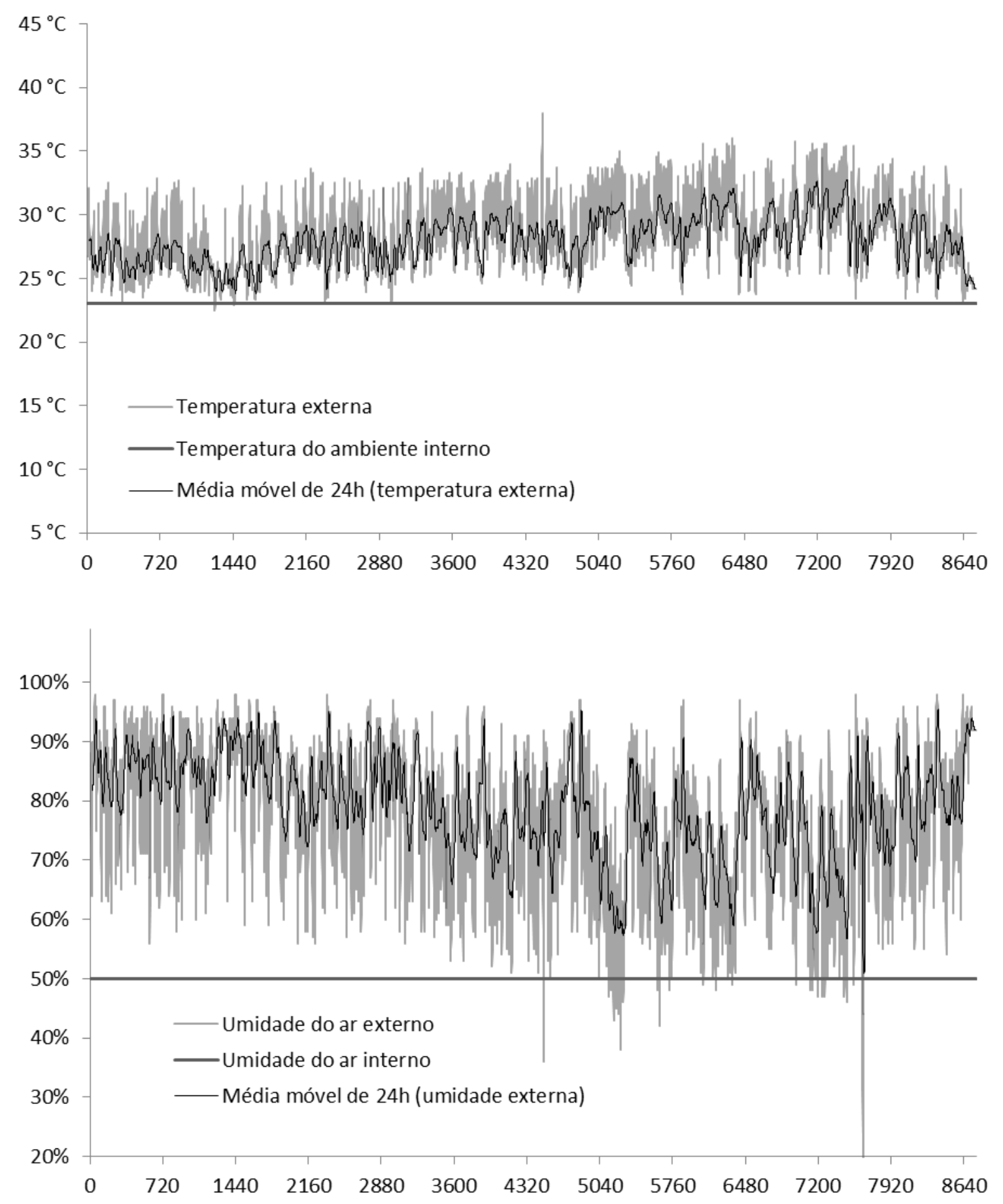

Figura 7.32 - Temperatura de bulbo seco e umidade relativa para a cidade de Manaus/AM no ano de 2012 (INMET, 2012)

\subsection{2 - Perfil de carga térmica}

O perfil de carga térmica foi levantado de acordo com as informações apresentadas na Tabela 6.1, juntamente com o perfil de ocupação apresentado no item 6.1.3. Para o levantamento do perfil de carga foi utilizado o software HAP do fabricante CARRIER. O componente de carga térmica devido ao ar de renovação foi calculado pela própria 
formulação da metodologia proposta, uma vez que o valor da carga depende do uso ou não dos sistemas de recuperação de energia e de controle de vazão de ar externo por $\mathrm{CO} 2$.

A Figura 7.33 apresenta o perfil de carga anual máximo (sem considerar a utilização do ERV e do controle de vazão de ar externo) para o perfil de ocupação original. A Figura 7.34 apresenta o perfil calculado com a utilização do ERV, uma vez que a utilização desse recurso diminui a carga térmica total:

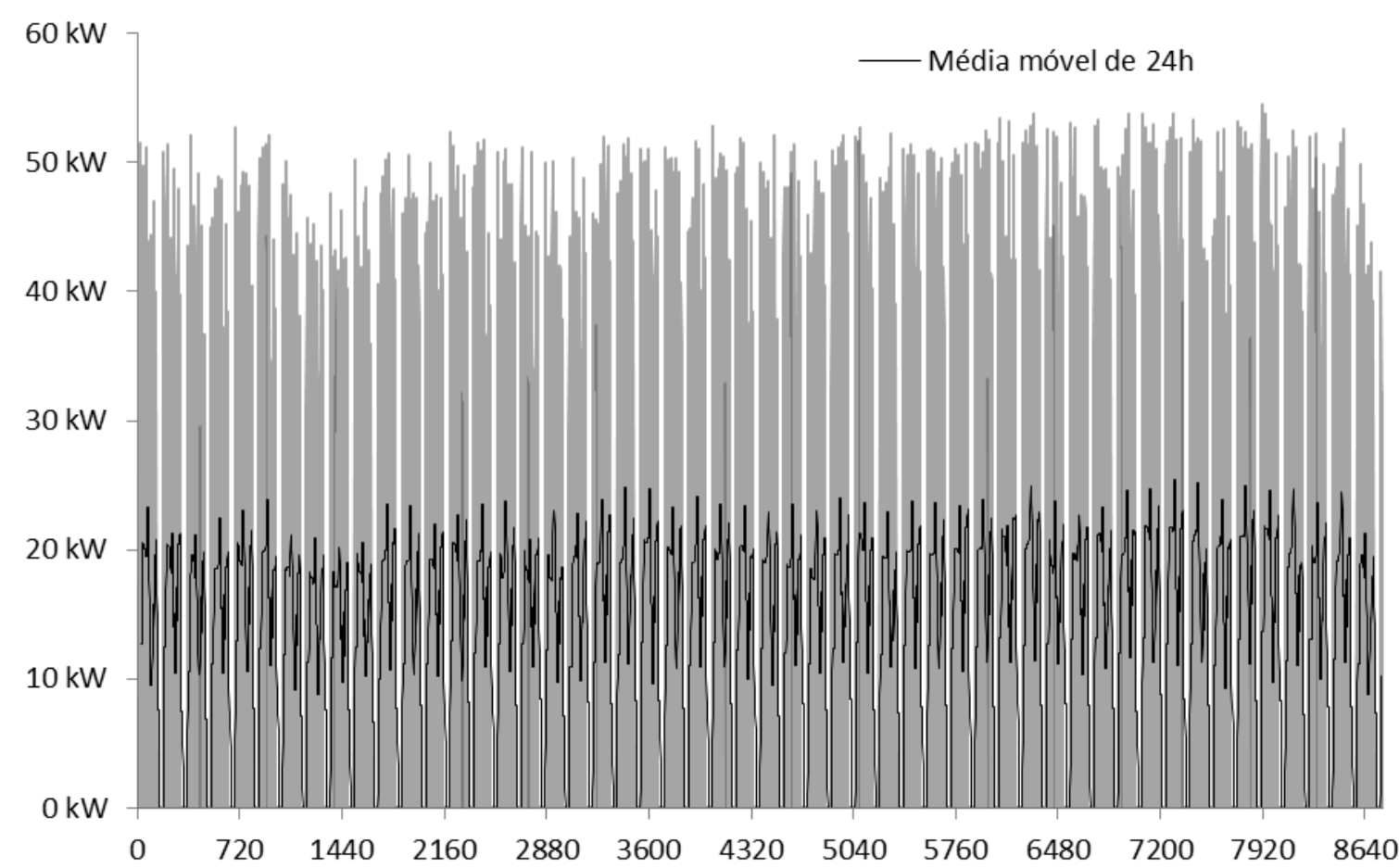

Figura 7.33 - Perfil de carga térmica anual $(\mathrm{kW}) \mathrm{x}$ horas do ano

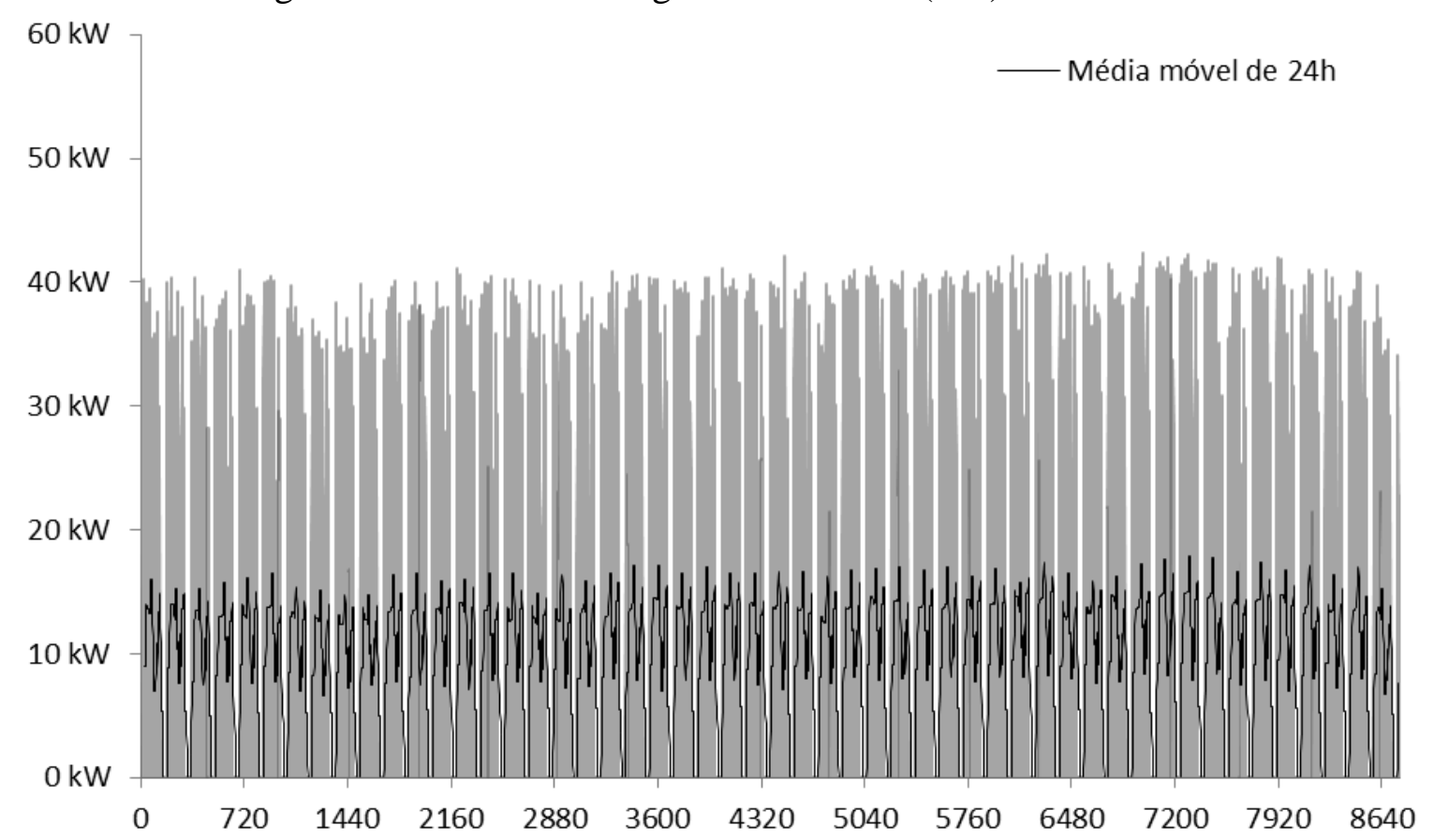

Figura 7.34 - Perfil de carga térmica anual $(\mathrm{kW}) \mathrm{x}$ horas do ano com o uso de ERV. 


\subsection{3 - Sistema de ar condicionado}

O sistema de ar condicionado projetado para atendimento do ambiente em questão possui a mesma concepção do sistema projetado para cidade de Brasília, com diferenças apenas nas potências dos equipamentos, já que a carga térmica do mesmo ambiente e com o mesmo perfil de ocupação na cidade de Manaus é maior.

Ainda, como o sistema de ar condicionado será dimensionado conforme o perfil de carga levantado, dois tipos de sistemas foram previstos, um para um carga de 12 TR e outra para uma carga de 15 TR, uma vez que a utilização do equipamento ERV reduz a carga térmica máxima de pico, possibilitando o dimensionamento de sistemas menores.

\subsubsection{1 - Sistema de ar condicionado padrão - 55 kW (15 TR)}

A Tabela 7.17 apresenta os dados de seleção do equipamento resfriador de líquido (chiller) selecionado para atendimento do ambiente em estudo. A seleção foi feita pelo software HAP do fabricante CARRIER, cujos dados de potência elétrica consumida e de desempenho são apresentados na Tabela 7.18, Figura 7.35 e Figura 7.36:

Tabela 7.17 - Principais características do Chiller de 15 TR (CARRIER, 2013, modificado)

\begin{tabular}{cc}
\hline Parâmetro & Valor \\
\hline Chiller & Resfriador de líquido com condensação a ar \\
Fabricante & CARRIER \\
Modelo & 30 RA018 \\
Capacidade máxima & $15 \mathrm{TR}$ \\
Potência elétrica máxima consumida & $22,4 \mathrm{~kW}$ \\
Compressor & Scroll \\
Temperatura de saída de água gelada & $6,7^{\circ} \mathrm{C}$ \\
Temperatura externa do ar & $35^{\circ} \mathrm{C}$ \\
Taxa de vazão no evaporador & $0,043 \mathrm{~L} /(\mathrm{s}-\mathrm{kW})$ \\
Carga mínima & $20 \%$ \\
\hline
\end{tabular}


Tabela 7.18 - Tabela de potência consumida para diversas cargas de operação e temperaturas do ar externo do Chiller 15 TR (CARRIER, 2013, modificado)

\begin{tabular}{ccccccccccc}
$\mathrm{T}$ & $\mathrm{P}$ & $100 \%$ & $90 \%$ & $80 \%$ & $70 \%$ & $60 \%$ & $50 \%$ & $40 \%$ & $30 \%$ & $20 \%$ \\
$\left({ }^{\circ} \mathrm{C}\right)$ & $(\mathrm{kW})$ & & & & & & & & & \\
\hline 46,1 & 30,4 & 30,4 & 26,6 & 22,9 & 19,3 & 16,5 & 13,7 & 10,9 & 8,2 & 5,7 \\
35,0 & 22,4 & 22,4 & 19,7 & 17 & 14,3 & 12,3 & 10,2 & 8,2 & 6,1 & 4,3 \\
29,4 & 18,2 & 18,2 & 16,1 & 13,9 & 11,8 & 10,1 & 8,4 & 6,7 & 5,1 & 3,5 \\
23,9 & 16,8 & 16,8 & 14,8 & 12,8 & 10,9 & 9,3 & 7,8 & 6,2 & 4,7 & 3,3 \\
$-17,8$ & 15,6 & 15,6 & 13,6 & 11,6 & 9,6 & 8,1 & 6,6 & 5 & 3,5 & 2
\end{tabular}

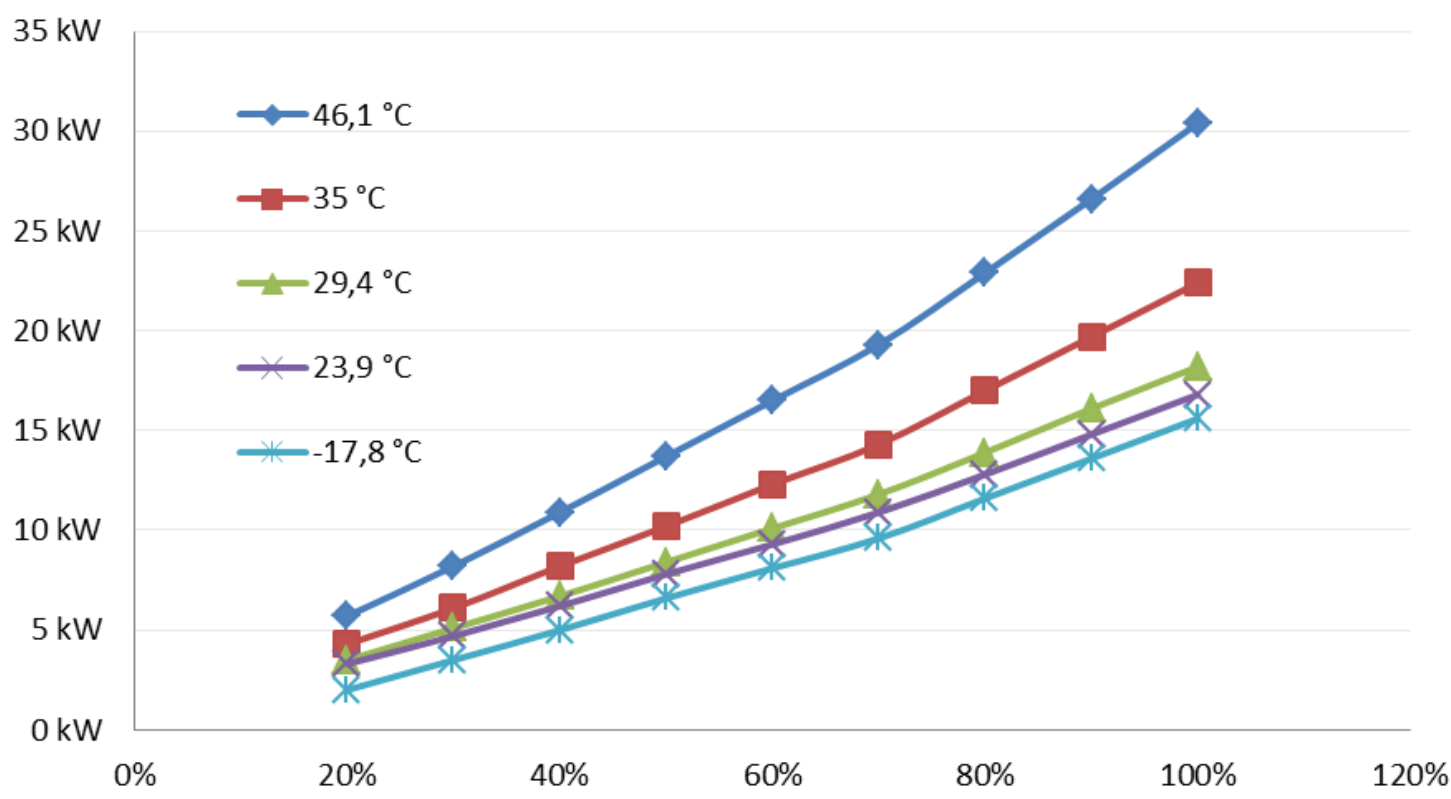

Figura 7.35 - Gráfico de "Potência consumida $(\mathrm{kW})$ x Carga de operação (\%)" para diversas temperaturas do ar externo - Chiller 15 TR (CARRIER, 2013, modificado)

As Equações das curvas da Figura 7.35 são definidas abaixo, e serão utilizadas na simulação para definir o consumo em cada hora de operação do chiller.

$$
\begin{gathered}
y=8,9226 x^{3}-5,9957 x^{2}+27,106 x+0,4302 ; \text { para temp. de } 46,1^{\circ} \mathrm{C} \\
y=6,9372 x^{2}+14,159 x+1,2671 \text {; para temp. de } 35^{\circ} \mathrm{C} \\
y=4,9567 x^{2}+12,319 x+0,9162 ; \text { para temp. de } 29,4^{\circ} \mathrm{C}
\end{gathered}
$$




$$
\begin{gathered}
y=4,697 x^{2}+11,13 x+0,94 ; \text { para temp. de } 23,9^{\circ} \mathrm{C} \\
y=4,5779 x^{2}+11,323 x-0,3471 ; \text { para temp. de }-17,8^{\circ} \mathrm{C}
\end{gathered}
$$

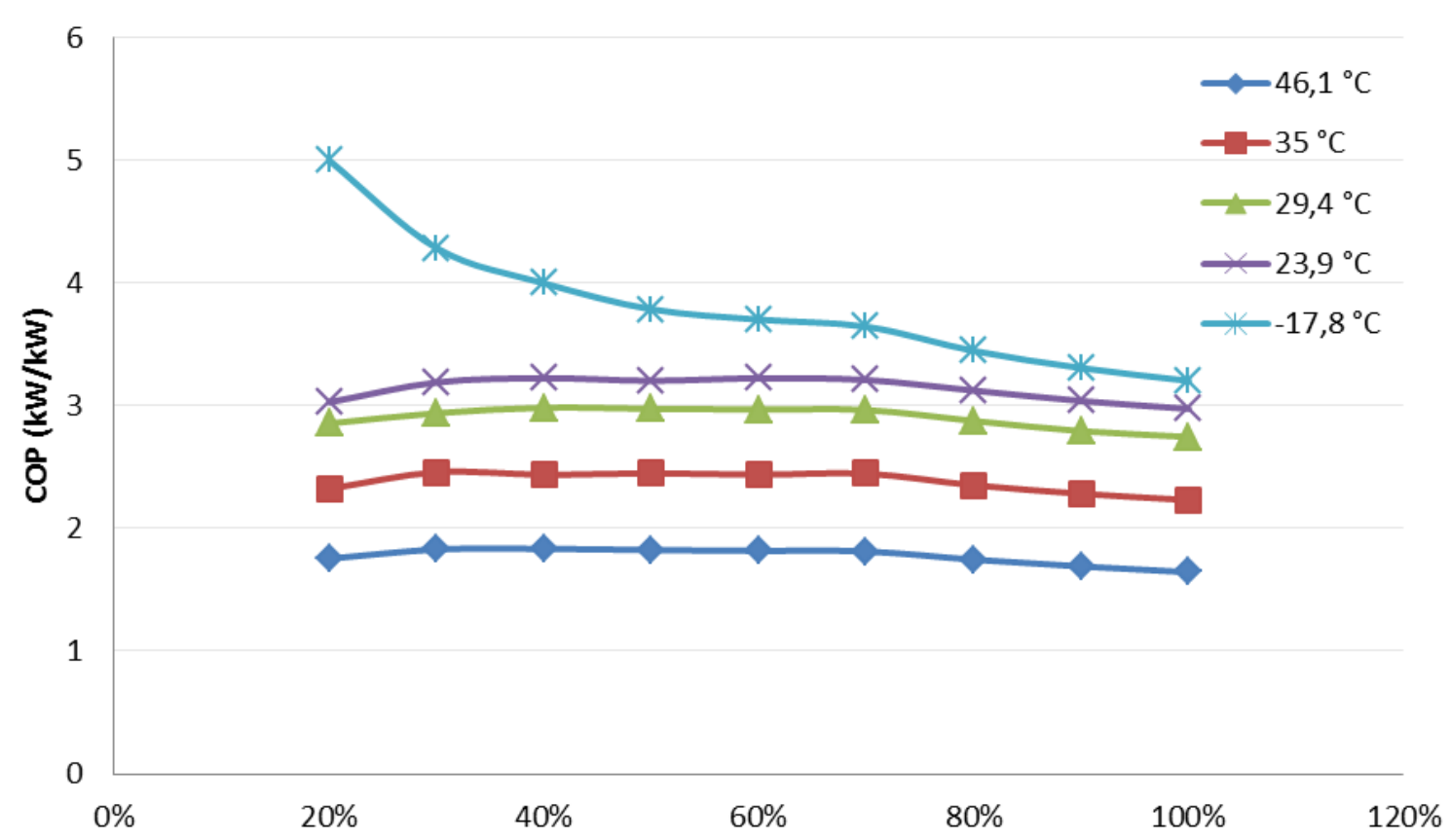

Figura 7.36 - Gráfico de "COP $(\mathrm{kW} / \mathrm{kW})$ x carga de operação (\%)" para diversas temperaturas do ar externo - Chiller 15 TR (CARRIER, 2013, modificado)

A Tabela 7.19, a seguir, apresenta os dados de seleção do equipamento condicionador tipo fan coil selecionado para atendimento do ambiente em estudo. A seleção foi feita pelo software AIV (Air Handler Vortex) do fabricante CARRIER, cujos dados de potência elétrica consumida são apresentados na Figura 7.37:

Tabela 7.19 - Principais características do fan coil de 15 TR (CARRIER, 2013, modificado)

\begin{tabular}{cc}
\hline Parâmetro & Valor \\
\hline Fan coil & Condicionador de ar \\
Fabricante & CARRIER \\
Modelo & VORTEX 39V15 \\
Capacidade máxima & $15 \mathrm{TR}$ \\
Potência elétrica consumida (cap. máxima) & $2,17 \mathrm{~kW}$ \\
Ventilador & Sirocco $18 / 18$ \\
Vazão de ar & $10.320 \mathrm{~m}^{3} / \mathrm{h}$ \\
\hline
\end{tabular}




\begin{tabular}{cc}
\hline Rotação & $825 \mathrm{RPM}$ \\
Vazão de água & $7,27 \mathrm{~m} / \mathrm{h}$ \\
Temperatura de entrada de água & $8{ }^{\circ} \mathrm{C}$ \\
\hline
\end{tabular}

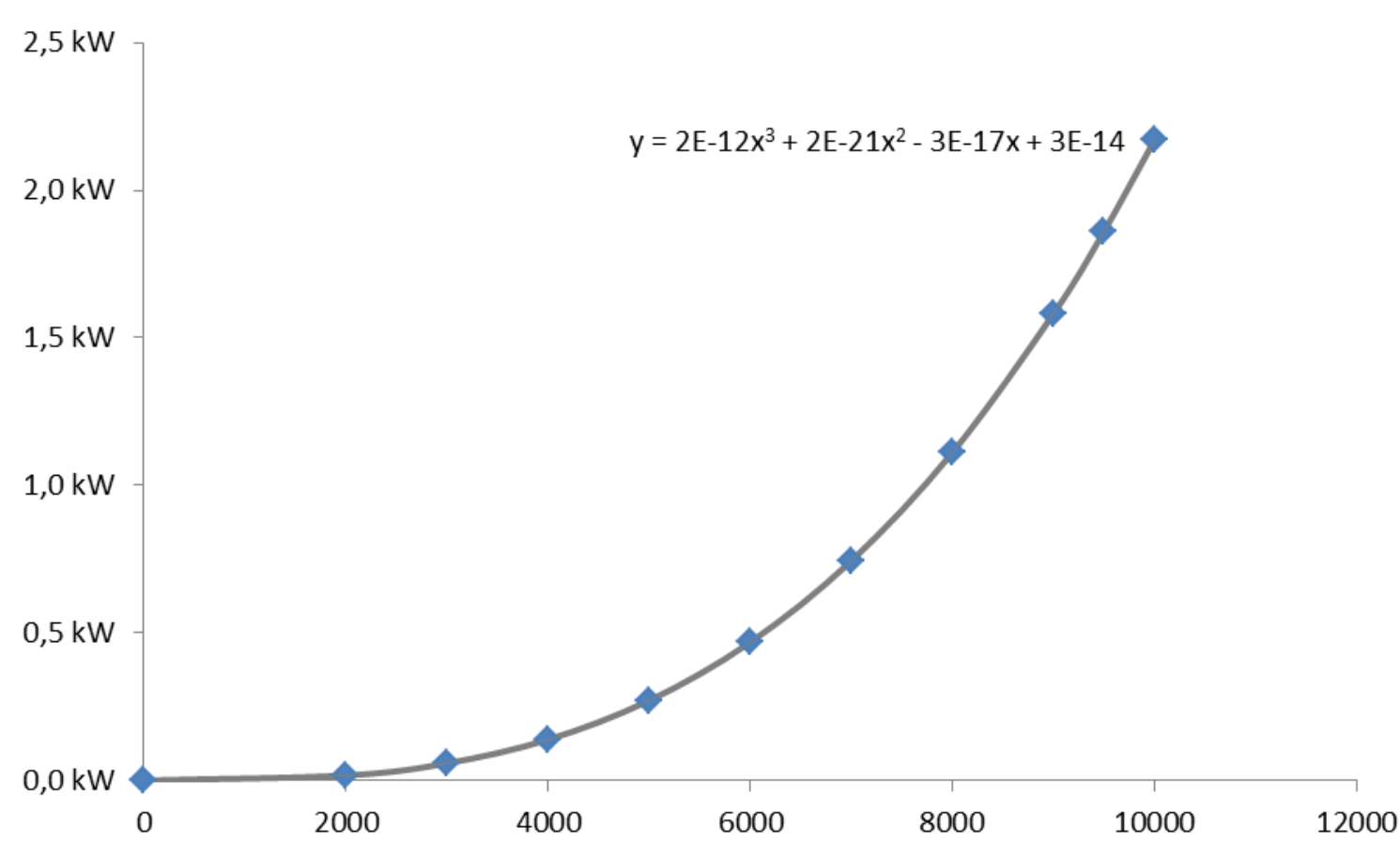

Figura 7.37 - Gráfico de "Potência elétrica consumida $(\mathrm{kW})$ x vazão de $\operatorname{ar}\left(\mathrm{m}^{3} / \mathrm{h}\right)$ " para o equipamento fan coil VORTEX 15 TR (CARRIER, 2013, modificado)

7.4.3.2 - Sistema de ar condicionado para uso com o ERV - 43 kW (12 TR)

O sistema de ar condicionado de 12 TR utilizado é o mesmo apresentado no Capítulo 6, item 6.1.4.1.

\subsection{4 - Cenário 1: Solução convencional $(\mathrm{CO2}=0 ; \mathrm{ERV}=0)$}

A Figura 7.38, abaixo, apresenta o perfil de carga térmica devido ao ar externo de renovação para o cenário em questão ao longo do ano. A Figura 7.39 apresenta os valores de entalpia do ar exterior e do ar interno, mostrando claramente a possibilidade de utilização de um equipamento de recuperação de energia durante todo o ano. Pela análise dos gráficos, também é possível perceber que a carga térmica média e a entalpia média do ar externo são praticamente constantes ao longo de todo o ano: 


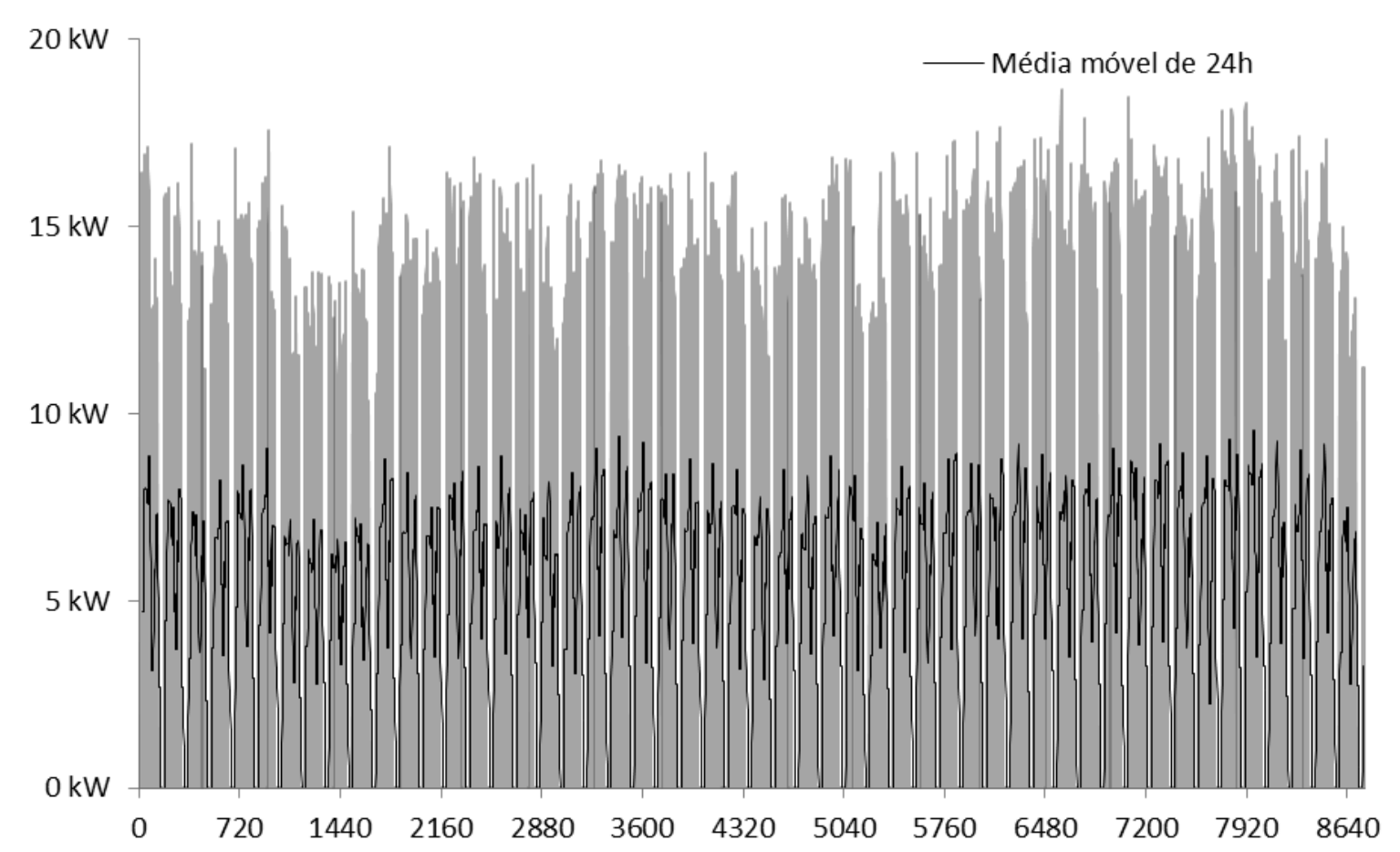

Figura 7.38 - Carga térmica do ar de renovação $(\mathrm{kW})$ x horas do ano (cenário 1)

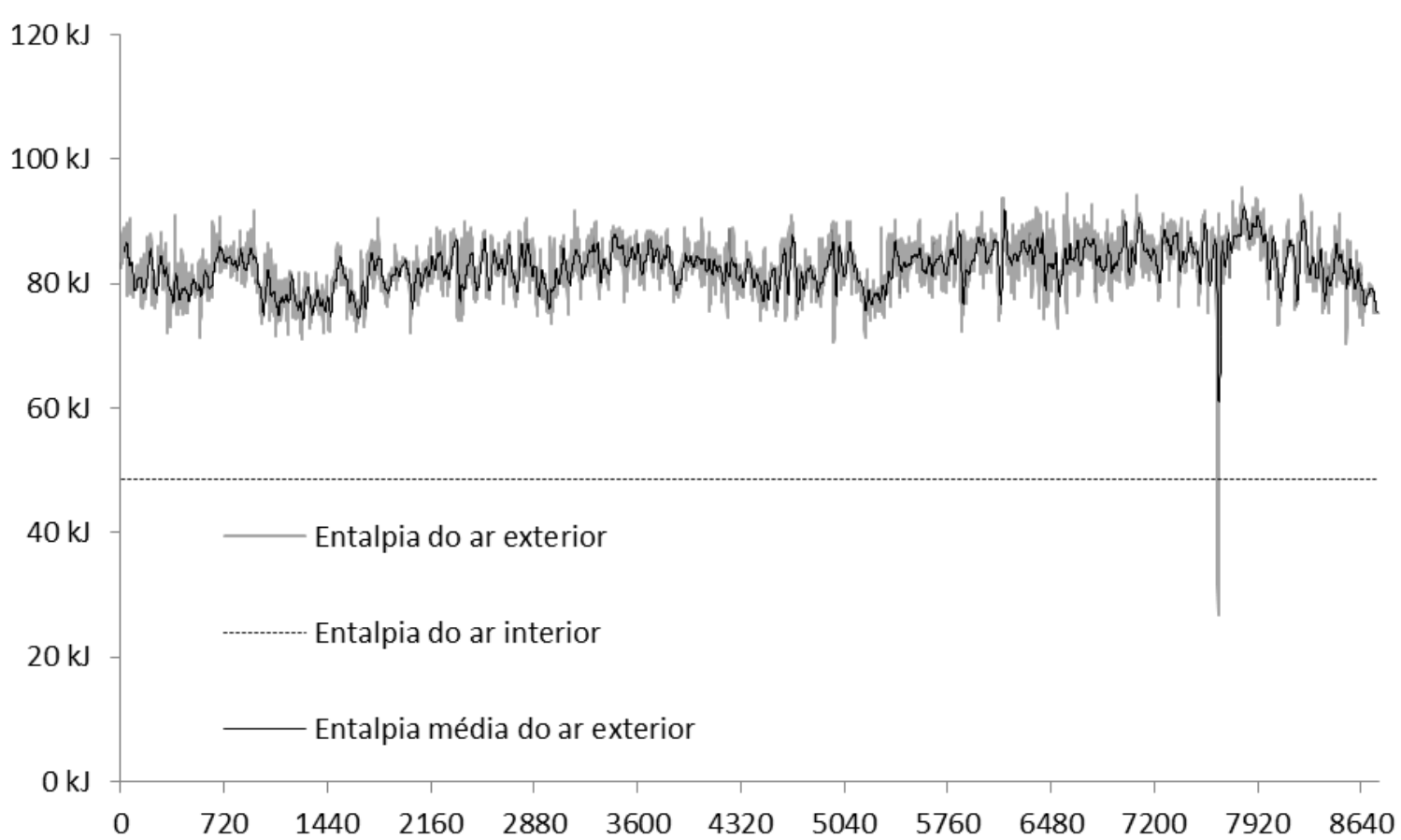

Figura 7.39 - Entalpia do ar externo e interno (kJ/kg) x horas do ano (cenário 1)

A Tabela 7.20, a seguir, apresenta os valores integralizados hora a hora ao longo do ano da carga térmica do ar externo de renovação, do consumo de energia elétrica dos ventiladores de renovação de ar, do fan coil, do chiller e o consumo elétrico total do cenário. As Figuras 7.40, 7.41, 7.42 e 7.43 apresentam esses consumos elétricos em cada 
mês do ano. O perfil referente ao consumo dos ventiladores (Figura 7.40) é praticamente constante ao longo dos meses, uma vez que o perfil de ocupação é semanal e a vazão de ar externo é sempre constante e igual ao valor máximo. As pequenas diferenças são devido às diferenças dos dias da semana que compõem cada mês, gerando uma pequena diferença na ocupação acumulada mensal.

Os perfis apresentados pelo consumo dos equipamentos de ar condicionado e pelo consumo total acompanham o perfil de carga térmica anual (Figura 7.33):

Tabela 7.20 - Valores integralizados anuais para o cenário 1

\begin{tabular}{cccc}
\hline $\begin{array}{c}\text { Carga térmica do } \\
\text { ar externo }\end{array}$ & $\begin{array}{c}\text { Consumo elétrico } \\
\text { dos ventiladores }\end{array}$ & $\begin{array}{c}\text { Consumo elétrico } \\
\text { do } \text { fan coil }\end{array}$ & $\begin{array}{c}\text { Consumo elétrico } \\
\text { do } \text { chiller }\end{array}$ \\
\hline & & & \\
\hline $42.519,06 \mathrm{kWh}$ & $3.624,00 \mathrm{kWh}$ & $3.267,79 \mathrm{kWh}$ & $33.752,30 \mathrm{kWh}$ \\
\hline
\end{tabular}

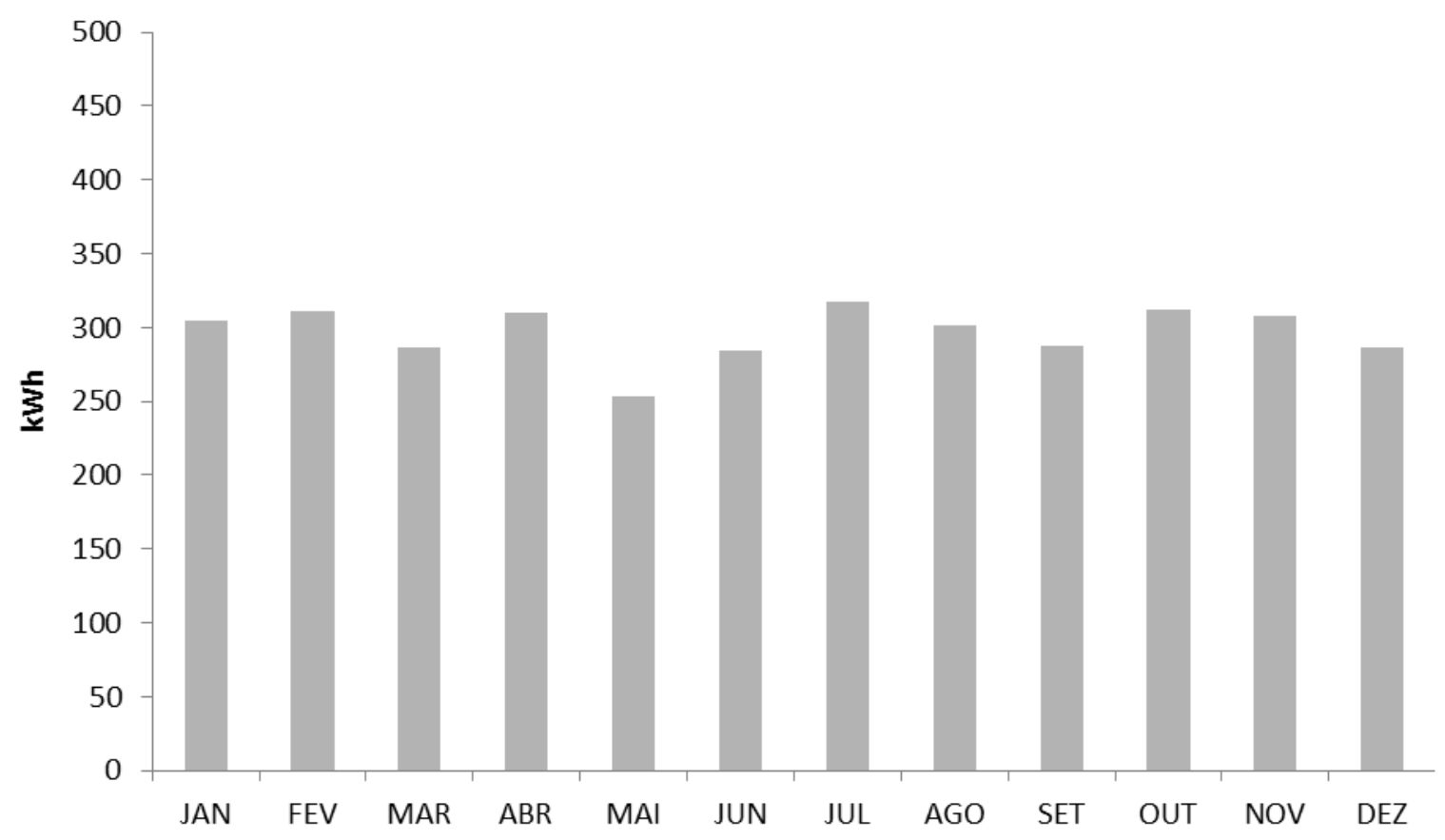

Figura 7.40 - Consumo elétrico mensal dos ventiladores (kWh) x meses do ano (cenário 1) 


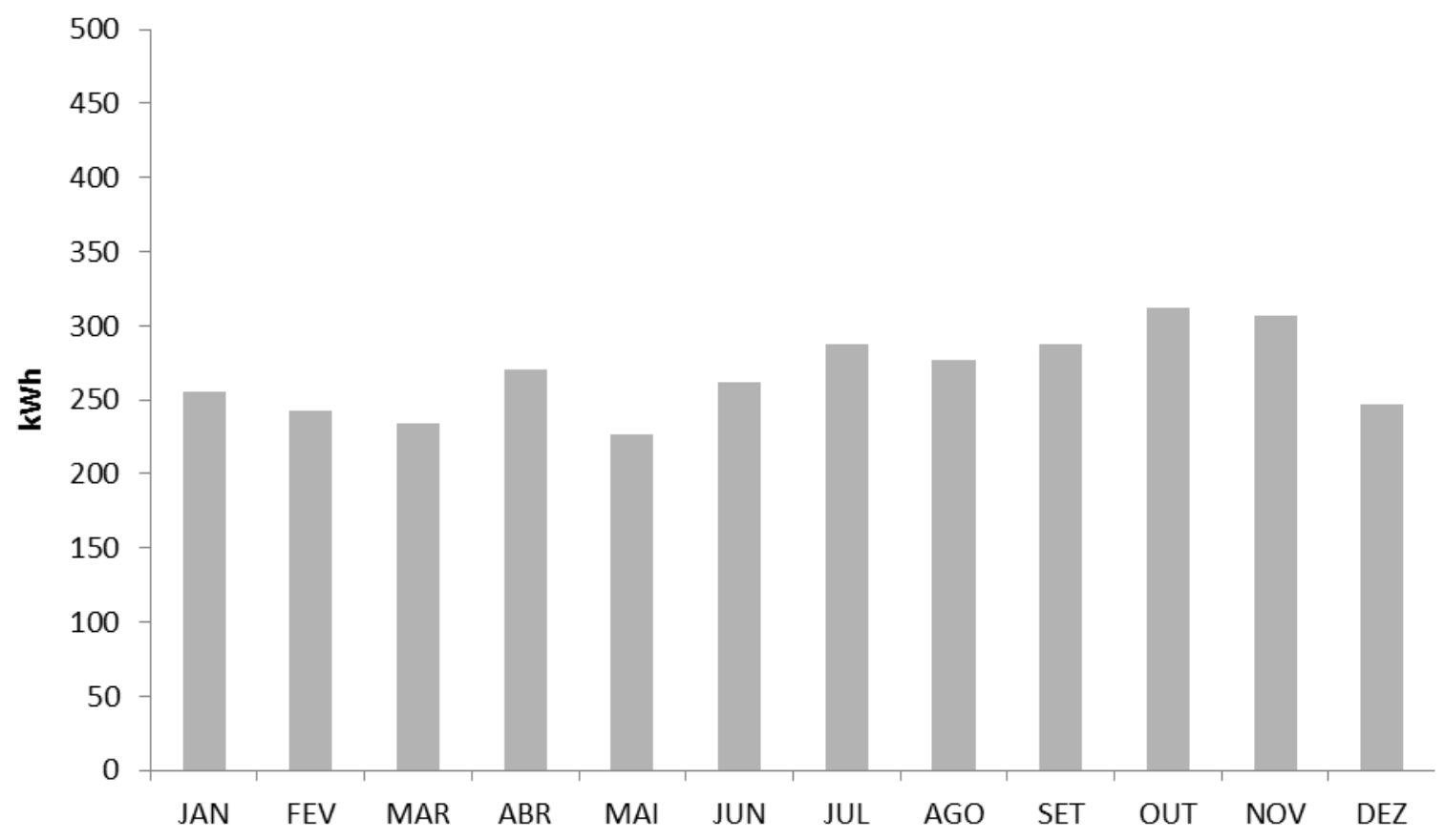

Figura 7.41 - Consumo elétrico mensal do fan coil (kWh) x meses do ano (cenário 1)

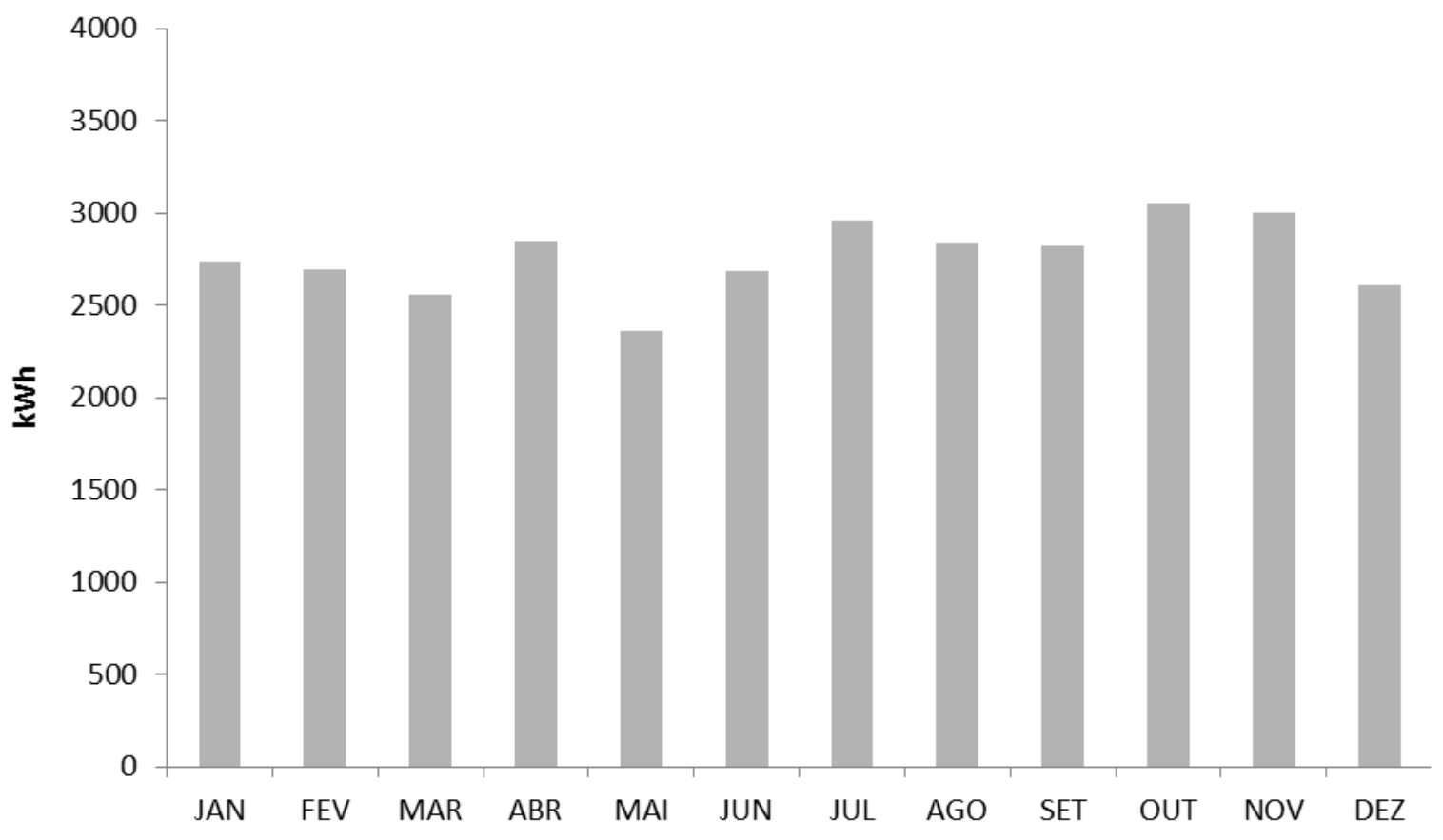

Figura 7.42 - Consumo elétrico mensal do chiller $(\mathrm{kWh})$ x meses do ano (cenário 1) 


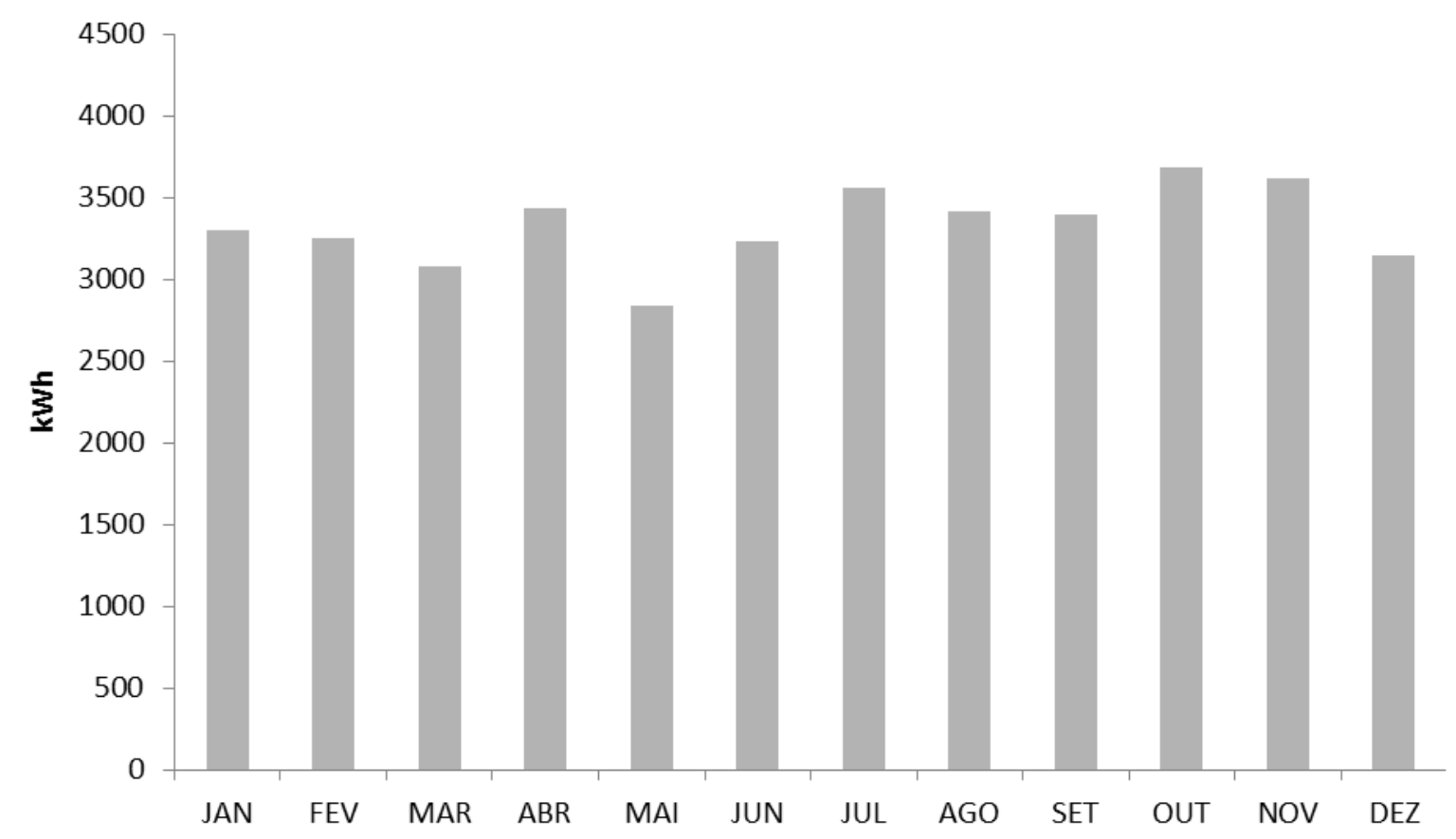

Figura 7.43 - Consumo elétrico mensal total $(\mathrm{kWh})$ x meses do ano (cenário 1)

\subsection{5 - Cenário 2: Solução com vazão de ar exterior variável $(C O 2=1 ; E R V=0)$}

A Figura 7.44, abaixo, apresenta o perfil de carga térmica devido ao ar externo de renovação para o cenário 2 ao longo do ano. Claramente é possível observar pelos valores médios diários que a carga térmica de renovação é menor que a carga apresentada no cenário 1 (Figura 7.38), devido ao recurso da vazão de ar exterior variável, conforme mostrado na Tabela 7.21, a seguir: 


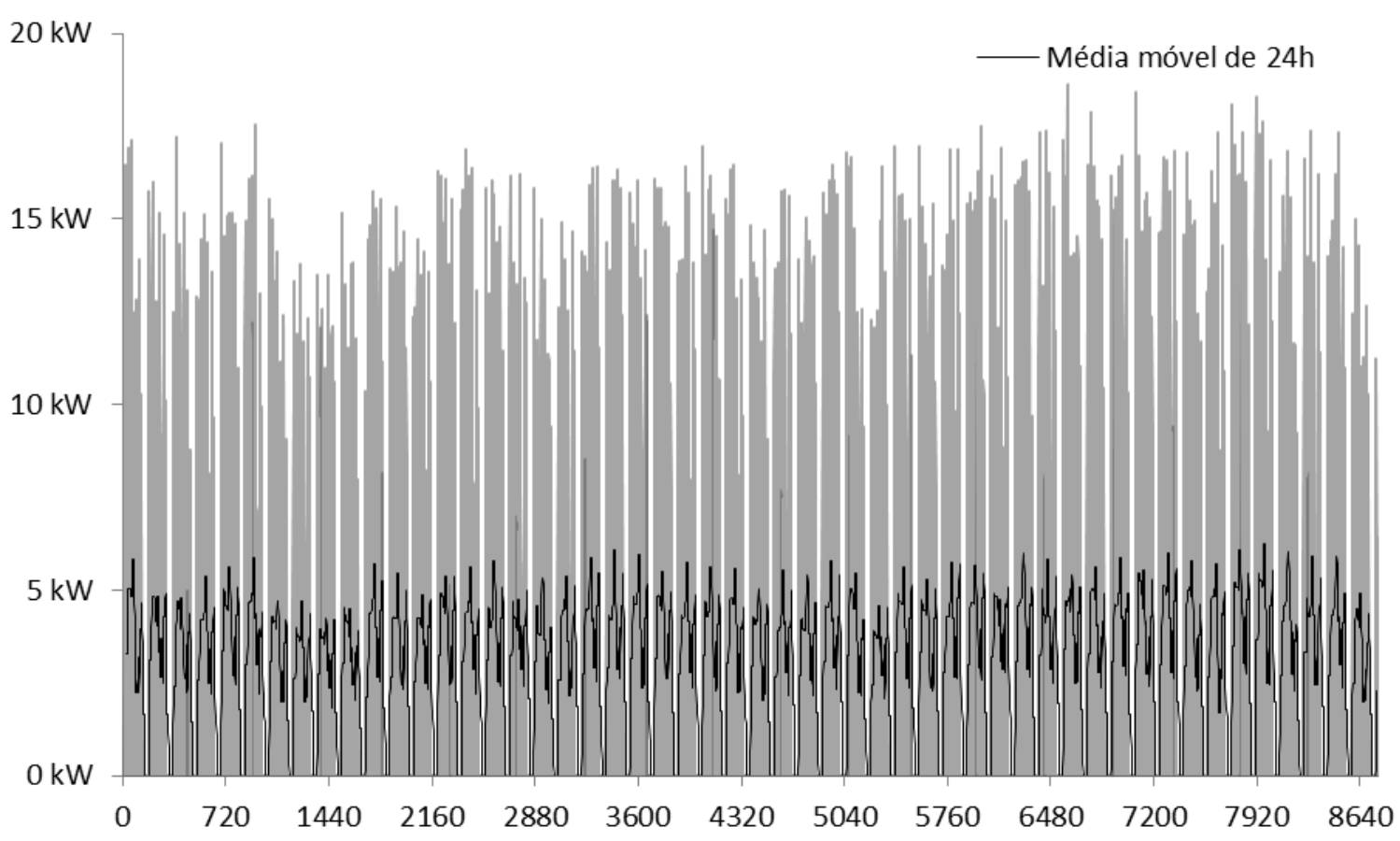

Figura 7.44 - Carga térmica do ar de renovação $(\mathrm{kW})$ x horas do ano (cenário 2)

A Tabela 7.21, abaixo, apresenta os valores integralizados ao longo do ano da carga térmica do ar externo de renovação, do consumo de energia elétrica dos ventiladores de renovação de ar, do fan coil, do chiller e o consumo elétrico total do cenário. As Figuras 7.45, 7.46, 7.47 e 7.48 apresentam esses consumos elétricos em cada mês do ano. O perfil referente ao consumo dos ventiladores (Figura 7.45) é praticamente constante ao longo dos meses, uma vez que o perfil de ocupação é semanal, porém, a vazão é variável de acordo com a ocupação, apresentando, assim, valores de consumo elétrico bem abaixo dos apresentados para o cenário 1 (Figura 7.40):

Os perfis apresentados pelo consumo dos equipamentos de ar-condicionado e pelo consumo total acompanham o perfil de carga térmica anual (Figura 7.33, p. 171). O consumo elétrico total desse cenário também é menor que o do cenário 1 , conforme mostra a Tabela a seguir:

Tabela 7.21 - Valores integralizados anuais para o cenário 2

\begin{tabular}{cccc}
\hline $\begin{array}{c}\text { Carga térmica do } \\
\text { ar externo }\end{array}$ & $\begin{array}{c}\text { Consumo elétrico } \\
\text { dos ventiladores }\end{array}$ & $\begin{array}{c}\text { Consumo elétrico } \\
\text { do } \text { fan coil }\end{array}$ & $\begin{array}{c}\text { Consumo elétrico } \\
\text { do } \text { chiller }\end{array}$ \\
\hline $26.823,04 \mathrm{kWh}$ & $1.625,97 \mathrm{kWh}$ & $2.619,49 \mathrm{kWh}$ & $28.996,50 \mathrm{kWh}$ \\
\hline
\end{tabular}




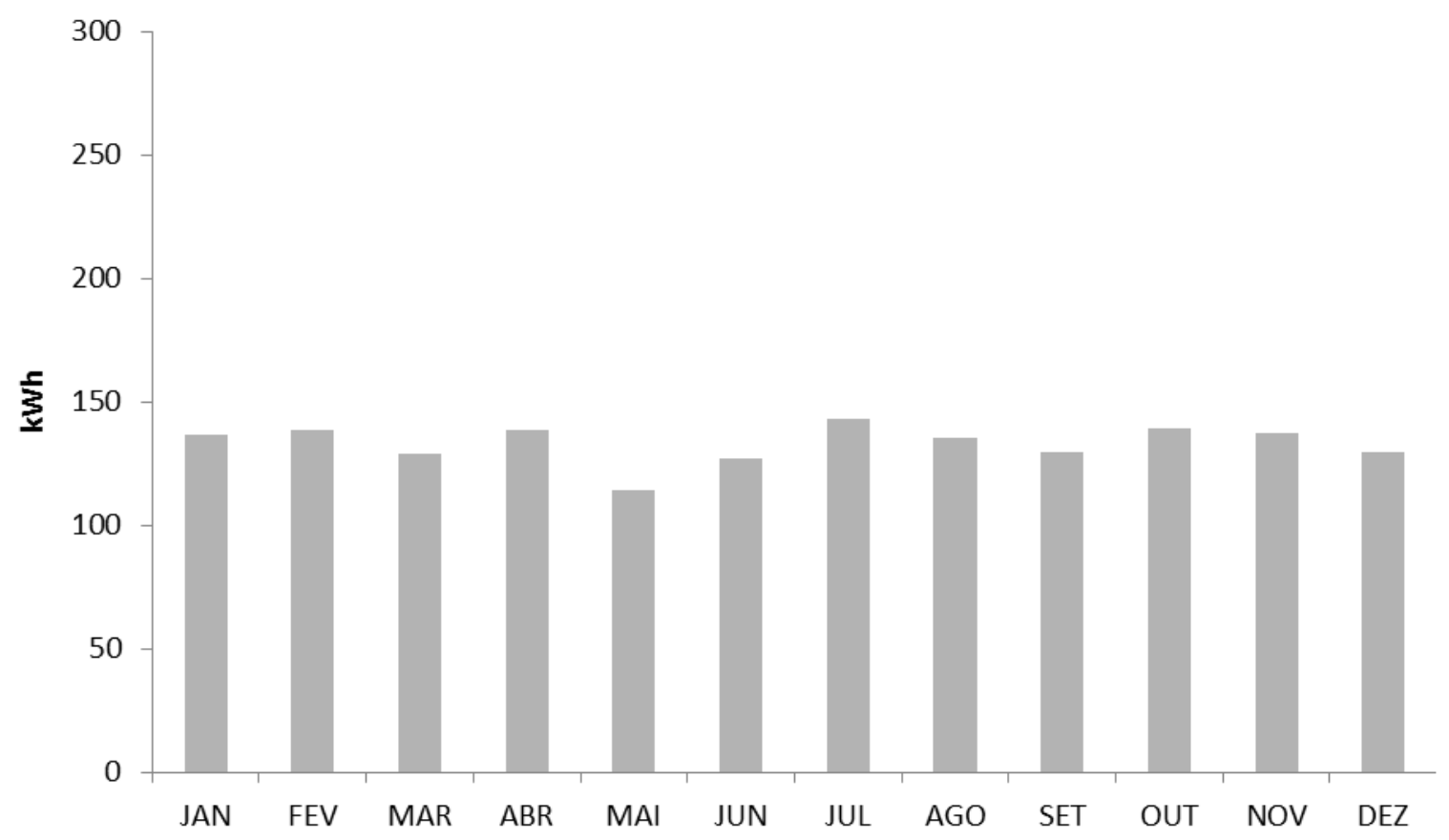

Figura 7.45 - Consumo elétrico mensal dos ventiladores (kWh) x meses do ano (cenário 2)

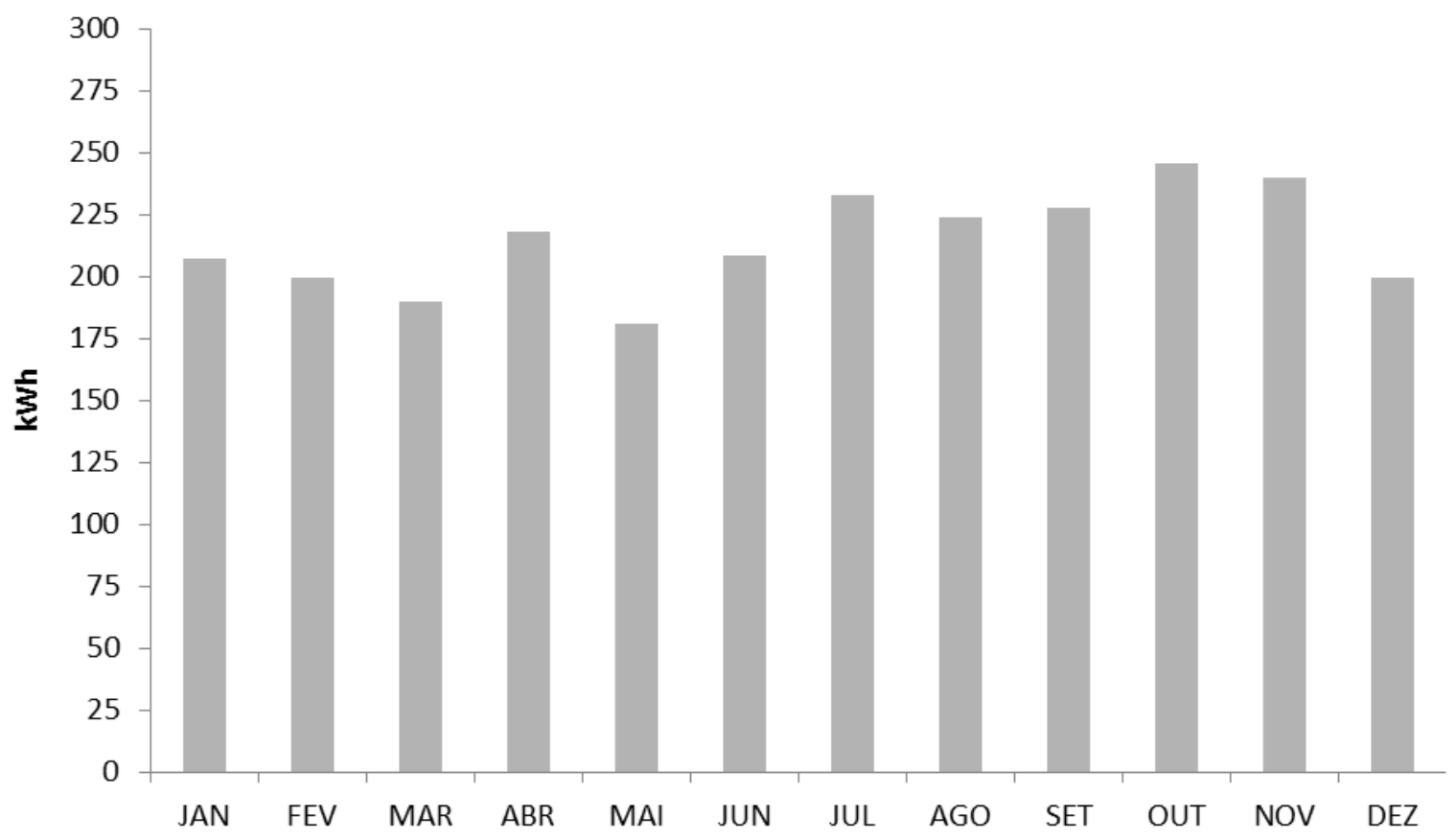

Figura 7.46 - Consumo elétrico mensal do fan coil (kWh) x meses do ano (cenário 2) 


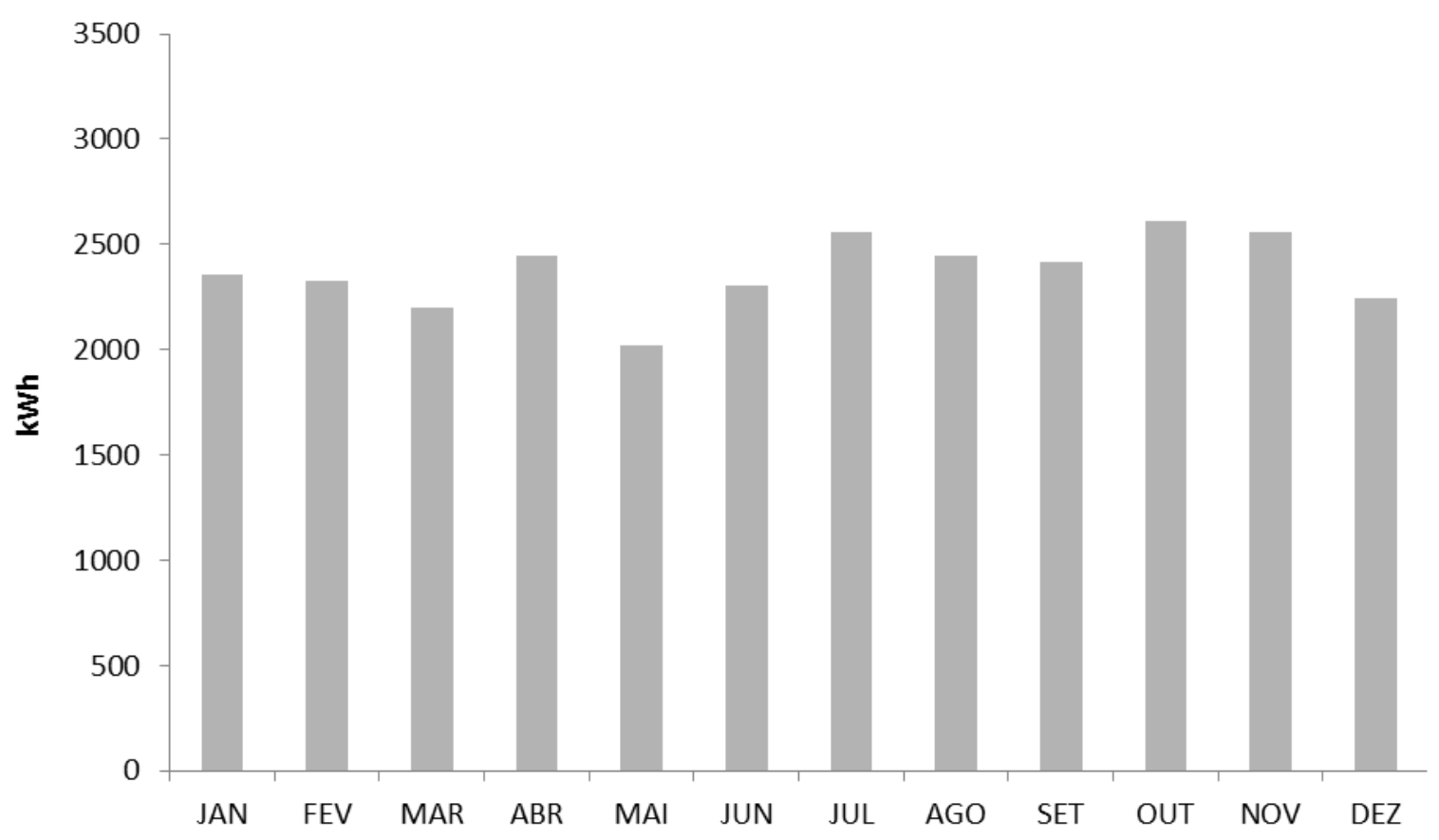

Figura 7.47 - Consumo elétrico mensal do chiller (kWh) x meses do ano (cenário 2)

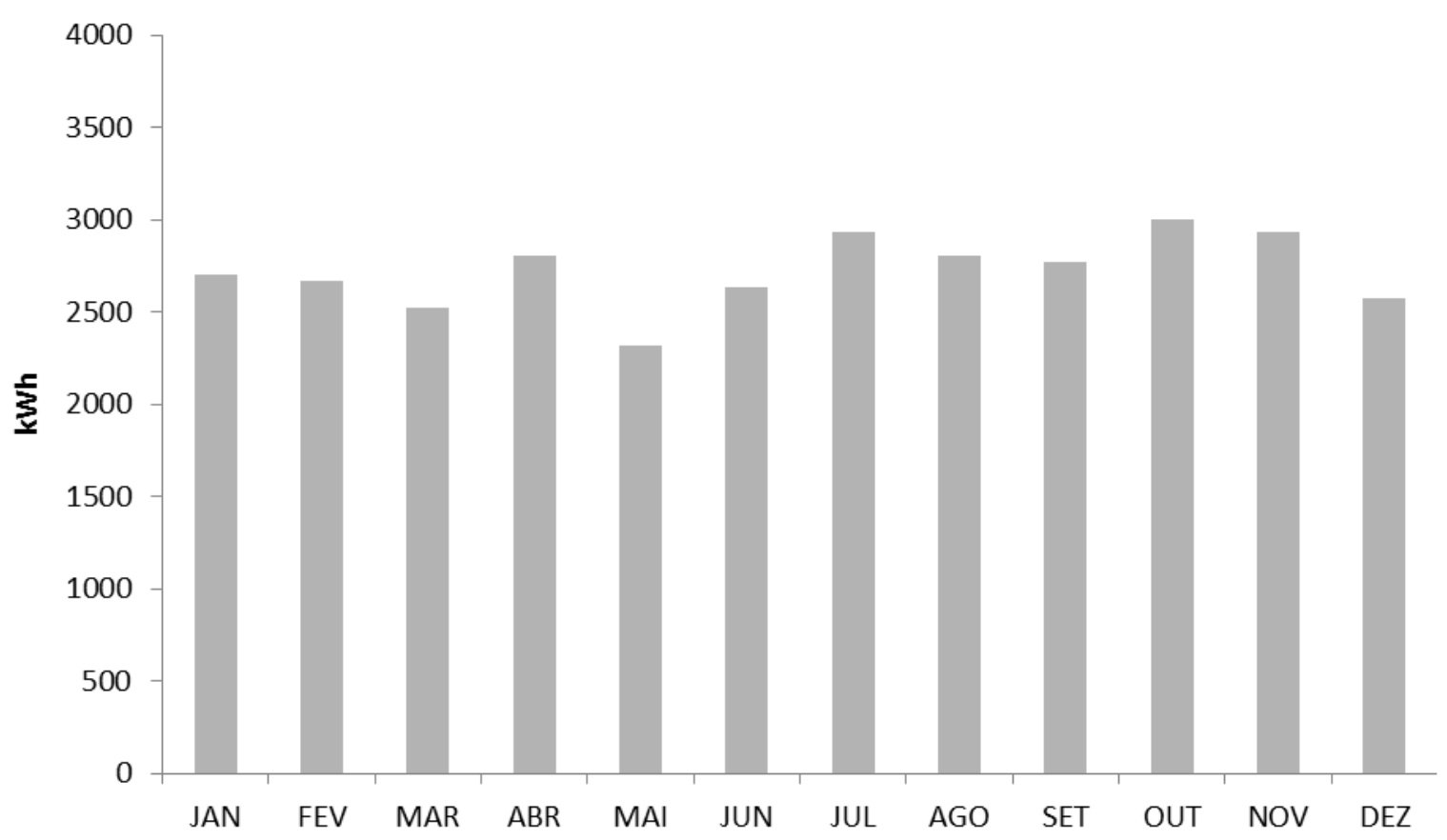

Figura 7.48 - Consumo elétrico mensal total $(\mathrm{kWh})$ x meses do ano (cenário 2)

\subsection{6 - Cenário 3: Solução com recuperação de energia $(\mathrm{CO2}=0 ; \mathrm{ERV}=1)$}

A Figura 7.49 apresenta o perfil de carga térmica devido ao ar externo de renovação para o cenário em questão ao longo do ano, que apresenta valores médios menores que os apresentados nos cenários 1 e 2. A Figura 7.50 apresenta os valores de entalpia do ar 
exterior, do ar interno e do ar na saída do ERV, mostrando claramente a redução da entalpia do ar externo que sai do ERV, e adentra o ambiente condicionado durante o ano.

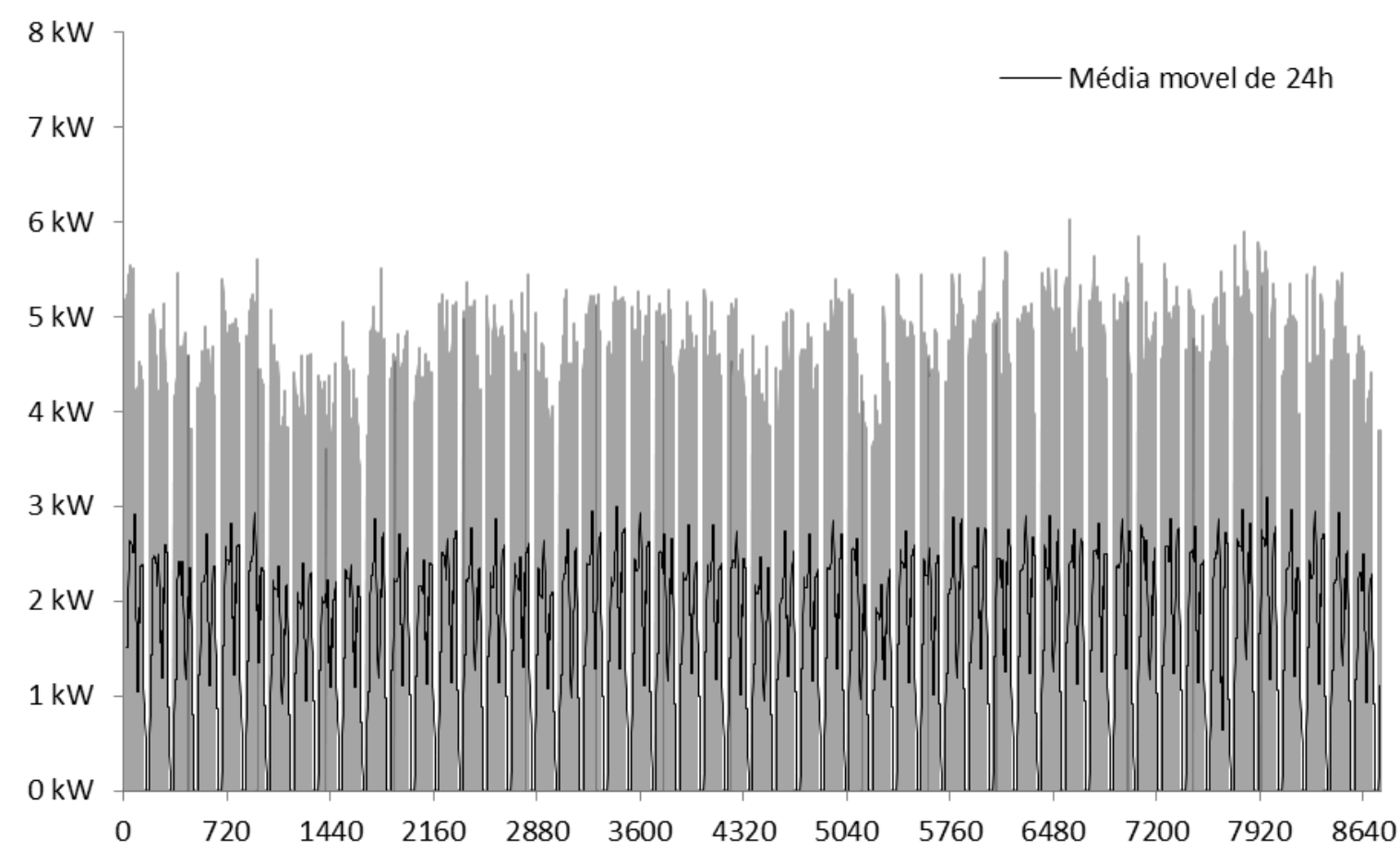

Figura 7.49 - Carga térmica do ar de renovação $(\mathrm{kW})$ x horas do ano (cenário)

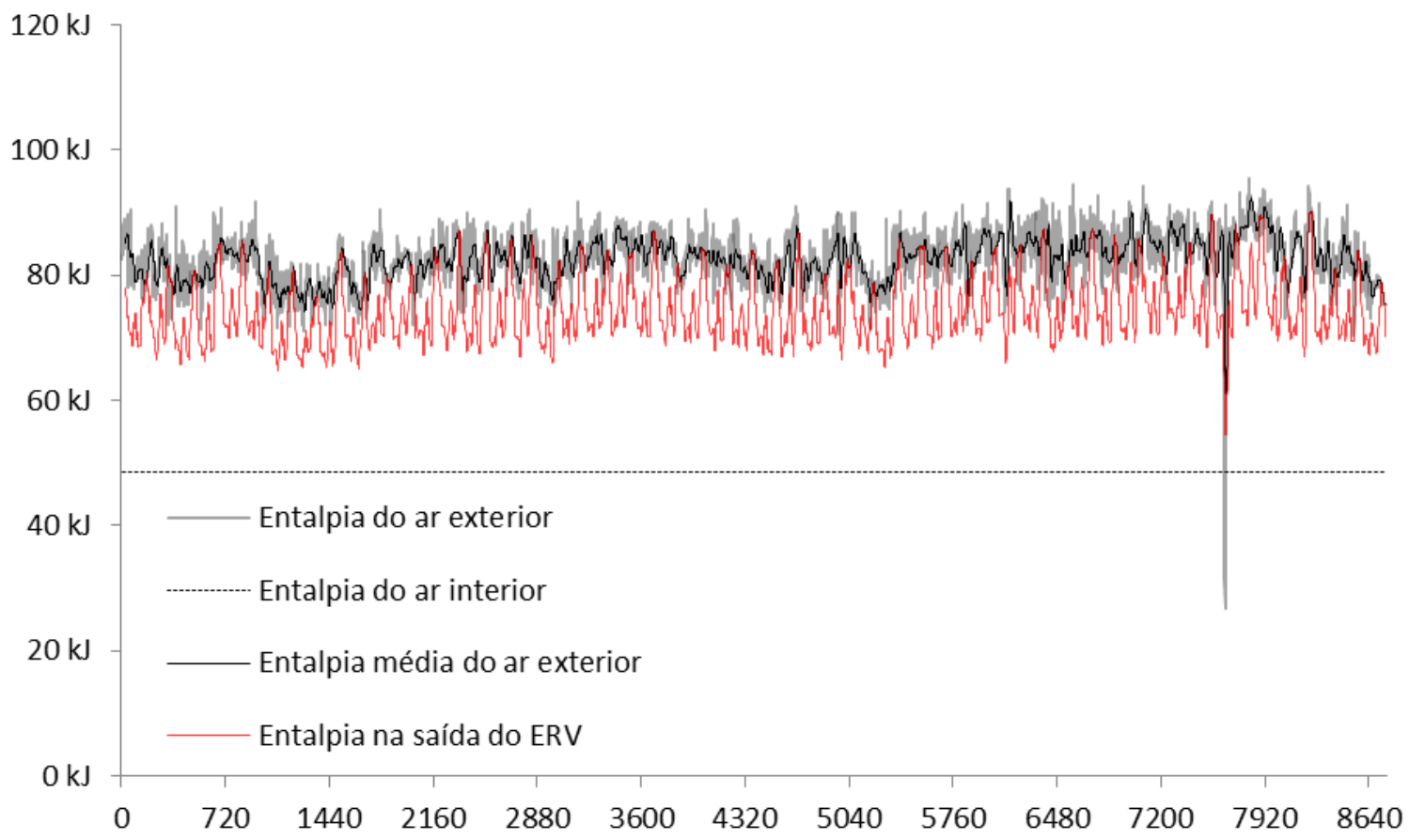

Figura 7.50 - Entalpia do ar externo e interno (kJ/kg) x horas do ano (cenário)

A Figura 7.51 apresenta os valores mensais integralizados hora a hora da recuperação de energia no ERV: 


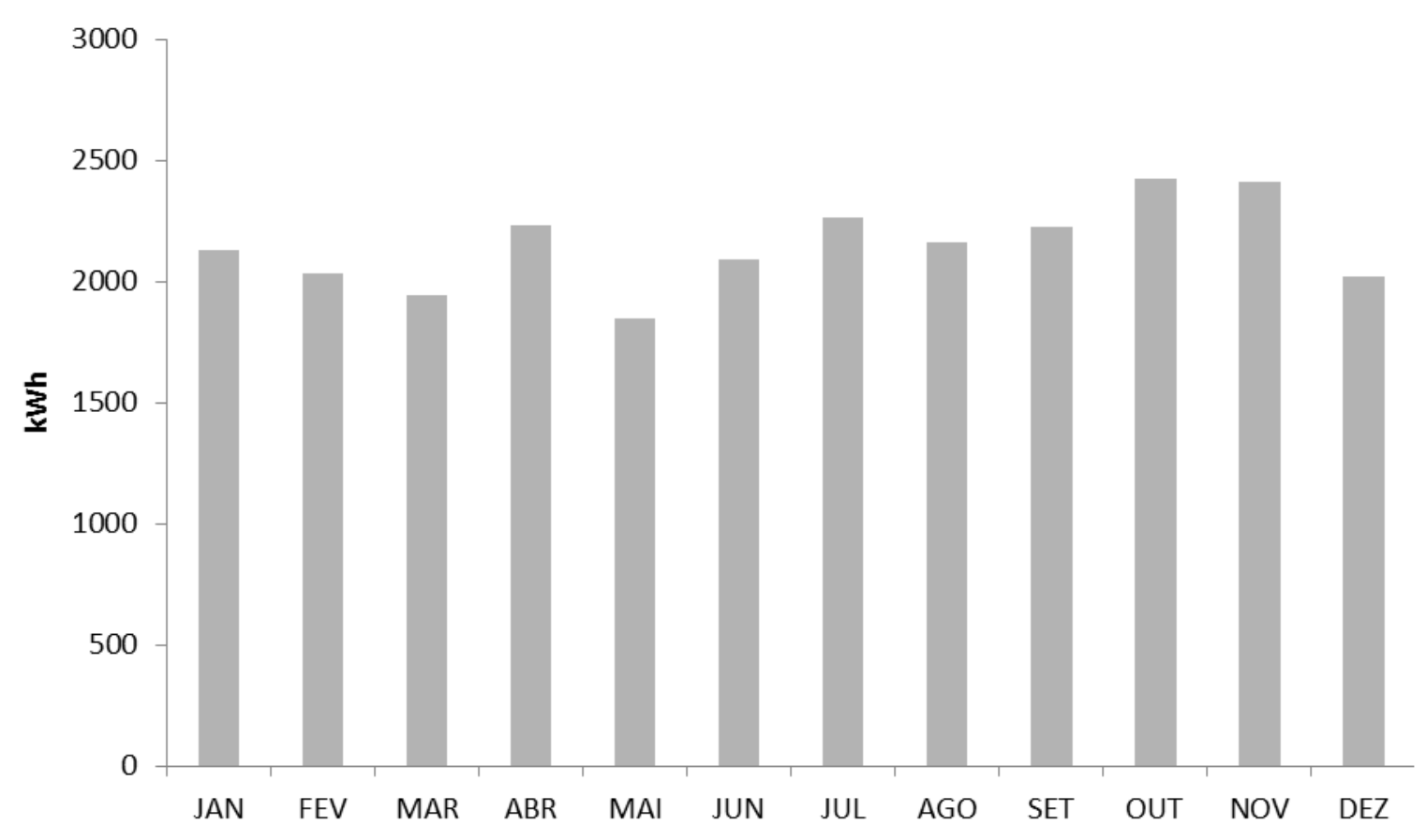

Figura 7.51 - Energia recuperada no VER $(\mathrm{kWh})$ x meses do ano (cenário 3)

A Tabela 7.22, a seguir, apresenta os valores integralizados ao longo do ano da carga térmica do ar externo de renovação, do consumo de energia elétrica dos ventiladores de renovação de ar, do fan coil, do chiller e o consumo elétrico total do cenário. As Figuras 7.52, 7.53, 7.54 e 7.55 apresentam esses consumos elétricos em cada mês do ano. O perfil referente ao consumo dos ventiladores (Figura 7.52) é praticamente constante ao longo dos meses, uma vez que o perfil de ocupação é semanal e a vazão de ar externo é sempre constante e igual ao valor máximo.

As pequenas diferenças são devido às diferenças dos dias da semana que compõem cada mês, gerando uma pequena diferença na ocupação acumulada mensal. $\mathrm{O}$ valor total do consumo elétrico dos ventiladores é igual ao consumo apresentado no cenário 1, uma vez que ambos os cenários não possuem controle de vazão do ar exterior.

O consumo elétrico total desse cenário também é menor que os consumos dos cenários 1 e 2, conforme mostra a Tabela 7.22, abaixo. Esse se fato se dá pela maior redução da carga térmica do ar de renovação, o que consequentemente reduziu o consumo dos equipamentos do sistema de ar condicionado:

Tabela 7.22 - Valores integralizados anuais para o cenário 3 


\begin{tabular}{cccc}
\hline $\begin{array}{c}\text { Carga térmica do } \\
\text { ar externo }\end{array}$ & $\begin{array}{c}\text { Consumo elétrico } \\
\text { dos ventiladores }\end{array}$ & $\begin{array}{c}\text { Consumo elétrico } \\
\text { do fan coil }\end{array}$ & $\begin{array}{c}\text { Consumo elétrico } \\
\text { do } \text { chiller }\end{array}$ \\
\hline $13.731,85 \mathrm{kWh}$ & $3.624,62 \mathrm{kWh}$ & $1.835,05 \mathrm{kWh}$ & $23.777,49 \mathrm{kWh}$ \\
\hline
\end{tabular}

Consumo elétrico total 29.237,16 kWh

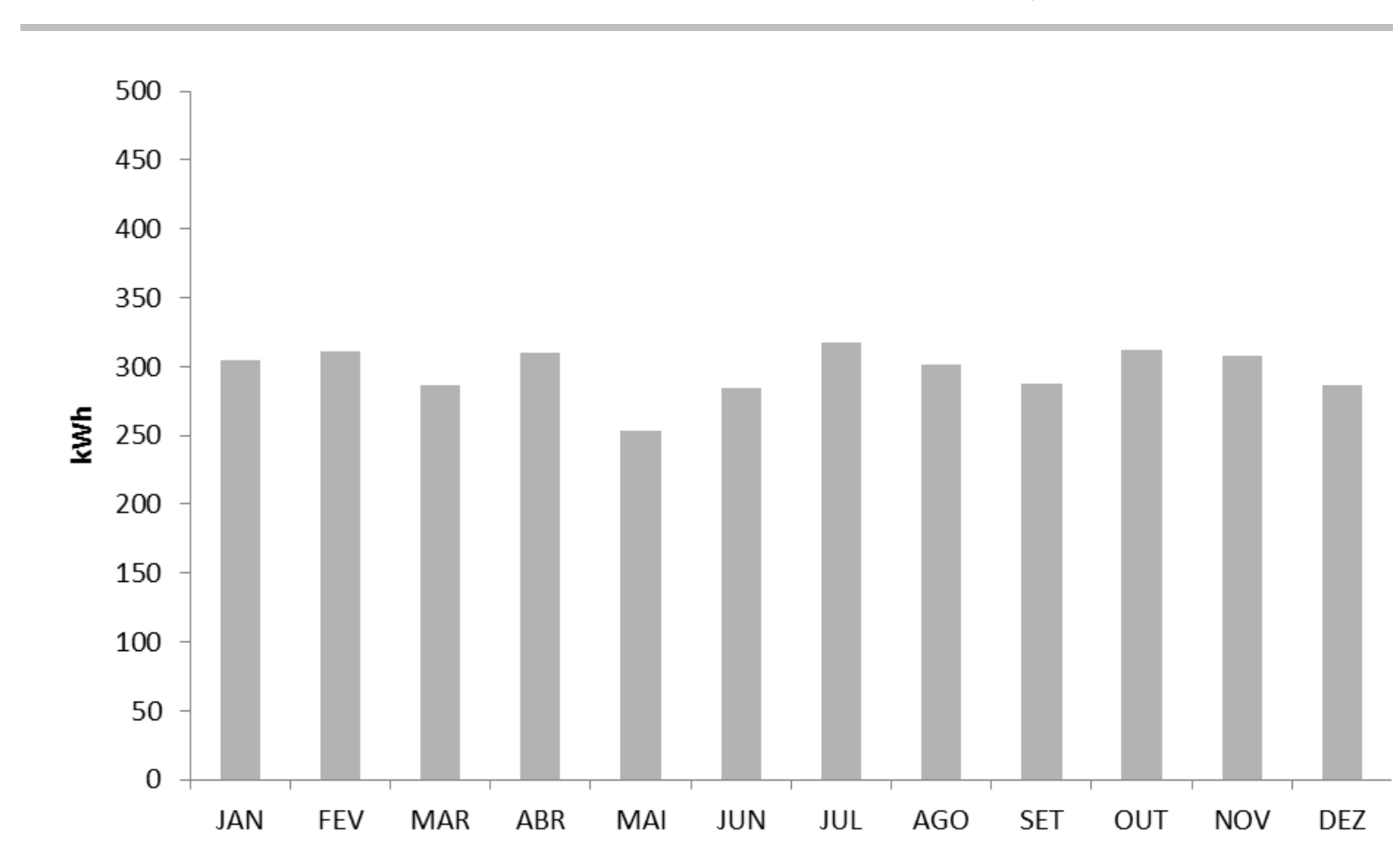

Figura 7.52 - Consumo elétrico mensal dos ventiladores (kWh) x meses do ano (cenário 3) 


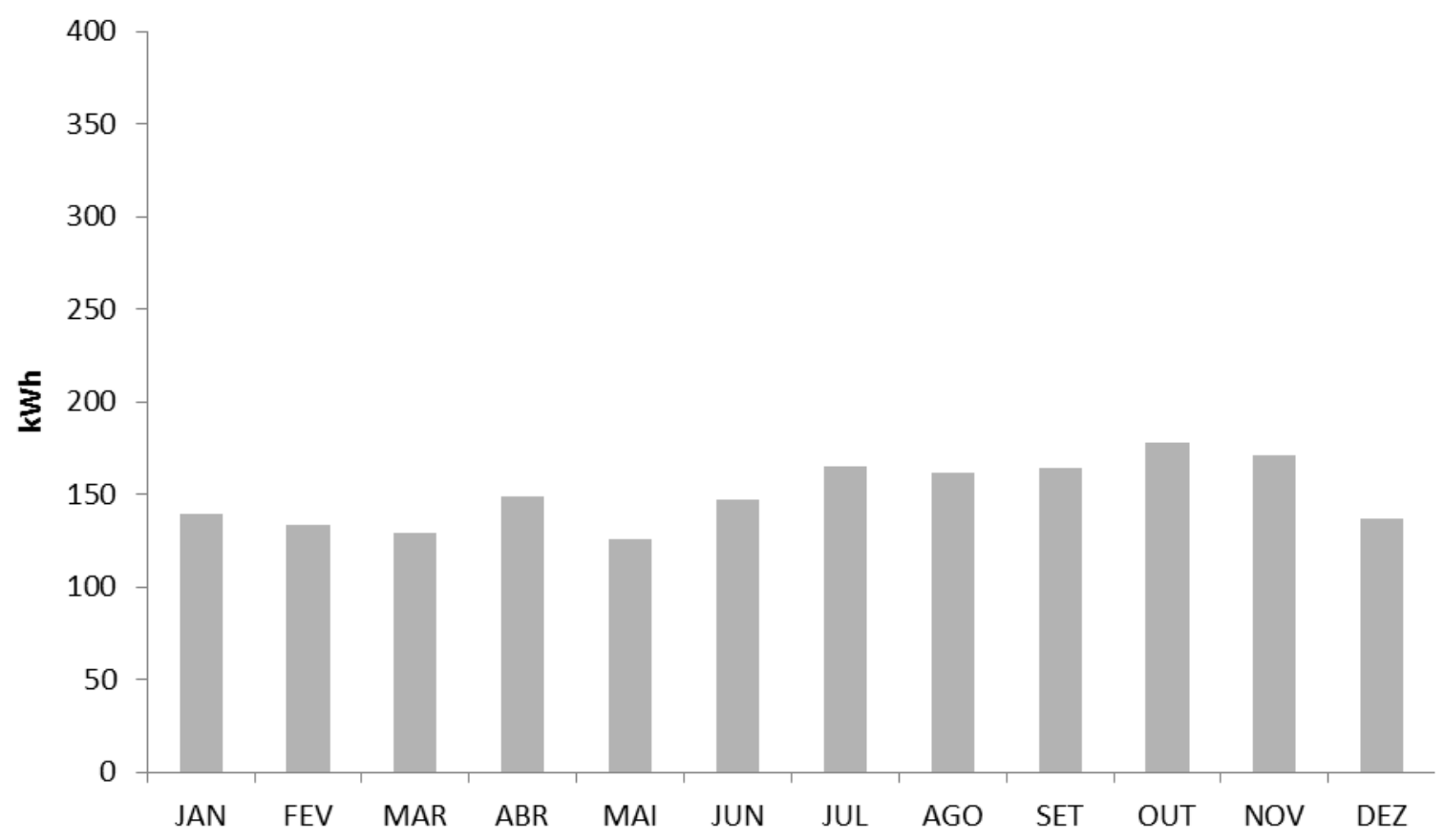

Figura 7.53 - Consumo elétrico mensal do fan coil (kWh) x meses do ano (cenário 3)

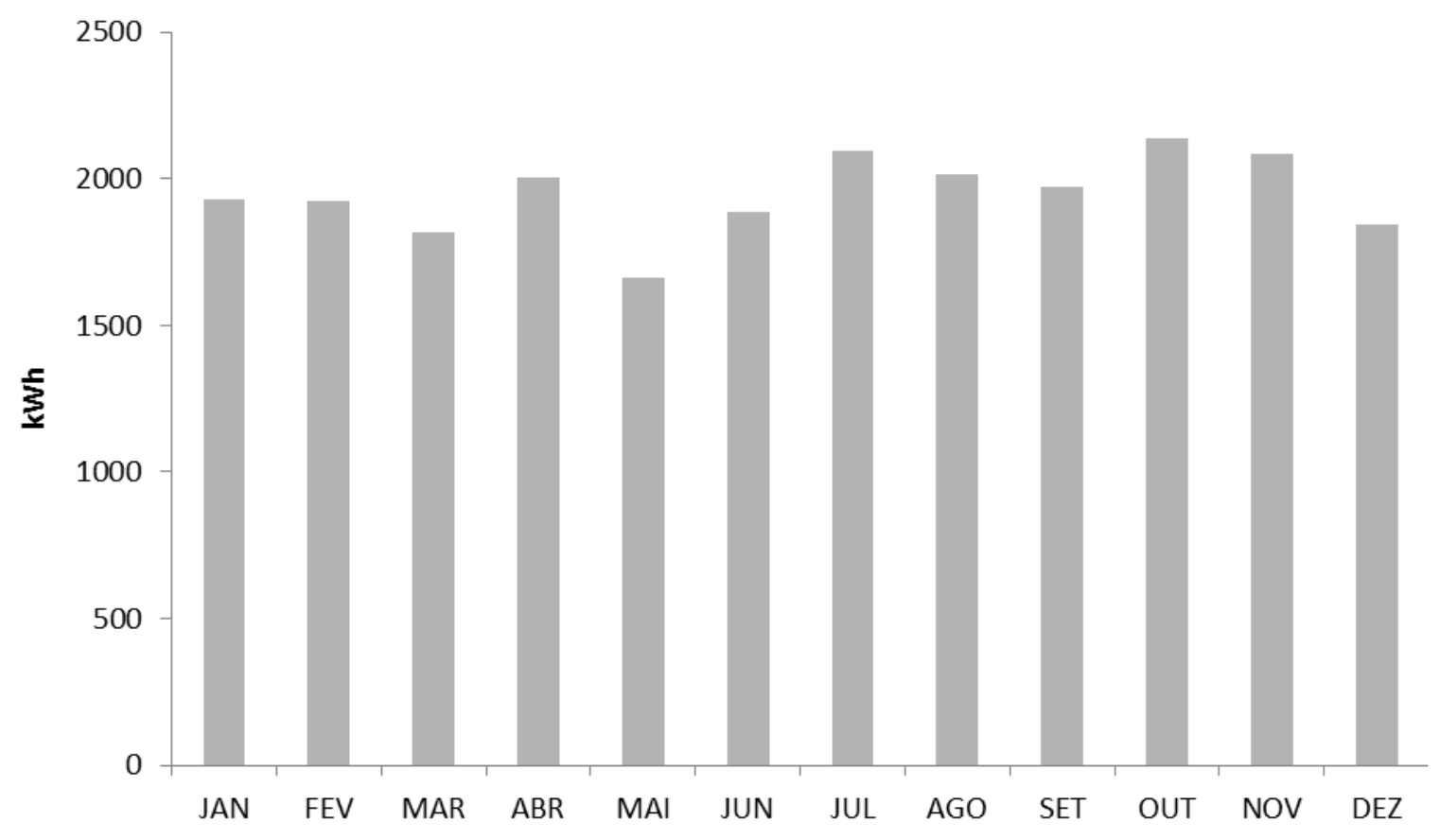

Figura 7.54 - Consumo elétrico mensal do chiller (kWh) x meses do ano (cenário 3) 


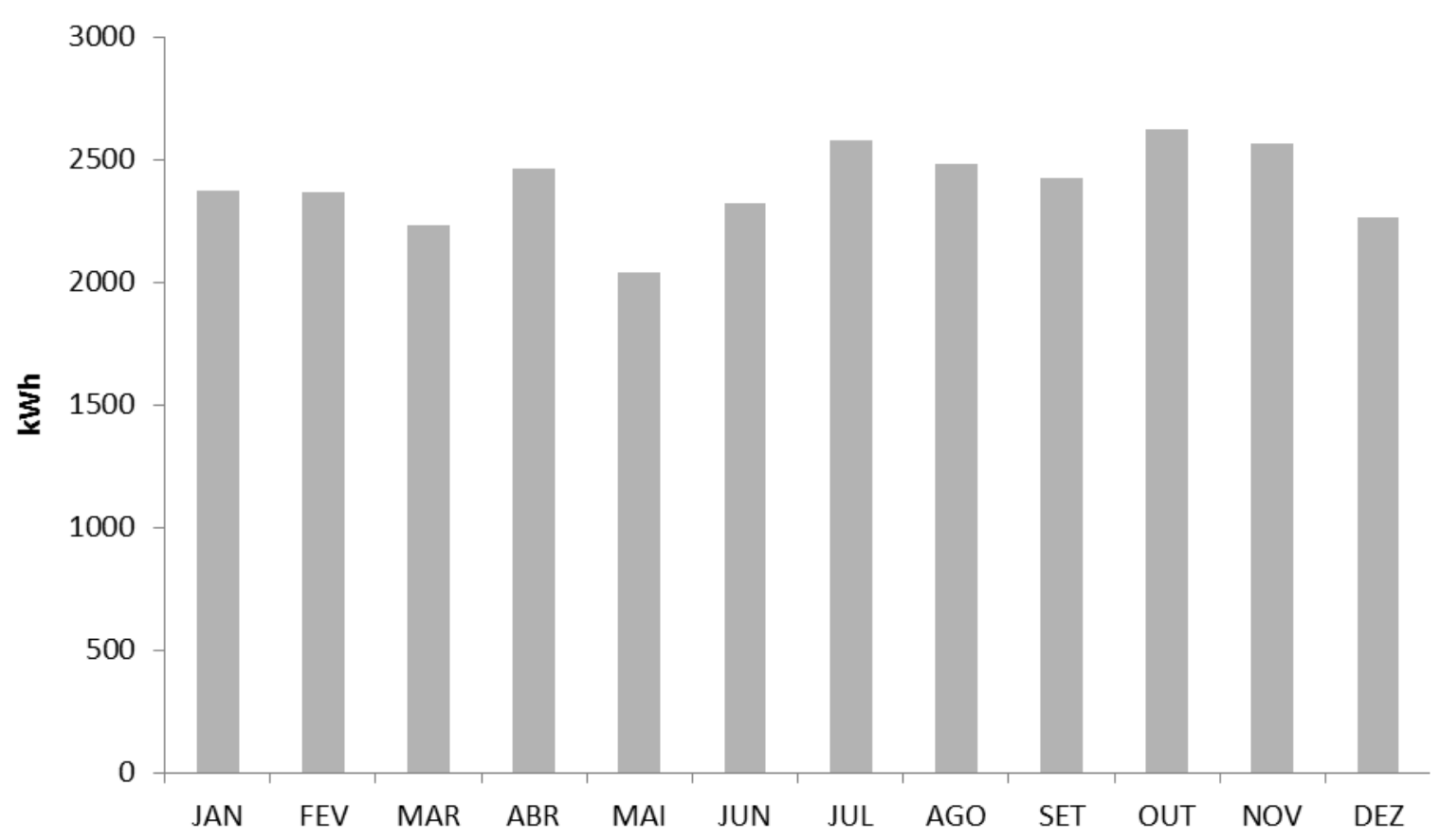

Figura 7.55 - Consumo elétrico mensal total $(\mathrm{kWh}) \times$ meses do ano (cenário 3)

\subsection{7 - Cenário 4: Solução completa $(\mathrm{CO} 2=1 ; \mathrm{ERV}=1)$}

A Figura 7.56, abaixo, apresenta o perfil de carga térmica devido ao ar externo de renovação para o cenário em questão ao longo do ano, que apresenta valores médios menores que os apresentados nos cenários 1,2 e 3 :

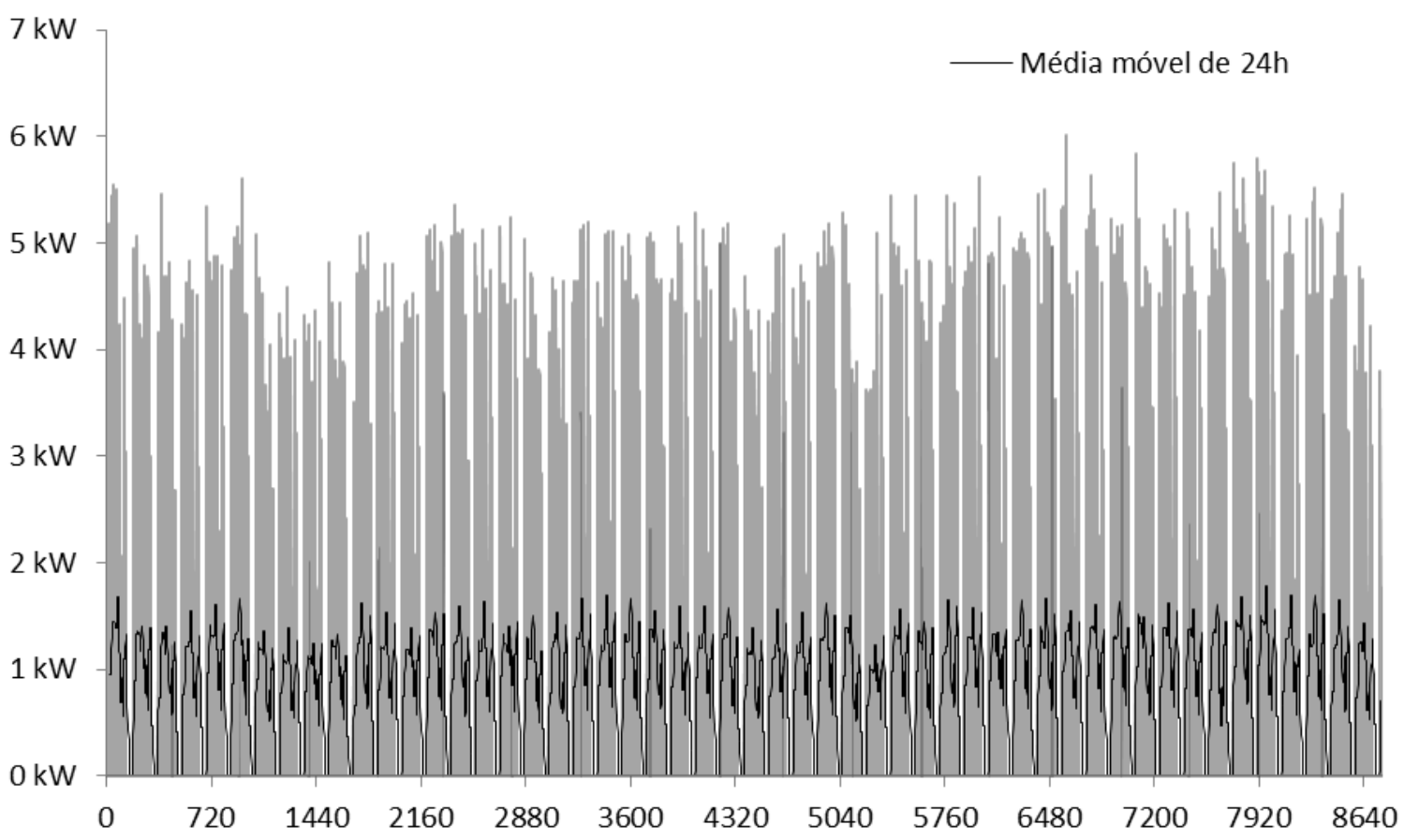

Figura 7.56 - Carga térmica do ar de renovação $(\mathrm{kW})$ x horas do ano (cenário 4) 
A Figura 7.57 apresenta os valores de entalpia do ar exterior, do ar interno e do ar na saída do ERV, mostrando claramente a redução da entalpia do ar externo que adentra o ambiente condicionado, reduzindo a carga térmica do ar de renovação durante todo o ano:

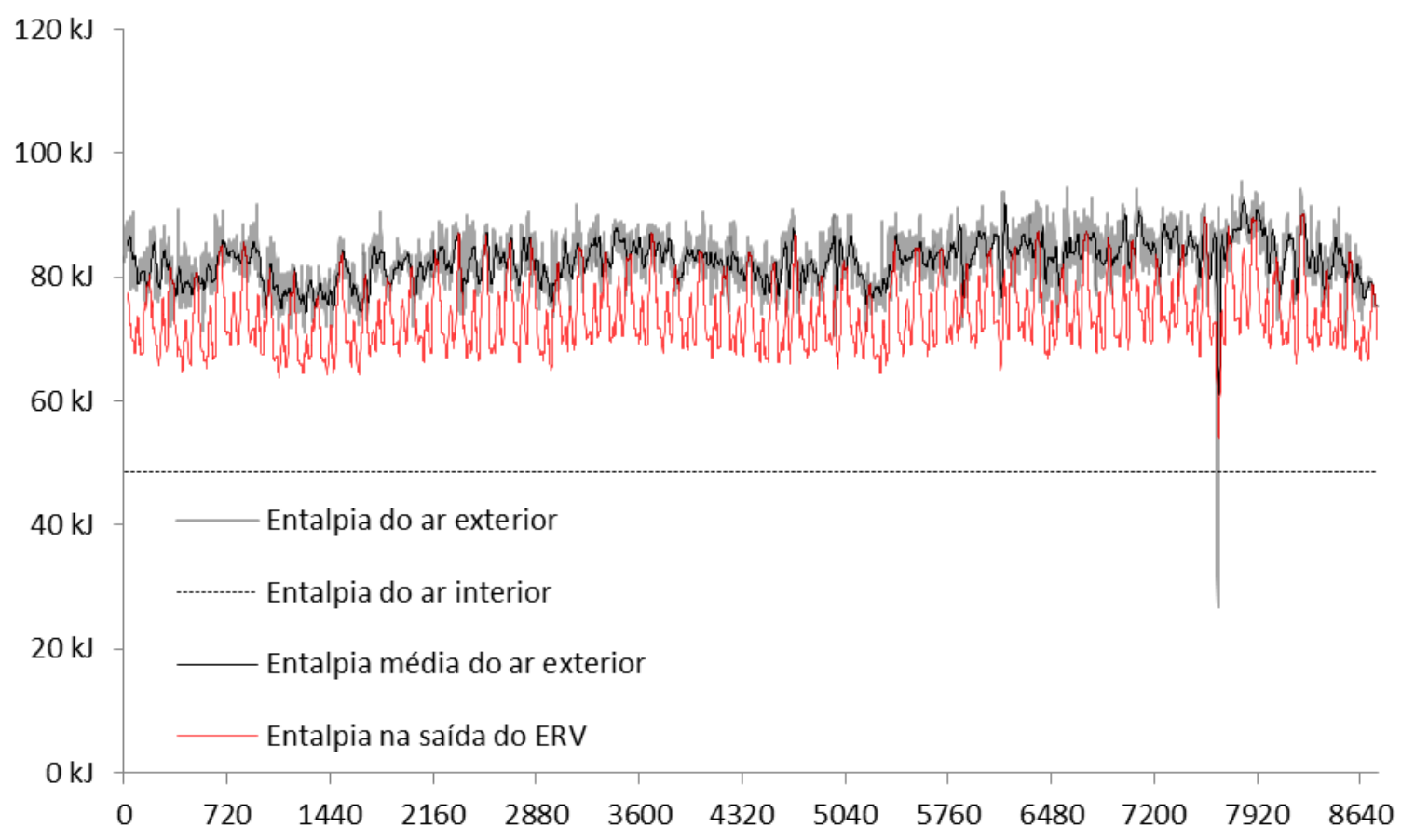

Figura 7.57 - Entalpia do ar externo e interno $(\mathrm{kJ} / \mathrm{kg})$ x horas do ano (cenário 4)

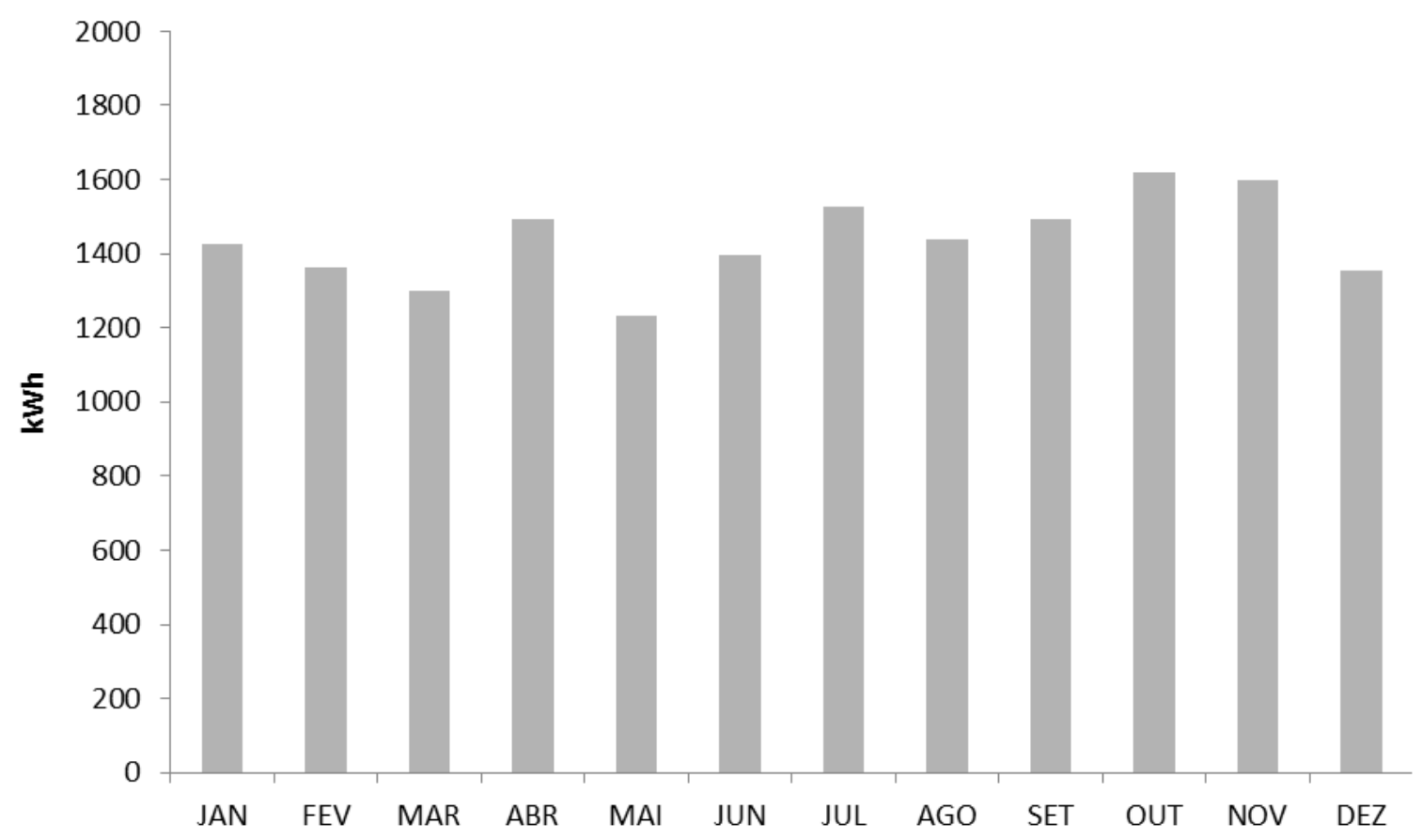

Figura 7.58 - Energia recuperada no ERV (kWh) x meses do ano (cenário 4) 
Essa última figura mostra que os valores médios de energia recuperada no ERV são menores nesse cenário do que os valores apresentados no cenário 3 (Figura 7.51), uma vez que as vazões médias são menores, já que há controle de vazão de ar exterior.

A Tabela 7.23, abaixo, apresenta os valores integralizados ao longo do ano da carga térmica do ar externo de renovação, do consumo de energia elétrica dos ventiladores de renovação de ar, do fan coil, do chiller e o consumo elétrico total do cenário. As Figuras 7.59, 7.60, 7.62 e 7.63 apresentam esses consumos elétricos em cada mês do ano. O perfil referente ao consumo dos ventiladores (Figura 7.59) é praticamente constante ao longo dos meses, uma vez que o perfil de ocupação é semanal e a vazão de ar externo é sempre constante e igual ao valor máximo.

As pequenas diferenças são devido às diferenças dos dias da semana que compõem cada mês, gerando uma pequena diferença na ocupação acumulada mensal. $\mathrm{O}$ valor total do consumo elétrico dos ventiladores é igual ao consumo apresentado no cenário 2 , uma vez que ambos os cenários possuem controle de vazão do ar exterior.

O consumo elétrico total desse cenário é menor que os consumos dos cenários 1,2 e 3, conforme mostra a Tabela (7.23), abaixo. Esse fato se dá pela maior redução da carga térmica do ar de renovação, devido aos recursos da recuperação de energia e controle de vazão do ar exterior, o que consequentemente reduziu o consumo dos equipamentos do sistema de ar condicionado:

Tabela 7.23 - Valores integralizados anuais para o cenário 4

\begin{tabular}{cccc}
\hline $\begin{array}{c}\text { Carga térmica do } \\
\text { ar externo }\end{array}$ & $\begin{array}{c}\text { Consumo elétrico } \\
\text { dos ventiladores }\end{array}$ & $\begin{array}{c}\text { Consumo elétrico } \\
\text { do fan coil }\end{array}$ & $\begin{array}{c}\text { Consumo elétrico } \\
\text { do } \text { chiller }\end{array}$ \\
\hline $7.574,60 \mathrm{kWh}$ & $1.625,97 \mathrm{kWh}$ & $1.610,21 \mathrm{kWh}$ & $22.032,75 \mathrm{kWh}$ \\
\hline
\end{tabular}




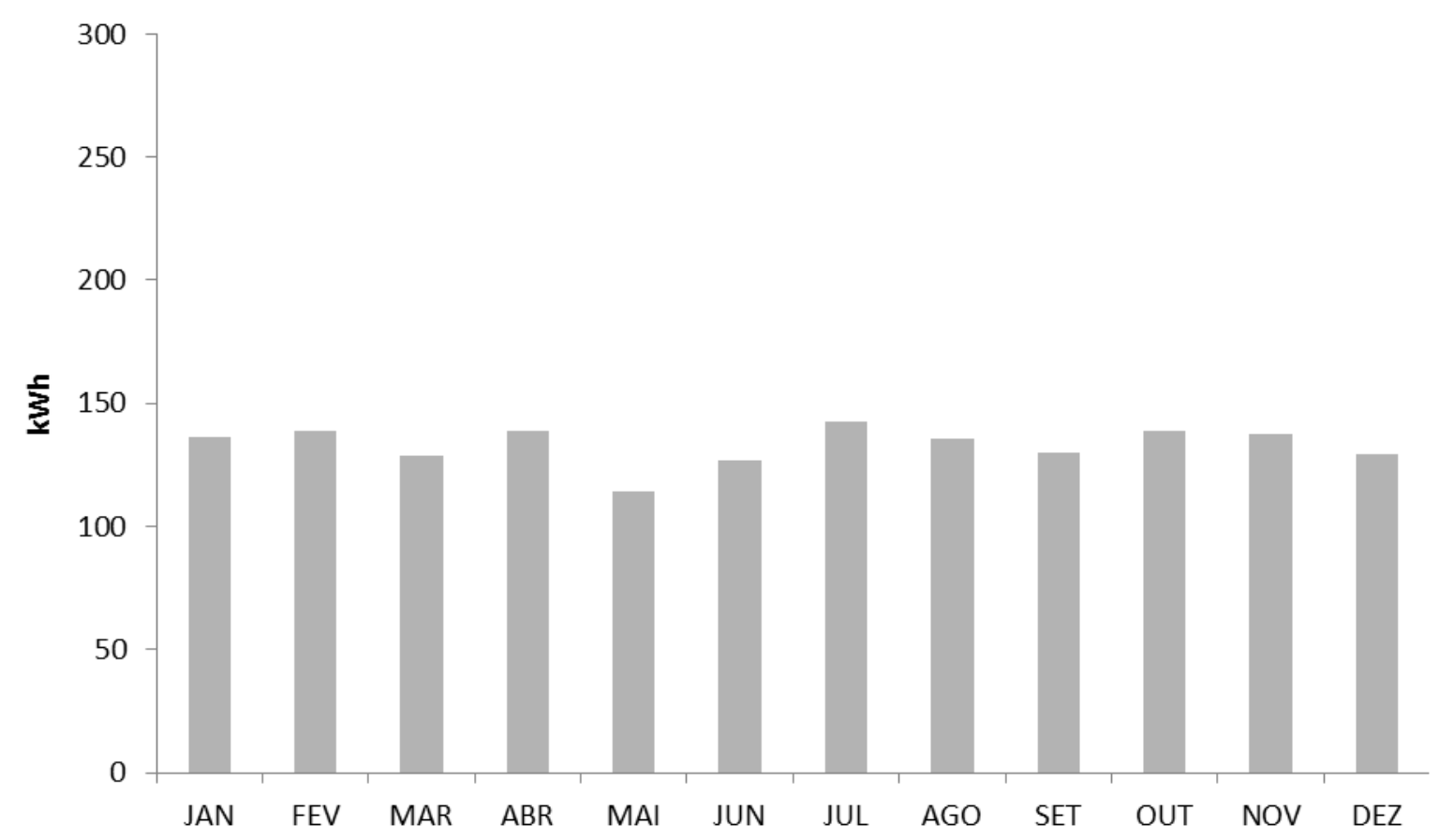

Figura 7.59 - Consumo elétrico mensal dos ventiladores (kWh) x meses do ano (cenário 4)

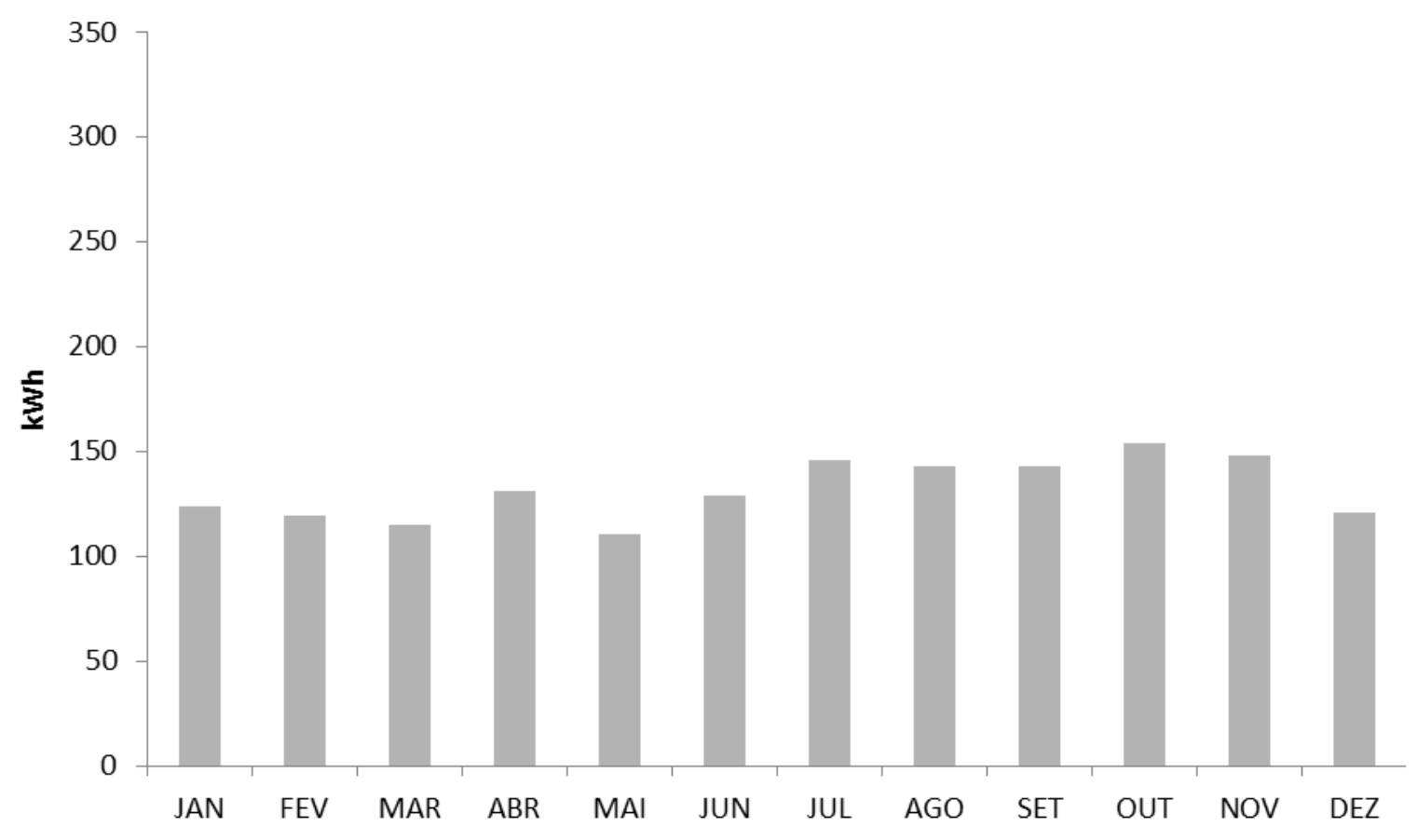

Figura 7.60 - Consumo elétrico mensal do fan coil (kWh) x meses do ano (cenário 4) 


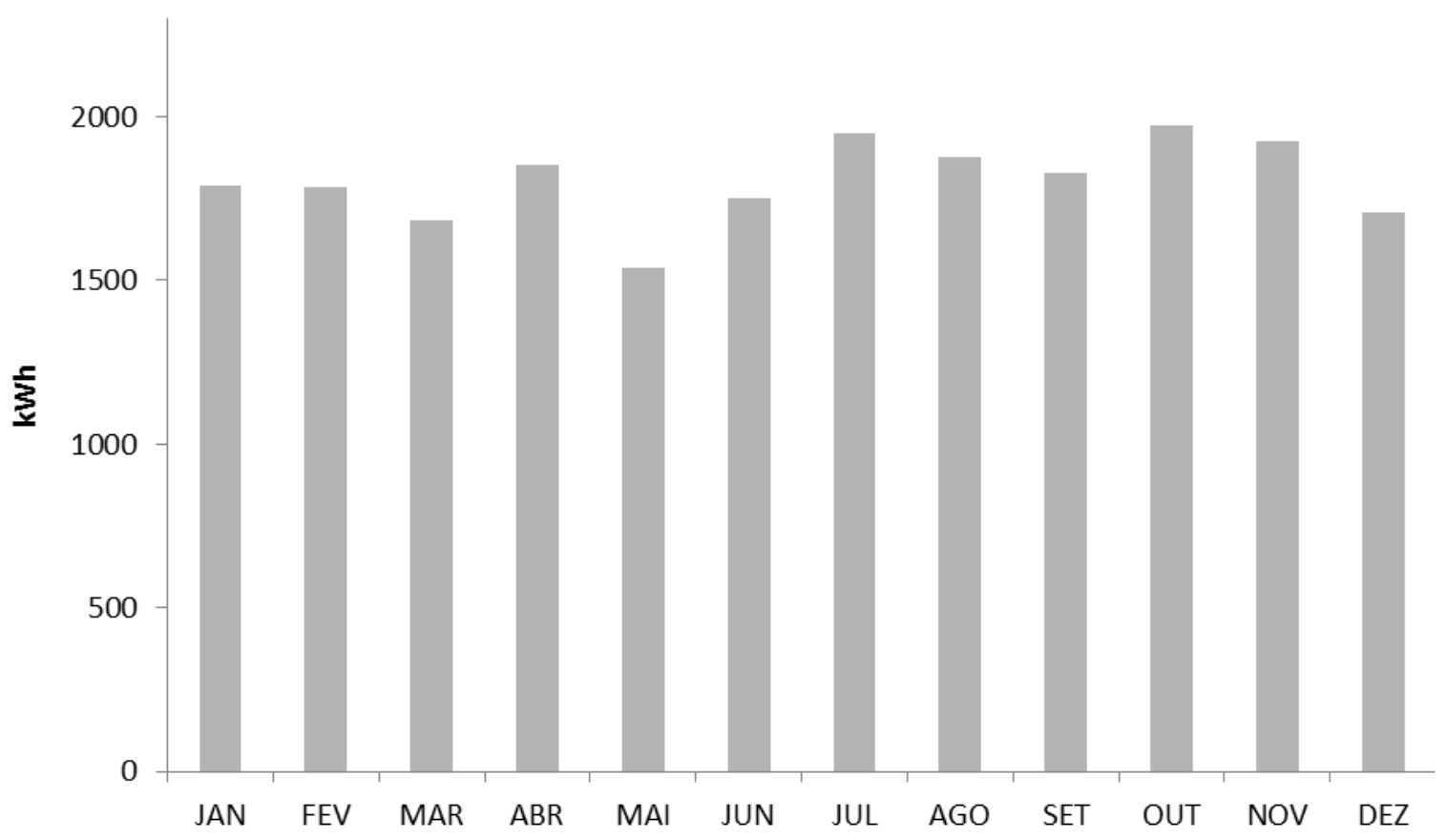

Figura 7.61 - Consumo elétrico mensal do chiller (kWh) x meses do ano (cenário 4)

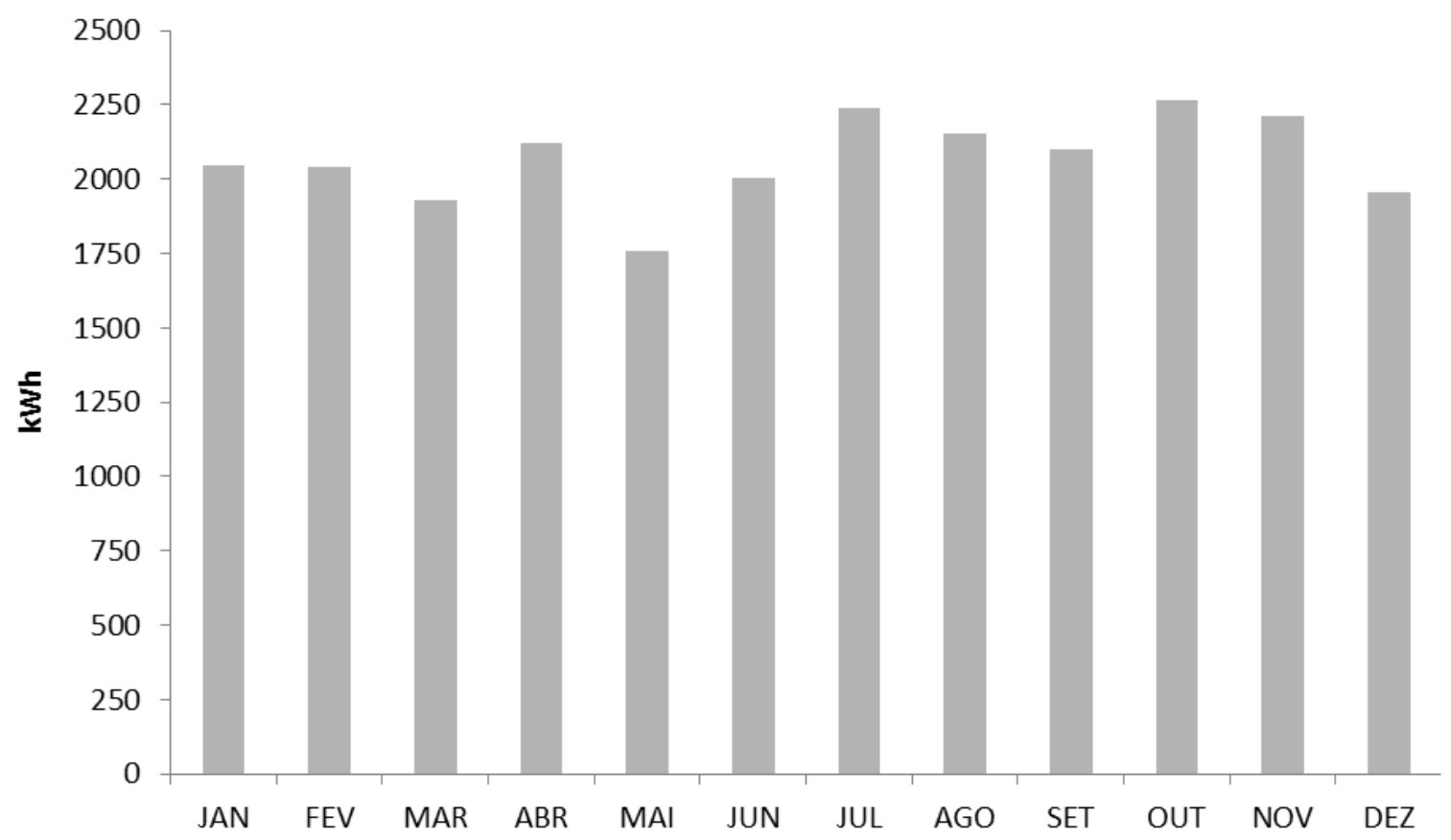

Figura 7.62 - Consumo elétrico mensal total $(\mathrm{kWh})$ x meses do ano (cenário 4)

\subsection{8 - Comparação entre os cenários}

A partir dos resultados apresentados é possível realizar uma análise comparativa, com o objetivo de verificar a economia de energia proporcionada pelos recursos 
apresentados em cada cenário, relacionando essa economia com os custos iniciais e operacionais com o intuito de avaliar o retorno do investimento de cada cenário.

A Figura 7.63, abaixo, apresenta os valores médios da carga térmica do ar de renovação para os quatro cenários propostos. A Figura 7.64 apresenta os valores da carga térmica do ar de renovação integralizados hora a hora ao longo do ano também para cada um deles:

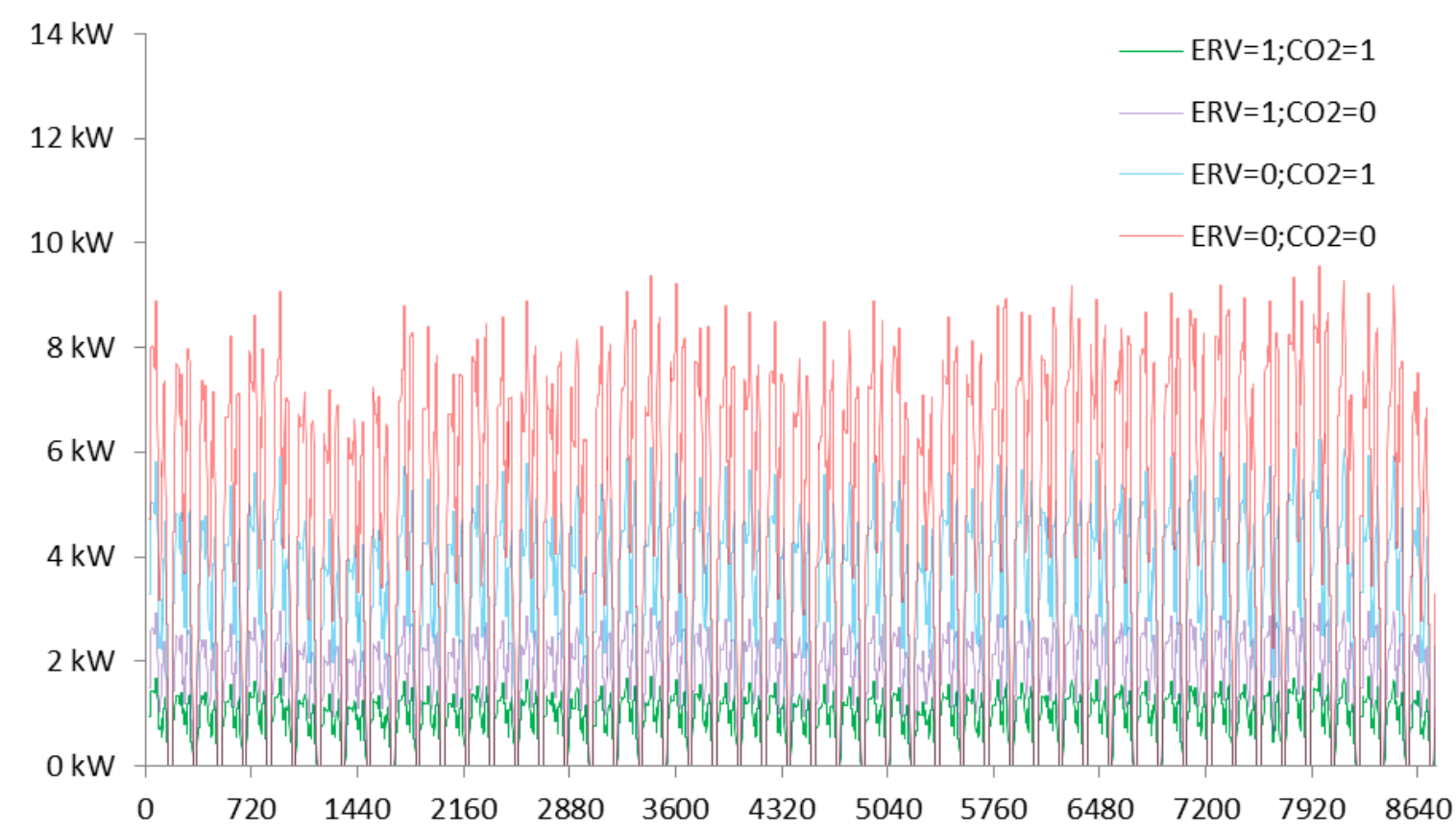

Figura 7.63 - Carga térmica do ar de renovação $(\mathrm{kW})$ x horas do ano (para os 4 cenários) 


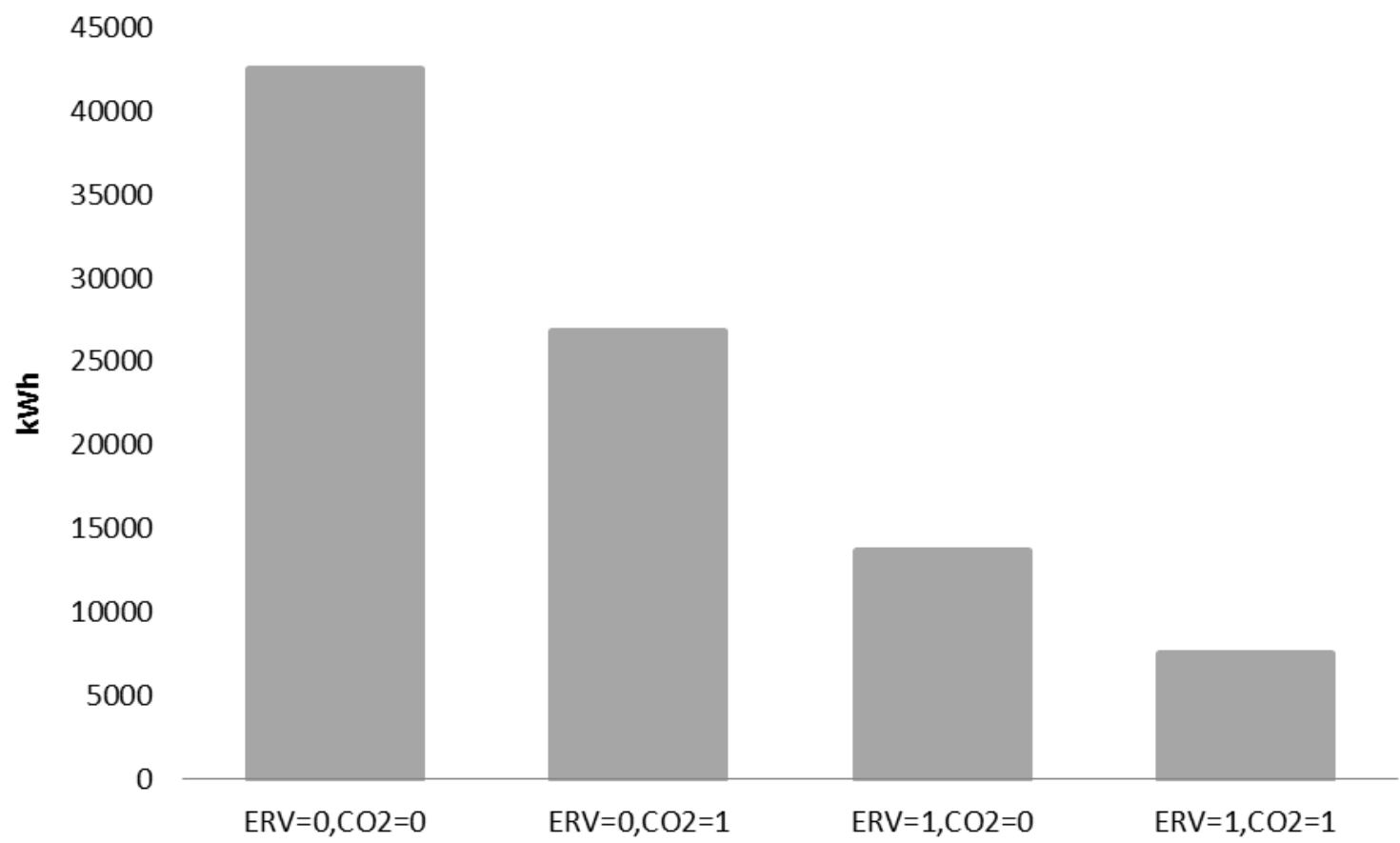

Figura 7.64 - Carga térmica do ar de renovação $(\mathrm{kWh})$ x cenário

A Tabela 7.24 é uma tabela comparativa entre os valores de consumo de energia apresentados para cada cenário, mostrando os valores integralizados anualmente da energia total consumida em cada um, a diferença da energia total dos cenários 2,3 e 4 em relação ao cenário 1 , o custo dessa energia total por ano, as economias absoluta e relativa dos cenários 2, 3 e 4 em relação ao cenário 1 e o custo total de cada cenário integralizado ao longo de cinco anos de operação. É possível verificar que a solução mais econômica é a proposta no cenário 4 , que resulta em uma economia anual de $37,83 \%$ no consumo de energia elétrica, conforme apresentado também na Figura 7.65:

Tabela 7.24 - Comparação dos custos energéticos para os quatro cenários

\begin{tabular}{ccccc}
\hline & Cenário 1 & Cenário 2 & Cenário 3 & Cenário 4 \\
\hline $\mathrm{E}(\mathrm{kWh})$ & $40.645,00$ & $33.242,00$ & $29.237,00$ & $25.269,00$ \\
$\mathrm{DE}(\mathrm{kWh}) *$ & - & $7.402,00$ & $11.407,00$ & $15.375,00$ \\
$\mathrm{R} \$$ /ano & $\mathrm{R} \$ 12.193,00$ & $\mathrm{R} \$ 9.973,00$ & $\mathrm{R} \$ 8.771,00$ & $\mathrm{R} \$ 7.581,00$ \\
Economia $(\mathrm{R} \$)$ & - & $\mathrm{R} \$ 2.221,00$ & $\mathrm{R} \$ 3.422,00$ & $\mathrm{R} \$ 4.613,00$ \\
Economia $(\%)$ & - & $18,21 \%$ & $28,07 \%$ & $37,83 \%$
\end{tabular}

Anos 


\begin{tabular}{lllll}
\hline 2 & $\mathrm{R} \$ 24.386,83$ & $\mathrm{R} \$ 19.945,18$ & $\mathrm{R} \$ 17.542,30$ & $\mathrm{R} \$ 15.161,36$ \\
3 & $\mathrm{R} \$ 36.580,24$ & $\mathrm{R} \$ 29.917,76$ & $\mathrm{R} \$ 26.313,44$ & $\mathrm{R} \$ 22.742,04$ \\
4 & $\mathrm{R} \$ 48.773,65$ & $\mathrm{R} \$ 39.890,35$ & $\mathrm{R} \$ 35.084,59$ & $\mathrm{R} \$ 30.322,72$ \\
5 & $\mathrm{R} \$ 60.967,06$ & $\mathrm{R} \$ 49.862,94$ & $\mathrm{R} \$ 43.855,74$ & $\mathrm{R} \$ 37.903,40$
\end{tabular}

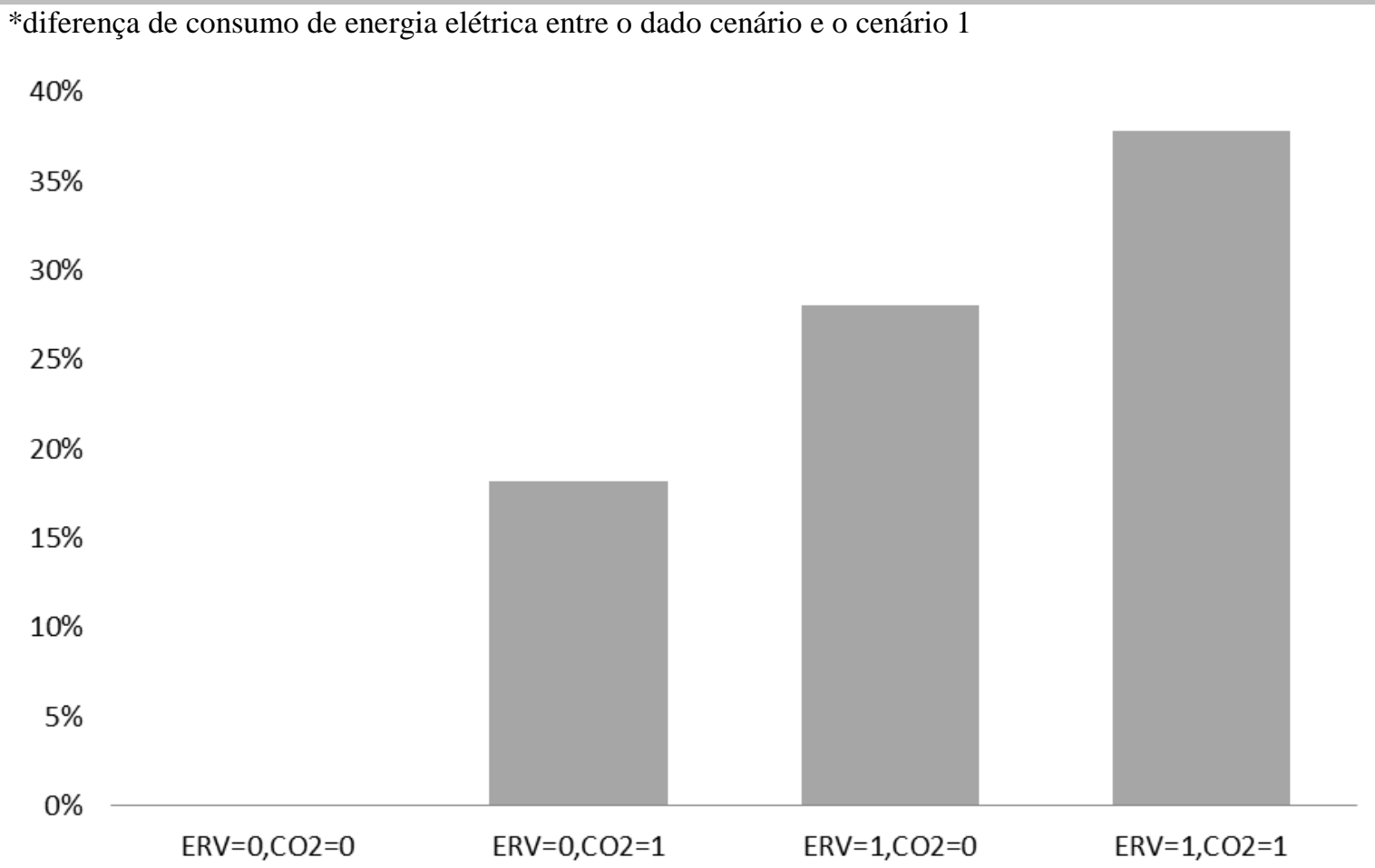

Figura 7.65 - Energia elétrica economizada anualmente $(\%)$ x cenário

Assim, como mostrado na Figura 7.65, é possível verificar que o recurso da recuperação de energia fornece uma economia de energia maior que o recurso do controle de vazão de ar exterior para o perfil de ocupação proposto no estudo de caso. Isso se deve principalmente ao fato de o recurso do ERV proporcionar uma maior redução da carga térmica do ar de renovação que o controle de vazão de ar exterior, e, como permite o dimensionamento de sistemas de ar condicionado com menos potência, o consumo também é menor, já que a carga térmica total é menor que em sistemas que operem sem esse recurso.

A partir dos dados dos custos operacionais com energia elétrica, é possível verificar o retorno do investimento de cada solução, como mostra as Tabelas 7.25, 7.26 e 7.27:

Tabela 7.25 - Custos iniciais dos cenários

Cenário
Cenário 1
Cenário 2
Cenário 3
Cenário 4
$(\mathrm{ERV}=0 ; \mathrm{CO} 2=0)$
$(\mathrm{ERV}=0 ; \mathrm{CO} 2=1)$
$(\mathrm{ERV}=1 ; \mathrm{CO2}=0)$
$(E R V=1 ; C O 2=1)$ 


\section{CUSTOS INICIAIS}

\begin{tabular}{|c|c|c|c|c|}
\hline $\begin{array}{l}\text { Sistema de } \\
12 \mathrm{TR}\end{array}$ & - & - & $\mathrm{R} \$ 60.000,00$ & $\mathrm{R} \$ 60.000,00$ \\
\hline $\begin{array}{l}\text { Sistema de } \\
15 \text { TR }\end{array}$ & $\mathrm{R} \$ 75.000,00$ & $\mathrm{R} \$ 75.000,00$ & - & - \\
\hline $\begin{array}{c}\text { Equipamento } \\
\text { ERV }\end{array}$ & - & - & $\mathrm{R} \$ 12.000,00$ & $\mathrm{R} \$ 12.000,00$ \\
\hline $\begin{array}{c}\text { Ventiladores } \\
\text { de ar }\end{array}$ & $\mathrm{R} \$ 3.600,00$ & $\mathrm{R} \$ 3.600,00$ & - & - \\
\hline $\begin{array}{l}\text { Controle de } \\
\text { vazão }\end{array}$ & - & $\mathrm{R} \$ 2.400,00$ & - & $\mathrm{R} \$ 2.400,00$ \\
\hline Automação & - & $\mathrm{R} \$ 7.299,88$ & $\mathrm{R} \$ 7.138,47$ & $\mathrm{R} \$ 10.204,07$ \\
\hline TOTAL & $\mathrm{R} \$ \mathbf{7 8 . 6 0 0 , 0 0}$ & $\mathrm{R} \$ \mathbf{8 8 . 2 9 9 , 8 8}$ & $R \$ 79.138,47$ & $R \$ 84.604,07$ \\
\hline \multicolumn{5}{|c|}{ Tabela 7.26 - Custos operacionais dos cenários } \\
\hline Cenário & $\begin{array}{c}\text { Cenário 1 } \\
(\mathrm{ERV}=0 ; \mathrm{CO}=0)\end{array}$ & $\begin{array}{c}\text { Cenário 2 } \\
(\mathrm{ERV}=\mathbf{0} ; \mathrm{CO2}=\mathbf{1})\end{array}$ & 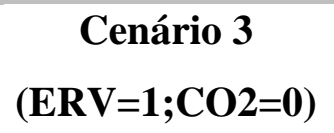 & $\begin{array}{c}\text { Cenário } 4 \\
(\mathrm{ERV}=\mathbf{1} ; \mathrm{CO} 2=1)\end{array}$ \\
\hline \multicolumn{5}{|c|}{ CUSTOS OPERACIONAIS } \\
\hline $\begin{array}{l}\text { Operação e } \\
\text { manutenção }\end{array}$ & $\mathrm{R} \$ 8.809,92$ & $\mathrm{R} \$ 8.809,92$ & $\mathrm{R} \$ 7.341,60$ & $\mathrm{R} \$ 7.341,60$ \\
\hline $\begin{array}{c}\text { Energia } \\
\text { consumida }\end{array}$ & $\mathrm{R} \$ 12.193,41$ & $\mathrm{R} \$ 9.972,59$ & $\mathrm{R} \$ 8.771,15$ & $\mathrm{R} \$ 7.580,68$ \\
\hline TOTAL & R\$ 21.003,33 & $\mathrm{R} \$ \mathbf{1 8 . 7 8 2 , 5 1}$ & $\mathbf{R} \$ 16.112,75$ & $\mathrm{R} \$ 14.922,28$ \\
\hline
\end{tabular}

Tabela 7.27 - Retorno do investimento de cada cenário

\begin{tabular}{|c|c|c|c|c|}
\hline Cenário & $\begin{array}{c}\text { Cenário } 1 \\
(\mathrm{ERV}=0 ; \mathrm{CO}=0)\end{array}$ & $\begin{array}{c}\text { Cenário 2 } \\
\text { (ERV=0;CO2=1) }\end{array}$ & $\begin{array}{c}\text { Cenário } 3 \\
(\mathrm{ERV}=\mathbf{1} ; \mathrm{CO}=\mathbf{0})\end{array}$ & $\begin{array}{c}\text { Cenário } 4 \\
(\mathrm{ERV}=\mathbf{1} ; \mathrm{CO} 2=1)\end{array}$ \\
\hline \multicolumn{5}{|c|}{ RETORNO DO INVESTIMENTO } \\
\hline Custos totais & $\mathrm{R} \$ 99.603,33$ & $\mathrm{R} \$ 107.082,39$ & $\mathrm{R} \$ 95.251,22$ & $\mathrm{R} \$ 99.526,35$ \\
\hline $\begin{array}{c}\text { Diferença } \\
\text { custos totais }\end{array}$ & $\mathrm{R} \$ 0,00$ & $\mathrm{R} \$ 7.479,06$ & - $\mathrm{R} \$ 4.352,12$ & - R\$ 76,98 \\
\hline Economia de & $\mathrm{R} \$ 0,00$ & $\mathrm{R} \$ 2.220,82$ & $\mathrm{R} \$ 3.422,27$ & $\mathrm{R} \$ 4.612,73$ \\
\hline
\end{tabular}


energia

\begin{tabular}{ccccc}
\hline $\begin{array}{c}\text { Retorno do } \\
\text { investimento }\end{array}$ & - & $\mathbf{3 , 3 6}$ anos & $-\mathbf{1 , 2 7}$ anos & $\mathbf{- 0 , 0 1 \text { anos }}$ \\
\hline $\begin{array}{c}\text { Economia } \\
\text { em } 10 \text { anos }\end{array}$ & $\mathbf{R} \mathbf{1 2 . 5 0 8 , 3 7}$ & $\mathbf{R} \$ \mathbf{3 5 . 1 5 2 , 5 0}$ & $\mathbf{R} \mathbf{4 1 . 5 9 1 , 5 9}$ \\
\hline
\end{tabular}

Pelos valores encontrados para o retorno do investimento para o estudo de caso em questão, verifica-se que os períodos de retorno de investimento dos cenários 3 e 4 são negativos, uma vez que os custos iniciais desses cenários são menores que os do cenário 1 , já que aqueles cenários utilizam equipamentos de ar-condicionado com menores potências de refrigeração. O cenário 4 é o que gera a maior economia anual na operação, superando a economia gerada pelo cenário 3 quando se leva em conta o valor acumulado ao longo de 10 anos, por exemplo.

\section{5 - ANÁLISE DA INFLUÊNCIA DO CLIMA DA CIDADE DE PROJETO}

Uma análise comparativa entre os resultados apresentados para as duas cidades de projeto mostram como os efeitos do clima sobre a operação dos cenários propostos. $\mathrm{O}$ clima de Manaus, como mostrado anteriormente na Figura 7.32, apresenta praticamente durante o ano todo valores de temperatura e umidade superiores aos valores do ambiente condicionado. Esse fato proporciona valores bem superiores de carga térmica do ar de renovação que, consequentemente, majoram os efeitos de economia de energia dos recursos de recuperação de energia e vazão de ar exterior variável.

As Figuras 7.66 e 7.67, abaixo, apresentam o perfil de energia recuperada no ERV nas cidades de Brasília e Manaus, respectivamente. A cidade de Manaus apresenta valores de energia recuperada bem superiores aos de Brasília pelos seguintes fatos: i) a troca de calor sensível e calor latente ocorre na mesma direção ao longo de todo o ano; ii) o equipamento ERV opera durante o ano todo na cidade, em todas as estações, aumentando o número de horas de operação em relação à cidade de Brasília e iii) Manaus registra maiores taxas de transferência de calor sensível e latente devido a maiores diferenças de temperatura e umidade existentes entre o ar exterior e o ar do ambiente condicionado: 


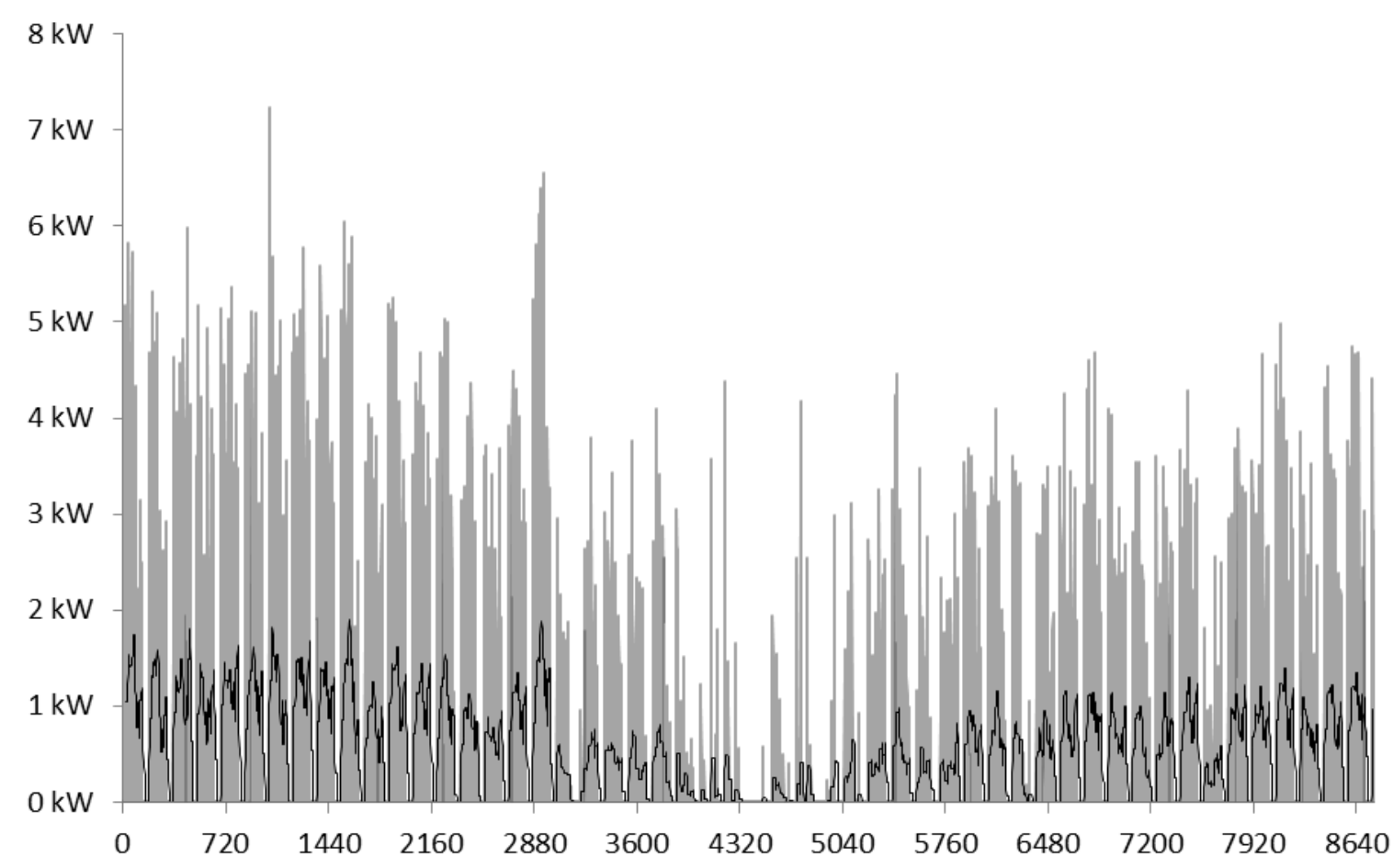

Figura 7.66 - Energia total recuperada pelo ERV $(\mathrm{kW})$ x horas do ano (Brasília/DF, no cenário 4)

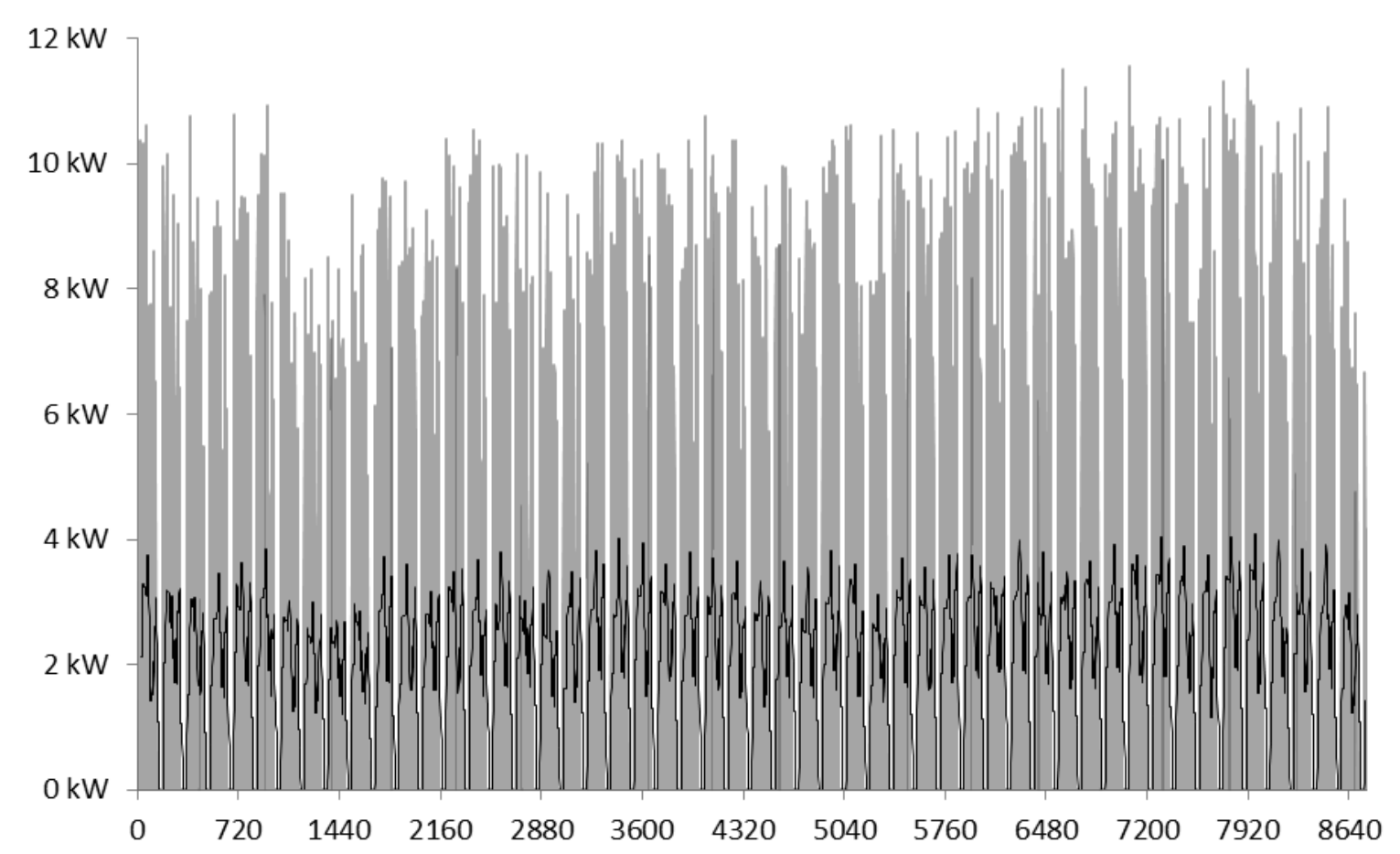

Figura 7.67 - Energia total recuperada pelo ERV $(\mathrm{kW}) \mathrm{x}$ horas do ano (cidade de Manaus/AM, no cenário 4) 


\subsection{1 - Análise dos coeficientes de calor sensível e latente}

De acordo com a formulação apresentada para avaliar o desempenho do equipamento ERV, a eficiência total de recuperação entálpica do equipamento varia em função dos coeficientes de ponderação das eficiências sensível e latente. Essas eficiências variam de acordo com as vazões de ar das correntes que atravessam o ERV, e a eficiência total leva em consideração essas variações, e ainda, as variações devidas à influência do clima da cidade de projeto.

Os coeficientes de ponderação sensível e latente são valores percentuais e apontam qual eficiência domina a eficiência total do equipamento. Quando a diferença de umidade relativa entre o ar externo $\mathrm{e} o$ ar interno é superior à diferença de temperatura entre esses mesmos ambientes, o coeficiente de eficiência entálpica é maior que o coeficiente sensível. Quando a diferença de temperatura é superior à diferença de umidade, o coeficiente de eficiência sensível é maior que o coeficiente latente.

As Figuras 7.68 e 7.69 abaixo apresentam as variações dos coeficientes de ponderação sensível e latente ao longo do ano para as cidades de Brasília e Manaus, respectivamente. Na cidade de Brasília, nos meses de outubro a abril, a eficiência de calor latente domina a eficiência total do equipamento. Nos equipamentos comerciais de ERV, os valores de eficiência latente são sempre menores que os valores de eficiência sensível (TIAX, 2013). Dessa forma, é possível verificar esse efeito na eficiência total nos meses de outubro a abril, uma vez que a eficiência latente é a dominante, tornando a eficiência total menor nesse período avaliado que nos outros meses do ano (Figura 7.70). Como o inverno na cidade de Brasília é bastante seco, o coeficiente sensível torna-se maior que o coeficiente latente.

Já na cidade de Manaus, como o clima é bastante úmido durante todo o ano, o coeficiente latente é que domina a eficiência total, conforme mostra a Figura 7.71, apresentando valores médios anuais menores que os valores da eficiência total para a cidade de Brasília: 


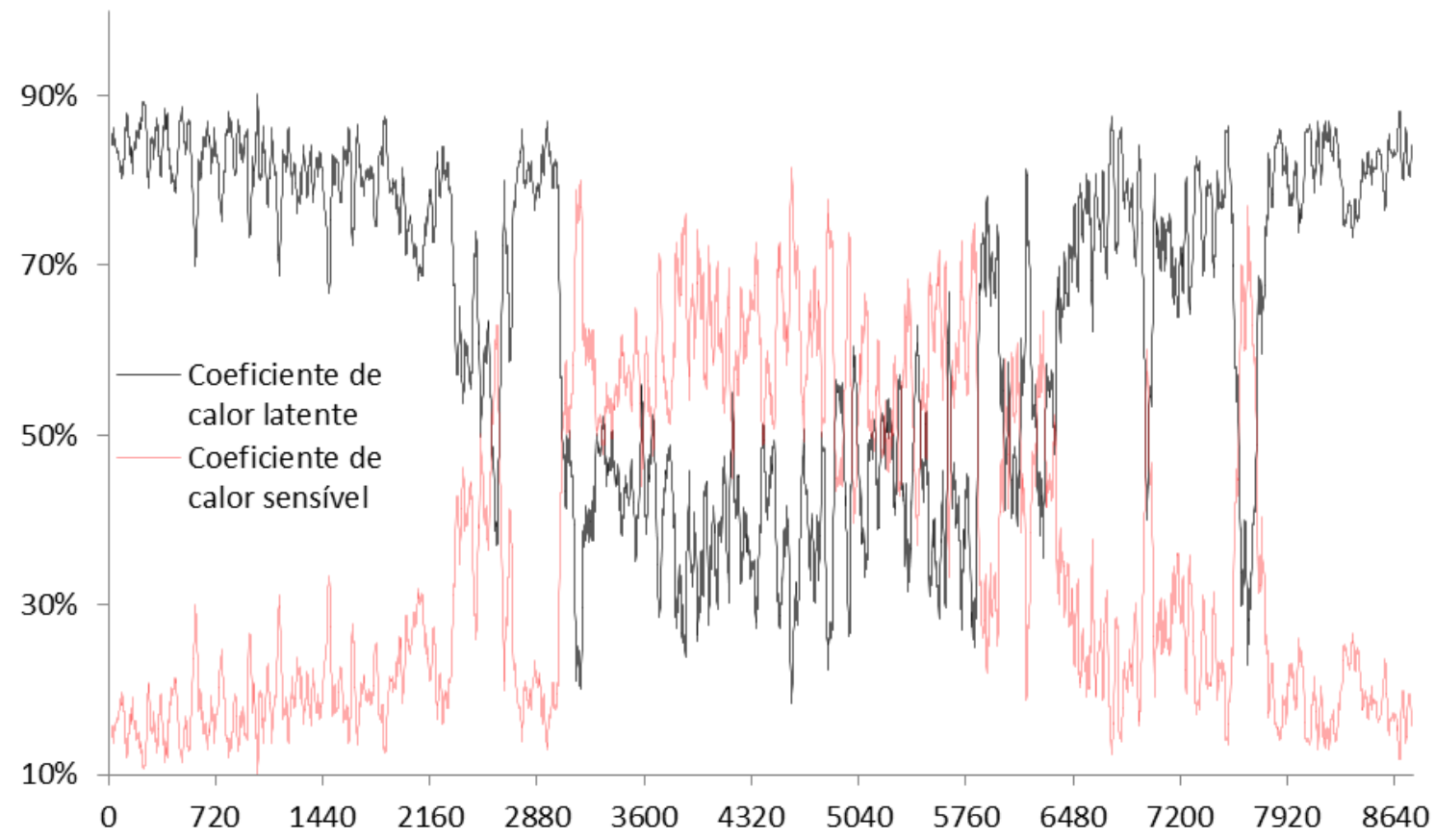

Figura 7.68 - Coeficientes de ponderação de calor sensível e latente (\%) x horas do ano (Brasília/DF)

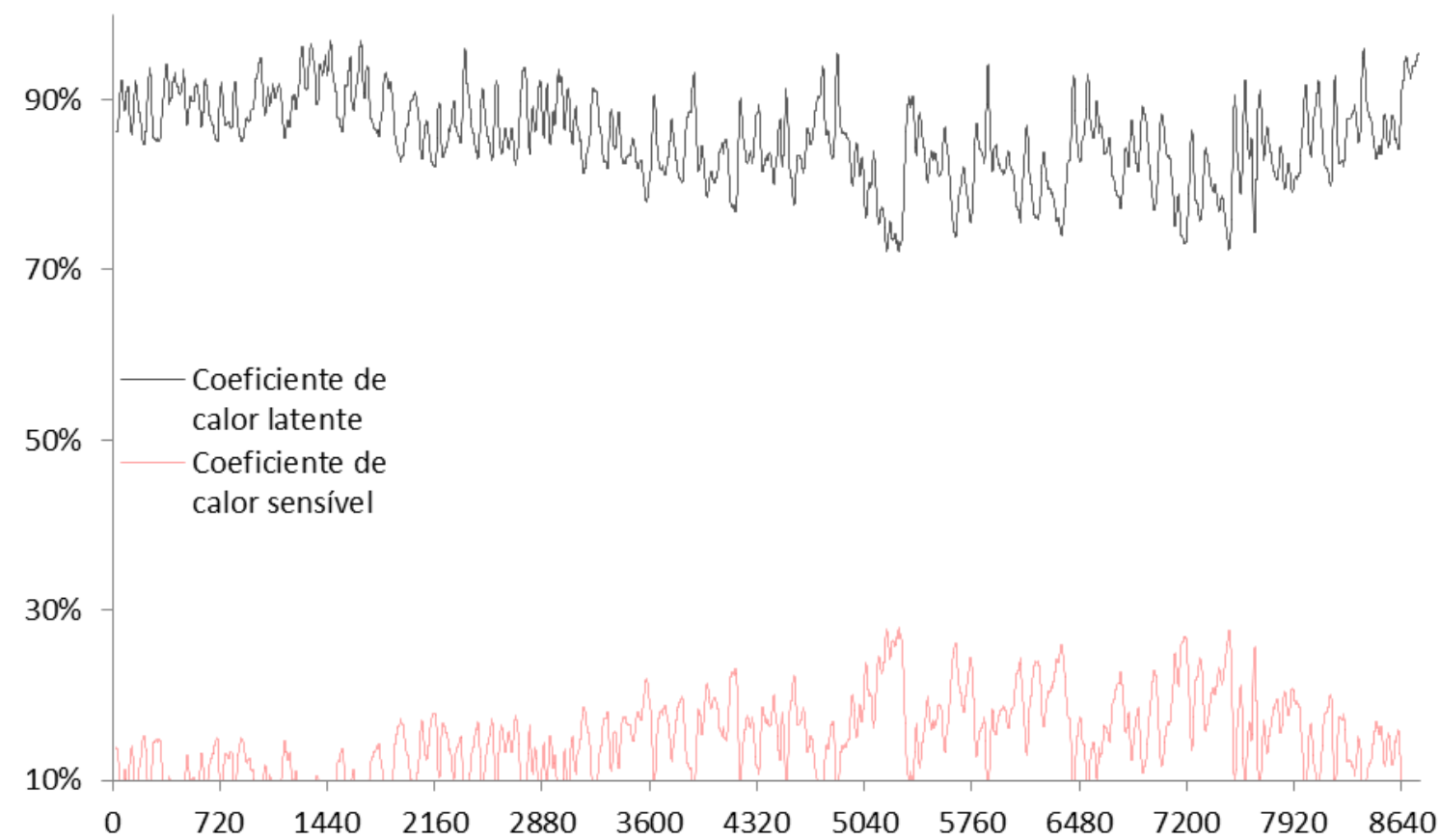

Figura 7.69 - Coeficientes de ponderação de calor sensível e latente (\%) x horas do ano (Manaus/AM) 


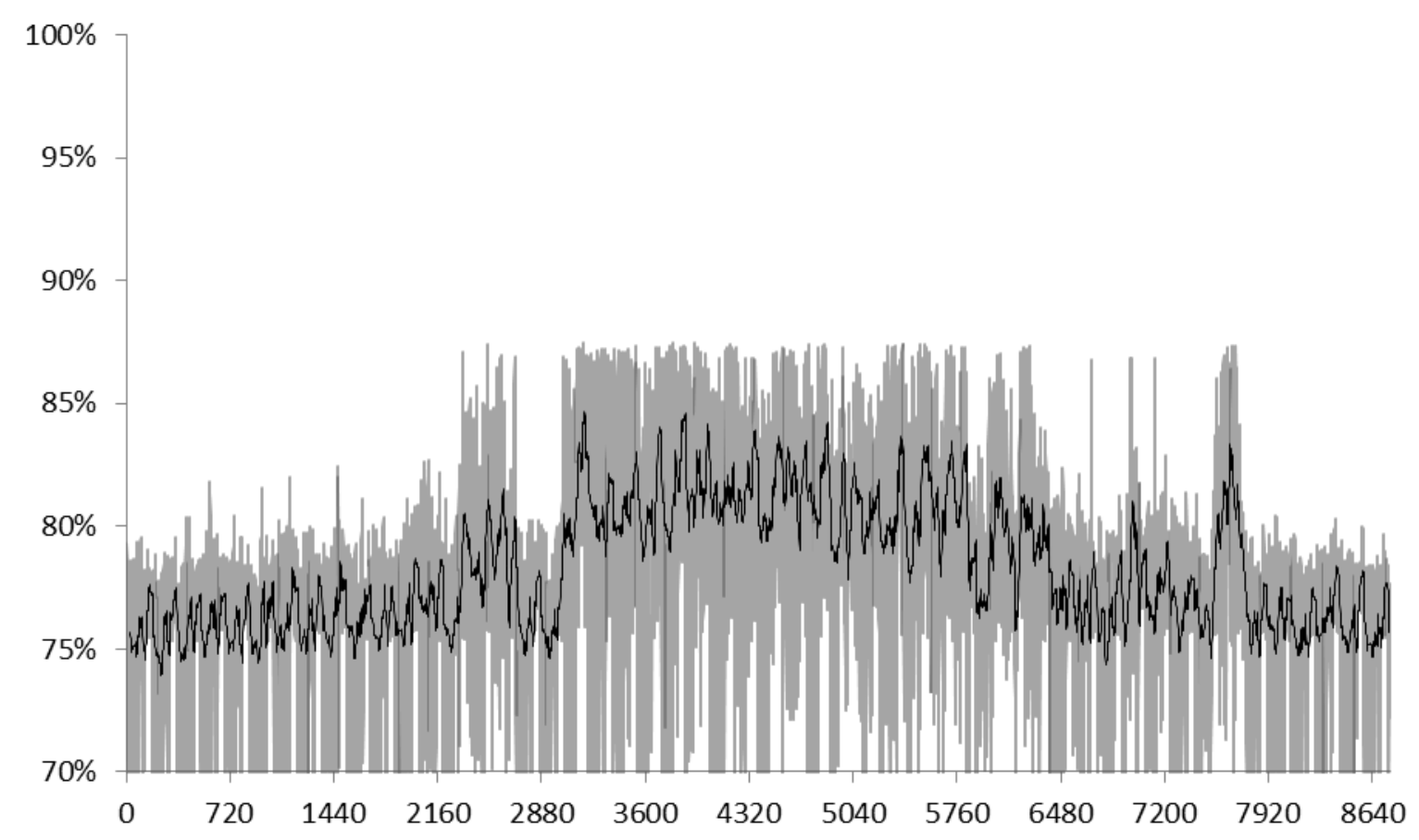

Figura 7.70 - Eficiência total do ERV (\%) x horas do ano (Brasília/DF)

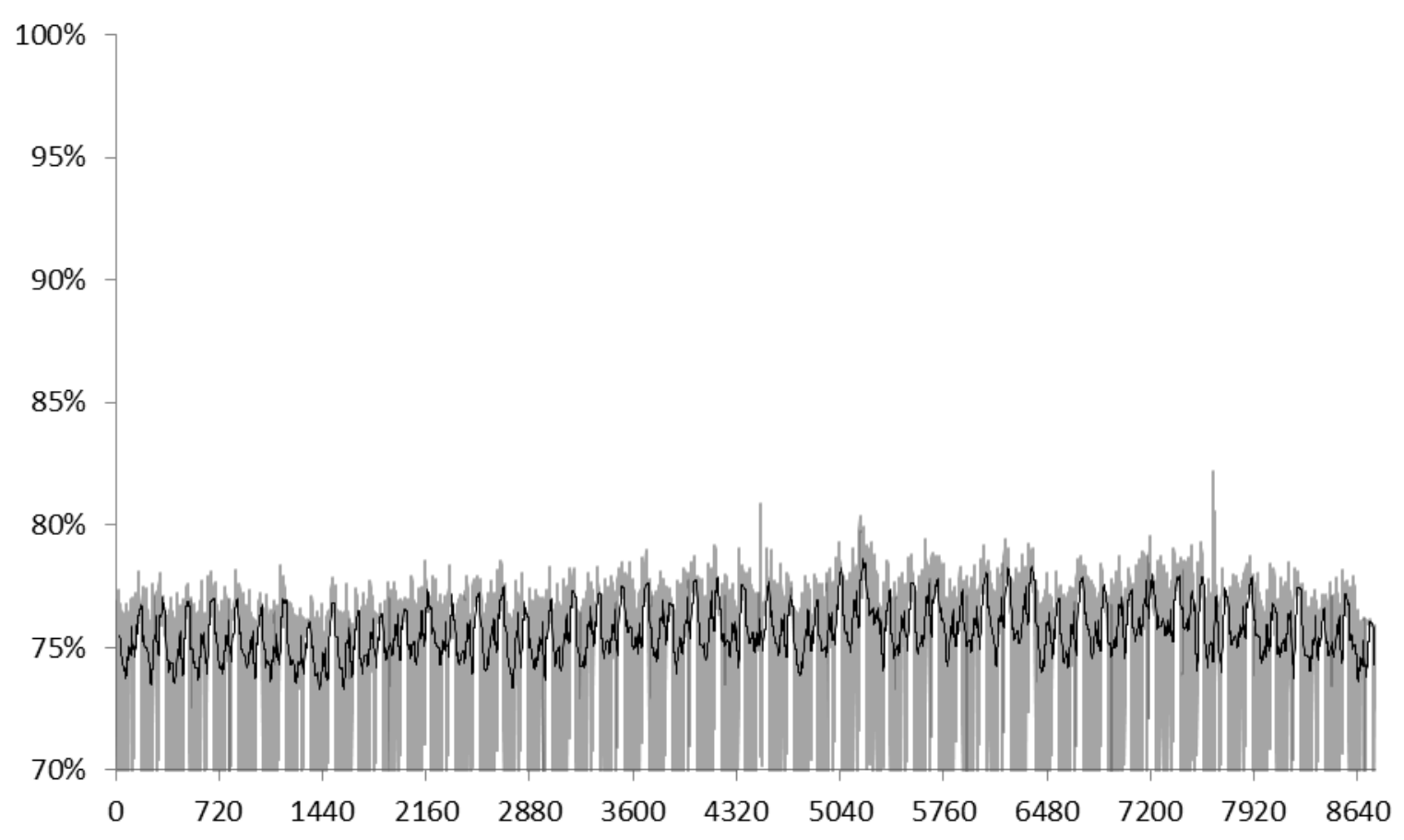

Figura 7.71 - Eficiência total do ERV (\%) x horas do ano (Manaus/AM)

\subsection{2 - Análise das quantidades de calor sensível e latente recuperadas}

As Figuras 7.72, 7.73, 7.74 e 7.75 apresentam, respectivamente, as quantidades de calor sensível e latente recuperadas nos ERV nas cidades de Brasília e Manaus. A 
quantidade de calor latente recuperado nas duas cidades é superior à quantidade de calor sensível, o que justifica a utilização de um equipamento de ERV ao invés de um equipamento HRV, que recupera calor sensível apenas.

Ainda, é importante frisar que a eficiência do equipamento de ERV é fundamental para que o recurso da recuperação de energia seja viável economicamente. Nos casos avaliados, quanto maior a eficiência latente do equipamento, mais energia era recuperada:

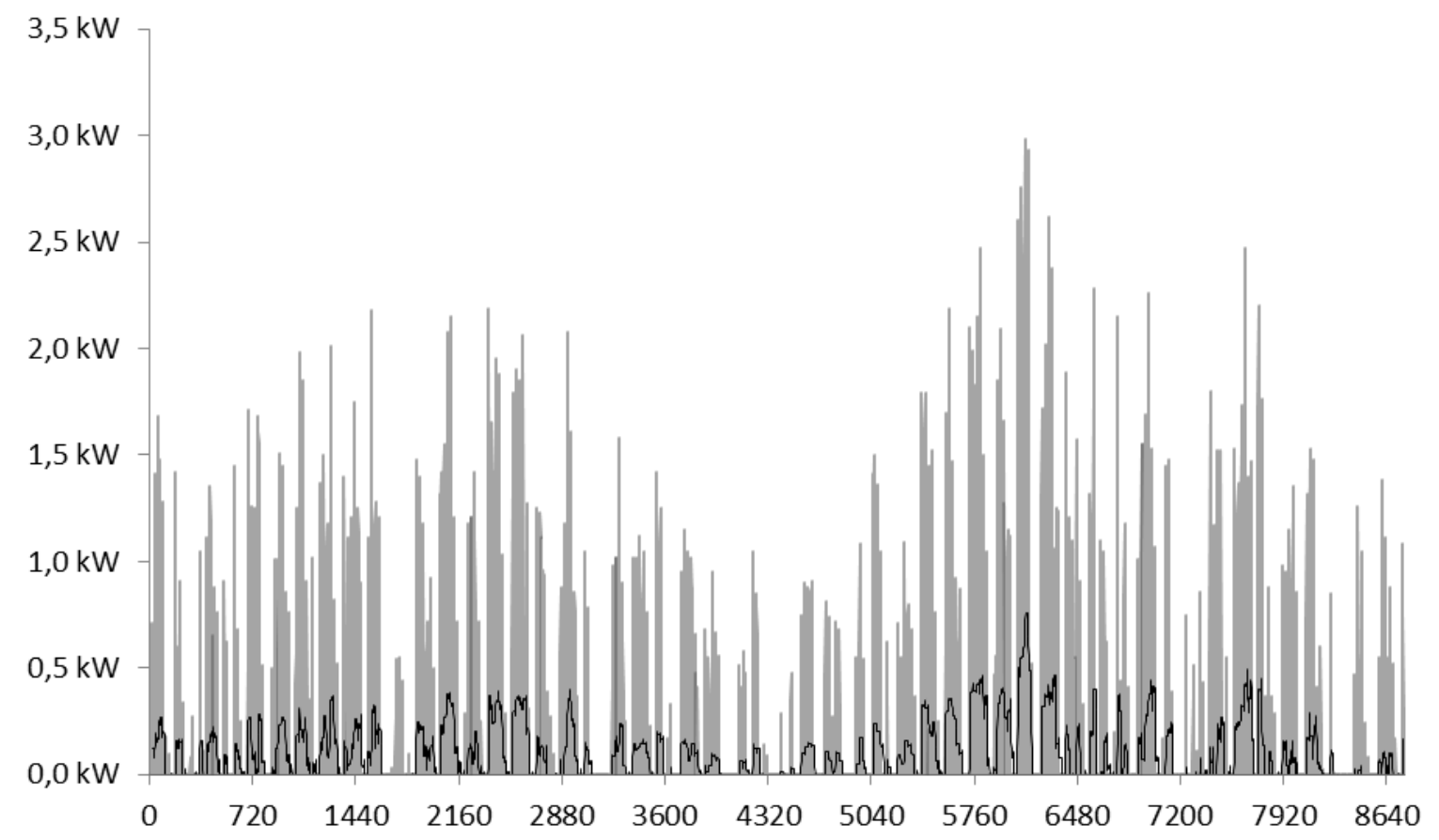

Figura 7.72 - Energia sensível recuperada no ERV $(\mathrm{kW})$ x horas de operação (Brasília/DF)

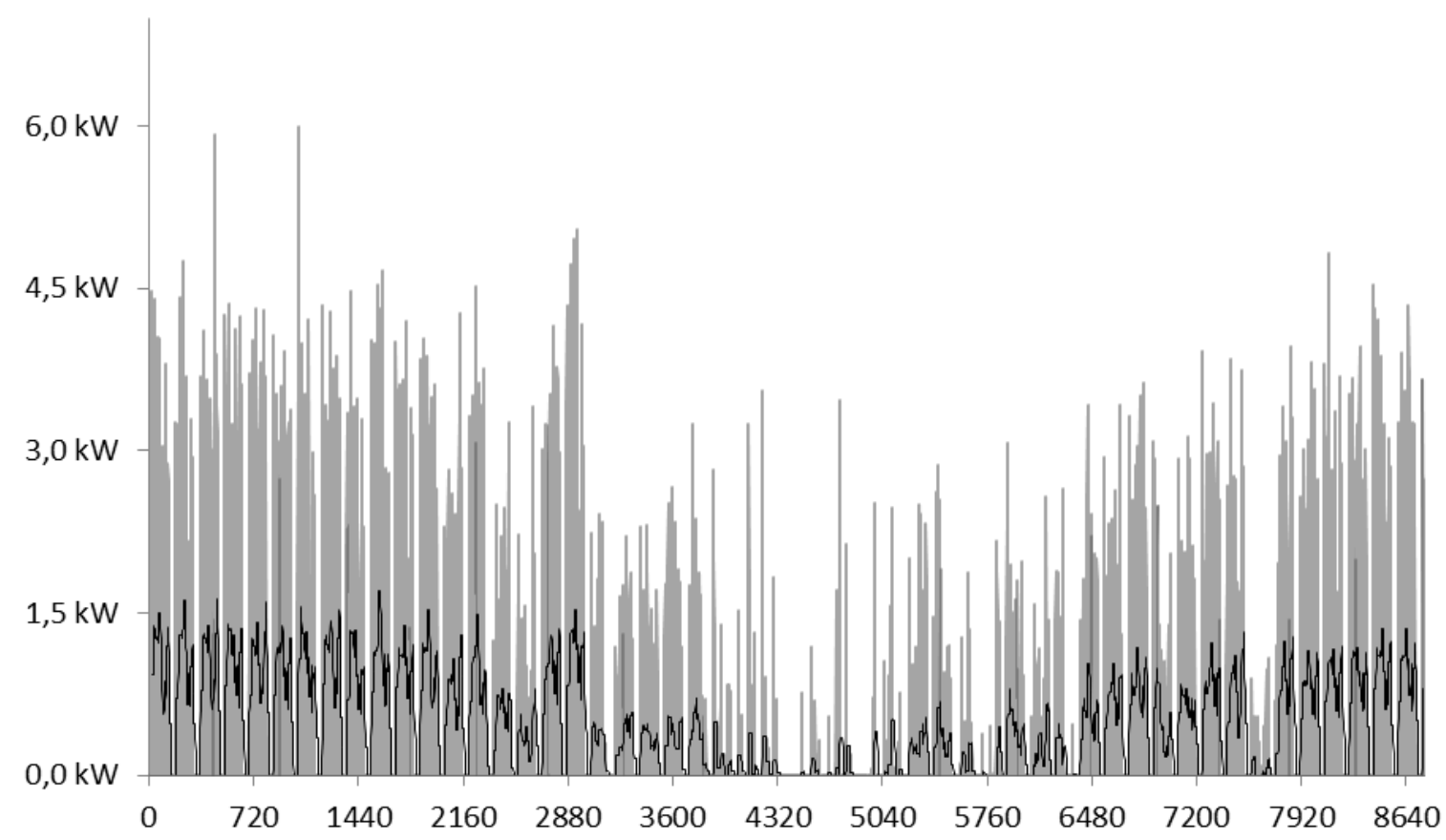

Figura 7.73 - Energia latente recuperada no ERV $(\mathrm{kW})$ x horas do ano (Brasília/DF) 


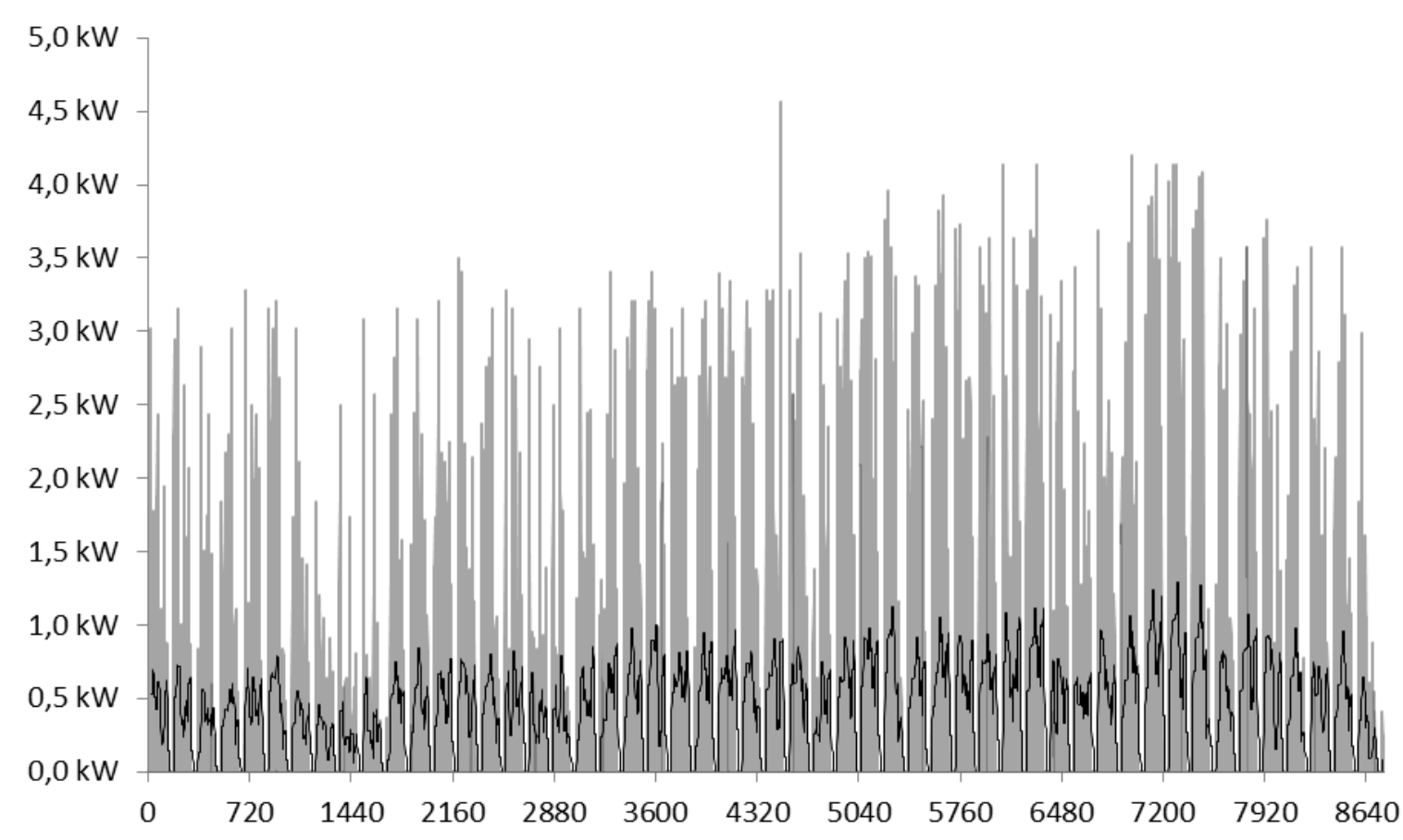

Figura 7.74 - Energia sensível recuperada no ERV (kW) x horas do ano (Manaus/AM)

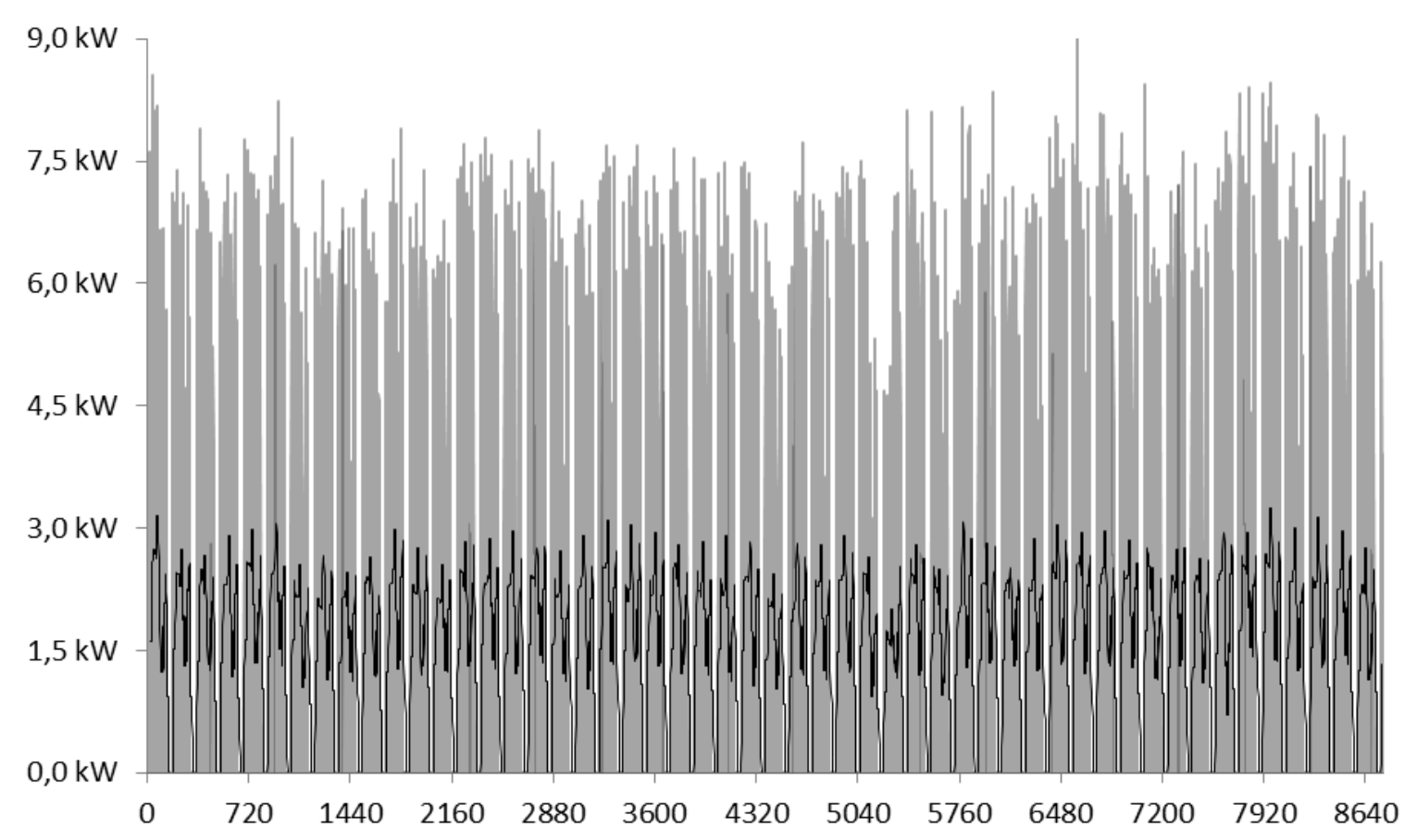

Figura 7.75 - Energia latente recuperada no ERV $(\mathrm{kW})$ x horas do ano (Manaus/AM)

\section{6 - AVALIAÇÃO DA METODOLOGIA PROPOSTA}

Com a finalidade de se avaliar a metodologia proposta, foi realizado um estudo de caso em que analisou-se a viabilidade econômica da utilização dos recursos da 
recuperação de energia e da vazão de ar exterior variável em um sistema de ar condicionado de um auditório localizado na cidade de Brasília/DF, e, posteriormente, no mesmo sistema na cidade de Manaus/AM.

Assim, gerou-se o perfil de carga térmica para esses ambientes, de acordo com os parâmetros climáticos de cada cidade e de acordo com os perfis ocupacionais propostos. Após a definição do perfil de carga térmica, foi definido o sistema de ar condicionado que melhor atenderia aos ambientes propostos e, com a utilização das curvas de consumo de cada equipamento do sistema, considerando, inclusive, a operação em cargas parciais, foi possível também estimar o consumo anual dos equipamentos do sistema. Com o levantamento dos custos iniciais e operacionais foi possível definir, finalmente, o período de retorno do investimento para cada cenário proposto.

A avaliação da metodologia no estudo de caso em questão demonstrou a clareza de seus resultados. Foi possível verificar a redução no perfil de carga térmica do ar de renovação ao longo do ano para cada cenário que utilizou algum dos recursos apresentados ou os dois em conjunto, conforme o esperado. Os períodos de retorno de investimento encontrados se mostraram totalmente em consonância com os valores apresentados na literatura.

Conforme apresentado no Capítulo 3, que trata da recuperação de energia, períodos de retorno de 3 anos são frequentemente encontrados com a utilização de equipamentos de ERV. Para a cidade de Brasília, com o perfil de ocupação original, foi encontrado um período de retorno de 3,25 anos para o cenário 4 (que utiliza tanto o recurso de recuperação de energia quanto o recurso de vazão de ar exterior variável). A literatura também menciona, conforme explicitado no Capítulo 2, que, para climas quentes e úmidos, o período de retorno de investimento frequentemente é inferior a um ano, o que também restou demonstrado nos resultados obtidos para o cenário 4 na cidade de Manaus.

Dentre as vantagens da metodologia proposta pode-se destacar a facilidade de inserção dos parâmetros de entrada e a centralização dos dados em apenas uma ferramenta (EES). Qualitativamente, os parâmetros de saída permitem que diversas avaliações sejam realizadas, verificando o consumo elétrico dos equipamentos, as reduções na carga térmica do ar de renovação, as eficiências e quantidades de energia recuperadas pelos ERVs, a análise da viabilidade de utilização de um ERV ou HRV, o coeficiente de performance do sistema de ar condicionado (COP), dentre outros. Todos esses dados auxiliam no dimensionamento dos equipamentos de condicionamento de ar, permitindo a seleção de equipamentos mais eficientes. 
A abordagem para o sistema de ar condicionado da metodologia proposta considera um sistema central de expansão indireta. Caso outra solução fosse adotada, como um sistema do tipo VRF (Variable Refrigerant Flow), ou um sistema com uma unidade resfriadora de líquido com condensação à agua, por exemplo, uma nova formulação deveria se proposta para caracterizar esse sistema. 


\section{8 - CONCLUSÕES E PROPOSTAS DE TRABALHOS FUTUROS}

\section{1 - CONCLUSÕES}

Este trabalho teve como objetivo principal a apresentação de uma metodologia para a análise da eficiência energética de sistemas de ar condicionado operando com as tecnologias de recuperação de energia (ERV) e de vazão de ar exterior variável. Além de esboçar também uma estratégia de controle ideal para que fossem maximizados os efeitos da recuperação de energia, o trabalho também caracterizou o funcionamento do equipamento de ERV, mostrando seu desempenho diante das variações climáticas e de vazões de ar externo requeridas.

Essa metodologia foi desenvolvida com base em uma formulação matemática apresentada na literatura a partir das equações de governo que regem as transferências de calor para os ERVs e de dados das eficiências apresentados pelo fabricante, sempre objetivando maximizar os efeitos do recuperador. Chegou-se a uma ferramenta de baixo custo que pode ser utilizada por projetistas de sistemas de AVAC para que seja avaliada a viabilidade econômica da aplicação dessas tecnologias em questão.

Ainda, foram levantados parâmetros de referência para projetos, apontando quais cenários apresentariam os menores períodos de retorno de investimento a partir de diversos perfis de ocupação populacional e de diversas horas de operação do sistema, fornecendo, assim, dados palpáveis para uma avaliação de viabilidade econômica inicial no que tange à utilização ou não dos recursos apresentados.

A partir dos resultados foi possível verificar que o cenário 4, o qual utiliza os dois recursos, sempre apresenta as maiores economias anuais, conforme esperado também. Porém, pelo fato de o custo inicial desse cenário ser maior, o seu período de retorno se mostrou superior ao do cenário 3, que utiliza apenas o ERV. Entretanto, no longo prazo, o cenário 4 é o mais econômico, já que seu custo operacional é menor e, ao longo dos anos, o montante economizado se torna superior ao montante do cenário 3.

Outra análise que pode ser feita é que o cenário 3 sempre apresenta menores períodos de retorno do investimento que o cenário 2, o qual utiliza apenas vazão de ar exterior variável. Esse fato se dá basicamente pelo fato de o ERV reduzir mais a carga térmica anual devido ao ar externo do que o recurso da vazão de ar exterior variável, o que possibilita o dimensionamento de sistemas de ar condicionado com menores capacidades de refrigeração, reduzindo o consumo anual. 
Por último, também foi possível observar que o cenário 3 sempre apresenta maiores valores de energia recuperada no ERV que o cenário 4, tendo em vista que as vazões são maiores no cenário 3, o que aumenta as taxas de transferência de calor entre as correntes de ar.

Posteriormente, foram realizadas simulações para verificar a sensibilidade das análises em relação às variações do perfil de ocupação do ambiente e em relação ao clima da cidade de projeto. Pelos resultados apresentados, foi possível verificar que quanto maior o número de horas de operação do sistema, mais os recursos de recuperação de energia e vazão de ar exterior variável possuem seus efeitos majorados, o que tende a reduzir o período de retorno do investimento.

Entretanto, quanto maior o perfil semanal de ocupação, menor é a economia de energia para o cenário 2 (utilização apenas de vazão de ar exterior variável), uma vez que os valores de vazão de ar externo tendem ao valor máximo para a ocupação máxima, o que prejudica a utilização desse recurso para esse tipo de perfil de ocupação.

Todavia, para o cenário 4, esse efeito tende a chegar em um ponto de equilíbrio, pois o aumento de vazão é bom para o equipamento de ERV, já que aumenta as taxas de troca de calor, porém é ruim para o recurso da vazão de ar exterior variável, conforme relatado anteriormente.

As análises de sensibilidade em relação ao clima mostraram como os resultados são fortemente afetados por esse parâmetro. Os resultados para a cidade de Brasília demonstraram que em certos meses do ano a entalpia do ar exterior é menor que a do ar interior, não havendo necessidade de utilização do recurso do ERV.

Já na cidade de Manaus, de acordo com os gráficos de temperatura e umidade, em praticamente todos os meses o equipamento de ERV operaria, já que as transferências de calor latente e sensível estão no mesmo sentido, da corrente do ar externo de alimentação para a corrente do ar interno de exaustão.

Como a carga devida ao ar exterior na cidade de Manaus é muito superior à carga da cidade de Brasília, os efeitos dos recursos de recuperação de energia e de vazão de ar exterior variável foram majorados, conforme apontam os resultados que mostram períodos de retorno de investimento calculados menores que um ano. Além disso, para a cidade de Manaus, não haveria a necessidade de se implementar um controle de operação para o ERV, já que ele opera durante todo o ano, minimizando ainda mais o custo inicial dos cenários 3 e 4. 
Ainda em relação ao clima, os resultados indicaram que a energia latente recuperada é superior à energia sensível recuperada em ambas as cidades. Esse efeito ocorre porque a diferença entre a umidade relativa externa e interna é maior que a diferença entre a temperatura externa e interna, elevando, assim, a quantidade de calor latente trocado entre as correntes.

Esse fato também tende a reduzir a eficiência total do equipamento de ERV, uma vez que, conforme a formulação apresentada, o coeficiente de ponderação latente prevalece em relação ao coeficiente de ponderação sensível, e, como a eficiência latente é menor que a eficiência sensível para a grande maioria dos ERVs, o valor global da eficiência total tende a ser menor. A grande quantidade de energia latente recuperada justifica totalmente a utilização de um equipamento ERV e não de um HRV nas aplicações propostas, e também direciona a escolha desse equipamento no sentido de que sua eficiência latente seja a maior possível.

Por fim, pode-se concluir que a utilização das tecnologias avaliadas gera grandes economias no custo operacional de sistemas de ar condicionado que atendem ambientes com perfil de ocupação bastante variável. Os valores encontrados variaram de $12 \%$ a $30 \%$ de economia de energia anual para a cidade de Brasília e de $18 \%$ a 37\% de economia para a cidade de Manaus, de acordo com o cenário utilizado.

Especificamente em relação ao equipamento de ERV, como seus efeitos são principalmente influenciados pelo clima da cidade de projeto e pelas vazões de ar, a sua utilização tem grande potencial de aplicação em diversos tipos de ambiente e em diversas cidades do Brasil. Esses equipamentos têm se tornado mais populares no Brasil e, com a redução do custo dessa tecnologia, sua aplicação se torna cada vez mais viável.

Ainda, conforme levantado na revisão bibliográfica, diversos países já possuem em suas normas de eficiência energética exigências relativas ao uso dessas tecnologias para diversas aplicações, visando a redução do consumo global de energia dos sistemas de ar condicionado. Assim, essa tendência também deveria pautar as próximas revisões das normas de eficiência energética do Brasil, bem como os requisitos dos programas nacionais de etiquetagem de edificações.

\section{2 - PROPOSTAS DE TRABALHOS FUTUROS}

No que tange à continuação desta pesquisa, diversas são as sugestões para trabalhos futuros, sob vários aspectos. Primeiramente, cabe ressaltar que a formulação proposta para 
a avaliação de desempenho do sistema de ar condicionado foi aqui baseada nas curvas de consumo apresentadas pelos fabricantes dos equipamentos, para o chiller, fan coil, ventiladores, etc. Entretanto, existem alguns softwares no mercado que realizam esse tipo de análise de desempenho energético de sistemas, gerando os custos anuais dos sistemas.

Sendo assim, essas informações poderiam servir como dados de entrada para a simulação de desempenho energético, utilizando-se, porém, o restante da formulação proposta para o sistema de recuperação de energia e de vazão de ar exterior variável.

Em relação às análises de retorno de investimento dos cenários, poderiam ser utilizadas metodologias de análise financeira como o LCC (custo do ciclo de vida), que leva em conta investimentos, taxas de juros, etc. Ainda, poderiam ser levantadas as tarifas contratadas para o custo do kWh para uma dada aplicação, de acordo com a demanda de potência da instalação, assim como as reduções de impacto ambiental provenientes dessas soluções, a partir de análises de créditos de carbono, redução de emissão de gases prejudiciais à camada de ozônio, etc.

Em relação ao ambiente de aplicação, poder-se-iam propor ainda análises climáticas de diversas cidades do Brasil juntamente com a possibilidade de utilização da recuperação de energia nessas cidades. Também, poderia ser proposta a avaliação de outros tipos de ambientes, como ambientes de escritório, restaurantes, hotéis, salas cirúrgicas e outras diversas aplicações, com o objetivo de verificar a viabilidade de utilização dos recursos aqui trabalhados nessas aplicações.

Ainda, poderiam ser realizadas análises de sensibilidade para outros perfis de ocupação do ambiente, contemplando a variação na eficiência de ventilação da zona de respiração, variação dos níveis (1,2 ou 3) de renovação de ar da norma ABNT 16401-3 e os demais parâmetros que afetam as vazões de ar externo, determinando qual seria seu impacto no período de retorno do investimento.

Além disso, sabe-se que, naturalmente, há uma degradação constante no desempenho dos equipamentos. Essa degradação poderia ser levada em consideração, já que ela tende a maximizar o custo operacional da instalação. Aumento na perda de carga, filtros sujos, incrustações, vazamentos de ar entre as correntes do ERV, desbalanceamentos entre as correntes de ar, corrosão e diversos outros parâmetros poderiam ser levados em consideração para aferir o real desempenho dos equipamentos de recuperação de energia e também dos equipamentos de ar-condicionado, trazendo dados mais reais para a verificação do custo benefício da instalação. 
Por fim, uma análise experimental poderia ser utilizada para comparar os valores reais de economia de energia e de retorno de investimento com os valores calculados neste trabalho. A partir de sensores, transdutores e placas de aquisição de dados, os valores reais dos parâmetros poderiam ser medidos e calculados, verificando as reais economias de energia fornecidas por essas tecnologias. Outros parâmetros poderiam também ser elencados para corrigirem as eficiências reais dos equipamentos, fornecendo dados específicos para que uma dada instalação possa ser bem avaliada em relação ao custo benefício da utilização desses recursos. 


\section{REFERÊNCIAS BIBLIOGRÁFICAS}

ABE, O.O.; SIMONSON, C.J.; BESANT, R.W.; SHANG, W.; Effectiveness of energy wheels from transient measurements. Part I. Prediction of effectiveness and uncertainty, Int. Journal of Heat and Mass Transfer 49, 2006.

ABNT NBR 16401 - Instalações de ar condicionado - sistemas centrais e unitários, partes 1,2 e 3.2008.

ANEEL, Atlas de Energia Elétrica do Brasil, Agência Nacional de Energia Elétrica, 2012.

ANEEL, Resolução No 1.606/2013. 2013.

ANVISA, Agência Nacional de Vigilância Sanitária. Resolução nº 09 de 16 de janeiro de 2003 - Padrões Referenciais de Qualidade do Ar Interior. 2003.

ASAEDA, M.; DU, L.D. Separation of alcohol/water gaseous mixtures by thin ceramic membrane. J. Chemical Engng. Jpn. 19: 72-77, 1986.

ASHRAE Handbookd Fundamentals, American Society of Heating, Refrigerating and AirConditioning Engineers, Inc, 1997.

ASHRAE Handbookd Systems and Equipments, American Society of Heating, Refrigerating and Air-Conditioning Engineers, Inc, 2012.

ASHRAE Standard 189.1-2009, Standard for the Design of High-Performance Green Buildings Except Low-Rise Residential Buildings, American Society of Heating, Refrigerating and Air-Conditioning Engineers, Atlanta, GA, 2009.

ASHRAE Standard 62.1-2010, Ventilation for Acceptable Indoor Air Quality, American Society of Heating, Refrigerating and Air-Conditioning Engineers, Atlanta, GA, 2010.

ASHRAE Standard 62-1989. Ventilation for acceptable indoor air quality. Atlanta, GA, 1989.

ASHRAE Standard 90.1-2010, Energy Standard for Buildings except Low-Rise Residential Buildings, SI edition, American Society of Heating, Refrigerating and AirConditioning Engineers, Atlanta, GA, 2010.

ASHRAE Standard 90-1975, Energy Conservation in New Building Design, American Society of Heating, Refrigerating and Air-Conditioning Engineers, Atlanta, GA, 1975.

BESANT, R.W.; SIMONSON, C. Air-to-air exchangers. ASHRAE Journal 45(4):42-50. 2003.

CALIFORNIA CODE OF REGULATIONS, Title 24, Part 6, 1978, Energy Efficiency Standards for Residential and Non-residential Buildings, 1978. 
CARRIER, HVAC Products and Services for commercial buildings applications. Catálogo online. Disponível

em: http://www.commercial.carrier.com/commercial/hvac/homepage/1,3052,CLI1_DIV12_ET I372,00.html. Acesso em 26/04/2013. 2013.

CHA, J.S.; LI, R.; SIRKAR, K.K. Removal of water vapor and VOCs from nitrogen in a hydrophilic hollow fiber gel membrane permeator. J. Membrane Sci. 119: 139-153, 1996.

CLARIDGE, D.E.; HARBERL, J.; LIU, M.; ATHAR, A. Can you achieve $150 \%$ of predicted retrofit savings?, in: Proceedings of the ACEEE 1994 Summer Study on Energy Efficiency in Buildings, American Council for an Energy Efficient Economy, Washington, DC, 1994.

COLMENAR-SANTOS, A.; DE LOBER, L.N.T.; BORGE-DIEZ, D.; CASTRO-GIL, M. Solutions to reduce energy consumption in the management of large building, Energy and Buildings 56, 2013.

COUNCIL DIRECTIVE 93/76/CEE of 13 September 1993 to Limit Carbon Dioxide Emissions by Improving Energy Efficiency, 1993.

COUNCIL OF AMERICAN BUILDING OFFICIALS (CABO), Model Energy Code, Falls Church, Virginia, 1983.

DHITAL, P.; BESANT, R.W.; SCHOENAU, G.J. Integrating run-around heat exchanger systems into the design of large office buildings, ASHRAE Transactions 101 (2), 1995

DIRECTIVE 2002/91/EC of the European Parliament and of the Council of 16 December 2002 on the Energy Performance Buildings, 2002.

DORER, V.; BREER, D. Residential mechanical ventilation systems: Performance criteria and evaluations, Energy and Buildings 27(3): 247-255, 1998.

EMMERICH, S. J.; A.K. PERSILY. State-of-the-Art Review of CO2 Demand-Controlled Ventilation Technology and Application. NISTIR 6729, National Institute of Standards and Technology, Gaithersburg, MD. 2001.

ENERGY POLICY ACT of 1992, PublicLaw102-486, Title I-Energy Efficiency, Subtitle A-Building, Sec. 101. Building Energy Efficiency Standards, October 24, 1992.

EPA, Environmental Protection Agency. Indoor Air Facts $n^{\circ} 4-$ Sick Building Syndrome. Disponível em: http://www.epa.gov/iaq.pubs. 1991.

EUROPEAN COMISSION, ACTION PLAN FOR ENERGY EFFICIENCY: Realising the Potencial, 2006, disponível em: http://ec.europa.eu (acessado em 10 de abril, 2013).

FAUCHOUX, M.T.; SIMONSON, C.J.; TORVI, D.A. The effect of energy recovery on perceived air quality, energy consumption, and the economics of an office building. ASHRAE Transactions 113, 2007. 
FERNANDES, A.E.P. As Torres Envidraçadas e o Consumo Energético. II Encontro Nacional de Conforto no Ambiente Construído, 2, 2001.

GREEN ANGEL ENERGY, ERV's and HRV's: What's the difference? Disponível em: http://greenangelenergy.ca/erv-hrv-difference/. Acesso em 03/10/2013. 2013.

INMET, Instituto Nacional de Meteorologia - Banco de Dados Meteorológicos para Ensino e Pesquisa. Disponível em: http://www.inmet.gov.br/portal/index.php?r=bdmep/bdmep. Acesso em: 26/04/2013. Dados de 2012.

JOHNSON, A.B., C.J. SIMONSON, and R.W. BESANT. Uncertainty analysis in the testing of air-to-air heat/energy exchangers installed in buildings. ASHRAE Transactions 104(1B):1639-1650. 1998.

JOHNSON, A.B.; BESANT, R.W.; SCHOENAU, G.J. Design of multi-coil run-around heat exchanger systems for ventilation air heating and cooling. ASHRAE Transactions 101(2): 967-978, 1995.

KIM, S.M.; LEEB, J.H.; KIM, S.; MOOND, H.J.; CHOE, J. Determining operation schedules of heat recovery ventilators for optimum energy savings in high-rise residential buildings. Energy and Buildings 46, 2012

KLEIN, H.; KLEIN, S.A.; MITCHELL, J.W. Analysis of regenerative enthalpy exchangers. Int. Heat Mass Trans. 33(4): 735-744, 1990.

KNIJNIK, D. C. Aplicação da norma ASHRAE 90.1 e da certificação LEED em edificação comercial, Universidade Federal do Rio Grande do Sul, 2011.

LG, ECO V Sistemas de Ventilação - Permutadores de calor de calor de alta eficiência. Catálogo online. Disponível em: http://www.portalinovar.com/media/manuals/support/2011/08/01/06_-_ECO_V_2011.pdf. Acesso em 26/04/2013. 2011.

LI, Z.; LIU, X.; JIANG, Y.; CHEN, X. New type of fresh air processor with liquid desiccant total heat recovery. Energy and Buildings 37, 2005.

LIU, J.; LI, W.; LIU, J.; WANG, B. Efficiency of energy recovery ventilator with various weathers and its energy saving performance in a residential apartment, Energy and Buildings 42, 2010.

MANSSON, L. "Demand Controlled Ventilation Systems in Non-industrial Buildings." In Proceedings of the European Conference on Energy Performance and Indoor Climate in Buildings, Vol. 3, pp. 895-900. November 24-26, 1994, Lyon, France. 1994.

MANZ, H.; HUBER, H.; SCHALIN, A.; WEBER, A.; FERRAZZINI, M.; STUDER, M. Performance of single room ventilation units with recuperative or regenerative heat recovery. Energy and Buildings 31(1): 37-47, 2000. 
MINISTÉRIO DA SAÚDE, Portaria 3.523 - Plano de Operação, Manutenção e Controle (PMOC) para sistemas de ar condicionado. Publicada em 28/08/98. 1998.

MUMMA, S.A.; Dedicated outdoor air-dual wheel system control requirements, ASHRAE Transactions 107, 2001.

MUNTERS, Heat Pipe Heat Exchanger. Catálogo online. Disponível em: http://www.munters.us/upload/Related\%20product\%20files/Heat\%20Pipe $\% 20 \mathrm{Heat} \% 20 \mathrm{Ex}$ changer.PDF. Acesso em 03/10/2013. 2012.

MURPHY, J. "CO2-Based Demand-Controlled Ventilation with ASHRAE Standard 62.12004." Trane Engineers Newsletter. 34-5:1-8, Trane, Lacrosse, WI. Disponível em: http://www.trane.com/Commercial/DNA/View.aspx?i=673. Acessado em: 26/04/2013. 2008.

NASIF, M.S.; MORRISON, G.L.; BEHNIA, M. Heat and mass transfer in air to air enthalpy heat exchangers. Proceedings of the $6^{\text {th }}$ World Conference on Experimental Heat Transfer, Fluid Mechanics, and Thermodynamics, Matsushima, Japan, 2005.

PAN, C.Y.; JENSEN, C.D.; BIELECH, C.; HABGOOD, H.W. Permeation of water vapor through cellulose triacetate membranes in hollow fiber form. J. Apllied Polymer Sci. 22: 2307-2323, 1978.

PARKER, J. The toxic zone. Buildings Services the CIBSE journal, v.15, n.03, p. 24-26, 1993.

PEREZ-LOMBARD, L.; et al. A review on buildings energy consumption information, Energy and Buildings 40, 2008.

PEREZ-LOMBARD, L.; ORTIZ, J.; CORONEL, J.F.; MAESTRE, I.R. A review of HVAC systems requirements in building energy regulations, Energy and Buildings 43, 2011.

PRADO, R.T.A; CARMO, A.T.; Qualidade do Ar Interno, Escola Politécnica da USP, São Paulo, 1999.

PROCEL, Etiquetagem de Eficiência Energética de Edificações. Ministério de Minas e Energia, 2009.

RASOULI, M.; SIMONSON, C.; BESANT, R. Applicability and optimum control strategy of energy recovery ventilators in different climatic conditions, Energy and Buildings 42, 2010 .

RAW, G. Indoor air quality: Key sources of pollution. Buildings Services the CIBSE journal, v.19, n.05, p.27-28, 1997.

ROBERTSON, G. Sick Buildings - Effects, causes, analysis and prevention. In: Council on Tall Buildings and Urban Habitat. Rehabilitation of Damaged Buildings. Bethlehem, Le High University, 1995. 
SAN, J.Y.; Heat and mass transfer in a two-dimension cross-flow regenerator with 2 solid conduction effect. Int. J. Heat Mass Transfer 36(3): 633-641, 1993.

SAND, J.R. Demand-Controlled Ventilation Using CO2 Sensors. Federal Energy Management Program, U.S. Department of Energy, Washington, DC. 2004.

SILVA, V.G.; SILVA, M.G.; VANHAN, A. Avaliação de Edifícios no Brasil: da avaliação ambiental para avaliação de sustentabilidade. Ambiente Construído, Porto Alegre. V. 3, n.3, p. 7-18. 2003.

SIMONSON, C.J., W. SHANG, and R.W. BESANT. Part-load performance of energy wheels: Part I - Speed control. ASHRAE Transactions 106(1): 286-300. 2000.

SIMONSON, C.J.; BESANT, R.W. Energy wheels effectiveness: Part I - Development of dimensionless groups. Int. J. Heat Mass Transfer 42: 2161-2170, 1999a.

SIMONSON, C.J.; BESANT, R.W. Energy wheels effectiveness: Part II - Correlations. Int. J. Heat Mass Transfer, 1999b.

SIMONSON, C.J.; BESANT, R.W. Heat and moisture transfer in energy wheels during sorption, condensation, and frosting conditions. ASME J. Heat Transfer 120:699-708, 1998.

SPHAIER, L.A.; WOREK, W.M. The effect of axial diffusion in desiccant and enthalpy wheels, Int. Journal of Heat and Mass Transfer 49, 2006.

STIESCH, G.; KLEIN, S.A.; MITCHELL, J.W. Performance of rotary heat and mass exchangers. HVAC\&R Research 1(4): 308-324, 1995.

TIAX LCC. Matching the Sensible Heat Ratio of Air Conditioning Equipment with the Building Load SHR. Disponível em: http://www.airxchange.com/Collateral/Documents/English-US/SHR_Report.pdf. Acessado em 27/04/2016. 2003.

VELOSO, M.D.; ELADI, G.A. Uma avaliação da Eficiência Energética em Edificações Hoteleiras em Natal/RN. Disponível em: http://projedata.grupoprojetar.ufrn.br/dspace/bitstream/123456789/78/1/Nutau\%2004_VE LOSO\%20e\%20ELALI.pdf. Acessado em 26/04/2013. 2011.

WANG, K.L.; MCCRAY, S.H.; NEWBOLD, D.D.; CUSSELER, E.L. Hollow fiber air drying. J. Membrane Sci. 72: 231-244, 1992.

WON, D.; W. YANG. The State-of-the-Art in Sensor Technology for Demand-Controlled Ventilation. IRC-RR-243, National Research Council Canada, Ottawa, Canada. 2005.

YAICI, W.; GHORAB, M.; ENTCHEV, E. Numerical analysis of heat and energy recovery ventilators performance based on CFD for detailed design, Applied Thermal Engineering 51, 2013.

YANMING, K.; KE, Z. Applicability of air-to-air heat recovery ventilators in China, Applied Thermal Engineering 29, 2009. 
YIN, P. Research on a new type of plat air-to-air energy recovery ventilator: product development and experiments, HV\&AC 35, 2005.

ZHANG, J.; LIU, G.; DASU, A. Review of Literature on Terminal Box Control, Occupancy Sensing Technology and Multi-zone Demand Control Ventilation (DCV). U.S. Department of Energy, 2012.

ZHANG, L.Z.; JIANG, Y. Heat and mass transfer in a membrane-based energy recovery ventilator. J. Membrane Sci. 163: 29-38, 1999.

ZHANG, L.Z.; JIANG, Y.; ZHANG, Y.P. Membrane-based humidity pump: performance and limitations. J. Membrane Sci. 171: 207-216, 2000.

ZHANG, L.Z.; NIU, J.L. Effects of wall thickness on the heat and moisture transfers in desiccant wheels for air dehumidification and enthalpy recovery. Int. Communications in Heat and Mass Transfer 29 (2), 2002.

ZHANG, L.Z.; NIU, J.L. Membrane-based enthalpy exchanger: Material considerations and clarification of moisture resistance. J. Membrane Sci. 189 (2): 179-191, 2001.

ZHOU, Y.P.; WU, J.Y.; WANG, R.Z. Performance of energy recovery ventilator with various weathers and temperature set-points, Energy and Buildings 39, 2007. 
APÊNDICES 


\section{APÊNDICE A - SISTEMAS E EQUIPAMENTOS DE RECUPERAÇÃO DE ENERGIA (ASHRAE, 2012) - CONTINUAÇÃO DO CAP. 3}

\section{A.1 - Idealizações para os Recuperadores de Energia Ar-Ar}

Características de um recuperador de energia ar-ar ideal:

1) Permite a transferência de calor entre as correntes de ar na direção da diferença de temperatura;

2) Permite a transferência de umidade entre as correntes de ar na direção da diferença de pressão parcial de vapor;

3) Minimiza a transferência de ar entre as correntes de ar, a transferência de poluentes, outros gases, contaminantes biológicos e partículas;

4) Aperfeiçoa o desempenho na recuperação de energia para minimizar a perda de carga, enquanto fornece custos razoáveis, dimensões e peso adequados.

A transferência de calor é um importante veículo de recuperação de energia entre correntes de ar que carregam calor residual. Entretanto, o papel da transferência de umidade como um processo de recuperação de energia é menos conhecido e merece maior detalhamento.

Considere um recuperador de energia ar-ar operando em um clima quente e úmido em uma aplicação de ar condicionado para conforto. Se o recuperador troca calor, mas não umidade, ele resfria o ar externo de ventilação quando esse passa por meio do trocador para o espaço interno. $\mathrm{O}$ calor flui do ar externo que entra para o ar de exaustão (mais frio) que sai do ambiente interno condicionado.

Essa operação faz muito pouco para mitigar a alta umidade carregada para dentro do ambiente interno pelo ar externo de ventilação, e pode causar um aumento na umidade relativa no espaço condicionado, resultando num aumento na carga de refrigeração para desumidificar o ar e deixá-lo em condições aceitáveis para o conforto interno. Por outro lado, se o recuperador de energia transfere tanto calor quanto umidade, a umidade do ar externo que entra é transferida para o ar menos úmido de exaustão. A redução na umidade do ar externo de ventilação requer menos energia para o condicionamento de conforto.

\section{A.2 - Arranjos de fluxo de ar}


A eficiência na troca de calor do recuperador depende fortemente da direção e do padrão das correntes de ar de alimentação e exaustão. Recuperadores com fluxos paralelos (Figura A.1a), em que ambas as correntes de ar se movem sobre a superfície do trocador de calor na mesma direção, possuem uma eficiência teórica máxima de 50\%. Recuperadores com fluxo contracorrente (Figura A.1b), nos quais as correntes se movem em direções opostas, podem ter uma eficiência teórica próxima de 100\%, mas as unidades típicas possuem eficiência menor. A eficiência teórica para o recuperador de fluxo cruzado é um pouco menor do que a do contracorrente, e as unidades típicas possuem eficiências variando entre $50 \%$ e $70 \%$ (Figura A.1c), e entre $60 \%$ e $85 \%$ para trocadores com passes múltiplos (Figura A.1d):

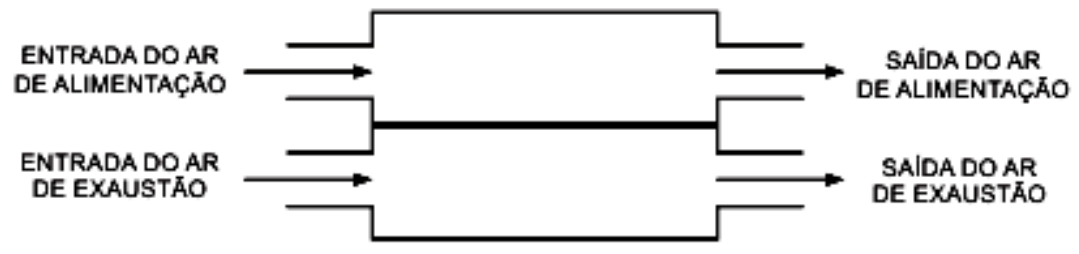

A. TROCADOR DE CALOR DE FLUXOS PARALELOS

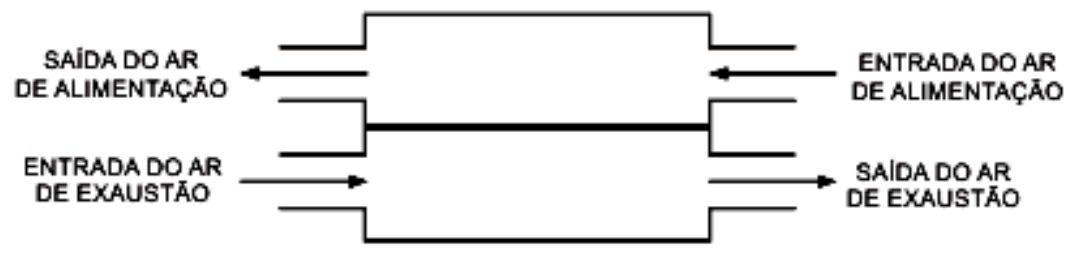

B. TROCADOR DE CALOR DE FLUXOS EM CONTRACORRENTE

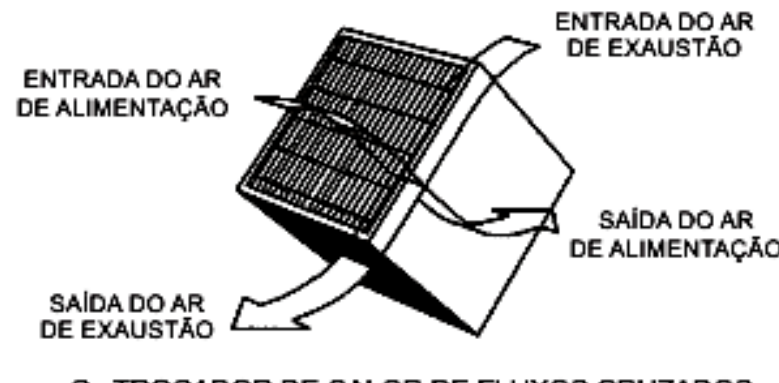

C. TROCADOR DE CALOR DE FLUXOS CRUZADOS 


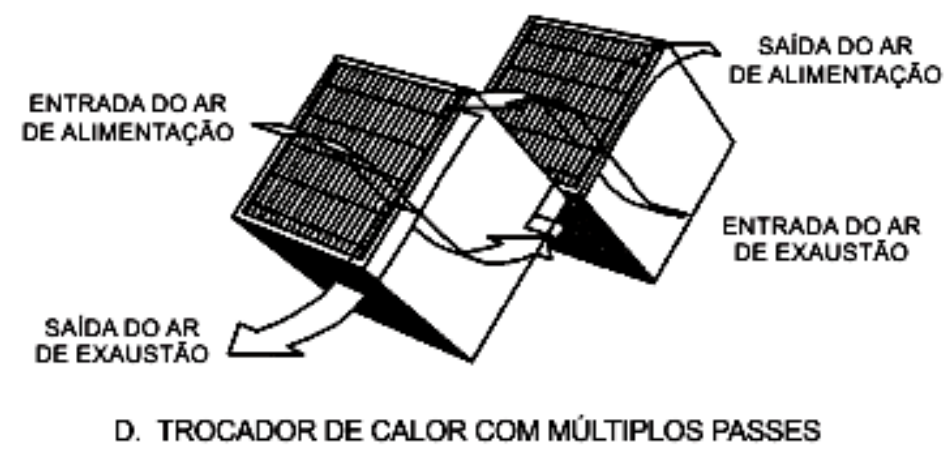

Figura A.1 - Tipos de arranjos de fluxo de ar para recuperadores de energia (ASHRAE, 2012, modificado)

\section{A.2.1 - Eficiência}

A eficiência dos recuperadores de calor ou de energia conforme definida na Equação (3.1) é usada para caracterizar cada tipo de transferência de energia nos trocadores ar-ar. Para uma dada combinação de propriedades de entrada e taxas de vazão, o conhecimento de cada tipo de eficiência permite ao projetista calcular as taxas de transferência de calor sensível, latente e total a partir das Equações (3.7), (3.25) e (3.26), respectivamente. Esses valores de eficiência podem ser determinados tanto a partir de dados de ensaios experimentais quanto a partir de correlações verificadas previamente na literatura.

Essas correlações também podem ser usadas para prever as taxas de transferência de energia e as propriedades do ar que sai do recuperador para condições de operações diferentes das utilizadas nos testes de certificação do equipamento. Prever a eficiência para condições de operação fora dos padrões das certificações é a forma mais comum de utilização das correlações em aplicações de sistemas de AVAC. Embora as correlações não sejam disponíveis para todos os tipos de recuperadores ar-ar em todas as condições de operação, elas estão disponíveis para os tipos mais comuns de recuperadores em condições de operação que não incluam condensação ou congelamento.

\section{A.2.2 - Taxa de Transferência de Energia (Number of Transfer Units - NTU)}

A taxa de transferência de energia depende das condições operacionais e de fatores intrínsecos às características do recuperador de energia, tais como geometria (fluxo paralelo/contracorrente/corrente cruzada, número de passes, aletas), condutividade térmica 
das paredes de separação das correntes e permeabilidade da parede para os diversos gases. Como em um recuperador convencional, a energia transferida entre as correntes de ar é conduzida pelo fluxo cruzado da diferença entre as temperaturas de bulbo seco.

A energia também é transferida entre as correntes por transferência de massa, que pode incluir ar, gases e vapor de água. Em outro modo de transferência de energia, o vapor de água condensa em uma das duas correntes de ar no recuperador. Esse processo de condensação libera calor latente, que é transferido para a outra corrente como calor sensível. Esse processo de duas etapas é também chamado de transferência de calor latente.

A transferência de energia latente entre as correntes ocorre apenas quando umidade é transferida de uma corrente de ar para a outra sem que haja condensação. Uma vez que a umidade atravessa de um fluxo para o outro, ela pode permanecer no estado de vapor ou condensar na segunda corrente de ar, dependendo da temperatura dessa corrente.

Rodas giratórias e recuperadores de placas planas fixas permeáveis são bastante utilizados devido a sua capacidade de transferir umidade. Alguma transferência de massa entre as correntes de ar pode ocorrer por meio de vazamentos, mesmo de forma não intencional. Isso pode alterar a eficiência do recuperador, mas para a maioria das aplicações de AVAC com exaustão de ar do espaço interno, essas pequenas transferências para o ar de alimentação não são importantes. Entretanto, essas transferências podem e devem ser avaliadas durante o projeto, e, em muitos casos, podem ser controladas.

A transferência de calor difere em princípio da transferência de massa. A transferência de calor ocorre apenas quando existe uma diferença de temperatura. No caso das trocas entre as corrente de ar de alimentação e exaustão, o calor é transferido por condução e convecção apenas quando existe uma diferença de temperatura entre essas correntes. Dessa forma, os seguintes fatos sobre as eficiências de calor/massa dos recuperadores devem ser reconhecidas: i) a eficiência de transferência de umidade pode não ser igual à eficiência de transferência de calor; ii) a eficiência total de energia transferida pode não ser igual à eficiência de calor sensível ou de calor latente.

A transferência e a eficiência de energia líquida total necessitam de um exame cuidadoso quando a direção da transferência sensível, conduzida pela temperatura, é oposta à direção de transferência latente, conduzida pela umidade ou vapor de água. $\mathrm{O}$ desempenho de um ERV é expresso pela magnitude da potência de bombeamento e da recuperação de energia sensível, latente ou total. A energia recuperada é estimada a partir das taxas de temperatura ou umidade de saída, que estão diretamente associadas à eficiência do equipamento. A eficiência é uma função de dois parâmetros: o número de 
unidades de transferência (number of transfer units - NTU) e a taxa de capacidade de fluxo térmico $\mathrm{C}_{\mathrm{r}}$ :

$$
\begin{aligned}
& \mathrm{NTU}=\mathrm{UA} / \mathrm{C}_{\text {min }} \\
& \mathrm{C}_{\mathrm{r}}=\mathrm{C}_{\text {min }} / \mathrm{C}_{\text {max }}
\end{aligned}
$$

$\mathrm{U}=\quad$ Coeficiente global de transferência de calor, relacionado às taxas de vazão e dimensões das trajetórias do escoamento do fluido no recuperador $\left[k W /\left(m^{2} \cdot K\right)\right]$;

$\mathrm{A}=\quad$ Área de troca de calor $\left[m^{2}\right]$;

$\mathrm{C}_{\max }=\quad$ Maior valor entre $\mathrm{c}_{\mathrm{ps}} \cdot \dot{\mathrm{m}}_{\mathrm{s}}$ e $\mathrm{c}_{\mathrm{pe}} \cdot \dot{\mathrm{m}}_{\mathrm{e}}$

\section{A.3 - Considerações técnicas adicionais}

A taxa de eficiência de recuperação de energia por unidade é obtida sob condições balanceadas para os fluxos de ar (vazões iguais para o ar de alimentação e de exaustão). Entretanto, essas condições ideais nem sempre existem devido à pressão positiva da edificação, à presença de vazamentos, incrustações, condensação, congelamento, e diversos outros fatores descritos abaixo.

\section{A.3.1 - Vazamentos de ar}

Os vazamentos de ar se referem a qualquer ar que entra ou sai das correntes de alimentação ou exaustão. A inexistência de vazamentos de ar requer vazões mássicas iguais nas entradas e saídas das correntes de alimentação e exaustão. Um vazamento externo ocorre quando o ar ambiente das fronteiras do recuperador flui para dentro (ou escapa) de uma ou de ambas as correntes de ar.

Um vazamento interno ocorre quando aberturas ou passagens são abertas entre as correntes de ar. As causas para esses vazamentos são dadas quando o projeto do recuperador permite: i) movimento tangencial de ar na direção de rotação da roda e ii) movimento de ar através de vazios na barreira entre as correntes. Sob certas condições de pressão diferencial, o ar vaza para dentro e para fora de cada corrente de ar em quantidades próximas, dando a ilusão de que não existem vazamentos. 
Os vazamentos variam conforme o tipo de recuperador e seu projeto, a diferença de pressão estática entre as correntes de ar e condições físicas. Eles raramente inexistem, uma vez que as pressões externas e internas são normalmente diferentes, causando o vazamento das regiões de alta pressão para as de baixa pressão. Vazamentos cruzados, contaminações cruzadas ou mistura entre as correntes de alimentação e exaustão podem ocorrer em recuperadores de energia ar-ar e podem ser um problema significativo se os gases de exaustão forem tóxicos ou odoríferos. Vazamentos de ar entre o ar de renovação e o ar de exaustão do ambiente condicionado podem ser classificados em dois mecanismos: fluxo cruzado e arraste.

Vazamentos de fluxo cruzado são causados principalmente pela diferença de pressão estática entre os estágios 2 e 3 e/ou entre os estágios 1 e 4, mostrados na Figura A.2. Outros fatores que podem ser levantados são a presença de geometrias irregulares e a distribuição local de velocidade das correntes. Essas causas ressaltam a importância da localização precisa dos ventiladores em que circulam as correntes.

O mecanismo de arraste, por sua vez, ocorre em unidades recuperadoras rotativas devido à rotação da roda de uma corrente de ar para a outra. $\mathrm{O}$ ar de exaustão preso em cavidades no meio da transferência de calor é transportado para a corrente de ar externo de alimentação pela roda.

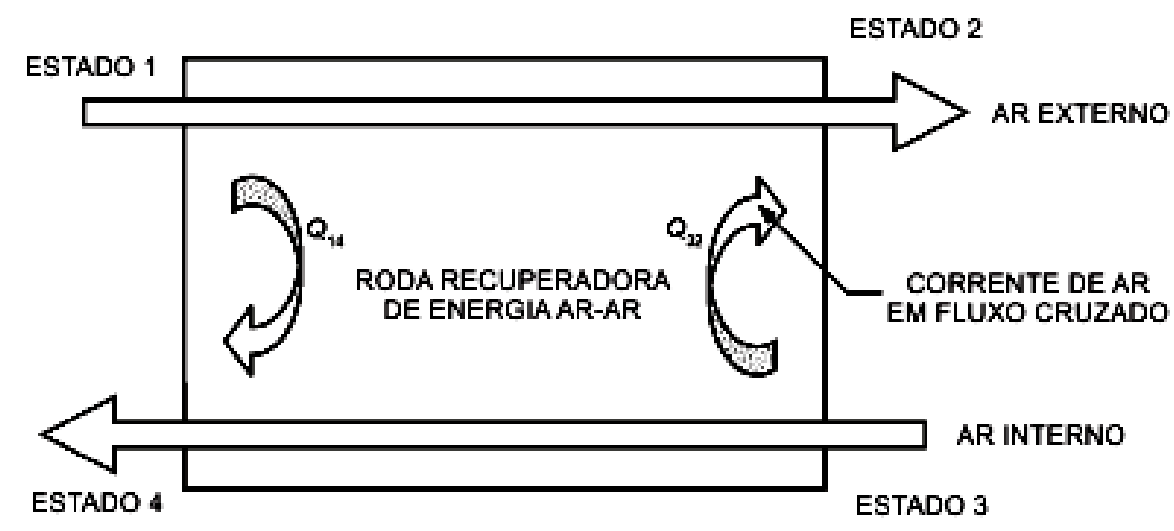

Figura A.2 - Vazamento de ar de fluxo cruzado em ERVs (ASHRAE, 2012, modificado)

\section{A.3.2 - Perda de carga}


A perda de carga de cada corrente de ar através do recuperador de energia depende de vários fatores, incluindo o projeto do equipamento, a taxa de vazão mássica, temperatura, umidade, e as conexões de ar de entrada e saída. Essa perda de carga deve ser vencida pelos ventiladores ou sopradores. Uma vez que a potência requerida para a circulação das correntes de ar através da unidade de recuperação é proporcional à perda de carga, essa perda deve ser conhecida. Ela pode ser utilizada em conjunto com a eficiência do ventilador para que seja caracterizada a energia usada pelo recuperador em termos de eficiência de uma dada aplicação.

\section{A.3.3 - Manutenção}

O método utilizado para limpar um recuperador de energia depende do meio de transferência ou mecanismo utilizado no equipamento e da natureza do material a ser removido. A acumulação de gordura dos gases de escape de cozinhas, por exemplo, muitas vezes é removido com um sistema de água de lavagem automática. Outros tipos de impurezas podem ser removidos por aspiração, soprando-se ar comprimido por meio dos orifícios, por limpeza a vapor, limpeza manual de pulverização, por imersão de unidades em água com sabão ou solventes, ou utilizando-se sopradores de fuligem. Os métodos de limpeza devem ser determinados durante o projeto, de modo que haja compatibilidade com o recuperador de calor a ser selecionado.

A limpeza também depende da qualidade do ar da corrente de exaustão. Sistemas AVAC residenciais e comerciais geralmente requerem limpezas eventuais, por outro lado, sistemas industriais já requerem uma periodicidade maior. Assim, os fornecedores dos equipamentos devem ser procurados a respeito de limpezas específicas e dos requisitos de manutenção dos sistemas que estão sendo considerados.

\section{A.3.4 - Filtragem}

Filtros são recomendados e devem ser alocados em ambas as correntes de ar visando reduzir a entrada de impurezas e as periodicidades de limpeza. Os filtros de exaustão são especialmente importantes caso os contaminantes sejam viscosos ou gordurosos, ou caso as partículas possam tapar as passagens de ar no recuperador. Filtros na corrente de alimentação evitam a entrada de insetos, folhas e outros materiais estranhos, 
protegendo tanto o recuperador quanto o equipamento de ar condicionado. Neve ou geada podem bloquear o filtro de alimentação e causar sérios problemas.

\section{A.3.5 - Controles}

Os controles dos recuperadores podem incluir o controle de formação de gelo ou a regulagem da quantidade de energia transferida entre as correntes de ar em dadas condições de operação. Por exemplo, sistemas de ventilação projetados para manter condições específicas para o ar interior em situações climáticas extremas podem requerer modulação na recuperação de energia para que seja atingida uma operação econômica, prevenindo o superaquecimento do ar externo de alimentação durante o inverno ou prevenindo o aumento excessivo de umidade no ar de alimentação. Métodos de modulação incluem a variação na rotação de rodas giratórias, ou pelo by-pass de parte de uma corrente de ar por fora do recuperador de energia por meio de dampers.

\section{A.3.6 - Incrustação}

A incrustação, uma acumulação de poeira ou condensado nas superfícies do recuperador de energia, reduz a eficiência do equipamento, uma vez que aumenta a resistência ao escoamento, interferindo no processo de transferência de massa e, geralmente, reduzindo os coeficientes de transferência de calor. $\mathrm{O}$ aumento da resistência ao escoamento aumenta a potência de ventilação requerida e pode reduzir a vazão de ar. $\mathrm{O}$ aumento na perda de carga do equipamento pode indicar a presença de incrustações, o que pode ser usado para estabelecer programas e periodicidades de limpeza. A redução na eficiência de transferência de massa (eficiência latente) indica incrustação da membrana permeável ou dos sítios de sorção dessecantes.

\section{A.3.7 - Corrosão}

Os processos de exaustão frequentemente contêm substâncias corrosivas. Se não são conhecidos quais são os materiais de construção mais resistentes à corrosão para uma dada aplicação, o projetista deve consultar a literatura disponível ou consultar os fornecedores dos equipamentos antes de selecionar os materiais. Deve haver um estudo dos 
processos de corrosão caso o meio em que o equipamento seja inserido seja crítico, visando evitar danos nas instalações com pouco tempo de uso do sistema. Corrosões moderadas ocorrem com o tempo, criando rugosidade em superfícies metálicas e aumentando seu coeficiente de transferência de calor. Corrosões severas reduzem o coeficiente global de transferência de calor e podem causar vazamentos cruzados entre as correntes de ar devido a perfurações ou falha mecânica.

\section{A.3.8 - Condensação e congelamento}

Condensação, formação de gelo e/ou congelamento podem ocorrer nas superfícies dos recuperadores de energia. Ignorando os efeitos de entrada e saída, quatro distintos regimes de ar/umidade podem ocorrer enquanto a corrente de ar quente esfria entre suas condições de entrada e saída. Uma vez que a corrente de ar quente esfrie abaixo do seu ponto de orvalho, existe uma região de condensação, que molha a superfície do recuperador de energia. Se a superfície do recuperador cai abaixo da temperatura de congelamento, essa região de condensação o congela. Finalmente, se a temperatura da corrente de ar quente cai abaixo do ponto de orvalho e também abaixo da temperatura de congelamento, a sublimação causa uma espécie de geada no recuperador.

Os locais dessas regiões e as taxas de condensação e congelamento dependem da duração das condições de congelamento, das vazões de ar, temperaturas e umidades do ar de entrada no equipamento, da eficiência do recuperador, sua geometria, configuração e orientação, e dos coeficientes de troca de calor. De qualquer modo, os recuperadores de energia geralmente são projetados com um sistema de drenagem contínua de condensado, ficando os problemas de congelamento restritos aos ambientes com invernos bastante rigorosos.

\section{A.4 - Avaliações de desempenho}

Testes experimentais em laboratórios certificados e modelos computacionais fornecem os valores de desempenho para: i) transferência de calor; ii) transferência de umidade; iii) transferência de ar em fluxos cruzados; iv) vazão mássica média de exaustão e v) vazão mássica de alimentação que deixa o recuperador. As taxas de eficiência para transferência de calor e massa de vapor de água devem ser determinadas separadamente 
em laboratórios cujos funcionários e instrumentos atendam as recomendações das normas ASHRAE Standard 84 e AHRI Standard 1061.

A norma ASHRAE Standard 84: i) estabelece um método uniforme de testes para obtenção dos dados de desempenho; ii) especifica as informações requeridas, cálculos a serem utilizados e reporta os procedimentos para teste de cada uma dos sete fatores independentes de desempenho e seus limites de incerteza e iii) especifica os tipos de testes de equipamentos. Os fatores independentes de desempenho são as eficiências latente, sensível e total; as perdas de carga das correntes de alimentação e exaustão; a taxa de transferência de ar de exaustão, que caracteriza a fração de ar de exaustão transferido para o ar de alimentação e o fator de correção do ar externo, que é a razão entre as vazões de ar de alimentação na entrada e na saída do equipamento.

A norma AHRI Standard 1061 é uma norma estabelecida pela indústria para teste de desempenho de recuperação de energia em equipamentos ERV. Essa norma, baseada na norma ASHRAE 84, estabelece definições, requisitos para marcações e dados de identificação, e condições de conformidade destinadas à indústria, incluindo fabricantes, engenheiros, instaladores, contratantes e usuários. Padrões de temperatura e umidade sob os quais os equipamentos devem ser testados são especificados para as estações de verão e inverno. Os valores de desempenho publicados devem ser reportados aos sete fatores de desempenho estipulados na norma ASHRAE 84.

\section{A.5 - Tipos e aplicações de recuperadores de energia ar-ar}

\section{A.5.1 - Recuperador de energia de placas fixas (Fixed-Plate Heat Exchangers)}

Recuperadores de placas estão disponíveis em várias configurações, materiais, tamanhos e padrões de escoamento. Muitos possuem módulos que podem ser arranjados para atender praticamente a qualquer vazão de ar, eficiência, e valores de perda de carga estabelecidos. As placas são construídas com espaçadores ou separadores (ovais, ondulados, etc) ou ainda com separadores externos (suportes, aparelhos, etc). As separações entre as correntes de ar são seladas por dobras, dobras múltiplas, cementação, solda ou qualquer combinação desses, dependendo da aplicação do fabricante. A facilidade para acesso e limpeza das superfícies depende da configuração e da instalação. 
A resistência à transferência de calor através das placas é pequena quando comparada com a resistência da camada limite da corrente de ar em cada lado das placas. A eficiência da transferência de calor não é substancialmente afetada pelo coeficiente de transferência de calor das placas. O alumínio é o material mais popularmente utilizado na construção das placas em virtude de sua durabilidade e não inflamabilidade. Recuperadores com placas poliméricas podem aumentar a transferência de calor devido à turbulência gerada no canal do escoamento e são populares por sua resistência à corrosão e seu bom custo-benefício.

Ligas de aço são utilizadas para temperaturas acima de $200{ }^{\circ} \mathrm{C}$ e para aplicações especiais em que o custo não é o fator determinante. Os recuperadores de placa normalmente conduzem apenas calor sensível, entretanto, materiais permeáveis ao vapor de água, tais como papel tratado e membranas poliméricas microporosas, podem ser usados para transferir umidade, provendo, assim, um equipamento recuperador de energia (recuperador entálpico).

Muitos fabricantes oferecem recuperadores de placas modulares. Os módulos possuem alcance de capacidade de 0,01 a $5 \mathrm{~m}^{3} / \mathrm{s}$ e podem ser arranjados em configurações que excedem $50 \mathrm{~m} 3 / \mathrm{s}$. Os vários tamanhos e configurações disponíveis permitem seleções que se encaixem nos espaços e requisitos de desempenho estabelecidos.

O espaço das placas varia de 2,5 a 12,5 mm, dependendo do projeto e da aplicação. O calor é transferido diretamente da corrente de ar quente através das placas de separação para a corrente de ar frio. Normalmente, o projeto, a construção e as restrições de custo resultam em uma seleção de recuperadores de fluxo cruzado, porém, os padrões adicionais de fluxos contracorrente podem aumentar a eficiência na transferência de calor.

Os recuperadores de placas fixas podem atingir altas eficiências de calor sensível e de energia total, uma vez que eles possuem apenas uma área de superfície primária de separação para a transferência de calor entre as correntes. Portanto, esses equipamentos não são inibidos por uma resistência secundária adicional (como o bombeamento de líquido em sistemas com serpentinas, por exemplo), inerente a alguns tipos de recuperador. Em um arranjo de fluxo cruzado (Figuras A.3 e A.4), eles usualmente não possuem uma eficiência sensível maior que $75 \%$, a menos que dois equipamentos sejam utilizados em série, como mostrado anteriormente na Figura A.1d. 


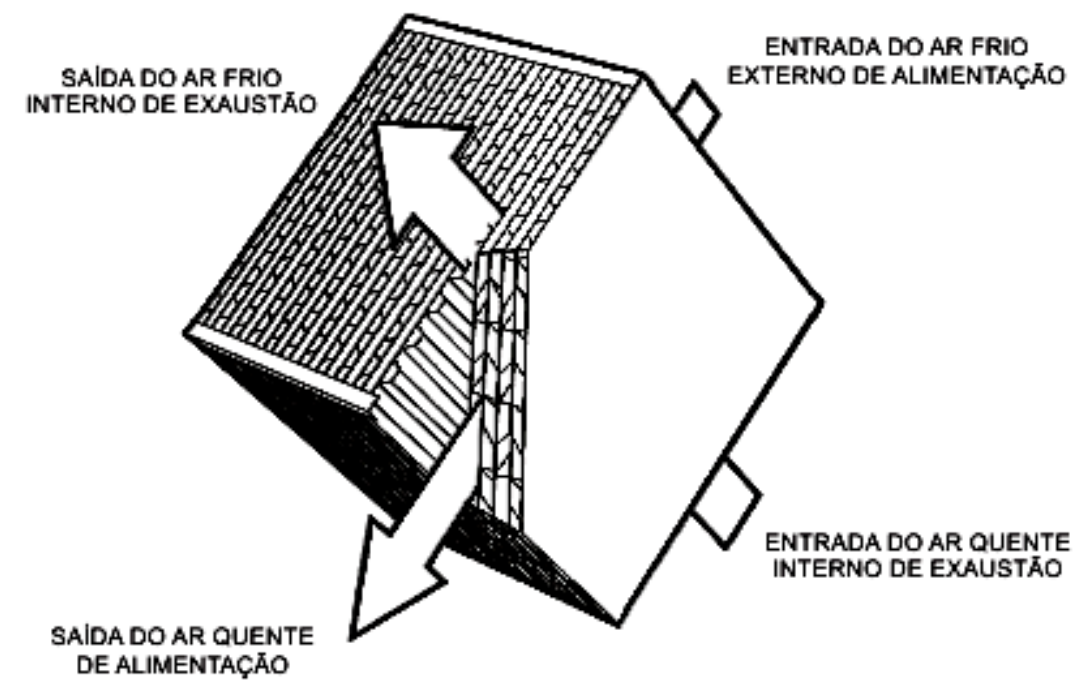

Figura A.3 - Recuperador de energia de placas fixas e fluxo cruzado (ASHRAE, 2012, modificado)

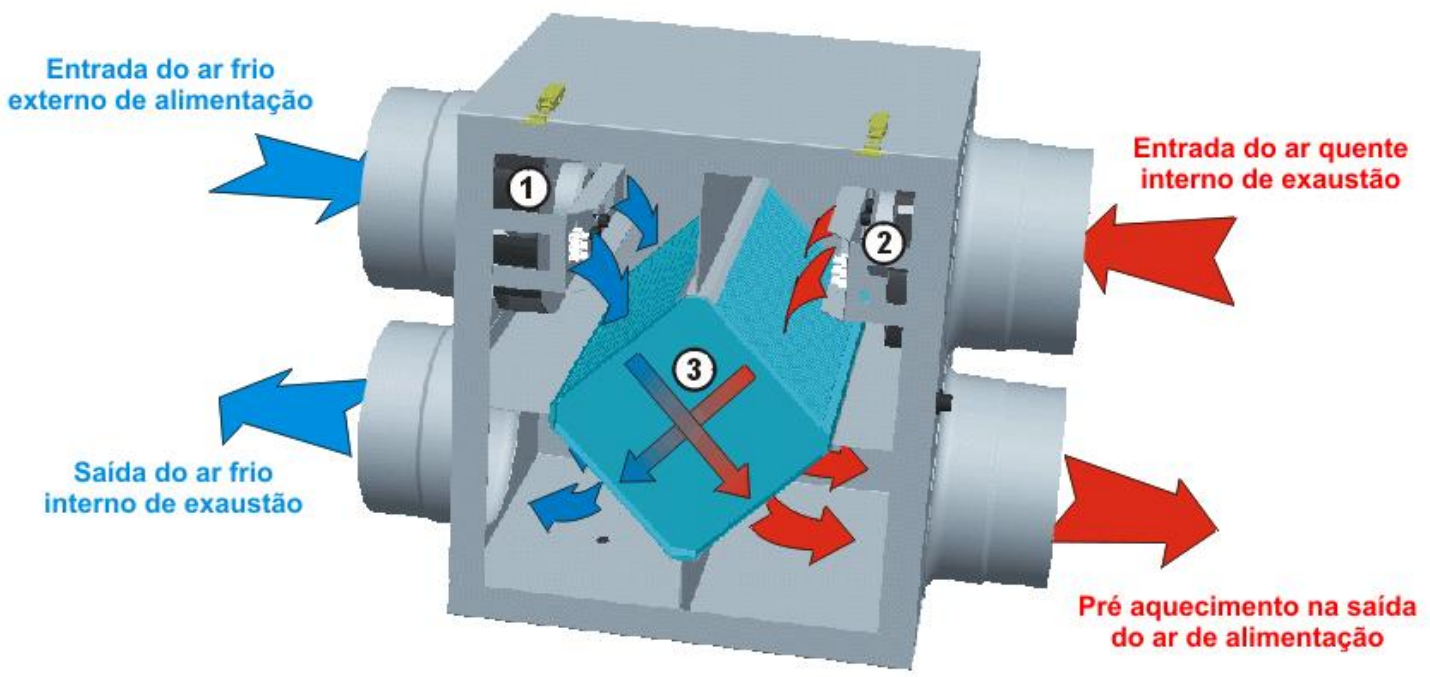

Figura A.4 - Recuperador de energia de placas fixas e fluxo cruzado (GreenAngel Energy, 2013, modificado) 


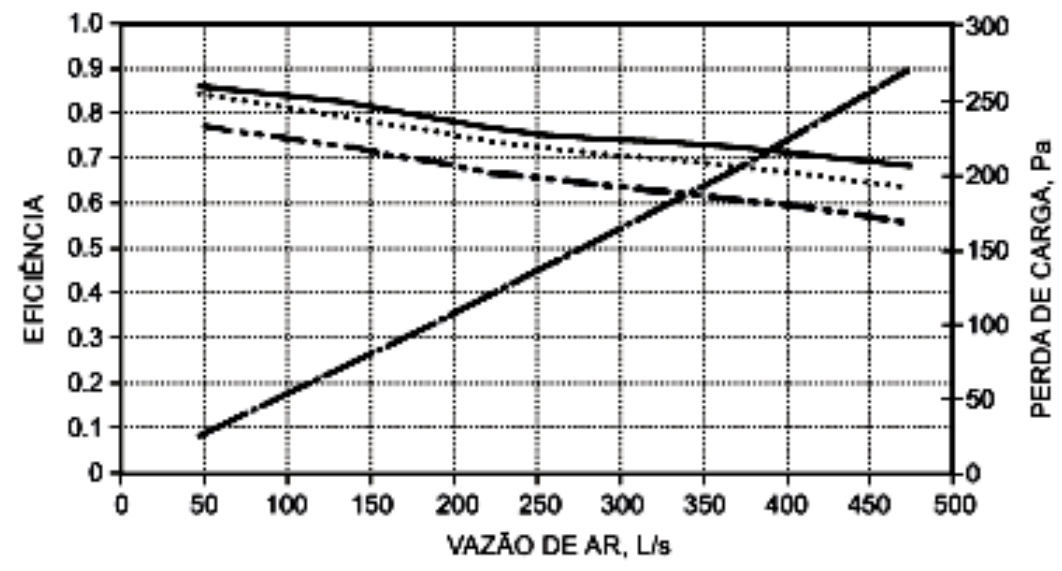

Figura A.5 - Variação na perda de carga e na eficiência com a vazão para recuperadores de placas (ASHRAE, 2012, modificado)

Uma vantagem do recuperador de placas fixas é que ele é um equipamento estático, com muito pouco ou nenhum vazamento de ar entre as correntes. Com o aumento da velocidade, a diferença de pressão entre as duas correntes aumenta (Fig. A.5). Grandes diferenças de pressão podem deformar as placas de separação e, caso seja excessiva, pode causar danos permanentes no recuperador, reduzindo significativamente a vazão no lado de baixa pressão, assim como a eficiência, e causando excessivo vazamento de ar.

Contudo, esse não é um problema comum, uma vez que o diferencial de pressão na maioria das aplicações é menor que $1 \mathrm{kPa}$. Em aplicações que exijam altas velocidades de ar, altas pressões estáticas ou ambas, trocadores de placas construídos para essas condições estão disponíveis e devem ser selecionados.

A maioria dos recuperadores de calor sensível possuem drenos para condensação, a fim de remover o condensado e também o resto de água dos sistemas de lavagem. O calor recuperado de uma corrente de ar de exaustão com alta umidade é mais bem recuperado por um HRV do que por um ERV, caso a transferência de umidade não seja desejada.

Os equipamentos de placas fixas podem ser feitos de membranas microporosas permeáveis, projetadas para maximizar a transferência de umidade e energia entre as correntes de ar, enquanto minimizam a transferência de ar (vazamentos). Os tipos mais adequados de membranas para essas tecnologias emergentes incluem celulose, polímeros e outros materiais sintéticos tais como eletrólitos hidrofílicos. Esses eletrólitos são feitos a partir de técnicas químicas de sulfonação e contêm íons carregados que atraem as moléculas polares de água. A adsorção e dessorção de água ocorrem no estado de vapor. 
As correntes de ar que saem do recuperador com arranjo de fluxo cruzado apresentam uma estratificação na temperatura quando há diferença de temperatura entre as duas correntes (Fig. A.6):

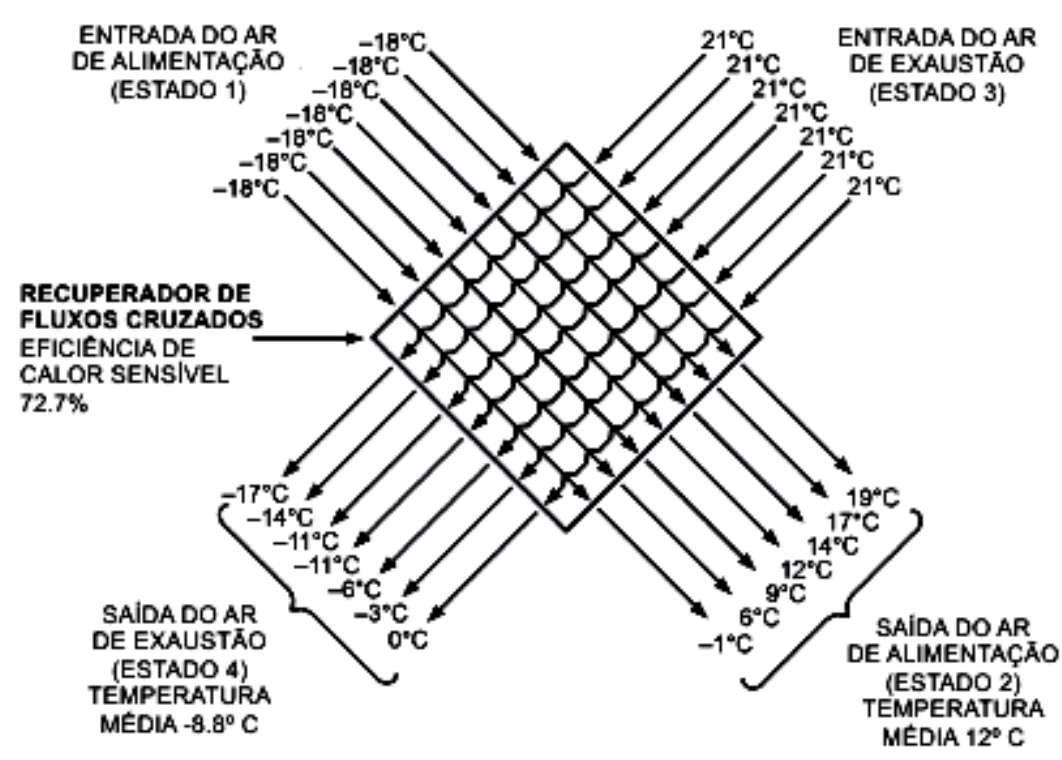

Figura A.6 - Típica estratificação de temperatura nas saídas de um ERV de fluxo cruzado modificada (ASHRAE, 2012)

A.5.2 - Recuperadores rotativos - Rodas giratórias entálpicas (Rotary enthalpy wheel)

Os recuperadores de energia rotativos ou rodas entálpicas possuem um cilindro rotativo preenchido com um meio permeável ao ar, com uma grande área superficial interna. As correntes adjacentes de ar de alimentação e exaustão escoam, cada uma, em metade da área do recuperador, em um padrão contracorrente (Figura A.7). O meio de transferência de calor pode ser selecionado para recuperar apenas calor sensível ou calor sensível e latente.

O calor sensível é transferido à medida que o meio de transferência armazena o calor da corrente quente e o entrega para a corrente fria. $\mathrm{O}$ calor latente é transferido quando o meio adsorve vapor de água da corrente mais úmida e o dessorve na corrente de menor umidade, sendo conduzido em cada caso pela diferença de pressão de vapor de água 
entre a corrente de ar e o meio de transferência de energia. Assim, a corrente de ar úmida é ressecada enquanto a corrente de ar seca é umidificada.

Em uma transferência total de energia, o calor sensível e o latente são transferidos simultaneamente. As rodas giratórias que transferem apenas calor sensível podem também transferir água por meio de um mecanismo de condensação e evaporação conduzido pelo ponto de orvalho e pela pressão de vapor, nesse caso, a eficiência varia fortemente com as condições de operação. Compactos, os recuperadores rotativos possuem uma configuração contracorrente e normalmente utilizam passagens para o escoamento de pequeno diâmetro, podendo atingir altas eficiências de transferência de energia.

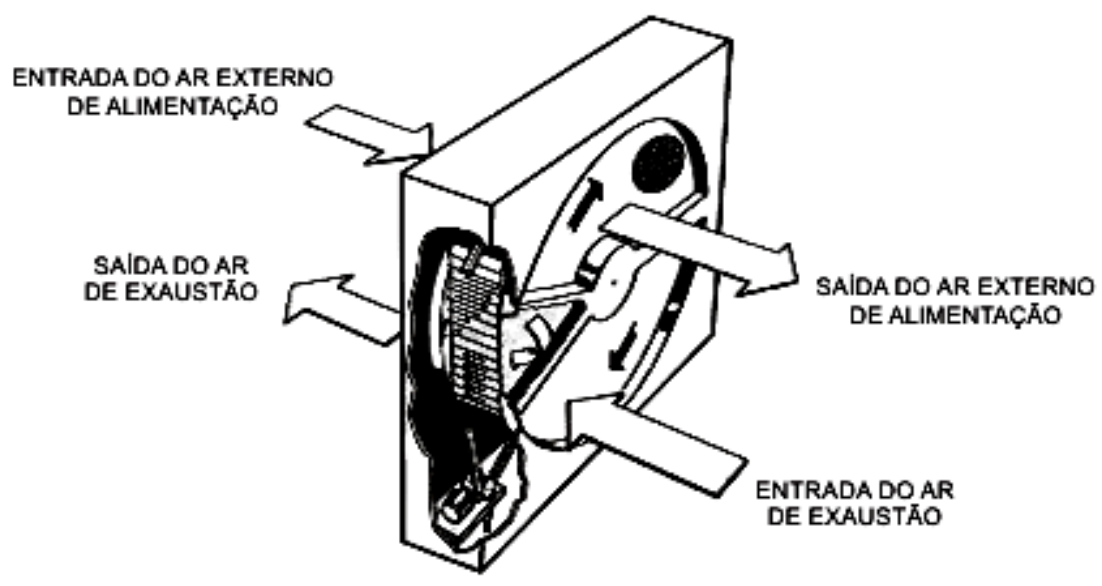

Figura A.7 - Recuperador de energia rotativo (ASHRAE, 2012, modificado)

Os contaminantes do ar, ponto de orvalho, temperatura do ar de exaustão e as propriedades do ar de alimentação influenciam a escolha dos materiais para o invólucro e a estrutura do rotor e o meio de transferência de energia para esses equipamentos. Alumínio, aço e polímeros são os materiais usuais para estruturas, invólucros e rotores para sistemas normais de ventilação para aplicações de conforto. O meio de transferência de energia é fabricado geralmente a partir de metais, minerais ou materiais sintéticos, e permitem escoamentos aleatórios ou direcionados através de suas estruturas.

Os meios de transferência para escoamentos aleatórios são feitos por arames tricotados dentro de um pano ou malha corrugada, sendo dispostos em camadas de acordo com a configuração desejada. Malhas de alumínio são embaladas em formato de torta nos segmentos da roda entálpica emalhas de aço inoxidável e monel são utilizadas para aplicações em altas temperaturas e em ambientes corrosivos. Esses meios devem ser usados apenas com correntes de ar limpas e filtradas, uma vez que eles tamponam 
facilmente. Ainda, esses meios para fluxos aleatórios requerem áreas de face maiores que os meios para fluxos orientados para uma dada condição de vazão e perda de carga.

\section{Os meios de transferência para os equipamentos com escoamento direcionado}

estão disponíveis em diversas geometrias de configuração. Os meios mais comuns consistem de pequenas passagens $(1,5$ a $2 \mathrm{~mm})$ de ar paralelas à direção do escoamento. Essas passagens são muito similares em seu desempenho, independentemente de suas formas (triangulares, hexagonais, placas paralelas ou outras). Folhas de alumínio, papel, plástico e outros materiais sintéticos são utilizados para serviços em médias e baixas temperaturas. Aços inoxidáveis e cerâmicos são utilizados para serviços em altas temperaturas e em atmosferas corrosivas.

As áreas superficiais dos meios expostos ao escoamento variam de 300 a mais de $4000 \mathrm{~m}^{2} / \mathrm{m}^{3}$, dependendo do tipo de meio e das configurações físicas. $\mathrm{O}$ meio ainda pode ser classificado de acordo com sua capacidade de recuperação de calor sensível ou de calor total. Os meios para recuperação de calor sensível são feitos de alumínio, cobre, aço inoxidável e monel, enquanto os destinados à recuperação de calor total podem ser de vários tipos de materiais e devem ser tratados com um material dessecante (zeólitos, peneiras moleculares, gel de sílica, alumina ativada, silicato de titânio, polímeros sintéticos, cloreto de lítio ou óxido de alumínio) para que possuam a característica de recuperação de umidade.

Vazamentos de ar entre os fluxos (misturas entre as correntes de alimentação e exaustão) podem ocorrer em recuperadores rotativos por meio de dois tipos de mecanismos: carregamento ou vazamento de selo. $\mathrm{O}$ vazamento entre fluxos pode ser reduzido a partir da introdução de sopradores, de modo que eles promovam o vazamento de ar da corrente de alimentação para a de exaustão. Um purgador também pode ser instalado no recuperador para reduzir o vazamento de ar entre os fluxos.

Em diversas aplicações, recircular parte do ar de insuflamento não é um problema, inclusive, é bastante usual, uma vez que essa operação geralmente economiza energia. Entretanto, aplicações críticas, tais como as de hospitais, laboratórios e salas limpas requerem controle restrito do mecanismo de vazamento de ar do tipo carregamento. Esse carregamento pode ser reduzido para menos de $0,1 \%$ do fluxo de ar de exaustão a partir da introdução de um purgador, mas não pode ser eliminado por completo.

O carregamento teórico de uma roda entálpica sem purgador é diretamente proporcional à velocidade da roda e ao volume de vazios do meio (75 a 95\% de vazios, dependendo do tipo e configuração). Nesse sentido, o ventilador de exaustão, que é 
geralmente localizado na saída do recuperador, deve ser dimensionado para incluir as vazões devidas a vazamentos e purgas de ar.

Dois métodos de controle são geralmente utilizados para regular a recuperação de energia da roda. No método de controle de by-pass do fluxo de alimentação ou exaustão, a quantidade de ar de alimentação que passa por meio da roda entálpica estabelece a temperatura do ar externo de alimentação. Um damper de by-pass, controlado por um sensor de temperatura na descarga do ar de alimentação do recuperador, regula a proporção de ar de alimentação que irá contornar a entrada do recuperador (by-pass).

O segundo método de controle regula a recuperação de energia por meio da variação de velocidade de rotação da roda. As unidades de velocidade variável mais frequentemente usadas são: (i) um retificador controlado de silício (SCR) com um motor DC (corrente contínua) de velocidade variável; (ii) um motor de velocidade constante AC (corrente alternada) com acoplamento em histerese e (iii) um inversor de frequência AC com um motor de indução AC.

A eficiência de desumidificação e de reaquecimento de uma roda entálpica pode variar de acordo com a velocidade da roda (Figura A.8), ou por meio do by-pass de ar por fora da roda entálpica (Figura A.9). A Figura A.8 é uma curva típica de capacidade pela variação de velocidade de rotação quando o ar externo está mais frio e mais seco do que o ar de exaustão. Quando as condições externas estão mais frias e mais úmidas, a capacidade pode aumentar em baixas rotações (Simonson et al., 2000):

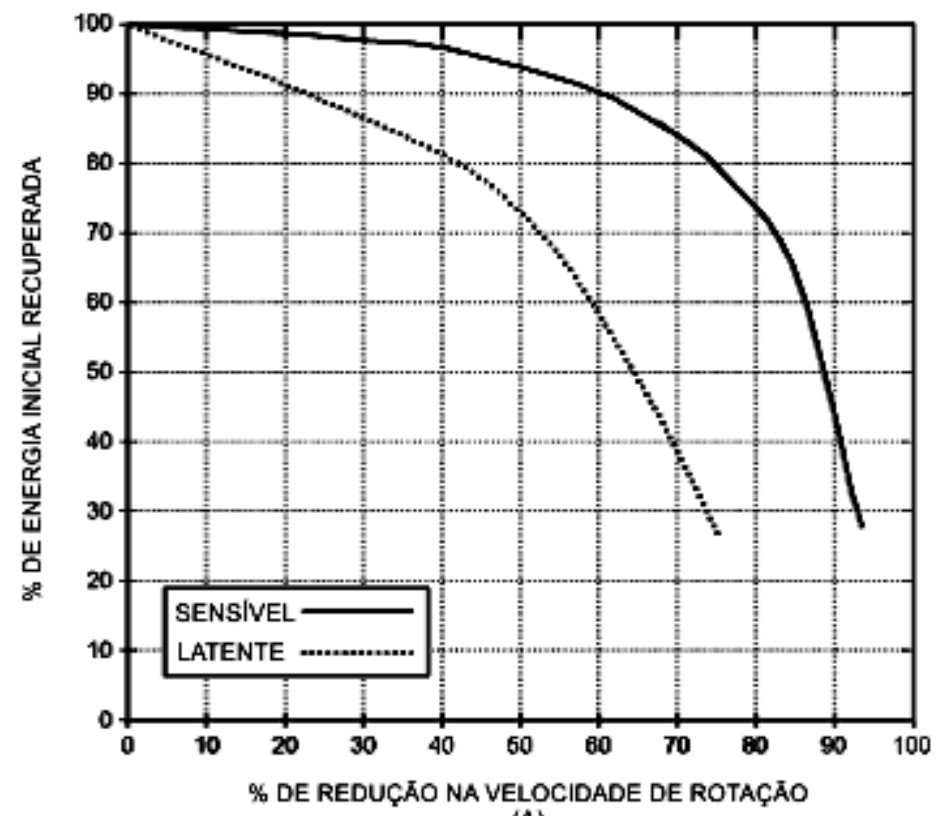

(A) 
Figura A.8 - Eficiências latente e sensível x Rotação da roda (ASHRAE, 2012, modificado)

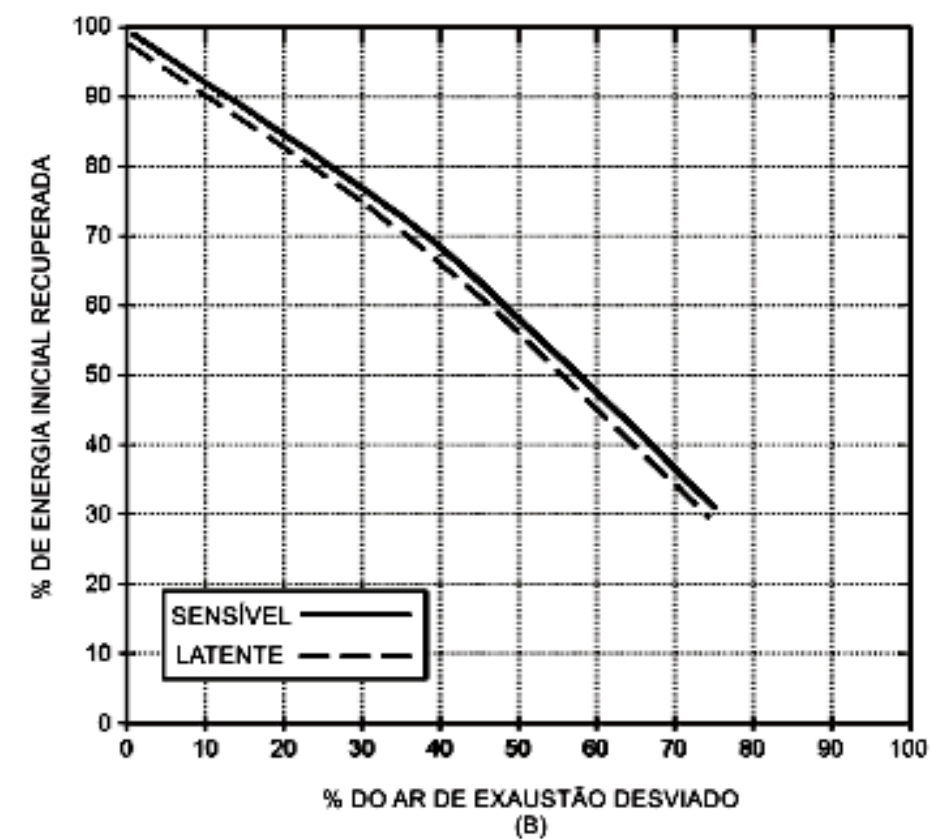

Figura A.9 - Eficiências latente e sensível x by-pass de ar (ASHRAE, 2012, modificado)

A Figura A.10 apresenta a eficiência de transferência de calor sensível apenas, com fluxos balanceados (vazões iguais para as correntes de alimentação e exaustão), relação de convecção-condução menor que quatro e sem vazamentos de um recuperador rotativo de calor em contracorrente versus o número de unidades de transferência (NTU). As rodas de energia ou rodas entálpicas são mais complexas que as rodas de calor, porém, pesquisas já caracterizaram seu comportamento a partir de testes de laboratório e operações em campo (Johnson et al., 1998). 


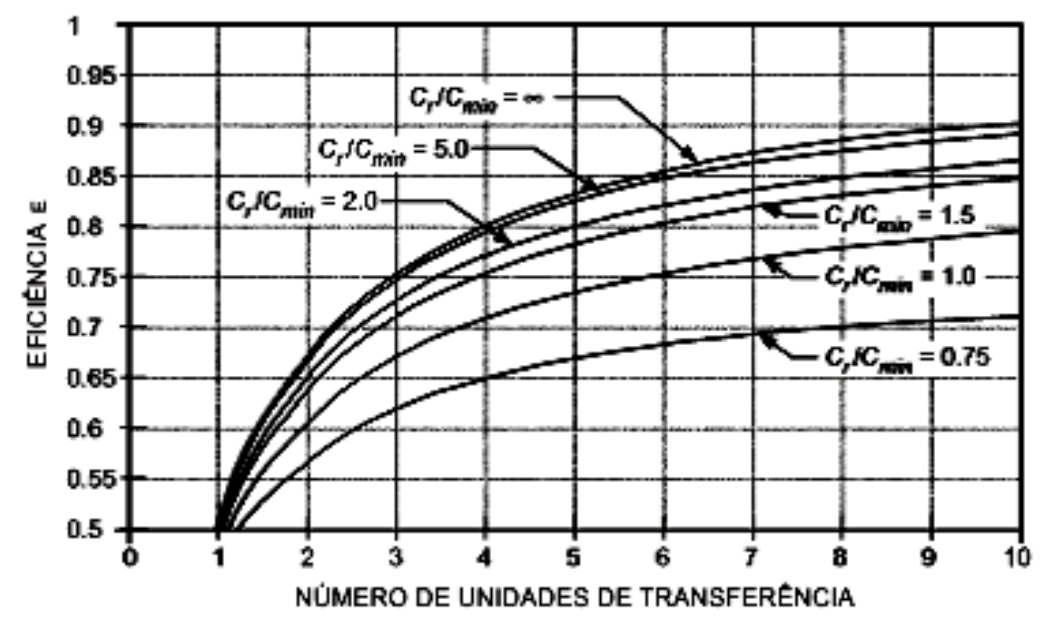

Figura A.10 - Eficiência de um recuperador de calor contracorrente (ASHRAE, 2012, modificado)

Um controle de zona morta, que para ou limita a operação do recuperador, pode ser necessário quando a recuperação não é desejável (quando a temperatura do ar externo é maior que a temperatura padrão para o ar de alimentação, mas é menor que a temperatura do ar de exaustão). Quando a temperatura do ar externo é maior que a do ar de exaustão, o equipamento opera em capacidade total para resfriar o ar de alimentação.

As rodas entálpicas requerem pequenas rotinas de manutenção e tendem a ser autolimpantes, uma vez que a direção do escoamento de ar é invertida para cada rotação da roda. As seguintes rotinas de manutenção são indicadas para otimizar o desempenho do equipamento: i) limpar o meio de transferência quando fiapos, poeira, ou outros materiais estranhos penetrarem no equipamento, de acordo com as instruções do fabricante e ii) manter o motor de partida de acordo com as recomendações do fabricante, sendo que motores com controle de velocidade que possuem comutadores e escovas requerem inspeções e manutenções mais frequentes que motores de indução. Nesse caso, as escovas devem ser substituídas e os comutadores devem ser periodicamente virados e minados; iii) inspecionar regularmente as rodas para manter adequadas as tensões de correias ou correntes e iv) atentar às recomendações do fabricante para as peças de reposição e substituição.

A.5.3 - Recuperadores de calor por meio de bombeamento de fluido em serpentinas multipasses (Coil Energy Recovery Loops) 


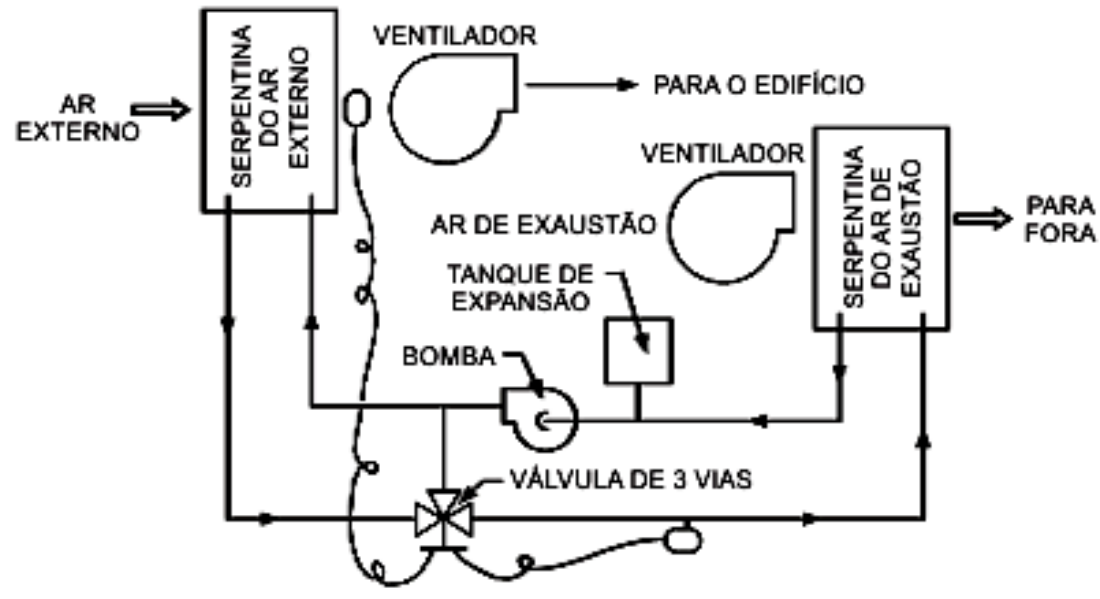

Figura A.11 - Recuperador de energia por meio de serpentina (ASHRAE, 2012, modificado)

Trata-se de um recuperador de energia típico por meio de serpentina que coloca uma superfície de troca estendida, por meio de serpentinas aletadas de água, nas correntes de ar de alimentação e exaustão. As serpentinas são conectadas por um laço fechado por tubos em contracorrente através dos quais circula um fluido intermediário para transferência de calor (tipicamente água ou alguma solução anti-congelante) por meio de bombeamento (Figura A.11).

Esse tipo de solução é utilizado principalmente em condições climáticas que requerem o aquecimento do ar exterior, uma vez que o fluido de transporte recebe calor na serpentina do ar de exaustão (temperatura do ar a $24^{\circ} \mathrm{C}$, por exemplo) e cede calor na serpentina de alimentação (temperatura externa abaixo de $0^{\circ} \mathrm{C}$ ). Para condições acima de $15^{\circ} \mathrm{C}$ de temperatura do ar externo, o ar de alimentação é resfriado a partir de um resfriador evaporativo localizado à montante da serpentina do ar de exaustão. Esse resfriador tem o objetivo de diminuir a carga térmica do ar de exaustão e retirar calor do fluido intermediário, que, por sua vez, retira calor do ar externo de alimentação na serpentina correspondente. Esses processos podem ser visualizados na Figura A.12: 


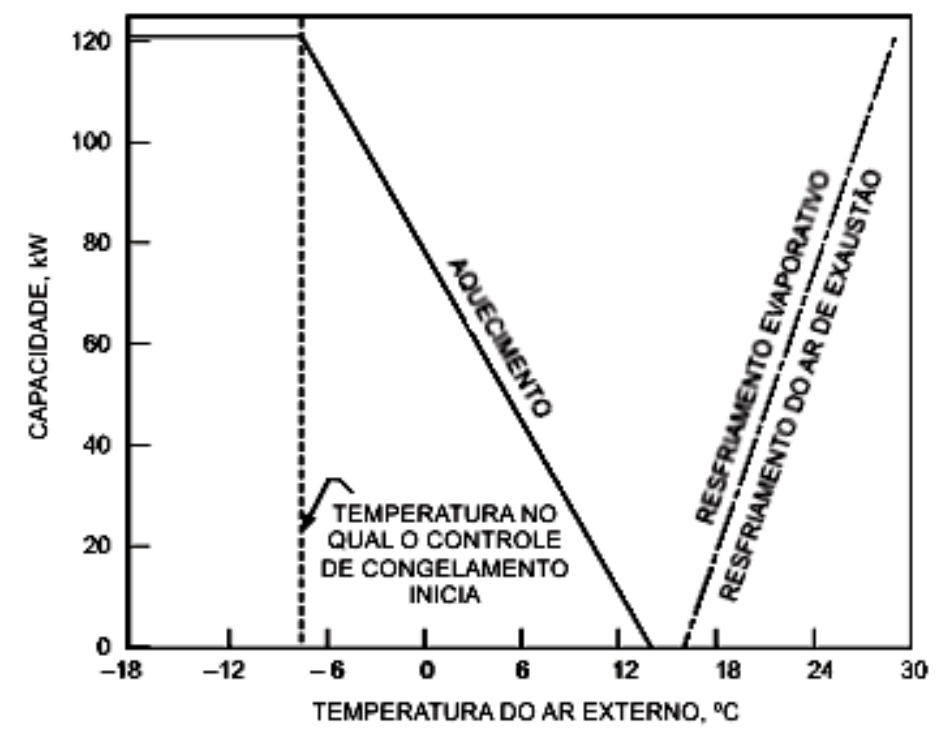

Figura A.12 - Capacidade de recuperação de energia x Temperatura do ar externo para um recuperador de serpentina (ASHRAE, 2012, modificado)

Esse sistema é bastante flexível e adequado a aplicações industriais e de renovação. O laço de serpentina pode ser acomodado em dutos independentes de alimentação e exaustão, permitindo instalações em grandes distâncias e transferência de energia simultânea entre múltiplas fontes e usos. Entretanto, esse sistema não transfere umidade entre as correntes de ar, sendo apenas um recuperador de calor sensível. Para operações com maior custo-benefício, para fluxos balanceados e sem condensação, os valores de eficiências típicas variam entre 45 e $65 \%$.

Outra vantagem do sistema é que a separação completa entre as correntes de ar elimina quaisquer tipos de fluxos cruzados. Ainda, requere pouca manutenção, uma vez que as únicas partes móveis são a bomba e a válvula de três vias. Entretanto, para uma operação ótima, as correntes de ar devem ser filtradas, as superfícies das serpentinas limpadas regularmente, a bomba e a válvula manutenidas adequadamente e o fluido de transporte completado ou substituído periodicamente.

\section{A.5.4 - Recuperadores de calor de tubos quentes (Heat Pipe Heat Exchangers)}

A Figura A.13 mostra um arranjo típico de tubos quentes. $\mathrm{O}$ ar quente que escoa no evaporador do dispositivo vaporiza o fluido de trabalho. O gradiente de pressão de vapor conduz o fluido para a zona de condensação, onde o vapor condensa, liberando energia 
latente de condensação (Figura A.14). O fluido condensado escoa de volta para o evaporador, onde é vaporizado novamente, completando o ciclo. O fluido de trabalho opera num ciclo fechado de condensação/evaporação que funciona enquanto existe diferença de temperatura para conduzir o processo:

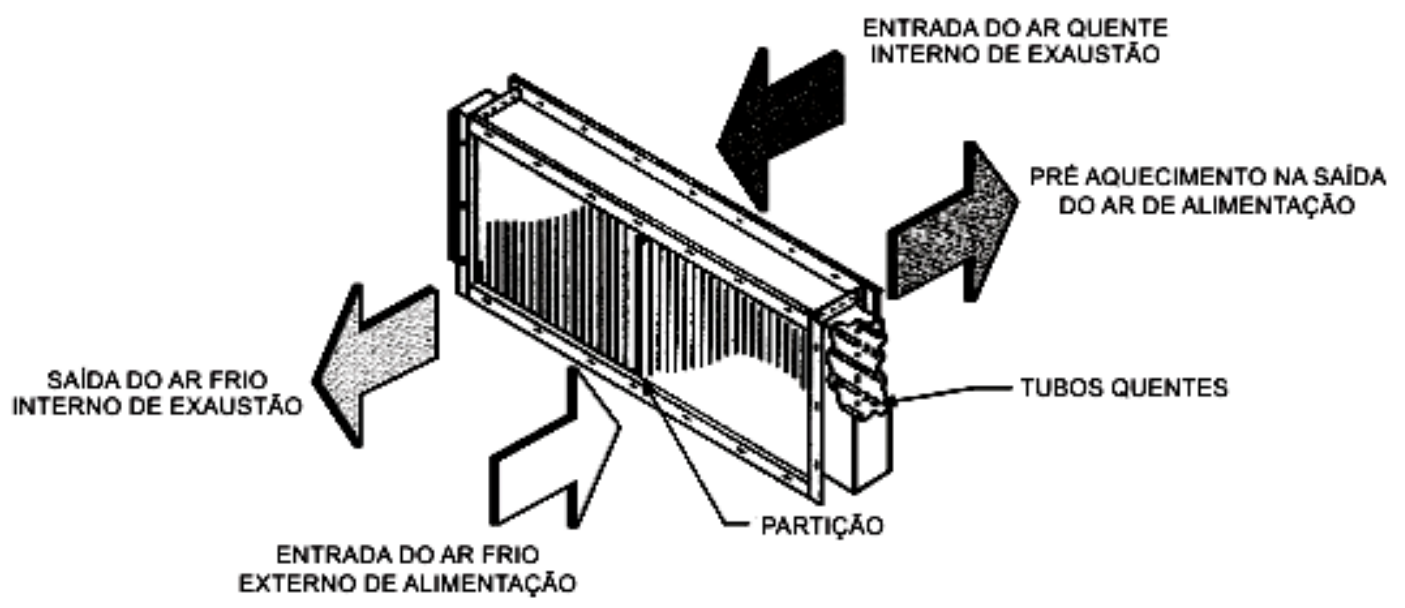

Figura A.13 - Arranjo de tubos quentes (ASHRAE 2012, modificado)

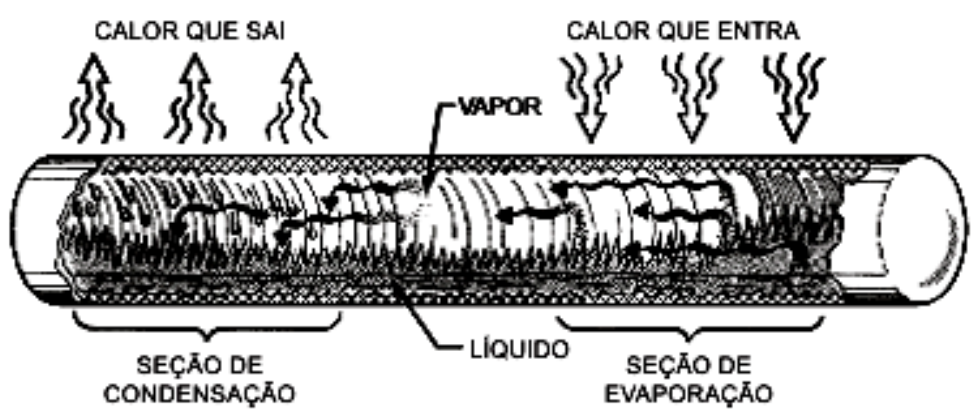

Figura A.14 - Operação de tubos quentes (ASHRAE, 2012, modificado)

A Figura A.15 apresenta os processos de transferência de calor sensível dos tubos quentes na carta psicométrica, considerando a operação em verão e inverno. A energia transferida pelos tubos quentes é frequentemente considerada como um processo isotérmico, no entanto, existe uma pequena queda de temperatura por meio da parede do tubo. A capacidade de transferência desse arranjo é afetada por diversos fatores, tais como o projeto, o diâmetro do tubo, o fluido de trabalho, e a orientação do tubo em relação à horizontal: 


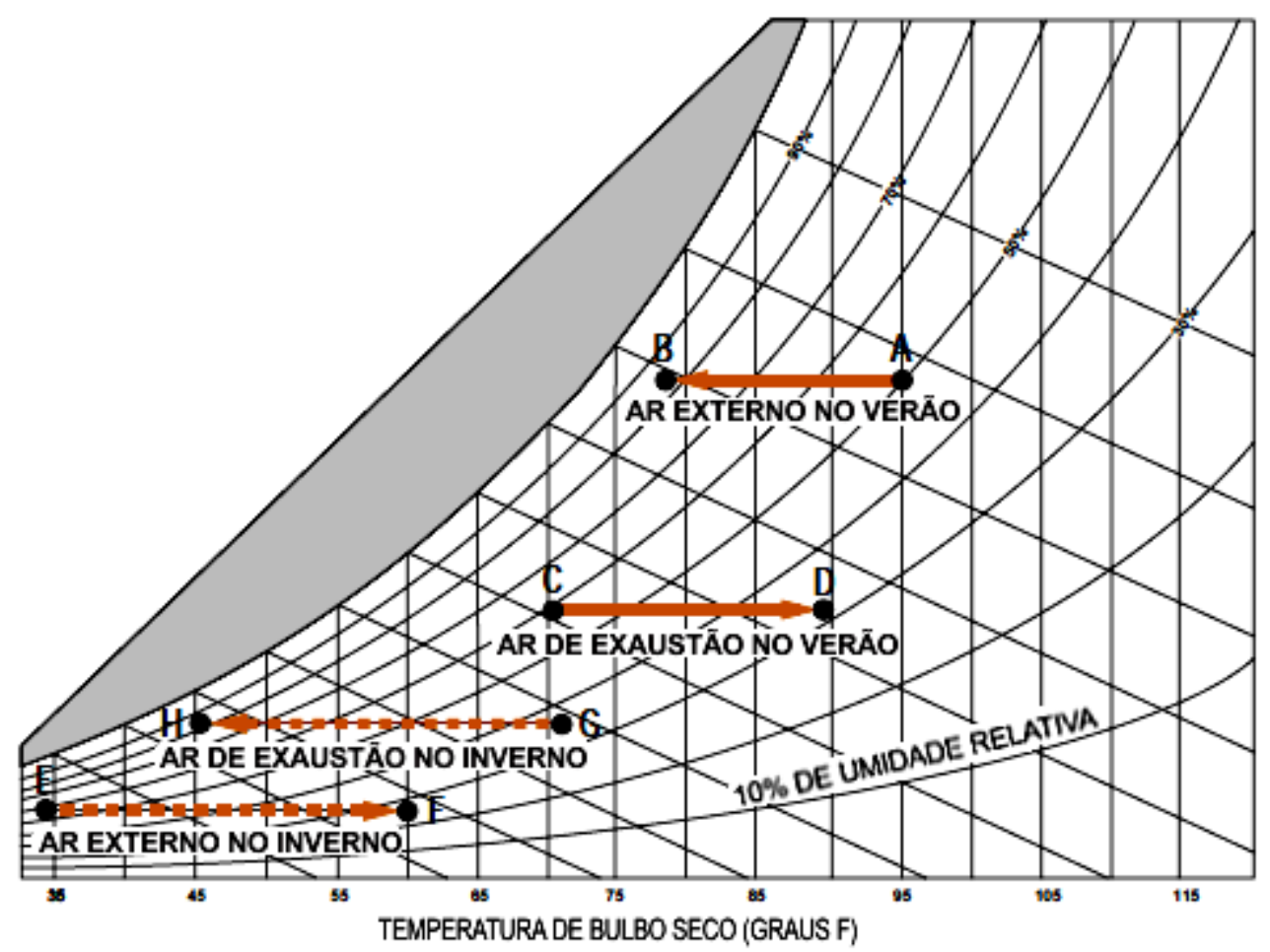

Figura A.15 - Processos de transferência de calor sensível no verão e no inverno (MUNTERS, 2012, modificado)

Sistemas de AVAC utilizam tubos quentes de cobre ou alumínio com aletas de alumínio. A seleção do fluido de trabalho visando à operação a longo prazo é um ponto crítico, pois ele deve possuir alto calor latente de vaporização, alta tensão superficial e uma baixa viscosidade ao longo da faixa de operação. Ainda, deve ser termicamente estável nas temperaturas de operação.

Os recuperadores de calor de tubos quentes normalmente não possuem contaminação cruzada entre as correntes de ar para diferenças de pressão de até $12 \mathrm{kPa}$. A capacidade de transferência de calor depende do projeto e da orientação do equipamento. A Figura A.15 mostra uma curva típica de eficiência para várias velocidades de face e passes de tubos. Com o aumento no número de passes, a eficiência também aumenta, porém numa taxa menor.

Por exemplo, dobrando o número de passes de tubos em uma eficiência de $60 \%$, a eficiência aumenta para 75\%. A eficiência de um recuperador de tubos quentes em contracorrente depende do número total de passes, de tal modo que duas unidades em série produzem a mesma eficiência que uma única unidade com o mesmo número de passes. Unidades em série são frequentemente utilizadas para facilitar o transporte, limpeza e manutenção. A eficiência também depende da temperatura do ar externo e das vazões mássicas das correntes de ar. 


\section{A.5.5 - Recuperadores de calor tipo termossifão (Thermosiphon Heat Exchangers)}

Recuperadores de calor tipo termossifão de duas fases são sistemas selados que consistem de um evaporador, um condensador, tubos de ligação e um fluido de trabalho que se apresenta nas fases de líquido e de vapor. Dois tipos de equipamentos são usados: tipo tubo selado (Figura A.16) e tipo serpentina (Figura A.17). No tubo selado, o evaporador e o condensador estão em extremidades opostas de um feixe retilíneo, os tubos individuais do termossifão e os dutos das correntes de alimentação e exaustão são adjacentes umas às outras (arranjo parecido com o do sistema de tubos quentes). No termossifão tipo serpentina, as serpentinas do evaporador e do condensador são instaladas de forma independente nos dutos e são interconectadas por tubos com um fluido de trabalho (arranjo parecido ao sistema de bombeamento de fluido por serpentina):

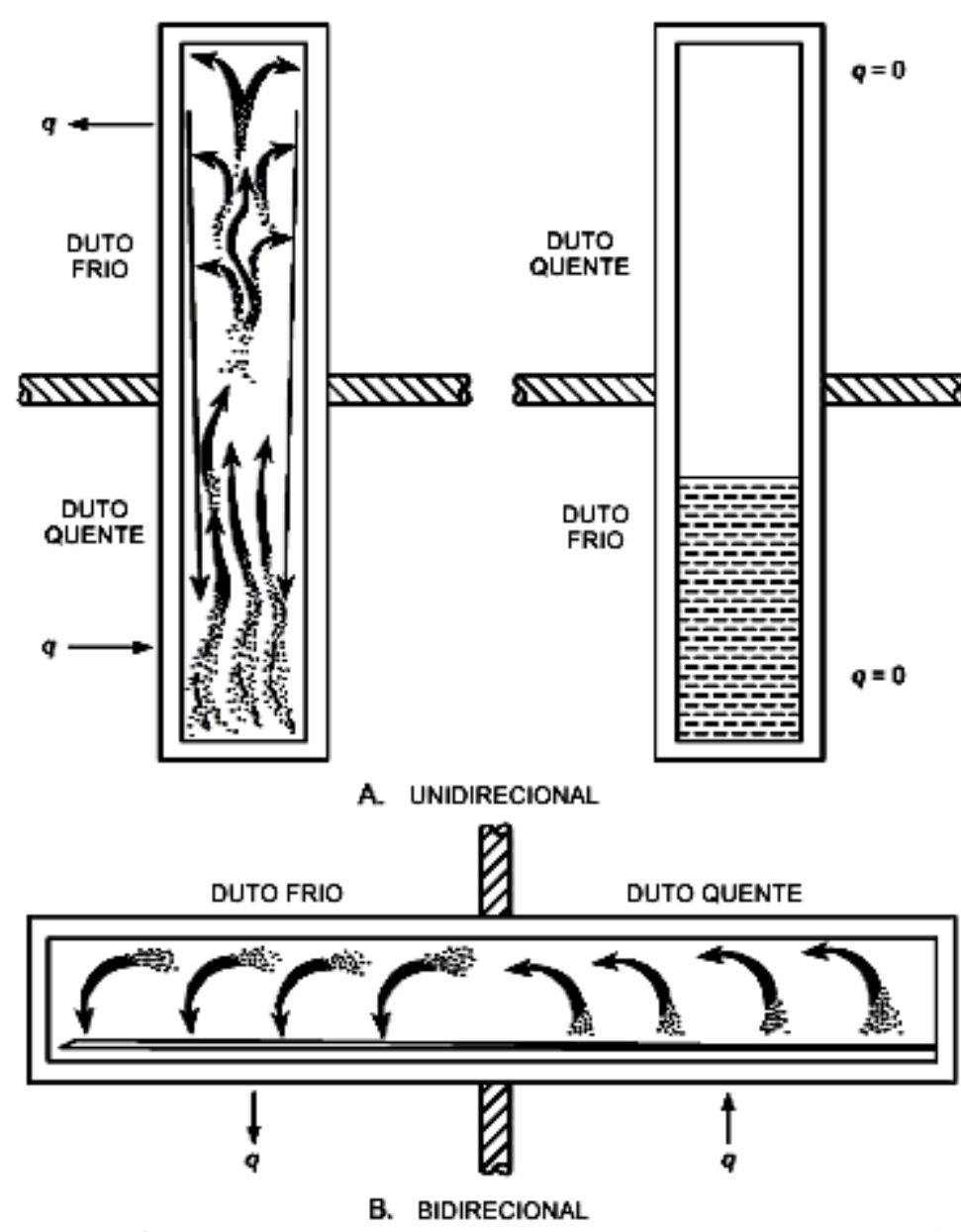

(TRANSFERENCIAS DE CALOR OCORREM IGUALITARIAMENTE EM CADA DIREÇAO)

Figura A.16 - Termossifão tipo tubo selado (ASHRAE, 2012, modificado) 
Um termossifão é um sistema selado contendo um fluido de trabalho em duas fases. Uma vez que parte do sistema contém vapor e outra parte contém líquido, a pressão no termossifão é governada pela temperatura do líquido na interface líquido/vapor. Se a vizinhança causa uma diferença de temperatura entre as regiões em que estão presentes as interfaces de líquido e vapor, a diferença de pressão resultante causa um fluxo de vapor da região mais quente para a região mais fria. O fluxo é sustentado pela condensação na região mais fria e pela evaporação na região mais quente. $\mathrm{O}$ condensador e o evaporador devem estar orientados para que o condensado possa retornar para o evaporador por gravidade (Figuras A.16 e A.17). Para termossifões tipo serpentina (Figura A.17), o nível estático do líquido ou a carga de refrigerante afetam significativamente o desempenho do sistema:
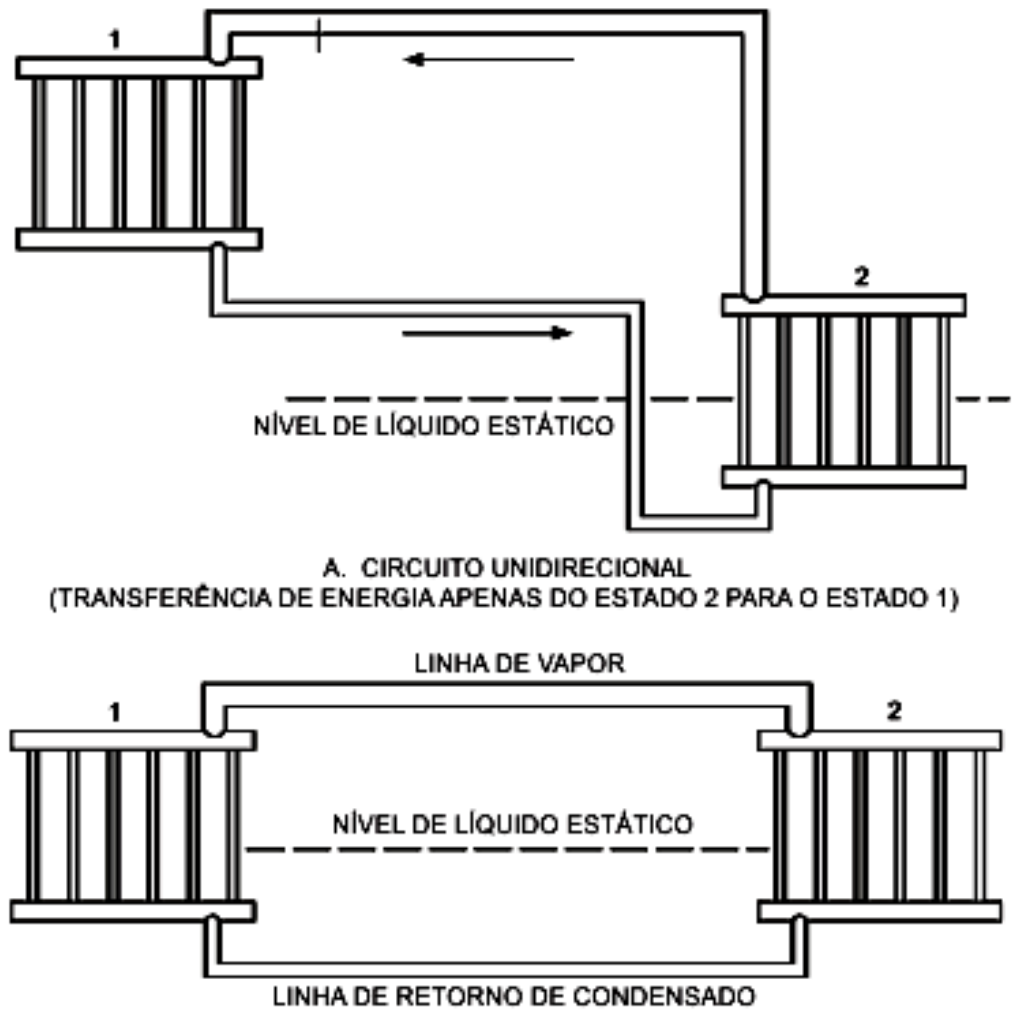

B. CICLO BIDIRECIONAL

(TRANSFERENCIA DE ENERGIA OCORRE NAS DUAS DIREÇOES)

Figura A.17 - Termossifão tipo serpentina (ASHRAE, 2012, modificado)

Em sistemas de termossifões, a diferença de temperatura e a força da gravidade são requisitos para que o fluido de trabalho circule entre o condensador e o evaporador. Como 
resultado, os termossifões podem ser projetados para transferir calor igualmente em cada direção (bidirecional), apenas em uma direção (unidirecional), ou em ambas as direções de maneira não igualitária.

Apesar de similares aos tubos quentes tanto na forma quanto na operação, os termossifões de tubos selados se diferem daqueles em dois pontos: (i) não requerem bomba para circular o fluido de trabalho e (ii) dependem ao menos incialmente de uma ebulição nucleada. Os termossifões tipo serpentina diferem dos sistemas de bombeamento de fluido em serpentina uma vez que os termossifões não requerem bombeamento, e, portanto, nenhuma fonte de alimentação externa. A Figura A.18 mostra o desempenho de um termossifão tipo serpentina com 8 passes, com espaçamento de aletas de $2 \mathrm{~mm}$, em modo unidirecional:

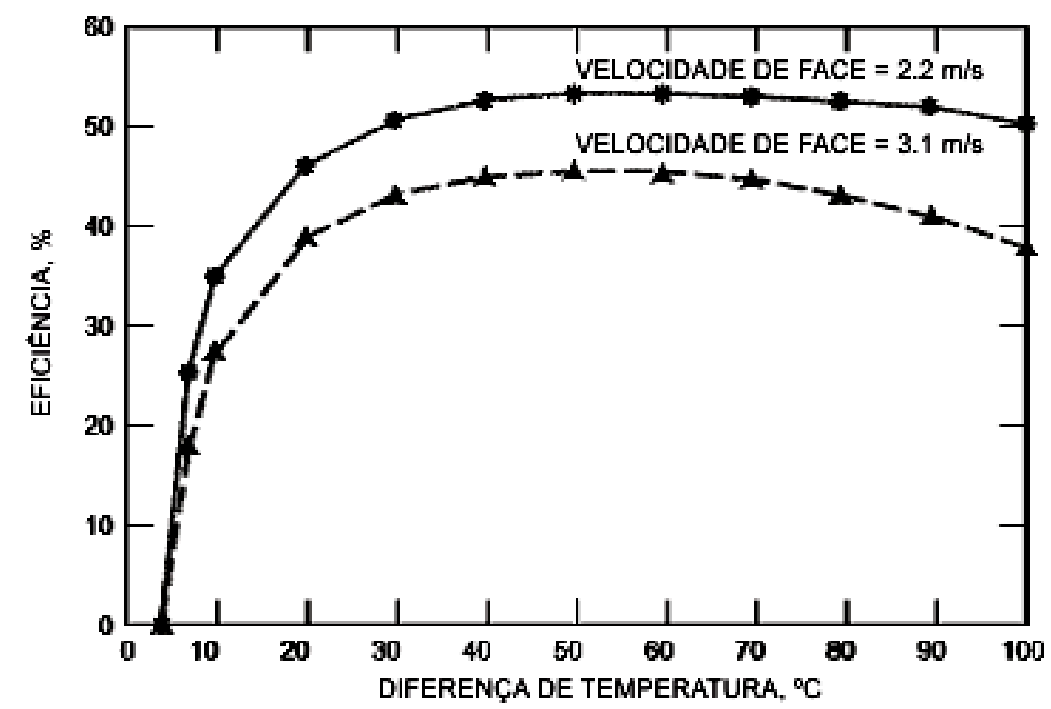

Figura A.18 - Termossifão tipo serpentina com 8 passes, $2 \mathrm{~mm}$ de espaço entre aletas, carga estática de $80 \%$ (ASHRAE, 2012, modificado)

\section{A.5.6 - Recuperadores de calor tipo torres gêmeas (Twin-Tower Enthalpy Recovery Loops)}

Um método de recuperação entálpica por meio da ventilação de ar é o sistema de líquido dessecante de torres gêmeas. Nesse sistema de recuperação ar-líquido/líquido-ar, um líquido absorvente circula continuamente entre as correntes de ar de alimentação e exaustão, alternativamente entrando em contato com ambas correntes de ar diretamente nas torres de contato (Figura A.19). Esse líquido transporta calor e vapor de água. A solução absorvente é normalmente composta de um sal de halogênio, tal como cloreto de lítio, 
cloreto de cálcio e água. Uma bomba faz a circulação da solução entre as torres de exaustão e alimentação.

Ambas as torres de contato, tanto com escoamento horizontal quanto vertical, estão disponíveis e podem ser combinadas em um sistema comum. Torres de contato de ambas as configurações são comumente disponíveis com capacidades de vazão acima de $40 \mathrm{~m} 3 / \mathrm{s}$.

Na configuração vertical, o ar de alimentação ou exaustão passa verticalmente pela superfície de contato em contracorrente com o líquido absorvente, de forma a atingir uma alta eficiência de contato. Na configuração horizontal, o ar passa horizontalmente através da superfície de contato em fluxo cruzado para o líquido absorvente, produzindo uma menor eficiência de contato.

O sistema de torres gêmeas não é desejável para aplicações em altas temperaturas. Durante o verão, esses sistemas operam eficientemente em edificações com temperaturas de ar externo até a faixa dos $46^{\circ} \mathrm{C}$. Para temperaturas na faixa de $-40^{\circ} \mathrm{C}$, durante o inverno, o sistema pode operar sem problemas de congelamento uma vez que a solução absorvente é um efetivo anticongelante. Devido à independência entre as torres de alimentação e exaustão, os ventiladores das correntes de alimentação e exaustão podem ser alocados em qualquer lugar desejado.

A contaminação cruzada de partículas não ocorre porque as partículas molhadas permanecem na solução até serem filtradas. Ainda, um termostato localizado na saída do ar da torre de contato de alimentação é comumente usado para controlar o aquecedor da solução, de forma a entregar ar a uma temperatura constante independentemente da temperatura externa. A adição de um repositor automático de água para manter fixa a concentração da solução absorvente permite o sistema de torres gêmeas entregar o ar de alimentação em uma umidade fixa durante o inverno. Assim, esse sistema provê o ar de alimentação em temperaturas e umidades fixadas, independentemente da utilização de serpentinas de reaquecimento ou de umidificadores.

Qualquer número de torres de alimentação podem ser combinadas com qualquer quantidade de torres de exaustão, conforme mostrado na Figura A.19b. Se existe uma diferença de elevação suficiente entre as torres, a gravidade pode ser usada para retornar a solução da torre mais alta ao invés de se usar bombeamento. O sistema de torres gêmeas pode ser aplicado em edifícios existentes por meio de um processo de retrofit, uma vez que as torres são conectadas por tubulações, que podem ser instaladas dentro ou fora da edificação. Entretanto, uma desvantagem desse sistema é o grande requisito de serviços de manutenção para que ele funcione adequadamente. Periodicamente, as bombas, bocais de 
spray, controles de transferência de líquidos e eliminadores de fumaça devem ser checados e ajustados ou manutenidos. As soluções absorventes também devem passar por um processo de análise química para que suas propriedades sejam mantidas nos limites adequados.

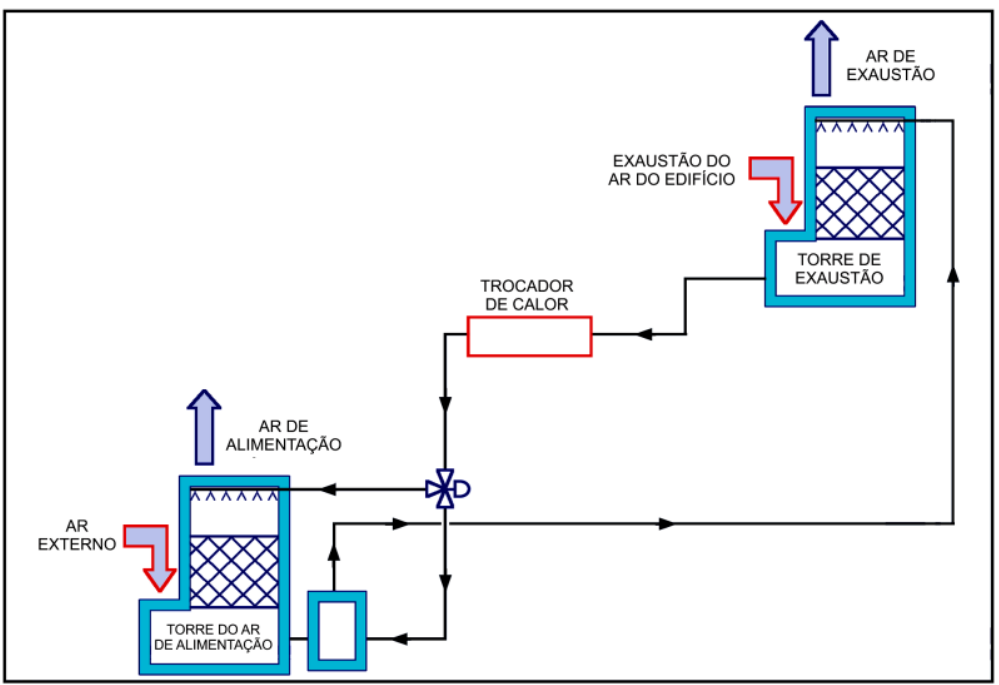

(A)

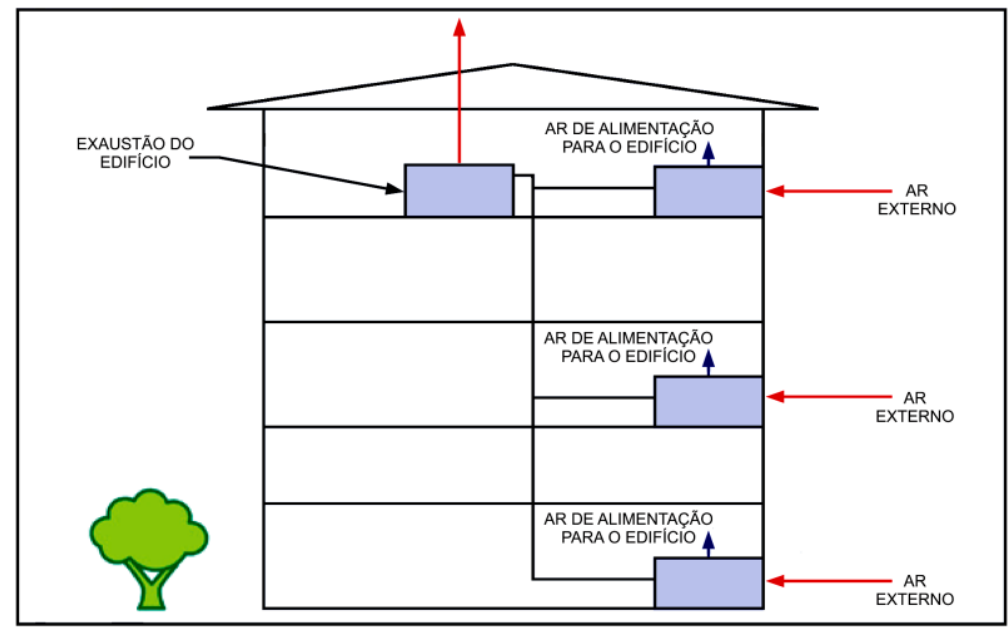

(B)

Figura A.19 - Sistema de torres gêmeas realizando um resfriamento evaporativo indireto do ar: (a) Esquema e (b) Instalação em um edifício (ASHRAE, 2012, modificado)

\section{A.6 - Comparação entre os sistemas de recuperação de energia ar-ar}

É bastante difícil comparar os diferentes tipos de sistemas de recuperação de energia ar-ar no desempenho global. Eles podem ser comprados com base nos parâmetros de classificação certificados, tais como eficiências sensível, latente e total ou vazamentos de ar. Para realizar uma comparação com base no período de retorno ou no custo máximo de energia economizada, valores precisos do custo de capital, vida útil e custos de 
manutenção, que variam de produto para produto para o mesmo tipo de sistema de recuperação, devem ser conhecidos. A partir de informações disponíveis na literatura, a Tabela A.1 pode ser utilizada para comparar características dos dispositivos mais comuns de recuperação de energia:

Tabela A.1 - Comparação entre os dispositivos de recuperação de energia ar-ar (ASHRAE, 2012, modificado)

\begin{tabular}{|c|c|c|c|c|}
\hline & Placas Fixas & $\begin{array}{c}\text { Membranas } \\
\text { Fixas }\end{array}$ & Roda Entálpica & Roda de Calor \\
\hline $\begin{array}{l}\text { Arranjo de } \\
\text { escoamento }\end{array}$ & $\begin{array}{l}\text { Contracorrente } \\
\text { Fluxo cruzado }\end{array}$ & $\begin{array}{l}\text { Contracorrente } \\
\text { Fluxo cruzado }\end{array}$ & $\begin{array}{l}\text { Contracorrente } \\
\text { Fluxo paralelo }\end{array}$ & Contracorrente \\
\hline $\begin{array}{c}\text { Faixa de } \\
\text { tamanho do } \\
\text { Equipamento } \\
(\mathrm{L} / \mathrm{s})\end{array}$ & 25 e acima & 25 e acima & $\begin{array}{c}25 \text { a } 35.000 \text { e } \\
\text { acima }\end{array}$ & $\begin{array}{c}25 \text { a } 35.000 \text { e } \\
\text { acima }\end{array}$ \\
\hline $\begin{array}{l}\text { Eficiência } \\
\text { sensível } \\
\text { típica* }(\%)\end{array}$ & 50 a 80 & 50 a 75 & 50 a 85 & 50 e acima \\
\hline $\begin{array}{l}\text { Eficiência } \\
\text { latente } \\
\text { típica* }(\%)\end{array}$ & - & 50 a 72 & 50 a 85 & 0 \\
\hline $\begin{array}{l}\text { Eficiência } \\
\text { Total* }(\%)\end{array}$ & - & 50 a 73 & 50 a 85 & - \\
\hline $\begin{array}{l}\text { Velocidade } \\
\text { nominal } \\
(\mathrm{m} / \mathrm{s})\end{array}$ & 1 a 5 & 1 a 3 & 2.5 a 5 & 2 a 5 \\
\hline $\begin{array}{l}\text { Perda de } \\
\text { carga }(\mathrm{Pa})\end{array}$ & 100 a 1000 & 100 a 500 & 100 a 300 & 100 a 300 \\
\hline $\operatorname{EATR}(\%)$ & 0 a 2 & 0 a 5 & 0.5 a 10 & 0.5 a 10 \\
\hline $\mathrm{OACF}$ & 0.97 a 1.06 & 0.97 a 1.06 & 0.99 a 1.1 & 1.1 a 1.2 \\
\hline $\begin{array}{c}\text { Faixa de } \\
\text { temperatura } \\
\left({ }^{\circ} \mathrm{C}\right)\end{array}$ & -60 a 800 & -40 a 50 & -55 a 800 & -55 a 800 \\
\hline $\begin{array}{l}\text { Modo típico } \\
\text { de aquisição }\end{array}$ & $\begin{array}{c}\text { Recuperador } \\
\text { apenas } \\
\text { Recuperador } \\
\text { dentro de uma } \\
\text { caixa } \\
\text { Recuperador e } \\
\text { ventiladores } \\
\text { Sistema completo }\end{array}$ & $\begin{array}{c}\text { Recuperador } \\
\text { apenas } \\
\text { Recuperador } \\
\text { dentro de uma } \\
\text { caixa } \\
\text { Recuperador e } \\
\text { ventiladores } \\
\text { Sistema completo }\end{array}$ & $\begin{array}{c}\text { Recuperador } \\
\text { apenas } \\
\text { Recuperador } \\
\text { dentro de uma } \\
\text { caixa } \\
\text { Recuperador e } \\
\text { ventiladores } \\
\text { Sistema completo }\end{array}$ & $\begin{array}{c}\text { Recuperador } \\
\text { apenas } \\
\text { Recuperador } \\
\text { dentro de uma } \\
\text { caixa } \\
\text { Recuperador e } \\
\text { ventiladores } \\
\text { Sistema completo }\end{array}$ \\
\hline Vantagens & $\begin{array}{c}\text { Sem partes } \\
\text { móveis } \\
\text { Baixa perda de } \\
\text { carga }\end{array}$ & $\begin{array}{c}\text { Sem partes } \\
\text { móveis } \\
\text { Baixa perda de } \\
\text { carga }\end{array}$ & $\begin{array}{c}\text { Transferência de } \\
\text { massa/umidade } \\
\text { Unidades grandes } \\
\text { compactas }\end{array}$ & $\begin{array}{l}\text { Unidades grandes } \\
\text { compactas } \\
\text { Baixa perda de } \\
\text { carga }\end{array}$ \\
\hline
\end{tabular}




\begin{tabular}{|c|c|c|c|c|}
\hline & De fácil limpeza & $\begin{array}{l}\text { Pequeno } \\
\text { vazamento de ar } \\
\text { Transferência de } \\
\text { massa/umidade }\end{array}$ & $\begin{array}{l}\text { Baixa perda de } \\
\text { carga } \\
\text { Disponível em } \\
\text { todas plataformas } \\
\text { de sistemas de } \\
\text { ventilação }\end{array}$ & De fácil limpeza \\
\hline Limitações & $\begin{array}{l}\text { Tamanhos } \\
\text { grandes para altas } \\
\text { taxas de vazão }\end{array}$ & $\begin{array}{l}\text { Poucos } \\
\text { fornecedores } \\
\text { Manutenção a } \\
\text { longo prazo } \\
\text { Desempenho } \\
\text { desconhecido }\end{array}$ & $\begin{array}{c}\mathrm{O} \text { ar de } \\
\text { alimentação pode } \\
\text { requerer mais } \\
\text { algum } \\
\text { resfriamento ou } \\
\text { aquecimento } \\
\text { Algum EATR } \\
\text { sem purga }\end{array}$ & $\begin{array}{l}\text { Algum EATR } \\
\text { com purga }\end{array}$ \\
\hline $\begin{array}{l}\text { Métodos de } \\
\text { controle de } \\
\text { recuperação } \\
\text { de calor }\end{array}$ & $\begin{array}{c}\text { Damper de by- } \\
\text { pass e dutos }\end{array}$ & $\begin{array}{c}\text { Damper de by- } \\
\text { pass e dutos }\end{array}$ & $\begin{array}{l}\text { Damper de by- } \\
\text { pass e controle de } \\
\text { velocidade da } \\
\text { roda }\end{array}$ & $\begin{array}{l}\text { Damper de by- } \\
\text { pass e controle de } \\
\text { velocidade da } \\
\text { roda }\end{array}$ \\
\hline $\begin{array}{r}* \text { Os valor } \\
\text { escoamento } \\
\text { aumentam lev } \\
\text { correntes de }\end{array}$ & $\begin{array}{l}\text { de eficiência são } p \\
\text { alanceados. Os val } \\
\text { nente se as vazões } \\
\text { r são maiores que a }\end{array}$ & $\begin{array}{l}\text { condições de } \\
\text { es de eficiência } \\
\text { uma ou das duas } \\
\text { vazões de teste. }\end{array}$ & \multicolumn{2}{|c|}{$\begin{array}{c}\text { EATR = Taxa de transferência de ar } \\
\text { de exaustão; } \\
\text { OACF = Fator de correção para o ar } \\
\text { externo }\end{array}$} \\
\hline
\end{tabular}

Tabela A.1 - Comparação entre os dispositivos de recuperação de energia ar-ar (continuação)

\begin{tabular}{ccccc}
\hline & $\begin{array}{c}\text { Tubos } \\
\text { Quentes }\end{array}$ & $\begin{array}{c}\text { Bombeamento em } \\
\text { serpertina }\end{array}$ & Termossifão & Torres Gêmeas \\
\hline $\begin{array}{c}\text { Arranjo de } \\
\text { escoamento }\end{array}$ & $\begin{array}{c}\text { Contracorrente } \\
\text { Fluxo paralelo }\end{array}$ & - & $\begin{array}{c}\text { Contracorrente } \\
\text { Fluxo paralelo }\end{array}$ & - \\
\hline $\begin{array}{c}\text { Faixa de } \\
\text { tamanho do } \\
\text { Equipamento } \\
\text { (L/s) }\end{array}$ & 50 e acima & 50 e acima & 50 e acima & - \\
\hline $\begin{array}{c}\text { Eficiência } \\
\text { sensível } \\
\text { típica (\%) }\end{array}$ & 45 a 65 & 45 a 65 & 40 a 60 & 40 a 60 \\
\hline $\begin{array}{c}\text { Eficiência } \\
\text { latente típica } \\
(\%)\end{array}$ & - & - & & - \\
\hline $\begin{array}{c}\text { Eficiência } \\
\text { Total }(\%)\end{array}$ & - & 50 a 73 & 50 a 85 & - \\
\hline $\begin{array}{c}\text { Velocidade } \\
\text { nominal } \\
(\mathrm{m} / \mathrm{s})\end{array}$ & 2 a 4 & 1.5 a 3 & 2 a 4 & 1.5 a 2.2 \\
\hline $\begin{array}{c}\text { Perda de } \\
\text { carga (Pa) }\end{array}$ & 150 a 500 & 150 a 500 & 150 a 500 & 170 a 300 \\
\hline
\end{tabular}




\begin{tabular}{|c|c|c|c|c|}
\hline $\operatorname{EATR}(\%)$ & 0 & 0 & 0 & 0 \\
\hline $\mathrm{OACF}$ & 0.99 a 1.01 & 1.0 & 1.0 & 1.0 \\
\hline $\begin{array}{l}\text { Faixa de } \\
\text { temperatura } \\
\left({ }^{\circ} \mathrm{C}\right)\end{array}$ & -40 a 40 & -45 a 500 & -40 a 40 & -40 a 46 \\
\hline $\begin{array}{l}\text { Modo típico } \\
\text { de aquisição }\end{array}$ & $\begin{array}{l}\text { Recuperador } \\
\text { apenas } \\
\text { Recuperador } \\
\text { dentro de uma } \\
\text { caixa } \\
\text { Recuperador e } \\
\text { ventiladores } \\
\text { Sistema } \\
\text { completo }\end{array}$ & $\begin{array}{l}\text { Serpentina apenas } \\
\text { Sistema completo }\end{array}$ & $\begin{array}{l}\text { Recuperador } \\
\text { apenas } \\
\text { Recuperador } \\
\text { dentro de uma } \\
\quad \text { caixa }\end{array}$ & Sistema completo \\
\hline Vantagens & $\begin{array}{c}\text { Sem partes } \\
\text { móveis } \\
\text { Localização do } \\
\text { ventilador não } \\
\text { é crítica } \\
\text { Diferencial de } \\
\text { pressão } \\
\text { permitido até } \\
15 \mathrm{kPa}\end{array}$ & $\begin{array}{l}\text { A corrente de ar de } \\
\text { exaustão pode ser } \\
\text { separada da de } \\
\text { alimentação } \\
\text { Localização do } \\
\text { ventilador não é crítica }\end{array}$ & $\begin{array}{l}\text { A corrente de } \\
\text { ar de exaustão } \\
\text { pode ser } \\
\text { separada da de } \\
\text { alimentação } \\
\text { Localização do } \\
\text { ventilador não } \\
\text { é crítica }\end{array}$ & $\begin{array}{c}\text { Transferência } \\
\text { latente a partir de } \\
\text { correntes de ar } \\
\text { remotas } \\
\text { Limpeza } \\
\text { microbiológica } \\
\text { eficiente de } \\
\text { ambas correntes } \\
\text { de ar }\end{array}$ \\
\hline Limitações & $\begin{array}{c}\text { Eficiência } \\
\text { limitada pela } \\
\text { perda de carga } \\
\text { e custo } \\
\text { Poucos } \\
\text { fornecedores }\end{array}$ & $\begin{array}{l}\text { Prever o desempenho } \\
\text { requer precisos modelos } \\
\text { de simulação }\end{array}$ & $\begin{array}{c}\text { Eficiência } \\
\text { limitada pela } \\
\text { perda de carga } \\
\text { e custo } \\
\text { Poucos } \\
\text { fornecedores }\end{array}$ & $\begin{array}{l}\text { Poucos } \\
\text { fornecedores } \\
\text { Manutenção e } \\
\text { desempenho } \\
\text { desconhecidos }\end{array}$ \\
\hline $\begin{array}{l}\text { Métodos de } \\
\text { controle de } \\
\text { recuperação } \\
\text { de calor }\end{array}$ & $\begin{array}{l}\text { Ângulo de } \\
\text { inclinação de } \\
\text { até } 10 \% \text { da } \\
\text { taxa máxima } \\
\text { de calor }\end{array}$ & $\begin{array}{l}\text { Válvula de by-pass ou } \\
\text { controle de rotação da } \\
\text { bomba }\end{array}$ & $\begin{array}{l}\text { Válvula de } \\
\text { controle sobre } \\
\text { a faixa total de } \\
\text { operação }\end{array}$ & $\begin{array}{l}\text { Válvula de } \\
\text { controle ou } \\
\text { controle de } \\
\text { rotação da bomba } \\
\text { sobre a faixa total } \\
\text { de operação }\end{array}$ \\
\hline \multicolumn{3}{|c|}{$\begin{array}{l}\text { * Os valores de eficiência são para condições de } \\
\text { escoamentos balanceados. Os valores de eficiência } \\
\text { aumentam levemente se as vazões de uma ou das duas } \\
\text { correntes de ar são maiores que as vazões de teste. }\end{array}$} & \multicolumn{2}{|c|}{$\begin{aligned} \text { EATR }= & \text { Taxa de transferência de } \\
& \text { ar de exaustão; } \\
\text { OACF }= & \text { Fator de correção para o } \\
& \text { ar externo }\end{aligned}$} \\
\hline
\end{tabular}

\section{A.6.1 - Caracterização da eficiência do sistema de HRV ou ERV}

Uma medida de desempenho de um ERV é a magnitude relativa da energia atual recuperada e a potência fornecida para os ventiladores circularem as correntes de ar. $\mathrm{O}$ custo relativo à potência de alimentação dos ventiladores depende da perda de carga das 
correntes de ar, da vazão volumétrica, e da eficiência combinada do sistema motorventilador. A qualidade da potência fornecida para os ventiladores é alta, e seu custo por unidade de energia é muito maior que a qualidade e o custo da energia recuperada no recuperador. A magnitude e os custos dessas duas formas de energia variam ao longo do ano. Besant e Simonson (2003) sugeriram que o parâmetro chamado relação de eficiência de recuperação (recovery efficiency ratio - RER) pode ser introduzido para caracterizar a eficiência dos ventiladores de recuperação:

$$
\operatorname{RER}=\frac{\int(\text { taxa de energia recuperada }) d t}{\int(\text { taxa de energia fornecida aos ventiladores }) d t}
$$

O RER é similar à taxa de eficiência energética (energy efficiency ratio - EER) para chillers ou equipamentos de ar condicionado unitários. Besant e Simonson (2003) também sugeriram que o desempenho total do sistema, incluindo o ERV, pode ser representado pela razão entre o COP (coeficiente de desempenho) e o RER.

O RER é tipicamente expresso em unidades de $[\mathrm{kJ} / \mathrm{Wh}]$, enquanto a energia recuperada pode ser sensível, latente ou total, em quilowatts e a energia utilizada para circular as correntes de alimentação e exaustão através do ERV, em watts. Assim, o RER total, sensível e latente são dados pelas seguintes equações, respectivamente:

$$
\begin{gathered}
\operatorname{RER}_{\text {TOTAL }}=\frac{\varepsilon_{\text {net,total }} \cdot \dot{\mathrm{m}}_{\text {min }} \cdot\left(\mathrm{h}_{1}-\mathrm{h}_{3}\right)}{\mathrm{P}_{\text {blower }}+\mathrm{P}_{\text {comp }}} \\
\text { RER }_{\text {SENSIBLE }}=\frac{\varepsilon_{\text {net,sensible }} \cdot \dot{\mathrm{m}}_{\text {min }} \cdot \mathrm{c}_{\mathrm{p}} \cdot\left(\mathrm{t}_{1}-\mathrm{t}_{3}\right)}{\mathrm{P}_{\text {blower }}+\mathrm{P}_{\text {comp }}} \\
\text { RER }_{\text {LATENT }}=\frac{\varepsilon_{\text {net,latent }} \cdot \dot{\mathrm{m}}_{\text {min }} \cdot \mathrm{h}_{\mathrm{fg}} \cdot\left(\mathrm{w}_{1}-\mathrm{w}_{3}\right)}{\mathrm{P}_{\text {blower }}+\mathrm{P}_{\text {comp }}}
\end{gathered}
$$

$\dot{\mathrm{m}}_{\text {min }}=\quad$ Vazão mássica mínima das correntes de alimentação e exaustão $[\mathrm{kg} / \mathrm{s}]$;

$\mathrm{h}_{1}=\quad$ Entalpia no estado $1[\mathrm{~kJ} / \mathrm{kg}]$

$\mathrm{t}_{1}=\quad$ Temperatura no estado $1[K]$; 
$\mathrm{w}_{1}=\quad$ Umidade no estado $1[\mathrm{~kg} / \mathrm{kg}]$;

$\mathrm{P}_{\text {comp }}=\quad$ Potência de entrada direta para o recuperador $[W]$;

$\mathrm{P}_{\text {blower }}=\quad$ Potência de ventilação para o recuperador $[W]$;

$$
\mathrm{P}_{\text {blower }}=\left[\frac{\mathrm{Q}_{\text {blower,supply }} \cdot \Delta \mathrm{P}_{\text {supply }}}{\eta_{\text {fan,motor,supply }}}\right]+\left[\frac{\mathrm{Q}_{\text {blower,exaust }} \cdot \Delta \mathrm{P}_{\text {exaust }}}{\eta_{\text {fan,motor,exaust }}}\right]
$$

$\Delta \mathrm{p}=\quad$ Perda de carga da corrente de ar de alimentação ou exaustão $[k P a]$;

$\mathrm{Q}_{\text {blower }}=$ Perda de carga da corrente de ar de alimentação ou exaustão $[L / s]$;

$\eta_{\mathrm{f}}=\quad$ Eficiência global do ventilador e do motor ou o produto dessas duas eficiências [-];

Outra maneira aceitável de tornar a caracterização da potência adicional de ventilação requerida mais precisa é a partir da comparação dos pontos de operação na curva do ventilador.

Para uma vazão de $470 \mathrm{~L} / \mathrm{s}$ e valores típicos para as perdas de carga e eficiências do motor e do ventilador, o RER sensível pode variar entre 26 a $32 \mathrm{~kJ} / \mathrm{Wh}$. Esse cálculo sugere que a energia recuperada é aproximadamente de 7,3 a 8,8 vezes a energia usada para operar a unidade de recuperação. Por sua vez, a qualidade da energia térmica é aproximadamente um terço da energia elétrica, assim, a energia atual recuperada é aproximadamente três vezes o custo da energia gasta na unidade de recuperação.

A eficiência combinada (combined efficiency - CEF) é a razão da capacidade líquida de resfriamento/aquecimento entregue pela potência elétrica total consumida. A CEF também pode ser relacionada com as energias sensível, latente e total recuperadas, sendo relacionadas pelo RER, pelo EER, que é tipicamente fornecida pelos fabricantes de equipamentos, e pela razão de carga Y. Esse fator Y representa a porcentagem da carga do sistema (resfriamento ou aquecimento) atendida pelo recuperador de energia. Uma alta razão de carga permite o uso de equipamentos menores, afetando, assim, os custos de capital. A CEF de resfriamento pode ser estimada por:

$$
\mathrm{CEF}_{\text {COOLING }}=\frac{1}{\mathrm{Y}_{\mathrm{c}} / \mathrm{RER}+\left(1-\mathrm{Y}_{\mathrm{c}}\right) / \mathrm{EER}}
$$


onde:

$$
\begin{gathered}
\mathrm{Y}_{\mathrm{c}}=\frac{\text { Capacidade líquida total de resfriamento de recuperador }}{\text { Capacidade líquida total de resfriamento do sistema }} \\
\mathrm{EER}=\frac{\text { Capacidade líquida total de resfriamento }}{\text { Consumo elétrico total }}
\end{gathered}
$$

Para valores típicos de EER=10 para um sistema unitário e uma razão de carga de 0,3, a CEF pode variar entre 15 a $19 \mathrm{~kJ} / \mathrm{Wh}$.

\section{A.6.2 - Seleção de um HRV ou ERV}

ERVs ou HRVs estão disponíveis como trocadores de calor apenas ou em um sistema completo, incluindo o trocador de calor e os sistemas de motor/ventilador, conforme indicado na Tabela 3.2. A recuperação de energia também está disponível quando esses equipamentos estão integrados em um equipamento unitário de ar condicionado ou em sistemas padrões ou customizados de tratamento de ar. A seleção de tais unidades é primariamente ditada pela quantidade de ar de ventilação. Diversos fabricantes têm desenvolvido programas ou tabelas para ajudar na seleção de tais unidades. Dessa forma, é necessário dimensionar o ventilador, caso apenas o trocador de calor seja comprado.

Entretanto, o verdadeiro desempenho geral do sistema é o custo do seu ciclo de vida (life-cycle cost - LCC), que leva em consideração os custos de capital e de manutenção.

\section{A.7 - Considerações econômicas}

Sistemas de recuperação de energia ar-ar são utilizados tanto em aplicações novas como em modernizações de instalações existentes. Esses sistemas devem ser projetados visando o maior custo benefício ou o menor custo de ciclo de vida (LCC), expresso em relação à vida de serviço ou anualmente e com aceitáveis períodos de retorno de investimento. 
Os custos anuais de aquisição, operação e manutenção são importantes para uma análise global. Geralmente, essa análise considera os custos de capital e juros nesse período como um valor simples, porém, na verdade, esses custos são uma função complexa do valor futuro do dinheiro, bem como das variáveis de projeto do recuperador de energia. Essas variáveis incluem a massa de cada material utilizado, o custo na formação desses materiais, o custo de equipamentos auxiliares e controles, e o custo de instalação.

O custo operacional de energia para sistemas de recuperação envolve funções integradas ao longo do tempo, incluindo variáveis tais como: vazão, perda de carga, eficiência do ventilador, custo da energia e taxa de recuperação de energia. Os cálculos são complexos porque as cargas de resfriamento ou aquecimento do ar são, para certa faixa de temperatura de ar externo, dependentes do tempo na maioria das edificações. Os horários de utilização para os edifícios também podem impor diferentes taxas de ventilação para cada hora do dia. As tarifas dos serviços elétricos muitas vezes variam de acordo com a hora do dia, a quantidade de energia utilizada, e a carga de potência de pico.

A eficiência total do recuperador deveria ser tão maior quanto possível, entretanto, uma alta eficiência implica em um alto custo de capital, mesmo quando o recuperador é projetado para minimizar a quantidade de material utilizado. Os custos de energia para ventiladores e bombas são geralmente muito importantes e acumulam o custo de operação mesmo quando o sistema de recuperação está em desuso. Dessa maneira, o problema de minimização do LCC global a fim de prover um projeto eficiente pode envolver dez ou mais variáveis de projeto independentes, assim como várias restrições especificadas e condições de operação (Besant e Johnson, 1995).

Além disso, sistemas de recuperação de energia em aplicações de conforto operam com diferenciais de temperatura muito menores e por isso requerem modelos de transferência de energia mais precisos para atingir o melhor custo benefício ou menor LCC. Ainda mais importante, a energia recuperada pode ser utilizada para reduzir a capacidade de resfriamento ou aquecimento dos equipamentos, o que pode gerar um efeito significativo no desempenho/eficiência de ambos os sistemas.

O período de retorno (payback period - $P P$ ) é melhor computado após a avaliação dos custos anuais. Ele é geralmente definido por:

$$
\mathrm{PP}=\frac{\text { Custo do capital e juros }}{\text { Custo operacional anual de energia economizada }}
$$




$$
\mathrm{PP}=\frac{\mathrm{C}_{\mathrm{s}, \text { init }}-\mathrm{ITC}}{\mathrm{C}_{\mathrm{e}} \cdot\left(1-\mathrm{T}_{\mathrm{inc}}\right)} \cdot \mathrm{CRF} \cdot\left(\mathrm{i}^{\prime}, \mathrm{n}\right)
$$

$$
\begin{aligned}
& \mathrm{C}_{\mathrm{s}, \text { init }}=\quad \text { Custo inicial do sistema; } \\
& \text { ITC }=\quad \text { Taxa de investimento para melhorias em eficiência energética; } \\
& \mathrm{C}_{\mathrm{e}}=\quad \text { Custo da energia para operar o sistema por um período de um ano; } \\
& \mathrm{T}_{\text {inc }}=\quad \text { Taxa de imposto de renda líquida aonde as taxas são baseadas no último } \\
& \text { dólar ganho (taxa marginal); } \\
& \mathrm{CRF}=\quad \text { Fator de recuperação de capital; } \\
& i^{\prime \prime}=\quad \text { Taxa de desconto efetivo ajustado pela inflação da energia; } \\
& \mathrm{n}=\quad \text { Número total de períodos avaliados. }
\end{aligned}
$$

O inverso desse termo é normalmente chamado de retorno do investimento (return of investment - ROI). Sistemas de recuperação de energia bem dimensionados normalmente possuem um PP de menos de 5 anos, e, frequentemente, inferior a 3 anos. Retornos de menos de 1 ano não são incomuns em aplicações de conforto em climas quentes e úmidos, principalmente por conta da redução no dimensionamento dos equipamentos de resfriamento requeridos.

\section{A.7.1 - Custo do sistema instalado}

O custo inicial de um sistema de AVAC instalado é geralmente menor para dispositivos de recuperação de energia ar-ar, uma vez que os equipamentos de refrigeração mecânica podem ser reduzidos em sua capacidade. Assim, um sistema mais eficiente de AVAC pode também ter um menor custo total instalado. $O$ custo de instalação do sistema de recuperação se torna mais baixo por unidade de vazão, assim como pela quantidade de ar externo utilizado para aumento da ventilação.

\section{A.7.2 - Custo do ciclo de vida (LCC)}

O custo-benefício dos recuperadores de energia é melhor avaliado considerando todo custo de capital, instalação, operação e de economia de energia sobre a vida útil do 
equipamento operando em condições normais, em termos do custo do ciclo de vida. Em regra, nem o mais eficiente e nem o mais caro dos dispositivos de recuperação será o mais econômico. Otimizar o LCC para o máximo de economia pode envolver diversas variáveis de projeto, requerendo uma cuidadosa estimativa de custos e o uso de um modelo preciso com todas as variáveis de projeto.

\section{A.7.3 - Custo de energia}

O custo absoluto da energia e o custo relativo das várias formas de energia são os maiores fatores econômicos envolvidos na implantação de um sistema AVAC. Altos custos da energia favorecem altos níveis de recuperação de energia também. Em regiões em que o custo elétrico é maior que o custo dos combustíveis, os dispositivos de recuperação com pequenas perdas de carga são preferíveis.

\section{A.7.4 - Grau de energia de exaustão}

Um alto grau de energia de exaustão (alta temperatura) é geralmente mais econômico para ser recuperado do que um baixo grau de energia. Assim, a recuperação de energia é mais econômica para grandes diferenças de temperatura entre a fonte de energia desperdiçada e o seu destino.

\section{A.7.5 - Ambiente de operação}

Altas temperaturas de operação ou a presença de corrosivos, gases condensáveis e particulados em alguma das correntes de ar resultam em equipamentos maiores e em maiores custos de manutenção. 


\section{APÊNDICE B - QUALIDADE DO AR INTERIOR - CONTINUAÇÃO DO CAP. 4}

\section{B.1 - Introdução}

Até algumas décadas atrás, a única exigência feita na construção de uma edificação visava propiciar ao homem as condições necessárias para desenvolver suas atividades, laborais ou de lazer. Com o passar do tempo, outras exigências foram progressivamente sendo adicionadas aos requisitos básicos já conhecidos (segurança da edificação, impermeabilidade e/ou estanqueidade a chuvas, ventos e neve, por exemplo). Cada vez mais, a questão do conforto - seja ele higrotérmico, visual, olfativo ou auditivo - foi sendo valorizada. Novos produtos foram criados, novas técnicas de construção foram incorporadas, sempre com o objetivo de garantir ao homem locais mais adequados para suas atividades, com o menor custo possível (Prado et al., 1999).

A evolução dos edifícios impôs um novo desafio, o da economia de energia. Esta necessidade ficou patente após a crise do petróleo na década de setenta. Com a alta dos preços dos combustíveis, houve uma tendência mundial em conservar energia, resultando em edifícios com poucas aberturas para ventilação (Prado et al., 1999).

Além dos edifícios se tornarem cada vez mais fechados, seu grau de automatização também aumentou. Sua dependência de controles computadorizados, sistemas forçados de ventilação, sistemas de ar condicionado, dentre outros, foi crescendo. Sistemas de ventilação tornaram-se mais sofisticados. Reduções nos gastos de energia foram possíveis pelo emprego de computadores para variar as quantidades de ar introduzidas no edifício, baseadas unicamente em requisitos de carga térmica nos espaços ocupados. Os únicos critérios utilizados em relação ao ar interior foram a temperatura e a umidade. Os outros parâmetros envolvendo a qualidade do ar utilizado dentro dos edifícios foram ignorados. Se, por um lado, houve uma preocupação crescente com a economia de energia, por outro, a qualidade do ar interno (QAI) foi deixada de lado (Prado et al., 1999).

Controles e avanços nos sistemas automatizados causaram uma redução dramática nas perdas de energia nos últimos trinta anos e as taxas de infiltração de ar caíram. $\mathrm{O}$ resultado disso é que as concentrações médias dos vários poluentes no ar interno aumentaram substancialmente. Registros externos (dampers) de entrada de ar eram dispostos de modo a permitir um mínimo de captação de ar, ou mesmo eram fechados para diminuir os gastos com refrigeração. Hoje, sabe-se que uma série de poluentes - dentre eles, monóxido de carbono, dióxido de carbono, amônia, óxido de enxofre e nitrogênio - 
são produzidos dentro do edifício por materiais de construção baseados em solventes orgânicos, por materiais de limpeza, mofo, bolor, metabolismo humano e também pelas próprias atividades do homem, como cozinhar ou lavar e secar roupas. Tais poluentes comprometem a saúde e o rendimento do trabalho dos usuários (Prado et al., 1999).

Alguns edifícios já estão sendo chamados de "doentes", devido à péssima qualidade do ar em seus recintos. Também foi criada a expressão "Sick Building Syndrome" (SBS), caracterizada por um estado doentio transitório dos usuários, já que os sintomas normalmente desaparecem quando as pessoas afetadas deixam o edifício. Sua origem está relacionada ao fato de que os edifícios com manutenção inadequada de suas torres de resfriamento e sistema de ventilação, por exemplo, são fontes de microrganismos, conforme a EPA (Environmental Protection Agency, 1991).

São chamados de "doentes" aqueles nos quais uma porção significativa dos usuários, em torno de 20\% segundo Robertson (1995), apresenta uma série de sintomas, tais como: dor de cabeça, náuseas, cansaço, irritação dos olhos, nariz e garganta, falta de concentração, problemas de pele, dentre outros. Tais edifícios possuem problemas no seu ambiente interno. Como já citado anteriormente, a qualidade do ar desempenha papel importante neste processo. Contudo, as condições de conforto também devem ser levadas em consideração, já que calor ou frio excessivos, correntes de ar, umidade inadequada, vibrações, ruídos e luminosidade interagem entre si e colaboram para o aumento das queixas dos usuários.

Alguns passos podem ser tomados para prevenir que a poluição interna do ar afete a saúde dos usuários. Tais passos diminuem o número de faltas, as despesas com tratamento médico e aumentam a produtividade. Eles fazem parte de um programa de monitoramento específico designado para inspecionar, analisar e avaliar o sistema de manejo do ar nos edifícios. Tal programa consiste, conforme indica Robertson (1995), em inspecionar o projeto e as práticas de operação dos sistemas de ventilação, controlar as taxas de admissão de ar externo, variando-as conforme a necessidade e examinar os sistemas de refrigeração, aquecimento e umidificação. Uma segunda etapa consistiria na coleta e análise das concentrações de gases nocivos em pontos específicos do edifício. A última fase consiste no monitoramento contínuo do que ocorre no mesmo, através da instalação de sensores fixos de gases, de inspeções e caminhadas de vistorias em intervalos de tempo prédeterminados, para fazer relatórios com metodologias, conclusões e recomendações.

Possuir um edifício saudável significa, ao menos, ter uma boa qualidade interior do ar, através do uso de adequadas taxas de ventilação, de sistemas de automação predial e de 
um monitoramento contínuo das instalações. Atualmente, há uma estimativa de que grande parte das pessoas, principalmente em ambientes urbanos, passa entre 80 e $90 \%$ do seu tempo dentro de edifícios (Prado et al., 1999). De acordo com Parker (1993), isto significa que, na maior parte do tempo, estamos sujeitos a um ambiente artificial que é modificado pelo espaço fechado do edifício. E o que é pior, modificado de maneira negativa, já que o problema da qualidade do ar é real e crescente. Segundo Raw (1997), sua natureza é difícil de avaliar, pois muitos componentes químicos diferentes estão envolvidos e alguns deles não são perceptíveis como, por exemplo, o radônio.

Problemas econômicos, legais e de saúde associados à qualidade do ar parecem destinados a torná-la uma questão dominante no próximo século. Certamente, os problemas de qualidade do ar tornaram o trabalho de engenheiros, arquitetos e gerentes mais difícil e trouxeram aos proprietários um grande risco. Pesquisas sobre esse tema tiveram um grande impulso nos anos 90, principalmente nos EUA e na Europa. Em alguns países, diversas agências particulares e do governo federal estão envolvidas em trabalhos relativos à melhoria da qualidade do ar interno das edificações (Prado et al., 1999).

\section{B.2 - Fatores que afetam a QAI.}

Diversos fatores afetam a QAI. Para cada fator existem os tipos de poluentes, fontes mais conhecidas e seus efeitos à saúde, assim como também planos específicos para a prevenção e resolução de problemas relativos a cada fator. Podem ser levantados os seguintes fatores: i) ventilação de ar externo; ii) contaminantes químicos: monóxido de carbono ( $\mathrm{CO}$ ), dióxido de carbono ( $\mathrm{CO} 2)$, óxido e dióxido de nitrogênio, dióxido de enxofre, amônia, formaldeído; iii) compostos voláteis: acetona, hidrocarbonetos alifáticos e aromáticos; iv) contaminantes biológicos: ácaros, fungos, bactérias e vírus; v) material particulado; vi) ocupantes do edifício, vii) outros contaminantes: asbesto e radônio (Prado et al., 1999).

\section{B.3 - Normas}

O condicionamento do ar ventilado pode consumir significativa energia de resfriamento, aquecimento e ventilação; portanto, a maioria dos sistemas mecânicos é projetada para atender os requisitos mínimos de ventilação, que são definidos por regulamentos e normas. As normas não só prescrevem as taxas nas quais o ar externo deve 
ser entregue em cada zona térmica de um edifício, mas também como calcular as taxas necessárias para cada nível de sistema, o que afeta grandemente o projeto e forma de controle dos sistemas de ventilação.

\section{B.3.1 - Norma ASHRAE 62.1-2010 (Ventilation for Acceptable Indoor Air Quality)}

Essa norma prescreve que o sistema de ventilação da edificação deve seguir um de seus três procedimentos para atender aos requisitos de ventilação: i) procedimento da taxa de ventilação (ventilation rate procedure - VRP); ii) procedimento da qualidade do ar interior (IAQ procedure); iii) procedimento de ventilação natural (natural ventilation procedure) (Zhang, 2012).

O VRP descreve o método de projeto pelo qual as taxas de ar externo são determinadas baseadas no tipo de espaço, densidade de ocupação e área. O procedimento de qualidade do ar interior é uma abordagem baseada no desempenho. Ele requer que os projetistas primeiramente identifiquem as fontes, limites de concentração, e o correspondente período de exposição para cada contaminante ou mistura de contaminantes relevantes. $\mathrm{O}$ alvo percentual de ocupantes que devem estar satisfeitos com a qualidade do ar é estabelecido (geralmente $80 \%$ ou acima). Um balanço de massa é então usado para determinar a mínima vazão de ar externo requerido para manter a concentração dos contaminantes dentro dos limites. Após a instalação do sistema e a ocupação do edifício, a norma exige uma avaliação subjetiva de satisfação pelos ocupantes à respeito da qualidade do ar interior. Se o percentual dos ocupantes satisfeitos for menor que o alvo estabelecido, as taxas mínimas de vazão de ar externo devem ser elevadas para outro nível, até que o percentual de ocupantes satisfeitos atinja o alvo (Zhang, 2012).

O procedimento de ventilação natural permite que o ar externo seja provido através de aberturas externas no envelope do edifício (como janelas operáveis) em conformidade com a norma. Entretanto, para que a ventilação natural sozinha seja confiável, o edifício deve possuir aberturas que estão sempre abertas durante os períodos de ocupação, possuir um sistema de ventilação natural aprovado pela autoridade local competente, ou não possuir equipamentos de resfriamento ou aquecimento (Zhang, 2012).

A maioria dos edifícios ventilados mecanicamente segue o procedimento da taxa de ventilação porque esse é um caminho prescritivo, e por isso, fácil de usar. Um conjunto de equações nesse procedimento determinam as taxas de ar externo para o sistema, o qual se destina a prover uma ventilação suficiente na zona de respiração a fim de diluir os 
contaminantes gerados pelos ocupantes e por outras fontes (Zhang, 2012). Nas primeiras versões da Standard 62.1 (1989, 1999, 2001), os requisitos para a zona de ventilação são especificados com base no número de ocupantes na zona ou na área da zona:

$$
\mathrm{V}_{\mathrm{bz}}=\mathrm{R}_{\mathrm{p}} \cdot \mathrm{P}_{\mathrm{z}}
$$

$\mathrm{V}_{\mathrm{bz}}=\quad$ Vazão volumétrica de ar externo com base no número de ocupantes $\left[\mathrm{m}^{3} / \mathrm{h}\right]$

$\mathbf{R}_{\mathrm{p}}=\quad$ Vazão volumétrica de ar externo por ocupante $\left[\mathrm{m}^{3} / \mathrm{h} /\right.$ pessoa $]$;

$\mathrm{P}_{\mathrm{Z}}=\quad$ Número de ocupantes do ambiente [-];

$$
\mathrm{V}_{\mathrm{bz}}=\mathrm{R}_{\mathrm{a}} \cdot \mathrm{A}_{\mathrm{z}}
$$

$\mathrm{V}_{\mathrm{bz}}=\quad$ Vazão volumétrica de ar externo com base na área do espaço $\left[\mathrm{m}^{3} / \mathrm{h}\right]$;

$\mathrm{R}_{\mathrm{a}}=\quad$ Vazão volumétrica de ar externo por unidade de área $\left[\mathrm{m}^{3} / \mathrm{h} / \mathrm{m}^{2}\right]$;

$\mathrm{A}_{\mathrm{Z}}=\quad$ Área do ambiente [-];

Versões mais recentes $(2004,2007,2010)$ prescrevem a combinação das duas taxas. A taxa por pessoa tem como função diluir os contaminantes gerados pelos ocupantes, e a taxa referente à área de ocupação para diluição das fontes poluidoras relativas à edificação. Assim, a taxa de ventilação da zona da respiração é:

$$
\mathrm{V}_{\mathrm{bz}}=\mathrm{R}_{\mathrm{p}} \cdot \mathrm{P}_{\mathrm{z}}+\mathrm{R}_{\mathrm{a}} \cdot \mathrm{A}_{\mathrm{z}}
$$

$\mathrm{V}_{\mathrm{bz}}=\quad$ Vazão volumétrica de ar externo necessária na zona de respiração $\left[\mathrm{m}^{3} / \mathrm{h}\right]$;

$\mathrm{R}_{\mathrm{p}}=\quad$ Vazão volumétrica de ar externo por ocupante $\left[\mathrm{m}^{3} / \mathrm{h} /\right.$ pessoa $]$;

$\mathrm{P}_{\mathrm{Z}}=\quad$ Número de ocupantes do ambiente [-];

$\mathrm{R}_{\mathrm{a}}=\quad$ Vazão volumétrica de ar externo por unidade de área $\left[\mathrm{m}^{3} / \mathrm{h} / \mathrm{m}^{2}\right]$;

$\mathrm{A}_{\mathrm{Z}}=\quad$ Área do ambiente [-];

Outra importante atualização da versão da norma de 2001 para a de 2004 melhorou o cálculo para sistemas de várias zonas com recirculação de ar, especialmente para sistemas com vazão de ar variável (VAV) de diversas zonas. Antes da atualização, a taxa de ar externo que adentrava era simplesmente a soma das vazões requeridas para cada 
zona. Nas versões de 2004, 2007 e 2010, os procedimentos de cálculo podem ser sumarizados nos seguintes passos (Zhang, 2012):

Passo 1: Calcular a vazão de ar externo para a zona de respiração.

Passo 2: Determinar a eficiência da zona de ventilação.

Passo 3: Calcular a vazão de ar da zona externa.

Passo 4: Calcular a fração de ar externo da zona primária (ou fração de ar externo da zona de descarga).

Passo 5: Determinar a vazão de ar externo de entrada corrigida.

Passo 6: Determinar a eficiência do sistema de ventilação.

Passo 7: Calcular a vazão de entrada de ar externo do sistema.

Esse novo procedimento considera o excesso de ventilação para as zonas não críticas do sistema de vazão variável (VAV) e para a eficiência de ventilação do sistema. Entretanto, ele frequentemente resulta em um valor maior de projeto para as vazões de entrada de ar externo do que o procedimento de cálculo usando o método de soma simples utilizado nas normas anteriores. A vazão de ar externo do sistema de ventilação determinada a partir do VRP para sistemas de recirculação multi-zona é uma taxa de pico baseada no pior caso de condições de operação. Embora essas condições apareçam apenas em curtos períodos de tempo, os equipamentos de AVAC devem ser dimensionados para o pior cenário. Para reduzir o impacto na energia e considerar as variações nas condições de operação, três opções de controle dinâmico são permitidas (mas não requeridas) pela norma Standard 62.1-2010: i) Ventilação por controle de demanda (Demand-controlled ventilation - $D C V$ ); ii) eficiência de ventilação; iii) fração de ar externo.

DCV: qualquer meio pelo qual a vazão de ar externo da zona de respiração pode ser variada pela ocupação do espaço ou pela área de ocupação, em relação à ocupação atual ou estimada e/ou aos requisitos de ventilação da zona ocupada. Essa é uma estratégia de controle de nível de zona.

Eficiência de ventilação: em sistemas multi-zona, com a mudança da eficiência da zona de distribuição de ar entres os modos de aquecimento ou resfriamento, ou com a mudanças de vazão devido às variações de carga térmica, a eficiência de ventilação do sistema muda.

Fração de ar externo: na maioria dos sistemas de VAV, cada unidade terminal tem um valor mínimo de vazão pré-definido. Quando o economizador de ar externo é 
ativado, o sistema usa mais ar externo para a operação. Durante a operação com o economizador, os valores mínimos de vazão para as VAVs podem ser redefinidos para valores menores, uma vez que o ar primário é mais rico em ar externo, possibilitando a redução de energia de ventilação.

Embora todas as três opções possam resultar em taxas de entrada de ar externo diferentes dos valores de projeto, eles focam em diferentes sistemas ou situações das zonas de operação. A operação do DCV ocorre em resposta à variação de ocupação da zona; a eficiência de ventilação muda em resposta à variação da vazão da zona por conta da variação de carga térmica. Essas duas opções são descritas independentemente na norma ASHRAE 90.1-2010. Quando o projeto de um edifício específico abrange ambas as categorias, as duas opções de controle (DCV e eficiência de ventilação) podem ser requeridas para que a norma seja atendida. A opção de controle por fração de ar externo é opcional. Todas as opções de controle mencionadas propiciam oportunidades para encomias de energia, mas elas também requerem um sistema de automação do edifício para que haja uma implementação adequada (Zhang, 2012).

\section{B.3.2 - Norma ASHRAE 90.1-2010 (Energy Standard for Buildings Except Low-Rise Residential Buildings)}

O propósito dessa norma é apresentar requisitos que garantam que os edifícios serão projetados para serem eficientes do ponto de vista energético. Para os requisitos mínimos de ventilação, a norma 90.1 se refere à norma 62.1.

A última atualização da ASHRAE 90.1 em 2010 apresentou um grande salto na evolução do padrão utilizado. No que compete a climatização, em uma abordagem simplificada, foram adotados novos critérios para alguns sistemas, como por exemplo, novos requisitos para vazões de ar variável, recuperação de energia através do ar rejeitado, consumo de energia, sistemas de exaustão, ventilação, controle de demanda, ventilação em garagens, entre outros.

Uma mudança significativa dessa nova versão é em relação ao volume de ar variável (VAV) sobre os sistemas de controle de zona única. Manipuladores de água gelada e ventiladores de $5 \mathrm{cv}$ ou superiores terão de possuir controle de velocidade através de inversores de frequiência (VFDs) ou duas velocidades pré-estabelecidas, quando a demanda for inferior a $50 \%$. 
Por último, a norma exige o sistema de DCV para espaços largos com mais de 500 pés quadrados de área, e com uma ocupação de projeto maior que 40 pessoas por cada 1000 pés quadrados de área, e servidos por sistemas com um ou mais: i) um ciclo economizador; ii) controle de modulação automático do damper de ar externo ou; iii) um projeto de vazão de ar externo maior que 3000 cfm (Zhang, 2012).

\section{B.3..3 - Norma ASHRAE 189.1-2009 (Standard for the Design of High-Performance} Green Buildings)

Essa norma, relativa aos requisitos de projeto para edifícios verdes, excede à norma 90.1 a partir da criação de uma nova definição para ambientes densamente ocupados, informando que são aqueles ambientes com densidade maior ou igual a 25 pessoas a cada 100 metros quadrados. Assim, essa norma exige que haja um sistema de DCV para esses ambientes densamente ocupados, relatando ainda detalhes dos tipos de sensores de $\mathrm{CO} 2$ a serem utilizados, seu posicionamento, precisão, etc (Zhang, 2012).

B.3.4 - ABNT NBR 16401-3/2008 (Instalações de ar condicionado - Sistemas centrais e unitários - Parte 3: Qualidade do ar interior)

Essa norma brasileira especifica os parâmetros básicos e requisitos mínimos para sistemas de ar condicionado, visando à obtenção de qualidade aceitável de ar interior para conforto, a partir das definições de vazões mínimas de ar exterior para ventilação, níveis mínimos de filtragem do ar e requisitos técnicos dos sistemas e componentes relativos à qualidade do ar. A norma se aplica à sistemas centrais de qualquer capacidade e à sistemas unitários com mais de $34.000 \mathrm{BTU} / \mathrm{h}$.

A vazão de ar exterior requerida nessa $\mathrm{ABNT}$ é determinada como estipulado na norma internacional ASHRAE 62.1. O conceito de vazão eficaz é constituído pela soma de duas partes, avaliadas separadamente: a vazão relacionada às pessoas e a vazão relacionada à área ocupada:

$$
\mathrm{V}_{\mathrm{ef}}=\mathrm{F}_{\mathrm{p}} \cdot \mathrm{P}_{\mathrm{z}}+\mathrm{F}_{\mathrm{a}} \cdot \mathrm{A}_{\mathrm{z}}
$$

\footnotetext{
$\mathrm{V}_{\text {ef }}=\quad$ Vazão eficaz de ar externo $\left[\mathrm{m}^{3} / \mathrm{h}\right]$

$\mathrm{F}_{\mathrm{p}}=\quad$ Vazão volumétrica de ar externo por ocupante $\left[\mathrm{m}^{3} / \mathrm{h} /\right.$ pessoa $]$;
} 
$\mathrm{P}_{\mathrm{Z}}=\quad$ Número máximo de ocupantes do ambiente [-];

$\mathrm{R}_{\mathrm{a}}=\quad$ Vazão volumétrica de ar externo por unidade de área $\left[\mathrm{m}^{3} / \mathrm{h} / \mathrm{m}^{2}\right]$;

$\mathrm{A}_{\mathrm{Z}}=\quad$ Área útil ocupada pelas pessoas do ambiente [-];

Os valores de vazão eficaz mínima são levantados em um tabela, para diversos locais de aplicação, em ordem crescente de níveis (1, 2 e 3), cujo nível 3 é o nível mais conservador (maior valor de vazão eficaz mínima). A vazão a ser suprida na zona da ventilação é a vazão eficaz corrigida pela eficiência da distribuição de ar na zona:

$$
\mathrm{V}_{\mathrm{z}}=\mathrm{V}_{\mathrm{ef}} / \mathrm{E}_{\mathrm{z}}
$$

$\mathrm{V}_{\mathrm{Z}}=\quad$ Vazão de ar externo a ser suprida na zona de ventilação $\left[\mathrm{m}^{3} / h\right]$;

$\mathrm{E}_{\mathrm{z}}=\quad$ Eficiência de distribuição de ar na zona [-];

A vazão a de ar exterior a ser suprida pelo sistema, consideração um sistema com zona de ventilação única:

$$
\mathrm{V}_{\mathrm{S}}=\mathrm{V}_{\mathrm{Z}}
$$

$\mathrm{V}_{\mathrm{S}}=\quad$ Vazão de ar externo na tomada de $\operatorname{ar}\left[\mathrm{m}^{3} / \mathrm{h}\right]$

Ainda, o Anexo $\mathrm{C}$ da norma em questão, baseado também na norma ASHRAE 62.1, apresenta um informativo em relação ao $\mathrm{CO} 2$ como indicador de qualidade do ar, sendo considerado um indicador válido do nível de poluição produzido pelas pessoas. Não sendo, porém, um indicador da qualidade do ar do recinto, pois inúmeros poluentes químicos presentes, além dos produzidos pelas pessoas, não têm nenhuma relação com a concentração de $\mathrm{CO} 2$. Uma equação simples determina a vazão de ar exterior necessária para manter a concentração volumétrica de $\mathrm{CO} 2$ no recinto abaixo de determinado nível:

$$
\mathrm{V}_{0}=\mathrm{N} /\left(\mathrm{C}_{\mathrm{s}}-\mathrm{C}_{0}\right)
$$

$\mathrm{V}_{0}=\quad$ Vazão de ar externo por pessoa $\left[\mathrm{m}^{3} / \mathrm{h} /\right.$ pessoa $]$;

$\mathrm{N}=\quad$ Taxa de geração de $\mathrm{CO} 2$ por pessoa $[$ ppm/hora/pessoa]; 
$\mathrm{C}_{\mathrm{S}}=\quad$ Concentração de $\mathrm{CO} 2$ no recinto $[p p m] ;$

$\mathrm{C}_{0}=\quad$ Concentração de $\mathrm{CO} 2$ no ar exterior $[\mathrm{ppm}]$

A concentração máxima de $\mathrm{CO} 2$ de 1000 ppm no recinto é frequentemente citada como critério de qualidade de ar aceitável do ar interior. Porém, esse critério pressupõe as seguintes condições essenciais, que pode levar à interpretações distorcidas: a concentração no ar exterior é assumida arbitrariamente em 300 ppm (quando normalmente este valor oscila entre 400 e 600 ppm). Uma medição acima de 1000 ppm não indica que o critério não é satisfeito, desde que a medição não ultrapasse em mais de 700 ppm a concentração de ar exterior.

\section{B.3.5 - Portaria 3.523/1998 do Ministério da Saúde}

A Portaria 3.523 tem por objetivo aprovar procedimentos que visem minimizar o risco potencial à saúde dos ocupantes. Além disso, também objetiva aprovar um regulamento técnico contendo medidas básicas referentes aos procedimentos de verificação visual do estado de limpeza, remoção de sujeiras por métodos físicos e manutenção do estado de eficiência e integridade de todos os componentes dos sistemas de climatização.

A ANVISA (Agência Nacional de Vigilância Sanitária) publicou em 16 de janeiro de 2003 a Resolução $\mathrm{n}^{\text {o }}$ 9, que contém medidas específicas referentes a padrões de qualidade do ar em ambientes climatizados, parâmetros físicos e composição química do ar interior, bem como identificação dos poluentes de natureza física, química e biológica, com suas tolerâncias e métodos de controle, e também alguns pré-requisitos para projetos de instalação e de execução de sistemas de climatização.

A portaria também impõe que todos os sistemas de climatização estejam em condições adequadas de limpeza, manutenção, operação e controle, exigindo a implantação de um Plano de Manutenção, Operação e Controle (PMOC) para sistemas com capacidade acima de $60.000 \mathrm{BTU} / \mathrm{h}$, por um responsável técnico habilitado. Esse plano deve conter a identificação do estabelecimento que possui ambientes climatizados, a descrição das atividades que serão desenvolvidas, a periodicidade das mesmas, e as recomendações a serem adotadas em situações de falha de equipamentos e de emergência. Por fim, a portaria estabelece o PMOC e uma tabela de classificação dos filtros de ar para utilização em ambientes climatizados, além de definir a taxa de renovação de ar externo em $27 \mathrm{~m} 3 / \mathrm{h}$ por pessoa que ocupa o recinto condicionado. 
B.3.6 - Comparação das normas

Pela evolução das normas americanas, percebe-se uma grande associação entre as normas relativas à qualidade do ar interior e as normas de uso de energia, uma vez que esses temas estão intimamente ligados. Esse fato se confirma nos itens das normas de energia que requerem controles de vazão de ar exterior de acordo com a demanda (DCV), com o intuito de economizar energia. As normas brasileiras, por sua vez, contemplam apenas os requisitos de qualidade do ar, uma vez que não apresentam exigências relativas ao controle e operação dos sistemas de ventilação.

Um ponto bastante controverso entre as normas se dá em relação aos valores e métodos utilizados para definição das vazões mínimas de ar externo, necessárias para manutenção da qualidade do ar em um sistema de ar condicionado. Esses métodos e valores sofreram alterações ao longo do tempo, e, ainda hoje, existem grandes diferenças entre as normas de qualidade do ar de diversos países (Tabela B.1). Percebe-se uma grande diferença entre os métodos existentes, sejam eles diretos (vazões estabelecidas a partir das concentrações reais do ambiente) ou indiretos (vazões definidas por base nas ocupações e áreas de projeto). Os métodos indiretos, por sua vez, foram modificados ao longo do tempo, levando em conta fatores e níveis mínimos diferentes, gerando valores bem distintos para uma mesma aplicação. Ainda, diversas normas de outros países consideram critérios diferentes, trazendo valores ainda mais discrepantes em relação ao padrão da norma americana.

$\mathrm{Na}$ Europa, as taxas de ventilação cresceram em relação aos níveis das taxas americanas, talvez em resposta às excessivas preocupações com a qualidade do ar interior, especialmente no norte europeu. Por exemplo, para edifícios de escritório com uma densidade de ocupação de $10 \mathrm{~m}^{2} /$ pessoa, a norma da Espanha aumentou recentemente sua taxa de ventilação em $25 \%$, chegando a 12,5 litros/segundo por pessoa, bem acima dos valores da norma dos Estados Unidos.

Tabela B.1 - Vazões mínimas de ar externo para edifício de escritórios com ocupação de $10 \mathrm{~m}^{2} /$ pessoa (Perez-Lombard et al., 2011, modificado)

\begin{tabular}{ccc}
\hline País & Norma & $\begin{array}{c}\text { Vazão de ar externo } \\
\text { (L/s/pes.) }\end{array}$ \\
\hline EUA & ASHRAE 62.1 & 5,5 \\
Califórnia/EUA & Title 24 & 7,6 \\
Inglaterra & Part F [53] & 10,0 \\
\hline
\end{tabular}




\begin{tabular}{ccc}
\hline Espanha & RITE & 12,5 \\
China & EEPB & 8,3 \\
Brasil & $3.523 / 98$ & 7,5 \\
Brasil & $16401-3$ nível 1 & 5,5 \\
Brasil & $16401-3$ nível 2 & 7,1 \\
Brasil & $16401-3$ nível 3 & 8,8 \\
\hline
\end{tabular}

Dessa forma, é importante que se adotem valores ótimos, de maneira a adequar a qualidade do ar interior com a economia de energia, evitando gastos desnecessários com excesso de ventilação. Cabe ressaltar, ainda, que esses valores de vazão ainda são corrigidos por um fator chamado eficiência de distribuição na zona, majorando ainda mais os valores. Assim, os sistemas de DCV constituem solução indispensável para que essas premissas sejam implementadas de forma sustentável.

Por último, percebe-se nas normas que há um lapso em relação às definições das condições nas quais se é permitido utilizar da ventilação natural para edifícios residenciais, garagens, áreas de estacionamento e casas de motores. As normas brasileiras, inclusive, só exigem os requisitos que visam a manutenção da qualidade do ar para sistemas unitários com mais de $10 \mathrm{~kW}$ (34.000 BTU/h, ABNT NBR 16401-3) e o PMOC para sistemas com mais de 60.000 BTU/h (Portaria 3.523/98). Nesse sentido, os pequenos escritórios, edificações residenciais, e demais ambientes atendidos por sistemas de menor porte não possuem exigências para renovação de ar, podendo ocorrer os diversos problemas para os ocupantes já mencionados anteriormente. Cada vez mais países desenvolvidos do norte europeu, China e EUA têm atualizado suas normas de qualidade do ar com critérios de eficiência energética, exigindo sistemas de DCV aliados com recuperadores de energia, com aplicações em edifícios comerciais e residenciais, uma vez que as pesquisas mais recentes tem demonstrado a economia de energia e melhoria da qualidade do ar dos ambientes atendidos por esses sistemas. 


\section{APÊNDICE C - FORMULAÇÃo MATEMÁtiCA INSERIDA NO EES PARA REALIZAÇÃO DAS SIMULAÇÕES}

\section{PROCEDURE}

ERV(Control_ERV;m_dot_a;T_a_ext_in;w_a_ext_in;h_a_ext_in;C_p;h_fg;f_ocup;P_bsb;Eta_sen;Eta_lat;Eta_total;T_a_indoor;w_a_indoor :

T_a_ext_out;w_a_ext_out; _a_ext_out;Q_dot_ERV_real;

Q_dot_ERV_lat_max;Q_dot_ERV_sen_max;Q_dot_ERV_max;Q_dot_ERV_sens;T_a_indoor_out;w_a_indoor_out;Q_dot_ERV_Eta_total;Q_d

ot_ERV_lat;Q_dot_ERV_sens_cor)

IF (f_ocup=0) THEN

T_a_ext_out:=T_a_ext_in

w_a_ext_out:=w_a_ext_in

h_a_ext_out:=h_a_ext_in

Q_dot_ERV_lat_max:=0

Q_dot_ERV_sen_max:=0

Q_dot_ERV_max:=0

Q_dot_ERV_sens:=0

T_a_indoor_out:=T_a_indoor

w_a_indoor_out:=w_a_indoor

Q_dot_ERV_Eta_total:=0

Q_dot_ERV_lat:=0

Q_dot_ERV_sens_cor:=0

Q_dot_ERV_real:=0

ELSE

IF (Control_ERV=0) THEN

T_a_ext_out:=T_a_ext_in

w_a_ext_out:=w_a_ext_in

$\mathrm{h}$ a ext out: $=\mathrm{h}$ a ext in

Q_dot_ERV_lat_max:=0 
ELSE

Q_dot_ERV_Eta_total)
Q_dot_ERV_sen_max:=0

Q_dot_ERV_max:=0

Q_dot_ERV_sens:=0

T_a_indoor_out:=T_a_indoor

w_a_indoor_out:=w_a_indoor

Q_dot_ERV_Eta_total:=0

Q_dot_ERV_lat:=0

Q_dot_ERV_sens_cor:=0

Q_dot_ERV_real:=0

Q_dot_ERV_lat_max:=(m_dot_a*h_fg*(w_a_ext_in-w_a_indoor $))$

Q_dot_ERV_sen_max:=(m_dot_a*C_p*(T_a_ext_in-T_a_indoor) $)$

Q_dot_ERV_max:=(Q_dot_ERV_lat_max+Q_dot_ERV_sen_max)

Q_dot_ERV_sens:=Eta_sen*Q_dot_ERV_sen_max

Q_dot_ERV_Eta_total:=Eta_total*QQ_dot_ERV_max

Q_dot_ERV_lat:=Eta_lat*Q_dot_ERV_lat_max

Q_dot_ERV_sens_cor:=Q_dot_ERV_sens-((Q_dot_ERV_sens+Q_dot_ERV_lat)-

T_a_indoor_out:=((Q_dot_ERV_sens $) /\left(\left(\mathrm{m} \_\right.\right.$dot_a*C_p $\left.\left.)+0,000001\right)\right)+\mathrm{T} \_\mathrm{a} \_$indoor w_a_indoor_out:=((Q_dot_ERV_lat $) /(($ m_dot_a*h_fg $)+0,000001))+w \_a$ indoor T_a_ext_out:=(Q_dot_ERV_sens_cor $\left.\left((-1)^{*} \mathrm{~m} \_d o t \_a^{*} \mathrm{C} \_\mathrm{p}\right)\right)+\mathrm{T} \_\mathrm{a}$-ext_in w_a_ext_out: $=\left(Q\right.$ Q_dot_ERV_lat $\left./\left((-1) * m \_d o t \_a * h \_f g\right)\right)+w \_a$ ext_in h_a_ext_out:=enthalpy(AirH2O;T=T_a_ext_out; w=w_a_ext_out; P=P_bsb) Q_dot_ERV_real:=Q_dot_ERV_sens_cor+Q_dot_ERV_lat

\section{IF (Q_dot_ERV_real<0) THEN}


Q_dot_ERV_max:=0

Q_dot_ERV_sens:=0

T_a_indoor_out:=T_a_indoor

w_a_indoor_out:=w_a_indoor

Q_dot_ERV_Eta_total:=0

Q_dot_ERV_lat:=0

Q_dot_ERV_sens_cor: $=0$

ENDIF

Q_dot_ERV_real:=0

ENDIF

ENDIF

END

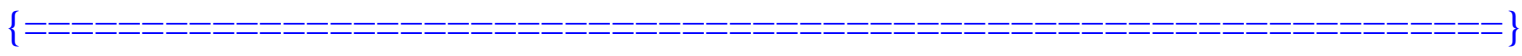

PROCEDURE CTRLCO2(V_ar_pes;A_amb;V_ar_amb;Control_CO2;N_ocup_max; f_ocup : N_ocup;V_dot_a)

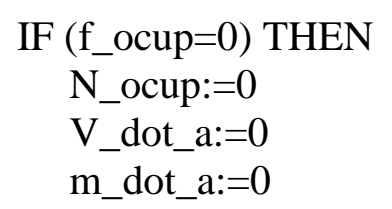

ELSE
IF (Control_CO2=0) THEN

ELSE

N_ocup:=N_ocup_max

V_dot_a=(N_ocup*V_ar_pes+A_amb*V_ar_amb)

ENDIF

N_ocup:=N_ocup_max*f_ocup

ENDIF

END 
PROCEDURE MASSA(V_dot_a;v_a_ext : m_dot_a)

m_dot_a=(V_dot_a/3600)/v_a_ext

IF (m_dot_a $<0,001)$ THEN

m_dot_a:=0

ENDIF

END

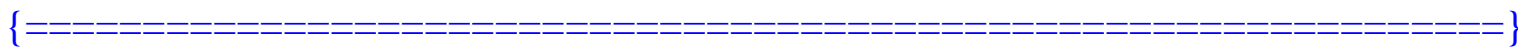

PROCEDURE COEF(Q_dot_ev;Control_ERV;T_a_ext_in :

V_a_10TR;V_a_FC10TR;P_FC10TR;V_a_15TR;V_a_FC15TR;P_FC15TR;CO_10TR;P_Ch10TR;CO_15TR;P_Ch15TR;COP_15TR;COP_10 TR)

IF(Control_ERV=0) THEN

$$
\begin{aligned}
& \text { V_a_10TR: }=0 \\
& \text { V_a_FC10TR: }=0 \\
& \text { P_FC10TR }:=0 \\
& \text { CO_10TR }:=0 \\
& \text { P_Ch10TR }:=0 \\
& \text { COP_10TR }:=0 \\
& \text { V_a_15TR }=10320 / 43
\end{aligned}
$$

vazão de ar por TR de refrigeração para o fancoil"

$$
\text { V_a_FC15TR=V_a_15TR*⿻__dot_ev }
$$

o fancoil de acordo com a carga térmica real"

P_FC15TR $=\left(\left(\mathrm{V} \_a \_F C 15 T^{\wedge}(2)\right) *(-1)^{*}\left(10^{\wedge}(-8)\right)\right)-\left(\left(\mathrm{V} \_\mathrm{a} \_\mathrm{FC} 15 \mathrm{TR}\right) * 0,000002\right)+0,3733+\left(\left(\mathrm{V} \_\mathrm{a} \_\mathrm{FC} 15 \mathrm{TR} \wedge(3)\right) *(3) *\left(10^{\wedge}(-12)\right)\right)$

$\{[\mathrm{kW}]\}$ "Potência consumida pelo ventilador do fan coil" 
do chiller"

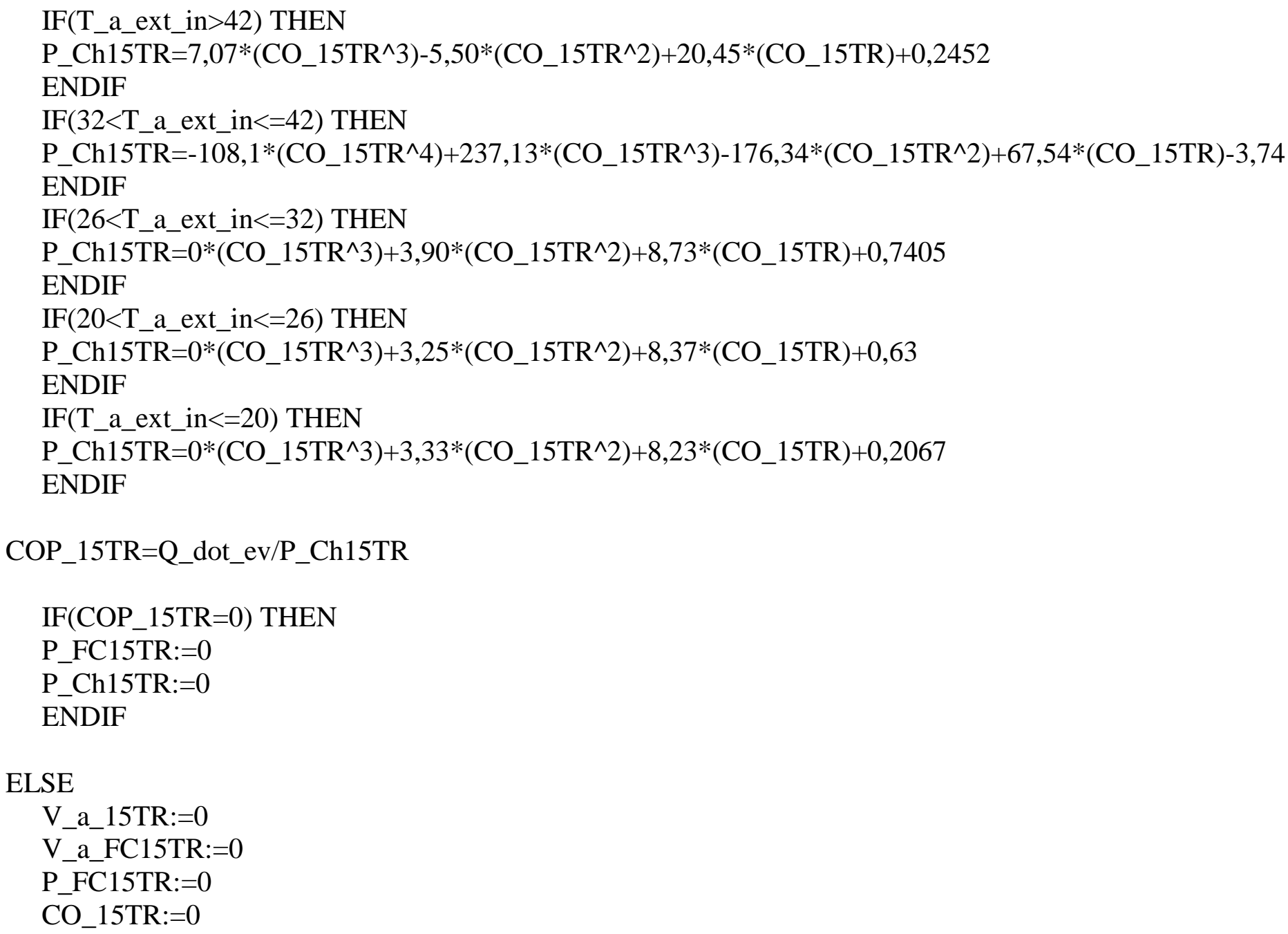


P_Ch15TR:=0

COP_15TR:=0

V_a_10TR=8150/35

vazão de ar por TR de refrigeração para o fancoil"

V_a_FC10TR=V_a_10TR*Q_dot_ev

o fancoil de acordo com a carga térmica real"

P_FC10TR $=\left(\left(\mathrm{V} \_ \text {a_FC10TR^}(2)\right)^{*}(-4)^{*}\left(10^{\wedge}(-8)\right)\right)+\left(\left(\mathrm{V} \_\mathrm{a} \_\mathrm{FC} 10 \mathrm{TR}\right) * 0,00001\right)+0,29+\left(\left(\mathrm{V} \_\mathrm{a} \_\mathrm{FC} 10 \mathrm{TR} \wedge(3)\right)^{*}(8)^{*}\left(10^{\wedge}(-12)\right)\right)$

$\{[\mathrm{kW}]\}$ "Potência consumida pelo ventilador do fan coil"

CO_10TR=Q_dot_ev/35

do chiller"

IF(T_a_ext_in>42) THEN

$\mathrm{P} \_\mathrm{Ch} 10 \mathrm{TR}=0 *\left(\mathrm{CO} \_10 \mathrm{TR}^{\wedge} 3\right)+5,15^{*}\left(\mathrm{CO} \_10 \mathrm{TR}^{\wedge} 2\right)+9,55 *\left(\mathrm{CO} \_10 \mathrm{TR}\right)+0,86$

ENDIF

IF(32<T_a_ext_in<=42) THEN

P_Ch10TR=-69,93*(CO_10TR^4)+150,83*(CO_10TR^3)-109,38*(CO_10TR^2)+41,99*(CO_10TR $)-1,9611$

ENDIF

IF $(26<$ T_a_ext_in $<=32)$ THEN

P_Ch10TR=0*(CO_10TR^3)+2,74*(CO_10TR^2)+6,06*(CO_10TR $)+0,5276$

ENDIF

IF(20<T_a_ext_in<=26) THEN

P_Ch10TR $=0 *\left(C O \_10 \mathrm{TR}^{\wedge} 3\right)+2,25 *\left(\mathrm{CO} \_10 \mathrm{TR}{ }^{\wedge} 2\right)+5,89 *\left(\mathrm{CO} \_10 \mathrm{TR}\right)+0,44$

ENDIF

IF(T_a_ext_in $<=20)$ THEN

$\mathrm{P} \_\mathrm{Ch} 10 \mathrm{TR}=0 *\left(\mathrm{CO} \_10 \mathrm{TR}{ }^{\wedge} 3\right)+2,33 *\left(\mathrm{CO} \_10 \mathrm{TR}^{\wedge} 2\right)+5,76 *\left(\mathrm{CO} \_10 \mathrm{TR}\right)-0,121$

ENDIF

COP_10TR=Q_dot_ev/P_Ch10TR

IF(COP_10TR=0) THEN

P_FC10TR:=0 


\section{P_Ch10TR:=0}

ENDIF

\section{ENDIF}

END

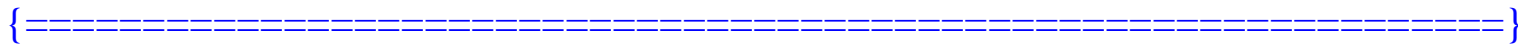

PROCEDURE POT(V_dot_a : P_s)

P_s $=\left(\left(\left(\left(V \_d o t \_a^{\wedge} 3\right)^{*} 4 *\left(10^{\wedge}(-7)\right)\right)-\left(\left(V \_d o t \_a^{\wedge} 2\right) * 5^{*}\left(10^{\wedge}(-4)\right)\right)+\left(\left(V \_d o t \_a\right)^{*} 1,66^{*}\left(10^{\wedge}(-1)\right)\right)+(149)\right) / 1000\right)^{* 2}$

IF (V_dot_a=0) THEN

$$
P_{-} s:=0
$$

ENDIF

END

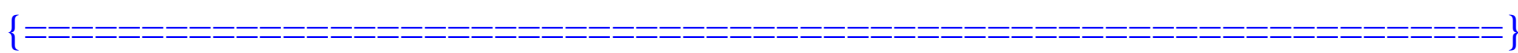

"Simulação numérica do desempenho de um ERV"

"Formulação Matemática"

"1) MEDIDAS DE ENTRADA"

"1.1) Parâmetros Climáticos"

\section{$\mathrm{P}$ bsb $=89$}

T_a_indoor $=23$

UR_a_indoor $=0,5$
$\{\mathrm{kPa}$, pressão atmosférica em Brasília $\}$

\{Temperatura do ar rejeitado - temperatura de conforto do ambiente interno

\{Umidade relativa do ar do ambiente interno 
time $=$ kount +0

\section{Control $\mathrm{CO} 2=1$}

Control_ERV=1

"1.2) Parâmetros do ERV"

Eta_sen $=\left(0,0 *\left(V \_d o t \_a^{\wedge} 3\right)-3 *\left(10^{\wedge}(-6)\right) *\left(V \_\right.\right.$dot $\left.\_a^{\wedge} 2\right)-0,001 *\left(V \_\right.$dot $\left.\left.\_a\right)+87,5\right) / 100$ ERV"

Eta_lat $=\left(0,0^{*}\left(V \_d o t \_a^{\wedge} 3\right)-4^{*}\left(10^{\wedge}(-6)\right)^{*}\left(V \_d o t \_a^{\wedge} 2\right)-0,0006^{*}\left(V \_d o t \_a\right)+75,33\right) / 100$ ERV"

Delta_P_s $=-5^{*}\left(10^{\wedge}(-8)\right)^{*}\left(\mathrm{~V} \_\right.$dot_$\left.\_\mathrm{a}^{\wedge} 3\right)+6^{*}\left(10^{\wedge}(-5)\right) *\left(\mathrm{~V} \_\right.$dot_a $\left.\mathrm{a}^{\wedge} 2\right)-0,153^{*}\left(\mathrm{~V} \_\right.$dot_a $)+370,54$ de alimentação"

Delta_P_e $=-5 *\left(10^{\wedge}(-8)\right)^{*}\left(V \_d o t \_a^{\wedge} 3\right)+6^{*}\left(10^{\wedge}(-5)\right) *\left(V \_d o t \_a^{\wedge} 2\right)-0,153 *\left(V \_d o t \_a\right)+370,54$ de exaustão"

\section{Eta_f $=0,8$}

motor"

"1.3) Parâmetros para o ciclo de compressão a vapor"

Q_dot_ev=Q_dot_ev_padrao+Q_dot_a

$\{[\mathrm{kW}]\}$ "Capacidade de evaporação ou carga térmica"

"1.3) Parâmetros para cálculo da vazão de ar externo"

N_ocup_max $=142$

V_ar_pes $=9$

\{número de ocupantes máximo no ambiente\}

\{vazão por pessoa para edifício de escritórios em $\mathrm{m}^{3} / \mathrm{h}$ \}
$\{[-]\}$ "Eficiência sensivel do fabricante do

$\{[-]\}$ "Eficiência latente do fabricante do

$\{[\mathrm{Pa}]\}$ "Perda de carga em Pa do ventilador

$\{[\mathrm{Pa}]\}$ "Perda de carga em Pa do ventilador

$\{[-]\}$ "Eficiência do conjunto ventilador- 
A_amb $=196$

V_ar_amb $=1,08$ \{área do ambiente em $\mathrm{m} 2\}$

\{vazão por unidade de área para edifício de escritórios em $\mathrm{m}^{3} / \mathrm{h}$ \}

Call CTRLCO2(V_ar_pes;A_amb;V_ar_amb;Control_CO2;N_ocup_max; f_ocup : N_ocup;V_dot_a)

"2) FÓRMULAS"

"2.1) Parâmetros para determinação das eficiências ponderadas do ERV"

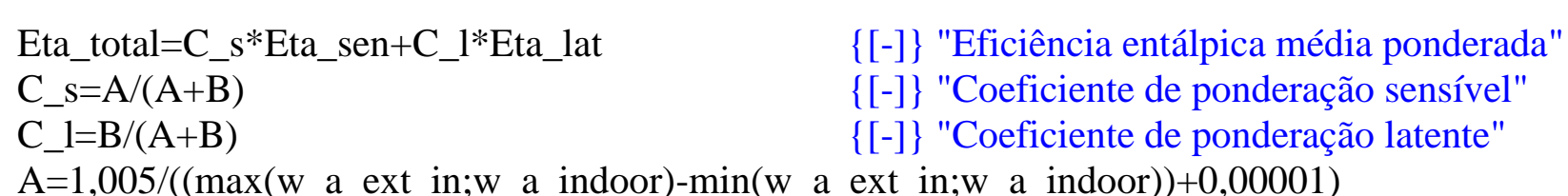

coeficientes de ponderação"

B=2500/((max)(T_a_ext_in;T_a_indoor)-min(T_a_ext_in;T_a_indoor) $)+0,00001)$

coeficientes de ponderação"

"2.4) Cálculo da recuperação térmica do ERV"

v_a_ext=volume(AirH2O;T=T_a_ext_in;w=w_a_ext_in;P=P_bsb)

$\{\mathrm{m} 3 / \mathrm{kg}\}$ "Volume específico do ar externo"

CALL MASSA(V_dot_a;v_a_ext : m_dot_a)

w_a_indoor=HumRat(AirH2O;T=T_a_indoor;r=UR_a_indoor;P=P_bsb)

w_a_ext_in = HumRat(AirH2O;T=T_a_ext_in;r=UR_a_ext_in;P=P_bsb)

de alimentação"
$\{[-]\}$ "Constante para determinação dos

$\{[-]\}$ "Constante para determinação dos $\{[\mathrm{kg} / \mathrm{kg}]\}$ "Umidade absoluta do ar interno"

$\{[\mathrm{kg} / \mathrm{kg}]\}$ "Umidade absoluta do ar externo 
h_a_ext_in=Enthalpy(AirH2O;T=T_a_ext_in;w=w_a_ext_in;P=P_bsb)

alimentação"

h_a_indoor=Enthalpy(AirH2O;T=T_a_indoor;r=UR_a_indoor;P=P_bsb)

ambiente"

Q_dot_a=m_dot_a*(h_a_ext_out-h_a_indoor)

renovação"

UR_a_ext_out=RelHum(AirH2O;T=T_a_ext_out;w=w_a_ext_out;P=P_bsb) entra no ambiente

C_p $=\mathrm{Cp}($ AirH2O;T=T_a_ext_in;w=w_a_ext_in;P=P_bsb)

h_fg=Enthalpy(Water;P=P_bsb;x=1)-enthalpy(water;P=P_bsb;x=0)
$\{[\mathrm{kJ} / \mathrm{kg}]\}$ "Entalpia do ar externo de

$\{[\mathrm{kJ} / \mathrm{kg}]\}$ "Entalpia do ar interno do

$\{[\mathrm{kW}]\}$ "Carga térmica devida ao ar de

$\{$ Umidade relativa do ar do externo que

\{Calor específico à pressão constante $\}$

\{Entalpia de vaporização\}

\section{CALL}

ERV(Control_ERV;m_dot_a;T_a_ext_in;w_a_ext_in;h_a_ext_in;C_p;h_fg;f_ocup;P_bsb;Eta_sen;Eta_lat;Eta_total;T_a_indoor;w_a_indoor :

T_a_ext_out;w_a_ext_out;h_a_ext_out;Q_dot_ERV_real;Q_dot_ERV_lat_max;Q_dot_ERV_sen_max;Q_dot_ERV_max;Q_dot_ERV_sens; T_a _indoor_out;w_a_indoor_out;Q_dot_ERV_Eta_total;Q_dot_ERV_lat;Q_dot_ERV_sens_cor)

CALL COEF(Q_dot_ev;Control_ERV;T_a_ext_in :

V_a 10TR;V_a_FC10TR;P_FC10TR;V_a_15TR;V_a_FC15TR;P_FC15TR;CO_10TR;P_Ch10TR;CO_15TR;P_Ch15TR;COP_15TR;COP_10 TR)

"2.5) Potência de ventilação"

CALL POT(V_dot_a : P_s)

P_e=((V_dot_a_e*Delta_P_e/3600)/Eta_f $) / 1000$ 


\section{CÓDIGO FONTE}




\section{Formulação Matemática}

\section{Equations}

procedure $\operatorname{ERV}\left(\right.$ Control $\left._{E R V} ; \dot{m}_{a} ; T_{a ; e x t ; i n} ; w_{a ; e x t ; i n} ; h_{a ; e x t ; i n} ; C_{p} ; h_{f g} ; f_{\text {ocup }} ; P_{b s b} ; \eta_{s e n} ; \eta_{l a t} ; \eta_{\text {total }} ; T_{a ; i n d o o r} ; w_{a ; i n d o o}\right) r$

$\left.T_{a ; \text { ext } ; \text { out }} ; w_{a ; e x t ; \text { out }} ; h_{a ; e x t ; \text { out }} ; \dot{Q}_{E R V ; \text { real }} ; \dot{Q}_{E R V ; l a t ; \text { max }} ; \dot{Q}_{E R V ; s e n ; \text { max }} ; \dot{Q}_{E R V ; \text { max }} ; \dot{Q}_{E R V ; s e n s} ; T_{a ; \text { indoor } ; \text { out }} ; w_{a ; \text { indoor;out }} ; \dot{Q}_{E R V ; \eta ; \text { total }} ; \dot{Q}_{E R V ; l a t} ; \dot{Q}_{E R V ; \text { sens;cor }}\right)$ If $\left(f_{\text {ocup }}=0\right)$ then

$T_{a ; e x t ; o u t}$

$=T_{a ; e x t ; i n}$

$w_{a ; e x t ; o u t}$

$=w_{a ; e x t ; i n}$

$h_{a ; \text { ext } ; \text { out }}$

$=h_{a ; e x t ; i n}$

$\dot{Q}_{E R V ; l a t ; \max }$

$=0$

$\dot{Q}_{E R V ; s e n ; \max }$

$=0$

$\dot{Q}_{E R V ; \max }$

$=0$

$\dot{Q}_{E R V ; s e n s}$

$=0$

$T_{a ; \text { indoor } ; \text { out }}$

$=T_{a ; i n d o o r}$ 
$=w_{a ; i n d o o r}$

$=0$

$=0$

$=0$

else

If $\left(\right.$ Control $\left._{E R V}=0\right)$ then

$=T_{a ; e x t ; i n}$

$w_{a ; e x t ; o u t}$

$=h_{a ; e x t ; i n}$

$\dot{Q}_{E R V ; l a t ; \max }$ 
$=0$

$T_{a ; \text { indoor } ; \text { out }}$

$=T_{a ; i n d o o r}$

$w_{a ; \text { indoor } ; o u t}$

$=w_{a ; \text { indoor }}$

$\dot{Q}_{E R V ; l a t}$

$=0$

$=\left(\dot{m}_{a} \cdot h_{f g} \cdot\left(w_{a ; \text { ext } ; \text { in }}-w_{a ; \text { indoor }}\right)\right)$

$\dot{Q}_{E R V ; \operatorname{sen} ; \max }$

$=\left(\dot{m}_{a} \cdot C_{p} \cdot\left(T_{a ; e x t ; i n}-T_{a ; i n d o o r}\right)\right)$

$\dot{Q}_{E R V ; \max }$ 
$=\left(\dot{Q}_{E R V ; l a t ; \max }+\dot{Q}_{E R V ; s e n ; \max }\right)$

$\dot{Q}_{E R V ; s e n s}$

(65)

$=\eta_{s e n} \cdot \dot{Q}_{E R V ; s e n ; \max }$

(66)

$\dot{Q}_{E R V ; \eta ; t o t a l}$

$=\eta_{\text {total }} \cdot \dot{Q}_{E R V ; \max }$

$\dot{Q}_{E R V ; l a t}$

(69)

$=\eta_{l a t} \cdot \dot{Q}_{E R V ; l a t ; \max }$

(70)

$\dot{Q}_{E R V ; s e n s ; c o r}$

$=\dot{Q}_{E R V ; s e n s}-\left(\left(\dot{Q}_{E R V ; s e n s}+\dot{Q}_{E R V ; l a t}\right)-\dot{Q}_{E R V ; \eta ; t o t a l}\right)$

$T_{a ; \text { indoor; out }}$

$=\left(\frac{\dot{Q}_{E R V ; s e n s}}{\left(\dot{m}_{a} \cdot C_{p}\right)+0,000001}\right)+T_{a ; \text { indoor }}$

$w_{a ; i n d o o r ; o u t}$

$=\left(\frac{\dot{Q}_{E R V ; l a t}}{\left(\dot{m}_{a} \cdot h_{f g}\right)+0,000001}\right)+w_{a ; \text { indoor }}$

$T_{a ; \text { ext } ; \text { out }}$

$=\left(\frac{\dot{Q}_{E R V ; s e n s ; c o r}}{(-1) \cdot \dot{m}_{a} \cdot C_{p}}\right)+T_{a ; e x t ; i n}$

$w_{a ; e x t ; \text { out }}$ 
$=\mathrm{h}\left(\right.$ AirH2O $\left.; \mathrm{T}=T_{a ; \text { ext } ; \text { out }} ; \mathrm{w}=w_{a ; \text { ext } ; \text { out }} ; \mathrm{P}=P_{b s b}\right)$

$=\dot{Q}_{E R V ; s e n s ; c o r}+\dot{Q}_{E R V ; l a t}$

$\operatorname{If}\left(\dot{Q}_{E R V ; \text { real }<0}\right)$ then

$=0$

$w_{a ; e x t ; o u t}$

$=w_{a ; e x t ; i n}$

$h_{a ; e x t ; o u t}$

$=h_{a ; e x t ; i n}$

$\dot{Q}_{E R V ; l a t ; \max }$

$=0$

$\dot{Q}_{E R V ; s e n ; \max }$

$=0$

$\dot{Q}_{E R V ; \max }$

$=0$

$T_{a ; \text { indoor } ; \text { out }}$

$=T_{a ; \text { indoor }}$

$w_{a ; \text { indoor } ; \text { out }}$ 


\begin{tabular}{|c|c|c|}
\hline & $\dot{Q}_{E R V ; \eta ; t o t a l}$ & $(104)$ \\
\hline & $=0$ & $(105)$ \\
\hline & $\dot{Q}_{E R V ; l a t}$ & (106) \\
\hline & $=0$ & $(107)$ \\
\hline & $\dot{Q}_{E R V ; s e n s ; c o r}$ & $(108)$ \\
\hline & $=0$ & $(109)$ \\
\hline & $\dot{Q}_{E R V ; r e a l}$ & $(110)$ \\
\hline & $=0$ & $(111)$ \\
\hline endif & & $(112)$ \\
\hline endif & & (113) \\
\hline endif & & $(114)$ \\
\hline end & & $(115)$ \\
\hline procedure $C l$ & CTRLCO2 $\left(V_{a r ; p e s} ; A_{a m b} ; V_{a r ; a m b} ;\right.$ Control $\left._{C O} ; N_{o c u p ; m a x} ; f_{o c u}\right) p$ & $(116)$ \\
\hline$N_{\text {ocup }} ; \dot{V}_{a}$ & & $(117)$ \\
\hline If $\left(f_{\text {ocup }}=\right.$ & $=0)$ then & $(118)$ \\
\hline$N_{\text {ocup }}$ & & $(119)$ \\
\hline$=0$ & & $(120)$ \\
\hline$\dot{V}_{a}$ & & $(121)$ \\
\hline$=0$ & & $(122)$ \\
\hline else & & (123) \\
\hline If $($ Cont & ntrol $_{\mathrm{CO}_{2}}=0$ ) then & (124) \\
\hline
\end{tabular}




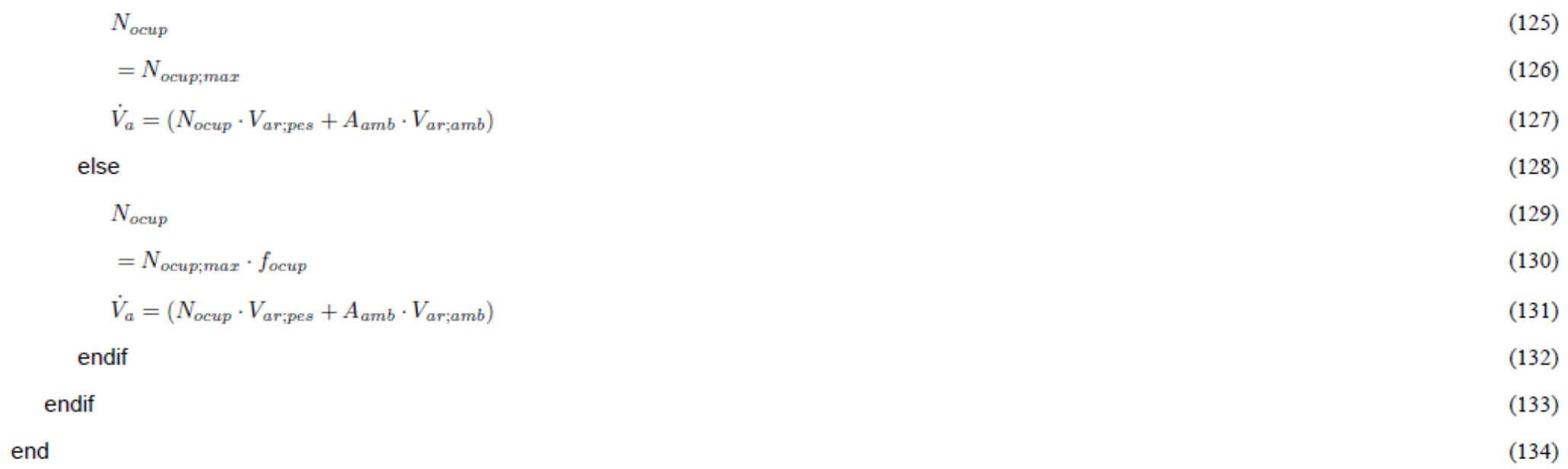

$=N_{\text {ocup } \text { max }}$

$\dot{V}_{a}=\left(N_{\text {ocup }} \cdot V_{a r ; p e s}+A_{a m b} \cdot V_{a r ; a m b}\right)$

(127)

else

$N_{\text {ocup }}$

(128)

$=N_{\text {ocup } ; \text { max }} \cdot f_{\text {ocup }}$

(129)

$\dot{V}_{a}=\left(N_{\text {ocup }} \cdot V_{a r ; p e s}+A_{a m b} \cdot V_{a r ; a m b}\right)$

endif

endif

(133)

end

(134)

Simulação numérica do desempenho de um ERV

Formulação Matemática

1) MEDIDAS DE ENTRADA

1.1) Parâmetros Climáticos

$P_{b s b}=89$

$T_{a ; \text { indoor }}=24$

$U R_{a ; \text { indoor }}=0,5$

(137)

time $=$ kount +0

(138)

Control $_{\mathrm{CO}_{2}}=0$

(139)

Control $_{E R V}=0$

(140)

1.2) Parâmetros do ERV

$\eta_{\text {sen }}=\frac{-0,00 \cdot\left(\dot{V}_{a}^{3}\right)+0,00 \cdot\left(\dot{V}_{a}^{2}\right)-0,06 \cdot\left(\dot{V}_{a}\right)+73,66}{100}$ 
Eficiência sensivel do fabricante do ERV

$\eta_{\text {lat }}=\frac{-0,00 \cdot\left(\dot{V}_{a}^{3}\right)+0,00 \cdot\left(\dot{V}_{a}^{2}\right)-0,06 \cdot\left(\dot{V}_{a}\right)+63,66}{100}$

Eficiencia latente do fabricante do ERV

$\delta_{P ; s}=-0,00 \cdot\left(\dot{V}_{a}^{3}\right)-0,00 \cdot\left(\dot{V}_{a}^{2}\right)-0,39 \cdot\left(\dot{V}_{a}\right)+276,69$

Perda de carga em $\mathrm{Pa}$ do ventilador de alimentação

$\delta_{P ; e}=-0,00 \cdot\left(\dot{V}_{a}^{3}\right)-0,00 \cdot\left(\dot{V}_{a}^{2}\right)-0,39 \cdot\left(\dot{V}_{a}\right)+276,69$

Perda de carga em Pa do ventilador de exaustão

$\eta_{f}=0,8$

Eficiência do conjunto ventilador-motor

1.3) Parâmetros para o ciclo de compressão a vapor

$T_{w e}=12$

Temperatura de entrada da água no evaporador

$\dot{Q}_{e v}=100+\dot{Q}_{0}$

Capacidade de evaporação ou carga térmica

$G=8$

Capacidade do evaporador

$F=9,39$

Capacidade do condensador

$k_{1}=137,402$

Constante para determinação da curva para a capacidade de refrigeração

$k_{2}=4,604$

Constante para determinação da curva para a capacidade de refrigeração

$k_{3}=0,061$ 
Constante para determinação da curva para a capacidade de refrigeração

$k_{4}=-1,118$

Constante para determinação da curva para a capacidade de refrigeração

$k_{5}=-0,0015$

Constante para determinação da curva para a capacidade de refrigeração

$k_{6}=-0,01$

Constante para determinação da curva para a capacidade de refrigeração

$k_{7}=-0,0004$

Constante para determinação da curva para a capacidade de refrigeração

$k_{8}=-0,00026$

Constante para determinação da curva para a capacidade de refrigeração $k_{9}=0,0000003$

Constante para determinação da curva para a capacidade de refrigeração

$k_{10}=1,006$

Constante para determinação da curva para a capacidade de refrigeração

$k_{11}=-0,89$

Constante para determinação da curva para a capacidade de refrigeração

$k_{12}=-0,01$

Constante para determinação da curva para a capacidade de refrigeração

$k_{13}=0,87$

Constante para determinação da curva para a capacidade de refrigeração

$k_{14}=-0,006$

Constante para determinação da curva para a capacidade de refrigeração

$k_{15}=-0,03$ 
Constante para determinação da curva para a capacidade de refrigeração

$k_{16}=-0,0002$

Constante para determinação da curva para a capacidade de refrigeração

$k_{17}=-0,00014$

Constante para determinação da curva para a capacidade de refrigeração

$k_{18}=0,000006$

Constante para determinação da curva para a capacidade de refrigeração

1.3) Parâmetros para cálculo da vazão de ar externo

$N_{\text {ocup; } \text { max }}=142$

$V_{\text {ar;pes }}=9$

$A_{a m b}=100$

$V_{\text {ar } ; a m b}=1,08$

call $C T R L C O 2\left(V_{\text {ar:pes }} ; A_{a m b} ; V_{a r ; a m b} ;\right.$ Control $\left._{C O 2} ; N_{\text {ocup;max }} ; f_{\text {ocu }}\right) p$

$\left.N_{\text {ocup }} ; \dot{V}_{a}\right)$

2) FÓRMULAS

2.1) Parâmetros para determinação das eficiências ponderadas do ERV $\eta_{\text {total }}=C_{s} \cdot \eta_{\text {sen }}+C_{l} \cdot \eta_{\text {lat }}$

Eficiência entálpica média ponderada

$C_{s}=\frac{A}{(A+B)}$

Coeficiente de ponderação sensivel

$C_{l}=\frac{B}{(A+B)}$ 
Coeficiente de ponderação latente

$A=\frac{1,005}{\left(\max \left(w_{a ; e x t ; \text { in }} ; w_{a ; \text { indoor }}\right)-\min \left(w_{a ; e x t ; i n} ; w_{a ; \text { indoor }}\right)\right)}$

Constante para determinação dos coeficientes de ponderação

$B=\frac{2500}{\left(\left(\max \left(T_{a ; \text { ext } ; \text { in }} ; T_{a ; \text { indoor }}\right)-\min \left(T_{a ; \text { ext } ; \text { in }} ; T_{a ; \text { indoor }}\right)\right)+0,00001\right)}$

Constante para determinação dos coeficientes de ponderação

2.2) Simulação do ciclo de compressão a vapor

$\dot{Q}_{e v}=k_{1}+k_{2} \cdot T_{e}+k_{3} \cdot\left(T_{e}^{2}\right)+k_{4} \cdot T_{c}+k_{5} \cdot\left(T_{c}^{2}\right)+k_{6} \cdot T_{e} \cdot T_{c}+k_{7} \cdot\left(\left(T_{e}^{2}\right) \cdot T_{c}\right)+k_{8} \cdot\left(T_{e} \cdot\left(T_{c}^{2}\right)\right)+k_{9} \cdot\left(\left(T_{e}^{2}\right) \cdot\left(T_{c}^{2}\right)\right)$

Capacidade de evaporação ou carga térmica

$\dot{Q}_{e v}=G \cdot\left(T_{w e}-T_{e}\right)$

Capacidade de evaporação

$\dot{Q}_{c d}=\dot{Q}_{e v}+P_{c o m p}$

Taxa de rejeição de calor no condensador

$C O P=\dot{Q}_{e v} / P_{\text {comp }}$

Coeficiente de performance

$P_{\text {comp }}=k_{10}+k_{11} \cdot T_{e}+k_{12} \cdot\left(T_{e}^{2}\right)+k_{13} \cdot T_{c}+k_{14} \cdot\left(T_{c}^{2}\right)+k_{15} \cdot T_{e} \cdot T_{c}+k_{16} \cdot\left(\left(T_{e}^{2}\right) \cdot T_{c}\right)+k_{17} \cdot\left(T_{e} \cdot\left(T_{c}^{2}\right)\right)+k_{18} \cdot\left(\left(T_{e}^{2}\right) \cdot\left(T_{c}^{2}\right)\right)$

Potência do compressor

2.4) Cálculo da recuperação térmica do ERV

$v_{a ; e x t}=\mathrm{v}\left(\right.$ AirH2O; $\left.\mathrm{T}=T_{a ; e x t ; i n} ; \mathrm{w}=w_{a ; e x t ; i n} ; \mathrm{P}=P_{b s b}\right)$

Volume especifico do ar externo

$\dot{m}_{a}=\dot{V}_{a} / 3600 / v_{a ; e x t}$

Vazão mássica do ar externo

$w_{a ; \text { indoor }}=\omega\left(\right.$ AirH $\left.2 O ; \mathrm{T}=T_{a ; \text { indoor }} ; \mathrm{r}=U R_{a ; \text { indoor }} ; \mathrm{P}=P_{b s b}\right)$ 
Umidade absoluta do ar interno

$w_{a ; e x t ; i n}=\omega\left(\operatorname{AirH} 2 O ; \mathrm{T}=T_{a ; e x t ; i n} ; \mathbf{r}=U R_{a ; e x t ; i n} ; \mathrm{P}=P_{b s b}\right)$

Umidade absoluta do ar externo de alimentação

$h_{a ; e x t ; i n}=\mathrm{h}\left(\right.$ AirH $\left.2 O ; \mathrm{T}=T_{a ; e x t ; i n} ; \mathbf{w}=w_{a ; e x t ; i n} ; \mathrm{P}=P_{b s b}\right)$

Entalpia do ar externo de alimentação

$h_{a ; \text { indoor }}=\mathrm{h}\left(\right.$ AirH $\left.2 O ; \mathrm{T}=T_{a ; \text { indoor }} ; \mathrm{r}=U R_{a ; \text { indoor }} ; \mathrm{P}=P_{b s b}\right)$

Entalpia do ar interno do ambiente

$\dot{Q}_{a}=\dot{m}_{a} \cdot\left(h_{a ; \text { ext } ; \text { out }}-h_{a ; \text { indoor }}\right)$

Carga térmica devida ao ar de renovação

$U R_{a ; e x t ; \text { out }}=\phi\left(\right.$ AirH $\left.2 O ; \mathrm{T}=T_{a ; e x t ; o u t} ; \mathrm{w}=w_{a ; e x t ; o u t} ; \mathrm{P}=P_{b s b}\right)$

$C_{p}=\mathrm{c}_{\mathrm{p}}\left(A i r H 2 O ; \mathrm{T}=T_{a ; e x t ; i n} ; \mathrm{w}=w_{a ; e x t ; i n} ; \mathrm{P}=P_{b s b}\right)$

$h_{f g}=\mathrm{h}\left(\right.$ Water $\left.; \mathrm{P}=P_{b s b} ; \mathrm{x}=1\right)-\mathrm{h}\left(\right.$ water $\left.; \mathrm{P}=P_{b s b} ; \mathrm{x}=0\right)$

call $\operatorname{ERV}\left(\right.$ Control $\left._{E R V} ; \dot{m}_{a} ; T_{a ; e x t ; i n} ; w_{a ; e x t ; i n} ; h_{a ; e x t ; i n} ; C_{p} ; h_{f g} ; f_{\text {ocup }} ; P_{b s b} ; \eta_{\text {sen }} ; \eta_{\text {lat }} ; \eta_{\text {total }} ; T_{a ; i n d o o r} ; w_{a ; i n d o o}\right) r$

$\left.T_{a ; e x t ; o u t} ; w_{a ; e x t ; o u t} ; h_{a ; e x t ; o u t} ; \dot{Q}_{E R V ; \text { real }} ; \dot{Q}_{E R V ; l a t ; \max } ; \dot{Q}_{E R V ; \text { sen } ; \text { max }} ; \dot{Q}_{E R V ; \text { max }} ; \dot{Q}_{E R V ; \text { sens }} ; T_{a ; \text { indoor } ; \text { out }} ; w_{a ; \text { indoor } ; \text { out }} ; \dot{Q}_{E R V ; \eta ; \text { total }} ; \dot{Q}_{E R V ; l a t} ; \dot{Q}_{E R V ; s e n s ; \text { cor }}\right)$

2.5) Potência de ventilação

$P_{s}=\frac{\left(\dot{V}_{a} / 3600\right) \cdot \frac{\delta_{P: s}}{\eta_{f}}}{1000}$

Potência de ventilação

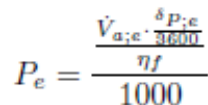

Potência de ventilação

$\dot{V}_{a ; e}=\dot{V}_{a}$

Vazão da corrente de exaustão 


\section{Air System Information}

Air System Name

Equipment Class

Auditório

CW AHU

Air System Type

SZCAV

Sizing Calculation Information

Zone and Space Sizing Method:

Zone L/s

Sum of space airflow rates

Space L/s Individual peak space loads
Number of zones

Floor Area

Location

Brasilia, Brazil

Calculation Months

Sizing Data
Jan to Dec User-Modified

\section{Zone Sizing Data}

\begin{tabular}{|c|c|c|c|c|c|c|c|}
\hline Zone Name & $\begin{array}{r}\text { Maximum } \\
\text { Cooling } \\
\text { Sensible } \\
(k W) \\
\end{array}$ & $\begin{array}{r}\text { Design } \\
\text { Air } \\
\text { Flow } \\
(\mathrm{L} / \mathrm{s})\end{array}$ & $\begin{array}{r}\text { Minimum } \\
\text { Air } \\
\text { Flow } \\
(\mathrm{L} / \mathrm{s}) \\
\end{array}$ & $\begin{array}{r}\text { Time } \\
\text { of } \\
\text { Peak } \\
\text { Load }\end{array}$ & $\begin{array}{r}\text { Maximum } \\
\text { Heating } \\
\text { Load } \\
(\mathrm{kW}) \\
\end{array}$ & $\begin{array}{r}\text { Zone } \\
\text { Floor } \\
\text { Area } \\
\left(\mathrm{m}^{2}\right) \\
\end{array}$ & $\begin{array}{r}\text { Zone } \\
\mathrm{L} /\left(\mathrm{s}-\mathrm{m}^{2}\right)\end{array}$ \\
\hline Zone 1 & 13,7 & 2167 & 2167 & Jan 2000 & 4,5 & 196,0 & 11,05 \\
\hline
\end{tabular}

\section{Zone Terminal Sizing Data}

No Zone Terminal Sizing Data required for this system.

\section{Space Loads and Airflows}

\begin{tabular}{|l|r|r|r|r|r|r|r|}
\hline $\begin{array}{c}\text { Zone Name / } \\
\text { Space Name }\end{array}$ & Mult. & $\begin{array}{r}\text { Cooling } \\
\text { Sensible } \\
\mathbf{( k W )}\end{array}$ & $\begin{array}{r}\text { Time } \\
\text { of } \\
\text { Load }\end{array}$ & $\begin{array}{r}\text { Air } \\
\text { Flow } \\
\mathbf{( L / s )}\end{array}$ & $\begin{array}{r}\text { Heating } \\
\text { Load } \\
(\mathbf{k W})\end{array}$ & $\begin{array}{r}\text { Floor } \\
\text { Area } \\
\left(\mathbf{m}^{2}\right)\end{array}$ & $\begin{array}{r}\text { Space } \\
\mathbf{L} /\left(\mathbf{s}-\mathbf{m}^{2}\right)\end{array}$ \\
\hline Zone 1 & & & & & & \\
\hline Auditório & 1 & 13,7 & Jan 2000 & 1086 & 4,5 & 196,0 & \\
\hline
\end{tabular}


1. Summary

Ventilation Sizing Method

Sum of Space OA Airflows

Design Ventilation Airflow Rate, Corrected for Exhaust Air ……………........ 638 L/s

Design Ventilation Airflow Rate ....................................................... 0 L/s

2. Space Ventilation Analysis Table

\begin{tabular}{|c|c|c|c|c|c|c|c|c|c|}
\hline Zone Name / Space Name & Mult. & $\begin{array}{r}\text { Floor } \\
\text { Area } \\
\left(\mathrm{m}^{2}\right)\end{array}$ & $\begin{array}{r}\text { Maximum } \\
\text { Occupants }\end{array}$ & $\begin{array}{r}\text { Maximum } \\
\text { Supply Air } \\
(\mathrm{L} / \mathbf{s})\end{array}$ & $\begin{array}{r}\text { Required } \\
\text { Outdoor Air } \\
(\mathrm{L} / \mathrm{s} / \text { person) }\end{array}$ & $\begin{array}{r}\text { Required } \\
\text { Outdoor Air } \\
\left(\mathbf{L} /\left(\mathbf{s}-\mathbf{m}^{2}\right)\right) \\
\end{array}$ & $\begin{array}{r}\text { Required } \\
\text { Outdoor Air } \\
(\mathrm{L} / \mathbf{s}) \\
\end{array}$ & $\begin{array}{r}\text { Required } \\
\text { Outdoor Air } \\
(\% \text { of supply })\end{array}$ & $\begin{array}{r}\text { Uncorrected } \\
\text { Outdoor Air } \\
(\mathrm{L} / \mathbf{s})\end{array}$ \\
\hline \multicolumn{10}{|l|}{ Zone 1} \\
\hline Auditório & 1 & 196,0 & 142,0 & 1086,0 & 0,00 & 0,00 & 0,0 & 0,0 & 0,0 \\
\hline Totals (incl. Space Multipliers) & & & & 0,0 & & & & & 0,0 \\
\hline
\end{tabular}




\begin{tabular}{|c|c|c|c|c|c|c|}
\hline & & N COOLIN & & & N HEATINC & \\
\hline & COOLING DATA & Jan 1700 & & HEATING DATA & DS HTG & \\
\hline & COOLING OA D & B $30,4^{\circ} \mathrm{C}$ & & HEATING OA DE & B $8,9^{\circ} \mathrm{C} /$ & \\
\hline ZONE LOADS & Details & $\begin{array}{r}\text { Sensible } \\
\text { (W) }\end{array}$ & $\begin{array}{r}\text { Latent } \\
(W)\end{array}$ & Details & $\begin{array}{r}\text { Sensible } \\
\text { (W) }\end{array}$ & $\begin{array}{r}\text { Latent } \\
\text { (W) }\end{array}$ \\
\hline Window \& Skylight Solar Loads & $0 \mathrm{~m}^{2}$ & 0 & - & $0 \mathrm{~m}^{2}$ & - & - \\
\hline Wall Transmission & $276 \mathrm{~m}^{2}$ & 4541 & - & $276 \mathrm{~m}^{2}$ & 4428 & - \\
\hline Roof Transmission & $0 \mathrm{~m}^{2}$ & 0 & - & $0 \mathrm{~m}^{2}$ & 0 & - \\
\hline Window Transmission & $0 \mathrm{~m}^{2}$ & 0 & - & $0 \mathrm{~m}^{2}$ & 0 & - \\
\hline Skylight Transmission & $0 \mathrm{~m}^{2}$ & 0 & - & $0 \mathrm{~m}^{2}$ & 0 & - \\
\hline Door Loads & $4 \mathrm{~m}^{2}$ & 34 & - & $4 \mathrm{~m}^{2}$ & 83 & - \\
\hline Floor Transmission & $0 \mathrm{~m}^{2}$ & 0 & 4 & $0 \mathrm{~m}^{2}$ & 0 & 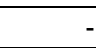 \\
\hline Partitions & $0 \mathrm{~m}^{2}$ & 0 & - & $0 \mathrm{~m}^{2}$ & 0 & - \\
\hline Ceiling & $0 \mathrm{~m}^{2}$ & 0 & - & $0 \mathrm{~m}^{2}$ & 0 & - \\
\hline Overhead Lighting & $6272 \mathrm{~W}$ & 5331 & - & 0 & 0 & - \\
\hline Task Lighting & $0 \mathrm{~W}$ & 0 & - & 0 & 0 & - \\
\hline Electric Equipment & $3000 \mathrm{~W}$ & 2801 & - & 0 & 0 & 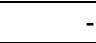 \\
\hline People & 0 & 0 & 0 & 0 & 0 & 0 \\
\hline Infiltration & - & 0 & 0 & - & 0 & 0 \\
\hline \begin{tabular}{|l|} 
Miscellaneous \\
\end{tabular} & - & 0 & 0 & - & 0 & 0 \\
\hline Safety Factor & $0 \% / 0 \%$ & 0 & 0 & $0 \%$ & 0 & 0 \\
\hline >> Total Zone Loads & - & 12707 & 0 & - & 4511 & 0 \\
\hline Zone Conditioning & - & 11957 & 0 & - & 4342 & 0 \\
\hline Plenum Wall Load & $0 \%$ & 0 & - & 0 & 0 & - \\
\hline Plenum Roof Load & $0 \%$ & 0 & & 0 & 0 & - \\
\hline \begin{tabular}{|l|} 
Plenum Lighting Load \\
\end{tabular} & $0 \%$ & 0 & - & 0 & 0 & - \\
\hline Return Fan Load & $2167 \mathrm{~L} / \mathrm{s}$ & 0 & 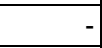 & $2167 \mathrm{~L} / \mathrm{s}$ & 0 & - \\
\hline Ventilation Load & $638 \mathrm{~L} / \mathrm{s}$ & 4241 & 0 & $638 \mathrm{~L} / \mathrm{s}$ & 8236 & 0 \\
\hline Supply Fan Load & $2167 \mathrm{~L} / \mathrm{s}$ & 0 & - & $2167 \mathrm{~L} / \mathrm{s}$ & 0 & - \\
\hline Space Fan Coil Fans & - & 0 & - & - & 0 & - \\
\hline Duct Heat Gain / Loss & $0 \%$ & 0 & 4 & $0 \%$ & 0 & 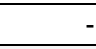 \\
\hline >> Total System Loads & - & 16198 & 0 & - & 12578 & 0 \\
\hline Central Cooling Coil & - & 16198 & 0 & - & 0 & 0 \\
\hline Central Heating Coil & - & 0 & - & - & 12578 & - \\
\hline >> Total Conditioning & - & 16198 & 0 & - & 12578 & 0 \\
\hline Key: & $\begin{array}{l}\text { Positiv } \\
\text { Negativ }\end{array}$ & $\begin{array}{l}\text { ues are clg } \\
\text { ues are ht }\end{array}$ & & $\begin{array}{l}\text { Positiv } \\
\text { Negativ }\end{array}$ & $\begin{array}{l}\text { ues are htg } \\
\text { ues are clg }\end{array}$ & \\
\hline
\end{tabular}




\begin{tabular}{|c|c|c|c|c|c|c|}
\hline \multirow[t]{3}{*}{ Zone 1} & \multicolumn{3}{|c|}{ DESIGN COOLING } & \multicolumn{3}{|c|}{ DESIGN HEATING } \\
\hline & \multicolumn{3}{|c|}{ COOLING DATA AT Jan 2000} & \multicolumn{3}{|c|}{ HEATING DATA AT DES HTG } \\
\hline & COOLING OA D & /B $25,6^{\circ} \mathrm{C}$ & & HEATING OA DI & B $8,9^{\circ} \mathrm{C} /$ & \\
\hline & \multicolumn{3}{|c|}{ OCCUPIED T-STAT $23,9{ }^{\circ} \mathrm{C}$} & \multicolumn{3}{|c|}{ OCCUPIED T-STAT $21,1^{\circ} \mathrm{C}$} \\
\hline ZONE LOADS & Details & $\begin{array}{r}\text { Sensible } \\
\text { (W) }\end{array}$ & $\begin{array}{r}\text { Latent } \\
(\mathrm{W})\end{array}$ & Details & $\begin{array}{r}\text { Sensible } \\
\text { (W) }\end{array}$ & $\begin{array}{r}\text { Latent } \\
\text { (W) }\end{array}$ \\
\hline Window \& Skylight Solar Loads & $0 \mathrm{~m}^{2}$ & 0 & - & $0 \mathrm{~m}^{2}$ & - & - \\
\hline Wall Transmission & $276 \mathrm{~m}^{2}$ & 5335 & - & $276 \mathrm{~m}^{2}$ & 4428 & - \\
\hline Roof Transmission & $0 \mathrm{~m}^{2}$ & 0 & - & $0 \mathrm{~m}^{2}$ & 0 & - \\
\hline Window Transmission & $0 \mathrm{~m}^{2}$ & 0 & & $0 \mathrm{~m}^{2}$ & 0 & \\
\hline Skylight Transmission & $0 \mathrm{~m}^{2}$ & 0 & & $0 \mathrm{~m}^{2}$ & 0 & - \\
\hline Door Loads & $4 \mathrm{~m}^{2}$ & 13 & - & $4 \mathrm{~m}^{2}$ & 83 & - \\
\hline Floor Transmission & $0 \mathrm{~m}^{2}$ & 0 & 1 & $0 \mathrm{~m}^{2}$ & 0 & - \\
\hline Partitions & $0 \mathrm{~m}^{2}$ & 0 & 1 & $0 \mathrm{~m}^{2}$ & 0 & - \\
\hline Ceiling & $0 \mathrm{~m}^{2}$ & 0 & & $0 \mathrm{~m}^{2}$ & 0 & 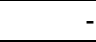 \\
\hline Overhead Lighting & $6272 \mathrm{~W}$ & 5532 & & 0 & 0 & \\
\hline Task Lighting & $0 \mathrm{~W}$ & 0 & & 0 & 0 & - \\
\hline Electric Equipment & $3000 \mathrm{~W}$ & 2843 & - & 0 & 0 & - \\
\hline People & 0 & 0 & 0 & 0 & 0 & 0 \\
\hline \begin{tabular}{|l|} 
Infiltration \\
\end{tabular} & - & 0 & 0 & - & 0 & 0 \\
\hline Miscellaneous & - & 0 & 0 & - & 0 & 0 \\
\hline Safety Factor & $0 \% / 0 \%$ & 0 & 0 & $0 \%$ & 0 & 0 \\
\hline > Total Zone Loads & - & 13724 & 0 & - & 4511 & 0 \\
\hline
\end{tabular}




\begin{tabular}{|c|c|c|c|c|c|c|}
\hline \multicolumn{7}{|l|}{ TABLE 1.1.A. } \\
\hline & \multicolumn{3}{|c|}{ DESIGN COOLING } & \multicolumn{3}{|c|}{ DESIGN HEATING } \\
\hline & \multicolumn{3}{|c|}{ COOLING DATA AT Jan 2000} & \multicolumn{3}{|c|}{ HEATING DATA AT DES HTG } \\
\hline & $\begin{array}{l}\text { COOLING OA D } \\
\text { OCCUPIED T-S } 1\end{array}$ & $\begin{array}{l}\text { /B } 25,6^{\circ} \mathrm{C} \\
23,9^{\circ} \mathrm{C}\end{array}$ & & $\begin{array}{l}\text { HEATING OA D } \\
\text { OCCUPIED T-S }\end{array}$ & $\begin{array}{l}\mathrm{B} 8,9^{\circ} \mathrm{C} / \\
21,1^{\circ} \mathrm{C}\end{array}$ & \\
\hline & & Sensible & Latent & & Sensible & Latent \\
\hline SPACE LOADS & Details & (W) & (W) & Details & (W) & $(W)$ \\
\hline Window \& Skylight Solar Loads & $0 \mathrm{~m}^{2}$ & 0 & - & $0 \mathrm{~m}^{2}$ & - & - \\
\hline Wall Transmission & $276 \mathrm{~m}^{2}$ & 5335 & - & $276 \mathrm{~m}^{2}$ & 4428 & 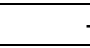 \\
\hline Roof Transmission & $0 \mathrm{~m}^{2}$ & 0 & - & $0 \mathrm{~m}^{2}$ & 0 & - \\
\hline Window Transmission & $0 \mathrm{~m}^{2}$ & 0 & - & $0 \mathrm{~m}^{2}$ & 0 & 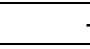 \\
\hline Skylight Transmission & $0 \mathrm{~m}^{2}$ & 0 & - & $0 \mathrm{~m}^{2}$ & 0 & 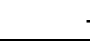 \\
\hline Door Loads & $4 \mathrm{~m}^{2}$ & 13 & - & $4 \mathrm{~m}^{2}$ & 83 & - \\
\hline Floor Transmission & $0 \mathrm{~m}^{2}$ & 0 & - & $0 \mathrm{~m}^{2}$ & 0 & - \\
\hline \begin{tabular}{|l|} 
Partitions \\
\end{tabular} & $0 \mathrm{~m}^{2}$ & 0 & - & $0 \mathrm{~m}^{2}$ & 0 & - \\
\hline Ceiling & $0 \mathrm{~m}^{2}$ & 0 & - & $0 \mathrm{~m}^{2}$ & 0 & . \\
\hline Overhead Lighting & $6272 \mathrm{~W}$ & 5532 & - & 0 & 0 & 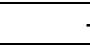 \\
\hline Task Lighting & $0 \mathrm{~W}$ & 0 & - & 0 & 0 & - \\
\hline Electric Equipment & $3000 \mathrm{~W}$ & 2843 & & 0 & 0 & \\
\hline People & 0 & 0 & 0 & 0 & 0 & 0 \\
\hline Infiltration & - & 0 & 0 & - & 0 & 0 \\
\hline Miscellaneous & - & 0 & 0 & - & 0 & 0 \\
\hline Safety Factor & $0 \% / 0 \%$ & 0 & 0 & $0 \%$ & 0 & 0 \\
\hline >> Total Zone Loads & - & 13724 & 0 & - & 4511 & 0 \\
\hline
\end{tabular}

\begin{tabular}{|c|c|c|c|c|c|c|}
\hline & ENVELOPE LOA & OR SPACE " & uditório & IONE "Zo & & \\
\hline & & & & COOLING & COOLING & HEATING \\
\hline & Area & U-Value & Shade & TRANS & SOLAR & TRANS \\
\hline & $\left(m^{2}\right)$ & $\left(W /\left(m^{2}-^{\circ} K\right)\right)$ & Coeff. & (W) & (W) & (W) \\
\hline \multicolumn{7}{|l|}{ N EXPOSURE } \\
\hline WALL & 66 & 1,280 & & 691 & - & 1033 \\
\hline DOOR & 4 & 1,703 & & 13 & - & 83 \\
\hline \multicolumn{7}{|l|}{ E EXPOSURE } \\
\hline WALL & 70 & 1,280 & - & 1301 & - & 1095 \\
\hline \multicolumn{7}{|l|}{ S EXPOSURE } \\
\hline WALL & 70 & 1,409 & & 1354 & - & 1205 \\
\hline \multicolumn{7}{|l|}{ W EXPOSURE } \\
\hline WALL & 70 & 1,280 & & 1988 & -1 & 1095 \\
\hline
\end{tabular}




\begin{tabular}{|c|c|c|c|c|c|c|c|c|c|c|}
\hline \multicolumn{11}{|c|}{ DESIGN MONTH: JANUARY } \\
\hline Hour & $\begin{array}{r}\text { OA } \\
\text { TEMP } \\
\left({ }^{\circ} \mathbf{C}\right) \\
\end{array}$ & $\begin{array}{r}\text { SUPPLY } \\
\text { AIRFLOW } \\
(\mathrm{L} / \mathbf{s}) \\
\end{array}$ & $\begin{array}{r}\text { CENTRAL } \\
\text { COOLING } \\
\text { SENSIBLE } \\
(\mathrm{kW}) \\
\end{array}$ & $\begin{array}{r}\text { CENTRAL } \\
\text { COOLING } \\
\text { TOTAL } \\
(\mathrm{kW}) \\
\end{array}$ & $\begin{array}{r}\text { CENTRAL } \\
\text { HEATING } \\
\text { COIL } \\
(\mathrm{kW}) \\
\end{array}$ & $\begin{array}{r}\text { PRECOOL } \\
\text { COIL } \\
(\mathrm{kW}) \\
\end{array}$ & $\begin{array}{r}\text { PREHEAT } \\
\text { COIL } \\
(\mathrm{kW}) \\
\end{array}$ & $\begin{array}{r}\text { TERMINAL } \\
\text { COOLING } \\
(\mathrm{kW})\end{array}$ & $\begin{array}{r}\text { TERMINAL } \\
\text { HEATING } \\
(\mathbf{k W})\end{array}$ & $\begin{array}{r}\text { ZONE } \\
\text { HEATING } \\
\text { UNIT } \\
(\mathrm{kW})\end{array}$ \\
\hline 0000 & 21,0 & 2167 & 5,2 & 5,2 & 0,0 & 0,0 & 0,0 & 0,0 & 0,0 & 0,0 \\
\hline 0100 & 20,4 & 2167 & 5,2 & 5,2 & 0,0 & 0,0 & 0,0 & 0,0 & 0,0 & 0,0 \\
\hline 0200 & 19,7 & 2167 & 4,4 & 4,4 & 0,0 & 0,0 & 0,0 & 0,0 & 0,0 & 0,0 \\
\hline 0300 & 19,2 & 2167 & 3,8 & 3,8 & 0,0 & 0,0 & 0,0 & 0,0 & 0,0 & 0,0 \\
\hline 0400 & 18,8 & 2167 & 3,3 & 3,3 & 0,0 & 0,0 & 0,0 & 0,0 & 0,0 & 0,0 \\
\hline 0500 & 18,7 & 2167 & 2,8 & 2,8 & 0,0 & 0,0 & 0,0 & 0,0 & 0,0 & 0,0 \\
\hline 0600 & 18,9 & 2167 & 2,8 & 2,8 & 0,0 & 0,0 & 0,0 & 0,0 & 0,0 & 0,0 \\
\hline 0700 & 19,6 & 2167 & 1,5 & 1,5 & 0,0 & 0,0 & 0,0 & 0,0 & 0,0 & 0,0 \\
\hline 0800 & 20,7 & 2167 & 4,5 & 4,5 & 0,0 & 0,0 & 0,0 & 0,0 & 0,0 & 0,0 \\
\hline 0900 & 22,4 & 2167 & 6,3 & 6,3 & 0,0 & 0,0 & 0,0 & 0,0 & 0,0 & 0,0 \\
\hline 1000 & 24,4 & 2167 & 7,8 & 7,8 & 0,0 & 0,0 & 0,0 & 0,0 & 0,0 & 0,0 \\
\hline 1100 & 26,6 & 2167 & 10,0 & 10,0 & 0,0 & 0,0 & 0,0 & 0,0 & 0,0 & 0,0 \\
\hline 1200 & 28,7 & 2167 & 11,5 & 11,5 & 0,0 & 0,0 & 0,0 & 0,0 & 0,0 & 0,0 \\
\hline 1300 & 30,2 & 2167 & 13,8 & 13,8 & 0,0 & 0,0 & 0,0 & 0,0 & 0,0 & 0,0 \\
\hline 1400 & 31,3 & 2167 & 14,6 & 14,6 & 0,0 & 0,0 & 0,0 & 0,0 & 0,0 & 0,0 \\
\hline 1500 & 31,7 & 2167 & 15,9 & 15,9 & 0,0 & 0,0 & 0,0 & 0,0 & 0,0 & 0,0 \\
\hline 1600 & 31,3 & 2167 & 15,6 & 15,6 & 0,0 & 0,0 & 0,0 & 0,0 & 0,0 & 0,0 \\
\hline 1700 & 30,4 & 2167 & 16,2 & 16,2 & 0,0 & 0,0 & 0,0 & 0,0 & 0,0 & 0,0 \\
\hline 1800 & 28,9 & 2167 & 15,0 & 15,0 & 0,0 & 0,0 & 0,0 & 0,0 & 0,0 & 0,0 \\
\hline 1900 & 27,2 & 2167 & 14,4 & 14,4 & 0,0 & 0,0 & 0,0 & 0,0 & 0,0 & 0,0 \\
\hline 2000 & 25,6 & 2167 & 13,4 & 13,4 & 0,0 & 0,0 & 0,0 & 0,0 & 0,0 & 0,0 \\
\hline 2100 & 24,1 & 2167 & 7,3 & 7,3 & 0,0 & 0,0 & 0,0 & 0,0 & 0,0 & 0,0 \\
\hline 2200 & 22,8 & 2167 & 6,6 & 6,6 & 0,0 & 0,0 & 0,0 & 0,0 & 0,0 & 0,0 \\
\hline 2300 & 21,8 & 2167 & 6,6 & 6,6 & 0,0 & 0,0 & 0,0 & 0,0 & 0,0 & 0,0 \\
\hline
\end{tabular}

\begin{tabular}{|c|c|c|c|c|c|c|c|c|c|c|}
\hline \multicolumn{11}{|c|}{ DESIGN MONTH: FEBRUARY } \\
\hline Hour & $\begin{array}{r}\text { OA } \\
\text { TEMP } \\
\left({ }^{\circ} \mathbf{C}\right)\end{array}$ & $\begin{array}{r}\text { SUPPLY } \\
\text { AIRFLOW } \\
(\mathrm{L} / \mathrm{s})\end{array}$ & $\begin{array}{r}\text { CENTRAL } \\
\text { COOLING } \\
\text { SENSIBLE } \\
(\mathrm{kW})\end{array}$ & $\begin{array}{r}\text { CENTRAL } \\
\text { COOLING } \\
\text { TOTAL } \\
(\mathrm{kW})\end{array}$ & $\begin{array}{r}\text { CENTRAL } \\
\text { HEATING } \\
\text { COIL } \\
(\mathrm{kW})\end{array}$ & $\begin{array}{r}\text { PRECOOL } \\
\text { COIL } \\
(\mathrm{kW})\end{array}$ & $\begin{array}{r}\text { PREHEAT } \\
\text { COIL } \\
(\mathrm{kW})\end{array}$ & $\begin{array}{r}\text { TERMINAL } \\
\text { COOLING } \\
(\mathrm{kW})\end{array}$ & $\begin{array}{r}\text { TERMINAL } \\
\text { HEATING } \\
(\mathbf{k W})\end{array}$ & $\begin{array}{r}\text { ZONE } \\
\text { HEATING } \\
\text { UNIT } \\
(\mathrm{kW})\end{array}$ \\
\hline 0000 & 21,0 & 2167 & 5,4 & 5,4 & 0,0 & 0,0 & 0,0 & 0,0 & 0,0 & 0,0 \\
\hline 0100 & 20,4 & 2167 & 4,1 & 4,1 & 0,0 & 0,0 & 0,0 & 0,0 & 0,0 & 0,0 \\
\hline 0200 & \begin{tabular}{|c|}
19,7 \\
\end{tabular} & 2167 & 4,0 & 4,0 & 0,0 & 0,0 & 0,0 & 0,0 & 0,0 & 0,0 \\
\hline 0300 & 19,2 & 2167 & 3,3 & 3,3 & 0,0 & 0,0 & 0,0 & 0,0 & 0,0 & 0,0 \\
\hline 0400 & 18,8 & 2167 & 2,9 & 2,9 & 0,0 & 0,0 & 0,0 & 0,0 & 0,0 & 0,0 \\
\hline 0500 & 18,7 & 2167 & 2,4 & 2,4 & 0,0 & 0,0 & 0,0 & 0,0 & 0,0 & 0,0 \\
\hline 0600 & 18,9 & 2167 & 2,4 & 2,4 & 0,0 & 0,0 & 0,0 & 0,0 & 0,0 & 0,0 \\
\hline 0700 & 19,6 & 2167 & 1,7 & 1,7 & 0,0 & 0,0 & 0,0 & 0,0 & 0,0 & 0,0 \\
\hline 0800 & 20,7 & 2167 & 4,0 & 4,0 & 0,0 & 0,0 & 0,0 & 0,0 & 0,0 & 0,0 \\
\hline 0900 & 22,4 & 2167 & 6,1 & 6,1 & 0,0 & 0,0 & 0,0 & 0,0 & 0,0 & 0,0 \\
\hline 1000 & 24,4 & 2167 & 7,5 & 7,5 & 0,0 & 0,0 & 0,0 & 0,0 & 0,0 & 0,0 \\
\hline 1100 & 26,6 & 2167 & 10,1 & 10,1 & 0,0 & 0,0 & 0,0 & 0,0 & 0,0 & 0,0 \\
\hline 1200 & 28,7 & 2167 & 11,4 & 11,4 & 0,0 & 0,0 & 0,0 & 0,0 & 0,0 & 0,0 \\
\hline 1300 & 30,2 & 2167 & 13,6 & 13,6 & 0,0 & 0,0 & 0,0 & 0,0 & 0,0 & 0,0 \\
\hline 1400 & 31,3 & 2167 & 14,2 & 14,2 & 0,0 & 0,0 & 0,0 & 0,0 & 0,0 & 0,0 \\
\hline 1500 & 31,7 & 2167 & 15,5 & 15,5 & 0,0 & 0,0 & 0,0 & 0,0 & 0,0 & 0,0 \\
\hline 1600 & 31,3 & 2167 & 15,2 & 15,2 & 0,0 & 0,0 & 0,0 & 0,0 & 0,0 & 0,0 \\
\hline 1700 & 30,4 & 2167 & 15,8 & 15,8 & 0,0 & 0,0 & 0,0 & 0,0 & 0,0 & 0,0 \\
\hline 1800 & 28,9 & 2167 & 14,7 & 14,7 & 0,0 & 0,0 & 0,0 & 0,0 & 0,0 & 0,0 \\
\hline 1900 & 27,2 & 2167 & 14,2 & 14,2 & 0,0 & 0,0 & 0,0 & 0,0 & 0,0 & 0,0 \\
\hline 2000 & 25,6 & 2167 & 12,3 & 12,3 & 0,0 & 0,0 & 0,0 & 0,0 & 0,0 & 0,0 \\
\hline 2100 & 24,1 & 2167 & 6,7 & 6,7 & 0,0 & 0,0 & 0,0 & 0,0 & 0,0 & 0,0 \\
\hline 2200 & 22,8 & 2167 & 5,5 & 5,5 & 0,0 & 0,0 & 0,0 & 0,0 & 0,0 & 0,0 \\
\hline 2300 & 21,8 & 2167 & 5,5 & 5,5 & 0,0 & 0,0 & 0,0 & 0,0 & 0,0 & 0,0 \\
\hline
\end{tabular}




\begin{tabular}{|c|c|c|c|c|c|c|c|c|c|c|}
\hline \multicolumn{11}{|c|}{ DESIGN MONTH: MARCH } \\
\hline Hour & $\begin{array}{r}\text { OA } \\
\text { TEMP } \\
\left({ }^{\circ} \mathrm{C}\right)\end{array}$ & $\begin{array}{r}\text { SUPPLY } \\
\text { AIRFLOW } \\
(\mathrm{L} / \mathbf{s})\end{array}$ & $\begin{array}{r}\text { CENTRAL } \\
\text { COOLING } \\
\text { SENSIBLE } \\
(\mathbf{k W})\end{array}$ & $\begin{array}{r}\text { CENTRAL } \\
\text { COOLING } \\
\text { TOTAL } \\
(\mathrm{kW}) \\
\end{array}$ & $\begin{array}{r}\text { CENTRAL } \\
\text { HEATING } \\
\text { COIL } \\
(\mathrm{kW})\end{array}$ & $\begin{array}{r}\text { PRECOOL } \\
\text { COIL } \\
(\mathrm{kW})\end{array}$ & $\begin{array}{r}\text { PREHEAT } \\
\text { COIL } \\
(\mathrm{kW})\end{array}$ & $\begin{array}{r}\text { TERMINAL } \\
\text { COOLING } \\
(\mathrm{kW})\end{array}$ & $\begin{array}{r}\text { TERMINAL } \\
\text { HEATING } \\
(\mathbf{k W})\end{array}$ & $\begin{array}{r}\text { ZONE } \\
\text { HEATING } \\
\text { UNIT } \\
(\mathrm{kW})\end{array}$ \\
\hline 0000 & 19,9 & 2167 & 4,1 & 4,1 & 0,0 & 0,0 & 0,0 & 0,0 & 0,0 & 0,0 \\
\hline 0100 & 19,2 & 2167 & 3,6 & 3,6 & 0,0 & 0,0 & 0,0 & 0,0 & 0,0 & 0,0 \\
\hline 0200 & 18,6 & 2167 & 3,5 & 3,5 & 0,0 & 0,0 & 0,0 & 0,0 & 0,0 & 0,0 \\
\hline 0300 & 18,1 & 2167 & 2,6 & 2,6 & 0,0 & 0,0 & 0,0 & 0,0 & 0,0 & 0,0 \\
\hline 0400 & 17,7 & 2167 & 2,4 & 2,4 & 0,0 & 0,0 & 0,0 & 0,0 & 0,0 & 0,0 \\
\hline 0500 & 17,6 & 2167 & 2,3 & 2,3 & 0,0 & 0,0 & 0,0 & 0,0 & 0,0 & 0,0 \\
\hline 0600 & 17,8 & 2167 & 1,9 & 1,9 & 0,0 & 0,0 & 0,0 & 0,0 & 0,0 & 0,0 \\
\hline 0700 & 18,5 & 2167 & 1,4 & 1,4 & 0,0 & 0,0 & 0,0 & 0,0 & 0,0 & 0,0 \\
\hline 0800 & 19,6 & 2167 & 3,2 & 3,2 & 0,0 & 0,0 & 0,0 & 0,0 & 0,0 & 0,0 \\
\hline 0900 & 21,3 & 2167 & 5,2 & 5,2 & 0,0 & 0,0 & 0,0 & 0,0 & 0,0 & 0,0 \\
\hline 1000 & 23,3 & 2167 & 6,3 & 6,3 & 0,0 & 0,0 & 0,0 & 0,0 & 0,0 & 0,0 \\
\hline 1100 & 25,5 & 2167 & 8,5 & 8,5 & 0,0 & 0,0 & 0,0 & 0,0 & 0,0 & 0,0 \\
\hline 1200 & 27,6 & 2167 & 10,0 & 10,0 & 0,0 & 0,0 & 0,0 & 0,0 & 0,0 & 0,0 \\
\hline 1300 & 29,1 & 2167 & 12,3 & 12,3 & 0,0 & 0,0 & 0,0 & 0,0 & 0,0 & 0,0 \\
\hline 1400 & 30,2 & 2167 & 13,2 & 13,2 & 0,0 & 0,0 & 0,0 & 0,0 & 0,0 & 0,0 \\
\hline 1500 & 30,6 & 2167 & 14,6 & 14,6 & 0,0 & 0,0 & 0,0 & 0,0 & 0,0 & 0,0 \\
\hline 1600 & 30,2 & 2167 & 14,3 & 14,3 & 0,0 & 0,0 & 0,0 & 0,0 & 0,0 & 0,0 \\
\hline 1700 & 29,3 & 2167 & 14,9 & 14,9 & 0,0 & 0,0 & 0,0 & 0,0 & 0,0 & 0,0 \\
\hline 1800 & 27,8 & 2167 & 13,7 & 13,7 & 0,0 & 0,0 & 0,0 & 0,0 & 0,0 & 0,0 \\
\hline 1900 & 26,1 & 2167 & 13,5 & 13,5 & 0,0 & 0,0 & 0,0 & 0,0 & 0,0 & 0,0 \\
\hline 2000 & 24,4 & 2167 & 11,7 & 11,7 & 0,0 & 0,0 & 0,0 & 0,0 & 0,0 & 0,0 \\
\hline 2100 & 23,0 & 2167 & 6,3 & 6,3 & 0,0 & 0,0 & 0,0 & 0,0 & 0,0 & 0,0 \\
\hline 2200 & 21,7 & 2167 & 5,7 & 5,7 & 0,0 & 0,0 & 0,0 & 0,0 & 0,0 & 0,0 \\
\hline 2300 & 20,7 & 2167 & 4,7 & 4,7 & 0,0 & 0,0 & 0,0 & 0,0 & 0,0 & 0,0 \\
\hline
\end{tabular}

\begin{tabular}{|c|c|c|c|c|c|c|c|c|c|c|}
\hline \multicolumn{11}{|c|}{ DESIGN MONTH: APRIL } \\
\hline Hour & $\begin{array}{r}\text { OA } \\
\text { TEMP } \\
\left({ }^{\circ} \mathbf{C}\right)\end{array}$ & $\begin{array}{r}\text { SUPPLY } \\
\text { AIRFLOW } \\
(\mathrm{L} / \mathrm{s})\end{array}$ & $\begin{array}{r}\text { CENTRAL } \\
\text { COOLING } \\
\text { SENSIBLE } \\
(\mathrm{kW})\end{array}$ & $\begin{array}{r}\text { CENTRAL } \\
\text { COOLING } \\
\text { TOTAL } \\
(\mathrm{kW})\end{array}$ & $\begin{array}{r}\text { CENTRAL } \\
\text { HEATING } \\
\text { COIL } \\
(\mathrm{kW})\end{array}$ & $\begin{array}{r}\text { PRECOOL } \\
\text { COIL } \\
(\mathrm{kW})\end{array}$ & $\begin{array}{r}\text { PREHEAT } \\
\text { COIL } \\
(\mathrm{kW})\end{array}$ & $\begin{array}{r}\text { TERMINAL } \\
\text { COOLING } \\
(\mathrm{kW})\end{array}$ & $\begin{array}{r}\text { TERMINAL } \\
\text { HEATING } \\
(\mathbf{k W})\end{array}$ & $\begin{array}{r}\text { ZONE } \\
\text { HEATING } \\
\text { UNIT } \\
(\mathrm{kW})\end{array}$ \\
\hline 0000 & 18,8 & 2167 & 3,8 & 3,8 & 0,0 & 0,0 & 0,0 & 0,0 & 0,0 & 0,0 \\
\hline 0100 & 18,1 & 2167 & 3,6 & 3,6 & 0,0 & 0,0 & 0,0 & 0,0 & 0,0 & 0,0 \\
\hline 0200 & 17,5 & 2167 & 3,1 & 3,1 & 0,0 & 0,0 & 0,0 & 0,0 & 0,0 & 0,0 \\
\hline 0300 & 17,0 & 2167 & 2,6 & 2,6 & 0,0 & 0,0 & 0,0 & 0,0 & 0,0 & 0,0 \\
\hline 0400 & 16,6 & 2167 & 1,7 & 1,7 & 0,0 & 0,0 & 0,0 & 0,0 & 0,0 & 0,0 \\
\hline 0500 & 16,4 & 2167 & 1,3 & 1,3 & 0,0 & 0,0 & 0,0 & 0,0 & 0,0 & 0,0 \\
\hline 0600 & 16,7 & 2167 & 1,8 & 1,8 & 0,0 & 0,0 & 0,0 & 0,0 & 0,0 & 0,0 \\
\hline 0700 & 17,4 & 2167 & 0,6 & 0,6 & 0,0 & 0,0 & 0,0 & 0,0 & 0,0 & 0,0 \\
\hline 0800 & 18,5 & 2167 & 2,1 & 2,1 & 0,0 & 0,0 & 0,0 & 0,0 & 0,0 & 0,0 \\
\hline 0900 & 20,2 & 2167 & 4,0 & 4,0 & 0,0 & 0,0 & 0,0 & 0,0 & 0,0 & 0,0 \\
\hline 1000 & 22,2 & 2167 & 4,7 & 4,7 & 0,0 & 0,0 & 0,0 & 0,0 & 0,0 & 0,0 \\
\hline 1100 & 24,4 & 2167 & 7,3 & 7,3 & 0,0 & 0,0 & 0,0 & 0,0 & 0,0 & 0,0 \\
\hline 1200 & 26,5 & 2167 & 9,4 & 9,4 & 0,0 & 0,0 & 0,0 & 0,0 & 0,0 & 0,0 \\
\hline 1300 & 28,0 & 2167 & 10,5 & 10,5 & 0,0 & 0,0 & 0,0 & 0,0 & 0,0 & 0,0 \\
\hline 1400 & 29,1 & 2167 & 12,6 & 12,6 & 0,0 & 0,0 & 0,0 & 0,0 & 0,0 & 0,0 \\
\hline 1500 & 29,4 & 2167 & 12,9 & 12,9 & 0,0 & 0,0 & 0,0 & 0,0 & 0,0 & 0,0 \\
\hline 1600 & 29,1 & 2167 & 13,4 & 13,4 & 0,0 & 0,0 & 0,0 & 0,0 & 0,0 & 0,0 \\
\hline 1700 & 28,1 & 2167 & 12,9 & 12,9 & 0,0 & 0,0 & 0,0 & 0,0 & 0,0 & 0,0 \\
\hline 1800 & 26,7 & 2167 & 13,1 & 13,1 & 0,0 & 0,0 & 0,0 & 0,0 & 0,0 & 0,0 \\
\hline 1900 & 25,0 & 2167 & 11,7 & 11,7 & 0,0 & 0,0 & 0,0 & 0,0 & 0,0 & 0,0 \\
\hline 2000 & 23,3 & 2167 & 10,6 & 10,6 & 0,0 & 0,0 & 0,0 & 0,0 & 0,0 & 0,0 \\
\hline 2100 & 21,9 & 2167 & 5,9 & 5,9 & 0,0 & 0,0 & 0,0 & 0,0 & 0,0 & 0,0 \\
\hline 2200 & 20,6 & 2167 & 4,9 & 4,9 & 0,0 & 0,0 & 0,0 & 0,0 & 0,0 & 0,0 \\
\hline 2300 & 19,6 & 2167 & 4,9 & 4,9 & 0,0 & 0,0 & 0,0 & 0,0 & 0,0 & 0,0 \\
\hline
\end{tabular}




\begin{tabular}{|c|c|c|c|c|c|c|c|c|c|c|}
\hline \multicolumn{11}{|c|}{ DESIGN MONTH: MAY } \\
\hline Hour & $\begin{array}{r}\text { OA } \\
\text { TEMP } \\
\left({ }^{\circ} \mathrm{C}\right)\end{array}$ & $\begin{array}{r}\text { SUPPLY } \\
\text { AIRFLOW } \\
(\mathrm{L} / \mathbf{s})\end{array}$ & $\begin{array}{r}\text { CENTRAL } \\
\text { COOLING } \\
\text { SENSIBLE } \\
(\mathbf{k W})\end{array}$ & $\begin{array}{r}\text { CENTRAL } \\
\text { COOLING } \\
\text { TOTAL } \\
(\mathrm{kW}) \\
\end{array}$ & $\begin{array}{r}\text { CENTRAL } \\
\text { HEATING } \\
\text { COIL } \\
(\mathrm{kW})\end{array}$ & $\begin{array}{r}\text { PRECOOL } \\
\text { COIL } \\
(\mathrm{kW})\end{array}$ & $\begin{array}{r}\text { PREHEAT } \\
\text { COIL } \\
(\mathrm{kW})\end{array}$ & $\begin{array}{r}\text { TERMINAL } \\
\text { COOLING } \\
(\mathrm{kW})\end{array}$ & $\begin{array}{r}\text { TERMINAL } \\
\text { HEATING } \\
(\mathbf{k W})\end{array}$ & $\begin{array}{r}\text { ZONE } \\
\text { HEATING } \\
\text { UNIT } \\
(\mathrm{kW})\end{array}$ \\
\hline 0000 & 17,1 & 2167 & 3,9 & 3,9 & 0,0 & 0,0 & 0,0 & 0,0 & 0,0 & 0,0 \\
\hline 0100 & 16,5 & 2167 & 3,1 & 3,1 & 0,0 & 0,0 & 0,0 & 0,0 & 0,0 & 0,0 \\
\hline 0200 & 15,8 & 2167 & 2,6 & 2,6 & 0,0 & 0,0 & 0,0 & 0,0 & 0,0 & 0,0 \\
\hline 0300 & 15,3 & 2167 & 2,1 & 2,1 & 0,0 & 0,0 & 0,0 & 0,0 & 0,0 & 0,0 \\
\hline 0400 & 14,9 & 2167 & 1,8 & 1,8 & 0,0 & 0,0 & 0,0 & 0,0 & 0,0 & 0,0 \\
\hline 0500 & 14,8 & 2167 & 0,5 & 0,5 & 0,0 & 0,0 & 0,0 & 0,0 & 0,0 & 0,0 \\
\hline 0600 & 15,0 & 2167 & 0,3 & 0,3 & 0,0 & 0,0 & 0,0 & 0,0 & 0,0 & 0,0 \\
\hline 0700 & 15,7 & 2167 & 0,2 & 0,2 & 0,0 & 0,0 & 0,0 & 0,0 & 0,0 & 0,0 \\
\hline 0800 & 16,9 & 2167 & 0,7 & 0,7 & 0,0 & 0,0 & 0,0 & 0,0 & 0,0 & 0,0 \\
\hline 0900 & 18,5 & 2167 & 1,2 & 1,2 & 0,0 & 0,0 & 0,0 & 0,0 & 0,0 & 0,0 \\
\hline 1000 & 20,5 & 2167 & 3,0 & 3,0 & 0,0 & 0,0 & 0,0 & 0,0 & 0,0 & 0,0 \\
\hline 1100 & 22,7 & 2167 & 5,5 & 5,5 & 0,0 & 0,0 & 0,0 & 0,0 & 0,0 & 0,0 \\
\hline 1200 & 24,8 & 2167 & 8,2 & 8,2 & 0,0 & 0,0 & 0,0 & 0,0 & 0,0 & 0,0 \\
\hline 1300 & 26,3 & 2167 & 9,1 & 9,1 & 0,0 & 0,0 & 0,0 & 0,0 & 0,0 & 0,0 \\
\hline 1400 & 27,4 & 2167 & 10,5 & 10,5 & 0,0 & 0,0 & 0,0 & 0,0 & 0,0 & 0,0 \\
\hline 1500 & 27,8 & 2167 & 10,9 & 10,9 & 0,0 & 0,0 & 0,0 & 0,0 & 0,0 & 0,0 \\
\hline 1600 & 27,4 & 2167 & 11,9 & 11,9 & 0,0 & 0,0 & 0,0 & 0,0 & 0,0 & 0,0 \\
\hline 1700 & 26,5 & 2167 & 11,5 & 11,5 & 0,0 & 0,0 & 0,0 & 0,0 & 0,0 & 0,0 \\
\hline 1800 & 25,0 & 2167 & 11,4 & 11,4 & 0,0 & 0,0 & 0,0 & 0,0 & 0,0 & 0,0 \\
\hline 1900 & 23,4 & 2167 & 9,9 & 9,9 & 0,0 & 0,0 & 0,0 & 0,0 & 0,0 & 0,0 \\
\hline 2000 & 21,7 & 2167 & 8,3 & 8,3 & 0,0 & 0,0 & 0,0 & 0,0 & 0,0 & 0,0 \\
\hline 2100 & 20,2 & 2167 & 5,6 & 5,6 & 0,0 & 0,0 & 0,0 & 0,0 & 0,0 & 0,0 \\
\hline 2200 & 18,9 & 2167 & 4,2 & 4,2 & 0,0 & 0,0 & 0,0 & 0,0 & 0,0 & 0,0 \\
\hline 2300 & 17,9 & 2167 & 4,4 & 4,4 & 0,0 & 0,0 & 0,0 & 0,0 & 0,0 & 0,0 \\
\hline
\end{tabular}

\begin{tabular}{|c|c|c|c|c|c|c|c|c|c|c|}
\hline \multicolumn{11}{|c|}{ DESIGN MONTH: JUNE } \\
\hline Hour & $\begin{array}{r}\text { OA } \\
\text { TEMP } \\
\left({ }^{\circ} \mathbf{C}\right)\end{array}$ & $\begin{array}{r}\text { SUPPLY } \\
\text { AIRFLOW } \\
(\mathrm{L} / \mathrm{s})\end{array}$ & $\begin{array}{r}\text { CENTRAL } \\
\text { COOLING } \\
\text { SENSIBLE } \\
(\mathrm{kW})\end{array}$ & $\begin{array}{r}\text { CENTRAL } \\
\text { COOLING } \\
\text { TOTAL } \\
(\mathbf{k W})\end{array}$ & $\begin{array}{r}\text { CENTRAL } \\
\text { HEATING } \\
\text { COIL } \\
(\mathrm{kW})\end{array}$ & $\begin{array}{r}\text { PRECOOL } \\
\text { COIL } \\
(k W)\end{array}$ & $\begin{array}{r}\text { PREHEAT } \\
\text { COIL } \\
(\mathrm{kW})\end{array}$ & $\begin{array}{r}\text { TERMINAL } \\
\text { COOLING } \\
(\mathrm{kW})\end{array}$ & $\begin{array}{r}\text { TERMINAL } \\
\text { HEATING } \\
(\mathbf{k W})\end{array}$ & $\begin{array}{r}\text { ZONE } \\
\text { HEATING } \\
\text { UNIT } \\
\text { (kW) }\end{array}$ \\
\hline 0000 & 16,0 & 2167 & 2,8 & 2,8 & 0,0 & 0,0 & 0,0 & 0,0 & 0,0 & 0,0 \\
\hline 0100 & 15,4 & 2167 & 2,7 & 2,7 & 0,0 & 0,0 & 0,0 & 0,0 & 0,0 & 0,0 \\
\hline 0200 & 14,7 & 2167 & 2,1 & 2,1 & 0,0 & 0,0 & 0,0 & 0,0 & 0,0 & 0,0 \\
\hline 0300 & 14,2 & 2167 & 1,2 & 1,2 & 0,0 & 0,0 & 0,0 & 0,0 & 0,0 & 0,0 \\
\hline 0400 & 13,8 & 2167 & 1,6 & 1,6 & 0,0 & 0,0 & 0,0 & 0,0 & 0,0 & 0,0 \\
\hline 0500 & 13,7 & 2167 & 0,7 & 0,7 & 0,0 & 0,0 & 0,0 & 0,0 & 0,0 & 0,0 \\
\hline 0600 & 13,9 & 2167 & 0,6 & 0,6 & 0,0 & 0,0 & 0,0 & 0,0 & 0,0 & 0,0 \\
\hline 0700 & 14,6 & 2167 & 0,0 & 0,0 & 0,0 & 0,0 & 0,0 & 0,0 & 0,0 & 0,0 \\
\hline 0800 & 15,7 & 2167 & 0,0 & 0,0 & 0,0 & 0,0 & 0,0 & 0,0 & 0,0 & 0,0 \\
\hline 0900 & 17,4 & 2167 & 0,9 & 0,9 & 0,0 & 0,0 & 0,0 & 0,0 & 0,0 & 0,0 \\
\hline 1000 & 19,4 & 2167 & 2,2 & 2,2 & 0,0 & 0,0 & 0,0 & 0,0 & 0,0 & 0,0 \\
\hline 1100 & 21,6 & 2167 & 4,4 & 4,4 & 0,0 & 0,0 & 0,0 & 0,0 & 0,0 & 0,0 \\
\hline 1200 & 23,7 & 2167 & 5,9 & 5,9 & 0,0 & 0,0 & 0,0 & 0,0 & 0,0 & 0,0 \\
\hline 1300 & 25,2 & 2167 & 8,3 & 8,3 & 0,0 & 0,0 & 0,0 & 0,0 & 0,0 & 0,0 \\
\hline 1400 & 26,3 & 2167 & 9,2 & 9,2 & 0,0 & 0,0 & 0,0 & 0,0 & 0,0 & 0,0 \\
\hline 1500 & 26,7 & 2167 & 10,2 & 10,2 & 0,0 & 0,0 & 0,0 & 0,0 & 0,0 & 0,0 \\
\hline 1600 & 26,3 & 2167 & 10,0 & 10,0 & 0,0 & 0,0 & 0,0 & 0,0 & 0,0 & 0,0 \\
\hline 1700 & 25,4 & 2167 & \begin{tabular}{|c|}
10,7 \\
\end{tabular} & 10,7 & 0,0 & 0,0 & 0,0 & 0,0 & 0,0 & 0,0 \\
\hline 1800 & 23,9 & 2167 & 9,7 & 9,7 & 0,0 & 0,0 & 0,0 & 0,0 & 0,0 & 0,0 \\
\hline 1900 & 22,2 & 2167 & 8,7 & 8,7 & 0,0 & 0,0 & 0,0 & 0,0 & 0,0 & 0,0 \\
\hline 2000 & 20,6 & 2167 & 7,4 & 7,4 & 0,0 & 0,0 & 0,0 & 0,0 & 0,0 & 0,0 \\
\hline 2100 & 19,1 & 2167 & 4,9 & 4,9 & 0,0 & 0,0 & 0,0 & 0,0 & 0,0 & 0,0 \\
\hline 2200 & 17,8 & 2167 & 4,3 & 4,3 & 0,0 & 0,0 & 0,0 & 0,0 & 0,0 & 0,0 \\
\hline 2300 & 16,8 & 2167 & 4,3 & 4,3 & 0,0 & 0,0 & 0,0 & 0,0 & 0,0 & 0,0 \\
\hline
\end{tabular}




\begin{tabular}{|c|c|c|c|c|c|c|c|c|c|c|}
\hline \multicolumn{11}{|c|}{ DESIGN MONTH: JULY } \\
\hline Hour & $\begin{array}{r}\text { OA } \\
\text { TEMP } \\
\left({ }^{\circ} \mathrm{C}\right)\end{array}$ & $\begin{array}{r}\text { SUPPLY } \\
\text { AIRFLOW } \\
(\mathrm{L} / \mathbf{s})\end{array}$ & $\begin{array}{r}\text { CENTRAL } \\
\text { COOLING } \\
\text { SENSIBLE } \\
(\mathbf{k W})\end{array}$ & $\begin{array}{r}\text { CENTRAL } \\
\text { COOLING } \\
\text { TOTAL } \\
(\mathrm{kW}) \\
\end{array}$ & $\begin{array}{r}\text { CENTRAL } \\
\text { HEATING } \\
\text { COIL } \\
(\mathrm{kW})\end{array}$ & $\begin{array}{r}\text { PRECOOL } \\
\text { COIL } \\
(\mathrm{kW})\end{array}$ & $\begin{array}{r}\text { PREHEAT } \\
\text { COIL } \\
(\mathrm{kW})\end{array}$ & $\begin{array}{r}\text { TERMINAL } \\
\text { COOLING } \\
(\mathrm{kW})\end{array}$ & $\begin{array}{r}\text { TERMINAL } \\
\text { HEATING } \\
(\mathbf{k W})\end{array}$ & $\begin{array}{r}\text { ZONE } \\
\text { HEATING } \\
\text { UNIT } \\
(\mathrm{kW}) \\
\end{array}$ \\
\hline 0000 & 15,5 & 2167 & 3,1 & 3,1 & 0,0 & 0,0 & 0,0 & 0,0 & 0,0 & 0,0 \\
\hline 0100 & 14,8 & 2167 & 2,9 & 2,9 & 0,0 & 0,0 & 0,0 & 0,0 & 0,0 & 0,0 \\
\hline 0200 & 14,2 & 2167 & 1,5 & 1,5 & 0,0 & 0,0 & 0,0 & 0,0 & 0,0 & 0,0 \\
\hline 0300 & 13,6 & 2167 & 1,6 & 1,6 & 0,0 & 0,0 & 0,0 & 0,0 & 0,0 & 0,0 \\
\hline 0400 & 13,2 & 2167 & 1,4 & 1,4 & 0,0 & 0,0 & 0,0 & 0,0 & 0,0 & 0,0 \\
\hline 0500 & 13,1 & 2167 & 0,5 & 0,5 & 0,0 & 0,0 & 0,0 & 0,0 & 0,0 & 0,0 \\
\hline 0600 & 13,4 & 2167 & 0,6 & 0,6 & 0,0 & 0,0 & 0,0 & 0,0 & 0,0 & 0,0 \\
\hline 0700 & 14,0 & 2167 & 0,0 & 0,0 & 0,0 & 0,0 & 0,0 & 0,0 & 0,0 & 0,0 \\
\hline 0800 & 15,2 & 2167 & 0,0 & 0,0 & 0,0 & 0,0 & 0,0 & 0,0 & 0,0 & 0,0 \\
\hline 0900 & 16,9 & 2167 & 0,0 & 0,0 & 0,0 & 0,0 & 0,0 & 0,0 & 0,0 & 0,0 \\
\hline 1000 & 18,8 & 2167 & 1,8 & 1,8 & 0,0 & 0,0 & 0,0 & 0,0 & 0,0 & 0,0 \\
\hline 1100 & 21,0 & 2167 & 3,3 & 3,3 & 0,0 & 0,0 & 0,0 & 0,0 & 0,0 & 0,0 \\
\hline 1200 & 23,1 & 2167 & 6,2 & 6,2 & 0,0 & 0,0 & 0,0 & 0,0 & 0,0 & 0,0 \\
\hline 1300 & 24,7 & 2167 & 7,3 & 7,3 & 0,0 & 0,0 & 0,0 & 0,0 & 0,0 & 0,0 \\
\hline 1400 & 25,7 & 2167 & 8,7 & 8,7 & 0,0 & 0,0 & 0,0 & 0,0 & 0,0 & 0,0 \\
\hline 1500 & 26,1 & 2167 & 9,1 & 9,1 & 0,0 & 0,0 & 0,0 & 0,0 & 0,0 & 0,0 \\
\hline 1600 & 25,7 & 2167 & 10,1 & 10,1 & 0,0 & 0,0 & 0,0 & 0,0 & 0,0 & 0,0 \\
\hline 1700 & 24,8 & 2167 & 9,7 & 9,7 & 0,0 & 0,0 & 0,0 & 0,0 & 0,0 & 0,0 \\
\hline 1800 & 23,4 & 2167 & 9,7 & 9,7 & 0,0 & 0,0 & 0,0 & 0,0 & 0,0 & 0,0 \\
\hline 1900 & 21,7 & 2167 & 8,2 & 8,2 & 0,0 & 0,0 & 0,0 & 0,0 & 0,0 & 0,0 \\
\hline 2000 & 20,0 & 2167 & 7,1 & 7,1 & 0,0 & 0,0 & 0,0 & 0,0 & 0,0 & 0,0 \\
\hline 2100 & 18,6 & 2167 & 4,4 & 4,4 & 0,0 & 0,0 & 0,0 & 0,0 & 0,0 & 0,0 \\
\hline 2200 & 17,3 & 2167 & 3,6 & 3,6 & 0,0 & 0,0 & 0,0 & 0,0 & 0,0 & 0,0 \\
\hline 2300 & 16,2 & 2167 & 3,4 & 3,4 & 0,0 & 0,0 & 0,0 & 0,0 & 0,0 & 0,0 \\
\hline
\end{tabular}

\begin{tabular}{|c|c|c|c|c|c|c|c|c|c|c|}
\hline \multicolumn{11}{|c|}{ DESIGN MONTH: AUGUST } \\
\hline Hour & $\begin{array}{r}\text { OA } \\
\text { TEMP } \\
\left({ }^{\circ} \mathbf{C}\right)\end{array}$ & $\begin{array}{r}\text { SUPPLY } \\
\text { AIRFLOW } \\
(\mathrm{L} / \mathrm{s})\end{array}$ & $\begin{array}{r}\text { CENTRAL } \\
\text { COOLING } \\
\text { SENSIBLE } \\
(\mathrm{kW})\end{array}$ & $\begin{array}{r}\text { CENTRAL } \\
\text { COOLING } \\
\text { TOTAL } \\
(\mathrm{kW})\end{array}$ & $\begin{array}{r}\text { CENTRAL } \\
\text { HEATING } \\
\text { COIL } \\
(\mathrm{kW})\end{array}$ & $\begin{array}{r}\text { PRECOOL } \\
\text { COIL } \\
(\mathrm{kW})\end{array}$ & $\begin{array}{r}\text { PREHEAT } \\
\text { COIL } \\
(\mathrm{kW})\end{array}$ & $\begin{array}{r}\text { TERMINAL } \\
\text { COOLING } \\
(\mathrm{kW})\end{array}$ & $\begin{array}{r}\text { TERMINAL } \\
\text { HEATING } \\
(\mathbf{k W})\end{array}$ & $\begin{array}{r}\text { ZONE } \\
\text { HEATING } \\
\text { UNIT } \\
(\mathrm{kW})\end{array}$ \\
\hline 0000 & 16,6 & 2167 & 3,9 & 3,9 & 0,0 & 0,0 & 0,0 & 0,0 & 0,0 & 0,0 \\
\hline 0100 & 15,9 & 2167 & 2,7 & 2,7 & 0,0 & 0,0 & 0,0 & 0,0 & 0,0 & 0,0 \\
\hline 0200 & 15,3 & 2167 & 2,7 & 2,7 & 0,0 & 0,0 & 0,0 & 0,0 & 0,0 & 0,0 \\
\hline 0300 & 14,7 & 2167 & 1,4 & 1,4 & 0,0 & 0,0 & 0,0 & 0,0 & 0,0 & 0,0 \\
\hline 0400 & 14,4 & 2167 & 1,9 & 1,9 & 0,0 & 0,0 & 0,0 & 0,0 & 0,0 & 0,0 \\
\hline 0500 & 14,2 & 2167 & 1,0 & 1,0 & 0,0 & 0,0 & 0,0 & 0,0 & 0,0 & 0,0 \\
\hline 0600 & 14,5 & 2167 & 0,2 & 0,2 & 0,0 & 0,0 & 0,0 & 0,0 & 0,0 & 0,0 \\
\hline 0700 & 15,1 & 2167 & 0,6 & 0,6 & 0,0 & 0,0 & 0,0 & 0,0 & 0,0 & 0,0 \\
\hline 0800 & 16,3 & 2167 & 0,5 & 0,5 & 0,0 & 0,0 & 0,0 & 0,0 & 0,0 & 0,0 \\
\hline 0900 & 18,0 & 2167 & 0,8 & 0,8 & 0,0 & 0,0 & 0,0 & 0,0 & 0,0 & 0,0 \\
\hline 1000 & 19,9 & 2167 & 3,3 & 3,3 & 0,0 & 0,0 & 0,0 & 0,0 & 0,0 & 0,0 \\
\hline 1100 & 22,2 & 2167 & 4,9 & 4,9 & 0,0 & 0,0 & 0,0 & 0,0 & 0,0 & 0,0 \\
\hline 1200 & 24,2 & 2167 & 7,1 & 7,1 & 0,0 & 0,0 & 0,0 & 0,0 & 0,0 & 0,0 \\
\hline 1300 & 25,8 & 2167 & 8,2 & 8,2 & 0,0 & 0,0 & 0,0 & 0,0 & 0,0 & 0,0 \\
\hline 1400 & 26,8 & 2167 & 10,1 & 10,1 & 0,0 & 0,0 & 0,0 & 0,0 & 0,0 & 0,0 \\
\hline 1500 & 27,2 & 2167 & 10,6 & 10,6 & 0,0 & 0,0 & 0,0 & 0,0 & 0,0 & 0,0 \\
\hline 1600 & 26,8 & 2167 & 11,1 & 11,1 & 0,0 & 0,0 & 0,0 & 0,0 & 0,0 & 0,0 \\
\hline 1700 & 25,9 & 2167 & 10,5 & 10,5 & 0,0 & 0,0 & 0,0 & 0,0 & 0,0 & 0,0 \\
\hline 1800 & 24,5 & 2167 & 10,7 & 10,7 & 0,0 & 0,0 & 0,0 & 0,0 & 0,0 & 0,0 \\
\hline 1900 & 22,8 & 2167 & 9,4 & 9,4 & 0,0 & 0,0 & 0,0 & 0,0 & 0,0 & 0,0 \\
\hline 2000 & 21,1 & 2167 & 8,3 & 8,3 & 0,0 & 0,0 & 0,0 & 0,0 & 0,0 & 0,0 \\
\hline 2100 & 19,7 & 2167 & 4,9 & 4,9 & 0,0 & 0,0 & 0,0 & 0,0 & 0,0 & 0,0 \\
\hline 2200 & 18,4 & 2167 & 4,9 & 4,9 & 0,0 & 0,0 & 0,0 & 0,0 & 0,0 & 0,0 \\
\hline 2300 & 17,3 & 2167 & 3,6 & 3,6 & 0,0 & 0,0 & 0,0 & 0,0 & 0,0 & 0,0 \\
\hline
\end{tabular}




\begin{tabular}{|c|c|c|c|c|c|c|c|c|c|c|}
\hline \multicolumn{11}{|c|}{ DESIGN MONTH: SEPTEMBER } \\
\hline Hour & $\begin{array}{r}\text { OA } \\
\text { TEMP } \\
\left({ }^{\circ} \mathrm{C}\right)\end{array}$ & $\begin{array}{r}\text { SUPPLY } \\
\text { AIRFLOW } \\
(\mathrm{L} / \mathrm{s})\end{array}$ & $\begin{array}{r}\text { CENTRAL } \\
\text { COOLING } \\
\text { SENSIBLE } \\
(\mathbf{k W})\end{array}$ & $\begin{array}{r}\text { CENTRAL } \\
\text { COOLING } \\
\text { TOTAL } \\
(\mathrm{kW})\end{array}$ & $\begin{array}{r}\text { CENTRAL } \\
\text { HEATING } \\
\text { COIL } \\
(\mathrm{kW})\end{array}$ & $\begin{array}{r}\text { PRECOOL } \\
\text { COIL } \\
(\mathrm{kW})\end{array}$ & $\begin{array}{r}\text { PREHEAT } \\
\text { COIL } \\
(\mathrm{kW})\end{array}$ & $\begin{array}{r}\text { TERMINAL } \\
\text { COOLING } \\
(\mathrm{kW})\end{array}$ & $\begin{array}{r}\text { TERMINAL } \\
\text { HEATING } \\
(\mathbf{k W})\end{array}$ & $\begin{array}{r}\text { ZONE } \\
\text { HEATING } \\
\text { UNIT } \\
(\mathrm{kW})\end{array}$ \\
\hline 0000 & 18,2 & 2167 & 3,4 & 3,4 & 0,0 & 0,0 & 0,0 & 0,0 & 0,0 & 0,0 \\
\hline 0100 & 17,6 & 2167 & 3,5 & 3,5 & 0,0 & 0,0 & 0,0 & 0,0 & 0,0 & 0,0 \\
\hline 0200 & 16,9 & 2167 & 2,5 & 2,5 & 0,0 & 0,0 & 0,0 & 0,0 & 0,0 & 0,0 \\
\hline 0300 & 16,4 & 2167 & 2,1 & 2,1 & 0,0 & 0,0 & 0,0 & 0,0 & 0,0 & 0,0 \\
\hline 0400 & 16,0 & 2167 & 2,5 & 2,5 & 0,0 & 0,0 & 0,0 & 0,0 & 0,0 & 0,0 \\
\hline 0500 & 15,9 & 2167 & 0,9 & 0,9 & 0,0 & 0,0 & 0,0 & 0,0 & 0,0 & 0,0 \\
\hline 0600 & 16,1 & 2167 & 1,2 & 1,2 & 0,0 & 0,0 & 0,0 & 0,0 & 0,0 & 0,0 \\
\hline 0700 & 16,8 & 2167 & 0,3 & 0,3 & 0,0 & 0,0 & 0,0 & 0,0 & 0,0 & 0,0 \\
\hline 0800 & 18,0 & 2167 & 1,2 & 1,2 & 0,0 & 0,0 & 0,0 & 0,0 & 0,0 & 0,0 \\
\hline 0900 & 19,7 & 2167 & 3,1 & 3,1 & 0,0 & 0,0 & 0,0 & 0,0 & 0,0 & 0,0 \\
\hline 1000 & 21,6 & 2167 & 5,0 & 5,0 & 0,0 & 0,0 & 0,0 & 0,0 & 0,0 & 0,0 \\
\hline 1100 & 23,8 & 2167 & 6,5 & 6,5 & 0,0 & 0,0 & 0,0 & 0,0 & 0,0 & 0,0 \\
\hline 1200 & 25,9 & 2167 & 9,1 & 9,1 & 0,0 & 0,0 & 0,0 & 0,0 & 0,0 & 0,0 \\
\hline 1300 & 27,5 & 2167 & 10,3 & 10,3 & 0,0 & 0,0 & 0,0 & 0,0 & 0,0 & 0,0 \\
\hline 1400 & 28,5 & 2167 & 12,1 & 12,1 & 0,0 & 0,0 & 0,0 & 0,0 & 0,0 & 0,0 \\
\hline 1500 & 28,9 & 2167 & 12,3 & 12,3 & 0,0 & 0,0 & 0,0 & 0,0 & 0,0 & 0,0 \\
\hline 1600 & 28,5 & 2167 & 13,2 & 13,2 & 0,0 & 0,0 & 0,0 & 0,0 & 0,0 & 0,0 \\
\hline 1700 & 27,6 & 2167 & 12,5 & 12,5 & 0,0 & 0,0 & 0,0 & 0,0 & 0,0 & 0,0 \\
\hline 1800 & 26,2 & 2167 & 12,4 & 12,4 & 0,0 & 0,0 & 0,0 & 0,0 & 0,0 & 0,0 \\
\hline 1900 & 24,5 & 2167 & 11,0 & 11,0 & 0,0 & 0,0 & 0,0 & 0,0 & 0,0 & 0,0 \\
\hline 2000 & 22,8 & 2167 & 9,9 & 9,9 & 0,0 & 0,0 & 0,0 & 0,0 & 0,0 & 0,0 \\
\hline 2100 & 21,3 & 2167 & 5,3 & 5,3 & 0,0 & 0,0 & 0,0 & 0,0 & 0,0 & 0,0 \\
\hline 2200 & 20,0 & 2167 & 4,9 & 4,9 & 0,0 & 0,0 & 0,0 & 0,0 & 0,0 & 0,0 \\
\hline 2300 & 19,0 & 2167 & 4,0 & 4,0 & 0,0 & 0,0 & 0,0 & 0,0 & 0,0 & 0,0 \\
\hline
\end{tabular}

\begin{tabular}{|c|c|c|c|c|c|c|c|c|c|c|}
\hline \multicolumn{11}{|c|}{ DESIGN MONTH: OCTOBER } \\
\hline Hour & $\begin{array}{r}\text { OA } \\
\text { TEMP } \\
\left({ }^{\circ} \mathbf{C}\right)\end{array}$ & $\begin{array}{r}\text { SUPPLY } \\
\text { AIRFLOW } \\
(\mathrm{L} / \mathrm{s})\end{array}$ & $\begin{array}{r}\text { CENTRAL } \\
\text { COOLING } \\
\text { SENSIBLE } \\
(\mathrm{kW})\end{array}$ & $\begin{array}{r}\text { CENTRAL } \\
\text { COOLING } \\
\text { TOTAL } \\
(\mathrm{kW})\end{array}$ & $\begin{array}{r}\text { CENTRAL } \\
\text { HEATING } \\
\text { COIL } \\
(\mathrm{kW})\end{array}$ & $\begin{array}{r}\text { PRECOOL } \\
\text { COIL } \\
(\mathrm{kW})\end{array}$ & $\begin{array}{r}\text { PREHEAT } \\
\text { COIL } \\
(\mathrm{kW})\end{array}$ & $\begin{array}{r}\text { TERMINAL } \\
\text { COOLING } \\
(\mathrm{kW})\end{array}$ & $\begin{array}{r}\text { TERMINAL } \\
\text { HEATING } \\
(\mathbf{k W})\end{array}$ & $\begin{array}{r}\text { ZONE } \\
\text { HEATING } \\
\text { UNIT } \\
(\mathrm{kW})\end{array}$ \\
\hline 0000 & 18,8 & 2167 & 3,9 & 3,9 & 0,0 & 0,0 & 0,0 & 0,0 & 0,0 & 0,0 \\
\hline 0100 & 18,1 & 2167 & 4,0 & 4,0 & 0,0 & 0,0 & 0,0 & 0,0 & 0,0 & 0,0 \\
\hline 0200 & 17,5 & 2167 & 3,2 & 3,2 & 0,0 & 0,0 & 0,0 & 0,0 & 0,0 & 0,0 \\
\hline 0300 & 17,0 & 2167 & 2,7 & 2,7 & 0,0 & 0,0 & 0,0 & 0,0 & 0,0 & 0,0 \\
\hline 0400 & 16,6 & 2167 & 2,2 & 2,2 & 0,0 & 0,0 & 0,0 & 0,0 & 0,0 & 0,0 \\
\hline 0500 & 16,4 & 2167 & 2,0 & 2,0 & 0,0 & 0,0 & 0,0 & 0,0 & 0,0 & 0,0 \\
\hline 0600 & 16,7 & 2167 & 0,6 & 0,6 & 0,0 & 0,0 & 0,0 & 0,0 & 0,0 & 0,0 \\
\hline 0700 & 17,4 & 2167 & 0,4 & 0,4 & 0,0 & 0,0 & 0,0 & 0,0 & 0,0 & 0,0 \\
\hline 0800 & 18,5 & 2167 & 2,4 & 2,4 & 0,0 & 0,0 & 0,0 & 0,0 & 0,0 & 0,0 \\
\hline 0900 & 20,2 & 2167 & 3,3 & 3,3 & 0,0 & 0,0 & 0,0 & 0,0 & 0,0 & 0,0 \\
\hline 1000 & 22,2 & 2167 & 5,9 & 5,9 & 0,0 & 0,0 & 0,0 & 0,0 & 0,0 & 0,0 \\
\hline 1100 & 24,4 & 2167 & 7,5 & 7,5 & 0,0 & 0,0 & 0,0 & 0,0 & 0,0 & 0,0 \\
\hline 1200 & 26,5 & 2167 & 9,9 & 9,9 & 0,0 & 0,0 & 0,0 & 0,0 & 0,0 & 0,0 \\
\hline 1300 & 28,0 & 2167 & 10,9 & 10,9 & 0,0 & 0,0 & 0,0 & 0,0 & 0,0 & 0,0 \\
\hline 1400 & 29,1 & 2167 & 12,5 & 12,5 & 0,0 & 0,0 & 0,0 & 0,0 & 0,0 & 0,0 \\
\hline 1500 & 29,4 & 2167 & 12,8 & 12,8 & 0,0 & 0,0 & 0,0 & 0,0 & 0,0 & 0,0 \\
\hline 1600 & 29,1 & 2167 & 13,7 & 13,7 & 0,0 & 0,0 & 0,0 & 0,0 & 0,0 & 0,0 \\
\hline 1700 & 28,1 & 2167 & 12,9 & 12,9 & 0,0 & 0,0 & 0,0 & 0,0 & 0,0 & 0,0 \\
\hline 1800 & 26,7 & 2167 & 12,9 & 12,9 & 0,0 & 0,0 & 0,0 & 0,0 & 0,0 & 0,0 \\
\hline 1900 & 25,0 & 2167 & 11,5 & 11,5 & 0,0 & 0,0 & 0,0 & 0,0 & 0,0 & 0,0 \\
\hline 2000 & 23,3 & 2167 & 10,4 & 10,4 & 0,0 & 0,0 & 0,0 & 0,0 & 0,0 & 0,0 \\
\hline 2100 & 21,9 & 2167 & 5,1 & 5,1 & 0,0 & 0,0 & 0,0 & 0,0 & 0,0 & 0,0 \\
\hline 2200 & 20,6 & 2167 & 4,6 & 4,6 & 0,0 & 0,0 & 0,0 & 0,0 & 0,0 & 0,0 \\
\hline 2300 & 19,6 & 2167 & 4,3 & 4,3 & 0,0 & 0,0 & 0,0 & 0,0 & 0,0 & 0,0 \\
\hline
\end{tabular}




\begin{tabular}{|c|c|c|c|c|c|c|c|c|c|c|}
\hline \multicolumn{11}{|c|}{ DESIGN MONTH: NOVEMBER } \\
\hline Hour & $\begin{array}{r}\text { OA } \\
\text { TEMP } \\
\left({ }^{\circ} \mathrm{C}\right)\end{array}$ & $\begin{array}{r}\text { SUPPLY } \\
\text { AIRFLOW } \\
(\mathrm{L} / \mathrm{s})\end{array}$ & $\begin{array}{r}\text { CENTRAL } \\
\text { COOLING } \\
\text { SENSIBLE } \\
(\mathrm{kW})\end{array}$ & $\begin{array}{r}\text { CENTRAL } \\
\text { COOLING } \\
\text { TOTAL } \\
(\mathrm{kW}) \\
\end{array}$ & $\begin{array}{r}\text { CENTRAL } \\
\text { HEATING } \\
\text { COIL } \\
(\mathrm{kW})\end{array}$ & $\begin{array}{r}\text { PRECOOL } \\
\text { COIL } \\
(\mathrm{kW})\end{array}$ & $\begin{array}{r}\text { PREHEAT } \\
\text { COIL } \\
(\mathrm{kW})\end{array}$ & $\begin{array}{r}\text { TERMINAL } \\
\text { COOLING } \\
(\mathrm{kW})\end{array}$ & $\begin{array}{r}\text { TERMINAL } \\
\text { HEATING } \\
(\mathbf{k W})\end{array}$ & $\begin{array}{r}\text { ZONE } \\
\text { HEATING } \\
\text { UNIT } \\
(\mathrm{kW})\end{array}$ \\
\hline 0000 & 19,3 & 2167 & 4,5 & 4,5 & 0,0 & 0,0 & 0,0 & 0,0 & 0,0 & 0,0 \\
\hline 0100 & 18,7 & 2167 & 4,1 & 4,1 & 0,0 & 0,0 & 0,0 & 0,0 & 0,0 & 0,0 \\
\hline 0200 & 18,0 & 2167 & 3,5 & 3,5 & 0,0 & 0,0 & 0,0 & 0,0 & 0,0 & 0,0 \\
\hline 0300 & 17,5 & 2167 & 2,6 & 2,6 & 0,0 & 0,0 & 0,0 & 0,0 & 0,0 & 0,0 \\
\hline 0400 & 17,1 & 2167 & 2,1 & 2,1 & 0,0 & 0,0 & 0,0 & 0,0 & 0,0 & 0,0 \\
\hline 0500 & 17,0 & 2167 & 1,9 & 1,9 & 0,0 & 0,0 & 0,0 & 0,0 & 0,0 & 0,0 \\
\hline 0600 & 17,3 & 2167 & 1,7 & 1,7 & 0,0 & 0,0 & 0,0 & 0,0 & 0,0 & 0,0 \\
\hline 0700 & 17,9 & 2167 & 1,4 & 1,4 & 0,0 & 0,0 & 0,0 & 0,0 & 0,0 & 0,0 \\
\hline 0800 & 19,1 & 2167 & 2,9 & 2,9 & 0,0 & 0,0 & 0,0 & 0,0 & 0,0 & 0,0 \\
\hline 0900 & 20,8 & 2167 & 4,9 & 4,9 & 0,0 & 0,0 & 0,0 & 0,0 & 0,0 & 0,0 \\
\hline 1000 & 22,7 & 2167 & 6,3 & 6,3 & 0,0 & 0,0 & 0,0 & 0,0 & 0,0 & 0,0 \\
\hline 1100 & 24,9 & 2167 & 9,0 & 9,0 & 0,0 & 0,0 & 0,0 & 0,0 & 0,0 & 0,0 \\
\hline 1200 & 27,0 & 2167 & 10,2 & 10,2 & 0,0 & 0,0 & 0,0 & 0,0 & 0,0 & 0,0 \\
\hline 1300 & 28,6 & 2167 & 12,3 & 12,3 & 0,0 & 0,0 & 0,0 & 0,0 & 0,0 & 0,0 \\
\hline 1400 & 29,6 & 2167 & 12,9 & 12,9 & 0,0 & 0,0 & 0,0 & 0,0 & 0,0 & 0,0 \\
\hline 1500 & 30,0 & 2167 & 14,2 & 14,2 & 0,0 & 0,0 & 0,0 & 0,0 & 0,0 & 0,0 \\
\hline 1600 & 29,6 & 2167 & 13,9 & 13,9 & 0,0 & 0,0 & 0,0 & 0,0 & 0,0 & 0,0 \\
\hline 1700 & 28,7 & 2167 & 14,5 & 14,5 & 0,0 & 0,0 & 0,0 & 0,0 & 0,0 & 0,0 \\
\hline 1800 & 27,3 & 2167 & 13,4 & 13,4 & 0,0 & 0,0 & 0,0 & 0,0 & 0,0 & 0,0 \\
\hline 1900 & 25,6 & 2167 & 13,3 & 13,3 & 0,0 & 0,0 & 0,0 & 0,0 & 0,0 & 0,0 \\
\hline 2000 & 23,9 & 2167 & 11,3 & 11,3 & 0,0 & 0,0 & 0,0 & 0,0 & 0,0 & 0,0 \\
\hline 2100 & 22,5 & 2167 & 6,0 & 6,0 & 0,0 & 0,0 & 0,0 & 0,0 & 0,0 & 0,0 \\
\hline 2200 & 21,2 & 2167 & 5,6 & 5,6 & 0,0 & 0,0 & 0,0 & 0,0 & 0,0 & 0,0 \\
\hline 2300 & 20,1 & 2167 & 4,7 & 4,7 & 0,0 & 0,0 & 0,0 & 0,0 & 0,0 & 0,0 \\
\hline
\end{tabular}

\begin{tabular}{|c|c|c|c|c|c|c|c|c|c|c|}
\hline \multicolumn{11}{|c|}{ DESIGN MONTH: DECEMBER } \\
\hline Hour & $\begin{array}{r}\text { OA } \\
\text { TEMP } \\
\left({ }^{\circ} \mathbf{C}\right)\end{array}$ & $\begin{array}{r}\text { SUPPLY } \\
\text { AIRFLOW } \\
(\mathrm{L} / \mathrm{s})\end{array}$ & $\begin{array}{r}\text { CENTRAL } \\
\text { COOLING } \\
\text { SENSIBLE } \\
(\mathrm{kW})\end{array}$ & $\begin{array}{r}\text { CENTRAL } \\
\text { COOLING } \\
\text { TOTAL } \\
(\mathrm{kW})\end{array}$ & $\begin{array}{r}\text { CENTRAL } \\
\text { HEATING } \\
\text { COIL } \\
(\mathrm{kW})\end{array}$ & $\begin{array}{r}\text { PRECOOL } \\
\text { COIL } \\
(\mathrm{kW})\end{array}$ & $\begin{array}{r}\text { PREHEAT } \\
\text { COIL } \\
(\mathrm{kW})\end{array}$ & $\begin{array}{r}\text { TERMINAL } \\
\text { COOLING } \\
(\mathrm{kW})\end{array}$ & $\begin{array}{r}\text { TERMINAL } \\
\text { HEATING } \\
(\mathbf{k W})\end{array}$ & $\begin{array}{r}\text { ZONE } \\
\text { HEATING } \\
\text { UNIT } \\
(\mathrm{kW})\end{array}$ \\
\hline 0000 & 20,5 & 2167 & 5,4 & 5,4 & 0,0 & 0,0 & 0,0 & 0,0 & 0,0 & 0,0 \\
\hline 0100 & 19,8 & 2167 & 4,8 & 4,8 & 0,0 & 0,0 & 0,0 & 0,0 & 0,0 & 0,0 \\
\hline 0200 & 19,2 & 2167 & 4,6 & 4,6 & 0,0 & 0,0 & 0,0 & 0,0 & 0,0 & 0,0 \\
\hline 0300 & 18,6 & 2167 & 3,1 & 3,1 & 0,0 & 0,0 & 0,0 & 0,0 & 0,0 & 0,0 \\
\hline 0400 & 18,2 & 2167 & 2,7 & 2,7 & 0,0 & 0,0 & 0,0 & 0,0 & 0,0 & 0,0 \\
\hline 0500 & 18,1 & 2167 & 2,1 & 2,1 & 0,0 & 0,0 & 0,0 & 0,0 & 0,0 & 0,0 \\
\hline 0600 & 18,4 & 2167 & 2,7 & 2,7 & 0,0 & 0,0 & 0,0 & 0,0 & 0,0 & 0,0 \\
\hline 0700 & 19,0 & 2167 & 1,0 & 1,0 & 0,0 & 0,0 & 0,0 & 0,0 & 0,0 & 0,0 \\
\hline 0800 & 20,2 & 2167 & 4,9 & 4,9 & 0,0 & 0,0 & 0,0 & 0,0 & 0,0 & 0,0 \\
\hline 0900 & 21,9 & 2167 & 5,3 & 5,3 & 0,0 & 0,0 & 0,0 & 0,0 & 0,0 & 0,0 \\
\hline 1000 & 23,8 & 2167 & 7,7 & 7,7 & 0,0 & 0,0 & 0,0 & 0,0 & 0,0 & 0,0 \\
\hline 1100 & 26,0 & 2167 & 9,5 & 9,5 & 0,0 & 0,0 & 0,0 & 0,0 & 0,0 & 0,0 \\
\hline 1200 & 28,1 & 2167 & 11,6 & 11,6 & 0,0 & 0,0 & 0,0 & 0,0 & 0,0 & 0,0 \\
\hline 1300 & 29,7 & 2167 & 12,7 & 12,7 & 0,0 & 0,0 & 0,0 & 0,0 & 0,0 & 0,0 \\
\hline 1400 & 30,7 & 2167 & 14,6 & 14,6 & 0,0 & 0,0 & 0,0 & 0,0 & 0,0 & 0,0 \\
\hline 1500 & 31,1 & 2167 & 15,0 & 15,0 & 0,0 & 0,0 & 0,0 & 0,0 & 0,0 & 0,0 \\
\hline 1600 & 30,7 & 2167 & 15,4 & 15,4 & 0,0 & 0,0 & 0,0 & 0,0 & 0,0 & 0,0 \\
\hline 1700 & 29,8 & 2167 & 14,9 & 14,9 & 0,0 & 0,0 & 0,0 & 0,0 & 0,0 & 0,0 \\
\hline 1800 & 28,4 & 2167 & 15,2 & 15,2 & 0,0 & 0,0 & 0,0 & 0,0 & 0,0 & 0,0 \\
\hline 1900 & 26,7 & 2167 & 14,0 & 14,0 & 0,0 & 0,0 & 0,0 & 0,0 & 0,0 & 0,0 \\
\hline 2000 & 25,0 & 2167 & 12,9 & 12,9 & 0,0 & 0,0 & 0,0 & 0,0 & 0,0 & 0,0 \\
\hline 2100 & 23,6 & 2167 & 7,5 & 7,5 & 0,0 & 0,0 & 0,0 & 0,0 & 0,0 & 0,0 \\
\hline 2200 & 22,3 & 2167 & 6,4 & 6,4 & 0,0 & 0,0 & 0,0 & 0,0 & 0,0 & 0,0 \\
\hline 2300 & 21,2 & 2167 & 5,7 & 5,7 & 0,0 & 0,0 & 0,0 & 0,0 & 0,0 & 0,0 \\
\hline
\end{tabular}




\begin{tabular}{|c|c|c|c|c|c|c|c|c|c|}
\hline \multicolumn{10}{|c|}{$\begin{array}{c}\text { ZONE: Zone } 1 \\
\text { DESIGN MONTH: JANUARY }\end{array}$} \\
\hline Hour & $\begin{array}{r}\text { OA } \\
\text { TEMP } \\
\left({ }^{\circ} \mathbf{C}\right)\end{array}$ & $\begin{array}{r}\text { ZONE } \\
\text { TEMP } \\
\left({ }^{\circ} \mathrm{C}\right)\end{array}$ & $\begin{array}{c}\mathbf{R H} \\
(\%)\end{array}$ & $\begin{array}{r}\text { ZONE } \\
\text { AIRFLOW } \\
(\mathrm{L} / \mathrm{s})\end{array}$ & $\begin{array}{r}\text { ZONE } \\
\text { SENSIBLE } \\
\text { LOAD } \\
(\mathrm{W})\end{array}$ & $\begin{array}{r}\text { ZONE } \\
\text { COND } \\
\text { (W) }\end{array}$ & $\begin{array}{r}\text { TERMINAL } \\
\text { COOLING } \\
\text { COIL } \\
(\mathrm{W})\end{array}$ & $\begin{array}{r}\text { TERMINAL } \\
\text { HEATING } \\
\text { COIL } \\
(\mathrm{W})\end{array}$ & $\begin{array}{r}\text { ZONE } \\
\text { HEATING } \\
\text { UNIT } \\
(\mathrm{W})\end{array}$ \\
\hline 0000 & 21,0 & 24,1 & & 2166,5 & 5640,2 & 5187,8 & 0,0 & 0,0 & 0,0 \\
\hline 0100 & 20,4 & 23,9 & - & 2166,5 & 4991,7 & 5208,1 & 0,0 & 0,0 & 0,0 \\
\hline 0200 & 19,7 & 24,0 & - & 2166,5 & 4377,4 & 4351,8 & 0,0 & 0,0 & 0,0 \\
\hline 0300 & 19,2 & 24,0 & - & 2166,5 & 3802,9 & 3803,0 & 0,0 & 0,0 & 0,0 \\
\hline 0400 & 18,8 & 23,9 & - & 2166,5 & 3268,1 & 3284,0 & 0,0 & 0,0 & 0,0 \\
\hline 0500 & 18,7 & 23,9 & - & 2166,5 & 2772,9 & 2798,4 & 0,0 & 0,0 & 0,0 \\
\hline 0600 & 18,9 & 23,9 & - & 2166,5 & 2318,3 & 2769,9 & 0,0 & 0,0 & 0,0 \\
\hline 0700 & 19,6 & 24,0 & & 2166,5 & 1929,2 & 1517,1 & 0,0 & 0,0 & 0,0 \\
\hline 0800 & 20,7 & 24,1 & 45 & 2166,5 & 7565,3 & 6756,5 & 0,0 & 0,0 & 0,0 \\
\hline 0900 & 22,4 & 24,0 & 45 & 2166,5 & 7901,8 & 7365,8 & 0,0 & 0,0 & 0,0 \\
\hline 1000 & 24,4 & 24,1 & 45 & 2166,5 & 8460,6 & 7562,0 & 0,0 & 0,0 & 0,0 \\
\hline 1100 & 26,6 & 24,1 & 45 & 2166,5 & 9118,7 & 8284,4 & 0,0 & 0,0 & 0,0 \\
\hline 1200 & 28,7 & 24,2 & 44 & 2166,5 & 9773,7 & 8453,6 & 0,0 & 0,0 & 0,0 \\
\hline 1300 & 30,2 & 24,1 & 45 & 2166,5 & 10367,0 & 9620,5 & 0,0 & 0,0 & 0,0 \\
\hline 1400 & 31,3 & 24,2 & 45 & 2166,5 & 10903,7 & 9769,1 & 0,0 & 0,0 & 0,0 \\
\hline 1500 & 31,7 & 24,1 & 45 & 2166,5 & 11458,0 & 10784,0 & 0,0 & 0,0 & 0,0 \\
\hline 1600 & 31,3 & 24,2 & 44 & 2166,5 & 12068,6 & 10801,8 & 0,0 & 0,0 & 0,0 \\
\hline 1700 & 30,4 & 24,1 & 45 & 2166,5 & 12706,7 & 11957,0 & 0,0 & 0,0 & 0,0 \\
\hline 1800 & 28,9 & 24,2 & 44 & 2166,5 & 13290,9 & 11831,7 & 0,0 & 0,0 & 0,0 \\
\hline 1900 & 27,2 & 24,2 & 44 & 2166,5 & \begin{tabular}{|c|}
13680,6 \\
\end{tabular} & \begin{tabular}{l|}
12362,3 \\
\end{tabular} & 0,0 & 0,0 & 0,0 \\
\hline 2000 & 25,6 & 24,2 & 44 & 2166,5 & 13723,7 & 12465,5 & 0,0 & 0,0 & 0,0 \\
\hline 2100 & 24,1 & 24,1 & 45 & 2166,5 & 7633,9 & 7262,1 & 0,0 & 0,0 & 0,0 \\
\hline 2200 & 22,8 & 24,0 & 45 & 2166,5 & 6990,8 & 6617,2 & 0,0 & 0,0 & 0,0 \\
\hline 2300 & 21,8 & 23,9 & 45 & 2166,5 & 6313,0 & 6596,0 & 0,0 & 0,0 & 0,0 \\
\hline
\end{tabular}

\begin{tabular}{|c|c|c|c|c|c|c|c|c|c|}
\hline \multicolumn{10}{|c|}{$\begin{array}{c}\text { ZONE: Zone } 1 \\
\text { DESIGN MONTH: FEBRUARY }\end{array}$} \\
\hline Hour & $\begin{array}{r}\text { OA } \\
\text { TEMP } \\
\left({ }^{\circ} \mathbf{C}\right)\end{array}$ & $\begin{array}{r}\text { ZONE } \\
\text { TEMP } \\
\left({ }^{\circ} \mathrm{C}\right)\end{array}$ & $\begin{array}{c}\mathbf{R H} \\
(\%)\end{array}$ & $\begin{array}{r}\text { ZONE } \\
\text { AIRFLOW } \\
(\mathrm{L} / \mathrm{s})\end{array}$ & $\begin{array}{r}\text { ZONE } \\
\text { SENSIBLE } \\
\text { LOAD } \\
\text { (W) }\end{array}$ & $\begin{array}{r}\text { ZONE } \\
\text { COND } \\
\text { (W) }\end{array}$ & $\begin{array}{r}\text { TERMINAL } \\
\text { COOLING } \\
\text { COIL } \\
\text { (W) }\end{array}$ & $\begin{array}{r}\text { TERMINAL } \\
\text { HEATING } \\
\text { COIL } \\
\text { (W) }\end{array}$ & $\begin{array}{r}\text { ZONE } \\
\text { HEATING } \\
\text { UNIT } \\
\text { (W) }\end{array}$ \\
\hline 0000 & 21,0 & 23,9 & 45 & 2166,5 & 5296,3 & 5445,1 & 0,0 & 0,0 & 0,0 \\
\hline 0100 & 20,4 & 24,1 & 45 & 2166,5 & 4688,0 & 4107,1 & 0,0 & 0,0 & 0,0 \\
\hline 0200 & 19,7 & 24,0 & 45 & 2166,5 & 4109,1 & 3977,8 & 0,0 & 0,0 & 0,0 \\
\hline 0300 & 19,2 & 24,0 & 45 & 2166,5 & 3565,3 & 3316,5 & 0,0 & 0,0 & 0,0 \\
\hline 0400 & 18,8 & 24,0 & 45 & 2166,5 & 3057,2 & 2909,8 & 0,0 & 0,0 & 0,0 \\
\hline 0500 & 18,7 & 24,0 & 45 & 2166,5 & 2585,0 & 2380,0 & 0,0 & 0,0 & 0,0 \\
\hline 0600 & 18,9 & 23,9 & 45 & 2166,5 & 2150,4 & 2384,5 & 0,0 & 0,0 & 0,0 \\
\hline 0700 & 19,6 & 23,9 & 45 & 2166,5 & 1763,1 & 1739,3 & 0,0 & 0,0 & 0,0 \\
\hline 0800 & 20,7 & 24,1 & 45 & 2166,5 & 7346,8 & 6327,5 & 0,0 & 0,0 & 0,0 \\
\hline 0900 & 22,4 & 24,0 & 45 & 2166,5 & 7608,5 & 7134,6 & 0,0 & 0,0 & 0,0 \\
\hline 1000 & 24,4 & 24,1 & 45 & 2166,5 & 8100,1 & 7255,0 & 0,0 & 0,0 & 0,0 \\
\hline 1100 & 26,6 & 24,0 & 45 & 2166,5 & 8709,2 & 8358,2 & 0,0 & 0,0 & 0,0 \\
\hline 1200 & 28,7 & 24,1 & 45 & 2166,5 & 9343,3 & 8341,7 & 0,0 & 0,0 & 0,0 \\
\hline 1300 & 30,2 & 24,0 & 45 & 2166,5 & 9942,2 & 9424,0 & 0,0 & 0,0 & 0,0 \\
\hline 1400 & 31,3 & 24,2 & 45 & 2166,5 & 10495,5 & 9368,2 & 0,0 & 0,0 & 0,0 \\
\hline 1500 & 31,7 & 24,1 & 45 & 2166,5 & 11064,3 & 10395,9 & 0,0 & 0,0 & 0,0 \\
\hline 1600 & 31,3 & 24,2 & 44 & 2166,5 & 11674,7 & 10427,1 & 0,0 & 0,0 & 0,0 \\
\hline 1700 & 30,4 & 24,1 & 45 & 2166,5 & 12290,6 & 11547,2 & 0,0 & 0,0 & 0,0 \\
\hline 1800 & 28,9 & 24,2 & 44 & 2166,5 & 12840,1 & 11474,5 & 0,0 & 0,0 & 0,0 \\
\hline 1900 & 27,2 & 24,2 & 45 & 2166,5 & 13197,2 & 12127,9 & 0,0 & 0,0 & 0,0 \\
\hline 2000 & 25,6 & 24,3 & 44 & 2166,5 & 13227,8 & 11447,9 & 0,0 & 0,0 & 0,0 \\
\hline 2100 & 24,1 & 24,1 & 45 & 2166,5 & 7158,2 & 6714,6 & 0,0 & 0,0 & 0,0 \\
\hline 2200 & 22,8 & 24,2 & 45 & 2166,5 & 6555,9 & 5507,4 & 0,0 & 0,0 & 0,0 \\
\hline 2300 & 21,8 & 24,1 & 45 & 2166,5 & 5924,4 & 5522,4 & 0,0 & 0,0 & 0,0 \\
\hline
\end{tabular}




\begin{tabular}{|c|c|c|c|c|c|c|c|c|c|}
\hline \multicolumn{10}{|c|}{$\begin{array}{c}\text { ZONE: Zone } 1 \\
\text { DESIGN MONTH: MARCH }\end{array}$} \\
\hline Hour & $\begin{array}{r}\mathrm{OA} \\
\mathrm{TEMP} \\
\left({ }^{\circ} \mathrm{C}\right) \\
\end{array}$ & $\begin{array}{r}\text { ZONE } \\
\text { TEMP } \\
\left({ }^{\circ} \mathrm{C}\right) \\
\end{array}$ & $\begin{array}{c}\mathbf{R H} \\
(\%)\end{array}$ & $\begin{array}{r}\text { ZONE } \\
\text { AIRFLOW } \\
(\mathrm{L} / \mathrm{s}) \\
\end{array}$ & $\begin{array}{r}\text { ZONE } \\
\text { SENSIBLE } \\
\text { LOAD } \\
(\mathrm{W})\end{array}$ & $\begin{array}{r}\text { ZONE } \\
\text { COND } \\
(\mathrm{W})\end{array}$ & $\begin{array}{r}\text { TERMINAL } \\
\text { COOLING } \\
\text { COIL } \\
(\mathrm{W}) \\
\end{array}$ & $\begin{array}{r}\text { TERMINAL } \\
\text { HEATING } \\
\text { COIL } \\
(\mathrm{W}) \\
\end{array}$ & $\begin{array}{r}\text { ZONE } \\
\text { HEATING } \\
\text { UNIT } \\
\text { (W) }\end{array}$ \\
\hline 0000 & 19,9 & 24,1 & 45 & 2166,5 & 4872,8 & 4073,3 & 0,0 & 0,0 & 0,0 \\
\hline 0100 & 19,2 & 24,1 & 45 & 2166,5 & 4266,4 & 3575,3 & 0,0 & 0,0 & 0,0 \\
\hline 0200 & 18,6 & 24,0 & 45 & 2166,5 & 3689,5 & 3485,9 & 0,0 & 0,0 & 0,0 \\
\hline 0300 & 18,1 & 24,1 & 45 & 2166,5 & 3147,4 & 2593,1 & 0,0 & 0,0 & 0,0 \\
\hline 0400 & 17,7 & 24,0 & 45 & 2166,5 & 2640,8 & 2421,8 & 0,0 & 0,0 & 0,0 \\
\hline 0500 & 17,6 & 23,9 & 45 & 2166,5 & 2170,0 & 2262,4 & 0,0 & 0,0 & 0,0 \\
\hline 0600 & 17,8 & 23,9 & 45 & 2166,5 & 1736,3 & 1859,3 & 0,0 & 0,0 & 0,0 \\
\hline 0700 & 18,5 & 23,9 & 45 & 2166,5 & 1345,8 & 1409,0 & 0,0 & 0,0 & 0,0 \\
\hline 0800 & 19,6 & 24,1 & 44 & 2166,5 & 6912,5 & 6228,9 & 0,0 & 0,0 & 0,0 \\
\hline 0900 & 21,3 & 24,0 & 44 & 2166,5 & 7152,4 & 6978,0 & 0,0 & 0,0 & 0,0 \\
\hline 1000 & 23,3 & 24,1 & 43 & 2166,5 & 7637,3 & 6856,9 & 0,0 & 0,0 & 0,0 \\
\hline 1100 & 25,5 & 24,1 & 43 & 2166,5 & 8263,1 & 7540,9 & 0,0 & 0,0 & 0,0 \\
\hline 1200 & 27,6 & 24,2 & 43 & 2166,5 & 8926,9 & 7728,7 & 0,0 & 0,0 & 0,0 \\
\hline 1300 & 29,1 & 24,1 & 43 & 2166,5 & 9559,9 & 8894,2 & 0,0 & 0,0 & 0,0 \\
\hline 1400 & 30,2 & 24,1 & 43 & 2166,5 & 10154,3 & 9110,7 & 0,0 & 0,0 & 0,0 \\
\hline 1500 & 30,6 & 24,1 & 43 & 2166,5 & 10765,7 & 10222,9 & 0,0 & 0,0 & 0,0 \\
\hline 1600 & 30,2 & 24,2 & 43 & 2166,5 & 11411,8 & 10213,2 & 0,0 & 0,0 & 0,0 \\
\hline 1700 & 29,3 & 24,1 & 43 & 2166,5 & 12046,5 & 11353,3 & 0,0 & 0,0 & 0,0 \\
\hline 1800 & 27,8 & 24,2 & 43 & 2166,5 & 12574,4 & 11253,0 & 0,0 & 0,0 & 0,0 \\
\hline 1900 & 26,1 & 24,1 & 43 & 2166,5 & 12864,8 & 12139,6 & 0,0 & 0,0 & 0,0 \\
\hline 2000 & 24,4 & 24,2 & 43 & 2166,5 & 12839,7 & 11514,0 & 0,0 & 0,0 & 0,0 \\
\hline 2100 & 23,0 & 24,1 & 43 & 2166,5 & 6744,1 & \begin{tabular}{ll|}
6346,2 \\
\end{tabular} & 0,0 & 0,0 & 0,0 \\
\hline 2200 & 21,7 & 24,0 & 44 & 2166,5 & 6132,9 & 5731,2 & 0,0 & 0,0 & 0,0 \\
\hline 2300 & 20,7 & 24,1 & 43 & 2166,5 & 5499,9 & 4708,4 & 0,0 & 0,0 & 0,0 \\
\hline
\end{tabular}

\begin{tabular}{|c|c|c|c|c|c|c|c|c|c|}
\hline \multicolumn{10}{|c|}{$\begin{array}{c}\text { ZONE: Zone } 1 \\
\text { DESIGN MONTH: APRIL }\end{array}$} \\
\hline Hour & $\begin{array}{r}\text { OA } \\
\text { TEMP } \\
\left({ }^{\circ} \mathbf{C}\right)\end{array}$ & $\begin{array}{r}\text { ZONE } \\
\text { TEMP } \\
\left({ }^{\circ} \mathrm{C}\right)\end{array}$ & $\begin{array}{c}\mathbf{R H} \\
(\%)\end{array}$ & $\begin{array}{r}\text { ZONE } \\
\text { AIRFLOW } \\
(\mathrm{L} / \mathrm{s})\end{array}$ & $\begin{array}{r}\text { ZONE } \\
\text { SENSIBLE } \\
\text { LOAD } \\
\text { (W) }\end{array}$ & $\begin{array}{r}\text { ZONE } \\
\text { COND } \\
\text { (W) }\end{array}$ & $\begin{array}{r}\text { TERMINAL } \\
\text { COOLING } \\
\text { COIL } \\
\text { (W) }\end{array}$ & $\begin{array}{r}\text { TERMINAL } \\
\text { HEATING } \\
\text { COIL } \\
\text { (W) }\end{array}$ & $\begin{array}{r}\text { ZONE } \\
\text { HEATING } \\
\text { UNIT } \\
\text { (W) }\end{array}$ \\
\hline 0000 & 18,8 & 24,1 & 43 & 2166,5 & 4383,8 & 3807,3 & 0,0 & 0,0 & 0,0 \\
\hline 0100 & 18,1 & 24,0 & 44 & 2166,5 & 3787,6 & 3588,9 & 0,0 & 0,0 & 0,0 \\
\hline 0200 & 17,5 & 24,0 & 44 & 2166,5 & 3219,9 & 3068,8 & 0,0 & 0,0 & 0,0 \\
\hline 0300 & 17,0 & 24,0 & 44 & 2166,5 & 2685,7 & 2645,4 & 0,0 & 0,0 & 0,0 \\
\hline 0400 & 16,6 & 24,0 & 44 & 2166,5 & 2185,9 & 1726,4 & 0,0 & 0,0 & 0,0 \\
\hline 0500 & 16,4 & 24,0 & 44 & 2166,5 & 1720,8 & 1251,0 & 0,0 & 0,0 & 0,0 \\
\hline 0600 & 16,7 & 23,9 & 44 & 2166,5 & 1292,0 & 1765,0 & 0,0 & 0,0 & 0,0 \\
\hline 0700 & 17,4 & 24,0 & 44 & 2166,5 & 904,2 & 613,8 & 0,0 & 0,0 & 0,0 \\
\hline 0800 & 18,5 & 24,1 & 42 & 2166,5 & 6470,5 & 5833,4 & 0,0 & 0,0 & 0,0 \\
\hline 0900 & 20,2 & 24,0 & 42 & 2166,5 & 6715,5 & 6575,7 & 0,0 & 0,0 & 0,0 \\
\hline 1000 & 22,2 & 24,2 & 42 & 2166,5 & 7211,5 & 6031,4 & 0,0 & 0,0 & 0,0 \\
\hline 1100 & 24,4 & 24,1 & 42 & 2166,5 & 7849,7 & 7105,0 & 0,0 & 0,0 & 0,0 \\
\hline 1200 & 26,5 & 24,1 & 42 & 2166,5 & 8525,0 & 7833,9 & 0,0 & 0,0 & 0,0 \\
\hline 1300 & 28,0 & 24,2 & 42 & 2166,5 & 9173,4 & 7882,8 & 0,0 & 0,0 & 0,0 \\
\hline 1400 & 29,1 & 24,1 & 42 & 2166,5 & 9795,8 & 9219,0 & 0,0 & 0,0 & 0,0 \\
\hline 1500 & 29,4 & 24,2 & 42 & 2166,5 & 10437,8 & 9362,8 & 0,0 & 0,0 & 0,0 \\
\hline 1600 & 29,1 & 24,2 & 42 & 2166,5 & 11103,1 & 10094,1 & 0,0 & 0,0 & 0,0 \\
\hline 1700 & 28,1 & 24,2 & 42 & 2166,5 & 11736,6 & 10253,0 & 0,0 & 0,0 & 0,0 \\
\hline 1800 & 26,7 & 24,1 & 42 & 2166,5 & 12225,7 & 11332,9 & 0,0 & 0,0 & 0,0 \\
\hline 1900 & 25,0 & 24,2 & 42 & 2166,5 & 12430,7 & 11182,3 & 0,0 & 0,0 & 0,0 \\
\hline 2000 & 23,3 & 24,2 & 42 & 2166,5 & 12346,1 & 11203,8 & 0,0 & 0,0 & 0,0 \\
\hline 2100 & 21,9 & 24,0 & 42 & 2166,5 & 6232,7 & 5883,9 & 0,0 & 0,0 & 0,0 \\
\hline 2200 & 20,6 & 24,1 & 42 & 2166,5 & 5623,8 & 4940,7 & 0,0 & 0,0 & 0,0 \\
\hline 2300 & 19,6 & 24,0 & 42 & 2166,5 & 5000,0 & 4858,3 & 0,0 & 0,0 & 0,0 \\
\hline
\end{tabular}




\begin{tabular}{|c|c|c|c|c|c|c|c|c|c|}
\hline \multicolumn{10}{|c|}{$\begin{array}{c}\text { ZONE: Zone } 1 \\
\text { DESIGN MONTH: MAY }\end{array}$} \\
\hline Hour & $\begin{array}{r}\text { OA } \\
\text { TEMP } \\
\left({ }^{\circ} \mathbf{C}\right)\end{array}$ & $\begin{array}{r}\text { ZONE } \\
\text { TEMP } \\
\left({ }^{\circ} \mathrm{C}\right) \\
\end{array}$ & $\begin{array}{c}\mathbf{R H} \\
(\%)\end{array}$ & $\begin{array}{r}\text { ZONE } \\
\text { AIRFLOW } \\
(\mathrm{L} / \mathrm{s}) \\
\end{array}$ & $\begin{array}{r}\text { ZONE } \\
\text { SENSIBLE } \\
\text { LOAD } \\
(\mathrm{W})\end{array}$ & $\begin{array}{r}\text { ZONE } \\
\text { COND } \\
(\mathrm{W})\end{array}$ & $\begin{array}{r}\text { TERMINAL } \\
\text { COOLING } \\
\text { COIL } \\
(\mathrm{W}) \\
\end{array}$ & $\begin{array}{r}\text { TERMINAL } \\
\text { HEATING } \\
\text { COIL } \\
(\mathrm{W}) \\
\end{array}$ & $\begin{array}{r}\text { ZONE } \\
\text { HEATING } \\
\text { UNIT } \\
\text { (W) }\end{array}$ \\
\hline 0000 & 17,1 & 23,9 & 43 & 2166,5 & 3639,3 & 3853,9 & 0,0 & 0,0 & 0,0 \\
\hline 0100 & 16,5 & 23,9 & 42 & 2166,5 & 3059,2 & 3135,4 & 0,0 & 0,0 & 0,0 \\
\hline 0200 & 15,8 & 23,9 & 43 & 2166,5 & 2505,5 & 2592,9 & 0,0 & 0,0 & 0,0 \\
\hline 0300 & 15,3 & 23,9 & 43 & 2166,5 & 1983,5 & 2070,9 & 0,0 & 0,0 & 0,0 \\
\hline 0400 & 14,9 & 23,9 & 43 & 2166,5 & 1494,1 & 1820,8 & 0,0 & 0,0 & 0,0 \\
\hline 0500 & 14,8 & 24,0 & 42 & 2166,5 & 1037,9 & 520,6 & 0,0 & 0,0 & 0,0 \\
\hline 0600 & 15,0 & 24,0 & 42 & 2166,5 & 616,9 & 304,6 & 0,0 & 0,0 & 0,0 \\
\hline 0700 & 15,7 & 23,9 & 43 & 2166,5 & 235,6 & 221,9 & 0,0 & 0,0 & 0,0 \\
\hline 0800 & 16,9 & 24,0 & 42 & 2166,5 & 5803,6 & 5543,9 & 0,0 & 0,0 & 0,0 \\
\hline 0900 & 18,5 & 24,1 & 42 & 2166,5 & 6039,0 & 4986,6 & 0,0 & 0,0 & 0,0 \\
\hline 1000 & 20,5 & 24,1 & 42 & 2166,5 & 6524,6 & 5489,4 & 0,0 & 0,0 & 0,0 \\
\hline 1100 & 22,7 & 24,1 & 42 & 2166,5 & 7158,6 & 6396,0 & 0,0 & 0,0 & 0,0 \\
\hline 1200 & 24,8 & 24,0 & 42 & 2166,5 & 7836,7 & 7612,5 & 0,0 & 0,0 & 0,0 \\
\hline 1300 & 26,3 & 24,1 & 42 & 2166,5 & 8495,0 & 7600,7 & 0,0 & 0,0 & 0,0 \\
\hline 1400 & 27,4 & 24,1 & 42 & 2166,5 & 9133,1 & 8304,9 & 0,0 & 0,0 & 0,0 \\
\hline 1500 & 27,8 & 24,2 & 42 & 2166,5 & 9788,9 & 8484,3 & 0,0 & 0,0 & 0,0 \\
\hline 1600 & 27,4 & 24,1 & 42 & 2166,5 & 10459,6 & 9686,2 & 0,0 & 0,0 & 0,0 \\
\hline 1700 & 26,5 & 24,2 & 42 & 2166,5 & 11086,1 & 9937,8 & 0,0 & 0,0 & 0,0 \\
\hline 1800 & 25,0 & 24,1 & 42 & 2166,5 & 11542,1 & 10775,9 & 0,0 & 0,0 & 0,0 \\
\hline 1900 & 23,4 & 24,2 & 42 & 2166,5 & 11681,0 & 10482,3 & 0,0 & 0,0 & 0,0 \\
\hline 2000 & 21,7 & 24,3 & 42 & 2166,5 & 11556,6 & 10031,7 & 0,0 & 0,0 & 0,0 \\
\hline 2100 & 20,2 & 24,0 & 42 & 2166,5 & 5439,8 & 5590,4 & 0,0 & 0,0 & 0,0 \\
\hline 2200 & \begin{tabular}{l|}
18,9 \\
\end{tabular} & 24,1 & 42 & 2166,5 & 4843,9 & 4167,4 & 0,0 & 0,0 & 0,0 \\
\hline 2300 & 17,9 & 23,9 & 42 & 2166,5 & 4237,9 & 4449,9 & 0,0 & 0,0 & 0,0 \\
\hline
\end{tabular}

\begin{tabular}{|c|c|c|c|c|c|c|c|c|c|}
\hline \multicolumn{10}{|c|}{$\begin{array}{c}\text { ZONE: Zone } 1 \\
\text { DESIGN MONTH: JUNE }\end{array}$} \\
\hline Hour & $\begin{array}{r}\text { OA } \\
\text { TEMP } \\
\left({ }^{\circ} \mathbf{C}\right)\end{array}$ & $\begin{array}{r}\text { ZONE } \\
\text { TEMP } \\
\left({ }^{\circ} \mathrm{C}\right)\end{array}$ & $\begin{array}{c}\mathbf{R H} \\
(\%)\end{array}$ & $\begin{array}{r}\text { ZONE } \\
\text { AIRFLOW } \\
(\mathrm{L} / \mathrm{s})\end{array}$ & $\begin{array}{r}\text { ZONE } \\
\text { SENSIBLE } \\
\text { LOAD } \\
\text { (W) }\end{array}$ & $\begin{array}{r}\text { ZONE } \\
\text { COND } \\
\text { (W) }\end{array}$ & $\begin{array}{r}\text { TERMINAL } \\
\text { COOLING } \\
\text { COIL } \\
\text { (W) }\end{array}$ & $\begin{array}{r}\text { TERMINAL } \\
\text { HEATING } \\
\text { COIL } \\
\text { (W) }\end{array}$ & $\begin{array}{r}\text { ZONE } \\
\text { HEATING } \\
\text { UNIT } \\
\text { (W) }\end{array}$ \\
\hline 0000 & 16,0 & 24,0 & 42 & 2166,5 & 3200,9 & 2822,0 & 0,0 & 0,0 & 0,0 \\
\hline 0100 & 15,4 & 23,9 & 42 & 2166,5 & 2623,9 & 2667,4 & 0,0 & 0,0 & 0,0 \\
\hline 0200 & 14,7 & 23,9 & 42 & 2166,5 & 2072,8 & 2078,9 & 0,0 & 0,0 & 0,0 \\
\hline 0300 & 14,2 & 24,0 & 42 & 2166,5 & 1553,2 & 1236,0 & 0,0 & 0,0 & 0,0 \\
\hline 0400 & 13,8 & 23,8 & 43 & 2166,5 & 1065,8 & \begin{tabular}{|c|}
1604,3 \\
\end{tabular} & 0,0 & 0,0 & 0,0 \\
\hline 0500 & 13,7 & 23,9 & 42 & 2166,5 & 611,5 & 728,2 & 0,0 & 0,0 & 0,0 \\
\hline 0600 & 13,9 & 23,9 & 43 & 2166,5 & 192,1 & 550,5 & 0,0 & 0,0 & 0,0 \\
\hline 0700 & 14,6 & 23,9 & 42 & 2166,5 & $-187,9$ & 39,2 & 0,0 & 0,0 & 0,0 \\
\hline 0800 & 15,7 & 23,9 & 38 & 2166,5 & 5375,3 & 5474,8 & 0,0 & 0,0 & 0,0 \\
\hline 0900 & 17,4 & 24,0 & 38 & 2166,5 & 5587,7 & 5332,2 & 0,0 & 0,0 & 0,0 \\
\hline 1000 & 19,4 & 24,0 & 38 & 2166,5 & 6049,3 & 5354,5 & 0,0 & 0,0 & 0,0 \\
\hline 1100 & 21,6 & 24,0 & 38 & 2166,5 & 6671,0 & 6040,7 & 0,0 & 0,0 & 0,0 \\
\hline 1200 & 23,7 & 24,1 & 38 & 2166,5 & 7348,5 & 6241,3 & 0,0 & 0,0 & 0,0 \\
\hline 1300 & 25,2 & 24,0 & 38 & 2166,5 & 8012,9 & 7444,5 & 0,0 & 0,0 & 0,0 \\
\hline 1400 & 26,3 & 24,1 & 38 & 2166,5 & 8654,7 & 7707,4 & 0,0 & 0,0 & 0,0 \\
\hline 1500 & 26,7 & 24,1 & 38 & 2166,5 & 9310,0 & 8432,2 & 0,0 & 0,0 & 0,0 \\
\hline 1600 & 26,3 & 24,2 & 37 & 2166,5 & 9978,8 & 8613,7 & 0,0 & 0,0 & 0,0 \\
\hline 1700 & 25,4 & 24,1 & 38 & 2166,5 & 10605,2 & 9813,9 & 0,0 & 0,0 & 0,0 \\
\hline 1800 & 23,9 & 24,2 & 37 & 2166,5 & 11065,8 & 9902,0 & 0,0 & 0,0 & 0,0 \\
\hline 1900 & 22,2 & 24,2 & 37 & 2166,5 & 11213,9 & 9997,8 & 0,0 & 0,0 & 0,0 \\
\hline 2000 & 20,6 & 24,2 & 37 & 2166,5 & 11098,3 & 9879,9 & 0,0 & 0,0 & 0,0 \\
\hline 2100 & 19,1 & 24,0 & 38 & 2166,5 & 4988,2 & 4884,4 & 0,0 & 0,0 & 0,0 \\
\hline 2200 & 17,8 & 24,0 & 38 & 2166,5 & 4397,6 & 4278,3 & 0,0 & 0,0 & 0,0 \\
\hline 2300 & 16,8 & 23,9 & 38 & 2166,5 & 3795,8 & 4300,5 & 0,0 & 0,0 & 0,0 \\
\hline
\end{tabular}




\begin{tabular}{|c|c|c|c|c|c|c|c|c|c|}
\hline \multicolumn{10}{|c|}{$\begin{array}{c}\text { ZONE: Zone } 1 \\
\text { DESIGN MONTH: JULY }\end{array}$} \\
\hline Hour & $\begin{array}{r}\mathrm{OA} \\
\mathrm{TEMP} \\
\left({ }^{\circ} \mathrm{C}\right) \\
\end{array}$ & $\begin{array}{r}\text { ZONE } \\
\text { TEMP } \\
\left({ }^{\circ} \mathrm{C}\right) \\
\end{array}$ & $\begin{array}{c}\mathbf{R H} \\
(\%)\end{array}$ & $\begin{array}{r}\text { ZONE } \\
\text { AIRFLOW } \\
(\mathrm{L} / \mathrm{s}) \\
\end{array}$ & $\begin{array}{r}\text { ZONE } \\
\text { SENSIBLE } \\
\text { LOAD } \\
(\mathrm{W})\end{array}$ & $\begin{array}{r}\text { ZONE } \\
\text { COND } \\
(\mathrm{W})\end{array}$ & $\begin{array}{r}\text { TERMINAL } \\
\text { COOLING } \\
\text { COIL } \\
(\mathrm{W}) \\
\end{array}$ & $\begin{array}{r}\text { TERMINAL } \\
\text { HEATING } \\
\text { COIL } \\
(\mathrm{W}) \\
\end{array}$ & $\begin{array}{r}\text { ZONE } \\
\text { HEATING } \\
\text { UNIT } \\
\text { (W) }\end{array}$ \\
\hline 0000 & 15,5 & 23,9 & 38 & 2166,5 & 3073,1 & 3149,3 & 0,0 & 0,0 & 0,0 \\
\hline 0100 & 14,8 & 23,9 & 38 & 2166,5 & 2486,3 & 2936,8 & 0,0 & 0,0 & 0,0 \\
\hline 0200 & 14,2 & 24,0 & 38 & 2166,5 & 1926,7 & 1511,0 & 0,0 & 0,0 & 0,0 \\
\hline 0300 & 13,6 & 23,9 & 38 & 2166,5 & 1399,6 & 1597,5 & 0,0 & 0,0 & 0,0 \\
\hline 0400 & 13,2 & 23,8 & 38 & 2166,5 & 905,9 & 1446,2 & 0,0 & 0,0 & 0,0 \\
\hline 0500 & 13,1 & 23,9 & 38 & 2166,5 & 446,1 & 511,8 & 0,0 & 0,0 & 0,0 \\
\hline 0600 & 13,4 & 23,8 & 38 & 2166,5 & 22,0 & 568,3 & 0,0 & 0,0 & 0,0 \\
\hline 0700 & 14,0 & 23,8 & 38 & 2166,5 & $-362,0$ & 40,1 & 0,0 & 0,0 & 0,0 \\
\hline 0800 & 15,2 & 23,8 & 36 & 2166,5 & 5197,3 & 5796,0 & 0,0 & 0,0 & 0,0 \\
\hline 0900 & 16,9 & 24,0 & 36 & 2166,5 & 5405,3 & 4772,6 & 0,0 & 0,0 & 0,0 \\
\hline 1000 & 18,8 & 24,0 & 36 & 2166,5 & 5862,6 & 5320,3 & 0,0 & 0,0 & 0,0 \\
\hline 1100 & 21,0 & 24,1 & 35 & 2166,5 & 6481,0 & 5389,9 & 0,0 & 0,0 & 0,0 \\
\hline 1200 & 23,1 & 24,0 & 36 & 2166,5 & 7156,4 & 6751,5 & 0,0 & 0,0 & 0,0 \\
\hline 1300 & 24,7 & 24,1 & 36 & 2166,5 & 7817,6 & 6923,5 & 0,0 & 0,0 & 0,0 \\
\hline 1400 & 25,7 & 24,1 & 36 & 2166,5 & 8450,7 & 7628,6 & 0,0 & 0,0 & 0,0 \\
\hline 1500 & 26,1 & 24,2 & 35 & 2166,5 & 9095,7 & 7810,9 & 0,0 & 0,0 & 0,0 \\
\hline 1600 & 25,7 & 24,1 & 36 & 2166,5 & 9758,9 & 9004,2 & 0,0 & 0,0 & 0,0 \\
\hline 1700 & 24,8 & 24,2 & 35 & 2166,5 & 10389,3 & 9269,3 & 0,0 & 0,0 & 0,0 \\
\hline 1800 & 23,4 & 24,1 & 36 & 2166,5 & 10875,3 & 10170,7 & 0,0 & 0,0 & 0,0 \\
\hline 1900 & 21,7 & 24,2 & 35 & 2166,5 & 11075,1 & 9898,2 & 0,0 & 0,0 & 0,0 \\
\hline 2000 & 20,0 & 24,2 & 35 & 2166,5 & 10992,4 & 9935,9 & 0,0 & 0,0 & 0,0 \\
\hline 2100 & 18,6 & 24,0 & 36 & 2166,5 & 4888,1 & 4437,5 & 0,0 & 0,0 & 0,0 \\
\hline 2200 & 17,3 & 24,1 & 36 & 2166,5 & 4290,9 & 3555,3 & 0,0 & 0,0 & 0,0 \\
\hline 2300 & 16,2 & 24,0 & 36 & 2166,5 & 3678,8 & 3403,1 & 0,0 & 0,0 & 0,0 \\
\hline
\end{tabular}

\begin{tabular}{|c|c|c|c|c|c|c|c|c|c|}
\hline \multicolumn{10}{|c|}{$\begin{array}{c}\text { ZONE: Zone } 1 \\
\text { DESIGN MONTH: AUGUST }\end{array}$} \\
\hline Hour & $\begin{array}{r}\text { OA } \\
\text { TEMP } \\
\left({ }^{\circ} \mathbf{C}\right)\end{array}$ & $\begin{array}{r}\text { ZONE } \\
\text { TEMP } \\
\left({ }^{\circ} \mathrm{C}\right) \\
\end{array}$ & $\begin{array}{c}\mathbf{R H} \\
(\%)\end{array}$ & $\begin{array}{r}\text { ZONE } \\
\text { AIRFLOW } \\
(\mathrm{L} / \mathrm{s}) \\
\end{array}$ & $\begin{array}{r}\text { ZONE } \\
\text { SENSIBLE } \\
\text { LOAD } \\
\text { (W) }\end{array}$ & $\begin{array}{r}\text { ZONE } \\
\text { COND } \\
(\mathrm{W})\end{array}$ & $\begin{array}{r}\text { TERMINAL } \\
\text { COOLING } \\
\text { COIL } \\
(\mathrm{W}) \\
\end{array}$ & $\begin{array}{r}\text { TERMINAL } \\
\text { HEATING } \\
\text { COIL } \\
(\mathrm{W}) \\
\end{array}$ & $\begin{array}{r}\text { ZONE } \\
\text { HEATING } \\
\text { UNIT } \\
\text { (W) }\end{array}$ \\
\hline 0000 & 16,6 & 23,9 & 36 & 2166,5 & 3550,7 & 3901,6 & 0,0 & 0,0 & 0,0 \\
\hline 0100 & 15,9 & 24,0 & 36 & 2166,5 & 2955,7 & 2685,6 & 0,0 & 0,0 & 0,0 \\
\hline 0200 & 15,3 & 23,9 & 36 & 2166,5 & 2388,8 & 2682,0 & 0,0 & 0,0 & 0,0 \\
\hline 0300 & \begin{tabular}{ll|}
14,7 \\
\end{tabular} & 24,0 & 36 & 2166,5 & 1855,5 & 1368,8 & 0,0 & 0,0 & 0,0 \\
\hline 0400 & 14,4 & 23,8 & 36 & 2166,5 & 1356,3 & 1907,9 & 0,0 & 0,0 & 0,0 \\
\hline 0500 & 14,2 & 23,9 & 36 & 2166,5 & 891,9 & 965,2 & 0,0 & 0,0 & 0,0 \\
\hline 0600 & 14,5 & 24,0 & 36 & 2166,5 & 463,8 & 209,6 & 0,0 & 0,0 & 0,0 \\
\hline 0700 & 15,1 & 23,8 & 36 & 2166,5 & 76,4 & 581,4 & 0,0 & 0,0 & 0,0 \\
\hline 0800 & 16,3 & 23,9 & 37 & 2166,5 & 5640,9 & 5631,1 & 0,0 & 0,0 & 0,0 \\
\hline 0900 & 18,0 & 24,1 & 37 & 2166,5 & 5878,1 & 4929,3 & 0,0 & 0,0 & 0,0 \\
\hline 1000 & 19,9 & 24,0 & 37 & 2166,5 & 6362,1 & 6003,3 & 0,0 & 0,0 & 0,0 \\
\hline 1100 & 22,2 & 24,1 & 37 & 2166,5 & 6987,5 & 6206,9 & 0,0 & 0,0 & 0,0 \\
\hline 1200 & 24,2 & 24,1 & 37 & 2166,5 & 7651,9 & 6937,8 & 0,0 & 0,0 & 0,0 \\
\hline 1300 & 25,8 & 24,2 & 36 & 2166,5 & 8290,7 & 7096,6 & 0,0 & 0,0 & 0,0 \\
\hline 1400 & 26,8 & 24,1 & 37 & 2166,5 & 8900,5 & 8268,3 & 0,0 & 0,0 & 0,0 \\
\hline 1500 & 27,2 & 24,1 & 36 & 2166,5 & 9528,2 & 8504,5 & 0,0 & 0,0 & 0,0 \\
\hline 1600 & 26,8 & 24,1 & 36 & 2166,5 & 10182,2 & 9228,0 & 0,0 & 0,0 & 0,0 \\
\hline 1700 & 25,9 & 24,2 & 36 & 2166,5 & 10812,3 & 9384,6 & 0,0 & 0,0 & 0,0 \\
\hline 1800 & 24,5 & 24,1 & 36 & 2166,5 & 11313,9 & 10479,6 & 0,0 & 0,0 & 0,0 \\
\hline 1900 & 22,8 & 24,2 & 36 & 2166,5 & 11550,3 & 10359,6 & 0,0 & 0,0 & 0,0 \\
\hline 2000 & 21,1 & 24,2 & 36 & 2166,5 & 11490,7 & 10390,0 & 0,0 & 0,0 & 0,0 \\
\hline 2100 & 19,7 & 24,1 & 37 & 2166,5 & 5389,6 & 4949,1 & 0,0 & 0,0 & 0,0 \\
\hline 2200 & 18,4 & 23,9 & 37 & 2166,5 & 4786,3 & 4900,6 & 0,0 & 0,0 & 0,0 \\
\hline 2300 & \begin{tabular}{l|l|}
17,3 \\
\end{tabular} & 24,1 & 37 & 2166,5 & 4165,3 & 3565,8 & 0,0 & 0,0 & 0,0 \\
\hline
\end{tabular}




\begin{tabular}{|c|c|c|c|c|c|c|c|c|c|}
\hline \multicolumn{10}{|c|}{$\begin{array}{c}\text { ZONE: Zone } 1 \\
\text { DESIGN MONTH: SEPTEMBER }\end{array}$} \\
\hline Hour & $\begin{array}{r}\text { OA } \\
\text { TEMP } \\
\left({ }^{\circ} \mathbf{C}\right)\end{array}$ & $\begin{array}{r}\text { ZONE } \\
\text { TEMP } \\
\left({ }^{\circ} \mathrm{C}\right) \\
\end{array}$ & $\begin{array}{c}\mathbf{R H} \\
(\%)\end{array}$ & $\begin{array}{r}\text { ZONE } \\
\text { AIRFLOW } \\
(\mathrm{L} / \mathrm{s}) \\
\end{array}$ & $\begin{array}{r}\text { ZONE } \\
\text { SENSIBLE } \\
\text { LOAD } \\
(\mathrm{W})\end{array}$ & $\begin{array}{r}\text { ZONE } \\
\text { COND } \\
(\mathrm{W})\end{array}$ & $\begin{array}{r}\text { TERMINAL } \\
\text { COOLING } \\
\text { COIL } \\
(\mathrm{W}) \\
\end{array}$ & $\begin{array}{r}\text { TERMINAL } \\
\text { HEATING } \\
\text { COIL } \\
(\mathrm{W}) \\
\end{array}$ & $\begin{array}{r}\text { ZONE } \\
\text { HEATING } \\
\text { UNIT } \\
\text { (W) }\end{array}$ \\
\hline 0000 & 18,2 & 24,1 & 37 & 2166,5 & 4122,3 & 3362,1 & 0,0 & 0,0 & 0,0 \\
\hline 0100 & 17,6 & 24,0 & 37 & 2166,5 & 3533,1 & 3482,2 & 0,0 & 0,0 & 0,0 \\
\hline 0200 & 16,9 & 24,0 & 37 & 2166,5 & 2971,2 & 2530,1 & 0,0 & 0,0 & 0,0 \\
\hline 0300 & 16,4 & 24,0 & 37 & 2166,5 & 2442,0 & 2053,2 & 0,0 & 0,0 & 0,0 \\
\hline 0400 & 16,0 & 23,8 & 37 & 2166,5 & 1946,5 & 2536,9 & 0,0 & 0,0 & 0,0 \\
\hline 0500 & 15,9 & 24,0 & 37 & 2166,5 & 1485,1 & 948,4 & 0,0 & 0,0 & 0,0 \\
\hline 0600 & 16,1 & 23,9 & 37 & 2166,5 & 1059,8 & 1171,4 & 0,0 & 0,0 & 0,0 \\
\hline 0700 & 16,8 & 24,0 & 37 & 2166,5 & 694,9 & 317,3 & 0,0 & 0,0 & 0,0 \\
\hline 0800 & 18,0 & 24,1 & 40 & 2166,5 & 6340,4 & 5376,1 & 0,0 & 0,0 & 0,0 \\
\hline 0900 & 19,7 & 24,1 & 40 & 2166,5 & 6652,8 & 6058,3 & 0,0 & 0,0 & 0,0 \\
\hline 1000 & 21,6 & 24,0 & 40 & 2166,5 & 7160,1 & 6605,0 & 0,0 & 0,0 & 0,0 \\
\hline 1100 & 23,8 & 24,1 & 40 & 2166,5 & 7763,5 & 6687,2 & 0,0 & 0,0 & 0,0 \\
\hline 1200 & 25,9 & 24,0 & 40 & 2166,5 & 8377,6 & 7889,3 & 0,0 & 0,0 & 0,0 \\
\hline 1300 & 27,5 & 24,1 & 40 & 2166,5 & 8955,3 & 8047,1 & 0,0 & 0,0 & 0,0 \\
\hline 1400 & 28,5 & 24,0 & 40 & 2166,5 & 9516,5 & 9056,4 & 0,0 & 0,0 & 0,0 \\
\hline 1500 & 28,9 & 24,1 & 40 & 2166,5 & 10111,7 & 9059,0 & 0,0 & 0,0 & 0,0 \\
\hline 1600 & 28,5 & 24,1 & 40 & 2166,5 & $\begin{array}{l}10742,4 \\
\end{array}$ & 10189,2 & 0,0 & 0,0 & 0,0 \\
\hline 1700 & 27,6 & 24,2 & 40 & 2166,5 & 11353,9 & 10157,8 & 0,0 & 0,0 & 0,0 \\
\hline 1800 & 26,2 & 24,1 & 40 & 2166,5 & 11842,8 & 11036,5 & 0,0 & 0,0 & 0,0 \\
\hline 1900 & 24,5 & 24,2 & 40 & 2166,5 & 12079,5 & 10828,8 & 0,0 & 0,0 & 0,0 \\
\hline 2000 & 22,8 & 24,2 & 40 & 2166,5 & 12028,3 & 10872,2 & 0,0 & 0,0 & 0,0 \\
\hline 2100 & 21,3 & 24,1 & 40 & 2166,5 & 5937,0 & 5273,3 & 0,0 & 0,0 & 0,0 \\
\hline 2200 & 20,0 & 24,1 & 40 & 2166,5 & 5342,9 & 4856,8 & 0,0 & 0,0 & 0,0 \\
\hline 2300 & 19,0 & 24,1 & 40 & 2166,5 & 4730,0 & 3977,0 & 0,0 & 0,0 & 0,0 \\
\hline
\end{tabular}

\begin{tabular}{|c|c|c|c|c|c|c|c|c|c|}
\hline \multicolumn{10}{|c|}{$\begin{array}{c}\text { ZONE: Zone } 1 \\
\text { DESIGN MONTH: OCTOBER }\end{array}$} \\
\hline Hour & $\begin{array}{r}\text { OA } \\
\text { TEMP } \\
\left({ }^{\circ} \mathbf{C}\right)\end{array}$ & $\begin{array}{r}\text { ZONE } \\
\text { TEMP } \\
\left({ }^{\circ} \mathrm{C}\right)\end{array}$ & $\begin{array}{c}\mathbf{R H} \\
(\%)\end{array}$ & $\begin{array}{r}\text { ZONE } \\
\text { AIRFLOW } \\
(\mathrm{L} / \mathrm{s})\end{array}$ & $\begin{array}{r}\text { ZONE } \\
\text { SENSIBLE } \\
\text { LOAD } \\
\text { (W) }\end{array}$ & $\begin{array}{r}\text { ZONE } \\
\text { COND } \\
(\mathrm{W})\end{array}$ & $\begin{array}{r}\text { TERMINAL } \\
\text { COOLING } \\
\text { COIL } \\
\text { (W) }\end{array}$ & $\begin{array}{r}\text { TERMINAL } \\
\text { HEATING } \\
\text { COIL } \\
\text { (W) }\end{array}$ & $\begin{array}{r}\text { ZONE } \\
\text { HEATING } \\
\text { UNIT } \\
\text { (W) }\end{array}$ \\
\hline 0000 & 18,8 & 24,0 & 40 & 2166,5 & 4321,4 & 3918,3 & 0,0 & 0,0 & 0,0 \\
\hline 0100 & 18,1 & 23,9 & 40 & 2166,5 & 3733,3 & 3957,1 & 0,0 & 0,0 & 0,0 \\
\hline 0200 & 17,5 & 23,9 & 40 & 2166,5 & 3172,1 & 3236,1 & 0,0 & 0,0 & 0,0 \\
\hline 0300 & 17,0 & 23,9 & 40 & 2166,5 & 2643,5 & 2718,1 & 0,0 & 0,0 & 0,0 \\
\hline 0400 & 16,6 & 23,9 & 40 & 2166,5 & 2148,4 & 2223,2 & 0,0 & 0,0 & 0,0 \\
\hline 0500 & 16,4 & 23,9 & 40 & 2166,5 & 1687,3 & 2031,7 & 0,0 & 0,0 & 0,0 \\
\hline 0600 & 16,7 & 24,1 & 40 & 2166,5 & 1262,5 & 606,0 & 0,0 & 0,0 & 0,0 \\
\hline 0700 & 17,4 & 24,0 & 40 & 2166,5 & 915,8 & 370,5 & 0,0 & 0,0 & 0,0 \\
\hline 0800 & 18,5 & 24,0 & 42 & 2166,5 & 6632,8 & 6143,8 & 0,0 & 0,0 & 0,0 \\
\hline 0900 & 20,2 & 24,1 & 42 & 2166,5 & 7011,8 & 5981,6 & 0,0 & 0,0 & 0,0 \\
\hline 1000 & 22,2 & 24,0 & 42 & 2166,5 & 7533,7 & 7176,0 & 0,0 & 0,0 & 0,0 \\
\hline 1100 & 24,4 & 24,1 & 42 & 2166,5 & 8107,7 & 7267,4 & 0,0 & 0,0 & 0,0 \\
\hline 1200 & 26,5 & 24,0 & 42 & 2166,5 & 8669,3 & 8273,3 & 0,0 & 0,0 & 0,0 \\
\hline 1300 & 28,0 & 24,1 & 42 & 2166,5 & 9189,8 & 8218,5 & 0,0 & 0,0 & 0,0 \\
\hline 1400 & 29,1 & 24,1 & 42 & 2166,5 & 9706,8 & 9144,7 & 0,0 & 0,0 & 0,0 \\
\hline 1500 & 29,4 & 24,2 & 42 & 2166,5 & 10270,3 & 9183,6 & 0,0 & 0,0 & 0,0 \\
\hline 1600 & 29,1 & 24,1 & 42 & 2166,5 & 10875,8 & 10279,8 & 0,0 & 0,0 & 0,0 \\
\hline 1700 & 28,1 & 24,2 & 42 & 2166,5 & 11472,1 & 10251,6 & 0,0 & 0,0 & 0,0 \\
\hline 1800 & 26,7 & 24,1 & 42 & 2166,5 & 11968,1 & 11148,6 & 0,0 & 0,0 & 0,0 \\
\hline 1900 & 25,0 & 24,2 & 42 & 2166,5 & 12230,7 & 10953,6 & 0,0 & 0,0 & 0,0 \\
\hline 2000 & 23,3 & 24,2 & 42 & 2166,5 & 12202,7 & 11006,3 & 0,0 & 0,0 & 0,0 \\
\hline 2100 & 21,9 & 24,2 & 42 & 2166,5 & 6124,5 & 5093,2 & 0,0 & 0,0 & 0,0 \\
\hline 2200 & 20,6 & 24,1 & 42 & 2166,5 & 5537,0 & 4629,1 & 0,0 & 0,0 & 0,0 \\
\hline 2300 & 19,6 & 24,1 & 42 & 2166,5 & 4927,4 & 4310,3 & 0,0 & 0,0 & 0,0 \\
\hline
\end{tabular}




\begin{tabular}{|c|c|c|c|c|c|c|c|c|c|}
\hline \multicolumn{10}{|c|}{$\begin{array}{c}\text { ZONE: Zone } 1 \\
\text { DESIGN MONTH: NOVEMBER }\end{array}$} \\
\hline Hour & $\begin{array}{r}\text { OA } \\
\text { TEMP } \\
\left({ }^{\circ} \mathbf{C}\right)\end{array}$ & $\begin{array}{r}\text { ZONE } \\
\text { TEMP } \\
\left({ }^{\circ} \mathrm{C}\right) \\
\end{array}$ & $\begin{array}{c}\mathbf{R H} \\
(\%)\end{array}$ & $\begin{array}{r}\text { ZONE } \\
\text { AIRFLOW } \\
(\mathrm{L} / \mathrm{s}) \\
\end{array}$ & $\begin{array}{r}\text { ZONE } \\
\text { SENSIBLE } \\
\text { LOAD } \\
(\mathrm{W})\end{array}$ & $\begin{array}{r}\text { ZONE } \\
\text { COND } \\
(\mathrm{W})\end{array}$ & $\begin{array}{r}\text { TERMINAL } \\
\text { COOLING } \\
\text { COIL } \\
(\mathrm{W}) \\
\end{array}$ & $\begin{array}{r}\text { TERMINAL } \\
\text { HEATING } \\
\text { COIL } \\
(\mathrm{W}) \\
\end{array}$ & $\begin{array}{r}\text { ZONE } \\
\text { HEATING } \\
\text { UNIT } \\
\text { (W) }\end{array}$ \\
\hline 0000 & 19,3 & 24,0 & 42 & 2166,5 & 4886,5 & 4481,4 & 0,0 & 0,0 & 0,0 \\
\hline 0100 & $\begin{array}{l}18,7 \\
\end{array}$ & 24,0 & 42 & 2166,5 & 4255,7 & 4133,0 & 0,0 & 0,0 & 0,0 \\
\hline 0200 & 18,0 & 24,0 & 42 & 2166,5 & 3657,3 & 3527,9 & 0,0 & 0,0 & 0,0 \\
\hline 0300 & 17,5 & 24,0 & 42 & 2166,5 & 3096,4 & 2606,8 & 0,0 & 0,0 & 0,0 \\
\hline 0400 & 17,1 & 24,0 & 42 & 2166,5 & 2573,3 & 2145,8 & 0,0 & 0,0 & 0,0 \\
\hline 0500 & \begin{tabular}{l|l}
17,0 \\
\end{tabular} & 24,0 & 42 & 2166,5 & 2088,1 & \begin{tabular}{l|l}
1946,2 \\
\end{tabular} & 0,0 & 0,0 & 0,0 \\
\hline 0600 & 17,3 & 23,9 & 43 & 2166,5 & 1642,3 & 1737,9 & 0,0 & 0,0 & 0,0 \\
\hline 0700 & 17,9 & 23,9 & 43 & 2166,5 & 1284,7 & 1408,9 & 0,0 & 0,0 & 0,0 \\
\hline 0800 & 19,1 & 24,1 & 44 & 2166,5 & 7022,3 & 6302,3 & 0,0 & 0,0 & 0,0 \\
\hline 0900 & 20,8 & 24,0 & 45 & 2166,5 & 7451,4 & 7077,8 & 0,0 & 0,0 & 0,0 \\
\hline 1000 & 22,7 & 24,1 & 44 & 2166,5 & 8037,8 & 7200,0 & 0,0 & 0,0 & 0,0 \\
\hline 1100 & 24,9 & 24,0 & 45 & 2166,5 & 8667,1 & 8330,4 & 0,0 & 0,0 & 0,0 \\
\hline 1200 & 27,0 & 24,1 & 44 & 2166,5 & 9260,1 & 8270,7 & 0,0 & 0,0 & 0,0 \\
\hline 1300 & 28,6 & 24,1 & 45 & 2166,5 & 9789,0 & 9226,9 & 0,0 & 0,0 & 0,0 \\
\hline 1400 & 29,6 & 24,2 & 44 & 2166,5 & 10299,9 & 9202,7 & 0,0 & 0,0 & 0,0 \\
\hline 1500 & 30,0 & 24,1 & 44 & 2166,5 & 10859,1 & 10216,5 & 0,0 & 0,0 & 0,0 \\
\hline 1600 & 29,6 & 24,2 & 44 & 2166,5 & 11479,1 & 10256,5 & 0,0 & 0,0 & 0,0 \\
\hline 1700 & 28,7 & 24,1 & 44 & 2166,5 & 12113,0 & 11407,0 & 0,0 & 0,0 & 0,0 \\
\hline 1800 & 27,3 & 24,2 & 44 & 2166,5 & 12660,6 & 11314,7 & 0,0 & 0,0 & 0,0 \\
\hline 1900 & 25,6 & 24,1 & 44 & 2166,5 & 12973,5 & 12280,0 & 0,0 & 0,0 & 0,0 \\
\hline 2000 & 23,9 & 24,2 & 44 & 2166,5 & 12951,9 & 11548,5 & 0,0 & 0,0 & 0,0 \\
\hline 2100 & 22,5 & 24,1 & 44 & 2166,5 & 6839,6 & $\begin{array}{l}6014,7 \\
\end{array}$ & 0,0 & 0,0 & 0,0 \\
\hline 2200 & 21,2 & 24,1 & 44 & 2166,5 & 6202,0 & 5588,4 & 0,0 & 0,0 & 0,0 \\
\hline 2300 & 20,1 & 24,1 & 44 & 2166,5 & 5540,6 & 4736,3 & 0,0 & 0,0 & 0,0 \\
\hline
\end{tabular}

\begin{tabular}{|c|c|c|c|c|c|c|c|c|c|}
\hline \multicolumn{10}{|c|}{$\begin{array}{c}\text { ZONE: Zone } 1 \\
\text { DESIGN MONTH: DECEMBER }\end{array}$} \\
\hline Hour & $\begin{array}{r}\mathrm{OA} \\
\mathrm{TEMP} \\
\left({ }^{\circ} \mathrm{C}\right) \\
\end{array}$ & $\begin{array}{r}\text { ZONE } \\
\text { TEMP } \\
\left({ }^{\circ} \mathrm{C}\right) \\
\end{array}$ & $\begin{array}{c}\mathbf{R H} \\
(\%)\end{array}$ & $\begin{array}{r}\text { ZONE } \\
\text { AIRFLOW } \\
(\mathrm{L} / \mathrm{s}) \\
\end{array}$ & $\begin{array}{r}\text { ZONE } \\
\text { SENSIBLE } \\
\text { LOAD } \\
\text { (W) }\end{array}$ & $\begin{array}{r}\text { ZONE } \\
\text { COND } \\
(\mathrm{W})\end{array}$ & $\begin{array}{r}\text { TERMINAL } \\
\text { COOLING } \\
\text { COIL } \\
(\mathrm{W}) \\
\end{array}$ & $\begin{array}{r}\text { TERMINAL } \\
\text { HEATING } \\
\text { COIL } \\
(\mathrm{W}) \\
\end{array}$ & $\begin{array}{r}\text { ZONE } \\
\text { HEATING } \\
\text { UNIT } \\
\text { (W) }\end{array}$ \\
\hline 0000 & 20,5 & 24,0 & 45 & 2166,5 & 5519,0 & 5396,9 & 0,0 & 0,0 & 0,0 \\
\hline 0100 & 19,8 & 24,0 & 45 & 2166,5 & 4861,5 & 4751,6 & 0,0 & 0,0 & 0,0 \\
\hline 0200 & 19,2 & 23,9 & 45 & 2166,5 & 4239,6 & 4574,4 & 0,0 & 0,0 & 0,0 \\
\hline 0300 & 18,6 & 24,1 & 45 & 2166,5 & 3658,5 & 3096,4 & 0,0 & 0,0 & 0,0 \\
\hline 0400 & 18,2 & 24,0 & 45 & 2166,5 & 3118,0 & 2718,2 & 0,0 & 0,0 & 0,0 \\
\hline 0500 & 18,1 & 24,0 & 45 & 2166,5 & 2617,6 & 2135,6 & 0,0 & 0,0 & 0,0 \\
\hline 0600 & 18,4 & 23,8 & 45 & 2166,5 & 2158,7 & 2738,4 & 0,0 & 0,0 & 0,0 \\
\hline 0700 & 19,0 & 24,1 & 44 & 2166,5 & 1783,0 & 1049,0 & 0,0 & 0,0 & 0,0 \\
\hline 0800 & 20,2 & 24,0 & 46 & 2166,5 & 7486,5 & 7443,5 & 0,0 & 0,0 & 0,0 \\
\hline 0900 & 21,9 & 24,1 & 46 & 2166,5 & 7894,4 & 6813,7 & 0,0 & 0,0 & 0,0 \\
\hline 1000 & 23,8 & 24,1 & 46 & 2166,5 & 8490,3 & 7893,1 & 0,0 & 0,0 & 0,0 \\
\hline 1100 & 26,0 & 24,1 & 46 & 2166,5 & 9155,4 & 8205,3 & 0,0 & 0,0 & 0,0 \\
\hline 1200 & 28,1 & 24,1 & 46 & 2166,5 & 9800,1 & 8912,0 & 0,0 & 0,0 & 0,0 \\
\hline 1300 & 29,7 & 24,2 & 45 & 2166,5 & 10381,9 & 9036,7 & 0,0 & 0,0 & 0,0 \\
\hline 1400 & 30,7 & 24,1 & 46 & 2166,5 & 10925,2 & \begin{tabular}{l|}
10124,5 \\
\end{tabular} & 0,0 & 0,0 & 0,0 \\
\hline 1500 & 31,1 & 24,2 & 46 & 2166,5 & 11498,4 & 10320,3 & 0,0 & 0,0 & 0,0 \\
\hline 1600 & 30,7 & 24,2 & 46 & 2166,5 & 12125,9 & 11013,0 & 0,0 & 0,0 & 0,0 \\
\hline 1700 & 29,8 & 24,3 & 45 & 2166,5 & 12769,9 & 11189,8 & 0,0 & 0,0 & 0,0 \\
\hline 1800 & 28,4 & 24,2 & 46 & 2166,5 & 13342,3 & 12319,1 & 0,0 & 0,0 & 0,0 \\
\hline 1900 & 26,7 & 24,2 & 45 & 2166,5 & 13696,3 & 12321,8 & 0,0 & 0,0 & 0,0 \\
\hline 2000 & 25,0 & 24,2 & 45 & 2166,5 & 13690,6 & 12367,9 & 0,0 & 0,0 & 0,0 \\
\hline 2100 & 23,6 & 24,0 & 46 & 2166,5 & 7563,0 & 7465,0 & 0,0 & 0,0 & 0,0 \\
\hline 2200 & 22,3 & 24,1 & 46 & 2166,5 & 6896,3 & 6410,4 & 0,0 & 0,0 & 0,0 \\
\hline 2300 & 21,2 & 24,1 & 46 & 2166,5 & 6203,1 & 5663,1 & 0,0 & 0,0 & 0,0 \\
\hline
\end{tabular}


TABLE 1: SYSTEM DATA

\begin{tabular}{|c|c|c|c|c|c|c|c|}
\hline Component & Location & $\begin{array}{r}\text { Dry-Bulb } \\
\text { Temp } \\
\left({ }^{\circ} \mathrm{C}\right)\end{array}$ & $\begin{array}{r}\text { Specific } \\
\text { Humidity } \\
(\mathrm{kg} / \mathrm{kg})\end{array}$ & $\begin{array}{r}\text { Airflow } \\
(\mathrm{L} / \mathrm{s}) \\
\end{array}$ & $\begin{array}{r}\text { CO2 Level } \\
(p p m)\end{array}$ & $\begin{array}{r}\text { Sensible } \\
\text { Heat } \\
(\mathrm{W}) \\
\end{array}$ & $\begin{array}{r}\text { Latent } \\
\text { Heat } \\
(\mathrm{W})\end{array}$ \\
\hline Ventilation Air & Inlet & 30,4 & 0,00950 & 638 & 400 & 4241 & 0 \\
\hline Vent - Return Mixing & Outlet & 26,0 & 0,00950 & 2167 & 417 & - & - \\
\hline Central Cooling Coil & Outlet & 18,9 & 0,00950 & 2167 & 417 & 16198 & 0 \\
\hline Central Heating Coil & Outlet & 18,9 & 0,00950 & 2167 & 417 & 0 & - \\
\hline Supply Fan & Outlet & 18,9 & 0,00950 & 2167 & 417 & 0 & - \\
\hline Cold Supply Duct & Outlet & 18,9 & 0,00950 & 2167 & 417 & - & - \\
\hline Zone Air & - & 24,1 & 0,00950 & 2167 & 425 & 11957 & 0 \\
\hline Return Plenum & Outlet & 24,1 & 0,00950 & 2167 & 425 & 0 & 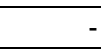 \\
\hline
\end{tabular}

Air Density x Heat Capacity $x$ Conversion Factor: At sea level = 1,207; At site altitude $=1,063 \mathrm{~W} /(\mathrm{L} / \mathrm{s}-\mathrm{K})$

Air Density $x$ Heat of Vaporization $x$ Conversion Factor: At sea level = 2947,6; At site altitude $=2595,3 \mathrm{~W} /(\mathrm{L} / \mathrm{s})$

Site Altitude $=1060,7 \mathrm{~m}$

TABLE 2: ZONE DATA

\begin{tabular}{|l|r|r|r|r|r|r|r|r|}
\hline & $\begin{array}{r}\text { Zone } \\
\text { Zensible } \\
\text { Load } \\
\text { Zone Name }\end{array}$ & $\begin{array}{r}\text { T-stat } \\
\text { Mode }\end{array}$ & $\begin{array}{r}\text { Zone } \\
\text { Cond } \\
(\mathbf{W})\end{array}$ & $\begin{array}{r}\text { Zone } \\
\text { Temp } \\
\left({ }^{\circ} \mathbf{C}\right)\end{array}$ & $\begin{array}{r}\text { Zone } \\
\text { Airflow } \\
(\mathbf{L} / \mathbf{s})\end{array}$ & $\begin{array}{r}\text { CO2 } \\
\text { Level } \\
(\mathbf{p p m})\end{array}$ & $\begin{array}{r}\text { Terminal } \\
\text { Heating } \\
\text { Coil } \\
(\mathbf{W})\end{array}$ & $\begin{array}{r}\text { Zone } \\
\text { Heating } \\
\text { Unit } \\
(\mathbf{W})\end{array}$ \\
\hline Zone 1 & 12707 & Cooling & 11957 & 24,1 & 2167 & 425 & 0 & 0 \\
\hline
\end{tabular}


TABLE 1: SYSTEM DATA

\begin{tabular}{|c|c|c|c|c|c|c|c|}
\hline Component & Location & $\begin{array}{r}\text { Dry-Bulb } \\
\text { Temp } \\
\left({ }^{\circ} \mathrm{C}\right)\end{array}$ & $\begin{array}{r}\text { Specific } \\
\text { Humidity } \\
(\mathrm{kg} / \mathrm{kg})\end{array}$ & $\begin{array}{r}\text { Airflow } \\
(\mathrm{L} / \mathrm{s})\end{array}$ & $\begin{array}{r}\text { CO2 Level } \\
(p p m)\end{array}$ & $\begin{array}{r}\text { Sensible } \\
\text { Heat } \\
(\mathrm{W}) \\
\end{array}$ & $\begin{array}{r}\text { Latent } \\
\text { Heat } \\
(\mathrm{W})\end{array}$ \\
\hline Ventilation Air & Inlet & 8,9 & 0,00400 & 638 & 400 & -8236 & 0 \\
\hline Vent - Return Mixing & Outlet & 17,5 & 0,00400 & 2167 & 417 & - & - \\
\hline Central Cooling Coil & Outlet & 17,5 & 0,00400 & 2167 & 417 & 0 & 0 \\
\hline Central Heating Coil & Outlet & 22,9 & 0,00400 & 2167 & 417 & 12578 & - \\
\hline Supply Fan & Outlet & 22,9 & 0,00400 & 2167 & 417 & 0 & - \\
\hline Cold Supply Duct & Outlet & 22,9 & 0,00400 & 2167 & 417 & - & - \\
\hline Zone Air & - & 21,0 & 0,00400 & 2167 & 425 & -4342 & 0 \\
\hline Return Plenum & Outlet & 21,0 & 0,00400 & 2167 & 425 & 0 & - \\
\hline
\end{tabular}

Air Density x Heat Capacity x Conversion Factor: At sea level = 1,207; At site altitude = 1,063 W/(L/s-K)

Air Density x Heat of Vaporization x Conversion Factor: At sea level = 2947,6; At site altitude = 2595,3 W/(L/s)

Site Altitude $=1060,7 \mathrm{~m}$

TABLE 2: ZONE DATA

\begin{tabular}{|c|c|c|c|c|c|c|c|c|}
\hline Zone Name & $\begin{array}{r}\text { Zone } \\
\text { Sensible } \\
\text { Load } \\
(\mathrm{W})\end{array}$ & $\begin{array}{l}\text { T-stat } \\
\text { Mode }\end{array}$ & $\begin{array}{r}\text { Zone } \\
\text { Cond } \\
(\mathrm{W})\end{array}$ & $\begin{array}{r}\text { Zone } \\
\text { Temp } \\
\left({ }^{\circ} \mathrm{C}\right)\end{array}$ & $\begin{array}{r}\text { Zone } \\
\text { Airflow } \\
(\mathrm{L} / \mathrm{s})\end{array}$ & $\begin{array}{r}\text { CO2 } \\
\text { Level } \\
(p p m)\end{array}$ & $\begin{array}{r}\text { Terminal } \\
\text { Heating } \\
\text { Coil } \\
(\mathrm{W}) \\
\end{array}$ & $\begin{array}{r}\text { Zone } \\
\text { Heating } \\
\text { Unit } \\
\text { (W) }\end{array}$ \\
\hline Zone 1 & -4511 & Heating & -4342 & 21,0 & 2167 & 425 & 0 & 0 \\
\hline
\end{tabular}




\section{APÊNDICE E - RELÁTORIO DE SELEÇÃO DO CHILLER DE 12 TR E DEMAIS DADOS DO CATÁLOGO DO FABRICANTE}

Chiller 12 TR

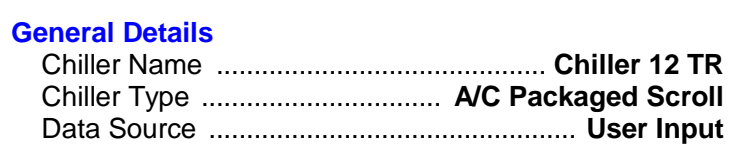

Notes:

Design Inputs

\begin{tabular}{|c|c|}
\hline (2) & ${ }^{\circ} \mathrm{C}$ \\
\hline Full Load OAT & ${ }^{\circ} \mathrm{C}$ \\
\hline Full Load Capacity & $\mathrm{kW}$ \\
\hline Full Load Power & $\mathrm{kW}$ \\
\hline Cooler Flow Rate & $\mathrm{L} /(\mathrm{s}-\mathrm{kW})$ \\
\hline 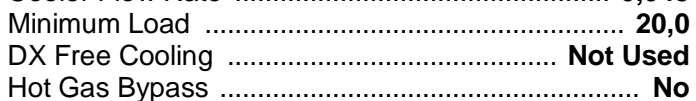 & $\%$ \\
\hline
\end{tabular}

Chiller Performance (kW)

\begin{tabular}{|c|c|c|c|c|c|c|c|c|c|c|}
\hline OAT $\left({ }^{\circ} \mathbf{C}\right)$ & Max Cap & $\mathbf{1 0 0} \%$ & $\mathbf{9 0} \%$ & $\mathbf{8 0} \%$ & $\mathbf{7 0} \%$ & $\mathbf{6 0} \%$ & $\mathbf{5 0} \%$ & $\mathbf{4 0} \%$ & $\mathbf{3 0} \%$ & $\mathbf{2 0} \%$ \\
\hline 46,1 & 22,2 & 22,2 & 19,5 & 16,7 & 14,1 & 12,1 & 10,1 & 8,0 & 6,0 & 4,2 \\
\hline 35,0 & 16,4 & 16,4 & 14,4 & 12,4 & 10,5 & 9,0 & 7,5 & 6,0 & 4,5 & 3,1 \\
\hline 29,4 & 13,4 & 13,4 & 11,8 & 10,2 & 8,6 & 7,4 & 6,2 & 4,9 & 3,7 & 2,6 \\
\hline 23,9 & 12,3 & 12,3 & 10,8 & 9,4 & 8,0 & 6,8 & 5,7 & 4,6 & 3,4 & 2,4 \\
\hline$-17,8$ & 11,4 & 11,4 & 9,9 & 8,5 & 7,1 & 5,9 & 4,8 & 3,7 & 2,6 & 1,5 \\
\hline
\end{tabular}

Performance LCHWT Factor a

$0,012331 / \mathrm{K}$

Performance LCHWT Factor $b$

Chiller Capacity (kW)

\begin{tabular}{|c|c|c|c|c|c|c|c|c|c|c|}
\hline $\left.\mathbf{O A T}^{(}{ }^{\circ} \mathbf{C}\right)$ & Max Cap & $\mathbf{1 0 0} \%$ & $\mathbf{9 0} \%$ & $\mathbf{8 0} \%$ & $\mathbf{7 0} \%$ & $\mathbf{6 0} \%$ & $\mathbf{5 0} \%$ & $\mathbf{4 0} \%$ & $\mathbf{3 0} \%$ & $\mathbf{2 0} \%$ \\
\hline 46,1 & 43,0 & 43,0 & 38,7 & 34,4 & 30,1 & 25,8 & 21,5 & 17,2 & 12,9 & 8,6 \\
\hline 35,0 & 43,0 & 43,0 & 38,7 & 34,4 & 30,1 & 25,8 & 21,5 & 17,2 & 12,9 & 8,6 \\
\hline 29,4 & 43,0 & 43,0 & 38,7 & 34,4 & 30,1 & 25,8 & 21,5 & 17,2 & 12,9 & 8,6 \\
\hline 23,9 & 43,0 & 43,0 & 38,7 & 34,4 & 30,1 & 25,8 & 21,5 & 17,2 & 12,9 & 8,6 \\
\hline$-17,8$ & 43,0 & 43,0 & 38,7 & 34,4 & 30,1 & 25,8 & 21,5 & 17,2 & 12,9 & 8,6 \\
\hline
\end{tabular}


Capacity LCHWT Factor a

$\mathbf{0 , 0 3 2 5 1} 1 / \mathrm{K}$

Capacity LCHWT Factor b

$0,00000 \quad 1 / K^{2}$

\section{DADOS FISICOS $60 \mathrm{~Hz}$ R-407}

\begin{tabular}{|c|c|c|c|c|c|c|c|c|c|c|c|c|c|}
\hline 30RA & & 12 & 15 & 18 & 20 & 24 & 27 & 30 & 35 & 40 & 50 & 65 & 75 \\
\hline Capacidade nominal & TR & 11.9 & 14.4 & 17.1 & 10.6 & 23.4 & 26.3 & 29.1 & 35.4 & 37.2 & $46 . \theta$ & 62.4 & 74.4 \\
\hline Capacidado nominal & $\mathrm{kW}$ & 42 & 50.6 & 60.3 & 65.4 & 92.3 & 92.6 & 102.4 & 124 & 130.7 & 164 & 219.4 & $2 \mathrm{BD} .1$ \\
\hline Peso em operaçáo com módulo hidrónico & $\mathrm{kg}$ & 536 & 595 & 610 & 625 & 642 & 1100 & 1112 & 1157 & 1224 & 1262 & 2056 & 2166 \\
\hline Carga de refrigerante & $\mathrm{kg}$ & \multicolumn{12}{|l|}{$\mathrm{R}-407 \mathrm{C}$} \\
\hline Circuito $A$ & & 10 & 13 & 14 & 12.5 & 18 & 10 & 10 & 10 & 12.5 & 18 & 21 & $2 \mathrm{~B}$ \\
\hline Circuito B & & $x$ & $x$ & $x$ & $x$ & $x$ & 13 & 14 & 18 & 12.5 & 18 & 28 & $2 \mathrm{~B}$ \\
\hline Compressores & & \multicolumn{12}{|c|}{ Compressor Scroll hermético } \\
\hline Quantidade, circuito $A$ & & 1 & 2 & 2 & 2 & 2 & 1 & 1 & 1 & 2 & 2 & 2 & 3 \\
\hline Quantidade, circuito B & & $x$ & $x$ & $x$ & $x$ & $x$ & 2 & 2 & 2 & 2 & 2 & 3 & 3 \\
\hline Número de estágios de capacidade & & 1 & 2 & 2 & 2 & 2 & 3 & 3 & 3 & 4 & 4 & 5 & B \\
\hline Capacidade mínima & $\%$ & 100 & 50 & 42 & 50 & 50 & 26 & 27 & 33 & 25 & 25 & 20 & 16.6 \\
\hline Tipo de controle & & \multicolumn{12}{|c|}{ PRO-DIALOG Plus } \\
\hline Condensadores & & \multicolumn{12}{|c|}{ Tubos de cobre ranhurados intemamente, aletas de alumínio } \\
\hline Ventiladores & & \multicolumn{12}{|c|}{ Ventiladares axiais Flying Bird com difusar rotativo } \\
\hline Quantidade & & 1 & 1 & 1 & 1 & 1 & 2 & 2 & 2 & 2 & 2 & 4 & 4 \\
\hline Vazáo total de ar (velocidade alta) & $\mathrm{m}^{\mathrm{P} / \mathrm{h}}$ & 16650 & 15910 & 17856 & 22285 & 25200 & 32560 & 34505 & 41850 & 44570 & 50400 & 75130 & 90430 \\
\hline Velocidade (alta/baixa velocidade) & грпा & 810,420 & $810 / 420$ & $810 / 420$ & $1128 / 559$ & $1128 / 558$ & $810 / 420$ & $810 / 420$ & $1128 / 558$ & $1128 / 558$ & $1128 / 558$ & $1128 / 420$ & $112 B / 558$ \\
\hline Evaporador & & \multicolumn{12}{|c|}{ Trocador de calor de expansăo direta com placa soldada (inox) } \\
\hline Volume de àgua & । & 3.6 & 4.6 & 5.9 & 6.5 & 7.6 & 8.2 & 9.5 & 11.2 & 13.0 & 15.2 & 22 & 26 \\
\hline $\begin{array}{l}\text { Pressåo máxima em operaçăo no lado água } \\
\text { (unidade sem módulo hidrônico) }\end{array}$ & $\mathrm{kPa}$ & 1000 & 1000 & 1000 & 1000 & 1000 & 1000 & 1000 & 1000 & 1000 & 1000 & 1000 & 1000 \\
\hline Módulo hidrônico & & \multicolumn{12}{|c|}{ Bomba, filtro de tela, vály. segurança, tạ. expansão (apcional), manômetro, válv. purga, chave de fluxo e válv. reduçáo do controle de vazâc } \\
\hline Bomba & & \multicolumn{12}{|c|}{ Bomba única unicelular centrifuga, $3500 \mathrm{rpm}$} \\
\hline Quantidade & & 1 & 1 & 1 & 1 & 1 & 1 & 1 & 1 & 1 & 1 & 1 & 1 \\
\hline Volume do tanque de expansáo (opcional) & I & 12 & 12 & 12 & 12 & 12 & 35 & 35 & 35 & 35 & 35 & 50 & 50 \\
\hline $\begin{array}{l}\text { Pressáa máxima em aperaçăa no lada água } \\
\text { (unidade com módulo hidrônico) }\end{array}$ & $\mathrm{kPa}$ & 300 & 300 & 300 & 300 & 300 & 300 & 300 & 300 & 300 & 300 & 400 & 400 \\
\hline Conexões de água & & \multicolumn{12}{|c|}{ Conexốes de rosca macha } \\
\hline Diâmetro da rosca para tubulaçăa & in & 2 & 2 & 2 & 2 & 2 & 2 & 2 & $2.1 / 2$ & $2.1 / 2$ & $2.1 / 2$ & 3 & 3 \\
\hline Diâmetro do tubo externo & $\begin{array}{l}\text { in } \\
\text { mm }\end{array}$ & $\begin{array}{l}2 \\
60.3 \\
\end{array}$ & $\begin{array}{l}2 \\
60.3 \\
\end{array}$ & $\begin{array}{l}2 \\
60.3 \\
\end{array}$ & $\begin{array}{l}2 \\
60.3 \\
\end{array}$ & $\begin{array}{l}2 \\
60.3 \\
\end{array}$ & $\begin{array}{l}2 \\
60.3 \\
\end{array}$ & $\begin{array}{l}2 \\
60.3 \\
\end{array}$ & $\begin{array}{l}3 \\
76.1 \\
\end{array}$ & $\begin{array}{l}3 \\
76.1 \\
\end{array}$ & $\begin{array}{l}3 \\
76.1 \\
\end{array}$ & $\begin{array}{l}3.1 / 2 \\
80.9\end{array}$ & $\begin{array}{l}3.1 / 2 \\
\text { 日日.9 }\end{array}$ \\
\hline
\end{tabular}

${ }^{\pi}$ Temperatura da àgua de entrada/saida do evaporador de $12^{\circ} \mathrm{CJ} 7^{\circ} \mathrm{C}$, temperatura do ar exterior de $35^{\circ} \mathrm{C}$ 


\section{APÊNDICE F - RELÁTORIO DE SELEÇÃO DO FAN COIL DE 12 TR E DEMAIS DADOS DO CATÁLOGO DO FABRICANTE}

Projeto

$\begin{array}{ll}\text { Cliente } & \text { :PGR } \\ \text { Obra } & \text { :Climatização } \\ & \text { Terceirizados } \\ \text { Tag } & \text { : Maquina 02 } \\ \text { Por } & \text { : Matheus Valverde }\end{array}$

Geral

$\begin{array}{ll}\text { Série } & : \text { Vortex } \\ \text { Modelo } & : 12 \mathrm{TR} \\ \text { Frequência } & : 60 \mathrm{~Hz} \\ \text { Posição } & : \text { Horizontal } \\ \text { Lado Hidraúlica } & : \text { Direito }\end{array}$

Módulos da Máquina

Motor Ventilador

Serpentina Água Gelada + Filtro

Resfriamento

$\begin{array}{lll}\text { Dados de Entrada } & & \\ \text { Vazão } & =10.320,00 \mathrm{~m} 3 / \mathrm{h} \\ \text { TBS } & =24,00 \mathrm{C} \\ \text { TBU } & =17,00 \mathrm{C} \\ \text { Umidade Relativa } & =51,71 \% \\ \text { Umidade Absoluta } & =0,0112 \mathrm{kgH} 2 \mathrm{O} / \mathrm{kgda} \\ \text { Pressäo } & =656,26 \mathrm{mmHg} \\ \text { Ro } & =1,01 \mathrm{kgda} / \mathrm{m} 3 \\ \text { Fluído } & =\text { Água Gelada } \\ \text { Concentração do Fluido } & =0,00 \% \\ \text { Vazão de Água } & =7,27 \mathrm{~m} 3 / \mathrm{h} \\ \text { Temperatura da Água } & =7,00 \mathrm{C} \\ \text { Dados de Saida da Serpentina } \\ \text { Carga Térmica } & =45,36 \mathrm{~kW} \\ \text { Carga Sensivel } & =35,47 \mathrm{~kW} \\ \text { TBS } & =12,07 \mathrm{C} \\ \text { TBU } & =11,72 \mathrm{C} \\ \text { Umidade Relativa } & =96,32 \% \\ \text { Ar Veloc. Face } & =3,19 \mathrm{~m} / \mathrm{s} \\ \text { Fluído Temperatura } & =12,36 \mathrm{C} \\ \text { Perda Carga Água } & =47,83 \mathrm{kPa} \\ \text { Dados de Insuflamento } & \\ \text { TBS } & =12,79 \mathrm{C} \\ \text { TBU } & =11,98 \mathrm{C} \\ \text { Capacidade Total } & =43,19 \mathrm{~kW} \\ \text { FCS } & =33,30 \mathrm{~kW} \\ & =0,77 \\ & & \\ \text { Capidade Sensivel } & & \\ & & \end{array}$

Serpentina de Resfriamento

$\begin{array}{lll}\text { Tubo } & =1 / 2^{\prime \prime} \text { Cobre } \\ \text { Aleta } & =\mathrm{Al} \\ \text { D. Int. } & =12,26 \mathrm{~mm} \\ \text { D. Ext. } & =13,06 \mathrm{~mm} \\ \text { Esp. } & =0,127 \mathrm{~mm} \\ \text { FPI } & =9 \mathrm{FPI} \\ \text { Área de Face } & =0,90 \mathrm{~m} 2 \\ \text { Comprimento Aletado } & =1.287,00 \mathrm{~mm} \\ \text { Fator Incrustação } & =0,044 \mathrm{~m}^{2} \mathrm{~K} / \mathrm{KW} \\ \text { Nro. Filas } & =6 \\ \text { Nro. Circuitos } & =11 \\ \text { Nro. Tubos } & =22 \\ \text { Conexão } & =1.1 / 4^{\prime \prime}\end{array}$

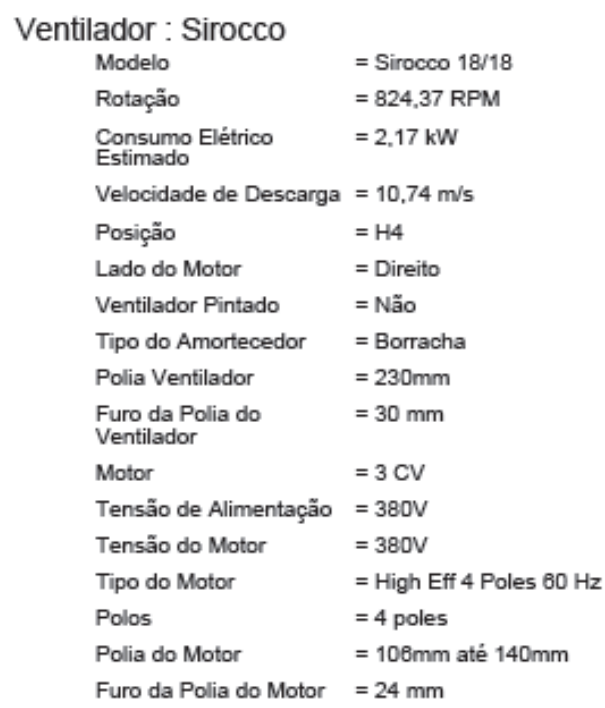

Perda de Carga do $\mathrm{Ar}$

$\begin{array}{ll}\text { Mistura } & =0,00 \mathrm{mmH} 20 \\ \text { Resfriamento } & =16,58 \mathrm{mmH} 20 \\ \text { Aquecimento } & =0,00 \mathrm{mmH} 20 \\ \text { Equalizador } & =0,00 \mathrm{mmH} 20 \\ \text { Resistência } & =0,00 \mathrm{mmH} 20 \\ \text { Atenuador } & =0,00 \mathrm{mmH} 20 \\ \text { Filtro Fino } & =0,00 \mathrm{mmH} 20 \\ \text { Filtro Absoluto } & =0,00 \mathrm{mmH} 20 \\ \text { Pré-Filtro } & =16,23 \mathrm{mmH} 20 \\ \text { Pressão Disponivel no } & =20,00 \mathrm{mmH} 20 \\ \text { Duto } & =52,81 \mathrm{mmH} 20\end{array}$

Filtros

$\begin{array}{ll}\text { Pré-Filtro } & =\mathrm{G} 4 \text { Moldura Metálica } 1 \\ \text { Filtro Fino } & =\mathrm{N} / \mathrm{A} \\ \text { Filtro Absoluto } & =\mathrm{N} / \mathrm{A} \\ \text { Observaçäo } & \end{array}$

Potência Sonora do Ventilador(dB(A))

Potência Sonora do Ventilador desconsiderando atenuação

$\begin{array}{ll}63 \mathrm{~Hz} & =66,6 \\ 125 \mathrm{~Hz} & =72,6 \\ 250 \mathrm{~Hz} & =72,6 \\ 500 \mathrm{~Hz} & =73,6 \\ 1000 \mathrm{~Hz} & =75,6 \\ 2000 \mathrm{~Hz} & =73,6 \\ 4000 \mathrm{~Hz} & =70,6 \\ 8000 \mathrm{~Hz} & =63,6 \\ \text { Global } & =81,44\end{array}$




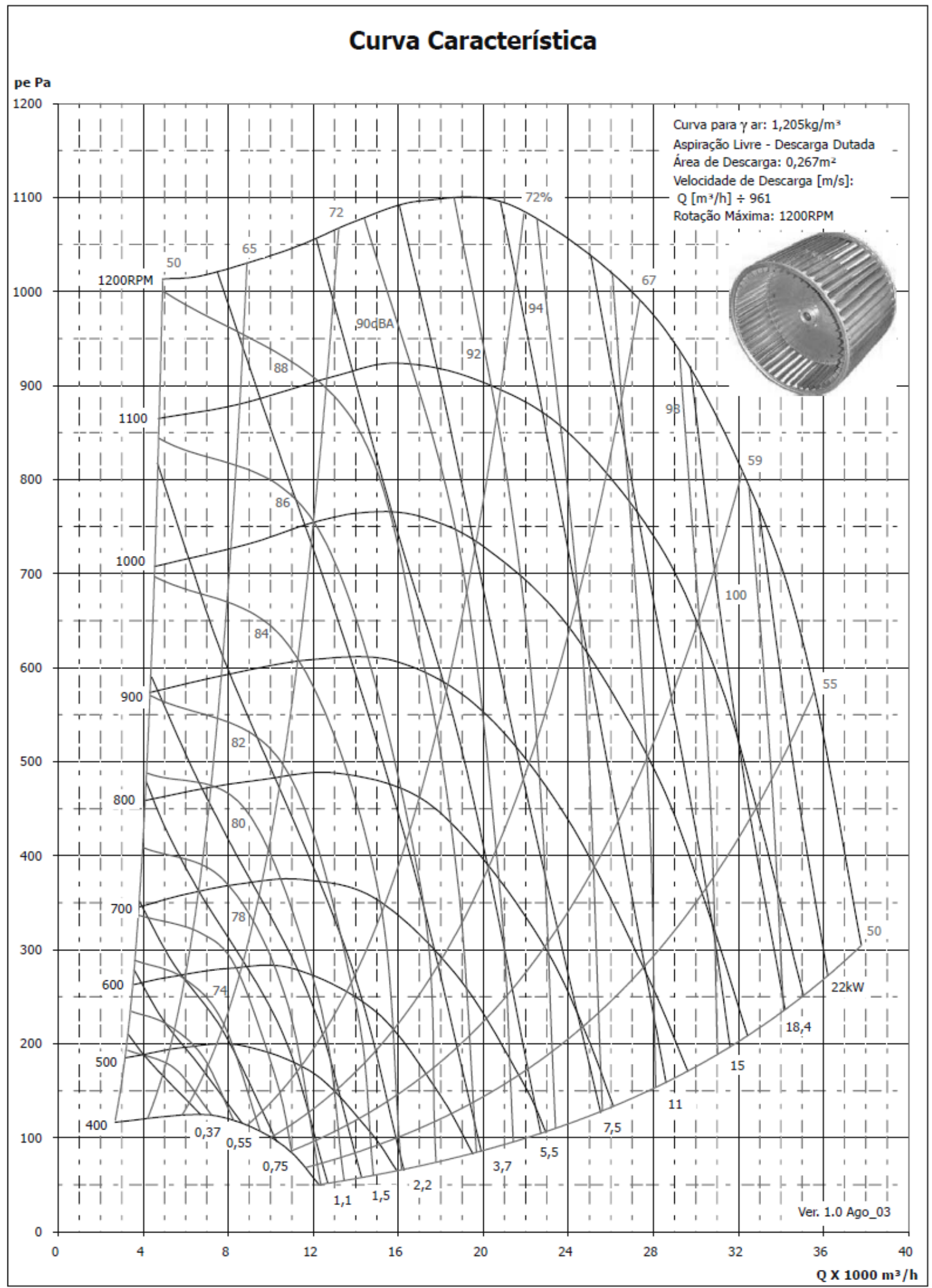




\section{APÊNDICE G - RELÁTORIO DE SELEÇÃO DO CHILLER DE 10 TR E DEMAIS DADOS DO CATÁLOGO DO FABRICANTE}

Chiller 10 TR

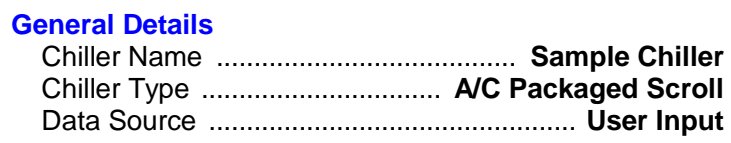

Chiller Performance (kW)

\begin{tabular}{|c|c|c|c|c|c|c|c|c|c|c|}
\hline $\mathbf{O A T}^{\circ}{ }^{\circ} \mathbf{C}$ ) & Max Cap & $\mathbf{1 0 0} \%$ & $\mathbf{9 0} \%$ & $\mathbf{8 0} \%$ & $\mathbf{7 0} \%$ & $\mathbf{6 0} \%$ & $\mathbf{5 0} \%$ & $\mathbf{4 0} \%$ & $\mathbf{3 0} \%$ & $\mathbf{2 0} \%$ \\
\hline 46,1 & 15,6 & 15,6 & 13,7 & 11,7 & 9,9 & 8,5 & 7,0 & 5,6 & 4,2 & 2,9 \\
\hline 35,0 & 11,5 & 11,5 & 10,1 & 8,7 & 7,4 & 6,3 & 5,2 & 4,2 & 3,2 & 2,2 \\
\hline 29,4 & 9,4 & 9,4 & 8,2 & 7,1 & 6,0 & 5,2 & 4,3 & 3,5 & 2,6 & 1,8 \\
\hline 23,9 & 8,6 & 8,6 & 7,6 & 6,6 & 5,6 & 4,8 & 4,0 & 3,2 & 2,4 & 1,7 \\
\hline$-17,8$ & 8,0 & 8,0 & 7,0 & 5,9 & 5,0 & 4,2 & 3,4 & 2,6 & 1,8 & 1,1 \\
\hline
\end{tabular}

Performance LCHWT Factor a $\mathbf{0 , 0 1 2 3 3} 1 / \mathrm{K}$

Performance LCHWT Factor b $0,000001 / K^{2}$

Chiller Capacity (kW)

\begin{tabular}{|c|c|c|c|c|c|c|c|c|c|c|}
\hline OAT $\left({ }^{\circ} \mathbf{C}\right)$ & Max Cap & $\mathbf{1 0 0} \%$ & $\mathbf{9 0} \%$ & $\mathbf{8 0} \%$ & $\mathbf{7 0} \%$ & $\mathbf{6 0} \%$ & $\mathbf{5 0} \%$ & $\mathbf{4 0} \%$ & $\mathbf{3 0} \%$ & $\mathbf{2 0} \%$ \\
\hline 46,1 & 35,0 & 35,0 & 31,5 & 28,0 & 24,5 & 21,0 & 17,5 & 14,0 & 10,5 & 7,0 \\
\hline 35,0 & 35,0 & 35,0 & 31,5 & 28,0 & 24,5 & 21,0 & 17,5 & 14,0 & 10,5 & 7,0 \\
\hline 29,4 & 35,0 & 35,0 & 31,5 & 28,0 & 24,5 & 21,0 & 17,5 & 14,0 & 10,5 & 7,0 \\
\hline 23,9 & 35,0 & 35,0 & 31,5 & 28,0 & 24,5 & 21,0 & 17,5 & 14,0 & 10,5 & 7,0 \\
\hline$-17,8$ & 35,0 & 35,0 & 31,5 & 28,0 & 24,5 & 21,0 & 17,5 & 14,0 & 10,5 & 7,0 \\
\hline
\end{tabular}




\begin{tabular}{|c|c|c|c|c|c|c|}
\hline \multicolumn{7}{|c|}{ Resfrlador de Liquldo com Condensação a ar 30AJ } \\
\hline \multicolumn{4}{|c|}{ Tamanhos } & 004 & 005 & 010 \\
\hline & 3.76 & 4.27 & 9.50 \\
\hline \multirow{7}{*}{ Caracteristicas } & \multicolumn{3}{|c|}{$\begin{array}{l}\text { Capacidade (TR) } \\
\text { Alimentaçāo Principal }\end{array}$} & \multicolumn{3}{|c|}{$220-380 \mathrm{~V} / 3 \mathrm{ph} / 60 \mathrm{~Hz}$} \\
\hline & \multicolumn{3}{|c|}{ Alimentaçāo de Comando } & \multicolumn{3}{|c|}{$24 \mathrm{~V} / 1 \mathrm{ph} / 60 \mathrm{~Hz}$} \\
\hline & \multicolumn{3}{|c|}{ Núm. Circuitos Frigorificos } & 1 & 1 & 1 \\
\hline & \multicolumn{3}{|c|}{ Núm. Estágios de Capacidade } & 1 & 1 & 1 \\
\hline & \multicolumn{3}{|c|}{ Refrigerante - Tipo } & \multicolumn{3}{|c|}{ R-22 } \\
\hline & \multicolumn{3}{|c|}{ Refrigerante - Carga (kg) } & 3.6 & 3.0 & 6.9 \\
\hline & \multicolumn{3}{|c|}{ Peso em Operaçāo (kg) } & 115 & 130 & 250 \\
\hline \multirow{6}{*}{ Compressor } & \multicolumn{3}{|c|}{ Tipo } & \multicolumn{3}{|c|}{ Scroll } \\
\hline & \multicolumn{3}{|l|}{ Modelo } & ZR47 & ZR57 & SM120 \\
\hline & \multicolumn{3}{|l|}{ Quantidade } & \multicolumn{3}{|c|}{1} \\
\hline & \multicolumn{3}{|c|}{ Rotaçāo (rpm) } & \multicolumn{3}{|c|}{3600} \\
\hline & \multicolumn{3}{|c|}{ Óleo Recomendado } & \multicolumn{3}{|c|}{ Petrobrás CP32RH, Suniso 3GS } \\
\hline & Carga de 0 & & & 1.24 & 1.95 & 3.25 \\
\hline & Tipo & & & Trocador & placas de & Soldado \\
\hline & Modelo & & & $\mathrm{B} 25 \times 22$ & B25x22 & V45x20 \\
\hline & Quantidade & & & & 1 & \\
\hline & Núm. Circuit & & & & 1 & \\
\hline Evaporador & Vazão de Ác & $(\mathrm{m} 3$ & & 2.28 & 2.58 & 5.74 \\
\hline & Perda de $\mathrm{C}$ & $a(m$ & & 3.7 & 4.7 & 5.8 \\
\hline & & Diâl & (Pol) & $1 "$ & $1 "$ & $11 / 7^{\prime \prime}$ \\
\hline & Conexōes & Tipc & & & BSP & \\
\hline & & Nún & Saída & & $1 / 1$ & \\
\hline & & Áre & ace $(\mathrm{m} 2)$ & 0.86 & 0.86 & 2.2 \\
\hline & & \begin{tabular}{|l|l} 
Nún \\
\end{tabular} & ilas & & 2 & \\
\hline & Aletado & Alet & egadas & & 15 & \\
\hline & & Diâr & do Tubo $(\mathrm{mm})$ & & 9.52 & \\
\hline & & Tipc & rcuito & Gold Fincol & obre Corr & rnamente \\
\hline & & Nún & uitos & 6 & 6 & 10 \\
\hline & & Tipc & 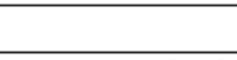 & & Axial & \\
\hline Condensador & Ventilador & Nún & ás...Diâmetro $(\mathrm{mm})$ & & 3...660 & \\
\hline & & Vaz & & 6600 & 6600 & 11200 \\
\hline & & Tipc & & & nofásico & \\
\hline & & Alim & & & $0 \mathrm{~V} / 1 \mathrm{~F} / 6 \mathrm{C}$ & \\
\hline & Motor & Rot & pm) & 850 & 850 & 880 \\
\hline & & Pot & & $1 / 6$ & $1 / 6$ & $1 / 2$ \\
\hline & & Car & BNT & & NEMA 48 & \\
\hline Dispositivos de Operaçao & Termostato & Oper & Set Point $\left({ }^{\circ} \mathrm{C}\right)$ & & 6 & \\
\hline & Press & & Alta (psig) & & $426 / \mathrm{Fec}$ & \\
\hline Dispositivos de Segurança & Press & & Baixa (psig) & & $27 / \mathrm{Fecl}$ & \\
\hline & Fusivel de C & nand & & & 4 & \\
\hline
\end{tabular}




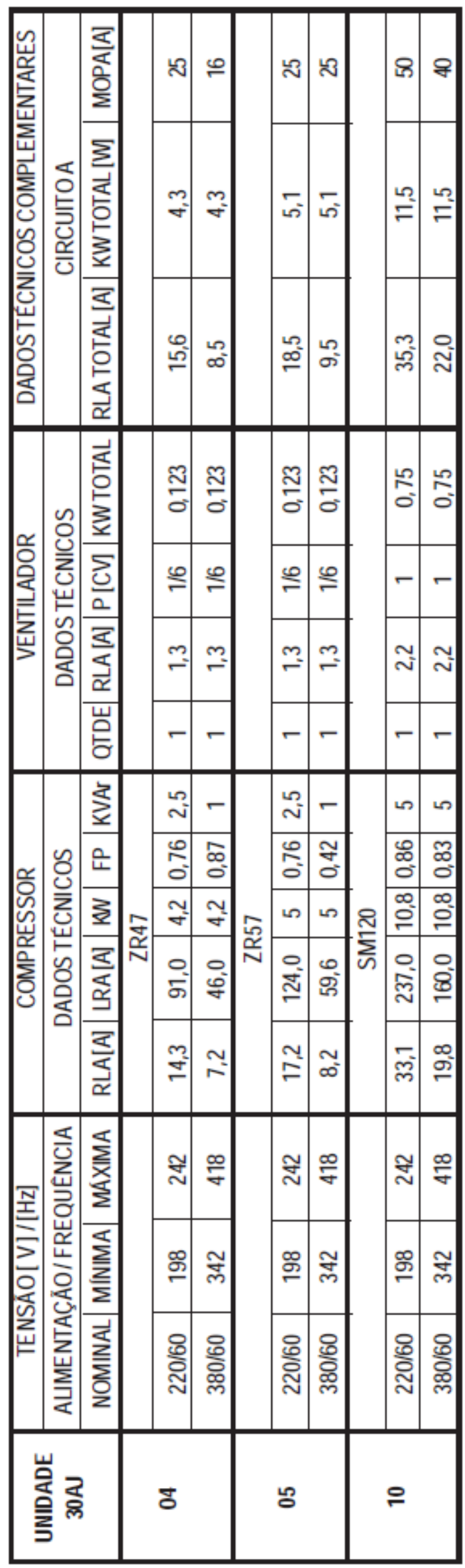




\section{APÊNDICE H - RELÁTORIO DE SELEÇÃO DO FAN COIL DE 10 TR E DEMAIS DADOS DO CATÁLOGO DO FABRICANTE}

\begin{tabular}{|c|c|}
\hline \multicolumn{2}{|l|}{ Projeto } \\
\hline Cliente & : PGR \\
\hline Obra & $\begin{array}{l}\text { : Climatização } \\
\text { Terceirizados }\end{array}$ \\
\hline Tag & : Maquina 01 \\
\hline Por & : Matheus Valverde \\
\hline \multicolumn{2}{|l|}{ Geral } \\
\hline Série & : Vortex \\
\hline Modelo & : $10 \mathrm{TR}$ \\
\hline Frequência & : $60 \mathrm{~Hz}$ \\
\hline Posição & : Vertical \\
\hline Lado Hidraúlica & : Direito \\
\hline \multicolumn{2}{|l|}{$\begin{array}{c}\text { Módulos da Máquina } \\
\text { Motor Ventilador }\end{array}$} \\
\hline \multicolumn{2}{|c|}{ Serpentina Água Gelada + Filtro } \\
\hline \multicolumn{2}{|l|}{$\begin{array}{l}\text { Resfriamento } \\
\text { Dados de Entrada }\end{array}$} \\
\hline Vazão & $=8.150,00 \mathrm{~m} 3 / \mathrm{h}$ \\
\hline TBS & $=24,00 \mathrm{C}$ \\
\hline TBU & $=17,00 \mathrm{C}$ \\
\hline Umidade Relativa & $=51,71 \%$ \\
\hline Umidade Absoluta & $=0,0112 \mathrm{kgH} 2 \mathrm{O} / \mathrm{kgda}$ \\
\hline Pressäo & $=656,26 \mathrm{mmHg}$ \\
\hline Ro & $=1,01 \mathrm{kgda} / \mathrm{m} 3$ \\
\hline Fluído & $=$ Fresh Water \\
\hline Concentração do Fluído & $=0,00 \%$ \\
\hline Vazão de Água & $=7.75 \mathrm{~m} 3 / \mathrm{h}$ \\
\hline Temperatura da Água & $=8,00 \mathrm{C}$ \\
\hline \multicolumn{2}{|c|}{ Dados de Saída da Serpentina } \\
\hline Carga Térmica & $=35,42 \mathrm{~kW}$ \\
\hline Carga Sensivel & $=27,95 \mathrm{~kW}$ \\
\hline TBS & $=12,09 \mathrm{C}$ \\
\hline TBU & $=11.78 \mathrm{C}$ \\
\hline Umidade Relativa & $=96,74 \%$ \\
\hline Ar Veloc. Face & $=2,98 \mathrm{~m} / \mathrm{s}$ \\
\hline Fluído Temperatura & $=11,92 \mathrm{C}$ \\
\hline Perda Carga Água & $=46,43 \mathrm{kPa}$ \\
\hline \multicolumn{2}{|l|}{ Dados de Insuflamento } \\
\hline TBS & $=12,97 \mathrm{C}$ \\
\hline TBU & $=12,11 \mathrm{C}$ \\
\hline Capacidade Total & $=33,30 \mathrm{~kW}$ \\
\hline Capacidade Sensivel & $=25,83 \mathrm{~kW}$ \\
\hline FCS & $=0,78$ \\
\hline
\end{tabular}

Serpentina de Resfriamento

$\begin{array}{lll}\text { Tubo } & =1 / 2^{\prime \prime} \text { Cobre } \\ \text { Aleta } & =\text { Al } \\ \text { D. Int. } & =12,26 \mathrm{~mm} \\ \text { D. Ext. } & =13,06 \mathrm{~mm} \\ \text { Esp. } & =0,127 \mathrm{~mm} \\ \text { FPI } & =9 \mathrm{FPI} \\ \text { Área de Face } & =0,76 \mathrm{~m} 2 \\ \text { Comprimento Aletado } & =1.088,00 \mathrm{~mm} \\ \text { Fator Incrustação } & =0,044 \mathrm{~m}^{2} \mathrm{~K} / \mathrm{KW} \\ \text { Nro. Filas } & =6 \\ \text { Nro. Circuitos } & =11 \\ \text { Nro. Tubos } & =22 \\ \text { Conexão } & =1.1 / 4^{\prime \prime}\end{array}$

\begin{tabular}{|c|c|}
\hline Modelo & $=$ Sirocco $15 / 15$ \\
\hline Rotação & $=922,01 \mathrm{RPM}$ \\
\hline $\begin{array}{l}\text { Consumo Elétrico } \\
\text { Estimado }\end{array}$ & $=2,12 \mathrm{~kW}$ \\
\hline Velocidade de Descarga & $=11,88 \mathrm{~m} / \mathrm{s}$ \\
\hline Posição & $=\mathrm{V}_{1}$ \\
\hline Lado do Motor & = Direito \\
\hline Ventilador Pintado & $=$ Não \\
\hline Tipo do Amortecedor & = Borracha \\
\hline Polia Ventilador & $=200 \mathrm{~mm}$ \\
\hline $\begin{array}{l}\text { Furo da Polia do } \\
\text { Ventilador }\end{array}$ & $=25.4 \mathrm{~mm}$ \\
\hline Motor & $=3 \mathrm{CV}$ \\
\hline Tensão de Alimentação & $=380 \mathrm{~V}$ \\
\hline Tensão do Motor & $=380 \mathrm{~V}$ \\
\hline Tipo do Motor & $=$ High Eff 4 Poles $60 \mathrm{~Hz}$ \\
\hline Polos & $=4$ poles \\
\hline Polia do Motor & $=106 \mathrm{~mm}$ até $140 \mathrm{~mm}$ \\
\hline Furo da Polia do Motor & $=24 \mathrm{~mm}$ \\
\hline $\begin{array}{c}\text { Perda de Carga do Ar } \\
\text { Mistura }\end{array}$ & $=0,00 \mathrm{mmH} 20$ \\
\hline Resfriamento & $=14,85 \mathrm{mmH} 20$ \\
\hline Aquecimento & $=0.00 \mathrm{mmH} 2 \mathrm{O}$ \\
\hline Equalizador & $=0,00 \mathrm{mmH} 2 \mathrm{O}$ \\
\hline Resistência & $=0.00 \mathrm{mmH} 20$ \\
\hline Atenuador & $=0,00 \mathrm{mmH} 20$ \\
\hline Filtro Fino & $=0.00 \mathrm{mmH} 20$ \\
\hline Filtro Absoluto & $=0.00 \mathrm{mmH} 20$ \\
\hline Pré-Filtro & $=14,20 \mathrm{mmH} 20$ \\
\hline $\begin{array}{l}\text { Pressão Disponivel no } \\
\text { Duto }\end{array}$ & $=20,00 \mathrm{mmH} 20$ \\
\hline Total & $=49,05 \mathrm{mmH} 20$ \\
\hline
\end{tabular}

Filtros

$\begin{array}{ll}\text { Pré-Filtro } & =\text { G4 Papeläo } 1 \\ \text { Filtro Fino } & =\text { N/A } \\ \text { Filtro Absoluto } & =\text { N/A } \\ \text { Observaçäo } & \end{array}$

Potência Sonora(dB(A))

$\begin{array}{ll}63 \mathrm{~Hz} & =66,5 \\ 125 \mathrm{~Hz} & =72,5 \\ 250 \mathrm{~Hz} & =72,5 \\ 500 \mathrm{~Hz} & =73,5 \\ 1000 \mathrm{~Hz} & =75,5 \\ 2000 \mathrm{~Hz} & =73,5 \\ 4000 \mathrm{~Hz} & =70,5 \\ 8000 \mathrm{~Hz} & =63,5 \\ \text { Global } & =81,26\end{array}$


Curva de vazão dos ventiladores - Sirocco 15-15

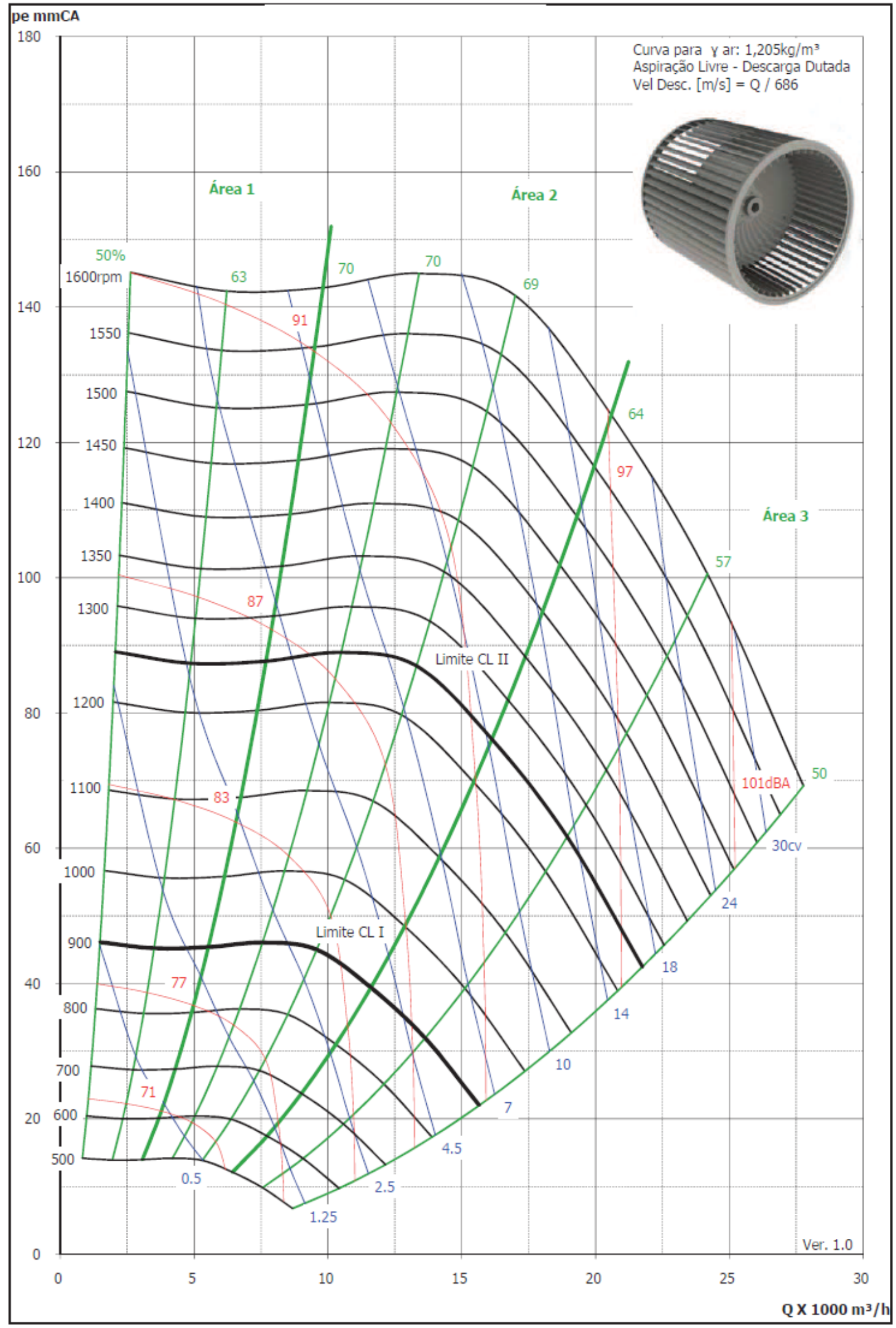




\section{APÊNDICE I - DADOS DO RECUPERADOR DE ENERGIA DO CATÁLOGO DO FABRICANTE LG}

\section{Especificações}

\begin{tabular}{|c|c|c|c|c|c|c|}
\hline \multicolumn{2}{|l|}{ Item } & Unit & LZ-H080GBA2 & LZ-H100GBA2 & LZ-H150GBA2 & LZ-H200GBA2 \\
\hline \multicolumn{2}{|l|}{ Capacidade Nominal } & $\mathrm{m}^{3} / \mathrm{h}($ LIS) & $800(471)$ & $1000(589)$ & $1500(883)$ & $2000(1177)$ \\
\hline \multicolumn{2}{|l|}{ Alimentação Eléctrica } & $\emptyset, \mathrm{V}, \mathrm{Hz}$ & $1,220-240,50-60$ & $1,220-240,50-60$ & $1,220-240,50-60$ & $1,220-240,50-60$ \\
\hline Intensidade Corrente & & - & SUPER ALTO / ALTO / BAIXO & SUPER ALTO / ALTO / BAIXO & SUPER ALTO / ALTO / BAIXO & SUPER ALTO / ALTO / BAIXO \\
\hline Corrente & $\mathrm{SA} / \mathrm{A} / \mathrm{B}$ & A & $2.77 / 2.16 / 1.44$ & $3.41 / 2.91 / 1.76$ & $5.6 / 5.4 / 2.9$ & $6.8 / 5.9 / 3.6$ \\
\hline$>$ Potência de Entrada & SA/A/B & W & $360 / 370 / 165$ & $470 / 385 / 210$ & $720 / 540 / 340$ & $930 / 770 / 420$ \\
\hline$\because$ Fluxo de Ar & SA/A/B & $\mathrm{m}^{3} / \mathrm{h}$ & $800 / 800 / 660$ & $1000 / 1000 / 800$ & $1500 / 1500 / 1200$ & $2000 / 2000 / 1600$ \\
\hline Pressäo Estática Disponivel & SA/A/B & $\mathrm{Pa}$ & $200 / 110 / 60$ & $160 / 90 / 50$ & $200 / 110 / 60$ & 160/90/50 \\
\hline Eficiência de Permuta Entálpica & SA/A/B & $\%$ & $79 / 79 / 82$ & $75 / 75 / 78$ & $79 / 79 / 82$ & $75 / 75 / 78$ \\
\hline$\Sigma$ Eficiência da Permuta Entálpica & Aquec. (SA/A/B) & $\%$ & $70 / 70 / 75$ & $66 / 66 / 71$ & $70 / 70 / 75$ & $66 / 66 / 71$ \\
\hline & Arref. (SA/A/B) & $\%$ & $65 / 65 / 70$ & $61 / 61 / 66$ & $65 / 65 / 70$ & $61 / 61 / 66$ \\
\hline Nivel de Ruido (Nivel de som,,$\overline{1,5 \mathrm{~m} \text { ) }}$ & SA/A/B & dBA & $36 / 34 / 30$ & $37 / 35 / 31$ & $39 / 37 / 33$ & $39 / 37 / 33$ \\
\hline Nivel & & - & SUPER ALTO / ALTO / BAIXO & SUPER ALTO / ALTO / BAIXO & SUPER ALTO / ALTO / BAIXO & SUPER ALTO / ALTO / BAIXO \\
\hline of Intensidade Corrente & SA/A/B & A & $2.77 / 2.16 / 1.44$ & $3.41 / 2.91 / 1.76$ & $5.6 / 5.4 / 2.9$ & $6.8 / 5.9 / 3.6$ \\
\hline Potência Absorvida & SA/A/B & W & $360 / 370 / 165$ & $470 / 385 / 210$ & $720 / 540 / 340$ & $930 / 770 / 420$ \\
\hline Fluxo de Ar & $\mathrm{SA} / \mathrm{A} / \mathrm{B}$ & $\mathrm{m}^{3} / \mathrm{h}$ & $800 / 800 / 660$ & $1000 / 1000 / 800$ & $1500 / 1500 / 1200$ & $2000 / 2000 / 1600$ \\
\hline \&ressāo Estática Disponivel & SA/A/B & $\mathrm{Pa}$ & $200 / 110 / 60$ & $160 / 90 / 50$ & $200 / 110 / 60$ & $160 / 90 / 50$ \\
\hline Eficiência de Permula Térmica & SA/A/B & $\%$ & \multicolumn{4}{|c|}{$-1-1-$} \\
\hline ¿ํํㄹ Eficiência da Permuta de Entálpica & Aquec. (SA/A/B) & $\%$ & \multicolumn{4}{|c|}{$-1-1-$} \\
\hline & Arref. (SA/A/B) & $\%$ & \multicolumn{4}{|c|}{$-1-1-$} \\
\hline Nivel de Ruido (Nivel de som, 1,5 m) & SA/A/B & dBA & \multicolumn{4}{|l|}{$36 / 34 / 30$} \\
\hline Permutador de Calor & Tipo & - & \multicolumn{4}{|c|}{ Fluxos Cruzados } \\
\hline Massa & & kg & \multicolumn{2}{|c|}{60} & \multicolumn{2}{|c|}{132} \\
\hline Dimensōes & LxAxP & $\mathrm{mm}$ & \multicolumn{2}{|c|}{$1062 \times 365 \times 1140(41.9 \times 14.4 \times 44.9)$} & \multicolumn{2}{|c|}{$1313 \times 737 \times 1140(51.7 \times 29.0 \times 44.9)$} \\
\hline \multirow[t]{2}{*}{ Condutas } & Qde. & $n^{0}$ & \multicolumn{2}{|c|}{4} & \multicolumn{2}{|c|}{$4+2$} \\
\hline & Dimensāo (Ø) & $\mathrm{mm}$ & \multicolumn{2}{|c|}{$\varnothing 250(\varnothing 9.84)$} & \multicolumn{2}{|c|}{$\emptyset 250(\varnothing 9.84)+\emptyset 350(\emptyset 13.77)$} \\
\hline \multirow[t]{2}{*}{ Ventilador de Insuflação de $\mathrm{Ar}$} & Qde. & $n^{0}$ & & 1 & & 2 \\
\hline & Tipo & - & \multicolumn{4}{|c|}{ Transmissāo Directa } \\
\hline \multirow[t]{2}{*}{ Ventilador de Extracçäo de Ar } & Qde. & $n^{0}$ & & 1 & & 2 \\
\hline & Tipo & - & \multicolumn{4}{|c|}{ Transmissäo Directa } \\
\hline \multirow[t]{3}{*}{ Filtros } & Qde. & $n^{0}$ & & 2 & 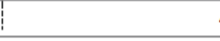 & 4 \\
\hline & Tipo & - & \multicolumn{4}{|c|}{ Lavável } \\
\hline & Dimensāo(LxAxP) & $\mathrm{mm}$ & $1056 \times 1$ & $10 \times 212.5$ & $1056 \times 1$ & $10 \times 212.5$ \\
\hline Controlo remoto & & & & PQRCVSLO / P & PQRCVSLOQW & \\
\hline Contacto Seco & & & & PQDSB / & PQDSB1 & \\
\hline
\end{tabular}

Notas:

1. modo $\theta c o$ - modo de Ventilaçāo com Recuperaçāo de Calor Entálpica

2. Nivel de Ruído:

- As condiçōes de funcionamento são considerados como sendo as padrāo.

- 0 som é medido 1,5 m abaixo do corpo central da unidade.

- O nível de som pode variar consoante diversos factores tais como a construção (coeficiente de absorção acústica) da sala específica na qual o equipamento é instalado. 
Ventilação

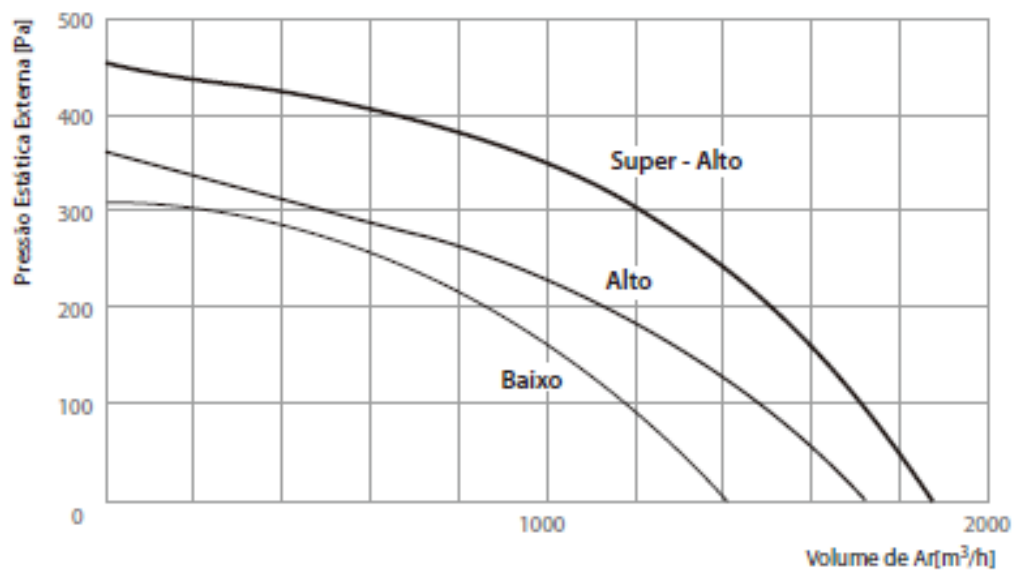

\section{Eficiência}

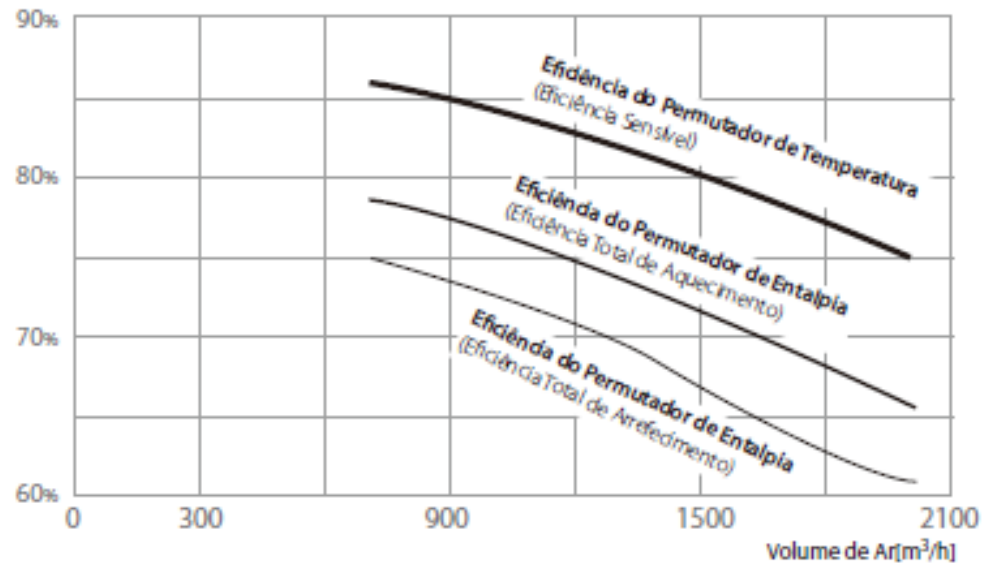




\title{
APÊNDICE J - PLANILHAS E CATÁlOGOS PARA LEVANTAMENTO DE CUSTOS DE EQUIPAMENTOS E CUSTOS DE MANUTENÇÃO
}

CATÁLOGO LG (2013)

\section{ecc $\mathbf{V}_{\mathrm{m}}$}

LZ-H080GBA2 / LZ-H100GBA2 / LZ-H150GBA2 LZ-H2OOGBA2

\author{
- High efficiency heat exchanger \\ - Bypass ventilation \\ - Efficient filter \\ - Flexible installation \\ - Easy cleaning and changable filter \\ - BLDC Fan motor \\ - Adjustable E.S.P using remote control
}

\section{Specifications}
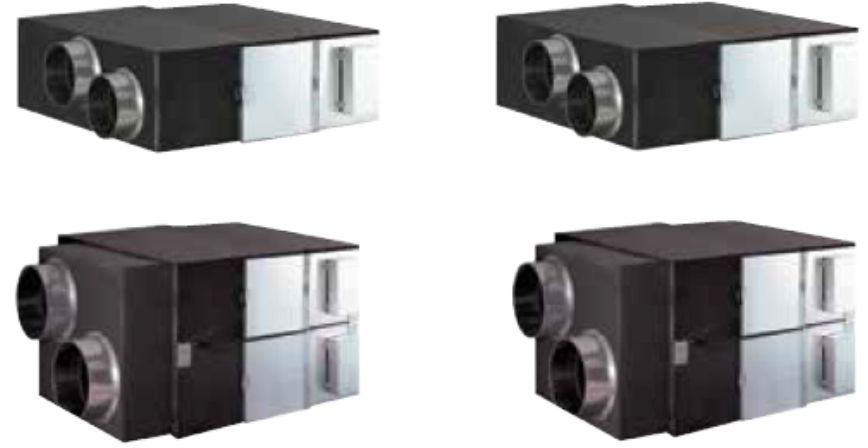

\begin{tabular}{|c|c|c|c|c|c|c|}
\hline \multicolumn{2}{|c|}{ Model } & Unit - ecoV & LZ-HO8OGBA2 & LZ-H10OGBA2 & LZ-H15OGBA2 & LZ-H2OOGBA2 \\
\hline \multicolumn{2}{|r|}{ Nominal Capacity } & $\mathrm{M}^{3} \mathrm{H}$ & 1800 & 1,000 & 1,500 & 2,000 \\
\hline \multicolumn{2}{|c|}{ Power Supply } & $\varnothing, \mathrm{V}_{1} \mathrm{~Hz}$ & $1,220-240,50$ & $1,220 \sim 240,50$ & $1,220-240,50$ & $1,220-240,50$ \\
\hline & Step & - & Super High / High / Low & Super High / High / Low & Super High / High / Low & Super High / High / Low \\
\hline & Current & $\mathrm{SH} / \mathrm{H} / \mathrm{L}$ & $2.77 / 2.16 / 1.44$ & $3.41 / 2.91 / 1.76$ & $5.60 / 5.40 / 2.90$ & $6.80 / 5.90 / 3.60$ \\
\hline & Power Input & $\mathrm{SH} / \mathrm{H} / \mathrm{L}$ & $360 / 270 / 165$ & $470 / 385 / 210$ & $720 / 540 / 340$ & $930 / 770 / 420$ \\
\hline & Air Flow & $\mathrm{M}^{3} \mathrm{H}(\mathrm{CFM})$ & $800 / 800 / 660$ & $1,000 / 1,000 / 800$ & $1,500 / 1,500 / 1,200$ & $2,000 / 2,000 / 1,600$ \\
\hline \multirow{2}{*}{$\begin{array}{l}\frac{\pi}{0} \\
\sum^{2} \\
> \\
\dot{g} \\
g\end{array}$} & & & $(471 / 471 / 388)$ & $(589 / 589 / 471)$ & $(883 / 883 / 706)$ & $(1,777 / 1,777 / 942)$ \\
\hline & \begin{tabular}{|l|} 
External Static Pressure \\
\end{tabular} & $\mathrm{SH} / \mathrm{H} / \mathrm{L}$ & $200 / 110 / 60$ & $160 / 90 / 50$ & $200 / 110 / 60$ & $160 / 90 / 50$ \\
\hline & Temperature Exchange Efficiency & $\mathrm{SH} / \mathrm{H} / \mathrm{L}$ & $79 / 79 / 82$ & $75 / 75 / 78$ & $79 / 79 / 82$ & $75 / 75 / 78$ \\
\hline & Enthalpy Exchange Efficiency & Heating $(\mathrm{SH} / \mathrm{H} / \mathrm{L})$ & $70 / 70 / 75$ & $66 / 66 / 71$ & $70 / 70 / 75$ & $66 / 66 / 71$ \\
\hline & & Cooling (SH/H/L) & $65 / 65 / 70$ & $61 / 61 / 66$ & $65 / 65 / 70$ & $61 / 61 / 66$ \\
\hline & \begin{tabular}{|l} 
Noise Level (Sound Level, $1.5 \mathrm{~m}$ ) \\
\end{tabular} & $\mathrm{SH} / \mathrm{H} / \mathrm{L}$ & $36 / 34 / 30$ & $37 / 35 / 31$ & $39 / 37 / 33$ & $39 / 37 / 33$ \\
\hline \multirow{9}{*}{ 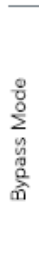 } & Step & - & Super High / High / Low & Super High / High / Low & Super High / High / Low & Super High / High / Low \\
\hline & Current & $\mathrm{SH} / \mathrm{H} / \mathrm{L}$ & $2.77 / 2.16 / 1.44$ & $3.41 / 2.91 / 1.76$ & $5.60 / 5.40 / 2.90$ & $6.80 / 5.90 / 3.60$ \\
\hline & Power Input & $\mathrm{SH} / \mathrm{H} / \mathrm{L}$ & $360 / 370 / 165$ & $470 / 385 / 210$ & $720 / 540 / 340$ & $930 / 770 / 420$ \\
\hline & Air Flow & $\mathrm{M}^{3} \mathrm{H}$ (CFM) & $\begin{array}{l}800 / 800 / 660 \\
(471 / 471 / 388)\end{array}$ & $\begin{array}{c}1,000 / 1,000 / 800 \\
(589 / 589 / 471)\end{array}$ & $\begin{array}{c}1,500 / 1,500 / 1,200 \\
(883 / 883 / 706)\end{array}$ & $\begin{array}{c}2,000 / 2,000 / 1,600 \\
(1,777 / 1,777 / 942)\end{array}$ \\
\hline & \begin{tabular}{|l} 
External Static Pressure \\
\end{tabular} & $\mathrm{SH} / \mathrm{H} / \mathrm{L}$ & $200 / 110 / 60$ & $160 / 90 / 50$ & $200 / 110 / 60$ & $160 / 90 / 50$ \\
\hline & Temperature Exchange Efficiency & $\mathrm{SH} / \mathrm{H} / \mathrm{L}$ & $-1-1-$ & $-1-1-$ & $-1-1-$ & $-1-1-$ \\
\hline & Enthalphy Exchange Efficiency & Heating $(\mathrm{SH} / \mathrm{H} / \mathrm{L})$ & $-1-1-$ & $-1-1-$ & $-1-1-$ & $-1-1-$ \\
\hline & & Cooling (SH/H/L) & $-1-1-$ & $-1-1-$ & $-1-1-$ & $-1-1-$ \\
\hline & Noise Level (Sound Level, $1.5 \mathrm{~m}$ ) & $\mathrm{SH} / \mathrm{H} / \mathrm{L}$ & $36 / 34 / 30$ & $37 / 35 / 31$ & $37 / 35 / 31$ & $37 / 35 / 31$ \\
\hline \multicolumn{2}{|c|}{ Heat Exchanger } & Type & Crossflow & Crossflow & Crossflow & Crossflow \\
\hline \multicolumn{2}{|c|}{ Weight } & $\mathrm{kg}(\mathrm{lb})$ & 60 (132) & $60(132)$ & $132(291)$ & $132(291)$ \\
\hline \multicolumn{2}{|c|}{ Dimension } & $\mathrm{W} \times \mathrm{H} \times \mathrm{D}$ & $1,062 \times 365 \times 1,140$ & $1,062 \times 365 \times 1,140$ & $1,313 \times 737 \times 1,140$ & $1,313 \times 737 \times 1,140$ \\
\hline \multirow{2}{*}{\multicolumn{2}{|c|}{ Duct Work }} & Qty & 4 & 4 & $4+2$ & $4+2$ \\
\hline & & Size $(\varnothing)$ & $\varnothing 250$ & $\varnothing 250$ & $\varnothing 250+\varnothing 350$ & $\varnothing 250+\varnothing 350$ \\
\hline \multirow{2}{*}{\multicolumn{2}{|c|}{ Supply Air Fan }} & Qty & 1 & 1 & 2 & 2 \\
\hline & & Type & Direct-Drive & Direct-Drive & Direct-Drive & Direct-Drive \\
\hline \multirow{2}{*}{\multicolumn{2}{|c|}{ Exhaust Air Fan }} & Qty & 1 & 1 & 2 & 2 \\
\hline & & Type & Direct-Drive & Direct-Drive & Direct-Drive & Direct-Drive \\
\hline \multirow{3}{*}{\multicolumn{2}{|c|}{ Filters }} & Qty & 2 & 2 & 4 & 4 \\
\hline & & Type & Cleanable & Cleanable & Cleanable & Cleanable \\
\hline & & Size $(W \times H \times D)$ & $1,056 \times 10 \times 212.5$ & $1,056 \times 10 \times 212.5$ & $1,056 \times 10 \times 212.5$ & $1,056 \times 10 \times 212.5$ \\
\hline \multicolumn{2}{|c|}{ List Price } & Outdoor & $£ 1,242$ & $f 1,480$ & $f 2,222$ & $f 2,897$ \\
\hline \multicolumn{7}{|c|}{ Accessories } \\
\hline \multicolumn{2}{|c|}{ PES-CORVO } & $\mathrm{CO}_{2}$ Sensor & $f 200$ & $f 200$ & $f 200$ & $f 200$ \\
\hline
\end{tabular}




\section{PLANILHA ORÇAMENTÁRIA DE OBRA DO TRIBUNAL DE CONTAS DA UNIÃO (TCU, 2013)}

\begin{tabular}{|c|c|c|c|c|c|c|}
\hline CADERNO 18 - AR CONDICIONADO & Unid & Qtd & MO unit & MAT unit & unitário & Total \\
\hline EQUIPAMENTOS CAG & & & & & & $1,160,296,42$ \\
\hline $\begin{array}{l}\text { CENTRÍFUGA CAPACIDADE } 300 \text { TR - MODELO } \\
\text { REFERENCIAL CVHE } 3 \text { - TRANE OU EQUIVALENTE } \\
\text { TÉCNICO }\end{array}$ & unid & 2,00 & $73,240,00$ & $320,000,00$ & $393,240,00$ & $786,480,00$ \\
\hline $\begin{array}{l}\text { TORRE DE RESFRIAMENTO VAZÃO } 130.000 \mathrm{~L} / \mathrm{H} \text { - } \\
\text { MODELO REFERENCIAL MD/12MA/4/II/GC/D2 }\end{array}$ & unid & 2,00 & $21,056,50$ & $61,033,00$ & $82,089,50$ & $164,179,00$ \\
\hline $\begin{array}{l}\text { BOMBA DE ÁGUA DE CONDENSAÇÃO - VAZÃO } 200 \\
\mathrm{M}^{3} / \mathrm{H} \text { - 15MCA - MEGANORM OU EQUIVALENTE } \\
\text { TÉCNICO }\end{array}$ & unid & 3,00 & $2,545,06$ & $6,998,92$ & $9,543,98$ & $28,631,94$ \\
\hline $\begin{array}{l}\text { BOMBA DE ÁGUA DE AGUA GELADA- SECUNDARIA - } \\
\text { VAZÃO } 114 \mathrm{M}^{3} / \mathrm{H}-50 \mathrm{MCA} \text { - MEGANORM OU } \\
\text { EQUIVALENTE TÉCNICO }\end{array}$ & unid & 3,00 & $2,545,06$ & $11,571,55$ & $14,116,61$ & $42,349,83$ \\
\hline $\begin{array}{l}\text { BOMBA DE ÁGUA AGUA GELADA - PRIMARIA - VAZÃO } \\
114 \mathrm{M}^{3} / \mathrm{H} \text { - 1OMCA - MEGANORM OU EQUIVALENTE } \\
\text { TÉCNICO }\end{array}$ & unid & 3,00 & $2,545,06$ & $4,301,16$ & $6,846,22$ & $20,538,66$ \\
\hline $\begin{array}{l}\text { FORNECIMENTO E INSTALAÇÃO DE UNIDADE } \\
\text { CONDENSADORA TIPO BARRIL - CAPACIDADE } 60.000 \\
\text { BTU - HITACHI OU EQUIVALENTE TÉCNICO }\end{array}$ & unid & 21,00 & 424,18 & $4,419,71$ & $4,843,89$ & $101,721,69$ \\
\hline $\begin{array}{l}\text { FORNECIMENTO E INSTALAÇÃO DE UNIDADE } \\
\text { CONDENSADORA TIPO BARRIL - CAPACIDADE } 36.000 \\
\text { BTU - HITACHI OU EQUIVALENTE TÉCNICO }\end{array}$ & unid & 3,00 & 424,18 & $2,495,86$ & $2,920,04$ & $8,760,12$ \\
\hline $\begin{array}{l}\text { FORNECIMENTO E INSTALAÇÃO DE UNIDADE } \\
\text { CONDENSADORA TIPO BARRIL - CAPACIDADE } 18.000 \\
\text { BTU - HITACHI OU EQUIVALENTE TÉCNICO }\end{array}$ & unid & 3,00 & 424,17 & $2,120,89$ & $2,545,06$ & $7,635,18$ \\
\hline EQUIPAMENTOS DO SISTEMA DE REFRIGERAÇÃO & & & & & & $2,342,111,31$ \\
\hline $\begin{array}{l}\text { FORNECIMENTO E INSTALAÇÃO DE EVAPORADORA } \\
\text { TIPO CASSETE - CAPACIDADE } 5 \text { TR - HITACHI OU } \\
\text { EQUIVALENTE TÉCNICO }\end{array}$ & unid & 9,00 & 424,18 & $1,894,16$ & $2,318,34$ & $20,865,06$ \\
\hline $\begin{array}{l}\text { FORNECIMENTO E INSTALAÇÃOFANCOIL HIDRÔNICO } \\
\text { TIPO CASSETE -CAPACIDADE 1,0TR-P.F=0,14- } \\
\text { 220V/1F/6OHZ - HITACHI OU EQUIVALENTE TÉCNICO }\end{array}$ & unid & 366,00 & 424,18 & $2,036,05$ & $2,460,23$ & $900,444,18$ \\
\hline $\begin{array}{l}\text { FORNECIMENTO E INSTALAÇÃO DE EVAPORADORA } \\
\text { TIPO CASSETE - CAPACIDADE 1,5 TR - HITACHI OU } \\
\text { EQUIVALENTE TÉCNICO }\end{array}$ & unid & 3,00 & 424,18 & $1,019,04$ & $1,443,22$ & $4,329,66$ \\
\hline
\end{tabular}




\begin{tabular}{|c|c|c|c|c|c|c|}
\hline $\begin{array}{l}\text { FORNECIMENTO E INSTALAÇÃOFANCOIL HIDRÔNICO } \\
\text { TIPO CASSETE-CAPACIDADE 1,5TR-P.F=0,14- } \\
220 \mathrm{~V} / 1 \mathrm{~F} / 60 \mathrm{HZ} \text { - HITACHI OU EQUIVALENTE TÉCNICO }\end{array}$ & unid & 125,00 & 424,17 & $1,785,00$ & $2,209,17$ & $276,146,25$ \\
\hline $\begin{array}{l}\text { FORNECIMENTO E INSTALACCÃOFANCOIL HIDRÔNICO } \\
\text { TIPO CASSETE-CAPACIDADE 2,OTR- HITACHI OU } \\
\text { EQUIVALENTE TÉCNICO }\end{array}$ & unid & 78,00 & 424,17 & $2,290,56$ & $2,714,73$ & $211,748,94$ \\
\hline $\begin{array}{l}\text { FORNECIMENTO E INSTALAÇÃO DE EVAPORADORA } \\
\text { TIPO EMBUTIR - CAPACIDADE } 5 \text { TR - HITACHI OU } \\
\text { EQUIVALENTE TÉCNICO }\end{array}$ & unid & 12,00 & 424,18 & $1,415,08$ & $1,839,26$ & $22,071,12$ \\
\hline $\begin{array}{l}\text { FORNECIMENTO E INSTALAÇÃOFANCOIL HIDRÔNICO } \\
\text { TIPO CASSETE-CAPACIDADE 2,0TR-P.F=0,14- } \\
\text { 220V/1F/6OHZ - HITACHI OU EQUIVALENTE TÉCNICO }\end{array}$ & unid & 42,00 & 424,17 & $2,290,56$ & $2,714,73$ & $114,018,66$ \\
\hline $\begin{array}{l}\text { FORNECIMENTO E INSTALAÇÃO DE EVAPORADORA } \\
\text { TIPO EMBUTIR - CAPACIDADE } 3 \text { TR - HITACHI OU } \\
\text { EQUIVALENTE TÉCNICO }\end{array}$ & unid & 3,00 & 424,18 & $1,019,04$ & $1,443,22$ & $4,329,66$ \\
\hline $\begin{array}{l}\text { FORNECIMENTO E INSTALAÇÃOFANCOIL HIDRÔNICO } \\
\text { TIPO CASSETE-CAPACIDADE 2,5TR-P.F=0,2- } \\
220 \mathrm{~V} / 1 \mathrm{~F} / 60 \mathrm{HZ} \text { - HITACHI OU EQUIVALENTE TÉCNICO }\end{array}$ & unid & 7,00 & 424,17 & $2,290,56$ & $2,714,73$ & $19,003,11$ \\
\hline $\begin{array}{l}\text { FORNECIMENTO E INSTALAÇÃOFANCOIL HIDRÔNICO } \\
\text { TIPO CASSETE-CAPACIDADE 3TR- HITACHI OU } \\
\text { EQUIVALENTE TÉCNICO }\end{array}$ & unid & 71,00 & 424,17 & $2,290,56$ & $2,714,73$ & $192,745,83$ \\
\hline $\begin{array}{l}\text { FORNECIMENTO E INSTALAÇÃO DE SELF DIVIDO } \\
\text { CAPACIDADE } 25 \text { TR- OU SPITÃO - CARRIER OU } \\
\text { EQUIVALENTE TÉCNICO }\end{array}$ & unid & 1,00 & 424,17 & $27,995,69$ & $28,419,86$ & $28,419,86$ \\
\hline $\begin{array}{l}\text { FORNECIMENTO E INSTALACCÃOFANCOIL HIDRÔNICO } \\
\text { TIPO CASSETE-CAPACIDADE 8,5TR- HITACHI OU } \\
\text { EQUIVALENTE TÉCNICO }\end{array}$ & unid & 4,00 & 424,17 & $8,398,71$ & $8,822,88$ & $35,291,52$ \\
\hline $\begin{array}{l}\text { CAIXA DE VENTILAÇÃO MOD BBF180-P.F=0,12KW-4 } \\
\text { POLOS-3F/220V-BERLINER LUFT }\end{array}$ & unid & 23,00 & 424,17 & $2,629,90$ & $3,054,07$ & $70,243,61$ \\
\hline $\begin{array}{l}\text { FORNECIMENTO E INSTALAÇÃO FANCOIL HIDRÔNICO } \\
\text { TIPO CASSETE - CAPACIDADE DE } 5 \text { TR - LG OU } \\
\text { EQUIVALENTE TÉCNICO }\end{array}$ & unid & 3,00 & 424,17 & $2,629,90$ & $3,054,07$ & $9,162,21$ \\
\hline $\begin{array}{l}\text { CAIXA DE VENTILAÇÃO MOD BBS160-P.F=0,55KW-4 } \\
\text { POLOS-3F/220V - } 25 \mathrm{mmCA} \text { - VAZAO: } 1300 \mathrm{M}^{3} / \mathrm{H}- \\
\text { BERLINER LUFT OU EQUIVALENTE TECNICO }\end{array}$ & unid & 3,00 & 424,17 & $2,450,05$ & $2,874,22$ & $8,622,66$ \\
\hline $\begin{array}{l}\text { FORNECIMENTO E INSTALAÇÃO FANCOIL HIDRÔNICO } \\
\text { TIPO CASSETE - CAPACIDADE DE } 4 \text { TR - LG OU } \\
\text { EQUIVALENTE TÉCNICO }\end{array}$ & unid & 39,00 & 424,18 & $2,375,39$ & $2,799,57$ & $109,183,23$ \\
\hline $\begin{array}{l}\text { INTERCAMBIADOR DE CALOR - } 1000 \mathrm{M}^{3} / \mathrm{H}-\mathrm{P} . \mathrm{F}= \\
560 \mathrm{~W}-1 \mathrm{~F} / 220 \mathrm{~V} / 60 \mathrm{HZ}-\mathrm{HITACHI} \text { LG OU } \\
\text { EQUIVALENTE TÉCNICO }\end{array}$ & unid & 24,00 & 424,18 & $6,786,83$ & $7,211,01$ & $173,064,24$ \\
\hline
\end{tabular}


EXAUSTOR DE EMBUTIR+GRELHA EXT.AUTO

FECHANTE-MOD 120-P.F=22W-IF/220V - MULTIVAC

unid
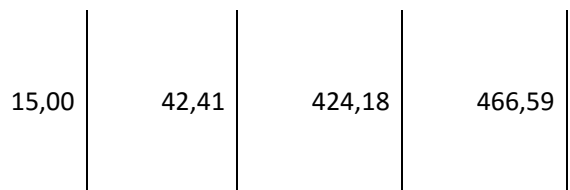

$6,998,85$ OU OU EQUIVALENTE TÉCNICO

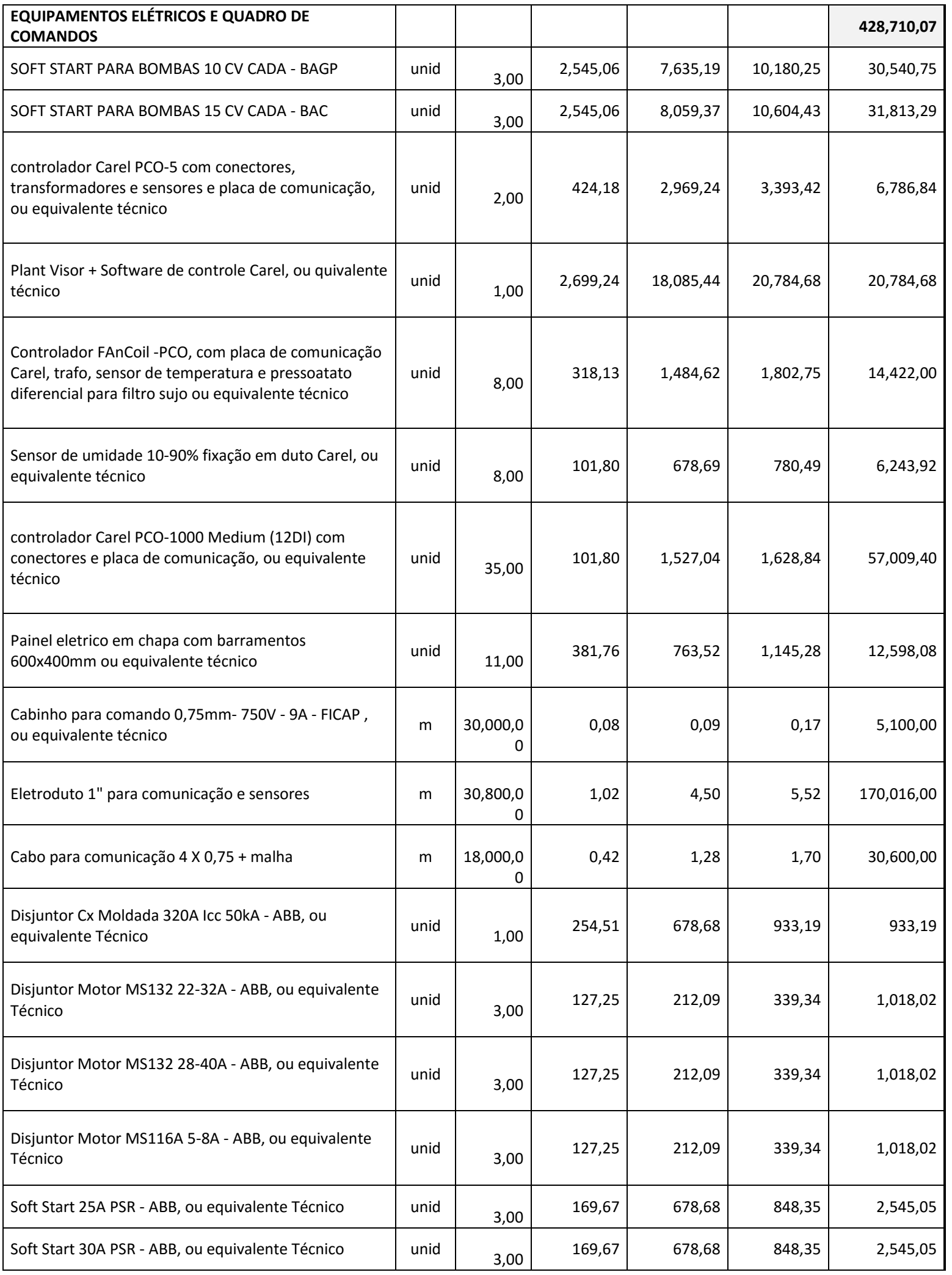




\begin{tabular}{|c|c|c|c|c|c|c|}
\hline $\begin{array}{l}\text { Inversor de frequencia } 45 \mathrm{~A} \text { ACS550 - ABB, ou } \\
\text { equivalente Técnico }\end{array}$ & unid & 4,00 & 424,18 & $3,393,41$ & $3,817,59$ & $15,270,36$ \\
\hline Seccionadora XLP-100 - ABB, ou equivalente Técnico & unid & 3,00 & 84,84 & 169,67 & 254,51 & 763,53 \\
\hline $\begin{array}{l}\text { Fusivel ultra rapido } 63 \mathrm{~A} \text {-Busmann, ou equivalente } \\
\text { Técnico }\end{array}$ & unid & 9,00 & 42,42 & 42,42 & 84,84 & 763,56 \\
\hline $\begin{array}{l}\text { Painel de comando avançado para inversor - ABB, ou } \\
\text { equivalente Técnico }\end{array}$ & unid & 3,00 & 16,97 & 509,01 & 525,98 & $1,577,94$ \\
\hline Rele falta de fase $380 \mathrm{~V}-\mathrm{ABB}$, ou equivalente Técnico & unid & 1,00 & 42,42 & 509,01 & 551,43 & 551,43 \\
\hline $\begin{array}{l}\text { Minidisjuntor tripolar 4A - S203-C04 - ABB, ou } \\
\text { equivalente Técnico }\end{array}$ & unid & 1,00 & 16,97 & 16,96 & 33,93 & 33,93 \\
\hline $\begin{array}{l}\text { Minidisjuntor bipolar 4A - S202-C10 - ABB, ou } \\
\text { equivalente Técnico }\end{array}$ & unid & 1,00 & 16,97 & 16,96 & 33,93 & 33,93 \\
\hline $\begin{array}{l}\text { Minidisjuntor bipolar 4A - S202-C04 - ABB, ou } \\
\text { equivalente Técnico }\end{array}$ & unid & 11,00 & 16,97 & 16,96 & 33,93 & 373,23 \\
\hline Led sinalização CL-523 - ABB, ou equivalente Técnico & unid & 13,00 & 12,73 & 16,96 & 29,69 & 385,97 \\
\hline Rele auxiliar CP - ABB, ou equivalente Técnico & unid & 20,00 & 21,21 & 50,90 & 72,11 & $1,442,20$ \\
\hline Contator 9A - A09DA-30-10 & unid & 6,00 & 25,45 & 67,87 & 93,32 & 559,92 \\
\hline Trafo $220 \times 24$ - Bluetrafo ou equivalente técnico & unid & 2,00 & 12,73 & 46,65 & 59,38 & 118,76 \\
\hline Controlador PCO3 - Carel ou equivalente técnico & unid & 2,00 & 593,85 & $3,563,09$ & $4,156,94$ & $8,313,88$ \\
\hline Sensores de temperatura Carel ou equivalente técnico & unid & 8,00 & 169,67 & 271,47 & 441,14 & $3,529,12$ \\
\hline
\end{tabular}


QUADRO COMPARATIVO DE PREÇOS PRATICADOS EM "ABRIL 2012"

\begin{tabular}{|c|c|c|c|c|c|c|}
\hline \multicolumn{2}{|c|}{ ARCOND/12 } & & & & \multicolumn{2}{|r|}{ Arq: VALOMANU } \\
\hline & INSTITUIÇÁO & $\begin{array}{l}\text { SENADO } \\
\text { FEDERAL }\end{array}$ & $\begin{array}{l}\text { CAMAARA } \\
\text { FEDERAL }\end{array}$ & PGR & STF & $\begin{array}{l}\text { STJ } \\
\text { atual }\end{array}$ \\
\hline \multirow[t]{3}{*}{1.} & EMPRESA CONTRATADA & ENTHERM & TECTENGE & ALMEIDA FRANÇA & ALMEIDA FRANÇA & BETTA INSTALAÇŐES \\
\hline & CONTATO & Paulo Zandonade & DOMINGOS I PAULO MARQUES & MATHEUS & DIEGO SILVA / MARINA & VANDER / FILIPE \\
\hline & TELEFONE & 33032339 & 32164491 & 31056500 & 32173113 & 33198473 \\
\hline \multirow[t]{2}{*}{ D } & PRECCO MENSAL (R\$) & $299.166,02$ & $212.073,48$ & $72.890,00$ & $65.800,33$ & $52.336,22$ \\
\hline & ÁREA $\left(\mathrm{m}^{2}\right)$ & 130.623 & 100.000 & 70.424 & 63.884 & 140.637 \\
\hline \multirow[t]{2}{*}{ A } & QUANT. FUNCIONÁRIOS & 72 & 51 & 20 & 15 & 14 \\
\hline & QUANT "TR" INSTALADA & 5000 & 3180 & 1150 & 1200 & 2400 \\
\hline \multirow[t]{2}{*}{ D } & QUANT FAN-COILS & 899 , incluido fancoletes & 1488 , incluído fancoletes & 125 & 50 & 213 , incluido fancoletes \\
\hline & $\begin{array}{l}\text { QUANT TORRES DE AR- } \\
\text { REFECIMENTO }\end{array}$ & 6 & 17 & 3 & $\begin{array}{c}4+3 \\
3\end{array}$ & 5 \\
\hline 0 & TERMO ACUMULAÇÃO & não & só na sede & sim & não & não \\
\hline \multirow[t]{6}{*}{ s } & SELF CONTAINED & 24 & 23 & 16 & 10 & 10 \\
\hline & SPLIT & 505 & 53 & 31 & 18 & 25 \\
\hline & CÂMARAS FRIGORIFICAS & 2 & 5 & 5 & não & 3 \\
\hline & SISTEMA DE VENTILACCÃO & sim & $\operatorname{sim}$ & sim & sim & sim \\
\hline & SISTEMA DE EXAUSTÄO & $\operatorname{sim}$ & $\operatorname{sim}$ & $\operatorname{sim}$ & $\operatorname{sim}$ & $\operatorname{sim}$ \\
\hline & FORNEC. DE PEÇAS & parcial & não & não & não & não \\
\hline 2. & \begin{tabular}{|l|} 
TRATAMENTO ÁGUA DAS \\
TORRES INCLUIDO
\end{tabular} & sim & sim & sim & $\operatorname{sim}$ & não \\
\hline 3. & PREÇO TOTAL & $299.166,02$ & $212.073,48$ & $72.890,00$ & $65.800,33$ & $52.336,22$ \\
\hline 4. & Custo por func. (R\$/func.) & $4.155,08$ & $4.158,30$ & $3.644,50$ & $4.386,69$ & $3.738,30$ \\
\hline 5. & Custo por área $\left(\mathrm{R} \$ / \mathrm{m}^{2}\right)$ & 2,29 & 2,12 & 1,04 & 1,03 & 0,37 \\
\hline 6. & Custo por $T R(R \$ / T R)$ & 59,83 & 66,69 & 63,38 & 54,83 & 21,81 \\
\hline
\end{tabular}

Obs: a) responsável pela pesquisa: Eng. Filipe / periodo da pesquisa: ABR 2012 / SIMEC 


\section{APÊNDICE L - TABELAS COM OS DIVERSOS PERFIS DE OCUPAÇÃO (CAPÍTULO 7)}

\section{Ocupação original: $\mathbf{3 5 , 8 3 \%}$}

As Tabelas L.1, L.2, L.3, L.4 e L.5 apresentam os perfis semanais de ocupação para 33 horas de operação, 43 horas, 57 horas, 65 horas e 80 horas, respectivamente. Todos esses perfis possuem uma ocupação relativa semanal acumulada de 35,83\%:

Tabela L.1 - Perfil de ocupação (\%) semanal do auditório para 33 horas de operação

\begin{tabular}{ccccccc}
\hline Horário & Seg. & Ter. & Qua. & Qui. & Sex. & Sáb. \\
\hline $08: 00$ & 0 & 0 & 0 & 0 & 0 & 0 \\
$09: 00$ & 0 & 0 & 0 & 0 & 0 & 0 \\
$10: 00$ & 0 & 100 & 100 & 100 & 0 & 0 \\
$11: 00$ & 0 & 0 & 0 & 0 & 0 & 0 \\
$12: 00$ & 0 & 0 & 0 & 0 & 0 & 0 \\
$13: 00$ & 0 & 0 & 0 & 0 & 0 & 0 \\
$14: 00$ & 100 & 100 & 100 & 100 & 100 & 100 \\
$15: 00$ & 100 & 100 & 100 & 100 & 100 & 100 \\
$16: 00$ & 100 & 100 & 100 & 100 & 100 & 100 \\
$17: 00$ & 100 & 100 & 100 & 100 & 100 & 100 \\
$18: 00$ & 100 & 100 & 100 & 100 & 100 & 100 \\
$19: 00$ & 0 & 0 & 0 & 0 & 0 & 0 \\
$20: 00$ & 0 & 0 & 0 & 0 & 0 & 0 \\
$21: 00$ & 0 & 0 & 0 & 0 & 0 & 0 \\
$22: 00$ & 0 & 0 & 0 & 0 & 0 & 0 \\
\hline
\end{tabular}

Tabela L.2 - Perfil de ocupação (\%) semanal do auditório para 43 horas de operação

\begin{tabular}{ccccccc}
\hline Horário & Seg. & Ter. & Qua. & Qui. & Sex. & Sáb. \\
\hline $08: 00$ & 0 & 0 & 0 & 0 & 0 & 0 \\
$09: 00$ & 0 & 0 & 0 & 0 & 0 & 0 \\
10:00 & 75 & 75 & 75 & 75 & 75 & 75 \\
$11: 00$ & 0 & 0 & 0 & 0 & 0 & 0 \\
$12: 00$ & 0 & 0 & 0 & 0 & 0 & 0 \\
$13: 00$ & 75 & 75 & 75 & 75 & 75 & 75 \\
$14: 00$ & 75 & 75 & 75 & 75 & 75 & 75
\end{tabular}




\begin{tabular}{ccccccc}
\hline $15: 00$ & 75 & 75 & 75 & 75 & 75 & 75 \\
$16: 00$ & 75 & 75 & 75 & 75 & 75 & 75 \\
$17: 00$ & 75 & 75 & 75 & 75 & 75 & 75 \\
$18: 00$ & 75 & 75 & 75 & 75 & 75 & 75 \\
$19: 00$ & 75 & 0 & 0 & 0 & 0 & 0 \\
$20: 00$ & 0 & 0 & 0 & 0 & 0 & 0 \\
$21: 00$ & 0 & 0 & 0 & 0 & 0 & 0 \\
$22: 00$ & 0 & 0 & 0 & 0 & 0 & 0 \\
\hline
\end{tabular}

Tabela L.3 - Perfil de ocupação (\%) semanal do auditório para 57 horas de operação

\begin{tabular}{ccccccc}
\hline Horário & Seg. & Ter. & Qua. & Qui. & Sex. & Sáb. \\
\hline $08: 00$ & 0 & 25 & 25 & 0 & 25 & 25 \\
$09: 00$ & 0 & 50 & 50 & 0 & 25 & 50 \\
$10: 00$ & 0 & 50 & 50 & 0 & 25 & 75 \\
$11: 00$ & 0 & 50 & 50 & 0 & 25 & 75 \\
$12: 00$ & 0 & 50 & 50 & 0 & 25 & 50 \\
$13: 00$ & 0 & 0 & 0 & 0 & 0 & 0 \\
$14: 00$ & 25 & 25 & 25 & 25 & 0 & 0 \\
$15: 00$ & 75 & 75 & 75 & 75 & 25 & 0 \\
$16: 00$ & 100 & 100 & 100 & 100 & 25 & 0 \\
$17: 00$ & 75 & 75 & 75 & 75 & 50 & 0 \\
$18: 00$ & 100 & 100 & 100 & 100 & 50 & 0 \\
$19: 00$ & 25 & 25 & 25 & 25 & 50 & 0 \\
$20: 00$ & 50 & 50 & 50 & 0 & 75 & 0 \\
$21: 00$ & 0 & 0 & 75 & 0 & 100 & 0 \\
$22: 00$ & 0 & 0 & 75 & 0 & 100 & 0
\end{tabular}

Tabela L.4 -Perfil de ocupação (\%) semanal do auditório para 65 horas de operação

\begin{tabular}{ccccccc}
\hline Horário & Seg. & Ter. & Qua. & Qui. & Sex. & Sáb. \\
\hline $08: 00$ & 0 & 0 & 0 & 0 & 0 & 0 \\
$09: 00$ & 50 & 50 & 50 & 50 & 50 & 0 \\
$10: 00$ & 50 & 50 & 50 & 50 & 50 & 50 \\
$11: 00$ & 50 & 50 & 50 & 50 & 50 & 50 \\
$12: 00$ & 50 & 50 & 50 & 50 & 50 & 50 \\
$13: 00$ & 50 & 50 & 50 & 50 & 50 & 50 \\
$14: 00$ & 50 & 50 & 50 & 50 & 50 & 50 \\
\hline
\end{tabular}




\begin{tabular}{ccccccc}
\hline $15: 00$ & 50 & 50 & 50 & 50 & 50 & 50 \\
$16: 00$ & 50 & 50 & 50 & 50 & 50 & 50 \\
$17: 00$ & 50 & 50 & 50 & 50 & 50 & 50 \\
$18: 00$ & 50 & 50 & 50 & 50 & 50 & 50 \\
$19: 00$ & 50 & 50 & 50 & 50 & 50 & 50 \\
$20: 00$ & 0 & 0 & 0 & 0 & 0 & 0 \\
$21: 00$ & 0 & 0 & 0 & 0 & 0 & 0 \\
$22: 00$ & 0 & 0 & 0 & 0 & 0 & 0 \\
\hline
\end{tabular}

Tabela L.5 - Perfil de ocupação (\%) semanal do auditório para 80 horas de operação

\begin{tabular}{ccccccc}
\hline Horário & Seg. & Ter. & Qua. & Qui. & Sex. & Sáb. \\
\hline 08:00 & 40 & 40 & 40 & 0 & 0 & 0 \\
09:00 & 40 & 40 & 40 & 40 & 40 & 40 \\
10:00 & 40 & 40 & 40 & 40 & 40 & 40 \\
$11: 00$ & 40 & 40 & 40 & 40 & 40 & 40 \\
$12: 00$ & 40 & 40 & 40 & 40 & 40 & 40 \\
$13: 00$ & 40 & 40 & 40 & 40 & 40 & 40 \\
14:00 & 40 & 40 & 40 & 40 & 40 & 40 \\
$15: 00$ & 40 & 40 & 40 & 40 & 40 & 40 \\
16:00 & 40 & 40 & 40 & 40 & 40 & 40 \\
17:00 & 40 & 40 & 40 & 40 & 40 & 40 \\
18:00 & 40 & 40 & 40 & 40 & 40 & 40 \\
19:00 & 40 & 40 & 40 & 40 & 40 & 40 \\
$20: 00$ & 40 & 40 & 40 & 40 & 40 & 40 \\
$21: 00$ & 40 & 40 & 40 & 40 & 40 & 40 \\
$22: 00$ & 0 & 0 & 0 & 0 & 0 & 0
\end{tabular}

\section{Variação de ocupação 1: 20\%}

As Tabelas L.6, L.7 e L.8 apresentam os perfis semanais de ocupação para 18 horas de operação, 36 horas e 72 horas, respectivamente. Todos esses perfis possuem uma ocupação relativa semanal acumulada de $20 \%$ :

Tabela L.6 - Perfil de ocupação (\%) semanal do auditório para 18 horas de operação

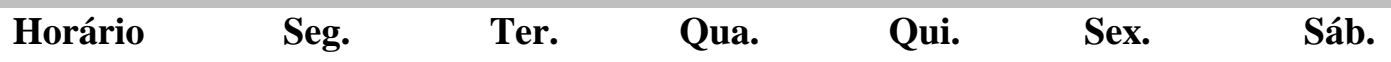




\begin{tabular}{ccccccc}
\hline $08: 00$ & 0 & 0 & 0 & 0 & 0 & 0 \\
$09: 00$ & 0 & 0 & 0 & 0 & 0 & 0 \\
$10: 00$ & 0 & 0 & 0 & 0 & 0 & 0 \\
$11: 00$ & 0 & 0 & 0 & 0 & 0 & 0 \\
$12: 00$ & 0 & 0 & 0 & 0 & 0 & 0 \\
$13: 00$ & 0 & 0 & 0 & 0 & 0 & 0 \\
$14: 00$ & 100 & 100 & 100 & 100 & 100 & 100 \\
$15: 00$ & 100 & 100 & 100 & 100 & 100 & 100 \\
$16: 00$ & 100 & 100 & 100 & 100 & 100 & 100 \\
$17: 00$ & 0 & 0 & 0 & 0 & 0 & 0 \\
$18: 00$ & 0 & 0 & 0 & 0 & 0 & 0 \\
$19: 00$ & 0 & 0 & 0 & 0 & 0 & 0 \\
$20: 00$ & 0 & 0 & 0 & 0 & 0 & 0 \\
$21: 00$ & 0 & 0 & 0 & 0 & 0 & 0 \\
$22: 00$ & 0 & 0 & 0 & 0 & 0 & 0
\end{tabular}

Tabela L.7 - Perfil de ocupação (\%) semanal do auditório para 36 horas de operação

\begin{tabular}{ccccccc}
\hline Horário & Seg. & Ter. & Qua. & Qui. & Sex. & Sáb. \\
\hline $08: 00$ & 0 & 0 & 0 & 0 & 0 & 0 \\
$09: 00$ & 0 & 0 & 0 & 0 & 0 & 0 \\
10:00 & 0 & 0 & 0 & 0 & 0 & 0 \\
$11: 00$ & 0 & 0 & 0 & 0 & 0 & 0 \\
$12: 00$ & 0 & 0 & 0 & 0 & 0 & 0 \\
$13: 00$ & 0 & 0 & 0 & 0 & 0 & 0 \\
14:00 & 50 & 50 & 50 & 50 & 50 & 50 \\
$15: 00$ & 50 & 50 & 50 & 50 & 50 & 50 \\
$16: 00$ & 50 & 50 & 50 & 50 & 50 & 50 \\
17:00 & 50 & 50 & 50 & 50 & 50 & 50 \\
18:00 & 50 & 50 & 50 & 50 & 50 & 50 \\
19:00 & 50 & 50 & 50 & 50 & 50 & 50 \\
$20: 00$ & 0 & 0 & 0 & 0 & 0 & 0 \\
$21: 00$ & 0 & 0 & 0 & 0 & 0 & 0 \\
22:00 & 0 & 0 & 0 & 0 & 0 & 0
\end{tabular}

Tabela L.8 - Perfil de ocupação (\%) semanal do auditório para 72 horas de operação

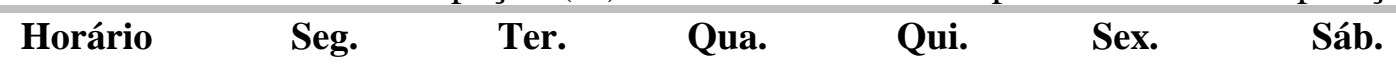




\begin{tabular}{ccccccc}
\hline $08: 00$ & 0 & 0 & 0 & 0 & 0 & 0 \\
$09: 00$ & 0 & 0 & 0 & 0 & 0 & 0 \\
$10: 00$ & 25 & 25 & 25 & 25 & 25 & 25 \\
$11: 00$ & 25 & 25 & 25 & 25 & 25 & 25 \\
$12: 00$ & 25 & 25 & 25 & 25 & 25 & 25 \\
$13: 00$ & 25 & 25 & 25 & 25 & 25 & 25 \\
$14: 00$ & 25 & 25 & 25 & 25 & 25 & 25 \\
$15: 00$ & 25 & 25 & 25 & 25 & 25 & 25 \\
$16: 00$ & 25 & 25 & 25 & 25 & 25 & 25 \\
$17: 00$ & 25 & 25 & 25 & 25 & 25 & 25 \\
$18: 00$ & 25 & 25 & 25 & 25 & 25 & 25 \\
$19: 00$ & 25 & 25 & 25 & 25 & 25 & 25 \\
$20: 00$ & 25 & 25 & 25 & 25 & 25 & 25 \\
$21: 00$ & 25 & 25 & 25 & 25 & 25 & 25 \\
$22: 00$ & 0 & 0 & 0 & 0 & 0 & 0
\end{tabular}

\section{Variação de ocupação 2: $46,67 \%$}

As Tabelas L.9, L.10, L.11 e L.12 apresentam os perfis semanais de ocupação para 42 horas de operação, 56 horas, 73 horas e 84 horas, respectivamente. Todos esses perfis possuem uma ocupação relativa semanal acumulada de 46,67\%:

Tabela L.9 - Perfil de ocupação (\%) semanal do auditório para 42 horas de operação

\begin{tabular}{ccccccc}
\hline Horário & Seg. & Ter. & Qua. & Qui. & Sex. & Sáb. \\
\hline $08: 00$ & 0 & 0 & 0 & 0 & 0 & 0 \\
$09: 00$ & 0 & 0 & 0 & 0 & 0 & 0 \\
$10: 00$ & 0 & 0 & 0 & 0 & 0 & 0 \\
$11: 00$ & 0 & 0 & 0 & 0 & 0 & 0 \\
$12: 00$ & 0 & 0 & 0 & 0 & 0 & 0 \\
$13: 00$ & 0 & 0 & 0 & 0 & 0 & 0 \\
$14: 00$ & 100 & 100 & 100 & 100 & 100 & 100 \\
$15: 00$ & 100 & 100 & 100 & 100 & 100 & 100 \\
$16: 00$ & 100 & 100 & 100 & 100 & 100 & 100 \\
$17: 00$ & 100 & 100 & 100 & 100 & 100 & 100 \\
$18: 00$ & 100 & 100 & 100 & 100 & 100 & 100 \\
\hline \hline
\end{tabular}




\begin{tabular}{ccccccc}
\hline $19: 00$ & 100 & 100 & 100 & 100 & 100 & 100 \\
$20: 00$ & 100 & 100 & 100 & 100 & 100 & 100 \\
$21: 00$ & 0 & 0 & 0 & 0 & 0 & 0 \\
$22: 00$ & 0 & 0 & 0 & 0 & 0 & 0 \\
\hline
\end{tabular}

Tabela L.10 - Perfil de ocupação (\%) semanal do auditório para 56 horas de operação

\begin{tabular}{ccccccc}
\hline Horário & Seg. & Ter. & Qua. & Qui. & Sex. & Sáb. \\
\hline 08:00 & 0 & 0 & 0 & 0 & 0 & 0 \\
09:00 & 0 & 0 & 0 & 0 & 0 & 0 \\
10:00 & 75 & 75 & 75 & 75 & 75 & 75 \\
$11: 00$ & 75 & 75 & 75 & 75 & 75 & 75 \\
$12: 00$ & 75 & 75 & 75 & 75 & 75 & 75 \\
$13: 00$ & 75 & 75 & 75 & 75 & 75 & 75 \\
$14: 00$ & 75 & 75 & 75 & 75 & 75 & 75 \\
$15: 00$ & 75 & 75 & 75 & 75 & 75 & 75 \\
$16: 00$ & 75 & 75 & 75 & 75 & 75 & 75 \\
$17: 00$ & 75 & 75 & 75 & 75 & 75 & 75 \\
18:00 & 75 & 75 & 75 & 75 & 75 & 75 \\
$19: 00$ & 75 & 0 & 0 & 0 & 0 & 0 \\
$20: 00$ & 75 & 0 & 0 & 0 & 0 & 0 \\
$21: 00$ & 0 & 0 & 0 & 0 & 0 & 0 \\
$22: 00$ & 0 & 0 & 0 & 0 & 0 & 0
\end{tabular}

Tabela L.11 - Perfil de ocupação (\%) semanal do auditório para 73 horas de operação

\begin{tabular}{ccccccc}
\hline Horário & Seg. & Ter. & Qua. & Qui. & Sex. & Sáb. \\
\hline $08: 00$ & 25 & 25 & 25 & 25 & 25 & 25 \\
$09: 00$ & 50 & 50 & 50 & 50 & 25 & 50 \\
$10: 00$ & 50 & 75 & 50 & 75 & 25 & 75 \\
$11: 00$ & 50 & 75 & 50 & 75 & 25 & 75 \\
$12: 00$ & 25 & 100 & 50 & 100 & 25 & 50 \\
$13: 00$ & 0 & 0 & 0 & 0 & 0 & 0 \\
$14: 00$ & 25 & 25 & 25 & 25 & 0 & 0 \\
$15: 00$ & 75 & 75 & 75 & 75 & 25 & 0 \\
$16: 00$ & 100 & 100 & 100 & 100 & 25 & 0 \\
$17: 00$ & 75 & 75 & 75 & 75 & 50 & 0 \\
$18: 00$ & 100 & 100 & 100 & 100 & 50 & 0 \\
\hline
\end{tabular}




\begin{tabular}{ccccccc}
\hline $19: 00$ & 25 & 25 & 50 & 25 & 50 & 0 \\
$20: 00$ & 50 & 50 & 75 & 50 & 75 & 0 \\
$21: 00$ & 50 & 50 & 75 & 75 & 100 & 0 \\
$22: 00$ & 25 & 0 & 75 & 50 & 100 & 0
\end{tabular}

Tabela L.12 - Perfil de ocupação (\%) semanal do auditório para 84 horas de operação

\begin{tabular}{ccccccc}
\hline Horário & Seg. & Ter. & Qua. & Qui. & Sex. & Sáb. \\
\hline $08: 00$ & 50 & 50 & 50 & 50 & 50 & 50 \\
$09: 00$ & 50 & 50 & 50 & 50 & 50 & 50 \\
$10: 00$ & 50 & 50 & 50 & 50 & 50 & 50 \\
$11: 00$ & 50 & 50 & 50 & 50 & 50 & 50 \\
$12: 00$ & 50 & 50 & 50 & 50 & 50 & 50 \\
$13: 00$ & 50 & 50 & 50 & 50 & 50 & 50 \\
$14: 00$ & 50 & 50 & 50 & 50 & 50 & 50 \\
$15: 00$ & 50 & 50 & 50 & 50 & 50 & 50 \\
$16: 00$ & 50 & 50 & 50 & 50 & 50 & 50 \\
$17: 00$ & 50 & 50 & 50 & 50 & 50 & 50 \\
$18: 00$ & 50 & 50 & 50 & 50 & 50 & 50 \\
$19: 00$ & 50 & 50 & 50 & 50 & 50 & 50 \\
$20: 00$ & 50 & 50 & 50 & 50 & 50 & 50 \\
$21: 00$ & 50 & 50 & 50 & 50 & 50 & 50 \\
$22: 00$ & 0 & 0 & 0 & 0 & 0 & 0
\end{tabular}

\section{Variação de ocupação 3: 75,56\%}

As Tabelas L.13, L.14 e L.15 apresentam os perfis semanais de ocupação para 68 horas de operação, 80 horas e 90 horas, respectivamente. Todos esses perfis possuem uma ocupação relativa semanal acumulada de $75,56 \%$ :

Tabela L.13 - Perfil de ocupação (\%) semanal do auditório para 68 horas de operação

\begin{tabular}{ccccccc}
\hline Horário & Seg. & Ter. & Qua. & Qui. & Sex. & Sáb. \\
\hline $08: 00$ & 0 & 0 & 0 & 0 & 0 & 0 \\
$09: 00$ & 100 & 0 & 0 & 0 & 0 & 0 \\
$10: 00$ & 100 & 100 & 100 & 100 & 100 & 100 \\
$11: 00$ & 100 & 100 & 100 & 100 & 100 & 100
\end{tabular}




\begin{tabular}{ccccccc}
\hline $12: 00$ & 100 & 100 & 100 & 100 & 100 & 100 \\
$13: 00$ & 100 & 100 & 100 & 100 & 100 & 100 \\
$14: 00$ & 100 & 100 & 100 & 100 & 100 & 100 \\
$15: 00$ & 100 & 100 & 100 & 100 & 100 & 100 \\
$16: 00$ & 100 & 100 & 100 & 100 & 100 & 100 \\
$17: 00$ & 100 & 100 & 100 & 100 & 100 & 100 \\
$18: 00$ & 100 & 100 & 100 & 100 & 100 & 100 \\
$19: 00$ & 100 & 100 & 100 & 100 & 100 & 100 \\
$20: 00$ & 100 & 100 & 100 & 100 & 100 & 100 \\
$21: 00$ & 100 & 0 & 0 & 0 & 0 & 0 \\
$22: 00$ & 0 & 0 & 0 & 0 & 0 & 0
\end{tabular}

Tabela L.14 - Perfil de ocupação (\%) semanal do auditório para 80 horas de operação

\begin{tabular}{ccccccc}
\hline Horário & Seg. & Ter. & Qua. & Qui. & Sex. & Sáb. \\
\hline 08:00 & 85 & 85 & 0 & 0 & 0 & 0 \\
$09: 00$ & 85 & 85 & 85 & 85 & 85 & 85 \\
$10: 00$ & 85 & 85 & 85 & 85 & 85 & 85 \\
$11: 00$ & 85 & 85 & 85 & 85 & 85 & 85 \\
$12: 00$ & 85 & 85 & 85 & 85 & 85 & 85 \\
$13: 00$ & 85 & 85 & 85 & 85 & 85 & 85 \\
$14: 00$ & 85 & 85 & 85 & 85 & 85 & 85 \\
$15: 00$ & 85 & 85 & 85 & 85 & 85 & 85 \\
$16: 00$ & 85 & 85 & 85 & 85 & 85 & 85 \\
$17: 00$ & 85 & 85 & 85 & 85 & 85 & 85 \\
$18: 00$ & 85 & 85 & 85 & 85 & 85 & 85 \\
$19: 00$ & 85 & 85 & 85 & 85 & 85 & 85 \\
$20: 00$ & 85 & 85 & 85 & 85 & 85 & 85 \\
$21: 00$ & 85 & 85 & 85 & 85 & 85 & 85 \\
$22: 00$ & 0 & 0 & 0 & 0 & 0 & 0 \\
\hline
\end{tabular}

Tabela L.15 - Perfil de ocupação (\%) semanal do auditório para 90 horas de operação

\begin{tabular}{ccccccc}
\hline Horário & Seg. & Ter. & Qua. & Qui. & Sex. & Sáb. \\
\hline $08: 00$ & 75 & 75 & 75 & 75 & 75 & 75 \\
$09: 00$ & 75 & 75 & 75 & 75 & 75 & 75 \\
10:00 & 75 & 75 & 75 & 75 & 75 & 75 \\
$11: 00$ & 75 & 75 & 75 & 75 & 75 & 75 \\
\hline
\end{tabular}




\begin{tabular}{ccccccc}
\hline $12: 00$ & 75 & 100 & 75 & 100 & 75 & 75 \\
$13: 00$ & 50 & 50 & 50 & 50 & 50 & 50 \\
$14: 00$ & 50 & 50 & 50 & 50 & 50 & 50 \\
$15: 00$ & 75 & 75 & 75 & 75 & 75 & 100 \\
$16: 00$ & 100 & 100 & 100 & 100 & 75 & 100 \\
$17: 00$ & 75 & 75 & 75 & 75 & 75 & 75 \\
$18: 00$ & 100 & 100 & 100 & 100 & 75 & 75 \\
$19: 00$ & 75 & 75 & 75 & 75 & 75 & 75 \\
$20: 00$ & 75 & 75 & 75 & 75 & 75 & 75 \\
$21: 00$ & 75 & 75 & 75 & 75 & 100 & 50 \\
$22: 00$ & 75 & 75 & 75 & 75 & 100 & 50 \\
\hline
\end{tabular}

\section{Variação de ocupação 4: 100\%}

A Tabela L.16 apresenta o perfil semanal de ocupação para 90 horas de operação, para uma ocupação relativa semanal acumulada de 100\%:

Tabela L.16 - Perfil de ocupação (\%) semanal do auditório para 90 horas de operação

\begin{tabular}{ccccccc}
\hline Horário & Seg. & Ter. & Qua. & Qui. & Sex. & Sáb. \\
\hline $08: 00$ & 100 & 100 & 100 & 100 & 100 & 100 \\
$09: 00$ & 100 & 100 & 100 & 100 & 100 & 100 \\
$10: 00$ & 100 & 100 & 100 & 100 & 100 & 100 \\
$11: 00$ & 100 & 100 & 100 & 100 & 100 & 100 \\
$12: 00$ & 100 & 100 & 100 & 100 & 100 & 100 \\
$13: 00$ & 100 & 100 & 100 & 100 & 100 & 100 \\
$14: 00$ & 100 & 100 & 100 & 100 & 100 & 100 \\
$15: 00$ & 100 & 100 & 100 & 100 & 100 & 100 \\
$16: 00$ & 100 & 100 & 100 & 100 & 100 & 100 \\
$17: 00$ & 100 & 100 & 100 & 100 & 100 & 100 \\
$18: 00$ & 100 & 100 & 100 & 100 & 100 & 100 \\
$19: 00$ & 100 & 100 & 100 & 100 & 100 & 100 \\
$20: 00$ & 100 & 100 & 100 & 100 & 100 & 100 \\
$21: 00$ & 100 & 100 & 100 & 100 & 100 & 100 \\
$22: 00$ & 100 & 100 & 100 & 100 & 100 & 100 \\
\hline \hline
\end{tabular}

